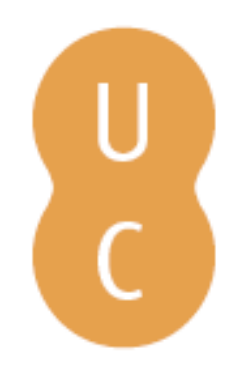

\title{
nommalina
}

\section{Espaços e paisagens: antiguidade clássica e heranças contemporâneas: Vol.3} História, Arqueologia e Arte \author{
$\begin{array}{ll}\text { Autor(es): } & \text { Congresso da Associação Portuguesa de Estudos Clássico, 7, Évora, } \\ 2008\end{array}$ \\ Publicado por: Associação Portuguesa de Estudos Clássicos; Centro de Estudos \\ Clássicos e Humanísticos; Imprensa da Universidade de Coimbra \\ URL \\ persistente: \\ URI:http://hdl.handle.net/10316.2/2376 \\ DOI: \\ DOI:http://dx.doi.org/10.14195/978-989-8281-69-2
}

Accessed : $\quad$ 26-Apr-2023 08:39:55

A navegação consulta e descarregamento dos títulos inseridos nas Bibliotecas Digitais UC Digitalis, UC Pombalina e UC Impactum, pressupõem a aceitação plena e sem reservas dos Termos e Condições de Uso destas Bibliotecas Digitais, disponíveis em https://digitalis.uc.pt/pt-pt/termos.

Conforme exposto nos referidos Termos e Condições de Uso, o descarregamento de títulos de acesso restrito requer uma licença válida de autorização devendo o utilizador aceder ao(s) documento(s) a partir de um endereço de IP da instituição detentora da supramencionada licença.

Ao utilizador é apenas permitido o descarregamento para uso pessoal, pelo que o emprego do(s) título(s) descarregado(s) para outro fim, designadamente comercial, carece de autorização do respetivo autor ou editor da obra.

Na medida em que todas as obras da UC Digitalis se encontram protegidas pelo Código do Direito de Autor e Direitos Conexos e demais legislação aplicável, toda a cópia, parcial ou total, deste documento, nos casos em que é legalmente admitida, deverá conter ou fazer-se acompanhar por este aviso.

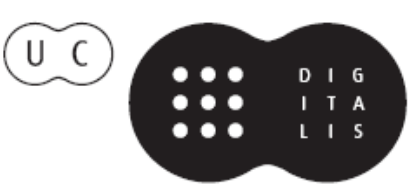




\section{Espaços e Paisagens}

Antiguidade Clássica

e Heranças Contemporâneas

Vol. III

Francisco Oliveira, Jorge Oliveira e Manuel Patrício

IMPRENSA DA UNIVERSIDADE DE COIMBRA 


\section{HVMANITAS SVPPLEMENTVM • ESTUDOS MONOGRÁFICOS}

ISSN: $2182-8814$

Apresentação: esta série destina-se a publicar estudos de fundo sobre um leque variado de temas e perspetivas de abordagem (literatura, cultura, história antiga, arqueologia, história da arte, filosofia, língua e linguística), mantendo embora como denominador comum os Estudos Clássicos e sua projeção na Idade Média, Renascimento e receção na actualidade. 
(Página deixada propositadamente em branco) 
(Página deixada propositadamente em branco) 


\section{Espaços e Paisagens}

Antiguidade Clássica e Heranças Contemporâneas

VII Congresso da Associação Portuguesa de Estudos Clássicos

Évora, 10-12 de Abril de 2008

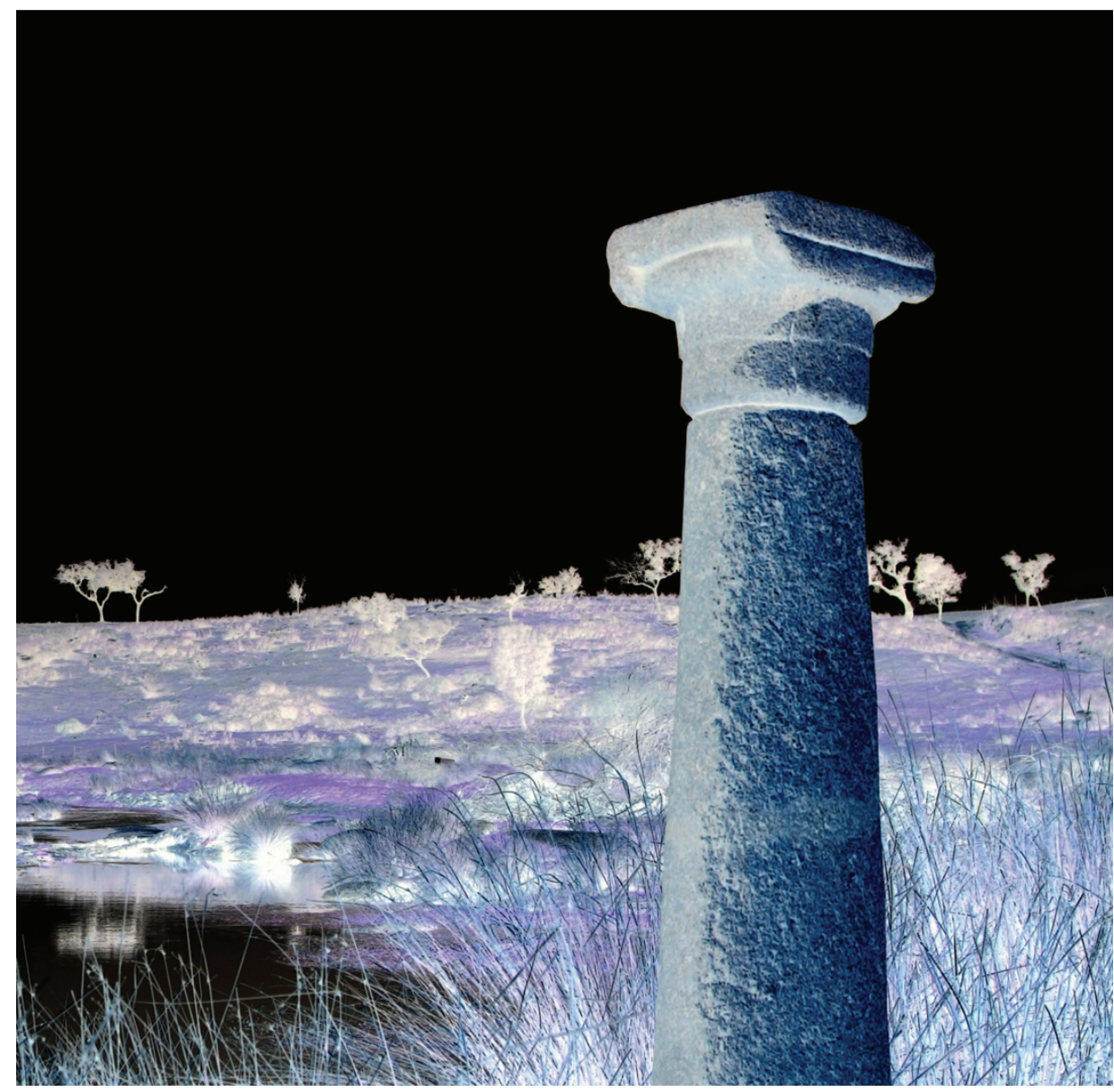


(Página deixada propositadamente em branco) 


\section{Espaços e Paisagens}

Antiguidade Clássica e Heranças

Contemporâneas

Vol. III História, Arqueologia e Arte

Francisco de Oliveira, Jorge de Oliveira, Manuel Patrocínio (Coords.) 
Todos os VOlumes Desta SÉRIE SÃo SUJEITOS A ARBITRAGEM CIENTÍfICA INDEPENDENTE.

Título • Espaços e Paisagens. Antiguidade Clássica e Heranças Contemporâneas Vol. III. História, Arqueologia e Arte

Coordenação • Francisco de Oliveira, Jorge de Oliveira, Manuel Patrocínio

\section{Série Hvmanitas Svpplementvm}

Coordenador Científico do plano de ediçâo: Maria do Céu Fialho

Conselho Editorial

José Ribeiro Ferreira

Francisco de Oliveira

Maria de Fátima Silva

Nair Castro Soares

Director Técnico: Delfim Leăo

Obra realizada no Âmbito das actividades da UI\&D

Centro de Estudos Clássicos e Humanísticos

\section{EDIÇÃo}

Imprensa da Universidade de Coimbra

URL: http://www.uc.pt/imprensa_uc

E-mail: imprensa@uc.pt

Vendas online:

http://www.livrariadaimprensa.com

\section{CoORdENAÇÃo EDITORIAL}

Imprensa da Universidade de Coimbra

Concepção gráfica \& Paginação

Rodolfo Lopes

Pré-IMPRESSÃo

Imprensa da Universidade de Coimbra

\author{
Impressáo e ACABAmento \\ www.artipol.net \\ ISBN \\ 978-989-26-0281-3 \\ ISBN DigITAL \\ 978-989-26-0292-9 \\ DOI \\ http://dx.doi.org/10.14195/978-989-8281-69-2 \\ Depósito Legal \\ $346983 / 12$ \\ 1 ${ }^{\text {a }}$ EDIÇĂO: $\mathrm{CECH} / \mathrm{APEC} \cdot 2010$ \\ 2a EDIÇÁo: IUC • 2012
}

(C) JULHO 2012.

IMPRENSA DA UNIVERSIDADE DE CoImbra

Classica Digitalia Vniversitatis Conimbrigensis (http://classicadigitalia.uc.pt)

Centro de Estudos Clássicos e Humanísticos da Universidade de Coimbra

Reservados todos os direitos. Nos termos legais fica expressamente proibida a reprodução total ou parcial por qualquer meio, em papel ou em edição electrónica, sem autorizaçáo expressa dos titulares dos direitos. É desde já excepcionada a utilizaçáo em circuitos académicos fechados para apoio a leccionaçáo ou extensấo cultural por via de e-learning. 


\section{Nota de Apresentação}

A Associação Portuguesa de Estudos Clássicos - APEC optou há alguns anos pela deslocalização do seu congresso periódico, o qual, de Coimbra, já peregrinou por Viseu, Aveiro, Faro, Braga, Lisboa e Évora.

Foi exactamente nesta belíssima cidade que se realizou o VII Congresso Internacional da APEC, nos dias 10-12 de Abril de 2008.

Nesse encontro, uma enorme plêiade de participantes desenvolveu um exercício de intensa interdisciplinaridade à volta do tema Espaços e paisagens. Antiguidade Clássica e heranças contemporâneas. Foi de cerca de uma centena o número de conferencistas presentes, um terço dos quais vindos de países estrangeiros, e é para eles que vai um primeiro agradecimento, em especial para os que aceitaram o desafio da publicação das suas comunicações.

O segundo agradecimento é dirigido às entidades que assumiram a coresponsabilidade da organização e da edição:

- o Centro de Estudos Clássicos e Humanísticos da Universidade de Coimbra, coordenado pela Professora Doutora Maria do Céu Zambujo Fialho;

- o Centro de História da Arte e de Investigação Artística da Universidade de Évora, dirigido pela Prof. Doutora Christine Zurbach;

- o Centro Interdisciplinar de História, Culturas e Sociedades da Universidade de Évora, coordenado pela Prof. Doutora Mafalda Soares da Cunha;

— o Laboratório de Arqueologia "Pinho Monteiro" da Universidade de Évora, presidido pelo Prof. Doutor Jorge de Oliveira;

- o Departamento de Linguística e Literaturas da Universidade de Évora. 
Os agradecimentos que endereçamos a estas entidades são extensivos às próprias instituições acolhedoras, a Universidade de Coimbra e a Universidade de Évora, e, nesta cidade, também ao Governo Civil de Évora, à Câmara Municipal de Évora, ao Comando da Unidade de Apoio e ao Banco Millenium BCP, cujos responsáveis mobilizaram toda a sua clarividência e generosidade para garantir as melhores condições para a realização deste evento cultural e científico.

Em terceiro lugar, manifestamos a nossa viva gratidão às entidades financiadoras, com particular relevo para o sempre solícito apoio da FCT - Fundação para a Ciência e Tecnologia, da Fundação Calouste Gulbenkian e da Fundação Engenheiro António de Almeida.

Mas seria injusto não valorizar também a colaboração da Dra Carla Braz, no secretariado, da Dra Ana Seiça Carvalho, da Dra Elizabete Grova e do Dr. Rodolfo Lopes, na preparação da edição digital, e do Doutor Delfim Leão, pelo interesse em promover a divulgação através de Classica Digitalia.

Estamos certos de que tais apoios, colaborações, financiamentos, patrocínios e responsáveis se sentirão compensados pela qualidade dos escritos dados ao prelo, organizados em três volumes com o título geral Espaços e Paisagens. Antiguidade Clássica e Heranças Contemporâneas e os subtítulos correspondentes:

\section{- vol. 1 Linguas e Literaturas. Grécia e Roma \\ - vol. 2 Linguas e Literaturas. Idade Média. Renascimento. Recep̧̧ão \\ - vol. 3 História, Arqueologia e Arte}

No seu conjunto, tais contributos, incluindo os de jovens investigadores, ilustram uma grande diversidade de perspectivas, uma enorme riqueza e variedade de temas, da filologia grega e latina e da tradição clássica à literatura comparada, da arte e do urbanismo à arqueologia e à economia, da política à filosofia, e desde a Antiguidade até aos nossos dias.

Por acréscimo, ficam assim também nobilitados os estudos clássicos, humanísticos, históricos, filosóficos e literários em Portugal, com a Associação Portuguesa de Estudos Clássicos — APEC a cumprir a missão cultural e científica consagrada nos seus estatutos, em especial no espaço da lusofonia e da União Europeia. 
Comissão Científica

Ana Cardoso de Matos

Arnaldo Espírito Santo

Cláudia Teixeira

Cristina Pimentel

Filipe Themudo Barata

Francisco de Oliveira

Hermínia Vilar

Jorge de Oliveira

José Alberto Gomes Machado

Leonor Rocha

Manuel Patrocínio

Mafalda Soares da Cunha

Maria de Fátima Sousa e Silva

Maria do Céu Fialho

Ricardo Santos

Teresa Santos
Comissão Organizadora

André Carneiro

Armando Martins

Carla Braz (secretariado)

Clara Oliveira

Cláudia Teixeira

Francisco de Oliveira

Jorge de Oliveira

Leonor Rocha

Manuel Patrocínio

Paula Barata Dias

Ricardo Santos

Valentina Castro

\section{Coordenação do Volume}

Francisco de Oliveira

Jorge de Oliveira

Manuel Patrocínio 
(Página deixada propositadamente em branco) 


\section{ÍNDICE}

\section{Vol.3 História, Arqueologia e Arte}

The natural origins of Greek art and culture, Greek landscape and the

Greek brain

JOHN ONIANS

Os jardins de Tera

Maria Helena da Rocha Pereira

De Etnia a Provincia: identidades colectivas en la Lusitania Antigua

Francisco BeLtrán Lloris

A construção do espaço numa sociedade proto-histórica, a arte rupestre do Vale do

Côa

LUís LUÍs

Contributo para o conhecimento da arqueologia romana no Alentejo

Central

Clara Oliveira, LeOnOr Rocha

Para uma cartografia dos cultos religiosos no Alto Alentejo em época

romana

André CARNEIRO

Epígrafe votiva de Arronches, notícia da sua identificação

André Carneiro, José d’EnCARnaÇão, Jorge de Oliveira,

Cláudia Teixeira

Algumas considerações sobre divindades e espaços sagrados, de

período romano, na região eborense

Amílcar Guerra

A romanização da paisagem na Lusitânia

Vasco Gil Mantas 
O impacto da cavalaria romana na paisagem

Jỗo Costa FerREIRA

A que passado regressar? Reconfigurar e renomear o urbanismo em Roma na época de Severo Alexandre: o caso do Palatino

RODRIGO FURTADO

Ammaia: transformação e mudança na paisagem urbana

SÉrgio PEREIRA

A pulverização da Ammaia na Alta Idade Média

Jorge de Oliveira, SÉrgio Pereira

Mértola - um espaço lendário e místico

Natália Maria Lopes Nunes

A fada-moura: do espaço galo-romano ao espaço peninsular

Ana Margarida Chora

A memória do espaço no espaço da memória: entre a analística e os primórdios da cronística medieval

Orlando Gama

Da Scallabis romana a Sanctaren medieval: espaço, gentes e lendas

Lina Maria SoARES

"Não tirem a luz nem a vista": o respeito pelo espaço dos outros

Adriana Freire NogUeIRA

André de Resende, um novo Alberti? Um ideólogo entre o Princeps e o Architectus na recuperação da $\operatorname{Vrbs}$ romana de Évora (1531-1537)

Susana Matos Abreu

Contributos para o estudo das fontes clássicas na produção de gárgulas em contexto quinhentista em Portugal

CATARINA BARREIRA

Sinais de uma Cultura da Monumentalidade: as formas clássicas na arquitectura programática alentejana dos Sécs. XVI-XVII

Manuel F. S. do Patrocínio 
A muralha, o templo e o aqueduto na tradição de Sertório construtor da Évora romana (Sécs. XVI-XIX)

Paulo Simões Rodrigues

A pré-existência do Cardo/ Decumanus no plano pombalino e a sua herança na Lisboa contemporânea

PAUla ANDRÉ

Traçados urbanos portugueses, simbiose de culturas

Manuel Teixeira

O contributo dos relatos e guias de viagens para o estudo da Antiguidade Clássica no Sul de Portugal

Ana Cardoso de Matos, Antónia Fialho Conde, Maria Ana

BERNARDO

Amadeo Modigliani (1884-1920) e o templo da beleza: uma utopia figurativa na arte moderna

Susana M. Loureiro Restier Grijó Poças

Índice de palavras-chave. 
(Página deixada propositadamente em branco) 


\title{
III VOLUME
}

\author{
História, Arqueologia e Arte
}


(Página deixada propositadamente em branco) 


\title{
THE NATURAL ORIGINS OF GREEK ART AND CULTURE. GREEK LANDSCAPE AND THE GREEK BRAIN
}

\author{
JOHN ONIANS \\ University of East Anglia
}

Keywords: Greek art, Greek brain, Greek culture, Greek landscape.

Palavras-chave: arte grega, cérebro grego, cultura grega, paisagem grega.

All Classicists know that the Greeks were distinguished for their interest in nature. They themselves are usually distinguished for their lack of interest in it; though that is not true of the organizers of this volume. Most Classicists study Greek natural philosophy and the naturalism of Greek art, but, in their explanation of them, they almost never themselves invoke nature. In this they are unlike their predecessors. In Antiquity the Hippocratic corpus and Strabo were in agreement that, following humoural theory, the main determinants of culture were climate and landscape. Thus the reason why the Athenians were more intelligent than the Boeotians was because their air was not moist and foggy, but dry and clear. In the eighteenth century, Winckelmann thought that Greek culture was fundamentally shaped by the climate and the influence it had on their brain, which he thought had finer fibres than those of the Egyptians and Persians. In the nineteenth, Hippolyte Taine agreed with ancient writers in claiming that the clarity of the Athenian air and the prismatic forms of their mountains played a crucial role in the emergence of the Athenian intellectual and aesthetic achievement. Such claims have tended to be treated as a joke by serious scholars, but now the joke is on them. Modern biology suggests that these neglected claims were essentially correct, although the basis for this opinion is not, of course, humoural theory, but neuroscience. In other words, while until recently anyone who argued that nature had an important role in shaping Greek culture would have been laughed at, we should now laugh at anyone who denies it. And surely, however skeptical we are, since the Greeks themselves were so interested in natural explanations we owe it to them to take such explanations seriously, which is why, in the next twenty five minutes, I intend to sketch out my own view of the way an understanding of the relation between two aspects of nature, the Greek brain and the Greek landscape, helps us to understand some of the most vital Greek achievements.

Since my argument may be unfamiliar to most of you I will first quickly outline its basis. I rely on two facts, one, the distinctive nature of the Greek landscape, and two, the distinctive nature of the Greek brain. For the Greek landscape was essentially different from that of all other areas of the world 
of a comparable state of development, a point which emerges starkly if one compares the Greek peninsula with the other three that project into the Mediterranean, Asia Minor, Italy and Spain. While all the others have closed and simple shapes, that of Greece is characterized by a bewildering variety of inlets and projections. These betray a unique geological history, which endowed the Greek peninsula with a unique topography, consisting of narrow fertile valleys divided from each other by steep mountains crowned by ridges of bare rock. This topography had a profound effect on the economic and social development of the peninsula, and it also had a profound effect on another natural phenomenon, the Greek brain. The point is not that the Greeks were born with special brains, but that the double influence of being exposed, both to such an environment itself, and to the economic and social practices that it nourished, caused their brains to develop in unprecedented ways. I don't have the time to fully lay out the neural basis of this claim, which I develop in my latest book, Neuroarthistory. From Aristotle and Pliny to Baxandall and Zeki, but the central point is the importance of neural plasticity. This is the principle that ensures that, although we are all born with a brain containing a hundred billion neurons, each of these neurons can have up to 100,000 connections to other neurons, and these connections are different in each of us, being formed and broken throughout our lives in response to all our individual experiences. This process is evident in the formation of connections in the infant cortex in the first two years of life. Its impact is most obvious when we consciously acquire a skill such as learning a language or playing a musical instrument, and its significance can be quantified if we observe the way repeating an activity, such as touching, over a few weeks causes a dramatic enlargement of the areas of the brain controlling the fingers involved. But what the historian of culture needs to know is that the same thing happens as we use all the other senses, for example as we look at the sky or the landscape and observe the movements of those around us. This is because the nerve cells in the visual system, such as the banks of neurons which respond to lines of different orientation, whose function in critical for our perception of form, respond better the more often they are activated. The principles governing the formation of our neural networks, mean that whatever the shapes of the natural and manmade objects we give attention to, and whatever the properties of the substances of which they are made, we will acquire a preference for looking at such shapes and a special empathy for those properties. Such unconscious and passive exposure is as important as that which is active and conscious. Indeed, since the unconscious process starts the moment we are born, and we only later develop conscious and active behaviours, the character of those later behaviours is profoundly influenced by our earlier experiences. And this of course is why it is so important to be aware of the consequence of such exposure in the context of this volume around the topic of landscape. There was no feature of the Greek environment, which was more striking and distinctive than landscape, and 
that alone is a reason for considering the role it might have had in shaping the Greek brain.

The influence of landscape on the brain is of two kinds. One is the direct influence of the landscape itself on neural networks, to which I will return at the end, but equally important is the influence of landscape on Greek life and social institutions, and here too we have to consider the consequences for the brain's passive exposure. Since the topography I have just described had a profound effect on the character of the Greek life-style and that lifestyle had a profound effect, both conscious and unconscious, on the Greek brain, we have to consider that effect as such. This effect is most clear in the way it affected the development of the urban institutions for which Greece is famous. The constraints inherent in the Greek landscape meant that the institutions that emerged in Greek towns were quite different from those found in towns in areas such as Egypt, Mesopotamia, and the Levant. In those areas the security of cities depended on the strength of rulers and the reliability of alliances. In Greece, the fractured landscape meant that security depended on very different factors. The villages that became towns as they grew in the separate valleys after $1000 \mathrm{BC}$ were all in rivalry with each other. They also had no wealthy protectors to look to. Instead, as the populations of each of these communities outgrew their local agricultural resources, each looked enviously at its rival's lands. Each city state needed an army, whether it was just to defend its own territory, or also to conquer that of its neighbour, and in the absence of protectors the only ways of increasing the army's effectiveness was to maximizing the strength of the only available body of fighting men, the limited numbers of the town's males. It was in response to these pressures that the Greek cities developed unique military tools. They thus concentrated on developing such attributes in the city's able bodied males as discipline, physical strength, rigorous co-ordination and equipped them with strong bronze body armour and iron weaponry. By doing so they enabled their warriors to form an impregnable regular formation, the phalanx. They also surrounded themselves with walls built out of squared blocks of limestone from the omnipresent mountains. So universal was the reliance on the phalanx and the stone wall that Homer already in the eighth century BC compares Achilles marshalling of his phalanx of Myrmidons, shield pressed against shield, their spears forming a fence, to a man building a wall out of tight fitting stones, and Greek soldiers were still being compared to stones in a wall by Plato in the fourth century.

The extent to which the unique techniques of warfare nurtured by the unique Greek landscape, deeply affected Greek culture is first apparent in the equally unique myths they had of their origin and nature. While all other peoples thought of themselves as being made of soft clay or descended from animals or plants, the Greeks were along in thinking of themselves as hard minerals. The Greek creation myth told how they were born when the only survivors after a great flood, Deucalion and Pyrrha, who were too old to have children, were told by the gods to throw stones over the shoulders. Those 
stones became the ancestors of the different Greek tribes. In a similar vein Hesiod in the Theogony talks of the succeeding populations of the gold, silver, bronze and iron ages and in the case of the bronze age at least, which was the one that preceded his own, told how the men themselves were made of bronze. The Greeks then, unlike all other peoples of the planet, liked to think of themselves as made of stone or metal, and, since those hard substances are the ones on which their landscape caused them to rely for defence there can be no doubt it was military priorities which inspired this chilling, but beneficial vision. There can be no doubt that an army of men who think of themselves as actually made of stone and metal would have had a critical psychological advantage when confronting one that thinks it is made of brittle clay, or descended from animals, as is confirmed by the Greek successes against their neighbourst to the East.

This empathetic relationship was critical for all aspects of culture, and this is nowhere more obvious than in art. For a start, the attributes of Greek so-called Geometric pottery, the rows of warriors with their regular shields and parallel spears, are a perfect illustration of the properties of the phalanx of Myrmidons as described in the Iliad. But even more striking is the unprecedented emergence of life-size and life-like statues in marble and bronze after 600BC. Since the Greeks had long been thinking of themselves as made of stone and metal it was entirely natural that they should represent themselves in those materials. In doing so they were not analytically trying to solve an artistic problem, as is often suggested, but doing no more than representing themselves for what they thought they were, made of hard stone and hard metal. The naturalistic style of the statues was also as much a product of the environment as the materials used, since all the sculptors were doing was representing those anatomical features, the deltoids, the biceps, the stomach muscles whose effectiveness had to be maximised in preparation for Greek warfare. Both material and style were thus indirectly a product of the Greek landscape.

The same distinctive military culture that produced Greek sculpture, also shaped Greek architecture. As we have seen, writers from Homer to Plato compared warriors to stones in a wall and this had implications for the Greek idea of the perfect man. Simonides for example around 500BC, later quoted enthusiastically by Plato, says that it is difficult to find the perfect man 'wrought four square', and since the only context in which being wrought four square was normal was the building of walls it sound as if he is thinking of the perfect man as a square block in just such a structure. This didn't just affect the way they thought about and represented themselves, as when they represented the most admired men as block-like herms, it also changed the way they thought about architecture. It gave them a preference for walls that were not like Egyptian walls, for example, smooth and seamless in their surface, but walls made up of individual stones visibly aligned in rows. Parallel to the analogy with rows of square blocks in a wall is the analogy with the rows of columns that are the most distinctive feature of the Greek temple. We often forget that nowhere in the world were the houses 16 
of deities surrounded by regular rows of stone columns, but, when we look for an explanation for this eccentric feature, one is ready to hand in the correspondence with the phalanx, a formation whose effectiveness depended on it members maintaining an absolutely rigid rectangular configuration, even when advancing at speed. The analogy is confirmed not just by the way the eight deep Parthenon corresponds with the Spartan phalanx, the best of all, which at the time was eight deep, but by the way Euripides makes Iphigeneia, at the beginning of Iphigeneia in Tauris, have a dream in which she sees the last column of her father's palace sprout golden hair from the capital and emit the voice of her brother, Orestes, because, as she says, the columns of a house are sons. The play was performed in the Theatre of Dionysus, just under the newly constructed Parthenon, and the audience would naturally have applied the experience to the columns of that temple, the most important in their lives. It was also just such an approach to columns that led the designer of the Erectheum around the same time to replace the columns in one porch by six statues of women, the fluting of their skirts carefully arranged to correspond with the flutes of the Ionic columns of the other two porches.

All this may sound a little difficult to argue convincingly unless we take into consideration the other natural element that we tend to disregard, the brain. The brain unconsciously supported the responses suggested above, because of both inherited and acquired neurally-driven inclinations. Our brain makes us all, as children, feel warm towards our parents and our parents' friends, and that means that it makes us feel warm towards phenomena that share attributes with our parents. In Greece that meant that infants would have been liable to feel warm towards lumps of stone. Ancient Greeks, like the modern descendants, would have had a light brown or bronzed colour, a colour that was like both weathered limestone and bronze, and Greek babies crawling and walking around their valley floor homes would have frequently encountered lumps of rock that had rolled down the mountains. These, because of their size and colour, would have had sufficient properties in common with their parents that they would have evoked similar feelings. Young Greeks would have felt that rocks were like people long before the social pressures also shaped by the landscape made them wish they had stone or metal ancestors. We can even confirm fotr them to really experienced such boulders as people, because Homer compares Hector's charge to the way a boulder rolls down a mountain and then stops. The combination of the Greek landscape and the Geek brain made them feel closer to stone than any other people on the planet before or since.

Many other aspects of Greek culture owe their origins if not directly to Greek landscape, at least to the military lifestyle it called forth. The first to consider is the interest in all aspects of mathematics and especially geometry. We have already seen how the requirement, enforced by the landscape, to maximise the efficiency of warriors in the military machine made the Greeks place an unprecedented emphasis on regularity, as in the phrases of Homer and the contemporary rows of warriors on Geometric vases. And it needs 
emphasising that the Greeks had no independent interest in geometry at this stage. What we call geometry is nothing more than the regularity required for effective warfare. The dependence of the need for order on military values is apparent throughout Greek history. Hesiod, for example, in an early acknowledgement of the role of music in Greek warfare describes how the function of the goddess Harmonia is to keep the ranks of the phalanx together. And the connection between music, mathematics and military values is explicit in Pythagoras. Pythagoras saw how Harmonia gave the universe the property of Kosmos that is battle order, such as that embodied in the phalanx, and his closest followers were the first mathematikoi at Croton, a city he sought out because its young men were the healthiest in the Greek world and whose population he is supposed to have incited to attack the neighbouring city of Sybaris, in order to demonstrate the superiority of warriors in whom mathematical knowledge was primary. Pythagoras defined the main elements of a mathematical training as arithmetic, geometry, music and astronomy and Plato adopted them as the core of the education of the phylakes, the guardians of his Republic, explaining each in military terms. Arithmetic was necessary to count the soldiers, geometry to organize them into formations, music to give them order and astronomy to determine the right season to fight. We have come to think that the Greek interest in mathematics was purely intellectual and abstract, and it certainly became that after they were conquered by the Romans, but in Greece it was rooted in the type of warfare nourished by the Greek landscape.

The same is true of the idea of education itself. It is well understood that the Greeks took the mental training of young men much further than any of their contemporaries, but it is not often realised why. It was only because it was the best way of maximising their efficiency in warfare. No one puts all that effort into the formation of the young unless it has a clear social benefit, and in Greece the benefit was military. Indeed the military roots of Greek education, and its specifically mathematical focus, are well illustrated by the sentence of Simonides quoted earlier in which it said it was difficult to find the perfect man, that is one made four square. As we said then, the reason why foursquare men were needed was because warriors had to be like square blocks in a wall. The more foursquare they were the better they would fit together. It was also significant that Simonides referred to men being 'wrought' four square, that is shaped, as by the chisel of a mason, which makes clear that the reference is to a man who is stone-like, and that reminds us that one of the great benefits of the Greeks thinking of themselves as stone-like was that it meant that they could be endlessly shaped and reshaped. The difference from the thinking of other peoples could not be clearer. Almost all other peoples thought of themselves as made of clay, as did the Chinese, a material which after its first moulding has a shape that is fixed until it is broken, at which time it becomes useless. When the Greeks thought of themselves as made of stone - or for that matter of metal - they thought of themselves as made of a material that could be endlessly reworked, that is was endlessly susceptible 
to reformation, the body by training and the mind by education. Since the Middle Eastern peoples who developed the idea that they were made of clay did so because they were brought up in valleys where the best things, the plants on which their prosperity depended, grew out of mud, and the Greek idea of themselves as made of stone and metal was born from exposure to a mountainous environment, in which the best things were the metal weapons and stone walls with which they defended themselves, the Greek self-image, was, like all other aspects of their culture, a product of the Greek landscape, and since thinking of themselves as mineral was crucial to the sense that they were endlessly reshapable it is clear that landscape was also crucial for the development of Greek ideas of education.

Reference to the importance of the linear clarity of geometry in Greek education brings me to my final point in this study of the relation between Greek culture and Greek landscape. We have seen that in antiquity the clarity of Athenian thought when compared to that of neighbouring Boeotia was associated with the limpid clarity of the Athenian air, and a hundred and fifty years ago Hippolyte Taine made a similar claim in relation to Athenian aesthetics: "...it is the physical structure of the land that has left on the intelligence of the race the imprint that we find in its works and in its history...The eye grasps effortlessly the shapes of objects and takes from them a clear image"". The fact that everywhere are bare rocky mountains only strengthens the effect, which is especially characteristic of Attica where the air is particularly clear: "It is thus that nature, by the forms with which it populates his spirit, inclines immediately the Greek to firm and clear conceptions". Taine was encouraged to make his bold assertion, which has often been ridiculed, by recent discoveries showing that the nervous system is made up of a myriad nerve cells connected to each other by tiny filaments here illustrated by the Spanish neuroscientist Ramon y Cajal, and now we can use the latest neuroscience to argue that he was probably right. The primary cells involved in form perception are, as we saw earlier, banks of neurons each of which respond to lines of a different orientation, and the more such cells are activated by exposure to such lines the more the connections between them develop, so enhancing the preference for such lines. There was much in the Greek environment that was more linear than in that of Mesopotamia and Egypt, especially the metal weapons they used to fight and the tools with which they worked the stones of their buildings, but even more omnipresent were the rocks of the surrounding mountains, often, after millions of years of that unusual geological history that had produced the land's extraordinary fractured silhouette, hard and sharp in outline and riven by a multitude of fissures. In no place was this more true than at Athens, where bare mountains ringed the city, and where the prismatic acropolis stood at its centre. Exposure to such an environment rich in lines, would have had a distinctive impact on the neural networks of Greek infants, giving them a sensitivity to line greater than that found in other populations elsewhere, and that effect would have been strengthened by exposure to the weapons and tools which 
were as essential to their lives as plants and animals were to others, giving them a preference for such properties as linearity and angularity. Indeed, exposure to these two elements of their environment, the natural and the manmade would have had a progressively incremental effect. Especially in the period after $650 \mathrm{BC}$, as they made more and more man-made objects out of the natural materials around them, incising black figure pottery with thin lines, and carving columns and entablatures with ever sharper mouldings and flutes, and giving their sculptures ever more graceful linear outlines, the distinctiveness of their neural networks and of the preferences they endowed them with would have become ever stronger. This would have been most true in Athens, where marble allowed linear properties maximal expression in the architecture and sculpture of the temple of Athena Nike, the Parthenon, the Erechtheum. And of course we should not forget that such exposure would also have allowed them to distinguish forms ever more clearly, building up unconsciously a clearer knowledge of the world than any available elsewhere.

Some of you may be reluctant to follow this argument, being doubtful if landscape can have such an effect on aesthetic sensibilities in other areas, so, in a last effort to persuade you, I will suggest that landscape also helps us to understand why the typical building of the Greeks, a pedimented temple, such as the Parthenon, is so different from the new types of building developed by the Romans, of which the Pantheon is the supreme example. It happens that Athens is surrounded by mountains, such as Mt Hymettus, chiseled by weather and geological pressures into rectangular massifs with long ridges along the top, while Rome is the only city in the world surrounded by tens of circular extinct volcanoes, their centres filled with round lakes, making them look as much like the Pantheon with its oculus as the mountains around Athens were like the Parthenon. Might exposure to those very different landscapes have had at least some influence on their neural networks, and so affected their tastes in architecture? If so it would be yet another example of how, far from being the product of conscious intellectual effort, as we have always been told, many, if not most, of the distinctive aspects of Greek culture are primarily the natural result of a purely passive exposure, either to landscape or to the social institutions that landscape inspired. 


\title{
OS JARDINS DE TERA
}

\author{
Maria Helena da Rocha Pereira \\ Universidade de Coimbra
}

\begin{abstract}
After a short geographical and historical outline of prehistoric Thera, special attention is paid to the frescoes depicting the beautiful landscape of the island, namely the so called "Subtropical landscape", the "sea daffodils" and, most of all, the "Spring fresco" with its flying swallows and flowering lillies.
\end{abstract}

Keywords: Cycladic art, frescoes, Minoan art, Prehistoric Thera

Palavras-chave: arte cicládica, arte minóica, frescos, Tera pré-histórica

Escreveu um dia o poeta Elytis, um dos maiores da Literatura Neo-helénica do nosso tempo, que "a Grécia repousa sobre o mar". Se olharmos para o mapa (fig. 1), logo nos aparece o seu perfil recortado, cercado de ilhas de extensão variável, em número de mais de três mil, conquanto não cheguem a duzentas as que são habitadas. Mesmo assim, basta referir algumas delas, para fazer ecoar na nossa memória os nomes de muitos dos grandes vultos que estão na base da cultura ocidental - e isto, mesmo que já poucos aceitem que Homero seja natural de Quios e alguns, como Barry Powell e outros tendam a colocar a passagem à escrita dos Poemas na ilha de Eubeia, um dos maiores reservatórios de surpresas dos últimos tempos.

Muito haveria que dizer dos vários arquipélagos em que se agrupam, mas é no das Cíclades que vamos centrar a nossa atenção. Em número de cinquenta e seis, formam quase um círculo em volta de Delos, lugar mítico do nascimento de Apolo.

Se daí lhes adveio o nome, ou se a origem desta é outra, muitos o discutem ${ }^{1}$. Interessante é saber que nelas predomina o mármore (e quem não se lembra dos mármores de Paros?), com excepção de duas situadas a Sul, Tera e Melos, que são de origem vulcânica.

Precisamente Tera, a mais meridional, terá sido habitada desde a segunda fase do Cicládico Antigo (3200 - 2000 a.C.). Porém, à volta de 1500 a.C., na sequência de uma grande erupção vulcânica, a ilha ficou de tal modo destruída que a sua configuração passou a assemelhar-se a uma meia-lua, e a sua extensão ficou reduzida a metade (fig. 2). Deixando de parte a sua história subsequente (que terá recomeçado com a ocupação micénica, no final do séc. XIII a.C. e passado pelas mãos de diversos outros povos), atentaremos de preferência nas consequências dessa erupção (fig. 3). A ilha fica coberta de cinzas e de lava. A espessura das camadas de cinza chega a atingir 50 a 60

${ }^{1}$ Das denominações da ilha e da sua história fala Heródoto 4.147-151, afirmando que a mais antiga era a de Strongule ("a arredondada"). Sobre o valor dessas informações, veja-se o comentário de Aldo Corcella na edição da colecção Lorenzo Valla (Milano 1993) 382 sqq. 
metros. A caldeira que hoje se observa tem impressionantes dimensões (fig. 4), e as suas paredes constituem para o geólogo "um museu estratigráfico único", conforme escreveu Chr. Doumas, actual director das escavações².

A vulcanologia encontra aqui um exemplo de erupção que só ocorre em determinadas situações. E Tera fica no encontro da placa tectónica egeia e africana. Com todas estas condições, preparam-se os caminhos para que à arqueologia e à história da arte se venham a deparar informações surpreendentes contidas em tão grande área soterrada.

Mas foi um longo processo, ainda em curso. Por mais surpreendente que pareça, o primeiro grande impulso proveio da tecnologia - ou tecno-ciência, se preferirem -, que alguma vez havia de dar vantagem às Ciências Humanas. Veio ele na sequência da abertura do Canal do Suez (1859-1869), que determinou a necessidade da procura de pedra-pomes em enorme quantidade, a fim de isolar os lados da construção sub-aquática. Ora essa matéria-prima encontrava-se e encontra-se em abundância, como já vimos, na ilha de Tera. É assim que principiam a aparecer nessa zona vestígios de edificações préhistóricas. Em 1867, quando o geólogo francês F. Fouqué começou a trabalhar na ilha, em breve formulou a hipótese de que ali poderia estar "uma Pompeia pré-histórica"”.

Porém, só passados muitos decénios, 1932, o arqueólogo grego Spyridon Marinatos decide comprovar a fidedignidade da antiga tradição, recolhida por Estrabão 10.4.8, segundo a qual Amnisos, na Creta oriental, fora o porto de mar do rei Minos. As escavações aí empreendidas pelo famoso especialista confirmaram a existência de edificações (uma delas com frescos florais), datáveis do Minóico Médio, que teriam sido destruídas e abandonadas cerca de 1500 a.C., e não mais habitadas. Relacionando estes dados com a hipótese de Philipson, de que a explosão do Krakatoa, em 1883, nas então chamadas Índias Orientais Neerlandesas, devia ter sido precedida por uma muito semelhante em Tera, o mesmo Marinatos apresentou em 1939 a sua teoria de que essa catástrofe estava na origem do declínio da civilização minóica e que também esse extremo oriental da ilha de Creta fora abrangido pela terrível erupção vulcânica.

Ora a importância de Creta era bem conhecida desde que, em 1900, Sir Arthur Evans revelara a existência e o esplendor do palácio de Minos, em Cnossos. Outros vieram juntar-se-lhe com o decorrer do tempo, como Phaistos, Mallia, Zakro. Mas já em Cnossos se haviam achado belas pinturas murais, como o célebre e enigmático "Salto do Touro", que todos conhecem, bem como a chamada "Parisiense" ou a decoração da Sala do Trono, e duas que vamos aqui recordar, pela sua sugestiva frescura: o Príncipe das Flores de Lis (fig. 5), que caminhava no meio de dois tufos de

\footnotetext{
${ }^{2}$ Chr. Doumas 19939.

${ }^{3}$ Chr. Doumas 1879.
} 
flores, e o Pássaro Azul, pousado numa rocha, ao lado de águas correntes, no meio dos caules finos das plantas (fig. 6).

A semelhança de motivos e de estilo com as pinturas que começaram a aparecer em Tera, no local de Akrotiri, onde escavou Marinatos entre 1967 e 1974, é notável. Pode mesmo afirmar-se que a sua arte é, em muitos aspectos, minóica, mas que, ao mesmo tempo, se distancia das convenções cretenses, pela sua maior liberdade de concepção, de desenho e de composição, que, como tem sido notado, a aproxima do naturalismo.

Antes, porém, de avançar nesta breve apresentação, façamos um parênteses, para especificar que estas pinturas são habitualmente chamadas frescos, mas, conforme acentuou Christos Doumas, o comentador da obra de Spyridon Marinatos, essa não é a designação apropriada $^{4}$. Efectivamente, a técnica usada não é a mesma. Supõe-se, diz ele, que o artista começava o seu trabalho quando o gesso estava ainda fresco nas paredes, mas que ele não se preocupava em o manter nesse estado, de modo que, quando a pintura ficava completa, já a superfície se encontrava completamente seca. Essa circunstância podia levar a que a cor empregada formasse escamas. De qualquer modo, a parte da parede destinada a ser pintada esfregava-se, supõe-se que com certos seixos, enquanto ainda estava húmida. Assenta esta explicação no facto de se terem encontrado centenas de seixos desses com superfícies lisas, originadas nessa prática. Note-se ainda que, numa e noutra ilha, as cores usadas eram vermelho, negro, amarelo, azul e preto.

Tal como em Creta, encontram-se em Tera motivos humanos, animais e vegetais. É sobretudo a estes últimos que vamos cingir-nos, principiando pela longa pintura que é costume chamar "Paisagem sub-tropical" (fig. 7). Aqui, um rio corre, sinuoso, entre margens onde crescem arbustos e florescem plantas. Numa dessas curvas e contracurvas avista-se um gato selvagem a avançar, rápido, de olhar feroz e boca aberta, em direcção a um pato selvagem desprevenido que, de cabeça voltada para trás, alisa as penas.

No mesmo aposento, vêem-se mais duas pinturas, que representam cada uma, embora em posições diferentes, um pescador a exibir o produto do seu trabalho (fig. 8). Repare-se como os peixes apanhados e presos a uma corda se dispõem simetricamente, tendo por trás um animal da mesma espécie, mas muito maior. A cabeça dos pescadores está envolvida numa espécie de touca pintada de azul, mas com mechas de cabelo negro agarradas. Uma representação semelhante ocorre no chamado "Fresco dos Jogadores de Boxe", onde duas crianças se exercitam na prática desse desporto. Em relação a estes últimos, Marinatos observa que parece tratar-se de cabeleiras, mas a cena poderá ser uma simples brincadeira, e não um combate a sério ${ }^{5}$. De

\footnotetext{
${ }^{4}$ Op. cit., 34.

${ }^{5}$ S. Marinatos 197221.
} 
qualquer modo, tal interpretação não parece poder aplicar-se aos pescadores que temos na nossa frente ${ }^{6}$.

Diversas são as questões suscitadas pelo fresco dos “Antílopes”, da espécie Onyx Beissa, originária da África oriental (fig. 9). Aqui todos admiram a sugestão da rapidez de movimentos desses animais, reforçada pelas linhas mais espessas de alguns contornos. Mas outra questão se põe: tratar-se-á de um motivo sugerido pela arte egípcia, onde ele é frequente, ou da observação directa de animais importados, existentes na fauna insular? Marinatos, que formula estas hipóteses, compara este fresco com o dos "Macacos" (fig. 10), que suscita dúvidas semelhantes à última mencionada, lembrando embora que ela também ocorre em relação à existência desse animal no rochedo de Gibraltar $^{7}$. A este propósito, seja-me permitido lembrar a surpresa com que se soube, há alguns anos, do aparecimento de ossadas de leão no palácio de Diomedes, em Tirinto, quando se julgava até aí que não havia explicação plausível para a presença dessa fera nos símiles homéricos.

Voltando ao fresco dos "Macacos", admira-se nele, e com toda a razão, a sugestão da rapidez na fuga desses animais, por cima dos rochedos. Talvez perseguidos por cães, só o último volta a cabeça para trás.

Exclusivamente vegetal é a decoração do friso da chamada "Casa das Damas" (fig. 11), com tufos de uma planta da família dos papiros (o pancratium maritimum), escalonados ao longo das paredes.

Mas o mais famoso de todos - e só estivemos a apreciar uma selecção - é o denominado "Fresco da Primavera", que ocupa três paredes do aposento $\Delta 2$ (fig. 12). De uma paisagem com altos e pontiagudos rochedos vulcânicos, brotam açucenas em flor, "a mais nobre criação do Festival Mediterrâneo da Primavera", como the chamou Marinatos ${ }^{8}$. O mesmo especialista observou ainda que tanto pode tratar-se do Lilium Candidum como do Lilium Chalcedonicum, ou seja, da açucena vermelha, que só na Grécia se encontra em estado selvagem. A esta profusão de elementos minerais e vegetais, acresce a representação de andorinhas em voo, que não podiam faltar num quadro destes. Ora em pares, como na parede de fundo, ora sozinhas, de perfil, na parede à esquerda do observador, ora de frente, a apanhar um insecto (fig. 13); ou novamente em pares, como na parede à direita (fig. 14) - tudo se conjuga para animar este cenário de vitalidade e de frescura.

$\mathrm{Na}$ ilha de Tera permanecem as casas no lugar onde Marinatos as descobriu (fig. 15). Numa delas, no lugar onde o grande arqueólogo perdeu a vida, guardam-se agora, por uma permissão extraordinária da Igreja Ortodoxa, os seus restos mortais. Os frescos, esses, estão hoje resguardados nas salas do último andar do Museu Nacional de Atenas. Mas todos os anos ressurgem do

\footnotetext{
${ }^{6}$ Note-se que o fresco da chamada "Sacerdotisa" dá uma versão feminina do mesmo uso.

${ }^{7}$ Op. cit., 21.

${ }^{8}$ Op. cit., 20.
} 
solo, entre miríades de flores, as açucenas vermelhas como as do fresco da Primavera.

\section{Anexos}

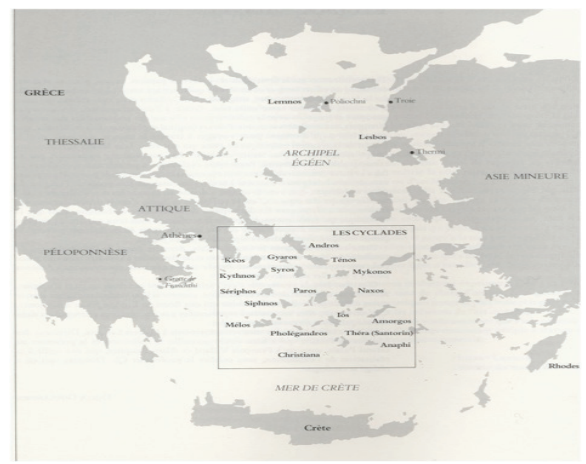

Fig.1. Mapa da Grécia com as Cíclades

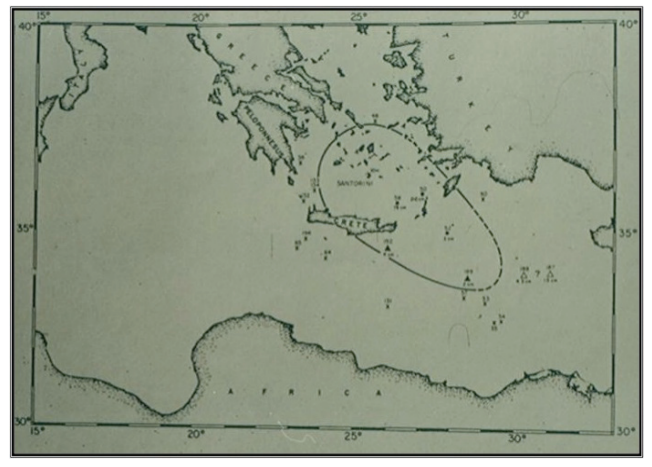

Fig.2. Mapa da ilha de Tera após a erupção 


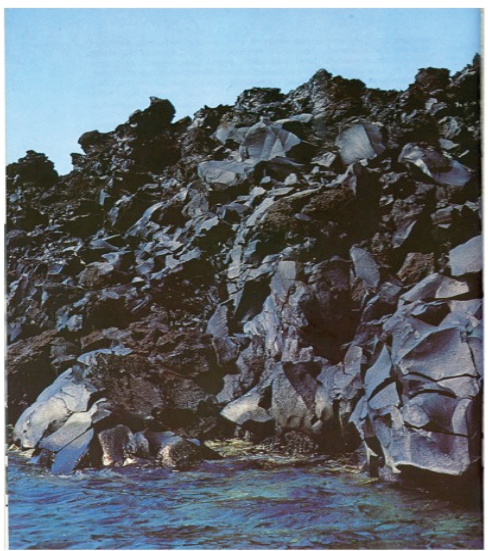

Fig.3. Vista das lavas de Tera

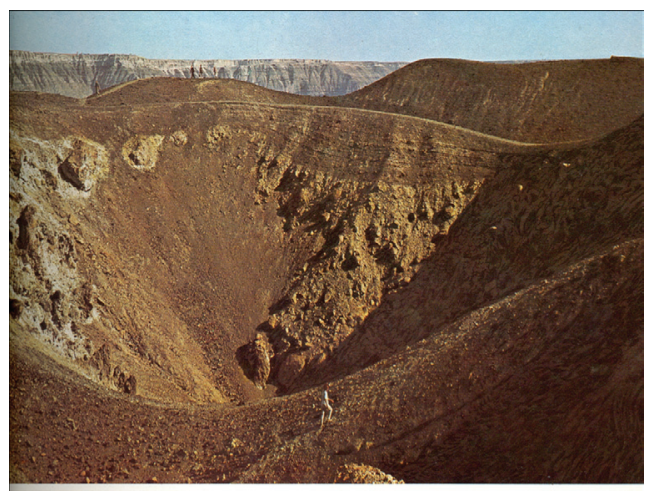

Fig.4. Caldeira 
Os Jardins de Tera

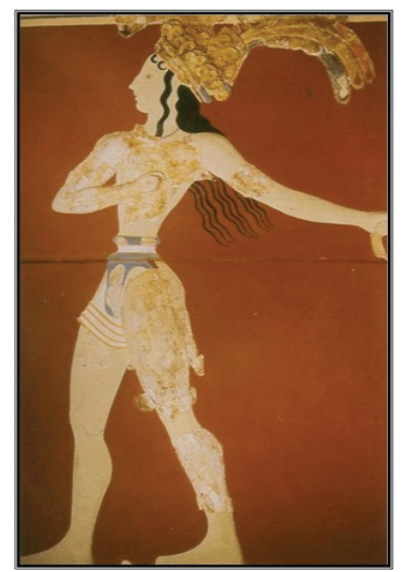

Fig.5. Príncipe das flores de Lis (Creta)

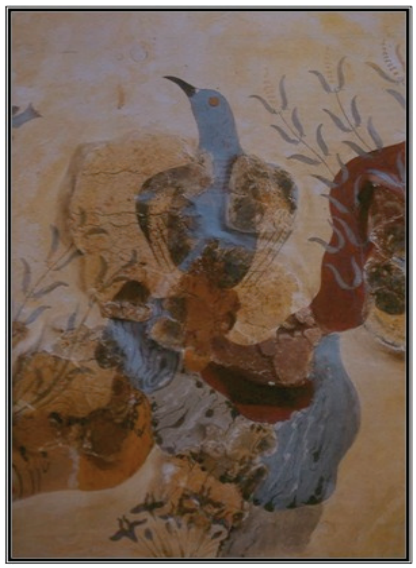

Fig.6. Pássaro Azul (Creta) 
Maria Helena da Rocha Pereira

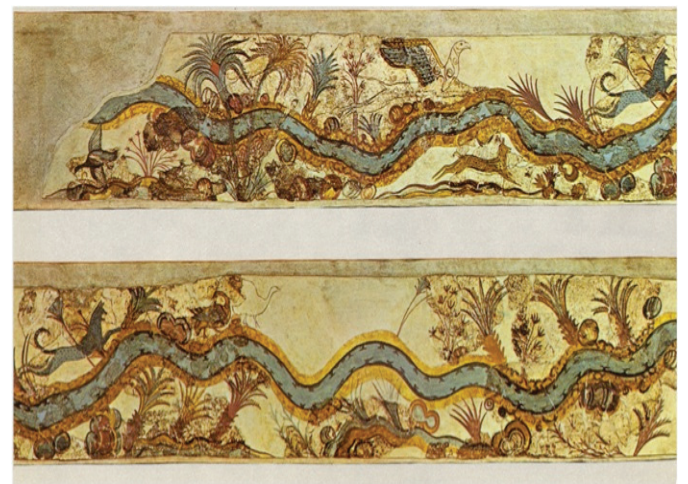

Fig.7. Paisagem sub-tropical
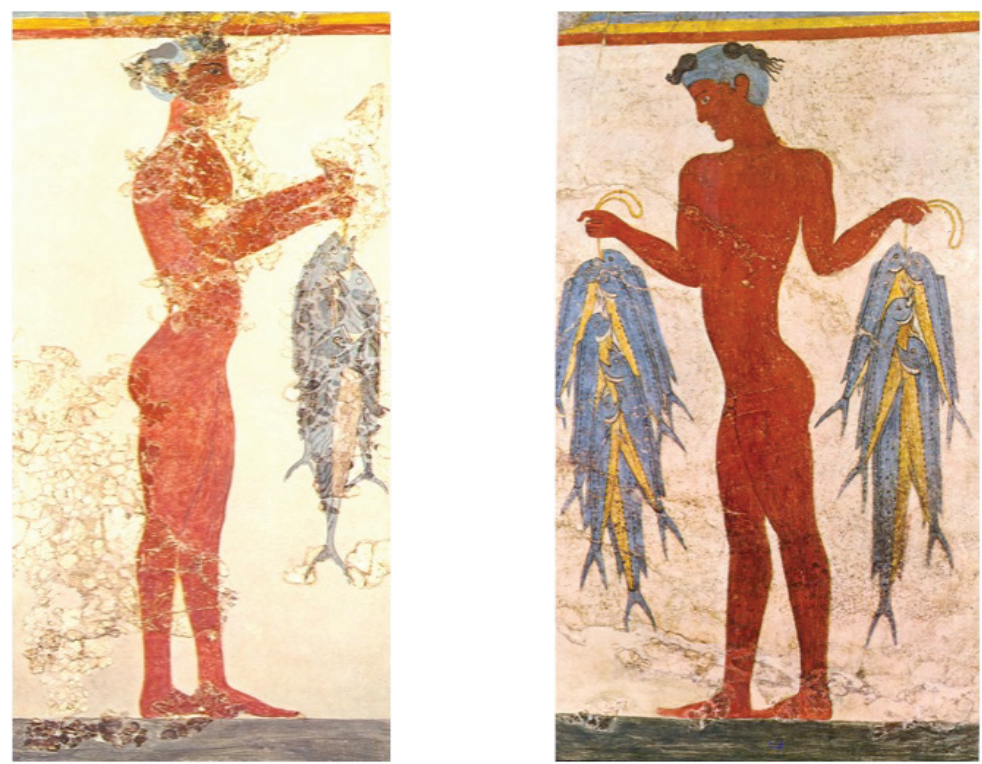

Fig.8. Pescadores 
Os Jardins de Tera

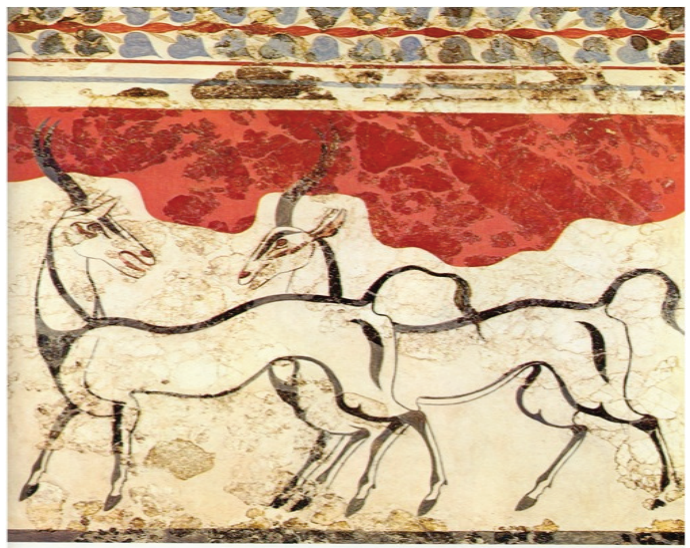

Fig.9. Antílopes

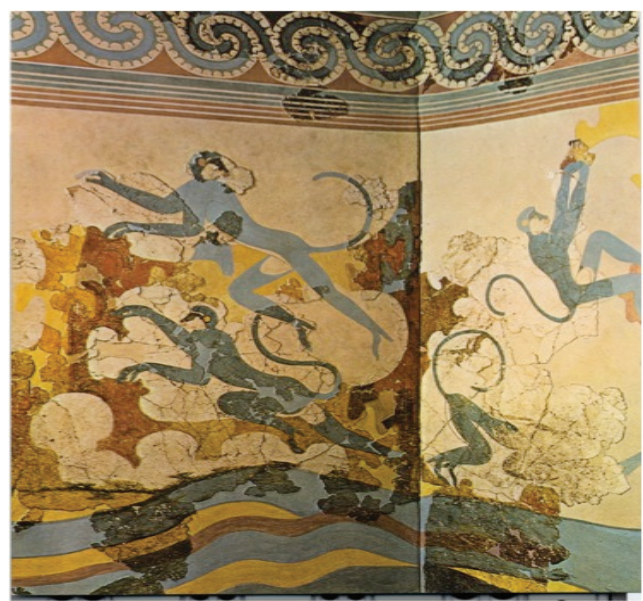

Fig.10. Macacos Azuis 
Maria Helena da Rocha Pereira

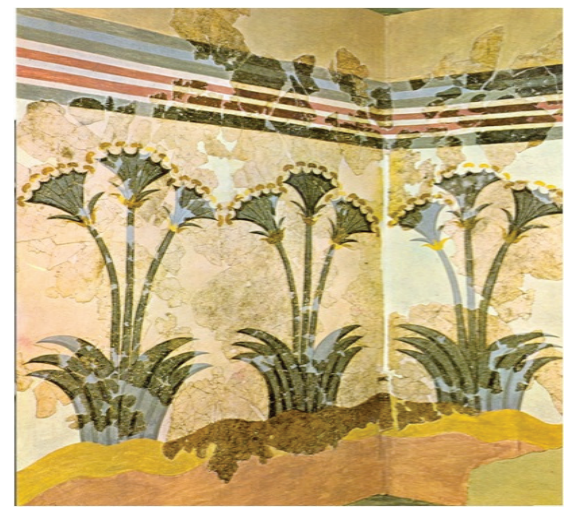

Fig.11. Papiros (pancratium maritimum)

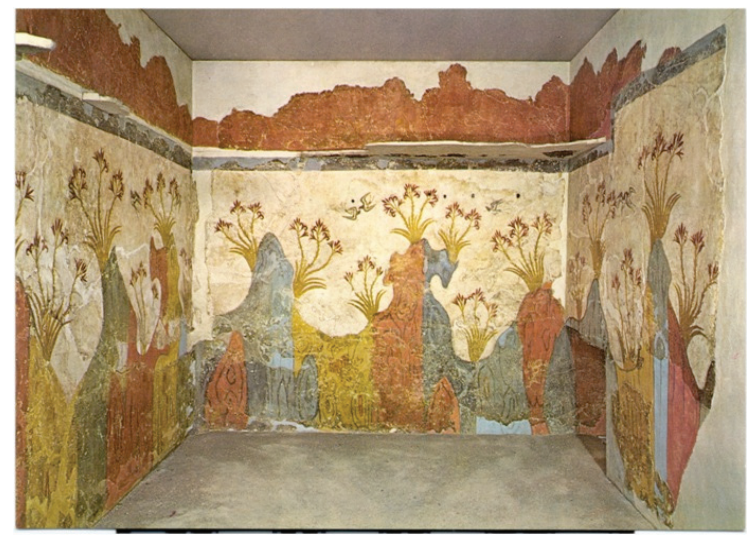

Fig.12. Fresco da Primavera (tudo) 


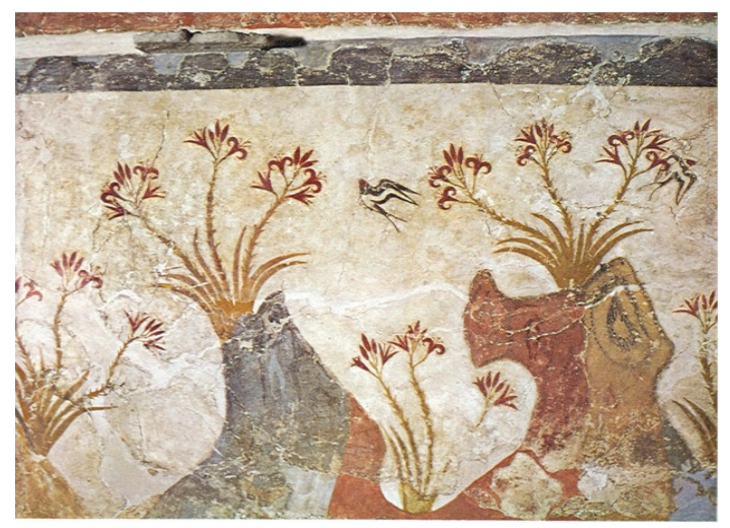

Fig.13. Fresco da Primavera, parede esquerda (andorinha em voo, de perfil; andorinha de frente, a apanhar um insecto)

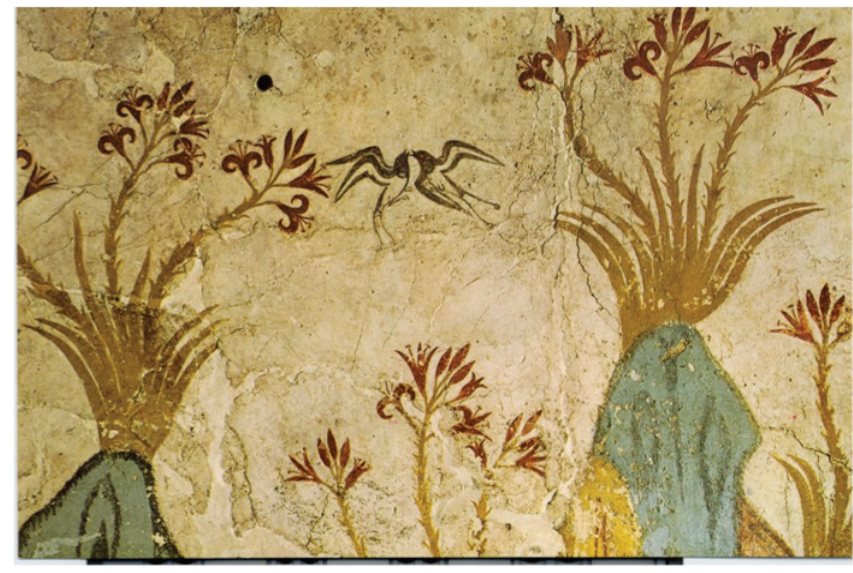

Fig.14. Fresco da Primavera, parede direita (par de andorinhas) 


\section{Bibliografia}

Chr. Doumas (1993), Santorini. A Guide to the Island and its Archaeological Treasures. Athens.

(1979), Santorini et ses éruptions. Paris.

S. Marinatos (1972), Life and Art in Prehistoric Thera. London. 


\title{
DE ETNIA A PROVINCIA: IDENTIDADES COLECTIVAS EN LA LUSITANIA ANTIGUA
}

\author{
Francisco BeLtrán LLORIS \\ Universidad de Zaragoza, \\ Grupo de Investigación Hiberus
}

\begin{abstract}
The ancient world knew different forms of collective identities. Three of them are particularly well attested in ancient sources and frequently addressed by scholars of Roman history: on the one hand, identities regarding ethnicity and the city-state or municipality and, on the other, the Roman one, starting from its civic origins until it reached an imperial scale. The purpose of this paper is to reflect on the construction of collective identities in ancient Lusitania from a double perspective, indigenous and Roman (or resorting to anthropological terminology, emic and etic), and to focus our attention on an intermediate slightly explored level, the province, which goes beyond the city or the ethnos, but stays inside the Roman frame. For this purpose Roman Lusitania is a convenient example, since it had powerful autochthonous cultural roots, it was the result not only of the dynamics of the conquest, but of the administrative imperial needs of Rome as well, and it had to compete with another kind of identity level which was also a product of the integration of the Iberian Peninsula in the Roman Empire: Hispania.
\end{abstract}

Keywords: ancient identities, ethnos, Hispania, Lusitania, province.

Palavras-chave: ethnos, Hispânia, identidades antigas, Lusitânia, província.

\section{Las identidades colectivas en el mundo romano}

El mundo antiguo conoció formas de identidad colectiva muy diversas, entre las que las mejor atestiguadas y más tratadas por los investigadores de la historia romana son las correspondientes a la etnia y a la ciudad-estado o municipio, por un lado, y la propiamente romana, desde sus orígenes cívicos hasta alcanzar una dimensión imperial, por otro ${ }^{1}$. El propósito de estas páginas es reflexionar sobre la formación de las identidades colectivas en el occidente de Hispania desde la doble perspectiva local y romana - o emic y etic, si se prefiere la terminología antropológica - , centrando la atención en un ámbito intermedio, menos explorado y muy fragmentariamente documentado, que desborda el marco ciudadano y étnico, pero queda comprendido dentro del romano imperial. Me refiero al ámbito provincial y, en concreto, al que ofrece Lusitania, una demarcación con poderosas raíces culturales autóctonas, pero fruto también de la dinámica histórica impuesta por la conquista así como

${ }^{1}$ Sobre las identidades colectivas en el mundo romano, véase recientemente E. Dench 2005; G. D. Farney 2007; y el luminoso ensayo de A. Giardina 2000; además, E. S. Gruen 1992; B. Linke y M. Stemmler 2000; F. Pina 2004; F. W. Walbank 1972; R. Laurence y J. Berry 1998; R. Miles 1999. Para el mundo griego son fundamentales J. M. Hall 1997; y N. Loraux 1981; recientemente J.-M. Luce 2007. Más general, Chr. Müller y F. Prost 2002. Para la Península Ibérica, entre otras aportaciones, G. Cruz Andreotti y B. Mora 2004; y F. Beltrán Lloris 2002. 
de las necesidades administrativas imperiales de Roma, e inextricablemente unida a una realidad más amplia de carácter no administrativo, pero surgida también como consecuencia de la integración de la Península Ibérica en el Imperio Romano: Hispania ${ }^{2}$.

Frente a las identidades municipal o romana, que, más allá de connotaciones culturales, se encuentran profundamente marcadas por su carácter político y por su vinculación con el ejercicio de unos derechos cívicos, las que vamos a explorar primordialmente aquí son de tres tipos: aquéllas fundamentadas en lazos de carácter étnico - como puedan ser las correspondientes a vetones, lusitanos, célticos, etc.- , que, pese a ser conocidas básicamente a través de los testimonios literarios clásicos, al menos en parte son previas a la integración de las comunidades hispanas en el mundo romano y pueden ser rastreadas a través de la documentación lingüística, los testimonios religiosos o el registro material ${ }^{3}$; las derivadas de las divisiones administrativas creadas por Roma, y ante todo de las provinciales, capaces de generar vínculos de unión entre comunidades e individuos a través de la dependencia de una administración común, de la práctica de los concilia prouinciae con sus manifestaciones de culto imperial, de los conuentus iuridici y otros mecanismos semejantes; y, finalmente, las surgidas de las necesidades de diferenciación en el seno del Imperio frente a otras comunidades culturales más vastas como los Itálicos, los Galos, los Germanos o los Griegos, por ejemplo.

Más, en concreto, el propósito específico de esta intervención es determinar, por una parte, si la creación de la provincia Lusitania responde más a la existencia de unos determinados vínculos entre las poblaciones comprendidas dentro de esos límites administrativos que a las necesidades administrativas de Roma, y si, independientemente de ello, esa realidad provincial contribuyó a generar una personalidad propia entre sus habitantes. Desde esta perspectiva, resulta primordial tener en cuenta que estas identidades colectivas carentes de virtualidad política deben ser entendidas ante todo como referentes mediante los cuales un individuo o un grupo se define en un determinado contexto cultural ${ }^{4}$, y, por lo tanto, como construcciones de perfiles vagos, cambiantes y sucesivamente reelaborados en función de las circunstancias históricas, que son extraordinariamente

\footnotetext{
${ }^{2}$ Entre el 8 y el 10 de mayo de 2008 tuvo lugar en Sevilla una reunión convocada por A. Caballos y S. Lefebvre sobre La construcción de la identidad provincial. La experiencia romana, en la que se expusieron diversas comunicaciones que afectan directa o indirectamente al tema del que nos ocupamos aquí, especialmente las contribuciones de S. Lefebvre, "Onomastique et identité provinciale: le cas de Lusitanus” y F. Beltrán Lloris, “... et sola omnium prouinciarum uires suas postquam uicta est intellexit. Hispania como referente identitario en el mundo romano". Una de las conclusiones alcanzadas en esta reunión fue precisamente la debilidad de las identidades provinciales peninsulares frente a la común hispana.

${ }^{3}$ Sobre las identidades étnicas puede verse el volumen de Cruz Andreotti y Mora 2004, particularmente F. Beltrán Lloris 87-145 sobre los celtíberos, y, más recientemente sobre los vascones F. Beltrán Lloris y J. Velaza 2009.

${ }^{4}$ Así, J. Huskinson 2000, espec. 10.
} 
difíciles de definir en términos objetivos, sobre todo cuando no se cuenta con testimonios discursivos endógenos - emic - a través de los cuales se especifique en qué vínculos se fundamenta ${ }^{5}$, como es el caso habitualmente en sociedades periféricas como las que ahora nos ocupan, según he tenido oportunidad de valorar, por ejemplo, a propósito de los celtíberos ${ }^{6}$. Así, a diferencia de los levísimos indicios que suministra el bilbilitano Marcial cuando se declara "nacido de Celtas e Iberos" (IV 55), poniendo el énfasis en el criterio de descendencia, o cuando se define como hispano frente a un griego de Corinto (X 65), recurriendo a rasgos físicos y culturales ${ }^{7}$, no se conserva ningún testimonio semejante a propósito de Lusitania, aunque en este sentido puedan proporcionar algunos indicios, como se verá más adelante, tanto la cultura material como, sobre todo, las inscripciones de época imperial.

\section{Los lusitanos y los restantes pueblos del occidente peninsular}

El mapa étnico del territorio que terminó por convertirse en la provincia de Lusitania no resulta fácil de fijar como consecuencia de las discrepancias que se derivan de la diferente cronología de nuestras fuentes literarias y de las no pocas contradicciones entre éstas, si bien los autores modernos tienden a establecer una nómina compuesta fundamentalmente por los Conios o Cinetes, mencionados sólo por las fuentes más antiguas como Heródoto (II 33; IV 49) o Polibio (X 7, 4), y los Turdetanos, en el Algarbe ${ }^{8}$, por los Célticos a caballo del Guadiana ${ }^{9}$, y, más al norte, entre el Tajo y el Duero, por los Lusitanos al oeste y por los Vetones ${ }^{10}$ en el interior ${ }^{11}$. Naturalmente, está breve lista debe considerarse tan sólo como una simplificación de un panorama sin duda más complejo: el propio Estrabón, cuando describe las tierras situadas al norte del Tajo y tras mencionar a los pueblos a su juicio más relevantes, señala que "los demás no son dignos de mención a causa de su reducido tamaño y su falta de renombre" (Strb. III 3, 3) ${ }^{12}$, y, en otro pasaje, sitúa la colonia Emerita Augusta

${ }^{5}$ Hall 199724 subraya cómo, según las circunstancias, pueden desempeñar un papel determinante o secundario rasgos como la creencia en un ancestro común, la existencia de una historia compartida, la religión, la lengua, la asociación con un territorio, las costumbres, etc., como, en el caso griego, queda bien de manifiesto en las diferentes definiciones de la helenidad sostenidas por Heródoto 8.144 e Isócrates. Paneg. 50.

${ }^{6} \mathrm{Al}$ respecto, F. Beltrán Lloris 2004 91-92.

${ }^{7}$ Farney 2007238 ss.; F. Beltrán Lloris (cit. n. 2).

${ }^{8}$ Tabula Imperii Romani. Hoja J-29: Lisboa (= TIR J-29), Madrid 1995, 66. Ptolomeo (II $5,2)$ atribuye a los turdetanos una serie de ciudades litorales como Balsa, Ossonoba o Salacia.

${ }^{9}$ TIR J-29, 60-61; L. Berrocal-Rangel 1992.

${ }^{10}$ TIR J-29, 162-163; M. Salinas 2001; sobre Viritato y los Lusitanos R. López Melero 1988.

${ }^{11}$ Sobre los pueblos indígenas véanse, por ejemplo, las síntesis de J. Alarcão 1974 17-20; C. Fabião 1993 79-299, espec. 168 ss.; o M. Salinas y J. Edmonson 2003 45-56, espec. 47.

${ }^{12}$ Para Estrabón, seguimos la traducción de J. Gómez Espelosín, G. Cruz Andreotti y M. V. García Quintela 2007. 
en tierras de los túrdulos (Strb. III 2,15), pueblo que según Plinio se extendía por las regiones béticas vecinas de la Beturia (NH III 13).

Precisamente a propósito de los Célticos, cuyo territorio étnico quedó dividido a partir de Augusto entre la Bética y la Lusitania, conservamos una de las pocas observaciones que los autores clásicos nos han dejado acerca de los criterios que, a sus ojos - es decir desde una perspectiva etic - , podían definir a un pueblo hispano. Se trata del comentado pasaje de Plinio en la descripción de la Bética donde señala: "Celticos a Celtiberis ex Lusitania aduenisse manifestum est sacris, lingua, oppidorum uocabulis, quae cognominibus in Baetica distinguntur", es decir "Los Célticos, de la estirpe de los Celtíberos, es evidente que llegaron desde la Lusitania a juzgar por su religión, su lengua y los nombres de las ciudades que en la Bética se distinguen por sus epítetos" (NH III 13), como resulta evidente en la sucesiva lista de ciudades béticas con topónimos claramente célticos, como Nertobriga o Segida, acompañados de cognomenta como Concordia Iulia o Restituta Iulia. Sin entrar ahora en el comentario detallado de este controvertido pasaje ${ }^{13}$, resulta evidente que Plinio consideraba afines a los Célticos de la Bética y a los que vivían al otro lado de la frontera lusitana - y también a los celtíberos - por compartir prácticas religiosas, lengua y topónimos, éstos, claramente diferenciados a sus ojos de los de pueblos béticos como los turdetanos o los bastetanos que, a diferencia de ellos, no pertenecían a la familia céltica con la que los autores clásicos se encontraban bien familiarizados - , pero semejantes a los de ciudades lusitanas como Augustobriga, Caesarobriga, Mirobriga, etc. ( $N H$ IV 118), que como la Nertobriga bética exhibían topónimos con el típico formante - briga.

Todo ello pone de manifiesto cómo, desde un punto de vista cultural, y desde la perspectiva etic de los autores clásicos, la lengua y la religión eran criterios que podían servir para definir la etnicidad, aunque ello no demuestra, desde luego, que para esos mismos pueblos hispanos fueran los criterios que determinaran fundamentalmente su cohesión.

De las etnias de Lusitania, la mejor documentada y la de mayor relevancia histórica es la éponima de la provincia, los Lusitanos, de quienes, al margen de su mención como mercenarios de Aníbal en 218 a. E. ${ }^{14}$, existen noticias desde comienzos del siglo II a. E., pues ya en 194 a. E. Livio documenta sus incursiones en las zonas pacificadas de la Hispania Ulterior (Liv. 35.1), que diez años después, en 184, motivaron la celebración de un triunfo ex Lusitanis et Celtiberis, como consecuencia de una campaña desarrollada en las cercanías de Toletum, en plena Carpetania (Liv. 39. 30-31). Junto con los celtíberos, los lusitanos protagonizaron la más dura resistencia que las armas romanas encontraron en Hispania, cuyos mejores símbolos son la figura de Viriato y las guerras de la segunda mitad del siglo II a. E., si bien sus acciones se desarrollaron normalmente fuera de sus fronteras, de suerte que hasta fines

\footnotetext{
${ }^{13}$ Del que me ocupo en 1994 ("Plin. NH III 13-14"), y 2005, y en 2004110.
}

${ }^{14}$ Liv. 21. 43; 57. 
de esa centuria no se emprendió la conquista y pacificación de su territorio patrimonial, en el que todavía había de intervenir César durante su gobierno de la Ulterior en 62 a. E. (Cass. Dio 37. 52; Liv. per. 103).

Si se exceptúa el testimonio de Estrabón relativo a unos grupos de lusitanos deportados por los romanos al sur del Tajo ${ }^{15}$, desde los tiempos de la conquista los historiadores señalan los límites del solar lusitano entre este río y el Duero (App. Iber. 57, 64, 73), si bien el geógrafo de Amasia parece dar a entender en varios pasajes que hasta hacía poco tiempo abarcaban también Galecia, al referirse a los ártabros como los pueblos más remotos de Lusitania hacia el norte (III 2,9) y al afirmar que a las gentes situadas al norte del Duero "unos llamaban anteriormente lusitanos y otros en la actualidad llaman galaicos" $(3.4,20)$, explicando este hecho porque los galaicos "como eran difíciles de combatir proporcionaron el sobrenombre al que había vencido a los lusitanos [e. d., Décimo Junio Bruto Galaico], y fueron la causa de que en la actualidad se les denomine galaicos a la mayor parte de los lusitanos"16 $(3.3,2)^{17}$.

Sin embargo y sin cuestionar la evidente afinidad cultural entre galaicos y lusitanos, esta explicación no resulta del todo convincente, pues todo induce a pensar que la designación de los pueblos del Noroeste como Galaicos no era un hecho reciente, como supone Estrabón y da por sentado la mayor parte de los historiadores modernos, sino que se remontaba cuando menos hasta el momento mismo en que Roma exploró por primera vez las tierras gallegas, es decir con la expedición conducida por Bruto en 138 a. E.: de otra forma, no tendría sentido ni el sobrenombre 'Galaico' que éste adoptó tras esa campaña ni que los Fasti triumphales recojan la celebración en 133 a. E. de su triunfo como ex Callaecis et Lusitanis. Lo que, a cambio, sí se había producido poco tiempo antes de que escribiera Estrabón era la rectificación de fronteras entre la Lusitania y la Tarraconense con la transferencia a ésta de los territorios de Asturia y Galecia antes pertenecientes a la provincia Ulterior ${ }^{18}$. Aquí radica seguramente el origen de las dudas de Estrabón, que confunde las realidades a las que designa el término Lusitania, la provincial y la étnica: los galaicos, efectivamente, habían estado vinculados a la Hispania Ulterior desde fines del siglo II a. E. hasta época de Augusto, pero dista de estar demostrado que hubieran formado parte de una sola etnia junto con los lusitanos.

\section{La provincia Lusitania}

Como es bien sabido, la división de la Hispania Ulterior en dos provincias $\mathrm{y}$, en consecuencia, la creación de Lusitania difícilmente pudo producirse en 27 a. E., pese al testimonio de Casio Dión (53.12, 4 s.), sino algunos años más tarde, tras el segundo viaje de Augusto a Hispania en 15 a. E. (Cass.

\footnotetext{
${ }^{15}$ Sobre las deportaciones, F. Pina 2004.

${ }^{16}$ Sobre los galaicos, G. Pereira 1984.

${ }^{17} \mathrm{Al}$ respecto de estos pasajes véanse los comentarios de Cruz Andreotti y García Quintela 2007 412-415.

18 También Plinio refleja esta situación cuando suministra las medidas de Lusitania incluyendo Asturia y Galecia (NH III 118).
} 
Dio $54.25,1)$, probablemente en torno al año 13 a. E., cuando el número de legiones estacionadas en Hispania se redujo a tres o cuatro en relación con el inicio de la política expansiva en el Rin y el Danubio ${ }^{19}$. En este momento se dividió la Ulterior en dos provincias, Bética y Lusitania, y se transfirieron los territorios de Galecia y Asturia, hasta entonces dependientes de la Ulterior, a la Citerior, convertida ahora en una provincia de rango consular, que es la situación que testimonia Estrabón $(3.4,20)$.

Según todos los indicios, la transferencia del noroeste hispánico a la Hispania Citerior fue consecuencia, ante todo, de las necesidades militares, que aconsejaban concentrar bajo un solo mando las tres legiones acantonadas en la región, dos en Asturia y otra en Cantabria, así como probablemente del deseo de reunir los recursos mineros del noroeste y del sureste en la misma circunscripción provincial ${ }^{20}$, pese a la notable extensión que con ello adquiría la Tarraconense, convertida así en la provincia más vasta del Imperio y la única de occidente - además de la Bética - que contaba con amplias fachadas al Mediterráneo y al Atlántico ${ }^{21}$. Por otra parte, la incorporación en una sola provincia de las tierras comprendidas entre Galecia y el Mediterráneo generaba un acusado contraste en su seno al oponerse las regiones más orientales correspondientes a pueblos de lengua ibérica o celtibérica, pacificadas desde tiempo atrás y dotadas de abundantes colonias y municipios, y las de occidente, de lengua indoeuropea, recién incorporadas, apenas urbanizadas y carentes de comunidades privilegiadas.

Por el contrario, en el caso de la provincia Ulterior el criterio fue distinto y se asemeja más al aplicado en las Galias, en donde frente a la Narbonense mediterránea, más antiguamente romanizada, se crearon en la fachada atlántica tres provincias independientes - Aquitania, Lugdunense y Bélgica - entre las que se distribuyeron las tierras conquistadas por César ${ }^{22}$. Así, por un lado, las tierras turdetanas e ibéricas, más tempranamente sometidas y más densamente dotadas de comunidades privilegiadas fueron integradas en una provincia, la Bética, que fue transferida por Augusto al senado, mientras que las regiones que se extendían entre el Guadiana y el Duero con su amplia fachada atlántica pasaron a constituir la provincia imperial de Lusitania, en la que, como en la Tarraconense, cabe distinguir dos áreas bien diferenciadas: una al sur del Tajo y en sus riberas, coincidente con el solar de los Célticos, Túrdulos y demás pueblos meridionales, en la que se concentraban las cinco colonias -Emerita Augusta (Mérida), Metellinum (Medellín), Pax Iulia (Beja), Norba Caesarina (Cáceres) y Scallabis (Santarém)-, el único municipio romano -Olisipo (Lisboa) - y los tres latinos -Ebora (Évora), Myrtilis (Mértola) y Salacia (Alcácer

${ }^{19}$ G. Alföldy 1969206 ss., 223 ss.; P. Le Roux 198284 ss. Ver contra L. Pérez Vilatela 2000. Sobre los viajes de Augusto a Hispania ver ahora J. M. Abascal 2006.

${ }^{20}$ La incorporación de las comarcas más orientales de la Ulterior Bética en la Tarraconense se produjo en un momento indeterminado entre 27 y 2 a. E., Alföldy 1969 225, nota 9.4.

${ }^{21}$ Acerca el papel que en esta decisión pudo tener la percepción de la Cordillera Cantábrica como una prolongación de los Pirineos, F. Beltrán y F. Pina 1994, espec. 121 ss.

${ }^{22}$ Beltrán y Pina 1994118. 
do Sal) - , todos ellos creados por César y Augusto (Plin. NH III 117); y otra, al norte del Tajo, mucho menos urbanizada y carente de comunidades privilegiadas, correspondiente grosso modo al solar de los Lusitanos y de los Vetones.

Esta división, en cualquier forma, contaba con algún precedente como el establecido por Pompeyo, quien en vísperas de la guerra con César distribuyó a sus tres legados situando a uno en la Hispania Citerior, a otro en la parte oriental de la Ulterior comprendida entre Castulo y el Guadiana, mientras que al tercero le confió las tierras occidentales situadas más allá del Guadiana Vettonum agrum Lusitaniamque - ${ }^{23}$, circunstancia que refuerza la condición estratégica de esta partición provincial.

Esta desigualdad entre sur y norte quedó plasmada en la designación como capital de Emerita, la colonia fundada por Augusto en 25 a. E., pese a ocupar una excéntrica situación, más adecuada para asegurar una rápida comunicación con el sur que como centro de vertebración de la provincia ${ }^{24}$, y con la ubicación en Pax Iulia y en Scallabis de las otras dos sedes de los conuentus iuridici, de manera que Scallabis y Emerita se convertían en los referentes para toda la mitad septentrional de la provincia que, de esta manera, dependía administrativamente - o judicialmente, al menos - de la mitad meridional, al tiempo que, en la gestión fiscal se compartían recursos con la Bética caso de la percepción de la uicesuma hereditatium que desde fines del siglo II d. E. dependía de un procurador per Hispanias Baeticam et Lusitaniam $^{25}$.

Si dejamos la perspectiva romana y centramos la atención en los rasgos culturales a los que las inscripciones y la cultura material permiten acceder, queda más reforzada aún esta contraposición entre las dos mitades, septentrional y meridional, de la provincia.

Atendiendo a la onomástica, en primer lugar ${ }^{26}$, la dispersión de los antropónimos permite dibujar dos áreas fundamentales. Una, meridional, corresponde al antiguo convento pacense y al moderno territorio portugués delimitado al norte por el Tajo, en la que la onomástica indígena es escasa y consiste en nombres específicos (Accenia, Betac(i)us, Bolb(i)us, Boudelus, Coilicus, Dobetianus) o bien vinculados con la Celtiberia en el territorio de los Célticos (Aplondus, Letondo, Mermandus), un hecho que parece dar la razón al citado comentario de Plinio en NH III 13. La mitad septentrional coincide con los territorios de Lusitanos y Vetones, en la que cabe señalar nombres de dos tipos: unos cuya dispersión afecta también al noroeste de la Tarraconense - a Galecia y Asturia sobre todo-(Pent-, Pint-Talau-, Talab-, Lobes(s)a / Louesius, Catur-) y otros que se localizan, exclusivamente o casi, dentro de los

${ }^{23}$ Caes. BC I 38; como señalara P. P. Spranger 1960, espec. 136.

${ }^{24}$ Sobre Emerita véase, por ejemplo, J. C. Saquete 199721 ss.

${ }^{25}$ M. Ojeda 1993 núms. 13, 15 y 20.

${ }^{26} \mathrm{Al}$ respecto véanse las clarificadoras observaciones de J. Gorrochategui y J. M. Vallejo, "La onomástica indígena", a la que remito para la documentación de los antropónimos que se citarán a continuación, y la monografía de J. M. Vallejo 2005 que actualizan las aportaciones de J. Untermann 1965 y M. L. Albertos 1983. 
límites de la provincia lusitana $(A l(l) u(c) q(u) i u s$, Sunua, Apan- / Apin-, Mae(i) l-, Tanc- / Tang-, Tonc-/Tong-), aunque excluyendo, además del convento pacense, la parte lusitana de Badajoz — túrdulo, según Estrabón-, el este de Salamanca y la provincia de Ávila, circunscripción esta última que cuenta con nombres exclusivos (Abata, Aelcius, Aetara, Arcatus, Ariucia, Arrellius, Balarus, Cadanus, Corconona, Culantius, Cuttira, Elgiamus, Monoua, Pusus, Titalus, Vaelcio), de manera que su extensión parece coincidir básicamente con los territorios de los antiguos lusitanos y vetones.

De esta zona proceden precisamente los cinco únicos textos conocidos hasta ahora en lo que se ha dado en llamar "lengua lusitana", en su mayoría pertenecientes al período imperial, aunque alguno como el recientemente descubierto en Arronches parezca de fecha temprana (¿I a. E.?) ${ }^{27}$.

Si ahora pasamos a los testimonios teonímicos, se observa un estado de cosas similar al de la antroponimia, pues se detecta una serie de nombres de dioses característicos del Noroeste, cuya dispersión afecta al área galaica - algunos exclusivos de ella como Cosus - y al norte de Lusitania, es decir al territorio étnico de los lusitanos (Bandua, Reue o Nabia). A cambio, privativos de Lusitania son los focos más concentrados regionalmente en los que se localizan los testimonios cultuales de Trebaruna en el solar lusitano, de Endouelicus, en el santuario de San Miguel da Mota (Alto Alentejo), y el de Ataecina con una mayor dispersión a partir del santuario de Santa Lucía del Trampal (Alcuéscar, Cáceres). Debe subrayarse, no obstante, que el fenómeno de los grandes santuarios así como el de los cultos regionales es por ahora un hecho característico del territorio occidental hispano, desde Galecia hasta San Miguel da Mota, frente a la Celtiberia o la Meseta donde dominan con algunas salvedades los teónimos epicóricos atestiguados en un solo $\operatorname{lugar^{28}}$. Por otra parte, junto a los cultos de raíces indígenas y los clásicos importados, debe señalarse también la emergencia de otros propiamente provinciales como los correspondientes a Iuppiter Repulsorius y Iuppiter Solutorius registrados en torno al curso medio del Tajo ${ }^{29}$.

Ahora bien, estos vínculos de afinidad entre las regiones septentrionales de Lusitania y Galecia tienen sus limitaciones. Así, determinadas manifestaciones culturales como las esculturas zoomorfas conocidas como 'verracos' tienen su área de difusión fundamentalmente por el territorio de lusitanos y vetones y áreas próximas de la $\mathrm{Citerior}^{30}$, mientras que al norte del Duero, en el territorio

${ }^{27}$ J. Untermann 1997 L.1.1, L.2.1, L.3.1; F. Villar y R. Pedrero 2001; A. Carneiro, J. d'Encarnação, J. de Oliveira y C. Teixeira 2008: la cronología temprana de la inscripción de Arronches, basada fundamentalmente en criterios paleográficos - P abierta, por ejemplofue sugerida durante las discusiones habidas en el $X$ Coloquio sobre lenguas y culturas paleohispánicas celebrado en Lisboa en febrero de 2008 (Acta Palaeohispanica X = Palaeohispanica 9, en prensa, que no recogen los resultados de la mesa redonda sobre el epígrafe de Arronches).

${ }^{28}$ Véase al respecto la síntesis de F. Marco 1999 y la monografía de B. M. Prósper 2002.

${ }^{29}$ F. Beltrán Lloris 2001-2002.

${ }^{30}$ J. Álvarez Sanchís 1999224 y mapa contiguo, y 345-373 con la difusión de los verracos, que abarca las provincias españolas de Ávila, Cáceres, Salamanca, Toledo, Zamora y Segovia, 
galaico se extiende la zona de los castros, reflejados en la epigrafía por el empleo del término castellum como origo, desconocido en Lusitania ${ }^{31}$, con manifestaciones escultóricas características como las 'pedras formosas' o los 'guerreros' ${ }^{32}$, diferencias que separan claramente el norte de Lusitania de Galecia $^{33}$.

Por otra parte y dentro de Lusitania debe señalarse la oposición, muy relevante en el terreno social, que supone la presencia de los grupos familiares comúnmente denominados 'organizaciones suprafamiliares', característicos del ámbito celtibérico y meseteño, exclusivamente en el territorio vetón (Salamanca, Ávila, Toledo y Cáceres) frente a su absoluta ausencia en el territorio lusitano ${ }^{34}$.

En definitiva, pues, y por no multiplicar estas observaciones, desde el punto de vista indígena y provincial, entendiendo como tal una serie de manifestaciones que poseen raíces vernáculas aunque se desarrollen fundamentalmente tras la conquista romana - mayoritariamente en época imperial - y en las que, por lo tanto, pudo jugar un papel importante la dinámica provincial introducida por Roma, el territorio sobre el que se constituyó la provincia Lusitania muestra tanto factores propios - aunque generalmente con una oposición entre las regiones situadas al norte y al sur del Tajo - como vinculaciones con las regiones vecinas de la Tarraconense y la Bética, de manera que se pueden señalar tanto elementos compartidos entre los territorios de galaicos, lusitanos y vetones como otros peculiares de cada uno de ellos o que encuentran afinidades en otras zonas de Hispania.

\section{Indicios de identidades colectivas}

Como se ha dicho, la integración de la Península Ibérica en el Imperio Romano propició la formación de diversos referentes identitarios y colectivos: (i) unos de carácterétnico, reforzando o reelaborando vínculos presumiblemente preexistentes, cuyo reflejo sobre diferentes indicadores culturales hemos examinado en el apartado anterior, caso de los correspondientes a Célticos, Túrdulos, Lusitanos, Vetones o Galaicos; (ii) otros generados a partir de hechos culturales y vicisitudes históricas como queda ilustrado por la designación supraétnica de carácter erudito que representa el término Celtíberos, aplicado

además de algunos casos en Burgos, Pontevedra, Orense y Lugo, y las circunscripciones portuguesas de Beira Alta, Beira Baixa, Douro Litoral, Minho y, sobre todo, Trás-os-Montes.

${ }^{31}$ M. L. Albertos 1975; G. Pereira 1978.

${ }^{32}$ Sobre las estatuas de guerreros, cuya difusión geográfica abarca desde el Duero hasta el Miño con Lugo como punto más septentrional y Alfândega da Fé como límite oriental esto es la zona correspondiente al convento bracaraugustano-, véase la breve síntesis de L. J. Gonçalves 2007 y las contribuciones correspondientes al seminario Die lusitanischgalläkischen Kriegerstatuen.

${ }^{33}$ Una síntesis de los pueblos galaico y lusitano en A. C. F. da Silva 2001 335-349 y bibliografía 391-392, quien pese a tratar estos dos pueblos conjuntamente, señala las marcadas diferencias entre la zona castreña situada al norte del Duero y la lusitana, cuyo estudio con razón separa Fabião 1993180 ss, 190 ss.

${ }^{34}$ M. C. González 1986; M. Salinas y J. J. Palao 2003. 
a una serie de pueblos célticos como los Belos, Titos, Lusones o Arévacos que se opusieron a Roma en el curso del siglo II a. E., y probablemente por la extensión a partir de fines del siglo II a. E. del término Galaicos a las comunidades situadas al norte del Duero; (iii) otros sustentados básicamente en criterios administrativos como son los provinciales o los conventuales; y, finalmente, (iv) los derivados de la aplicación al conjunto de los pueblos peninsulares de una común identidad hispánica.

Hay indicios consistentes de que estos cuatro tipos de referentes identitarios, sin entrar ahora en su entidad efectiva, fueron interiorizados por los habitantes de la Península Ibérica haciéndolos compatibles a la vez con su condición de munícipes de una determinada comunidad y de integrantes del Imperio Romano. Así, por citar sólo algunos ejemplos, Marcial se manifiesta en sus poemas como bilbilitano, celtíbero, hispano y ciudadano romano ${ }^{35}$; un flamen provincial de la Hispania Citerior y su mujer se proclaman en el siglo II d. E. el uno, Lucio Antonio Modesto, Intercatiensis ex gente Vaccaeorum y la otra, Petinia Paterna, Amocensis Cluniensis ex gente Cantabrorum en una inscripción de Tarraco $^{36}$, combinando referentes municipales, conventuales y étnicos; y en las tábulas de hospitalidad y patronato las ciudades hispanas precisan su situación con diversas referencias geográficas, étnicas o administrativas: la ciuitas Bocchoritana de Mallorca, ex insula Baliarum maiore ${ }^{37}$; la ciuitas Lougeiorum, ex gente Asturum conuentus Arae Augustae ${ }^{38}$; Clunia y Baetulo, ex Hispania citeriore ${ }^{39}$, al igual que los Coelerni, que añaden su pertenencia al conuentus Bracarus ${ }^{40}$, y Munigua que se caracteriza como Hispaniae Vlterioris ${ }^{41}$.

Por desgracia, los indicios disponibles para examinar la cuestión en Lusitania son mucho menos abundantes y sólo permiten señalar ciertas tendencias.

(i) Por un lado, pueden resultar significativos determinados nombres personales formados a partir de étnicos como parece ser el caso de Vetto que, a juzgar por su dispersión, está vinculado al territorio de los Vetones ${ }^{42}-$ observación que, a cambio, no parece que pueda hacerse extensiva al nomen Vettius $^{43}$-, en lo que puede suponer una cierta asunción de una identidad vetona, corroborada también, desde la perspectiva administrativa romana, por la denominación de las unidades de auxiliares y de los procuratores prouinciae

\footnotetext{
${ }^{35}$ Beltrán Lloris 2004133 ss,

${ }^{36}$ CIL II 4233.

37 AE 1957 317; CIL II 3695.

38 AE 1984553.

${ }^{39}$ CIL II 5792; AE 193666.

${ }^{40} A E 1972282$.

${ }^{41} A E 1962147$.

42 J. M. Abascal 1994 543-544; AALR 339 mapa 324. Su distribución es fundamentalmente hispana: B. Lörincz 2002163.

${ }^{43}$ AALR 339 mapa 323, pero véase su notable dispersión por otras partes de Hispania en Abascal 1994245.
} 
Lusitaniae et Vettoniae de los siglos II y III d.E. ${ }^{44}$. Ello desde luego no significa que forzosamente todos los portadores de este nombre fueran vetones como es el caso del Valerius Veto, miles c(ohortis) I Lam(auorum) (centuria) Lucani, atestiguado en un epitafio de Sala (Rabat) de mediados del siglo I d. E. ${ }^{45}$, si, en efecto, esta unidad fue reclutada, como parece, entre los Lemaui del convento lucense ${ }^{46}$ y Veto pertenecía a este grupo.

A cambio no está atestiguado con seguridad el nombre Lusitanus $^{47}$ y tan sólo una vez el cognomen Celticus ${ }^{48}$.

(ii) Otro indicio lo pueden suministrar los nombres de las unidades auxiliares reclutadas en Lusitania, que, como es habitual, exhiben nombres de tipo étnico ${ }^{49}$, incluyendo varias cohortes de Lusitanos ${ }^{50}$ y un ala de Hispani Vettones $^{51}$.

En lo que respecta a las cohortes de Lusitanos, de las que conocemos al menos media docena ${ }^{52}$, cabe preguntarse en principio si el nombre hace referencia a la etnia o a la provincia, cuestión esta sobre la que sólo algunas inscripciones suministran argumentos.

Es el caso de la dedicatoria a los Dii Deaeque Coniumbric(enses) colocada por Ti(berius) Claudius Sailcius ${ }^{53}$, eq(ues) c(o)hor(tis) III Lusitanorum, en Numão (Vila Nova de Foz Côa, Guarda) ${ }^{54}$, muy cerca del Duero, cuyo dedicante lleva un nombre característico de la provincia Lusitania (con las variantes Saelcius, Saelgus), sobre todo del convento emeritense, cuyos paralelos más próximos proceden de Hinojosa de Duero y Casas de Millán ${ }^{55}$, en el territorio lusitano y vetón, pese a lo cual ha sido considerado conimbrigense debido al nombre de la divinidad a la que honra, circunstancia que dista de ser segura,

${ }^{44} A E 1988$ 1023; CIL VI 41271.

${ }^{45} A E 1983$ 995. Le Roux 1982 276, sin embargo, parece considerarlo vetón, pese a que no se expresa en este sentido en 193 núm. 79.

${ }^{46}$ Plin. NH III 28; Ptol. 2.6.25.

47 I. Kajanto 1965 199. Sobre el cognomen Lusitanus y los de tipo étnico hispano como Celtiber presentaron sendas contribuciones al congreso sevillano La construcción de una identidad provincial. La experiencia hispana (cit.n. 2): S. Lefebvre ("Onomastique et identité provinciale: le cas de Lusitanus") y M. Navarro (sobre los nombres formados a partir de etnónimos hispanos).

48 AALR 140.

${ }^{49}$ Al respecto J. M. Roldán 1974265 ss. con un listado que incluye varias unidades de Hispanos, otras con nombres propiamente étnicos - Arauaci, Astures, Cantabri, Gallaeci, Varduli y Vascones -, superétnicos - Celtiberi- o correspondientes a ciuitates no urbanas - Gigurri, Lemaui, Carietes et Veniaeses - así como a circunscripciones conventuales Bracari y (Gallaeci) Lucenses - , islas - Baliares - o, excepcionalmente, a ciuitates urbanas - Ausetani- o una provincia, caso de la cohors Baetica.

${ }^{50}$ Roldán 1974 528-532.

${ }^{51}$ RIB 403; Roldán 1974 136, 377.

${ }^{52}$ Roldán 197478 ss, 82 s., 99 ss., 121, 133, 151 ss., 153, 156 ss., 157; Le Roux 198294 , 150, 191-192, 227, 276, 336.

${ }^{53}$ Sobre el cognomen, leído tradicionalmente sanecius, véase AALR 291, núm. 306.

${ }^{54}$ CIL II 432.

55 AALR 291. 
pues nada impide considerarlo oriundo de la zona en la que fue hallado el epígrafe, a la que habría regresado tras su licenciamiento, aunque ello no afecte a su verosímil procedencia del territorio étnico lusitano.

Hacia esta misma zona apunta la onomástica de [T]oncius [T]oncetami $f{ }^{56}$, miles, sicnifer coh(ortis) II Lus(itanorum), quien a mediados del siglo I d. E. hizo colocar un epígrafe en honor de Victoria en ciuitas Igaeditanorum (Idanha-a-Velha, Idanha-a-Nova, Castelo Branco) ${ }^{57}$, su ciudad de origen según consta en un ara a Trebarune aparecida en esta misma localidad ${ }^{58}$.

Finalmente, de las proximidades de Collippo, concretamente de Porto de Mós (Leiria), procede el cenotafio de C. Sulpicius Pelius Celti f., miles co(ho)rtis Lusitanorum, muerto en Clunia, oriundo sin duda de la zona en la que fue hallada la inscripción ${ }^{59}$.

Estos tres testimonios, caso de ser significativos, parecen indicar que las cohortes de Lusitanos no fueron reclutadas en la provincia Lusitania en general, sino más concretamente en el territorio étnico lusitano ${ }^{60}$ y que, por lo tanto, su designación responde al mismo mecanismo que produjo las unidades de Arauaci, Astures, Cantabri, Varduli o Vascones.

Éste es evidentemente también el caso de la única unidad de Vetones atestiguada, el ala Hispanorum Vettonum ciuium Romanorum ${ }^{61}$, en la que debe subrayarse que el epíteto que acompaña a la designación étnica no haga referencia a la provincia Lusitania - lo que, por otra parte, podría dar lugar a equívocos con el étnico de los lusitanos-, sino a Hispania, como ocurre con otras muchas unidades denominadas exclusivamente Hispanorum ${ }^{62}$, circunstancia que pone de manifiesto el predominio de este referente, junto a los étnicos en sentido estricto, en la designación de las unidades auxiliares en detrimento de los nombres provinciales de los que tenemos un único y polémico ejemplo: la cohors Baetica ${ }^{63}$.

(iii) Un tercer tipo de indicios al que podemos recurrir son las referencias sobre el propio origen que hacen constar en las inscripciones los soldados procedentes de Lusitania ${ }^{64}$, de mayor valor que los nombres de las unidades militares, pues frente a éstos, condicionados por las prácticas de reclutamiento

\footnotetext{
${ }^{56}$ AALR 320-322.

${ }^{57}$ EE VIII 14.

${ }^{58}$ EE VIII 15.
}

${ }^{59}$ CIL II 5238. De cerca de Collippo también procede el epitafio de un eques de una unidad de nombre perdido denominado Tiberius Claudius Maximus (CIL II 343), al respecto Le Roux 1982 191, núm. 74.

${ }^{60}$ En este sentido ya, Le Roux 1982 96; a cambio, Roldán 1974 267, dudaba entre la provincia y la 'tribu' como lugar de origen de estas unidades.

${ }^{61}$ Roldán 1974 136-137.

${ }^{62}$ Sólo otra unidad aúna un nombre étnico con el término Hispanus: la cohors II Hispanorum Vasconum, Roldán 1974129 s.

${ }_{63}$ Al respecto, Roldán 1974154 s. y J. González Rincón 1994 179-188, defendiendo su reclutamiento en la Bética.

${ }^{64}$ Otros casos, además de los estudiados aquí, en Lefebvre (cit. n. 2). 
romanas, constituyen testimonios que expresan en mayor o menor medida los referentes con los que esas personas se identificaban.

Entre ellos entraña particular interés el epígrafe de un eques de la mencionada ala Hispanorum Vettonum ciuium Romanorum ${ }^{65}$, datable en época flavia y procedente de la localidad de Aquae Sulis (Bath), en Britania, provincia en la que la unidad estuvo destinada durante el Principado ${ }^{66}$. Se trata del epitafio de L. Vitellius Mantai f. Tancinus, con un característico nombre 'lusitano' ${ }^{67}$, que, sin embargo, se autodefine significativamente como ciues (!) ${ }^{68}$ Hisp(anus), al igual que su unidad, precisando además su origo Caurie(n)sis, localidad del territorio vetón correspondiente a la actual Coria ${ }^{69}$. De esta manera, para definirse en ese lugar alejado de su patria el neociudadano romano Tancinus acumulaba tres referentes: su ciudad de origen, Caurium, su pertenencia étnica deducible del nombre de la unidad y su condición de Hispanus.

Sin embargo, antes de extraer de este epígrafe conclusiones precipitadas, debe señalarse que de la misma zona de la Vetonia podría proceder, a juzgar por el nombre Mantaus, típico del Tajo medio y atestiguado también en Coria, como se ha visto ${ }^{70}$, el eques del ala I Pannoniorum Ti. Claudius Mantai f. Cilius, enterrado en Phua (Numidia) a mediados del siglo I d. E. ${ }^{71}$, que, a cambio, se proclama Lusitanus, en lo que sería el único caso comprobado, si efectivamente Cilius era vetón, en el que se precisa la origo con una referencia a la provincia. Hay constancia de otros dos casos en los que un auxiliar o un legionario reclutado en la provincia es caracterizado como Lusitanus $^{72}$, sin embargo en ninguno de los dos casos puede precisarse si se trata de una referencia étnica o provincial por carecer ambos de origo y estar su nombre incompleto, caso del [---] Seueri $f$. atestiguado en un diploma militar de 154 d. E. ${ }^{73}$, o perdido, caso de los dos Lusitani del monumento dacio de Adam-Klissi ${ }^{74}$, Ahora bien, debe señalarse que en el caso del eques enterrado en Phua los indicios para precisar su origen son puramente onomásticos y que, de los dos nombres que exhibe, si bien Mantaus es característico del ámbito vetón, se encuentra atestiguado también en el extremo oriental del territorio lusitano ${ }^{75}$, mientras

${ }^{65}$ Roldán 1974 136-137.

${ }^{66}$ CIL VII 52; Le Roux 1982 193-194 núm. 81.

${ }^{67}$ AALR 315.

${ }^{68}$ Seguramente la palabra ciuis haga referencia a su condición de ciudadano romano, pues cuando murió había cumplido ya los veintiséis años de servicio preceptivos.

${ }^{69}$ En esta ciudad está atestiguada una dedicatoria a la divinidad Arantius Tanginiciaecus [al respecto. J. d'Encarnação 1975 98-101], de donde se ha inferido que Tancinus pertenecería a un grupo social dominante de su ciudad (Le Roux 1982 339), en cuyo hipotético caso el testimonio sería todavía más significativo.

${ }^{70}$ Es el nombre del padre de Tancinus. AALR 227, mapa 189; AE 1975513.

${ }^{71}$ CIL VIII 6309; Le Roux 1982190 núm. 70 parece sugerir una origo cauriense.

${ }^{72}$ Cf. Epigraphische Datenbank Heidelberg, en búsqueda realizada el 15 de marzo de 2008.

73 AE 195766.

${ }^{74}$ CIL III 14214.

${ }^{75}$ AALR 226-227 mapa 189. 
que Cilius es frecuente en un amplio territorio comprendido entre el Tajo y el Guadiana que abarca igualmente el solar lusitano ${ }^{76}$, por lo que no debe descartarse la posibilidad de que el término Lusitanus no se refiera a la provincia, sino que tenga carácter étnico, lo que en principio resulta más verosímil.

En cualquier caso, conviene subrayar que ambos casos son excepcionales pues en las inscripciones correspondientes a legionarios y auxiliares, desde una perspectiva identitaria, predomina ante todo el espíritu de cuerpo ${ }^{77}$, de manera que es la pertenencia a una determinada unidad militar la que asume el papel de referente principal, en muchos casos sin alusión alguna a la ciudad de procedencia o al origen étnico o geográfico, si bien es cierto que en el caso de las unidades auxiliares, al menos cuando coincide la designación con el origen étnico del soldado, éste queda implícito en aquélla. La segunda referencia en orden de frecuencia, como era de esperar, es la ciuitas de procedencia como se puede comprobar en un buen número de emeritenses ${ }^{78}$ y en ciudadanos de Olisipo $^{79}$, Norba $^{80}$, Pax Iulia $^{81}$, Scallabis $^{82}$ Capera $^{83} \ldots$ en su mayoría legionarios, mientras que en el caso de los auxiliares, al menos hasta fines del siglo I d. E., predomina la indicación del domicilio ${ }^{84}$.

Frente a éstas, las referencias de otra índole son excepcionales y en el caso de los soldados reclutados en Hispania pueden reducirse prácticamente al dudoso ejemplo de Cilius al proclamarse Lusitanus. Más frecuentes, a cambio, son las referencias a Hispania: así, un legionario narbonense de la IIII Macedónica se presenta como in Hispania miles ${ }^{85}$, un italicense de la X Gémina se caracteriza como ex Hispania en su epitafio de la región de Aquileya ${ }^{86}$, un eques enterrado en Larinum se define como Hispanus, domo Leonica, ciudad del convento cesaraugustano $^{87}$, un epitafio de las cercanías de Ferrara alude a un legionario natione Hispano ${ }^{88} \mathrm{y}$, por no alargar esta lista, otro de Thamugadi en Numidia, a un veterano de Clunia, Hispanus, todos ellos datables entre mediados del siglo I y fines del II d. E. A cambio en el III d. E. se hacen más frecuentes las referencias provinciales, caso de un italicense ex prouincia Baetica enterrado

${ }^{76}$ AALR 143 mapa 91.

77 Así, Le Roux 1982 277-278.

${ }^{78}$ CIL II 1016; AE 1929, 187; Le Roux 1982194 núm. 85; CIL II 5212, 4177; EE IX 1058, 1063, 1064; Le Roux 1982222 núm. 177.

${ }^{79} A E 1953268$.

${ }^{80}$ CIL XIII 5975.

${ }^{81}$ CIL II 2425.

${ }^{82}$ CIL VIII 3812.

${ }^{83}$ CIL II 812.

${ }^{84}$ Le Roux 1982189 ss.

${ }^{85}$ CIL XII 4336.

${ }^{86}$ CIL V 932.

${ }^{87}$ CIL IX 733.

${ }^{88}$ AE 1978342. 
en Tarraco $^{89}$ o de un legionario domiciliado en Bracara Augusta ex Hispania Citeriore sepultado en Augusta Vindelicorum (Raecia) ${ }^{90}$.

\section{A modo de conclusión}

Al término de estas rápidas observaciones resulta evidente que las preguntas que formulábamos más arriba difícilmente pueden ser respondidas de una manera terminante.

Respecto de la primera, a saber si la creación de la provincia Lusitania respondía más a la existencia de unos determinados vínculos entre las poblaciones comprendidas dentro de ella que a las necesidades administrativas de Roma, parece evidente que la constitución de Lusitania fue consecuencia ante todo de criterios estratégicos que, a la hora de definir sus límites, pesaron más, por ejemplo, que la afinidad cultural entre lusitanos o galaicos y propiciaron la segmentación entre dos provincias de pueblos como los Célticos o los Túrdulos. Al mismo tiempo la necesidad de contar dentro de la provincia con regiones más desarrolladas y dotadas de colonias y municipios para contrapesar la limitada urbanización y romanización de las tierras de lusitanos y vetones aconsejó englobar dentro de la provincia a las tierras situadas al sur del Tajo que, en muchos sentidos, tenían más en común con las vecinas regiones béticas que con las septentrionales, de suerte que la creación de la provincia difícilmente puede entenderse como consecuencia del reconocimiento de una homogeneidad cultural que contradicen los testimonios lingüísticos, onomásticos, religiosos, así como los relativos a las estructuras familiares o la cultura material.

En las tierras septentrionales el dominio romano parece haber contribuido a consolidar los referentes étnicos, sobre todo en lo que respecta a los Vetones y a los Lusitanos que son los únicos etnónimos que conservan plena vigencia durante el Principado en la provincia hasta el punto de servir como origo - si, en efecto, el Cilius de Phua era lusitano - y de marco de reclutamiento militar, o de mantenerse en la terminología administrativa - caso de los procuratores prouinciae Lusitaniae et Vettoniae - , al margen, naturalmente, de haber servido el de los lusitanos de epónimo para la provincia, vinculación evidente por mucho que Plinio se hiciera eco de sofisticadas etimologías eruditas, quizás atribuibles a Varrón, cuando explica las denominaciones de Lusitania e Hispania diciendo: Lusum enim Liberi patris aut lyssam cum eo bacchantium nomen dedisse Lusitaniae et Pana praefectum eius uniuersae (NH III 8), es decir "pues los misterios de Liber Pater o el delirio de las bacantes que le acompañaban dieron su nombre a Lusitania y Pan, su lugarteniente, a toda ella". El recurso esporádico a la lengua 'lusitana' en la región para inscribir textos religiosos así como los testimonios onomásticos personales y divinos, entre otros, contribuyen a reforzar esta impresión, sin perder de vista las diferencias que, por ejemplo, en lo tocante a las estructuras familiares denota

\footnotetext{
${ }^{89}$ CIL II 4154.

${ }^{90} A E 1972359$.
} 
la presencia en tierras vetonas de los nombres familiares característicos de la Celtiberia y desconocidos entre los lusitanos.

Sin embargo, más allá de los referentes étnicos y de la potente identidad cívica, que, al menos en lo que respecta a las inscripciones de militares se manifiesta sobre todo en ciudades privilegiadas más meridionales como Emerita, Scallabis, Pax Iulia, Olisipo, ..., la documentación existente no abona la posibilidad de la emergencia de una fuerte personalidad provincial, aun sin cuestionar que la pertenencia a la misma circunscripción pudiera generar vínculos comunes entre sus habitantes, pues, al igual que ocurrió con la Tarraconense y la Bética, contaba con un poderoso competidor en el referente que suponía Hispania y que, independientemente, de las múltiples diferencias existentes entre las comunidades peninsulares, sirvió desde época republicana ${ }^{91}$ para identificarles dentro del mundo romano frente a galos, itálicos, griegos, africanos, sirios y demás comunidades culturales del imperio por encima de las divisiones provinciales, como queda claro en hechos como que habitualmente los autores clásicos, incluido Augusto ${ }^{92}$, hicieran referencia a las tres provincias conjuntamente con la designación de Hispania o Hispaniae ${ }^{93}$, que en la plástica las provincias no fueran representadas por separado, sino subsumidas en la figura alegórica de Hispania ${ }^{94}$, y que, por no alargar esta enumeración, Vespasiano concediera el derecho latino uniuersae Hispaniae ${ }^{95}$.

Así queda perfectamente plasmado en un pasaje del historiador Floro, coetáneo del ascenso al trono imperial de los hispanos Trajano y Adriano, al que su residencia en Tarraco otorga un valor especial (I 33, 3-4) ${ }^{96}$ :

Hispaniae numquam animus fuit adversum nos universae consurgere, numquam conferre vires suas libuit, neque aut imperium experiri aut libertatem tueri suam publice. Alioquin ita undique mari Pyrenaeoque vallata est, ut ingenio situs ne adiri quidem potuerit. Sed ante a Romanis obsessa est quam se ipsa cognosceret, et sola omnium provinciarum vires suas postquam victa est, intellexit.

Nunca concibió Hispania alzarse toda ella contra nosotros, nunca le resultó grato oponernos sus fuerzas ni tentar nuestro poderío o defender su propia libertad colectivamente. Por lo demás, queda tan cercada por todas partes por el mar y los Pirineos que por su situación natural nadie habría podido acercarse siquiera. Sin

${ }^{91}$ Sea en las acuñaciones del siglo II a. E. con la leyenda HISPANORVM de Morgantina, K. T. Erim 198934 ss., sea en el bronce de Ascoli, CIL I² 709. Ver F. Beltrán Lloris (cit. n. 2).

${ }^{92} \operatorname{RgdA} 25$.

${ }_{93}$ Plin. NH III 30; 74; 102; XIV 149; Suet. Tib. 49; Galb. 12; etc.

${ }^{94}$ P. Biénkowski 1900 24. Sobre la iconografía monetal, F. Beltrán Lloris 1975; las supuestas imágenes de la Hispania Ulterior y Citerior que aparecerían en las emisiones de Gneo Magno y M. Minacio Sabino de los años 46-45 a. E. y que serían los únicos ejemplos de representación no de Hispania, sino de una de sus provincias, son rechazadas como tales por M. H. Crawford 1974480 núm. 470 que prefiere identificarlas como alegorías de Corduba y de otra ciudad hispana. Ver ahora F. Beltrán Lloris (cit. n. 2).

${ }_{95}$ Plin. NH III 30.

${ }^{96}$ Sobre la controvertida biografía de Floro y su particular vinculación con Hispania, véase G. Hinojo e I. Moreno 2000 11-19 y 61-68. 
embargo, quedó sitiada por los romanos antes de que se conociera a sí misma y fue la única de todas las provincias que tuvo conciencia de sus propias fuerzas después de haber sido vencida. (trad. Hinojo y Moreno).

\section{Bibliografia}

J. M. Abascal (1994), Los nombres personales en las inscripciones latinas de Hispania. Murcia.

J. M. Abascal (2006 [2009]), "Los tres viajes de Augusto y su relación con la promoción jurídica de las ciudades", Iberia 9 63-78.

J. Alarcão (1974), Portugal romano. Lisboa.

M. L. Albertos (1975), "Organizaciones suprafamiliares en la Hispania antigua", BSAA 40-41 5-66.

M. L. Albertos (1983), "Onomastique personnelle indigène de la Péninsule Ibérique sous la domination romaine", ANRW II 29.2 853-892

G. Alföldy (1969), Fasti Hispanienses. Senatorische Reichsbeamte und Offiziere in den Spanischen Provinzen des römischen Reiches von Augustus bis Diokletian. Wiesbaden.

J. Álvarez Sanchís (1999), Los Vettones. Madrid.

F. Beltrán Lloris (1975), "Las representaciones de Hispania en las monedas romanas", Miscelánea arqueológica Antonio Beltrán. Zaragoza, 245-250.

F. Beltrán Lloris (1994), “Plin. NH. 3. 13-14: ¿Beturia céltica o convento hispalense? Sobre la estructura de la descripción pliniana de la Bética", in III Congreso Peninsular de Historia Antigua. Vitoria (Preactas II, pp. 413-426).

F. Beltrán Lloris (2001-2002), "Iuppiter Repulsor(ius) y Iuppiter Solutorius: dos cultos provinciales de la Lusitania interior”, Veleia 18-19 117-128.

F. Beltrán Lloris (2002), "Identidad cívica y adhesión al príncipe en las emisiones municipales hispanas", in F. Marco, F. Pina y J. Remesal, eds., Religión y propaganda política en el mundo romano. Barcelona, 159-187.

F. Beltrán Lloris (2004), "Nos Celtis genitos et ex Hiberis. Apuntes sobre las identidades colectivas en Celtiberia", in Cruz Andreotti y Mora, eds., 91-92.

F. Beltrán, F. Pina (1994), "Roma y los Pirineos: la formación de una frontera", Chiron 24 103-133.

F. Beltrán Lloris, J. Velaza (2009), "De etnias y monedas: las “cecas vasconas”, una revisión crítica", in J. Andreu, ed., Los vascones de las fuentes antiguas: en torno a una etnia de la antigüedad peninsular. Barcelona, 99-126.

L. Berrocal-Rangel (1992), Los pueblos célticos del Suroeste de la Península Ibérica. Madrid.

P. Biénkowski (1900), De simulacris barbarorum gentium apud Romanos. Krakau.

A. Carneiro, J. d'Encarnação, J. de Oliveira y C. Teixeira (2008), "Uma inscrição votiva em língua lusitana", Palaeohispanica 8, 167-178.

M. H. Crawford (1974), Roman Republican Coinage. Cambridge.

G. Cruz Andreotti y B. Mora, eds. (2004), Identidades étnicas - Identidades políticas en el mundo prerromano hispano. Málaga.

G. Cruz Andreotti, M. V. García Quintela (2007). Estrabón. Geografía de Iberia. Madrid.

E. Dench (2005), Romulus' asylum. Roman Identities from the Age of Alexander to the Age of Hadrian. Oxford.

Die lusitanisch-galläkischen Kriegerstatuen (2003). Madrider Mitteilungen 44.

J. d'Encarnação (1975), Divindades indígenas sob o domínio romano em Portugal. Lisboa.

T. Erim (1989), "The mint of Morgantina", in Th. V. Buttrey, K. T. Erim, Th. D. Groves y R. R. Holloway, The Coins. Morgantina Studies. 2, Princeton. 
C. Fabião (1993), “O passado proto-histórico e romano”, in J Mattoso (ed.), História de Portugal. 1 79-299.

G. D. Farney (2007), Ethnic Identity and Aristocratic Competition in Republican Rome. Cambridge.

A. Giardina (2000), L'Italia romana. Storie di un'identità incompiuta. Roma - Bari.

L. J. Gonçalves (2007), Escultura romana em Portugal, uma arte do quotidiano. Mérida.

M. C. González (1986), Las unidades organizativas indígenas del área indoeuropea de Hispania. Vitoria / Gasteiz.

J. Gorrochategui, J. M. Vallejo (2003), "La onomástica indígena”, AALR 359-399.

E. S. Gruen (1992), Culture and National Identity in Republican Rome, Ithaca.

J. M. Hall (1997), Ethnic Identity in Greek Antiquity. Cambridge.

G. Hinojo e I. Moreno (2000), Floro. Epitome de la historia de Tito Livio. Madrid.

J. Huskinson (2000), "Looking for identity, culture and power", in J. Huskinson, ed., Experiencing Rome, Culture, Identity and Power in the Roman Empire. London, 3-27.

I. Kajanto (1965), The Latin cognomina. Helsinki / Helsingfors.

R. Laurence y J. Berry, eds. (1998), Cultural Identity in the Roman Empire. London - New York.

P. Le Roux (1982), L'armée romaine et l'organisation des provinces ibériques d'Auguste à l'invasion de 409. Paris.

B. Linke y M. Stemmler, eds. (2000), Mos maiorum. Untersuchungen zu den Formen der Identitätsstiftung und Stabilisierung in der römischen Republik. Stuttgart.

R. López Melero (1988), "Viriatus Hispaniae Romulus", Espacio, Tiempo y Forma $1247-262$.

N. Loraux (1981), L'invention d'Athènes: histoire de l'oraison funèbre dans la 'cité classique'. Paris.

B. Lörincz (2002), Onomasticon provinciarum Europae Latinarum. Wien.

J.-M- V. Luce, ed. (2007), Identités ethniques dans le monde grec antique. Pallas. Toulouse.

F. Marco (1999), "Divinidades indígenas en la Hispania indoeuropea", Veleia $1633-$ 49.

R. Miles (1999), Constructing Identities in Late Antiquity. London - New York.

Chr. Müller, F. Prost, eds. (2002), Identités et cultures dans le monde méditerranéen Antique. Paris.

M. Ojeda (1993), El servicio administrativo imperial ecuestre en la Hispania romana durante el Alto Imperio. I. Prosopografía. Sevilla.

G. Pereira (1984), "La formación histórica de los pueblos del Norte de Hispania: El caso de Gallaecia como paradigma", Veleia 1 271-288.

G. Pereira (1978), "Caeleo Cadroiolonis f. Cilenus $>$ Berisamo et al. Centuria or castellum. A discussion", HA 8 271-280.

L. Pérez Vilatela (2000), "De la Lusitania independiente a la creación de la provincia", in J.-G. Gorges y T. Nogales, eds., Sociedad y cultura en Lusitania romana. Mérida, 73-84.

F. Pina (2004a), "Die nützliche Erinnerung: Geschichtschreibung, mos maiorum und die römische Identität", Historia 53 147-172.

F. Pina (2004b), "Deportaciones como castigo e instrumento de colonización durante la República romana. El caso de Hispania", in F. Marco, F. Pina y J. Remesal, eds., Vivir en tierra extraña: emigración e integración cultural en el mundo antiguo. Barcelona, 211-229.

B. M. Prósper (2002), Lenguas y religiones prerromanas del occidente de la Península Ibérica. Salamanca.

J. M. Roldán (1974), Hispania y el ejército romano. Salamanca.

J. González Rincón (1994), “Cohors V Baetica”, Habis 25 179-188. 
M. Salinas y J. Edmonson (2003), "La provincia de Lusitania”, in M. Navarro, J.-P. Bost, J. L. Ramírez y M. Salinas (eds.), Atlas antroponímico de la Lusitania romana $(=A A L R)$, Mérida - Burdeos.

M. Salinas y J. J. Palao (2003), "Estructuras familiares en el medio indígena", AALR 401-406.

M. Salinas (2001), Los Vettones: indigenismo y romanización en el occidente de la Meseta. Salamanca.

J. C. Saquete (1997), Las elites sociales de Augusta Emerita. Mérida.

A. C. F. da Silva (2001), "Los pueblos lusitano-galaicos", in Celtas y Vettones. Ávila P. P. Spranger (1960), "Die Namengebung der römischen Provinz Hispania", MM 1 $122-141$.

J. Untermann (1965), Elementos de un atlas antroponímico de la Península Ibérica. Madrid.

J. Untermann (1997), Monumenta linguarum Hispanicarum. IV. Wiesbaden.

J. M. Vallejo (2005), Antroponimia indígena de la Lusitania romana. Vitoria - Gasteiz. F. Villar y R. Pedrero (2001), “Arroyo de la Luz III”, Palaeohispanica 1, 235-274.

F. W. Walbank (1972), "Nationality as a factor in Roman history", HSPh 76 145-168. 
(Página deixada propositadamente em branco) 


\title{
A CONSTRUÇÃO DO ESPAÇO NUMA SOCIEDADE PROTO-HISTÓRICA A ARTE RUPESTRE DO VALE DO CÔA ${ }^{1}$
}

\author{
Luís Luís \\ Parque Arqueológico do Vale do Côa
}

\begin{abstract}
We shall analyse the Iron Age Côa Valley rock art based on a social construction of spatial approach. We base our assumptions on its geography and on an iconographic analysis, confronted with classic sources and Celtic mythology.
\end{abstract}

Keywords: iconography, iconology, Iron Age, landscape, rock art.

Palavras-chave: arte rupestre, iconografia, iconologia, Idade do Ferro, paisagem.

\section{Arte na Paisagem}

Entendemos a paisagem como a percepção do espaço geográfico e dos territórios humanos, uma construção mental, individual ou colectiva (Mangado 2006 82). Ela é um ordenamento cognitivo ou simbólico do espaço, um testemunho das vidas e trabalhos de gerações passadas, que a habitaram, deixando aí qualquer coisa delas (Ingold 2000). O espaço é assim socialmente construído (Tilley 1994 10), envolvendo uma dimensão subjectiva, não podendo ser compreendido desligado das vidas e sentidos que lhe são atribuídos pelos actores sociais.

A paisagem materializa-se em tinta numa tela, escrita no papel, em terra, pedra, água ou vegetação no solo (Daniels e Cosgrove 1988 1). Nas sociedades sem escrita teremos de nos socorrer das escritas contemporâneas ou dos vestígios materiais. De entre estes, interessa-nos aqui a arte rupestre. A representação iconográfica pode ser uma das principais vias de acesso ao conhecimento das concepções das diferentes sociedades sobre o espaço.

Não tratamos aqui necessariamente de uma representação artística da paisagem, mas antes de uma paisagem definida pela arte. Não se trata de arte paisagística, mas de Land art, no sentido do movimento artístico do século $\mathrm{XX}$, que consiste numa intervenção sobre a paisagem. O espaço físico é o meio da criação. Não é o contentor da obra de arte, mas é antes definido por esta.

A arte rupestre relaciona-se com esta perspectiva e tem assim um valor único para a compreensão das concepções do espaço dos diferentes povos.

1 Por limitações de espaço, o presente texto é uma versão abreviada de um texto originalmente mais desenvolvido em L. Luís (2009), "Per petras et per signos": A arte rupestre do Vale do Côa enquanto construtora do espaço na Proto-história. In: Sanabria Marcos, P.J., ed., Lusitanos y vettones: Los pueblos prerromanos en la actual demarcación Beira Baixa - Alto Alentejo - Cáceres, Cáceres, Junta de Extremadura; Museo de Cáceres (Memorias; 9) 213-240. 
Pela sua própria natureza, ela expressa a intervenção directa de uma sociedade sobre o natural, humanizando-o e ordenando-o, conferindo-lhe sentido pela iconografia que apresenta.

Tal como na actual Land Art, a relação inextricável entre o símbolo e o suporte confere à arte rupestre um papel inigualável na compreensão do espaço.

Em 1991 foram identificadas as primeiras gravuras rupestres do Vale do Côa (fig. 1). Para além da arte paleolítica ao ar livre, que justificou a sua classificação como Património da Humanidade, rapidamente foi compreendido que a arte do Côa apresentava uma tradição de 25.000 anos, até ao presente. Essa longa tradição artística tem os seus grandes momentos na Pré-história Recente, na Idade do Ferro e dos séculos XVII à década de 1960.

Os primeiros motivos da Idade do Ferro da região foram identificados em 1982, no contexto da construção da barragem do Pocinho, no Vale da Casa (Baptista 1983 e 1983-84). Depois de sumariamente estudado, este conjunto, que se situava na margem esquerda do Douro, poucos quilómetros a jusante da foz do Côa, foi submergido pela albufeira.

Nos anos 90, já no contexto da descoberta da arte paleolítica do Vale do Côa, iniciou-se a inventariação da maioria dos motivos rupestres sidéricos na região. Em 1996 desenvolveu-se o projecto "Etched in Time", que visava o estudo do núcleo da Vermelhosa, mas os resultados conhecidos limitam-se à publicação, de forma insuficiente, de duas rochas (Fossatti 1996, Abreu et alii 2000). O Centro Nacional de Arte Rupestre tem publicado alguns motivos, de forma não sistemática (Baptista 1998 e 1999, Baptista e Gomes 1998, Baptista e Reis 2008). Apesar disso, esta equipa tem vindo a realizar um trabalho de prospecção (Baptista e Reis 2008) e levantamento de algumas rochas e motivos sidéricos, que aguarda publicação.

Os motivos da Idade do Ferro constituem hoje o segundo mais importante momento artístico do vale, figurando em cerca de 300 rochas ao longo do vale (Mário Reis, por comunicação pessoal).

Já noutro local analisámos a distribuição da arte sidérica do Côa e as suas características gerais (Luís, no prelo), que aqui resumimos.

A unidade geográfica que denominamos por Vale do Côa situa-se no limite ocidental da grande unidade geomorfológica que é a Meseta ibérica (Ferreira 1978 8) (ver fig. 1). Esta grande superfície de aplanamento cede lugar aos planaltos centrais e à faixa litoral nas imediações do Côa e da falha Longroiva/ Vilariça. Se, a Norte, a Meseta continua um pouco mais para Ocidente, até ao Sabor, a Sul do Douro o rio Côa, fortemente encaixado a jusante de Cidadelhe, funciona como uma fronteira natural com escassos pontos de passagem (Cordeiro e Rebelo 1996 13).

Consideramos pois que o curso final do rio Côa serve de fronteira natural, dividindo duas grandes unidades geomorfológicas (Luís, no prelo). A presença de arte rupestre neste espaço não será alheia a esse facto.

Ampliando a área de análise, verificamos que as cerca de 300 rochas conhecidas se agrupam em mais de duas dezenas de núcleos ao longo dos 
últimos 10 quilómetros do rio Côa, mas sobretudo na zona da confluência deste com o Douro (fig. 2).

Esta vinculação à água reforça-se ao nível da implantação topográfica, que se expressa segundo três tipos distintos: 1) encostas de grande pendente, voltadas para os rios Côa e Douro, desde o planalto até ao nível actual do rio; 2) cursos de água temporários, mais ou menos cavados, que levam as águas da chuva desde o planalto até aos rios, localmente chamados de canadas ou canados; 3) zonas ribeirinhas dos rios. Deste último tipo, temos hoje apenas conhecimento do terraço fluvial Vale da Casa, identificado ainda antes da construção da barragem do Pocinho.

Ao nível do suporte, com a excepção do Vale da Casa, todas as gravuras do Vale do Côa se inscrevem nos típicos painéis verticais, formados pelas diáclases do xisto, sobretudo da formação de Desejosa, mas também de Pinhão, inseridas no Super Grupo Douro-Beiras. No Vale da Casa, o substrato é idêntico, mas, neste terraço fluvial, a acção das águas erosiva das águas criou painéis horizontais.

A técnica de gravação dos motivos sidéricos do Vale do Côa e do Douro consiste quase exclusivamente na incisão fina, pouco profunda. Notamos algumas variantes, como a incisão reiterada um pouco mais profunda na cena das aves da rocha 3 da Vermelhosa, e a abrasão, com perfil em V, na falcata da rocha 6 do Vale da Casa (Baptista 1983 59).

\section{Iconografia}

Das cerca de 300 rochas já identificadas com arte rupestre de cronologia sidérica no Vale do Côa e Douro, conhecemos o desenho de apenas oito rochas completas e um conjunto de desenhos e fotografias de motivos soltos de seis outras rochas (Abreu et alii 2000, Baptista 1983, 1983-84 e 1999, Baptista e Gomes 1998, Carvalho, Zilhão e Aubry 1996)

A figura do guerreiro é um dos motivos fundamentais desta arte, cujo exemplo maior é o da rocha 1 da Vermelhosa. Estes podem surgir a pé ou a cavalo, brandindo lança e caetra. Um determinado número destas figuras são definidas por um ornitocefalismo (fig. 3). Esta característica apresenta relevantes paralelos com os diademas de Mones (Piloña, Astúrias), que foram interpretados como a expressão simbólica das crenças sobre o acesso ao Além, que se processa através do elemento aquático (Marco Simón 1994).

Também aí as figuras humanas, cavaleiros, infantes e outros, são representadas com cabeça de ave. Esta sua característica foi interpretada a partir de ideias de metamorfose na mitologia céltica, que nos conta que os guerreiros mortos se transformavam em pássaros no Além (idem: 340).

Esta característica ornitocefálica surge também num vaso de Numância (Quesada Sanz 1997 960, fig. 64), em El Monastil, num cavaleiro armado de lança (Poveda Navarro e Uroz Rodríguez 2007 127, fig. 4), ou num 
vaso de San Miguel de Llíria, onde surge no contexto de uma complexa cena aquática (Quesada Sanz 1997 944, fig. 2).

Na rocha 3 da Vermelhosa surge a representação de uma figura com cabeça de pássaro que apresenta aquilo que à primeira vista poderia ser interpretado como um capacete de cornos (Abreu et alii 2000: fig. 2) (fig. 4). Contudo, a observação de uma segunda figura, um pouco acima, neste mesmo painel, leva-nos a recusar esta interpretação. Esta segunda figura, que curiosamente não surge representada no único levantamento integral desta rocha publicado (idem: fig. 1), existe de facto e apresenta os braços levantados segurando as linhas em $\mathrm{S}$ que lhe saem da cabeça. A posição dos braços esclarece-nos que não estamos perante uma personagem com chifres, mas antes uma personagem que transporta um vaso ou caldeiro à cabeça.

Tratar-se-á de uma alusão ao "caldeirão da ressurreição", tal como surge representado no diadema de Mones, aí de maiores dimensões e transportados pela mão. Estes objectos, cujo mais famoso exemplar é o caldeirão de Gundestrup, são contentores através dos quais se alcançaria a imortalidade e se faria reviver os guerreiros mortos em combate, como o exemplifica a mitologia galesa do Mabinogion (Marco Simón 1994: 338-339).

Igualmente ornitocefálicas são as figuras envolvidas numa cena de coito posterior na rocha 3 de Vale de Cabrões. Uma delas, exibindo o seu falo erecto, penetra outra figura idêntica de braços abertos.

Em termos de armamento (fig. 5), predominam as lanças, com nervura central, providas, por vezes, do respectivo conto. Esta seria a arma por excelência dos povos pré-romanos (Quesada Sanz 1997).

A rocha 10 do Vale da Casa apresenta quatro falcatas, surgindo uma outra, aparentemente embainhada, na rocha 6 do mesmo núcleo, e mais sete na Foz do Côa (Baptista e Reis 2008). Esta arma tipicamente ibérica, que surge na costa mediterrânica peninsular entre finais do século V, inícios do IV a.C., terá chegado ao interior da península mais tardiamente, perdurando até às guerras sertorianas (Quesada Sanz 1997 80-83).

Por entre as sobreposições da rocha 10 surge ainda a gravura de uma espada e quatro punhais biglobulares em duas rochas da Foz do Côa (Baptista e Reis 2008).

$\mathrm{O}$ armamento defensivo mais comum é a caetra com umbo central, representada geralmente de perfil. As linhas em ziguezague na zona dos gémeos de um dos lutadores da rocha 3 da Vermelhosa podem ser interpretadas como representações de cnémides de couro.

A figuração de capacetes é mais duvidosa, sendo de descartar a interpretação das cabeças em forma de pássaro como elmos ou máscaras (Baptista 1999 146, 167 e 173). Como atrás vimos, julgamos estar perante uma transformação física do guerreiro, que toma esta forma.

A cena de duelo da rocha 3 da Vermelhosa é exemplar relativamente à panóplia registada nas rochas do Côa (fig. 6). Já noutro local (Luís, no prelo) confrontámos esta cena com a passagem de Estrabão (Geografia, 3.3.6) relativa ao armamento dos lusitanos. Trata-se de uma descrição quase literal 
desta representação, com referências aos vários dardos ou lanças de cada guerreiro, ao pequeno escudo circular, à couraça de linho e às protecções para as pernas. Apenas as referências ao punhal e aos capacetes ficam sob dúvida. Não queremos com isto atribuir directamente esta representação a uma etnia específica, uma vez que esta temática surge repetidamente na iconografia dos povos peninsulares pré-romanos.

Exemplo disso são as cenas de duelo presentes num vaso de Numância (Sopeña 2005 375), no cabo de punhal de Las Ruedas (Marco Simón 2005 327) e no fecho de cinturão de La Osera (Álvarez-Sanchís 2004 310) ou na estela de Tona (Osona) (Sanmartí i Grego 2008 fig. 10).

A temática da monomaquia tem larga tradição literária. Ela pode ser entendida de duas formas distintas, mas complementares. Em primeiro lugar, o duelo é uma forma de evitar o combate generalizado entre dois exércitos. Recordemos a tentativa frustrada de evitar a guerra de Tróia, resolvendo-se a disputa por Helena através de um combate singular entre Páris e Menelau, por intermediação de Aquiles (Ilíada, 3.86-94). Apiano (História de Roma, 6.53) relata-nos uma situação semelhante durante o cerco de Intercatia.

Os combates por ocasião dos funerais do pai e tio de Públio Cornélio Cipião, o Africano (Tito Lívio, Ab Vrbe Condita, 28.21) aliam esta noção de resolução de conflitos com a homenagem aos chefes mortos. Neles participaram homens livres, de forma gratuita, nomeadamente representantes dos príncipes aliados, guerreiros para honrar os seus generais mortos, outros por desejo de vitória e ainda outros para resolver conflitos que não conseguiam resolver de outra forma.

Também o funeral de Viriato foi marcado por combates junto ao seu túmulo (Apiano, História de Roma, 6.75).

Esta prática ilustra a aceitação da morte pelo guerreiro, a mais profunda e exigente das responsabilidades humanas (Olmos 1996 174). Os guerreiros combatem olhando-se e oferecem a sua morte, enobrecendo-se assim. Trata-se de uma acto típico dos aristoi. Os melhores trocam a prolongação de uma vida confortável, mas efémera, pela fama duradoura na memória dos mortais. Por outro lado, ela afirma que a fidelidade do guerreiro face ao chefe ultrapassa as fronteiras entre a vida e a morte (idem).

Esta relação entre a cena da rocha 3 da Vermelhosa e a morte reforça-se ainda pelo facto de ambos os combatentes se apresentarem despidos. Este facto, que ocorre igualmente nos diademas de Mones, foi relacionado com a nudez ritual com que os guerreiros celtas se apresentariam na batalha, garantindo-lhes uma protecção sobrenatural. Eles mostrariam assim a sua falta de medo perante a morte, que era entendida apenas como o meio caminho de uma longa vida (Marco Simón 1994331 e nota 46).

As figuras zoomórficas parecem dominar em termos de motivos, nomeadamente na Foz do Côa (Baptista e Reis 2008). No entanto, o bestiário 
é reduzido, sendo o cavalo a figura dominante, seguida pelos canídeos e cervídeos.

As montadas não apresentam sela ou estribos, reduzindo-se o seu equipamento aos arreios. O cavalo surge aqui associado às técnicas da guerra, mas também como elemento de prestígio. Exemplo maior disso é o facto de o guerreiro maior da cena de combate da rocha 3 da Vermelhosa ter amarrado a si um cavalo.

Existe uma relação directa entre a representação de cavaleiros armados e a heroificação de guerreiros mortos, aludindo à última viagem destes. Essa relação deverá ter origem na I Idade do Ferro, como mostra a estela de Benaciate (Silves), que apresenta um cavaleiro segurando as rédeas, gravado em relevo (Gomes 1990 83-5). Estes exemplos de cavaleiros heroificados continuam até ao século I a.C. por toda a Península, desde a pintura e escultura ibéricas, às estelas de Baixo Aragão e Catalunha e ao diadema de Mones.

Os cervídeos são o segundo conjunto de animais representados (fig. 7). $\mathrm{O}$ veado surge relacionado com a actividade aristocrática da caça, mas também como símbolo do mundo inferior, nomeadamente como atributo do deus céltico Cernunnos, que surge representado com armações de veado.

Em termos de representações zoomórficas seguem-se os canídeos. Também este animal tem uma dupla significação. Ele é elemento de prestígio, que o auxilia na caça e guarda a casa do senhor. Lembremo-nos da fidelidade de Argos, enquanto esperava o regresso do seu dono a Ítaca, sendo o primeiro a identificá-lo. Por outro lado, o cão tem igualmente um conotação com a morte, nomeadamente na tradição clássica, como é o caso de Cérbero. Exemplos há em que os cães acompanhavam mesmo os seus donos na morte, onde os continuavam a servir, como a incineração de Pátroclo e dos seus cães (Ilíada, 23.173-174) (idem: 80).

Um bom exemplo da relação entre cavalos, cervídeos e canídeos está expressa na cena da rocha 23 do Vale da Casa. Aí, um cavaleiro, armado de lança e auxiliado por cães, um deles apresentando uma espécie de açaime ou coleira, persegue um grupo de veados, dominado por um macho de hastes exuberantes. Apesar desta cena diferir no pormenor do relato de Xenofonte no Cynegeticus (9), ela retrata uma mesma realidade. A actividade da caça é "um sinal de fertilidade, de viagem e de combate, substituindo, em termos estratégicos e psicológicos, a principal ocupação das élites ( $\mathrm{sic}$ ) militares, a guerra, conferindo-lhes estatuto e prestígio social" (ibid.: 80).

Esta actividade cinegética tem também uma conotação funerária (ibid.: 79), nomeadamente a caça ao veado, pela sua relação com Cernunnos, o deus com hastes de cervídeo. Recordemos uma passagem da mitologia galesa do Mabinogion, onde Pwyll, depois de inadvertidamente ter reclamado um veado abatido pelos cães de Arawn, o rei do Outro Mundo, foi obrigado a trocar 
identidade com Arawn, tornando-se rei de Annwn durante um ano (Parker 2003).

Esta cena da rocha 23 é explicitada por uma inscrição pré-latina, que não foi até ao momento estudada com detalhe.

Na rocha 3 da Vermelhosa, sob a monomaquia, surgem representadas duas aves que debicam um peixe (fig. 8).

Uma vez mais esta cena apresenta grandes semelhanças com algumas figuras dos diademas de Mones. Aí, por entre as figuras humanas, surgem grandes peixes, interpretados como salmões, e pequenas aves aquáticas com pequenos peixes no bico. Francisco Marco Simón (1994 335) interpreta as aves aquáticas com o peixe no bico como símbolos ascensionais. $\mathrm{O}$ peixe é visto como um símbolo primordial, sendo-lhe por vezes atribuída uma significação psicopompa análoga ao golfinho no mundo greco-romano. Entre os povos indo-europeus, o peixe é um símbolo da água, da fecundidade e da sabedoria. Atravessando os rios, distribui a chuva e controla a fecundidade. Já os salmões são depositários da sabedoria no Além. Eles são uma das formas em que se metamorfoseavam os deuses, expressando o espírito dos cursos de água (idem: 341).

No entanto, as aves da rocha 3 da Vermelhosa não se assemelham a aves aquáticas mas a necrófagas, como o abutre ou o grifo. Elas apresentam uma semelhança formal com as aves da estela de El Palao (Alcañiz, Teruel), onde podemos observar um cavaleiro brandindo lança e caetra junto a uma figura humana jacente, cercada por três aves semelhantes às que analisamos e um canídeo deitado (Sopeña 2005 383). Esta cena sugere aliás uma outra muito semelhante representada na rocha 153 da Foz do Côa (Reis e Baptista 2008).

Também a estela de Binéfar (Huesca) oferece uma representação semelhante, com a diferença de, em vez de um guerreiro prostrado, figurarem partes de corpos mutilados, junto de uma ave (Sanmartí i Grego 2007 2467). Na estela de Zurita vemos dois guerreiros a pé, armados com escudo e lança, junto a um cavalo, enquanto sob os pés dos guerreiros surgem uma outra figura humana e uma ave.

Para além das estelas, podemos relacionar este tema com a pintura vascular. Exemplo disso são também dois vasos numantinos idênticos, onde figura uma ave debicando um guerreiro deitado (Quesada Sanz 1997 960, n. ${ }^{\circ} 65$ e 66, Sopeña 2005 381), ou o vaso de Puntal dels Llops (Valência), onde, sob dois duelistas, surge um abutre (idem: 95, fig. 29, Aranegui Gascó 2007, fig. 13).

Apesar de não ser consensual (Alfayé Villa 2004), tem-se relacionado a representação destas aves com três passagens clássicas. Sílio Itálico (Punica, 13.470-471) diz-nos que, entre os iberos, os corpos eram devorados por um abutre sinistro. No mesmo sentido é interpretada a passagem de Cláudio Eliano (De Natura Animalium, 10.22), que precisa que este costume se destinava, entre os Vaceus, aos guerreiros valorosos que morriam em combate. Pausânias (10.22.3) relata-nos que em 279 a.C., aquando da sua incursão sobre Delfos, os gauleses fizeram o mesmo com os seus mortos, abandonando-os no campo 
de batalha às aves necrófagas. A exposição dos corpos dos caídos em combate parece pois ter sido uma prática entre os povos celtas (Sopeña 2004).

No caso do Côa, julgamos poder interpretar a cena das aves e do peixe neste sentido. Esta cena faz a ligação entre o peixe, habitante dos rios e conhecedor do Além, com os abutres que transportam os mortos até lá. Ela parece ligar as figuras de Mones com as restantes representações de necrofagia comuns na Península Ibérica, num sobrecarregar a cena de indícios de um sentido, procurando explicitá-la, como observamos aliás nas monomaquias de Puntal dels Llops e da estela de Tona (Sanmartí i Grego 2007, fig. 10), que são acompanhadas, num registo inferior, por um abutre e por um canídeo, respectivamente.

Finalmente, surgem os motivos serpentiformes, como na rocha 139 da Foz do Côa, onde são figurados dois traços interpretados como duas "orelhas" ou a duplicação do "corno" da víbora-cornuda (Baptista e Reis 2008). A serpente cornuda está precisamente relacionada com o deus Cernunnos e surge representada com ele no caldeirão de Gundestrup, juntamente com a árvore (Marco Simón 1994 339). Também o falo do duelista da rocha 3 da Vermelhosa apresenta uma glande em forma de cabeça de serpente e na sua ponta duas linhas que sugerem uma língua bífida ou uns cornos.

\section{Iconologia}

A arte sidérica do Vale do Côa é a expressão das crenças dos seus autores. Uma vez descodificada, ela permitir-nos-á entrever as concepções do espaço e do Mundo que estas sociedades desenvolveram. Do exposto, julgamos perceber uma mensagem, apesar do carácter fragmentário e diminuto do nosso conhecimento desta arte.

A mensagem fala-nos de um caminho, de uma viagem: uma catábase. A catábase é a descida do herói aos infernos, como Héracles no seu décimo segundo trabalho, Orfeu em busca de Eurídice, Ulisses para consultar Tirésias ou Eneias para pedir conselho a seu pai.

No caso da iconografia do Côa, como noutras, as imagens assinalam o ponto de separação e o espaço de encontro entre mortos e vivos (Olmos 1996).

Nesta última viagem, os guerreiros transformam-se em pássaros.

O caminho de acesso é através das águas. Neste sentido, o contexto imediato da arte do Baixo Côa e Douro não podia ser mais esclarecedor: é em volta dos cursos de água perene e sazonal que se distribuem os painéis gravados (fig. 9). O rio conduz assim, não apenas até à costa, mas até ao Outro Mundo, o que nos recorda a sugestiva geografia infernal da Odisseia (9.508515), que a localiza junto a uma rocha na confluência dos "rios retumbantes".

Num contexto mais próximo, citemos o fim da expedição conjunta entre Túrdulos e Célticos após a travessia do rio Limes, também chamado Letes (Estrabão, Geografia, 3.3.5). O primeiro romano a atravessá-lo será Décimo 
Júnio Bruto (Apiano, 6.72), apesar das dificuldades em convencer as suas tropas na travessia do rio do Olvido (Tito Lívio, Ab Urbe Condita, 55).

Os veículos que o aristocrata usa para aceder ao Outro Mundo são sobretudo o cavalo e o carro. Trata-se de veículos que ao mesmo tempo transportam e heroificam (Olmos 1996 172). O caminho heroificador levado a cabo pelo cavaleiro implica um esforço, uma vontade, o controlo do homem sobre o seu destino (idem: 173).

Nesse caminho, ele é auxiliado por um conjunto de animais, os psicopompos. Desde logo o cavalo, mas também as aves, que juntamente com o lobo transportam o morto nas suas entranhas (ibid.: 172). Em ambientes costeiros, o golfinho, amigo do homem, acompanha-o na última viagem marinha; no interior, o peixe, nomeadamente o salmão, que sazonalmente sobe os rios, parece ocupar um lugar idêntico (ibid: 172).

Muito mais do que aceder ao mundo dos mortos, o objectivo último desta viagem é a heroificação, a glorificação das elites guerreiras, e com ela a manutenção da ordem social para além da morte do indivíduo. A uma determinada base económica e política corresponde uma super-estrutura ideológica expressa por símbolos. Existe pois uma "política da paisagem" (título de obra James Turner apud Daniels e Cosgrove 1988 7), que pode ser expressa na sua representação e construção.

A propósito do livro XI da Odisseia, Jung diz-nos que "a Nekyia não é uma queda no abismo puramente destrutiva e sem objectivo, mas uma significativa katabasis eis antron, uma descida até à gruta da iniciação e do conhecimento secreto" (1966 § 213).

Só o príncipe tem o privilégio de antever a sua própria morte e de, como memória, a relatar aos demais. Só os heróis puderam contemplar em vida o espaço e os caminhos da morte (Olmos 1996 169-170), tomando caminhos que exigem conhecimento prévio e intimidade com os deuses.

No caso do Côa, ao inscrever-se na pedra, buscando a eternidade, este sentido é atribuído ao natural. Ele é conferido à paisagem e passa a ser a ordem natural das coisas. Interpretamos assim a arte rupestre sidérica do Vale do Côa como um mecanismo de reprodução social. Ele não se inscreve apenas no espaço, mas define-o e confere-lhe sentido.

Esta construção da paisagem serviu pois para definir e manter uma determinada ordem social, uma determinada ideologia aristocrática de poder. É nesse sentido que interpretamos as duas representações de natureza sexual do Vale do Côa. O entumecimento do bulbus glandis dos canídeos do Vale de José Esteves impede a inseminação por outro membro da matilha que não o macho alfa. De igual modo, a cena de coito posterior da rocha 3 do Vale de Cabrões, entre duas figuras com bico de pássaro, sugere a endogamia entre estes seres, sejam eles de género distinto, ou - até mais esclarecedoramente se forem do mesmo.

Estamos ainda numa fase muito incipiente da compreensão da arte rupestre da Idade do Ferro do Vale do Côa, por insuficiente documentação e reflexão. 
No entanto, a sua indiscutível riqueza parece desde já apontar caminhos para uma interpretação.

O que aqui quisemos trazer foi o esboço de um desses caminhos, a partir da noção de construção social do espaço. Para esta interpretação concorrem o contexto físico da arte e o sentido da sua mensagem.

Como expusemos mais demoradamente noutro local (Luís, no prelo), consideramos estar perante um território de fronteira. Essa definição paisagística surge materializada através da arte rupestre, enquanto espaço socialmente construído, que ganha sentido através da sua relação com o espaço físico onde se insere.

Nesse texto definimos três níveis de fronteira: a delimitação entre o povoado e o resto do território; entre diferentes populi ou etnias; e finalmente, entre vivos e mortos. Tratar-se-ia assim de uma fronteira polissémica.

Uma das questões em aberto continua a ser a cronologia da sociedade que assim construiu o seu espaço. Se podemos radicar a temática da heroicização guerreira nas estelas do Bronze final, ela encontra-se igualmente comprovada durante a I Idade do Ferro, nomeadamente através das duas estelas alentejanas referidas acima - Benaciate e Abóbada I (Gomes 1990 67-85). No entanto, a cronologia apontada para alguns dos paralelos aqui trazidos indicia já momentos mais tardios, entre os séculos III-II e I a.C., ou já mesmo d.C., nomeadamente os diademas de Mones (Marco Simón 2006 332), a cerâmica de Monastil (Poveda Navarro e Uroz Rodríguez 2007 126), e Llíria (Aranegui Gascó 2007 173) e as estelas do Baixo Aragão e Catalunha, que podem ir desde o século VI à época Republicana (Sanmartí i Grego 2007).

Até ao momento, apenas conseguimos ter um vislumbre de uma ideologia, de uma ordem social, mas, ao não conseguirmos encontrar arqueologicamente os subordinados dessa ordem, aqueles cuja voz não ficou registada nas rochas do Vale do Côa, estamos a contribuir para a sua manutenção e perpetuação. Interessa pois sair da paisagem e aceder ao território e a todos os seus actores.

\section{Anexos}

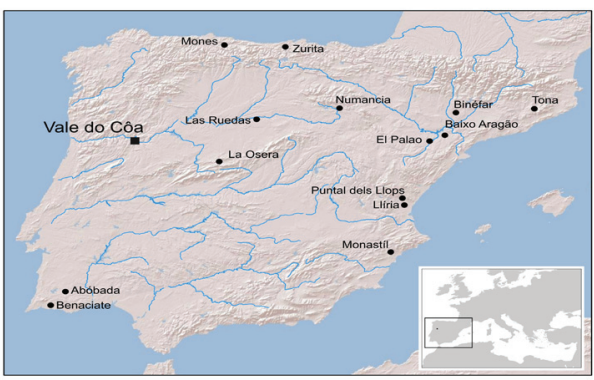

Fig.1. Localização do Vale do Côa na Península Ibérica (No mapa surgem indicados os sítios referidos ao longo do texto) 


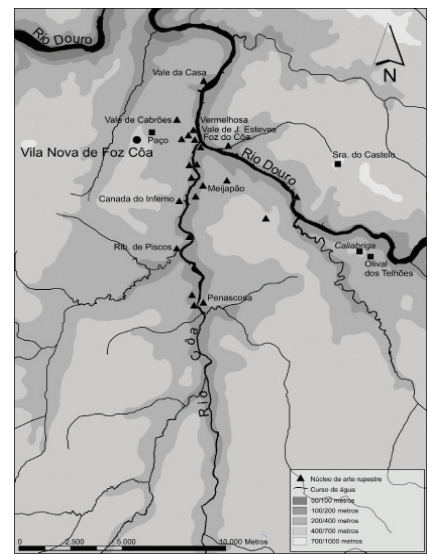

Fig.2. Distribuição da arte rupestre sidérica do Vale do Côa (No mapa surgem indicados os sítios referidos ao longo do texto)

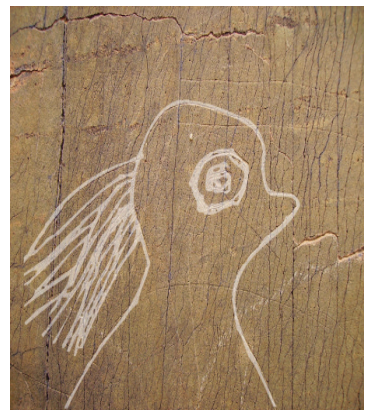

Fig.3. Pormenor da cabeça do grande guerreiro da rocha 3 da Vermelhosa

(linhas da figura realçadas a branco)

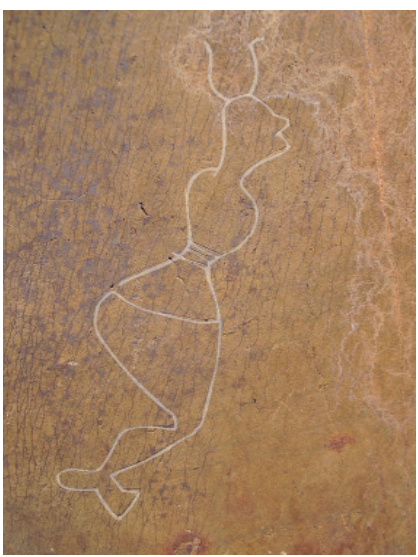

Fig.4. Figura com cabeça de pássaro transportando vaso na cabeça na rocha 3 da Vermelhosa (linhas da figura realçadas a branco) 


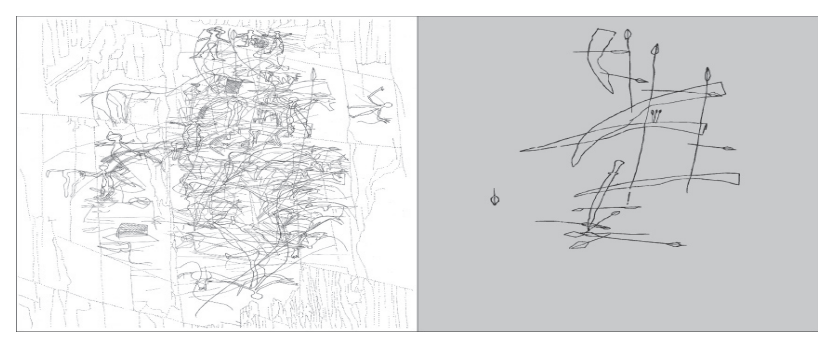

Fig.5. Rocha 10 do Vale da Casa (Baptista 1999 175) com as armas do painel individualizadas à esquerda

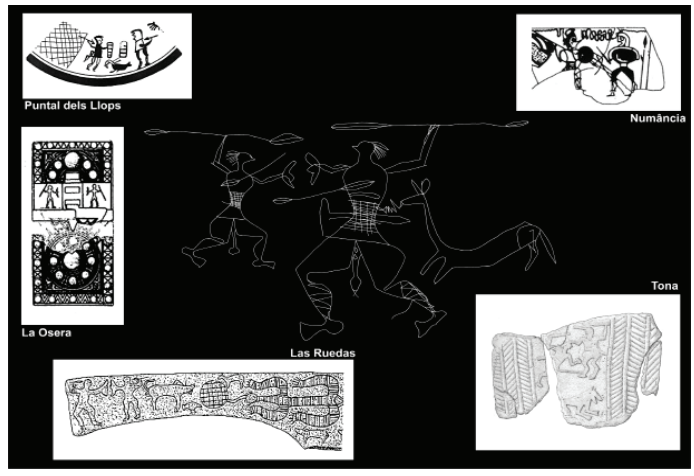

Fig.6. Monomaquia da rocha 3 da Vermelhosa, comparada com outros motivos peninsulares (contém elementos de Baptista 1999 167, Sopeña 2005 375, Marco Simón 2005 327, Álvarez-Sanchís 2004310 e Sanmartí i Grego 2008, fig. 10)

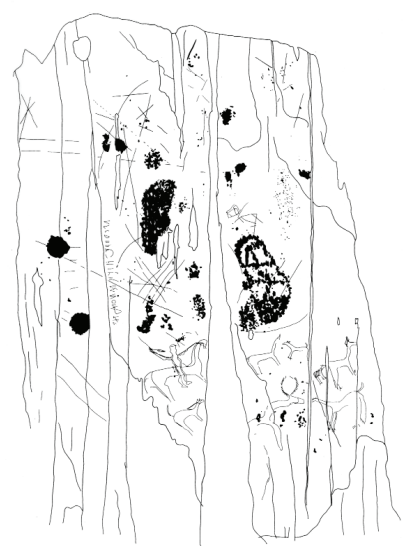

Fig.7. Cena de caça acompanhada de inscrição pré-latina na rocha 23 do Vale da Casa (Baptista 1999 181) 


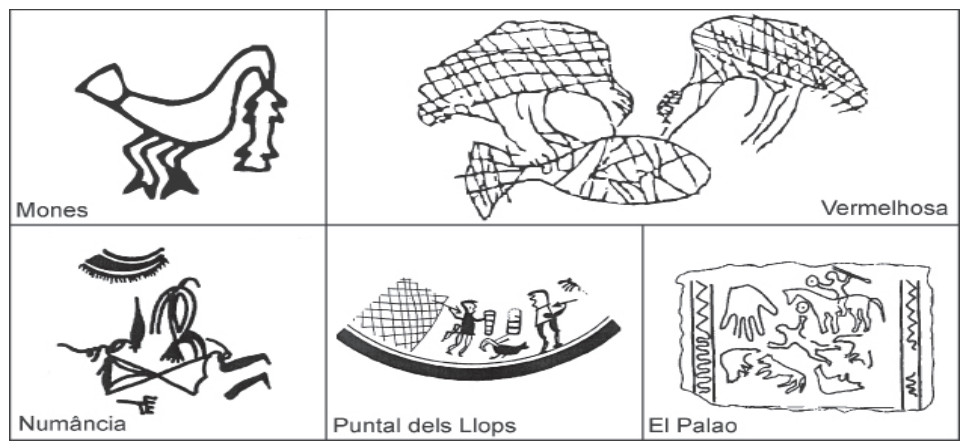

Fig.8. Cena das aves e peixe na rocha 3 da Vermelhosa, comparada com outros motivos peninsulares (contém elementos de Abreu et al. 2000, fig. 1, Lorrio 1997, Marco Simón 2005, Quesada Sanz 1997)

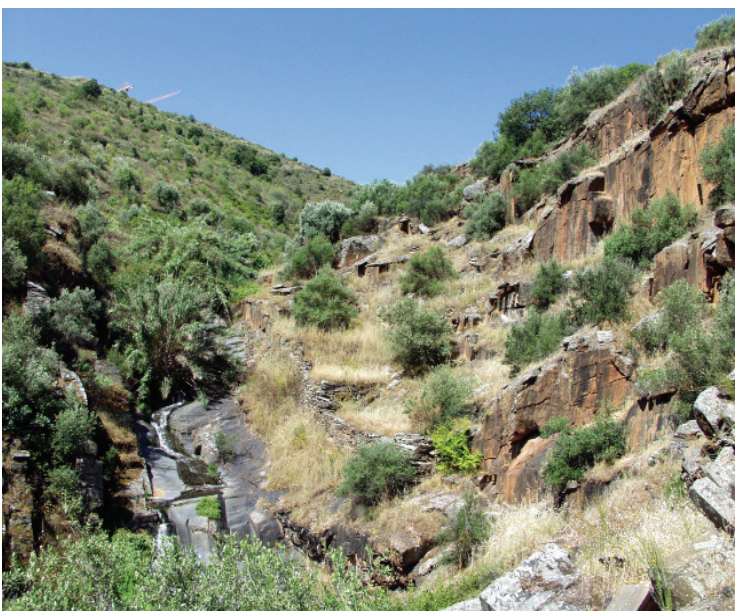

Fig.9. Vista da zona final do Vale de José Esteves após chuvada, com a água correndo pela canada até ao Douro 


\section{Bibliografia}

M. S. Abreu, A. Arcà, L. Jaffe, A. Fossati (2000), “As gravuras rupestres de idade do ferro no vale de Vermelhosa (Douro - Parque Arqueológico do Vale do Côa). Notícia preliminar", in V. O. Jorge, ed., Proto-história da Península Ibérica (Actas do 3. ${ }^{\circ}$ Congresso de Arqueologia Peninsular. Vol. V). Porto, 403-406.

S. Alfayé Villa (2004), "Rituales de aniquilación del enemigo en la Estela de Binéfar (Huesca)", in L. Hernández Guerra, J. Alvar, eds, XXVIII Congreso Internacional Girea-Arys IX. Historia Antigua. Jerarquías religiosas y control social en el Mundo Antiguo. Valladolid, 63-74.

J. R. Álvarez-Sanchís (2004), "Etnias y fronteras. Bases arqueológica para el estudio de los pueblos prerromanos en el occidente de Iberia", in M. C. Lopes, R. Vilaça, eds, O Passado em cena. Narrativas e fragmentos. Coimbra, Porto, 299-327.

C. Aranegui Gascó (2007), "Arte ibérico en Edetania" in L. Abad Casal, J. A. Soler Díaz, eds., Arte Ibérico en la España Mediterránea. Actas del Congreso (Alicante, 24-27 de octubre de 2005). Alicante, 167-183.

A. M. Baptista (1983), "O complexo de gravuras rupestres do Vale da Casa (Vila Nova de Foz Côa)", Arqueologia 8 57-69.

A. M. Baptista (1983-84), "Arte rupestre do norte de Portugal. Uma perspectiva", Portugália, 4-5 (nova série) 71-82.

A. M. Baptista (1998), "A arte do Côa e Alto-Douro e o Centro Nacional de Arte Rupestre (CNART)", in A. C. P. S. Lima, ed., Terras do Côa. Da Malcata ao Reboredo. Os valores do Côa. Maia, 196-201.

A. M. Baptista (1999), No tempo sem tempo. A arte dos caçadores paleolíticos do Vale do Côa. Com uma perspectiva dos ciclos rupestres pós-glaciares. Vila Nova de Foz Côa.

A. M. Baptista, M. V. Gomes (1998), “Arte Rupestre”, in J. Zilhão, ed., Arte Rupestre e Pré-História do Vale do Côa. Trabalhos de 1995-1996. Lisboa, 211-409.

A. M. Baptista, M. Reis (2008), "Prospecção da Arte Rupestre na Foz do Côa. Da iconografia do Paleolítico superior à do nosso tempo, com passagem pela II ${ }^{\mathrm{a}}$ Idade do Ferro", in III Congresso de Arqueologia de Trás-os-Montes, Alto Douro e Beira Interior. Actas das Sessões. Vol. 1 - Pré-história: Gestos intemporais. Porto, ACDR de Freixo de Numão, 62-95.

A. C. Carvalho, J.Zilhão, T. Aubry (1996), Vale do Côa. Arte Rupestre e Pré-História . Lisboa.

A. M. R. Cordeiro, F. Rebelo (1996), "Carta geomorfológica do vale do Côa a jusante de Cidadelhe", Cadernos de Geografia 15 11-33.

S. Daniels, D. Cosgrove (1988), "Introduction. Landscape and Iconography" in D. Cosgrove, S. Daniels, eds., The Iconography of Landscape. Essays on the Symbolic. Cambridge, 1-10.

A. B. Ferreira (1978), Planaltos e montanhas do Norte da Beira. Estudo de geomorfologia. Lisboa.

A. Fossati (1996), "The Iron Age in the Rock Art of Vermelhosa, Portugal" [em linha]. In Tracce. 5. 26 de Outubro de 1996. [citado em 17 de Fevereiro de 2003]. Disponível em <http://www.geocities.com/RainForest/3982/coaferro.html>. 
M. V. Gomes (1990), “O Oriente no Ocidente. Testemunhos iconográficos na Protohistória do Sul de Portugal. Smiting gods ou deuses ameaçadores", Estudos Orientais 4 53-106

T. Ingold (2000), "The Temporality of the Landscape", in The Perception of the Environment. Essays in Livelihood, Dwelling and Skill. Londres, 189-208.

C. Jung (1966), Collected Works. Vol. 15. Londres.

L. Luís (2009), "Em busca dos cavaleiros com cabeça de pássaro. Perspectivas de investigação da Proto-história no Vale do Côa", in R. Balbín Behrmann, ed., Arte al aire libre en el Sur de Europa (Curso de Arte Rupestre al Aire Libre. Investigación, Protección, Conservación y Difusión [Salamanca, 15, 16 y 17 de junio de 2006]).

J. Mangado (2006), "El aprovisionamiento en materias primas líticas. Hacia una caracterización paleocultural de los comportamientos paleoeconómicos", Trabajos de Prehistoria 63.2 79-91.

F. Marco Simón (1994), "Heroización y tránsito acuático. Sobre las diademas de Mones (Piloña, Asturias), in J. Mangas, J. Alvar, eds, Homenaje a J. M. Blázquez. 2. Madrid, 318-348.

F. Marco Simón (2005), "Religion and Religious Practices of the Ancient Celts of the Iberian Peninsula", e-Keltoi. Journal of Interdisciplinary Celtic Studies 6 287-345. [Disponível em http://www.uwm.edu/Dept/celtic/ekeltoi/volumes/ vol6/6_6].

R. Olmos (1996), "Caminos escondidos. Imaginarios del espacio en la muerte", Complutum Extra 6.2 167-176.

W. M. Parker (2003), The Four Branches of the Mabinogi. [s. 1.] [Consultado a 6 de Maio de 2008, a partir de: http://www.mabinogi.net/pwyll.htm].

A. M. Poveda Navarro, H. Uroz Rodríguez (2007), "Iconografía vascular en El Monastil" in L. Abad Casal, J. A. Soler Díaz, eds, Arte Ibérico en la España Mediterránea. Actas del Congreso (Alicante, 24-27 de octubre de 2005). Alicante, 125-139.

F. Quesada Sanz (1997), El armamento ibérico. Estudio tipológico, geográfico, funcional y simbólico de las armas en la Cultura ibérica (siglos VI-I a.C.). Montagnac.

J. Sanmartí i Grego (2007), "El arte de la Iberia septentrional", in L. Abad Casal, J. A. Soler Díaz (eds), Arte Ibérico en la España Mediterránea. Actas del Congreso (Alicante, 24-27 de octubre de 2005). Alicante, 239-264.

G. Sopeña (2004), "El mundo funerario celtibérico como expresión de un "ethos" agonístico", Historiae 1 56-108.

G. Sopeña (2005), "Celtiberian Ideologies and Religion", e-Keltoi. Journal of Interdisciplinary Celtic Studies 6 347-410. [Disponível em http://www.uwm.edu/ Dept/celtic/ekeltoi/volumes/vol6].

C. Tilley (1994), A Phenomenology of Landscape. Places, Paths and Monuments. Oxford. 
(Página deixada propositadamente em branco) 


\title{
CONTRIBUTO PARA O CONHECIMENTO DA ARQUEOLOGIA ROMANA NO ALENTEJO CENTRAL
}

\author{
Clara Oliveira \\ LEONOR ROCHA \\ Universidade de Évora \\ (Departamento de História) \\ Laboratório de Arqueologia Pinho Monteiro
}

\begin{abstract}
With the available information for the Alentejo Central the authors tried to systematize it through understand the evolution (and dispersion) of the roman settlement.
\end{abstract}

Keywords: Alentejo Central, Roman settlement.

Palavras-chave: Alentejo Central, povoamento romano.

\section{Introdução}

A arqueologia portuguesa teve um notável incremento a partir dos últimos anos do séc. XX, mercê da normalização e transposição de algumas leis europeias para a nossa legislação. A criação do Instituto Português de Arqueologia (entretanto extinto) serviu de complemento a estas directivas, uma vez que tinha por competência gerir e inventariar o património arqueológico português.

De forma a cumprir estes objectivos foi criada a base de dados Endovélico, que, de uma forma ágil e expedita, possibilita controlar toda a actividade arqueológica portuguesa e também servir de Carta Arqueológica nacional, on line. Apesar de se encontrar em permanente actualização, permitiu-nos tirar algumas conclusões que se apresentam nos quadros e gráficos seguintes.

Optou-se ainda por analisar não só o período romano, mas também a Idade do Ferro e o Período Medieval, de modo a perspectivar-se melhor a (in)(e) volução do povoamento nesta área.

De salientar ainda a diversidade de tipologias utilizadas para a classificação, que variam consoante as bases de dados consultadas.

\section{Os dados disponíveis}

Como se referiu anteriormente, os dados aqui apresentados baseiamse na informação actualmente acessível, quer através das bases de dados Endovélico, quer das Cartas Arqueológicas ou outras publicações (Quadro Geral de Referência da EDIA e PDMs). Traduz também o estado actual das investigações, sendo evidente que existem áreas melhor conhecidas, devido 
à existência de Planos de Minimização de Impactes (Alqueva), de projectos de Avaliação de Impacte Ambiental (AIAs) ou de projectos de investigação e inventariação de sítios arqueológicos (Redondo, Évora, Alandroal).

Não foram inseridos os elementos que constam nos trabalhos publicados sobre os concelhos de Arraiolos e de Portel, por se tratar de um trabalho parcelar, no primeiro caso, e, no segundo, por conter informações de carácter mais etnográfico. Nestes casos, aparecem os dados existentes em Endovélico e, para Portel, também os da EDIA.

No entanto, a informação resultante destes trabalhos é de tal forma heterogénea que, para se tornar mais perceptível, se optou por analisar cada fonte, em separado, apresentando os dados referentes ao período Romano e, depois, a Idade do Ferro e o período Medieval, de modo a tentar avaliar a evolução do povoamento no Alentejo Central.

\subsection{Fonte: Cartas arqueológicas}

As cartas arqueológicas são, por definição, um documento em permanente actualização, pelo que os dados apresentados são o resultado de uma prospecção essencialmente selectiva, em função da análise espacial que os seus autores consideraram mais adequada.

Quadro 1. Tipo de sítios, por período, em Cartas Arqueológicas

\begin{tabular}{|l|l|l|l|l|}
\hline & & Romano & Idade Ferro & Medieval \\
\hline \multirow{4}{*}{$\begin{array}{l}\text { Carta Arqueológica } \\
\text { do Alandroal } \\
(1993)\end{array}$} & Achado isolado & 9 & - & 2 \\
\cline { 2 - 6 } & Habitat & $\mathbf{7 2}$ & $\mathbf{1 5}$ & $\mathbf{4}$ \\
\cline { 2 - 6 } & Villa & 7 & - & - \\
\cline { 2 - 6 } & Necrópole & 14 & 2 & 3 \\
\cline { 2 - 6 } & Indeterminado & 1 & - & - \\
\cline { 2 - 6 } & Santuário & 1 & 1 & 3 \\
\cline { 2 - 6 } & Mina & 1 & - & 3 \\
\hline \multirow{4}{*}{$\begin{array}{l}\text { Carta Arqueológica } \\
\text { de Redondo }\end{array}$} & Achado isolado & 4 & Idade Ferro & Medieval \\
\cline { 2 - 6 } & Habitat & $\mathbf{1 9 4}$ & $\mathbf{1 1}$ & $\mathbf{4 2}$ \\
\cline { 2 - 6 } & Villa & 12 & - & - \\
\cline { 2 - 6 } & Necrópole & 10 & 1 & 3 \\
\hline
\end{tabular}

Apesar de possuírem paisagens e recursos naturais bastante diferenciados, a análise dos dados sobre o povoamento romano nestes dois concelhos 
demonstra um incremento da população, que regride, posteriormente, no Período Medieval, sobretudo no caso do concelho do Alandroal.

\subsection{Fonte: Quadro Geral Referência da EDIA}

O quadro geral de referência da EDIA apresenta um tipo de informação completamente diferente. De facto, apesar de se tratar, também, de dados de prospecção, esta foi, em princípio, sistemática e numa faixa de terreno bem definida, a área de regolfo da barragem do Alqueva.

Em relação aos dados relativos ao distrito de Évora, para além de se verificar a existência de um maior número de registos relativos ao Período Romano, é de salientar a fraca expressividade de sítios da Idade do Ferro nos três concelhos analisados.

Para o Período Medieval temos um novo afunilamento do povoamento, menos evidente no concelho de Mourão, que apresenta dados muito similares para os períodos romano e medieval. A imprecisão das cronologias nestes registos também introduz alguma imprecisão nesta avaliação, uma vez que se pode tratar de sítios já relacionados com a Reconquista e o reforço das áreas fronteiriças pós Tratado de Alcanizes (1297).

Quadro 2. Tipo de sítios, por concelho e cronologia

\begin{tabular}{|c|c|c|c|c|c|}
\hline & & & Romano & Idade Ferro & Medieval \\
\hline \multirow{8}{*}{$\begin{array}{l}\text { Q u a d ro } \\
\text { Geral de } \\
\text { Referência } \\
\text { A l qu e v a } \\
\text { EDIA } \\
(1996)\end{array}$} & \multirow{3}{*}{$\begin{array}{l}\text { Reguengos } \\
\mathrm{d} \text { e } \\
\text { Monsaraz }\end{array}$} & Achado isolado & 1 & - & - \\
\hline & & Habitat & 60 & 1 & 27 \\
\hline & & Necrópole & 3 & & 1 \\
\hline & \multirow{3}{*}{ Mourão } & Achado isolado & 1 & - & - \\
\hline & & Habitat & 25 & 1 & 25 \\
\hline & & Necrópole & 3 & - & - \\
\hline & \multirow[b]{2}{*}{ Portel } & Habitat & 8 & - & 3 \\
\hline & & Necrópole & 1 & - & - \\
\hline
\end{tabular}

\subsection{Fonte: PDM de Évora}

Os dados apresentados num PDM são, tal como os das cartas arqueológicas, o resultado de uma recolha da informação bibliográfica existente e também de trabalho de campo realizado, mas que nunca é um trabalho que se pode considerar terminado.

Os dados do PDM de Évora demonstram uma grande dinâmica do povoamento durante o Período Romano comparativamente à Idade do Ferro e ao Período Medieval. 
Gráfico 1. Número de sítios, por cronologia

PDM ÉVORA

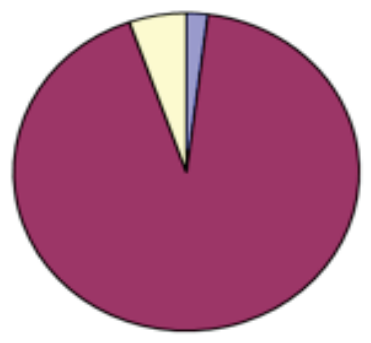

Gráfico 2. Tipo de sítios registados no período romano

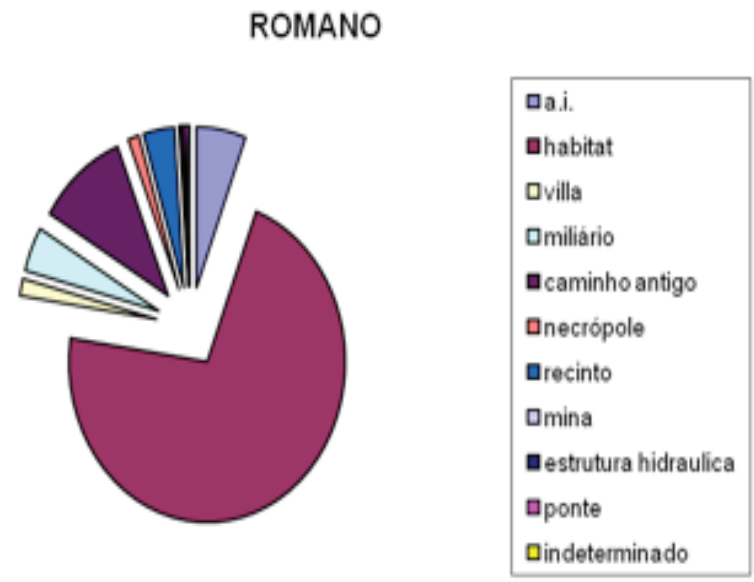

No que diz respeito à Época Romana, no concelho de Évora, é de realçar não só a existência de um elevado número de sítios de habitat, como também o registo de caminhos e marcos miliários.

\subsection{Fonte: Endovélico}

A última fonte considerada neste estudo foi a base de dados do Ministério da Cultura, o Endovélico. Neste caso, analisámos o total de sítios inventariados para todo o Distrito de Évora.

A informação fornecida pelo Endovélico é parcelar, uma vez que se encontra, também, em permanente actualização em função dos trabalhos 
arqueológicos que se vão realizando. Também alguns dos dados de trabalhos realizados, nas últimas décadas, podem não estar ainda disponíveis devido ao seu elevado número e consequente tratamento informático.

Analisando os dados actualmente disponíveis, verificamos a existência de um total de 1005 sítios referenciados para o período romano (Gráfico 3), dos quais 543 foram intervencionados (Gráfico 4).

Gráfico 3. Total de sítios registados no distrito de Évora (Fonte: Endovélico)

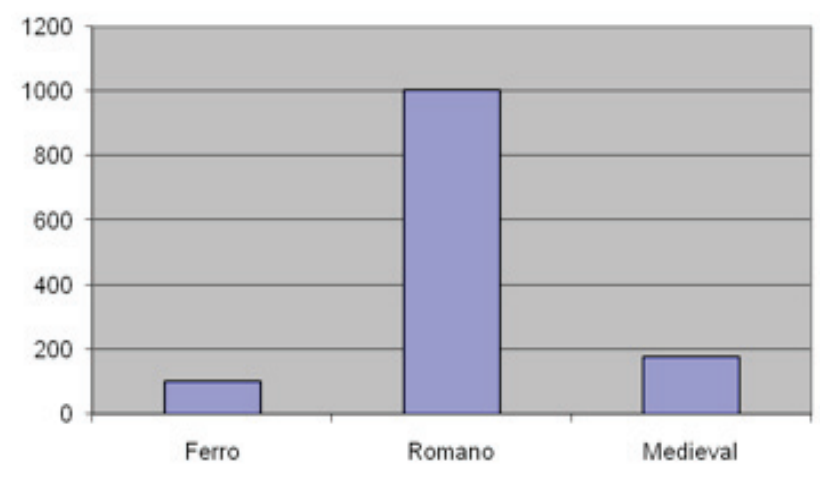

Gráfico 4. Sítios registados e intervencionados no distrito de Évora (Fonte: Endovélico)

Periodo Romano

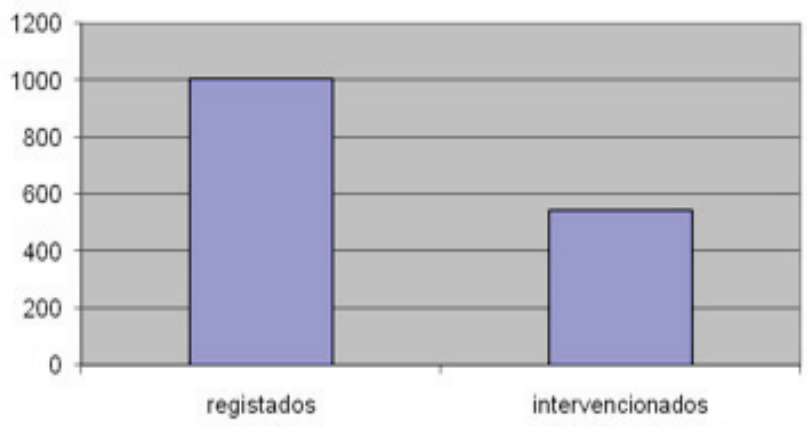


Estes vestígios encontram-se repartidos por 42 categorias, o que torna difícil o seu tratamento estatístico (Quadro 3) e também a comparação com os dados disponibilizados pelas outras fontes que são, regra geral, muito mais concisos.

O maior número de registos é para categorias relacionadas com o povoamento (habitats, vestígios diversos e achados isolados), para além de que muitas das definições tipológicas nos suscitam grandes reservas.

Quadro 3. Tipos de sítios do período romano. Fonte: Endovélico

\begin{tabular}{|l|l|l|l|}
\hline TIPO & $\mathbf{N}^{\mathbf{0}}$ & TIPO & $\mathbf{N}^{\mathbf{0}}$ \\
\hline Anfiteatro & 1 & Mina & 4 \\
\hline Atalaia & 1 & Pedreira & 4 \\
\hline Balneário & 1 & Ponte & 4 \\
\hline Estação ar livre & 1 & Recinto & 6 \\
\hline Fonte & 1 & Sepultura & 6 \\
\hline Granja & 1 & Via & 6 \\
\hline Mosteiro & 1 & Estrutura & 7 \\
\hline Poço & 1 & Fortim & 7 \\
\hline Poldra & 1 & Fortificação & 10 \\
\hline Santuário & 1 & Miliário & 13 \\
\hline Termas & 1 & Indeterminado & 14 \\
\hline Viaduto & 1 & Casal rústico & 17 \\
\hline Barragem & 2 & Vestígios superfície & 27 \\
\hline Canalização & 2 & Inscrição & 30 \\
\hline Castelo & 2 & Povoado & 36 \\
\hline Edifício & 2 & Mancha Ocupação & 39 \\
\hline Muralha & 2 & Necrópole & 41 \\
\hline Templo & 3 & Villa & 48 \\
\hline Tesouro & 3 & Achado isolado & $\mathbf{7 3}$ \\
\hline Vicus & 3 & Vestígios diversos & $\mathbf{1 3 4}$ \\
\hline Calçada & 4 & Habitat & $\mathbf{4 4 3}$ \\
\hline
\end{tabular}

No que diz respeito à Idade do Ferro, verifica-se a existência de 101 sítios, sendo que, mais uma vez, o maior número é referente ao povoamento (habitat, povoado e povoado fortificado), seguido das necrópoles (Quadro 4 e Gráfico 5). Este inventário traduz também, naturalmente, a maior visibilidade deste tipo de sítios, sobretudo os povoados. 
Quadro 4. Tipos de sítios da Idade do Ferro

\begin{tabular}{|l|l|}
\hline TIPO & $\mathbf{N}^{\mathbf{0}}$ \\
\hline Achado Isolado & 2 \\
\hline Arte rupestre & 2 \\
\hline Castelo & 1 \\
\hline Fortio & 2 \\
\hline Habitat & $\mathbf{2 2}$ \\
\hline Indeterminado & 2 \\
\hline Inscrição & 1 \\
\hline Mancha ocupação & 2 \\
\hline Necrópole & 8 \\
\hline Menires & 2 \\
\hline Povoado & $\mathbf{3 2}$ \\
\hline Pov. Fortificado & $\mathbf{1 6}$ \\
\hline Santuário & 1 \\
\hline Templo & 1 \\
\hline Vestígios diversos & 4 \\
\hline Villa & 1 \\
\hline
\end{tabular}

Gráfico 5. Vestígios da Idade do Ferro no distrito de Évora

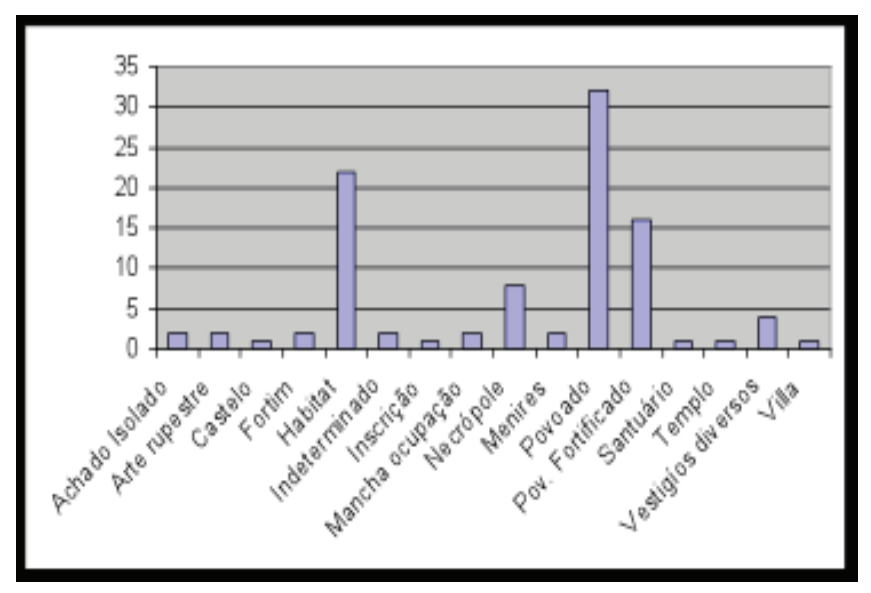

No que se reporta ao Período Medieval, existem 177 ocorrências repartidas por 29 categorias, destacando-se com valores mais elevados, novamente, os sítios relacionados com os habitats. 
Quadro 5. Tipos de sítios da Idade Média

\begin{tabular}{|l|l|l|l|}
\hline TIPO & $\mathbf{N}^{\mathbf{}}$ & TIPO & $\mathbf{N}^{\mathbf{0}}$ \\
\hline Achado isolado & 2 & Menir & 1 \\
\hline Atalaia & 5 & Mosteiro & 1 \\
\hline Casal rústico & 6 & Muralha & 1 \\
\hline Castelo & 7 & Necrópole & $\mathbf{9}$ \\
\hline Cisterna & 1 & Poço & 1 \\
\hline Convento & 4 & Povoado & 1 \\
\hline Edifício & 1 & Povoado Fortificado & 5 \\
\hline Ermida & 2 & Recinto & 1 \\
\hline Estrutura & 1 & Silo & 3 \\
\hline Fortificação & 1 & Sinagoga & 1 \\
\hline Habitat & $\mathbf{8 8}$ & Templo & 2 \\
\hline Azenha & 1 & Vestígios de Superfície & 3 \\
\hline Igreja & 6 & Vestígios Diversos & $\mathbf{1 7}$ \\
\hline Indeterminado & 1 & Via & 3 \\
\hline Mancha de Ocupação & 1 & & \\
\hline
\end{tabular}

Gráfico 6. Vestígios da Idade Média no distrito de Évora

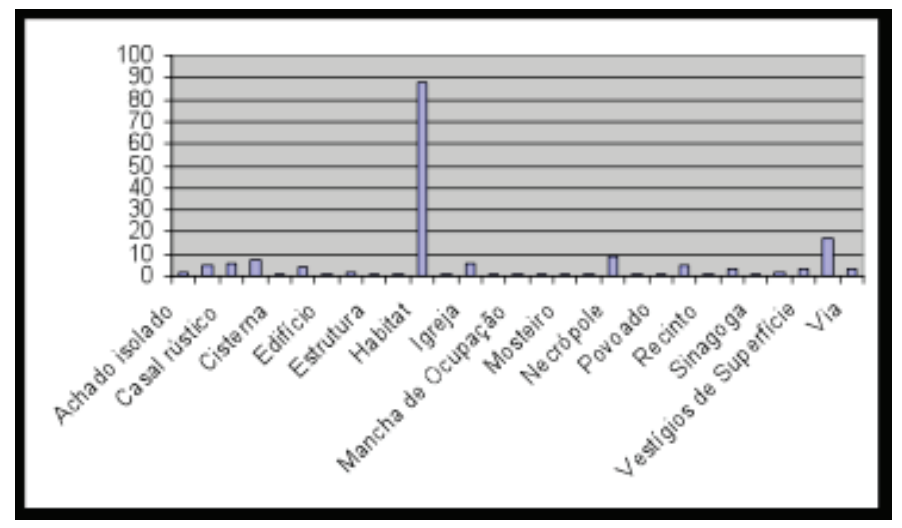


Ao analisar-se os dados referentes ao distrito de Évora, verifica-se que o Período Romano evidencia uma grande dinâmica do povoamento, que não se encontra nem no período anterior, nem no posterior.

\section{Perspectivas para o futuro}

Ao realizarmos este trabalho de consulta e análise dos dados publicados deparámo-nos com realidades que, embora perceptíveis, não foram objecto de sistematização e síntese. Até ao momento, a maioria dos trabalhos produzidos e publicados resulta, sobretudo, de intervenções e estudos pontuais ou geograficamente mais circunscritos, não sendo analisada uma área geográfica tão alargada e diversa como todo o distrito de Évora.

Outro aspecto que convém destacar é que, nos trabalhos publicados, a maior ou menor incidência de ocorrências para um determinado período cronológico poderá também estar pré-determinada pelo olhar mais treinado do investigador para vestígios arqueológicos do período que cientificamente mais domina, verificável principalmente nos números que são apresentados para os achados isolados.

Se até há algumas décadas, devido aos trabalhos maioritariamente de teor epigráfico e numismático, o Período Romano era, por excelência, o de maior e mais evidente na ocupação humana do Alentejo Central, os trabalhos mais recentes vieram preencher o vazio pré e pós romano para o Distrito de Évora, evidenciando, por vezes, uma ocupação pré-romana bastante significativa.

Por outro lado, as características da paisagem também influenciaram, de forma determinante, a ocupação durante o Período Romano. De facto, apesar de não possuirmos dados para todos os concelhos, em relação aos que pudemos analisar, verifica-se que os que possuem terrenos com maior aptidão agrícola, melhor rede hidrográfica e uma paisagem menos acidentada, apresentam um maior índice de ocupação romana.

Por outro lado, estas são também as áreas que actualmente se encontram com uma agricultura intensiva que tem vindo a provocar nos últimos anos uma grande destruição e/ou afectação dos sítios romanos.

Depreende-se assim, pelos elementos acima apresentados, que a dinâmica da ocupação da paisagem, desde a Idade do Ferro até ao Período Medieval, apresenta uma maior incidência de sítios romanos, o que de alguma forma já se perspectivava, mas que, até ao momento, não havia sido demonstrado. Por outro lado, evidencia-se com este estudo que a presença proto-histórica, até hoje pouco reconhecida, está, no entanto, bem presente, nos testemunhos arqueológicos desta região. Assim, reconhece-se uma contínua e ininterrupta ocupação da paisagem do Alentejo Central, variando a sua densidade em função das 
tensões socioeconómicas e da capacidade de exploração dos recursos endógenos.

\section{Anexos}

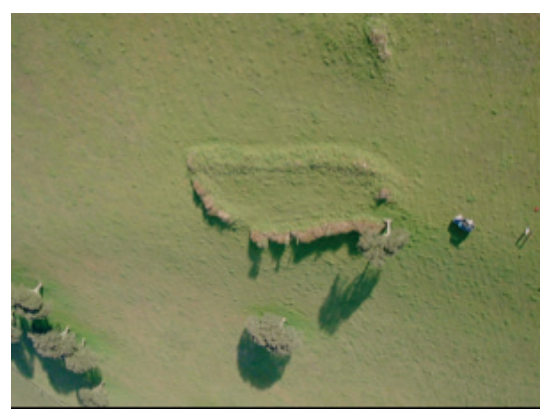

Fig.1. Casa Velha (Évora). Foto de Manuel Calado

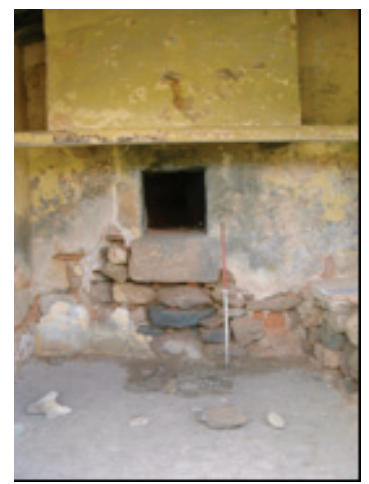

Fig.2. Elemento arquitectónico reutilizado. Sobral (Évora). Foto de Manuel Calado

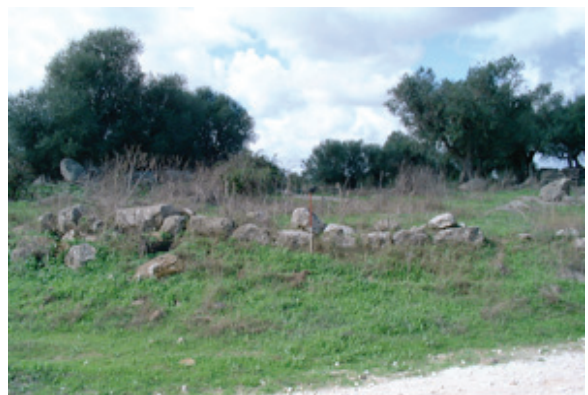

Fig.3. Recinto da Herdade do Pau (Évora). Foto de Manuel Calado 


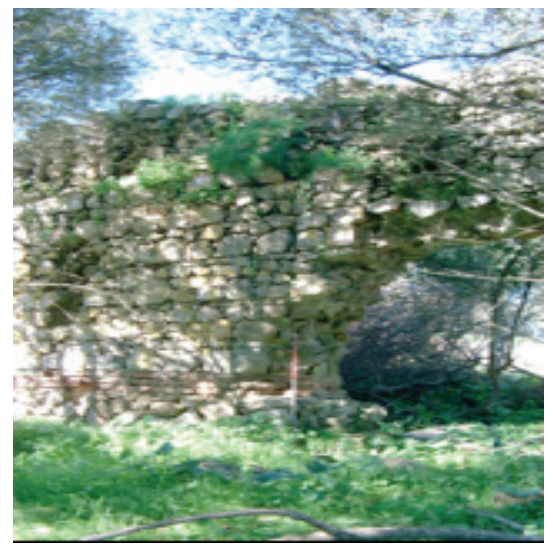

Fig.4. Herdade das Paredes (Évora). Foto de Manuel Calado

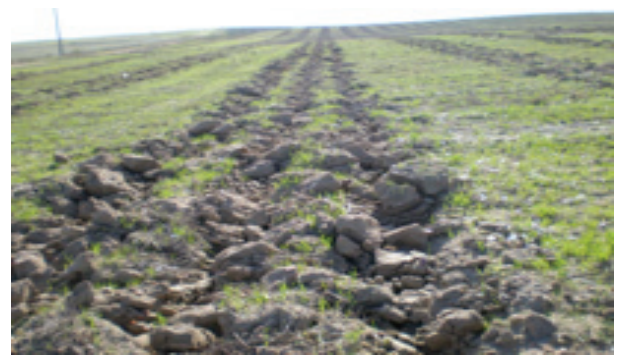

Fig.5. Aspecto da surriba na villa da Mesquita (Évora)

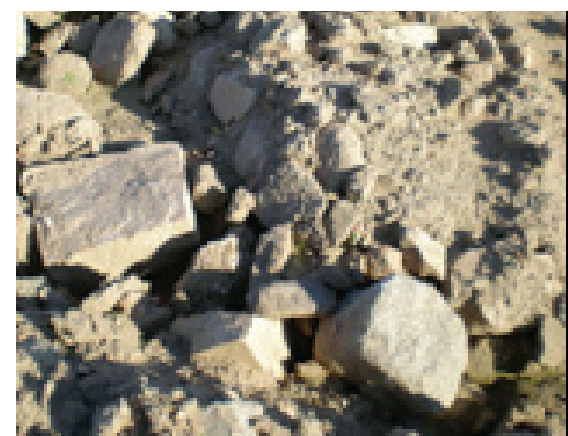

Fig.6. Pormenor dos materiais na villa da Mesquita (Évora) 


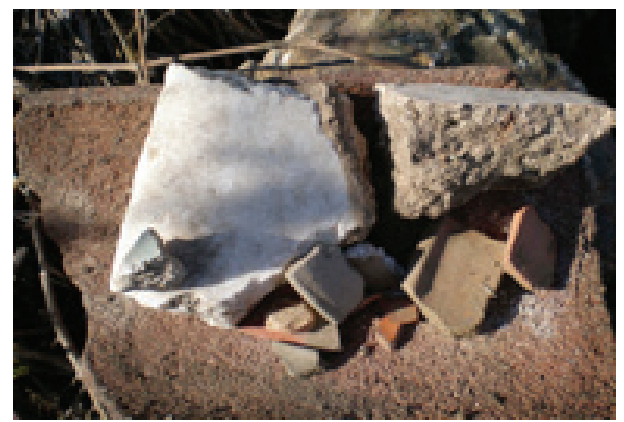

Fig.7. Pormenor dos materiais na villa da Mesquita (Évora)

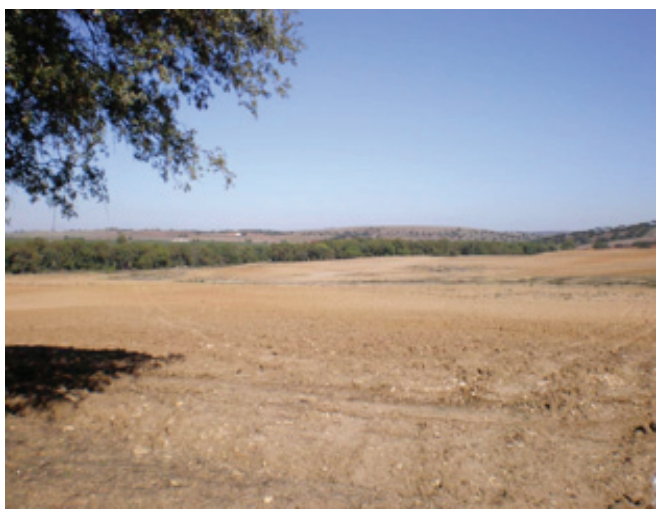

Fig.8. Aspecto dos campos para plantação de olivais

\section{Bibliografia}

M. Calado (1995), Carta Arqueológica do Alandroal. Alandroal: Câmara Municipal de Alandroal.

M. Calado, R. Mataloto (1997), Carta Arqueológica do Concelho de Redondo. Redondo: Câmara Municipal de Redondo.

M. Calado, J. Santos, M. Carvalho (2007), PDM de Évora. Évora: Câmara Municipal de Évora.

P. Lima (1992), Património de Portel: recenseamento preliminar (áreas rurais), 1. Portel: Câmara Municipal de Portel.

A. C. Silva, coord. (1996), Património Arqueológico no Regolfo do Alqueva. Quadro Geral de Referência da EDIA. Beja: EDIA.

A. C. Silva, J. Perdigão (1998), Contributo para a Carta Arqueológica de Arraiolos. Arraiolos: Câmara Municipal de Arraiolos.

Endovélico (http://www.ippar.pt/pt/patrimonio/pesquisa/geral/arqueologico-endovelico/). 


\title{
PARA UMA CARTOGRAFIA DOS CULTOS RELIGIOSOS NO ALTO ALENTEJO EM ÉPOCA ROMANA
}

André CARNeIRo

Universidade de Évora

CIDEHUS

\begin{abstract}
The set of epigraphs of votive character from Upper Alentejo totals over forty examples. Some considerations regarding the possible provenance of the pieces will be presented.
\end{abstract}

Keywords: divinities, Roman settlement, votive epigraphy

Palavras-chave: divindades, epigrafia votiva, povoamento romano.

\section{Introdução}

A investigação arqueológica realizada no território do Alto Alentejo permitiu identificar até ao momento um conjunto de mais de quarenta epígrafes de formulário votivo. Trata-se de um número relevante, tendo em consideração a descontinuidade e o ainda incipiente estado dos trabalhos, com numerosas áreas regionais onde o grau de conhecimentos é relativamente escasso.

$\mathrm{O}$ aspecto que aqui mais interessa explorar tem a ver com a tentativa de determinação do contexto arqueológico de proveniência. Em alguns dos casos a informação é um pouco mais específica, embora em nenhum seja absolutamente precisa ${ }^{1}$; como veremos, em alguns casos podemos determinar o sítio arqueológico, em outros o possível local de proveniência, mas na maior parte das situações a epígrafe aparece-nos como uma peça solta, desgarrada de qualquer local ou de contexto de proveniência.

\section{Catálogo e comentários}

Apresenta-se o elenco das epígrafes votivas do Alto Alentejo, comentandose o seu local concreto de proveniência ${ }^{2}$.

\section{Salavessa (Nisa)}

$\mathrm{LV}[\mathrm{P}] \mathrm{VS} \bullet \mathrm{LAN} / \mathrm{CI} \bullet[$ filius $] \mathrm{QVAN} / \mathrm{CEIO} \bullet \mathrm{TAN} / \mathrm{NGO} \bullet / \mathrm{V}($ otum $) \bullet \mathrm{S}($ olvit $)$

\footnotetext{
${ }^{1}$ Ou seja, não há uma única epígrafe sobre a qual saibamos o exacto local onde a peça foi achada. Não dispomos de nenhuma planta ou fotografia da estrutura ou enquadramento de proveniência, mesmo nas raras situações em que a descoberta ocorreu em contexto de escavação.

${ }^{2}$ As referências bibliográficas são as principais; nelas o leitor poderá encontrar indicações mais específicas.
} 
Não existe qualquer informação sobre o seu contexto de proveniência. $\mathrm{Na}$ zona de Salavessa não são conhecidos sítios romanos que possam ser relacionáveis com esta peça. Próximo do aglomerado urbano existe a Salavessa Velha ou Salavessinha, mas trata-se de um sítio medieval sem ocupação no contexto temporal em análise.

Bibliografia: PDM Nisa ${ }^{\circ} 135$; IRCP $n^{\circ} 641$; RP 6/18.

\section{Capela da Senhora dos Prazeres (Nisa) \\ $[\ldots] \mathrm{VS} \bullet \mathrm{Q} /[\mathrm{VAN}] / \mathrm{CEI}[\mathrm{O}] / \mathrm{TAN}[\mathrm{GO}$ ?] $\mathrm{V}($ otum $) \bullet \mathrm{S}($ olvit $) \bullet \mathrm{L}($ ibens $) \bullet$ $\mathrm{M}($ erito $)$}

Ara votiva que se encontra embutida em lintel de um anexo na Capela da Senhora dos Prazeres, no complexo cultual da Senhora da Graça. Por se encontrar em contexto secundário, desconhece-se a sua proveniência original.

Bibliografia: FE $23 n^{\circ} 106$; PDM Nisa ${ }^{\circ} 57$

\section{Cruzeiro da Senhora da Graça (Nisa)}

\section{[...] QV/[AN]GEO V(otum) / A(nimo) L(ibens) $[\mathrm{S}($ olvit $)]$}

Esta epígrafe e a precedente serão certamente provenientes do próprio monte de Senhora da Graça, um santuário de grande relevância na organização simbólica do actual espaço a Norte de Nisa, cuja elevação alberga um povoado com ocupações da Idade do Ferro e romana. Vigiando a passagem da ribeira de Nisa, onde actualmente se encontra uma ponte de provável fábrica romana, o local terá perpetuado uma relevância cultual e religiosa até à actualidade. Próximo do cruzeiro terá existido um povoado romano, insuficientemente caracterizado e ainda hoje conhecido como Nisa Velha.

Bibliografia: FE 23, n ${ }^{\circ} 103$; PDM Nisa ${ }^{\circ} 58$

\section{Pêro Galego (Nisa)}

Deste local são provenientes três aras:

IV.1.

CELTIVS / TONGI / F(ilius) $\bullet$ IOVI R/EPVLSO(ri) / A(nimo) L(ibens) $\mathrm{V}($ otum $) \bullet \mathrm{S}($ olvit $)$ 
Bibliografia: IRCP n ${ }^{\circ} 638$; PDM Nisa nº 181

IV. 2.

CIRME / CRI • SER/ VOTVM / SOLVIT

Bibliografia: PDM Nisa $n^{\circ} 183$; IRCP nº 639

IV.3.

TANGINVS / DOCQUIRI F(ilius) IO/VI REPVLSORI / [ANI]MO [LIBE]/

NS [V(otum) S(olvit)?]

Bibliografia: IRCP n ${ }^{\circ}$ 640; PDM Nisa n ${ }^{\circ} 182$; RP 6/20

As três epígrafes configuram uma das situações mais interessantes que esta área regional apresenta: a possibilidade de estarmos perante uma estrutura cultual de homenagem a Iupiter, aqui com o epíteto Repulsori. As indicações expressas por Leite de Vasconcelos não são esclarecedoras: "herdade de Pero Galego [...] onde apareceram as lapides no sitio da Fonte de Feia, numa vinha" (1930-1931: 183), estando duas em contexto secundário, reaproveitadas em construções. Uma terceira (IV.2.) apareceu posteriormente à visita do fundador do actual Museu Nacional de Arqueologia (MNA): “[...] o D ${ }^{\text {or }}$ Basso [...] trouxe-me a boa nova do aparecimento de mais uma ara nesta última herdade [...] (1930-1931: 184). Esta informação de Leite de Vasconcelos pode ser confirmada pela leitura do seu epistolário, depositado no MNA. Em carta enviada pelo seu correspondente José Fraústo Basso, datada de 05-05-1931, lê-se: Comunico hoje a agradavel noticia de que nesta data seguiram para Belem em quatro caixotes, com o peso total de 450 quilogramas, as quatro inscrições romanas [....] três das pedras que seguem foram encontradas no sitio da Fonte da Feia ${ }^{3}$. A vinha referida já não existe, o que inviabiliza a definição correcta do achado. No topo da elevação e encosta oriental nenhum indício material foi encontrado, sendo evidente a implantação dominadora. Dada a inexistência de notícias de achados nesta herdade, é de supor que a proveniência das epígrafes seja de uma estrutura cultual e não do âmbito doméstico de uma villa. Seja como for, trata-se de um micro-território que mereceria um programa de prospecções muito sistemáticas.

\section{Tapada de PaiAnes (Nisa ou Castelo de Vide) \\ $\mathrm{P}($ ublius $)$ CARMINI / VS MACER EX VOTO}

\footnotetext{
${ }^{3}$ Correspondente $n^{\circ} 2998$, carta 1756. A estadia de José Leite de Vasconcelos na região decorreu em Abril desse ano; portanto, o envio das epígrafes foi feito nos dias imediatamente posteriores.
} 
O caso da Tapada de PaiAnes é paradigmático das dificuldades que se colocam no rastrear dos contextos de campo a partir das informações antigas e do modo como as alterações na estruturação da paisagem - neste caso, dos registos de propriedade - colocam entraves a uma correcta percepção do percurso dos materiais e dos próprios sítios. Na margem esquerda da ribeira de Paianes, já no actual concelho de Castelo de Vide, encontra-se um notável sítio arqueológico. Trata-se do local de Mosteiros, onde nos anos setenta foi escavado um forno romano no âmbito dos trabalhos da Carta Arqueológica de Castelo de Vide ${ }^{4}$. Embora a autora refira uma vasta área e que os vestígios do domínio romano estendem-se por terrenos de diversos proprietários (p. 139), parte dos núcleos estruturais parecem não ter sido detectados, pois não estão mencionados. Mas a situação não escapou à atenção de Leite de Vasconcelos, que expressamente declara que a sua extensão é que era muito grande [...] não inferior a quatro hectares (1930-1931: 179). É através deste autor que se esclarece a situação: Passemos às ruinas. Ficam na antiga herdade da nobre família de Linhares, que a aforou em vários lotes - herdade situada entre a vila de Nisa e o lugar de Póvoa e Meadas. [...] Ao lavrar-se a terra, descobriram aí os arados, este ano, alicerces antigos de casas [...]. Dr. Basso [...] mandou fazer pesquisas cautelosas [...] não havia duvida que elas [ruinas] eram romanas. (p. 178). A progressiva compartimentação de uma grande propriedade levou às subsequentes alterações toponímicas, e hoje o terreno é conhecido por Mato da Póvoa ou, no caso específico, de Mosteiros, fruto da existência no local de antigas construções medievais que, aliás, reaproveitam abundantes materiais e cavalgam estruturas romanas. O próprio Dr. Basso, na epístola já citada ${ }^{5}$, apresenta a restante [epígrafe] no Mato da Povoa ou Pai Anes.

Bibliografia: PDM Nisa n ${ }^{\circ} 106$; IRCP n 637

\section{Ammaia (Marvão)}

Da cidade são provenientes as seguintes epígrafes:

\section{1.}

GENIO • OPPID[I] / CONSTITVT[I] / SACRVM // C(aius) ANNIVS / VALENS / A(nimo) L(ibens) $\mathrm{D}$ (edit)

Bibliografia: IRCP n 604

VI. 2.

I (ovi) O(ptimo) MAX(imo) / AELIA [?] / MAXIM/A TITVL/I (filia) A(nimo)

$\cdot \mathrm{L}[\mathrm{IBEN}] / \mathrm{S} \bullet \mathrm{V}($ otum $) \bullet \mathrm{S}($ olvit $)$

${ }^{4}$ Rodrigues 1975 139-14; é por esta menção que o local surge em inventários posteriores, como em RP 6/35 (entrada PaiAnes) e 6/36 (entrada Mosteiros) e Gorges 1979 464-465.

${ }^{5}$ Ver nota 4. 
Bibliografia: IRCP n 605

VI. 3.

IOVI / O (ptimo $) \bullet \mathrm{M}($ aximo $)$ / T(itus $)$ CATEIVS [?] / QVIETVS

Bibliografia: IRCP n 606

VI. 4.

$\mathrm{IOVI} / \mathrm{SACRVM} / \mathrm{FAVSTVS} \bullet / \mathrm{BASSI} \bullet \mathrm{LIB}($ ertus $) / \mathrm{A}($ nimo $) \bullet \mathrm{L}($ ibens $) \bullet$ $\mathrm{V}($ otum $) \bullet \mathrm{S}($ olvit $) \bullet$

Bibliografia: IRCP n 607

VI. 5.

$\mathrm{IOVI} \bullet \mathrm{O}($ ptimo $) \bullet / \mathrm{M}($ aximo $) \bullet \mathrm{FVSCA} \bullet / \mathrm{VITVLI} \bullet \mathrm{LIB}($ erta $) / \mathrm{A}($ nimo $) \bullet$ $\mathrm{L}($ ibens $) \bullet \mathrm{S}($ olvit $)$

Bibliografia: IRCP n 608

VI. 6.

OCRIMIR/AE • SAC $($ rum $) \bullet /$ IVLIA $\bullet \mathrm{SA} / \mathrm{TVRISCA} / \mathrm{A}($ nimo $) \bullet \mathrm{L}($ ibens $) \bullet$ $\mathrm{V}($ otum $) \cdot \mathrm{S}($ olvit $)$

Bibliografia: IRCP n 609

Sobre este conjunto epigráfico obviamente não há grandes considerações a tecer em termos de proveniência, dado que se trata da consabida cidade de Ammaia. A concentração de epígrafes a Iovi Óptimo Máximo também não é surpreendente, tendo em conta a expressão do culto imperial consubstanciada na estrutura do templo que coroava o fórum. Quanto à manifestação de Ocrimira, uma divindade local,é de considerar a hipótese já proposta por Vasco Mantas de haver no complexo do fórum (ou em outro ponto do aglomerado urbano) um segundo templo, congregador das comunidades locais ${ }^{6}$. De referir ainda que todas as epígrafes são dedicadas por indígenas ou libertos, o que diz muito do substrato étnico que compunha a população da cidade ${ }^{7}$.

Desta área regional, eventualmente da cidade ou das suas imediações, temos a seguinte epígrafe:

${ }^{6}$ Mantas 2000 405-408. Sendo interessante notar que, embora o formulário seja absolutamente latino, a dedicante será indígena.

7 "Em 1998 surgiu uma segunda ara, dedicada ao genio ammaiensi, no sítio das Hortas Velhas (Alvarrões) [...], embora em prospecções ali realizadas não registássemos qualquer vestígio arqueológico" (Pereira 2005 59). Desta peça ainda não foi apresentada leitura. 


\section{7. Barretos (Marvão)}

TOGAE $\bullet \mathrm{AL} / \mathrm{MAE} \mathrm{S}($ acrum $) \bullet \mathrm{NO} / \mathrm{VELA} \bullet \mathrm{NA} / \mathrm{NIAE} \bullet \mathrm{LIB} / \mathrm{ERTA} / \mathrm{V}($ otum $)$

- $\mathrm{A}($ nimo $) \cdot \mathrm{L}($ ibens $) \cdot \mathrm{S}($ olvit $)$

Bibliografia: IRCP n ${ }^{\circ}$ 611; Oliveira, Pereira e Parreira: $n^{\circ}$ 159; RP 6/62A

A epígrafe é proveniente de um local com topónimo sugestivo, Fonte dos Mortos, onde Afonso do Paço (1953 109) identificou uma necrópole relacionada com um local de habitat.

\section{Mascarro (Castelo de Vide)}

[...] / [VS?] IVNII / IQALV [?] / ARI [?] A(nimo) L(ibens) / V(otum) S(olvit)

É seguro o contexto de proveniência da peça, tratando-se de uma villa que foi inclusivamente alvo de trabalhos de escavação (Rodrigues 1975: 170). Todavia, não é mencionado o exacto local de proveniência da epígrafe, que nos aparece assim como um elemento descontextualizado, embora provavelmente fizesse parte de um lararium doméstico. De salientar o contraste entre o bom modelamento do suporte pétreo da peça e a fruste gravação do campo epigráfico, o que pode indicar que a peça foi adquirida e só mais tarde gravada no sítio.

Bibliografia: IRCP nº 613; RP 6/57

\section{Colegiada (Castelo de Vide)}

[...] / MAR[CI F(ilius)] (?) / EX CO[NS(ulto)] (?) / ANDAIECQ / P(ius?) $\mathrm{P}($ osuit?)

Recolha de superfície em zona onde se encontram alguns alinhamentos de muros que podem corresponder à existência de uma villa. A memória de existência de uma igreja sobreviveu na tradição oral.

Bibliografia: FE $49 \mathrm{n}^{\circ} 221$

\section{Monte do Chocanal (Crato) \\ IOVI / OPTVMO / MAXVMO / VICANI / CAMALO / C [...] IN [?]}

Uma das epígrafes mais interessantes para esta região, não tanto pelo teónimo indicado (aliás repetitivo), mas pelo raro exemplo do dedicante: os vicani camalo[cani?, censis?], que nos indicam a existência de um 
aglomerado urbano de importância secundária próximo da actual localidade de Crato.

Não tem sido fácil encontrar uma correspondência entre a menção e as realidades materiais no terreno. A respectiva ficha de sítio menciona uma área de cerca de $1200 \mathrm{~m}^{2}$, obviamente pouco coincidente com a importância de um vicus, e ainda um muro construído com grandes blocos de granito, eventual podium de uma estrutura ${ }^{8}$. Junto à actual casa agrícola encontravam-se alguns blocos de granito que não foram poupados pelas recentes obras de recuperação do imóvel, e em alguns pontos dispersos são visíveis manchas de cerâmica de construção. Dada a raridade da menção epigráfica, trata-se de (mais um) local que merecia uma investigação atenta e devidamente estruturada.

Bibliografia: IRCP n ${ }^{\circ}$ 609; RP 6/104

\title{
$X$. Reguengo (Alter do Chão)
}

\author{
[...] [ITA?] / [...] RECIP [...] / [A]VITI • F(ilius $) / \mathrm{V}($ otum $) \bullet \mathrm{A}($ nimo $) \bullet$ \\ $\mathrm{L}($ ibens $) \cdot[\mathrm{S}($ olvit $)]$
}

Uma das situações onde é mais difícil a correspondência entre a peça e o local de proveniência. Foi encontrada numa arrecadação da Coudelaria de Alter, mas provém de um sítio próximo denominado Reguengo (Timóteo et alii 1978: 282). Apesar de um projecto de investigação recente ter realizado prospecções sistemáticas no perímetro da Coudelaria, a situação permaneceu inconclusiva: Desconhecemos onde estes autores terão obtido essa informação, contudo, na área do Reguengo, tanto no interior da Coudelaria, como fora, não identificámos vestígios romanos que justificassem a presença desta ara (Oliveira 2006 226). Uma questão em aberto, portanto.

Bibliografia: IRCP n ${ }^{\circ} 614$

\section{Revelhos (Arronches)}

\author{
LIBI/RAII
}

Epígrafe com menção insólita, pois são pouco frequentes as dedicatórias feitas exclusivamente a Libera; a deusa surge associada, dum modo geral,

${ }^{8}$ De resto, as referências seguintes são bem mais enigmáticas: Na vertente oeste, aparece [?] a camada de destruição [?], constituída por ímbrices. De acordo com a Base de Dados Endovélico, http://www.ipa.min-cultura.pt/. 
a Liber, formando um par favorável à fecundidade ligado ao movimento dionisíaco $\left(\right.$ IRCP $\left.\mathrm{n}^{\circ} 567\right)$.

Subjacente à elevação onde se ergue a igreja de S. Bartolomeu, sede da antiga freguesia homónima, encontra-se uma extensa villa romana, infelizmente muito afectada pelos usos posteriores do solo. No local já António Thomaz Pires (1901 213) havia recolhido algum material arqueológico para o Museu de Elvas, registando-se ainda a existência de mosaicos. O local encontra-se a curta distância de um troço de via romana, possivelmente, do Itinerário XV de Antonino. Os vestígios são suficientemente relevantes para que Mário Saa (1967 40-41) tivesse proposto aqui a localização da mansio de Matusarum.

Bibliografia: IRCP $n^{\circ}$ 567; RP 6/157

\section{Ervedal (Avis)}

FONTAN[O] [?] / SACRVM / THREPTVS C(aii) APPVLEI / SILONIS • $\mathrm{SER}($ vus $) \mathrm{V}($ otum $) \mathrm{S}($ olvit $) \mathrm{L}($ ibens $) \bullet \mathrm{A}($ nimo $) / \mathrm{OB} \bullet \mathrm{AQVAS} \bullet \mathrm{INVENTAS}$

A notícia da identificação da epígrafe é-nos dada por José Leite de Vasconcelos: [...] a ara encontrou-se em 1870 num campo chamado Tapada da Alameda [...]. Ao pé havia uma nascente grande de agoa [...]. À superficie do terreno descobrem-se muitos cacos antigos (Vasconcelos 1913: 620-621). $\mathrm{O}$ sítio encontra-se actualmente em escavações promovidas pela Câmara Municipal de Avis, esperando-se que seja possível determinar a funcionalidade e características estruturais deste local.

Bibliografia: IRCP n ${ }^{\circ}$ 437; RP 6/135

\section{Castelo (Avis)}

RVFINV/S RVFI F(ilius) / BANDI • SIAISABRIO $\bullet \mathrm{V}($ otum $) \mathrm{A}($ nimo $) \mathrm{L}($ ibens $)$ $\mathrm{S}($ olvit $)$

Epígrafe que apresenta conteúdos muito interessantes, dada a menção a um teónimo já conhecido, pertencente ao grupo Band-, com o epíteto (local?) Saisabro.

Apesar do sugestivo topónimo não se conhecem ocupações antigas no local ${ }^{9}$. Todavia, na base da elevação encontra-se a villa de Bembelide, em cujas casas do monte a peça foi recolhida, um sítio que foi objecto de intervenção

\footnotetext{
${ }^{9}$ Situação observada nas prospecções no âmbito da Carta Arqueológica de Avis efectuadas por Ana Ribeiro, a quem agradeço a informação.
} 
arqueológica nos anos setenta, tendo sido posteriormente destruída por movimentação de terras (Endovélico).

Bibliografia: FE 46 n $^{\circ}$ 206, 1994

\section{Torre de Palma (Monforte)}

\section{$\mathrm{M}($ arcus $) \bullet \mathrm{COELI}[\mathrm{VS}]$ / CEL[S]VS / MARTI / A(nimo) L(ibens)}

Executado por um dos prováveis proprietários da villa, um raro testemunho epigráfico do culto a Marte. Infelizmente, apesar de se tratar de um sítio extensamente escavado, não conseguimos perceber qual o contexto de descoberta da epígrafe. Apenas merece uma lacónica menção de Manuel Heleno: [...] uma grande igreja do séc. XIV. Próximo encontrouse posteriormente uma ara [...] (1962: 337). A análise da correspondência enviada por João Lino da Silva, funcionário do MNA encarregue de orientar os trabalhos no terreno, menciona o achado da ara dentro de um poço ${ }^{10} \mathrm{o}$ que objectivamente não é muito esclarecedor e inviabiliza a possibilidade de percebermos onde estaria o lararium doméstico no qual a peça certamente estaria colocada.

Bibliografia: IRCP $n^{\circ}$ 568; RP 6/144

\section{Santa Maria (Monforte)}

NYMPHIS / AVITVS / PROCVLI / F(ilius) $\bullet$ PRO SA/LVTE •FLA/CCILLAE $\bullet \mathrm{FL} / \mathrm{ACCI}($ filiae $) \bullet \mathrm{VC} / \mathrm{XORIS} \bullet \mathrm{SVAE} / \mathrm{V}($ otum $) \bullet \mathrm{L}($ ibens $) \bullet \mathrm{A}($ nimo $) \bullet \mathrm{S}($ olvit $)$

Segundo testemunho do culto às ninfas recenseado nesta zona, aqui com propriedades salutíferas (PRO SALVTE). A epígrafe, hoje em paradeiro desconhecido, foi encontrada depositada na igreja de Santa Maria. Pela inexistência de nascentes termais em Monforte - apesar de um topónimo "Fadagosa" - será proveniente do balneário de Cabeço de Vide, com comprovada ocupação romana.

Bibliografia: IRCP $n^{\circ}$ 569; RP 6/147

\section{Monte das Esquilas (Monforte)}

\section{LARIBVS/ VIALIBVS / L・P・}

O único testemunho do culto aos Lares Viales encontrado na província é proveniente da Herdade da Fonte Branca: Continuando pela via imperial, 300 MNA.

${ }^{10}$ Cartas de J. Lino da Silva, Maço Extra, entrada de 17.XI.62, Arquivo Manuel Heleno, 
metros adiante das Esquilas, achamos, em um pequeno outeiro, e rente do caminho restos de volumosa silharia granítica dum templo romano, do qual exumei um altar, consagrado aos deuses dos caminhos, os Lares Viais [...] (Saa 1956 292). Dois aliciantes: a menção a uma estrutura de enquadramento da peça, para mais com elementos monumentais, e a proximidade a um troço de via, possivelmente o Itinerário XIV de Antonino. A prática agrícola no local terá fortemente destruído ambas as evidências. No terreno apenas é visível uma mancha de cerâmica de construção, pouco significativa.

Bibliografia: RP 6/178

\title{
XVII. Herdade da Defesinha (Campo Maior)
}

\author{
$\mathrm{Q}[. ..] \mathrm{P}[. ..] \mathrm{D}($ eae $) \mathrm{S}$ (anctae) [Turubrigensi] /V(otum) $\mathrm{Q}($ uod) $\mathrm{F}($ ecit $) \mathrm{A}($ nimo $)$ \\ $\mathrm{L}($ ibens $)[\mathrm{P}($ osuit $)]$ / ... / $\mathrm{E}(x) \mathrm{M}($ onitu $)$
}

Mais um dos numerosos casos com que nos deparamos neste território de uma informação de proveniência aparentemente precisa, mas que na prática nada esclarece: A ara tinha aparecido quando se arava com um tractor na Herdade da Defesinha (Diogo 1984 9). No terreno deparamos com uma propriedade que se estende por várias centenas de hectares, e onde, na área percorrida, constituída por extensos terraços fluviais, não se detectam quaisquer vestígios. Na margem oposta, no extenso arco entre Lapagueira, Malha-Pão e Pombinha, existem recolhas diversas de materiais que apontam para contextos de necrópole (epígrafe funerária) e de uma villa, para além de ser óbvia a relação espacial com o itinerário da via XV materializada nos impressionantes alicerces da ponte de N. Sr. ${ }^{a}$ da Enxara ${ }^{11}$. Uma última nota para referir que o epíteto Turubrigensi é meramente especulativo.

Bibliografia: FE 8 n $^{\circ} 32$; RP 6/166

\section{Santa Eulália [Santa Catarina] (Elvas)}

VALGIVS / MARCI F(ilius) / ARAM BE / LLONAE / DE VOTO [POS]V[I] $\mathrm{T}(?)$

Atribuída genericamente a Santa Eulália, a notícia da sua descoberta é mais precisa: Foi achada, em 1993, no leito seco da barragem do Caia, no meio das pedras que serviam de base ao altar, em ruinas, da antiga capela da invocação de Santa Catarina [...]. [...] esta capela assentava sobre construções romanas $[\ldots]^{12}$. Hoje está semi-coberta

\footnotetext{
${ }^{11}$ Ver, por exemplo, Alarcão 2006 230, com bibliografia.

${ }^{12} \mathrm{FE} \mathrm{46,n^{ \circ }} 207,1994$.
} 
pelas águas da albufeira do Caia, e por isso sofrendo grande degradação estrutural.

Bibliografia: FE $46 n^{\circ} 207$

\section{Termo desconhecido (Elvas)}

SECVNDYTIV/S • VICTORIN[NVS • E] [?] / [...ENSIBVS?] / [PRO $\mathrm{SALVTE} \mathrm{SVA}$ ?] / V (otum $) \bullet \mathrm{A}($ nimo $) \bullet \mathrm{L}($ ibens $) \bullet \mathrm{S}($ olvit $)$

Um caso onde se levantam fundadas dúvidas em relação ao contexto de proveniência. A peça foi depositada no Museu de Elvas, sem mais esclarecimentos. Dadas as dificuldades de leitura do texto, poderá haver uma ténue hipótese de ser a mesma epígrafe que Mário Saa encontrou Entre Esquilas e S.ta Eulália, não longe do M.te de D. Miguel, apareceu uma ara consagrada à deusa Victoria (Saa 1956 195). Mas as dúvidas são ainda mais amplas: é possível que se trate de uma epígrafe dedicada por um Victorinus a um teónimo indeterminado.

Bibliografia: IRCP n ${ }^{\circ} 575$

\section{Termo desconhecido (Elvas)}

DEE SANCTE/BVRRVLOBRI[I] / [G]ENSI Q(uintus?) I(ulius?) EM(eritus?) $/[\mathrm{A}($ nimo $)] \bullet \mathrm{L}($ ibens $) \bullet \mathrm{V}($ otum $) \bullet \mathrm{S}($ olvit $)$

Leite de Vasconcelos refere que estive no Museu de Elvas, onde vi uma lapide apparecida nessa cidade [...] (1905 174), sem mais pormenores. Esta peça levou à especulativa hipótese de atribuição do topónimo Burrolobriga ao local de implantação da cidade de Elvas, cujo perfil de ocupação em época romana nunca foi devidamente esclarecido, mas nada garante que a peça seja originária do núcleo urbano.

Bibliografia: IRCP n ${ }^{\circ} 566$

\section{As aras a Prosérpina na região de Elvas (Elvas)}

XXI.1. Fonte Branca (Elvas)

PROSERP(inae) / TONCIVS / [...] / [...]

Bibliografia: IRCP $\mathrm{n}^{\circ} 574$

XXI.2. Fonte Branca (Elvas)

DEAE PROSER/ PINAE [...] / RVSTRI V (otum $) \bullet \mathrm{L}($ ibens $) \bullet \mathrm{A}($ nimo $) \bullet \mathrm{S}($ olvit $)$ 
Bibliografia: IRCP n 573

\section{XXI.3. Termo de Elvas}

$\mathrm{Q}$ (uintus) • HELVIVS / SILVANVS / PROSERPIN / AE • VOTVM / s(uum?)

- $\mathrm{NA}($ imo $) \mathrm{L}($ ibens $) \cdot \mathrm{P}($ osuit $)$

Bibliografia: IRCP $\mathrm{n}^{\circ} 570$

\section{XXI.4. Termo de Elvas}

PROSER/ PINAE / SANCTAE / G(aius) • IVLIVS / PARTHENOP / AEVS • $\operatorname{VOT}($ um $) / \mathrm{QVOT}[$ sic $] \bullet \mathrm{FECIT} \mathrm{/} \mathrm{A} \mathrm{(nimo}) \bullet \mathrm{L}($ ibens $) \bullet \mathrm{P}($ osuit $)$

Bibliografia: IRCP n ${ }^{\circ} 571$

\section{XXI.5. Termo de Elvas}

PROSERPINAE / SERVATRICI / C (aius) $\bullet$ VETTIVS • SIL/ VINVS • PRO • $\mathrm{EV} / \mathrm{NOIDE} \bullet \mathrm{PLAVTIL} / \mathrm{LA} \bullet \mathrm{CONVIGE} \bullet \mathrm{SIBI} / \mathrm{RESTITVTA} \bullet \mathrm{V}($ otum $) \bullet \mathrm{S}($ uum? $)$

- $\mathrm{A}($ nimo $) \cdot \mathrm{L}($ ibens $) \cdot \mathrm{P}($ osuit $)$

Bibliografia: IRCP n ${ }^{\circ} 572$

Conjunto de grande relevância cultural e de notável homogeneidade. As duas primeiras epígrafes são atribuídas ao sítio de Fonte Branca, enquanto as restantes foram encontradas em depósito no Paço de Vila Viçosa, mas é de supor que a proveniência seja a mesma, até porque o provável depositante, Abel Viana, trabalhou na zona de Elvas. Sobre a localização de Fonte Branca, hoje um irrelevante subúrbio da cidade de Elvas, encontramos a referência no notável Dicionário de Vitorino d'Almada, esforço de labor individual que nunca logrou a dignidade que legitimamente merecia:

\section{Fonte Branca (Torre da)}

Atalaia de que resta uma só face, perto do sitio deste nome, à direita da estrada real para Badajoz. Foi provavelmente destruida pelos espanhoes na guerra da acclamação. Este paredão fica a 1106 braças do Outeiro do Paraizo e a 919 do do Ouradinho ${ }^{13}$.

O local ainda hoje existe, com a estrutura arquitectónica referida por Almada marcando a paisagem. No terreno são evidentes os materiais cerâmicos indicadores de uma estrutura romana, à qual eventualmente se devem alguns taludes que são perceptíveis. A alvenaria do edifício incorpora blocos de granito que terão pertencido a construções anteriores. Mais uma vez a relação

\footnotetext{
${ }^{13}$ Almada [s.d.] Vol. 18 - Fil-Fon, Arquivo Municipal de Elvas.
} 
com um itinerário viário é evidente, tratando-se possivelmente da via XII que cruzaria o Guadiana um pouco mais a Este, próximo de Alfarófia.

\title{
XXII. Senhora dos Mártires (Estremoz)
}

\author{
$\mathrm{M}$ (atri) $\mathrm{D}$ (eum) $\mathrm{S}$ (acrum) // I(ulius) MAXIMI/ANVS A(nimo) L(ibens) \\ $\mathrm{P}($ osuit $)$ / PRO H(uius) $\mathrm{M}$ (onumenti) $\mathrm{N}$ (umini) $\mathrm{E}$ (rectionem) / PECVLIVM
}

Único testemunho do culto à Deusa Cíbele nesta região. O seu local de proveniência é um dos mais interessantes desta zona, embora nunca devidamente tratado: [...] o achador [...] declarou que eles provinham da grande estação arqueológica da Senhora dos Mártires, a sueste de Estremoz, da qual faz parte o conhecido «Tanque dos Mouros» (Almeida e Ferreira, 1967 47). Esta estrutura hidráulica, infelizmente quase ignorada e nunca devidamente valorizada, seria peça fundamental de um conjunto de sistemas hídricos ligados à actividade de extracção e transformação de mármores e ao abastecimento de um aglomerado urbano secundário, possível vicus, situado na envolvente da actual Igreja da Senhora dos Mártires. O conjunto estaria também relacionado com a passagem da via XII do Itinerário de Antonino.

Bibliografia: IRCP $n^{\circ}$ 440; RP 6/208

\section{Bencatel (Vila Viçosa)}

FONTANO / ET • FONTANAE / PRO SALVT $(e) \bullet \mathrm{AL} / \mathrm{BI} \bullet \mathrm{FAVSTI} \bullet \mathrm{ALBIA}$ / $\mathrm{PACINA} \bullet \mathrm{V}($ otum $) \bullet \mathrm{S}($ olvit $) \bullet \mathrm{A}($ nimo $) \bullet \mathrm{L}($ ibens $)$

A epígrafe tem sido genericamente atribuída a "Bencatel", sem uma localização mais específica. Uma leitura mais atenta da notícia de recolha permite definir o seu contexto de proveniência: [...] a ara achou-se nos campos dos Vilares (Bencatel), no sítio da Acenha das Freiras, ao pé de uma fonte. [e em nota de rodapé:] Já ai estive. A fonte é terrenha, i.é, brota do chão. Podia ser transformação da antiga, caso ali tivesse tido, realmente, a sua sede o culto de Fontanus e Fontana. No terreno em volta vi muitos fragmentos de tegulas e pedras-mármores aparelhadas; e soube também que ali apareceram moedas romanas. (Vasconcelos 1905 256). A componente sacra do local é evidente: próximo de Aldeia da Freira encontrase, ainda hoje, a Azenha da Saúde, e mais tarde constrói-se nas proximidades um edifício dedicado a Santa Ana, um dos hagiotopónimos que encontramos com frequência cristianizando locais de culto anteriores.

Bibliografia: IRCP $n^{\circ}$ 438; RP 6/245

\section{Termo de Borba? (Borba ?)}

$\mathrm{C}($ aius $) \bullet \mathrm{LICINIVS} ・ \mathrm{VEGETVS} \mathrm{/} \mathrm{QVANGEIO} \mathrm{・} \mathrm{TVRICAECO} \mathrm{/} \mathrm{V(otum})$ 
Epígrafe completamente desgarrada de qualquer contexto arqueológico, pois foi encontrada em colecção de um antiquário de Borba, vila conhecida por esta actividade comercial em que os seus empenhados agentes têm grande alcance territorial na angariação de peças. O teónimo (aqui com um etnónimo inédito, Turicaeco) já é nosso conhecido, com ocorrências no extremo norte da área territorial aqui tratada. Não é líquido, como afirma o autor, que tenha sido achada nas proximidades da vila.

Bibliografia: FE 38, n 174

\section{Vale de Ourigo (Borba)}

IOVI [SA]/CRVM / [.] RA [.] O /IVS [...] / ON ANIMO/O LIBE(n)S PO(suit $)$

Sem contexto arqueológico específico, uma vez que foi encontrada em colecção particular. Em Vale de Ourigo não se conhecem pontos de povoamento em época romana.

Bibliografia: Cardim 2002422

\section{Pardais ? (Vila Viçosa ?)}

SALUTI/PRO SALU/TE ACILI RU/FINI CANIE/IUS M(erito) A(nimo) $\mathrm{L}($ ibens $) / \mathrm{V}($ otum $) \mathrm{S}($ olvit $)$

Designação genérica de "Pardais", o aglomerado urbano sede de freguesia,mas existem fundadas dúvidas sobre a proveniência da peça (IRCP $\mathrm{n}^{\circ}$ 375). No imediato entorno da localidade conhecem-se vários pontos de povoamento relacionados sobretudo com a actividade de exploração de pedreiras de mármore. Infelizmente a exploração contemporânea destruiu muitos desses sítios romanos, como o caso dos importantes povoados (villae?) de São Marcos e de Fonte Soeiro. Com a sua habitual eloquência, Saa localiza aqui a estação de $A d$ Adrum Flumen e descreveu o que ainda pode observar: A «cidade» dos Vilares, como aqui se diz, existira em torno da capela ou ermida de S. Marcos. A «cidade» desenvolvia-se para leste da capela, por terrenos extraordinàriamente impregnados de fragmentos de telhas, no largo espaço que compreende Fonte da Moura e Fonte Soeiro. Colunas de mármore (pedra da região), silharia, pavimentos do costumado mosaico policrómico (em profusa quantidade), ladrilhos, objectos, inscrições, tudo aí aparece, e muito mais apareceu noutras idades, como referem monografias locais. (Saa 
1956 138). Hoje temos verdadeiras crateras onde da época romana nada restou.

Bibliografia: IRCP ${ }^{\circ} 375$

\section{Considerações gerais}

Em síntese, o elenco pode ser sistematizado da seguinte forma:

\begin{tabular}{|c|c|c|c|c|}
\hline \multicolumn{2}{|c|}{ Concelhos } & Divindades & Vias & Sítios \\
\hline Nisa & 6 & $\begin{array}{l}\text { Quangeio Tango (3), Jupiter Repulsor } \\
\text { (3) }\end{array}$ & $?$ & Santuários (?) \\
\hline Gavião & 0 & - & - & - \\
\hline $\begin{array}{l}\text { Castelo de } \\
\text { Vide }\end{array}$ & $2+1 ?$ & Andaeco (1) & $?$ & $\begin{array}{l}\text { Villa, } \\
\text { Santuário? }\end{array}$ \\
\hline Marvão & 7 & $\begin{array}{l}\text { IOM (4) Ocrimira (1) Toga Alma (1) } \\
\text { Génio (1) }\end{array}$ & ? & $\begin{array}{l}\text { Cidade, } \\
\text { Santuário }\end{array}$ \\
\hline Portalegre & 0 & - & - & - \\
\hline Crato & 1 & IOM (1) & XV & Vicus \\
\hline Alter do Chão & 1 & $?$ & XIV & $?$ \\
\hline Ponte de Sôr & 0 & - & - & - \\
\hline Fronteira & $1(?)$ & Ninfas & XIV & Balneário \\
\hline Arronches & 1 & Libera & $\mathrm{XV}$ & Villa \\
\hline Monforte & 2 & Lares Viales (1) Marte (1) & XIV & $\begin{array}{l}\text { Villa } \\
\text { Santuário }\end{array}$ \\
\hline Avis & 2 & Fontano, Bande Saisabro & $?$ & Villa \\
\hline Sousel & 0 & - & - & - \\
\hline Campo Maior & 1 & Dea Sancta (Atégina) & XV & Villa \\
\hline Elvas & 8 & $\begin{array}{l}\text { Proserpina (5) Belona (1) Victoria } \\
\text { (?.1) Ategina (1) }\end{array}$ & XII & Santuário \\
\hline Estremoz & 1 & Cíbele & XII & $\begin{array}{l}\text { Santuário de } \\
\text { vicus }\end{array}$ \\
\hline Borba & 2 & Quangeio Turicaeco (1) Jupiter (1) & XII & $?$ \\
\hline Vila Viçosa & $1+1$ ? & Fontano (1) Salus (1) & XII & Villa? \\
\hline
\end{tabular}

Em visão geral podemos considerar que, também neste campo, observamos a existência de duas grandes áreas culturais. Temos por um lado o âmbito noroeste, no arco de Avis, Ponte de Sôr, Gavião, Nisa, Castelo de Vide e Marvão, onde as epígrafes são numericamente mais escassas e estão claramente vinculadas, quer no campo antroponímico, quer teonímico, a um fundo cultural onde a romanização parece ser mais superficial ou epidérmica. Da outra parte o bloco sudeste, mais multicultural, plenamente romanizado, aberto inclusive a influências alógenas, com divindades de âmbito oriental e dedicantes de onomástica grega, configurando um universo cultural de sólida adesão à mundividência clássica. Dito em discurso mais determinista, uma diferença entre o mundo que encontramos nas duas margens do Tejo e o existente no espaço da bacia do Guadiana, funcionando esta como área de 
prolongamento natural das influências civilizacionais que irradiam a partir da capital provincial.

A heterogeneidade de estruturas integradoras das epígrafes é relevante: para além dos aglomerados urbanos (de primeira e segunda ordem) e de villae, teríamos santuários ou mesmo complexos cultuais, o que manifestamente merece uma atenção apurada na identificação das realidades de terreno.

\section{Bibliografia}

1. Abreviaturas

$\mathrm{FE}=$ Ficheiro Epigráfico

IRCP = José d'Encarnação (1984), Inscrições Romanas do Conventus Pacensis. Coimbra.

RP = Jorge de Alarcão (1988), Roman Portugal. London.

\section{Geral}

Rafael Alfenim (1991), "Ex-voto a Quangeio Turicaeco", Ficheiro Epigráfico 38, n 174.

J. M. Almeida e F. B. Ferreira (1967), "Varia epigraphica", Revista de Guimarães 77 47-69.

José Ribeiro Cardim, coord. (2002), Religiões da Lusitânia. Loquuntur Saxa. Lisboa. Rogério Carvalho (1987), "Ara votiva de N. Sr. a dos Prazeres (Nisa)", Ficheiro Epigráfico 23, $\mathrm{n}^{\circ} 106$.

Fernando Patrício Curado (1987), "Fragmento de ara de Nisa", Ficheiro Epigráfico $23, \mathrm{n}^{\circ} 103$.

António Dias Diogo (1984), “Ara votiva de Ouguela, Campo Maior (Conventus Pacensis)", Ficheiro Epigráfico 8, $\mathrm{n}^{\mathrm{o}} 32$.

José d' Encarnação (1994), "Ara votiva identificada em Avis (Conventus Pacensis)", Ficheiro Epigráfico 46, nº 206.

\section{Coimbra.}

(1995) "Ara votiva da Colegiada", Ficheiro Epigráfico 49, n 221.

Jean-Gérard Gorges (1979), Les Villas Hispano-Romaines: inventaire et problématique archéologiques. Paris.

Manuel Heleno (1962), "A villa lusitano-romana de Torre de Palma (Monforte)", $O$ Arqueólogo Português, Série IV, 313-338.

T. Maciel, J. Maciel, J. Encarnação (1994), “Ara a Belona, de Santa Eulália (Elvas) (Conventus Emeritensis)", Ficheiro Epigráfico 46, nº 207.

Vasco Mantas (2000), "A sociedade luso-romana do município de Ammaia", in J. G. Gorges e T. Nogales Basarrate, coord., Sociedad y cultura en Lusitania romana, $\mathrm{IV}^{\mathrm{a}}$ mesa redonda internacional. Mérida, Junta de Extremadura, 391420. 
Jorge de Oliveira (2006), Património arqueológico da Coudelaria de Alter. Lisboa/ Évora.

Jorge de Oliveira, Sérgio Pereira, João Parreira (2007), "Nova Carta Arqueológica do concelho de Marvão", Ibn-Maruan 14.

Afonso do Paço (1953), "Carta Arqueológica do concelho de Marvão", Congresso luso-espanhol para o progresso das ciências $-7^{a}$ secção. Ciências históricas e filológicas. Lisboa, Associação Portuguesa para o Progresso das Ciências, 93-119.

Sérgio Pereira (2005), "A freguesia da Aramenha sob o domínio romano", in Jorge de Oliveira, coord., "São Salvador da Aramenha. Histórias e Memórias da Freguesia", Ibn-Maruan 13 35-61.

António Thomaz Pires (1901), "Catalogo do Museu Archeologico de Elvas", $O$ Archeologo Português 4 209-236.

Maria da Conceição Rodrigues (1975), Carta Arqueológica do concelho de Castelo de Vide. Lisboa.

Mário de Saa (1956-1967), As grandes vias da Lusitânia: O itinerário de Antonino Pio. Lisboa, 6 volumes [vol. I 1956, III 1967].

Maria Abranches Timóteo (1978), "Arqueologia romana do concelho de Alter do Chão (Subsídios para o seu estudo)" in Actas das III Jas Jornadas Arqueológicas. Lisboa, Associação dos Arqueólogos Portugueses, 273-292.

José Leite de Vasconcellos (1905-1913), Religiões da Lusitânia. Lisboa, 3 vols.[ Vol. II 1905, III 1913].

Português, Série 129 173-185. 
(Página deixada propositadamente em branco) 


\title{
EPÍGRAFE VOTIVA DE ARRONCHES NOTÍCIA DA SUA IDENTIFICAÇÃO
}

\author{
ANDRÉ CARNeiro \\ JosÉ D'ENCARNAÇÃO \\ JORGE DE OLIVEIRA \\ Cláudia Teixeira \\ CEAUCP - Centro de Estudos Arqueológicos \\ das Universidades de Coimbra e Porto
}

\section{Résumé}

Le contact des Romains avec les indigènes, qui parlaient, bien entendu, un autre langage mérite, de plus en plus, l'attention des chercheurs, parce qu'on s'aperçoit qu'il y a eu de notables influences réciproques. L'inscription en langue dite «lusitanienne» trouvée à Arronches (Lusitania - ager Emeritensis?), dont la première étude on présente ici, atteste exactement l'adoption d'un rituel semblable à celui de la suovetaurilia, où sont invoquées des divinités indigènes connues (Banda, Reva, Munis, Cantibidona) et une autre dont on ne connaissait rien jusqu'à présent (Broeneia). La possibilité d'intégrer tous ces rituels dans le cadre de la transhumance antique est, à la fois, très vraisemblable et séduisant.

Mots-clé: divinités indigènes, langue «lusitanienne», transhumance à l'époque romaine.

Palavras-chave: divindades indígenas, língua «lusitana», transumância na época romana.

Antes de nos debruçarmos sobre a epígrafe romana recolhida no vale da Ribeira da Venda, a norte da vila de Arronches (Portalegre), na propriedade designada "Monte do Coelho", e de que tivemos conhecimento em meados de 2007, permita-se-nos que, para melhor se enquadrar o seu real interesse histórico, recordemos três premissas metodológicas:

1 - Os Estudos Clássicos, mesmo que entendidos apenas numa óptica literária, carecem de debruçar-se sobre as línguas que os Romanos encontraram nas zonas onde vieram a instalar-se. E, nesse aspecto, o conceito 
de "romanização" implica um olhar nos dois sentidos: romano / indígena / romano.

2 - A influência da oralidade foi, nesse contacto, muito mais sensível do que, a princípio, se pensava.

3 - O universo religioso detém, nesse domínio, bem relevante papel na compreensão da aculturação registada.

Acrescente-se que, na Lusitânia romana, das línguas dos povos indígenas pouco ou nada se conhece:

$\left.1^{\circ}\right)$ porque os indígenas, ao que parece, não tinham o hábito da escrita;

$2^{\circ}$ ) porque rapidamente se adaptaram aos esquemas formais latinos;

$3^{\circ}$ ) porque a chamada «escrita do Sudoeste», pesem muito embora as soluções que amiúde se apresentam como peremptórias e definitivas, continua um enigma por decifrar.

Há, contudo, um 'estrato linguístico' (digamos assim) que o saudoso Prof. António Tovar ousou designar de «lusitano», por apresentar características morfológicas e linguísticas singulares e individualizantes. Torna-se difícil determinar - por falta de elementos quer do contexto arqueológico quer de âmbito paleográfico - uma data mais ou menos precisa para essas inscrições, designadamente as que ocorrem em penedias; contudo, à que ora nos ocupa, uma cronologia de primórdios do século I da nossa era ou mesmo de finais do século I a. C. afigura-se-nos muito plausível, atendendo, de modo especial, à paleografia e ao modo de identificação dos possíveis antropónimos e dos teónimos (já conhecidos doutras epígrafes).

Um dos textos estudados por António Tovar - e sobre o qual muitos outros autores se têm debruçado - é o do penedo de Lamas de Moledo, concelho de Castro Daire ${ }^{1}$. Uma das suas interpretações plausíveis:

RVFINVS. ET
TIRO SCRIP
SERVNT
VEAMINICORI
DOENTI
AN(?)COM
LAMATICOM
CROVGEAI MAGA
REAICOI. PETRANIOI. T

${ }^{1}$ Cf., sobre estas epígrafes, entre outros, os seguintes estudos (que indicam bibliografia anterior): Jürgen Untermann 2002; F. Patrício Curado 2002 e J. L. Inês Vaz 1989. 
ADOM. PORGOM INOVEA

.CAIELOBRIGOI

É esta uma tradução aceitável, ainda que não isenta de muitas dúvidas:

«Rufino e Tirão escreveram: os Veaminicórios oferecem 'ancom lamaticom' a Crouga, protectora dos Magariaicos; os Petrânios, um porco 'tadom' a Ióvea, protectora dos Caielóbrigos».

Num outro penedo, em Cabeço das Fráguas (Pousafoles, Sabugal), lê-se:

OILAM. TREBOPALA.

INDI. PORCOM. LABBO.

COMAIAM. ICCONA.LOIM

INNA. OILAM. VSSEAM.

TREBARNVE. INDI.TAVROM

IFADEM

REVE. $\underline{R E}$...

De acordo com as interpretações mais correntes, estaríamos, aqui, perante a oferta de um cordeiro a Trebopala; de um leitão a Laebo; de uma vitela (?) a Iccona Loimina; de um cordeiro de um ano a Trebaruna; e de um touro semental a Reva.

Como se verá, a epígrafe de Arronches situa-se no mesmo horizonte cultural e religioso, não só porque também aí se revela o sacrifício de animais a divindades, mas sobretudo porque é recorrente a palavra oilam, interpretada como variante 'interpretada' de oviculam, tal como porcom sem dificuldade se poderá considerar variante de porcum; e porque há referência a divindades indígenas conhecidas doutros ex-votos.

As epígrafes de Arroyo de la Luz (Cáceres) ${ }^{2}$ inserem-se também no mesmo plano, ainda que, por se ter perdido a mais antiga referenciada, só conhecida através de uma cópia de finais do século XVIII, e por serem fragmentárias as outras, não seja possível estabelecer um paralelismo tão evidente.

O monumento de Arronches é uma laje de grauvaque, cuja superfície epigrafada terá sido previamente alisada para receber a epígrafe, mantendo-se, porém, a irregularidade do conjunto. Podem causar alguma estranheza as suas dimensões $-88 \mathrm{~cm}$ de altura, 75 de largura e, de modo especial, a sua escassa espessura: $3,5 \mathrm{~cm}$. Certo é que, quando dela tivemos conhecimento, já ela fora reutilizada numa lareira; o proprietário, ao remodelar a casa, considerou que a laje ficaria bonita montada na fachada da casa e não a destruiu. Quando um de nós (JO) foi alertado para a descoberta, conseguiu convencer o proprietário a não a incrustar na parede, permitindo, assim, o seu estudo - o que penhoradamente agradecemos. Fica-nos, porém, a dúvida se, com essas reutilizações e considerando a facilidade com que o grauvaque se 'corta', a

\footnotetext{
${ }^{2}$ Francisco Villar e Rosa Pedrero 2001.
} 
peça não teria originalmente uma espessura maior, até para ser mais fácil a gravação. A não ser que tivesse sido gravada num penedo donde, em seguida, foi cortada.

Lemos:

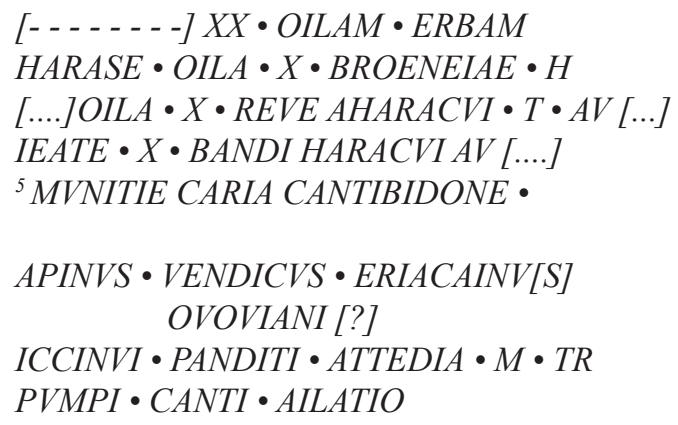

A paginação é cuidada, se atendermos, de modo especial, à regularidade dos espaços interlineares, à pontuação e ao cuidado posto na gravação (por goiva). O texto ocupa o espaço disponível no sentido da largura e, na altura, houve a preocupação de o situar na parte superior da laje, o que poderá indiciar que não seria para colocar em posição acima do olhar normal mas sim no solo. Há um espaço vazio entre as linhas 5 e 6, certamente para dar uma ideia de separação de conteúdos, o que é, para já, de muito realçar, uma vez que daí se depreende uma cultura epigráfica não despicienda.

Os caracteres - com 2,8 cm de altura média - são actuários e gravados com cuidado: barras horizontais breves; letras (como o A, o M, o N...) bem largas; $\mathrm{B}$ assimétrico e grafado em apenas dois movimentos; $\mathrm{P}$ aberto; $\mathrm{R}$ feito a partir do P.

Claro que importaria tecer considerações alargadas acerca das dificuldades de leitura e das várias hipóteses de interpretação. Deixamo-las para outra ocasião, limitando-nos, nesta notícia preliminar, a destacar dois ou três pontos que se nos afiguram de maior interesse imediato - pois temos a certeza de que, pelas inúmeras dúvidas que suscita, pelas novidades que traz em termos de designação de divindades e, até, de outra terminologia ainda por decifrar, esta epígrafe constitui, seguramente, um dos achados mais importantes dos últimos anos na epigrafia da Lusitânia romana.

Uma hipótese de interpretação poderá ser:

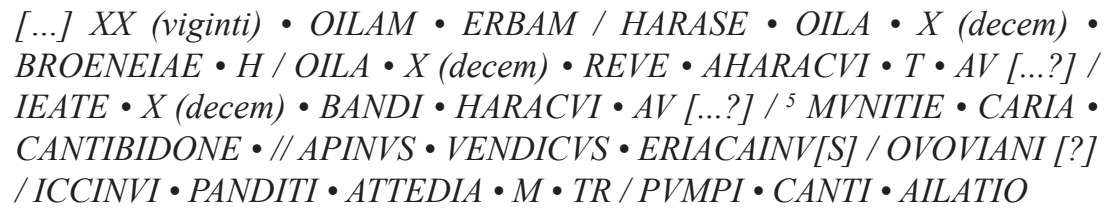


Poderia corresponder-lhe uma tradução deste género:

Para (...) vinte (...). Um cordeiro de erva para Harase. Dez cordeiros para Broineia H(arácua). Dez cordeiros para Reva Aharácuo. Dez T(?) AV(?) IEATE para Banda Harácuo. AV(?) para Municia Caria Cantibidone.

Os ovelheiros Apino, Vendico, Eriacno.

Revelai-nos a vossa vontade por um sinal.

Gravamos esta oração de júbilo.

A principal dificuldade reside, pois, no facto de todo o texto apresentar palavras estranhas ao vocabulário habitual em inscrições romanas, designadamente na sua segunda parte, sem dúvida a mais problemática, dado o seu teor. Se, por exemplo, ovoviani significar, como preconizamos, «ovelheiros», esse será, sem dúvida, um dado assaz interessante de todos os pontos de vista.

Reconhecemos, contudo, além da referida palavra oilam, teónimos como Reva, Banda e Munis (Broeneia é que jamais fora registada até ao momento) e poder-se-á afirmar, sem grande medo de errar, que se atesta aqui um ritual muito semelhante ao da suovetaurilia, sendo várias as divindades invocadas e sob um epíteto seguramente tópico, Haracui ou Aharacui ou mesmo Harase (numa diferença de grafia que outras vezes se documenta em relação às divindades indígenas, fruto do atrás referido 'contágio' da oralidade) ou, ainda, sob a forma da sigla H. De realçar, ainda, a novidade de nos parecer que o teónimo Munis vem grafado como Munitia e qualificado com dois epítetos, um (Caria) relacionável com outros teónimos indígenas, o segundo (Cantibidone) já documentado em relação a divindade conhecida, Erbina ${ }^{3}$.

Que significado atribuir a Haracui? A palavra hara poderá estar ligada ao mundo da pecuária: curral, chiqueiro de porcos; por outro lado, se apontarmos para um topónimo, torna-se aliciante 'encontrar' o termo na raiz semântica do nome da vila de Arronches! Como se sabe, de acordo com o Itinerário de Antonino, teríamos nestas zonas uma mansio: Ad Septem Aras... Estaria, sem dúvida, entre Arronches e Campo Maior, talvez por alturas de Degolados, onde importantes testemunhos da época têm sido encontrados ${ }^{4}$. E um pouco mais para oeste situa-se... Arronches!

Sugestiva é, ainda, essa perspectiva, se atentarmos numa eventual ligação com as rotas de transumância para a Beira Interior ${ }^{5}$, rotas que deixaram marcas

\footnotetext{
${ }^{3}$ HEp 4, 1994, inscrições n ${ }^{\text {os }} 1042-1043$.

${ }^{4}$ Cf. J. Alarcão 1992 (sobretudo p. 72) ou J. Alarcão 198899.

${ }^{5}$ Cf. J. Gómez-Pantoja 2001.
} 
toponímicas na paisagem arronchense, como "Canada"; ou, ainda, com a via atrás mencionada, de Emerita para Olisipo.

Mais as perplexidades, portanto, que as certezas. Mas destas há algumas que podemos garantir como dados verdadeiramente inovadores.

No que concerne à religiosidade pré-romana, dir-se-ia que a epígrafe figuraria num local aonde a população se ajuntava para honrar os seus deuses em determinadas épocas do ano, hipótese que também se coloca para Lamas de Moledo, Cabeço das Fráguas e para o altar identificado em Marecos (Penafiel), testemunho de um solene ritual agrário ligado ao ciclo da vegetação e da reprodução animal ${ }^{6}$.

Poderão ser referidas na epígrafe outras vítimas, mas a que não parece oferecer dúvida é o cordeiro, em número de dez (o que também constitui uma novidade) e, expressamente, uma vez indicado como erbam, ou seja, se a nossa interpretação está correcta, como já estando em idade de pastar (não apenas 'de leite').

No domínio da Linguística, escusado será sublinhar quanto esta epígrafe, por estar redigida em língua considerada «lusitana» e por, na verdade, se ler sem grandes dúvidas, vai contribuir para esclarecer questões em aberto.

Como fonte para os estudos históricos propriamente ditos, o facto de, desta sorte, como que se fechar, pelo Sul, a zona atribuída aos Lusitanos, na sequência do que temos vindo a afirmar sobre a presença de onomástica 'lusitana' no Nordeste alentejano ${ }^{7}$ - Lamas de Moledo a ocidente, Cabeço das Fráguas a norte, Arroyo de la Luz a oriente e Arronches a sul -, reveste-se, doravante, de importância relevante, a matizar o que Jorge Alarcão tem vindo a considerar o território deste "povo'8.

${ }^{6}$ Cf. HEp 1994, 6 n ${ }^{\circ}$ 1069, citando Patrick Le Roux (1994), «Cultes indigènes et religion romaine en Hispanie sous l'Empire», in L'Afrique, la Gaule, la Religion à l'Époque Romaine. Mélanges à la mémoire de Marcel Le Glay... Bruxelas 560-567. Pode ver-se a respectiva ficha in J. Cardim Ribeiro 2002 371, foto na p. 372.

${ }^{7}$ Cf. J. d'Encarnação 1987. 


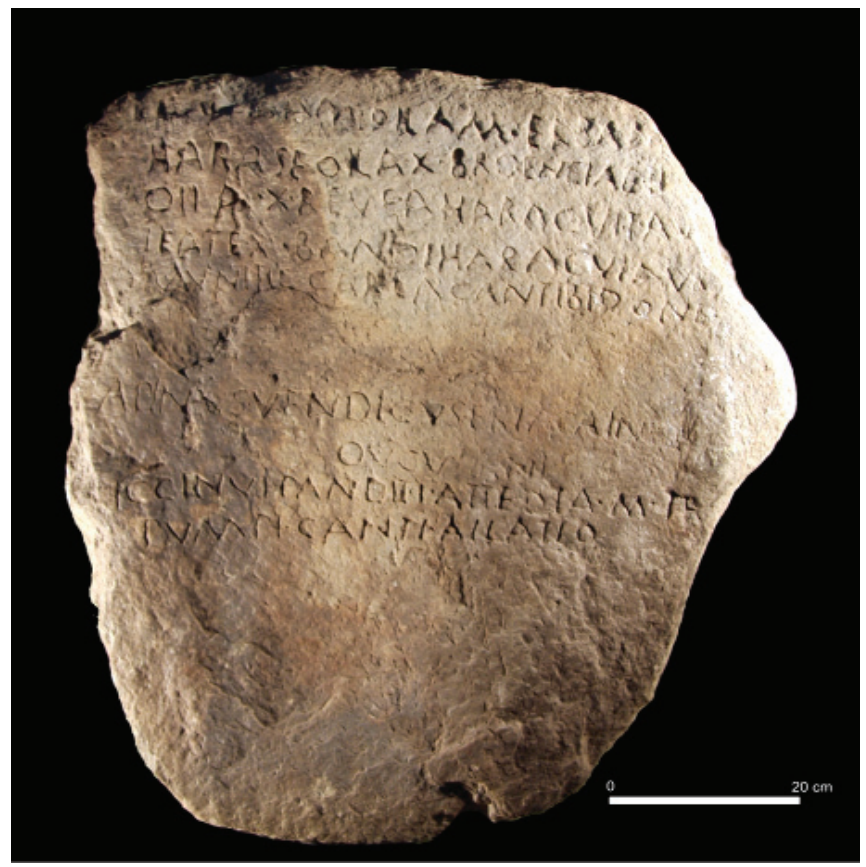

\section{Bibliografia}

J. Alarcão (1988), O Domínio Romano em Portugal. Mem Martins.

J. Alarcão (1992), “As estradas romanas de Portugal”, Encuentros sobre el Tajo: El Territorio y las Comunicaciones. Madrid, Cuadernos de San Benito 3 67-75.

J. Cardim Ribeiro, coord. (2002), Religiões da Lusitânia - Loquuntur Saxa. Lisboa, Museu Nacional de Arqueologia.

J. d'Encarnação (1987), "A população romana do Nordeste alentejano", in las Jornadas de Arqueologia do Nordeste Alentejano 85 - Actas. Castelo de Vide, 167-170.

J. Gómez-Pantoja (coord.) (2001), Los Rebaños de Gerion: Pastores y Trashumancia en Iberia Antigua y Medieval. Madrid, Casa de Velázquez. (1996), Hispania Epigraphica (=HEp) 6 nº 1069.

F. Patrício Curado (2002), «A "ideologia tripartida dos indoeuropeus" e as religiões de tradição paleohispânica no Ocidente peninsular», in J. Cardim Ribeiro, coord. (2002), Religiões da Lusitânia - Loquuntur Saxa. Lisboa, Museu Nacional de Arqueologia, 71-77.

J. Untermann (2002), “A epigrafia em língua lusitana e a sua vertente religiosa”, in J. Cardim Ribeiro, coord., Religiões da Lusitânia - Loquuntur Saxa. Lisboa, Museu Nacional de de Arqueologia, 67-70.

J. L. Inês Vaz 1989, "Divindades indígenas na inscrição de Lamas de Moledo (Castro Daire Portugal", Beira Alta 47.3-4 345-358.

F. Villar, R. Pedrero (2001), "La nueva inscripción lusitana: Arroyo de la Luz III", in Francisco

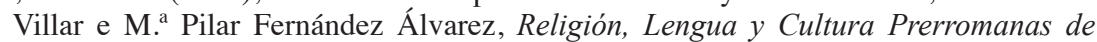
Hispania. Salamanca, 663-698. 
(Página deixada propositadamente em branco) 


\title{
ALGUMAS CONSIDERAÇÕES SOBRE DIVINDADES E ESPAÇOS SAGRADOS, DE PERÍODO ROMANO, NA REGIÃO EBORENSE
}

\author{
AmílCAR GUERRA \\ Universidade de Lisboa \\ Departamento de História da Faculdade Letras \\ Centro de Arqueologia (UNIARQ)
}

\begin{abstract}
The Roman conquest of Iberia and the subsequent period reveal, in an exemplary way, the dichotomy between continuity and change. In the context of Lusitania the changes occurring in the rural sanctuaries assume a particular significance. The most remarkable records on the subject in the Ebora Liberalitas Iulia territory will be examined: the temple of Santana do Campo (Arraiolos) and its god Carneus Calanticensis, as well as the example of Endovellicus and the famous area of his shrine, at S. Miguel da Mota (Terena, Alandroal). They are undoubtedly two examples that illustrate the complexity of the Romanization process. This paper aims to clarify some aspects of this process concerning those particular deities and their worship.
\end{abstract}

Keywords: Carneus Calanticensis, Ebora, Endovélico, Lusitania, Roman shrines.

Palavras-chave: Carneus Calanticensis, Ebora, Endovelicus, Lusitânia, santuários romanos

1.

A ideia de progresso que se generalizou no nosso tempo associa-o com frequência a acções humanas que acarretam uma forte transformação na paisagem. O lançamento de grandes obras públicas revela-se, no entanto, apenas uma das faces mais visíveis das alterações que marcam as últimas décadas. De forma mais ampla, quase todos os espaços habitados reflectem, de modo mais ou menos evidente, as consequências que decorrem de uma extraordinária capacidade que o homem moderno detém para produzir significativas alterações do meio em que vive.

O desenvolvimento tecnológico e o considerável aumento da capacidade económica que caracterizaram o último meio século não deixam dúvidas sobre as consequências, durante este período, de um processo cada vez mais rápido e eficaz de modificação das paisagens urbanas e rurais do nosso tempo. Mesmo que não se esqueça o legado patrimonial do passado e se conduzam alguns programas para o salvaguardarem, o engenho e os recursos são especialmente orientados para a renovação, ampliação e, acima de tudo, construção ex novo de estruturas destinadas a satisfazer novas necessidades do homem ou apenas para dar cumprimento a certas ideias discutíveis de progresso.

Quando se aprecia este incremento da capacidade construtiva, a qual assume paralelamente uma faceta destruidora, é inevitável estabelecer algum paralelo com as transformações que marcaram o processo de romanização. Nesta área, como de uma maneira geral em todo o Ocidente europeu, a 
integração do território na esfera romana encontra-se estreitamente ligada a um leque de transformações com evidentes reflexos nas cidades e nos campos. Em boa parte deste finis terrarum a presença itálica teve como consequência uma intensa actividade edilícia que alterou profundamente a fisionomia dos aglomerados populacionais, criando, pela primeira vez na maioria dos casos, realidades verdadeiramente urbanas, bem como novas e mais eficientes vias de comunicação.

Os espaços citadinos ganhavam uma fisionomia tipicamente romana, nos quais a mais evidente transformação consistia num urbanismo característico, organizado em torno de um espaço característico, o forum, concebido como centro da via pública nas suas vertentes política, jurídica, religiosa, social e económica. Mas esta constitui apenas a vertente mais conhecida desse processo que se materializou em muitas outras obras, tanto de natureza pública como privada, geralmente levantadas em função da riqueza que os seus cidadãos iam acumulando. Menos conhecidas, mas igualmente relevantes eram certamente as habitações particulares, que reflectiam a prosperidade e ao mesmo tempo o desejo de ostentação que cada família possuía.

Este desenvolvimento de estruturas urbanas, marcas da romanidade, eram indissociáveis de programas escultóricos, que nesta área atingiram uma dimensão e importância sem igual. No caso concreto de Ebora Liberalitas Iulia, apesar de escassamente documentado, o acervo dos materiais decorativos do conjunto forense permite entrever o que seria a sua riqueza e diversidade ${ }^{1}$.

Ao mesmo tempo o espaço rural sentiu de forma igualmente marcante as consequências do progresso tecnológico com essa mesma origem itálica, reflectido em algumas realidades concretas bem conhecidas: por um lado, implanta-se uma rede de comunicações que rompe com a tradição, impondo padrões mais evoluídos e aptos ao contacto entre as estruturas urbanas progressivamente criadas; por outro lado desenvolvem-se igualmente novas formas de aproveitamento do potencial agrícola, com uma maior capacidade de construir estruturas necessárias a uma mais eficiente exploração dos recursos; para além disso criam-se as condições para transformar esses espaços rurais em lugar de descanso e de prazer para os seus proprietários, edificando-se residências que muitas vezes superam em monumentalidade e conforto as correspondentes realidades urbanas.

Ao falar de vias romanas da área eborense é inevitável uma referência à ligação terrestre entre Olisipo e Augusta Emerita que, segundo o bem informado Itinerário de Antonino, passava precisamente pela cidade de Ebora, dirigindo-se depois para $\mathrm{NE}$, como o atestam os marcos que assinalavam as distâncias miliárias.

Referindo-se as propriedades agrícolas dessa mesma região, impõe-se uma alusão à villa da Tourega, uma propriedade agrícola ligada a uma importante família que tinha o privilégio de possuir entre os seus membros algumas

\footnotetext{
${ }^{1}$ T. Nogales, L. J. Gonçalves 2005 34-35.
} 
figuras que integravam a ordem senatorial, como o atesta a inscrição IRCP 382, facto de extraordinária relevância no contexto da Lusitânia².

Mais do que em outras épocas, o período que se segue à conquista romana, com especial relevo para o principado de Augusto, patenteia uma ruptura com o período precedente. Ainda que, pela sua dimensão, as alterações em fase recente provoquem maior impacto ecológico, as incidências do processo de romanização representam um corte muito mais acentuado com a tradição préromana, não apenas na vertente cultural, mas igualmente em todos os restantes domínios.

\section{2.}

Essa capacidade de intervir e modificar o território, tão evidente no período romano, é a faceta material associada a um conjunto de alterações culturais igualmente significativas. É impensável dissociar a criação de Ebora, com o seu forum e o seu notável templo, de outras transformações, entre elas a utilização sistemática do latim nesses espaços urbanos.

Quando se analisa genericamente a região eborense e as peculiaridades do processo de transformação do território, não pode esquecer-se a circunstância de a cidade vir referida em Plínio como um oppidum veteris Latii ${ }^{3}$. Quaisquer que sejam as consequências jurídicas desta atribuição - e muito se tem discutido a este respeito -, está fora de causa que a cidade detinha um estatuto de privilégio em relação à maioria das 45 entidades da Lusitânia do início do principado integradas na categoria dos oppida stipendiaria. O mesmo estatuto, recorde-se, se atribui, nessa lista, a Salacia e Myrtilis, duas cidades cuja importância estratégica é evidente.

Esta integração é compatível com a ideia de que o processo de romanização se desenvolveu a diferentes ritmos, situando-se a cidade na área que mais rapidamente se adapta às novas realidades, de feição itálica.

De qualquer modo, quando olhamos globalmente para o território provincial, sobressai a ideia de que a região eborense se situa numa área de transição. No plano geográfico, a informação de Ptolomeu aponta, para o espaço meridional da província, duas entidades - Turdetanos e Célticos - acima das quais se explana a região dos lusitanos, onde Ebora se inclui. Esta acepção geográfica do étnico, típica de uma fase imperial, corresponde à que se tornou mais comum no contexto da historiografia moderna. Nestas populações lusitanas situadas entre Tejo e Douro se reconhece em geral um conservadorismo mais acentuado e, em consequência, o seu território proporciona mais ampla documentação sobre as realidades culturais das entidades pré-romanas.

Não se sabe quanto tempo tarda a generalização da língua de Roma nessa região ou o total apagamento dos falares locais. De qualquer modo, a circunstância de contarmos hoje apenas com magros vestígios da realidade

\footnotetext{
${ }^{2}$ Curchin 1991133.

${ }^{3}$ Plin. Nat. 4.117.
} 
linguística pré-romana, transmitidos essencialmente através da documentação epigráfica, constitui um facto já de si esclarecedor.

Numa região em que o processo de conquista se conclui pouco depois de meados do séc. II a. C., as alterações políticas e as mudanças culturais eram já consideráveis nos inícios do principado, momento em que a produção epigráfica começa a ganha uma outra dimensão. Por essa razão se constata que, por via da regra, as línguas locais já não se mantém como veículo de comunicação, mas apenas se manifestam de forma residual, em circunstâncias muito particulares. É mais habitual a sua conservação nas diferentes vertentes da onomástica hispânica, inevitavelmente mantida, por exemplo, na toponímia, sem dúvida um dos domínios mais conservadores. Mesmo a própria cidade que se afirma como o centro político desta área, a que inclusivamente se atribui uma fundação romana, possui um a componente toponímica inequivocamente local.

Por outro lado, o conjunto da onomástica pessoal assume-se, sem dúvida, como o âmbito em que se conservam mais elementos linguísticos préromanos, apresentando uma distribuição sintomática. Nela se manifesta, de forma clara, a dicotomia entre a cidade e o espaço rural no que concerne à perduração das tradições locais de designação dos indivíduos. Enquanto o centro urbano revela uma sociedade onde o nome das pessoas patenteia a sua integração social e cultural no mundo romano, o território envolvente fornece ainda abundantes exemplos de pessoas que, para além de manifestarem a sua condição de peregrini, denunciam o seu profundo apego a tradições onomásticas que a cultura latina não obliterou ${ }^{4}$.

No que concerne, todavia, à perduração das línguas hispânicas a par do latim, não pode esquecer-se que um recente documento dado a conhecer neste mesmo volume vem contribuir com alguns dados sugestivos para uma abordagem mais fundamentada desta questão. $\mathrm{O}$ aparecimento em Arronches de mais uma das raras inscrições em língua lusitana (A. Carneiro et alii 2008), achado que constitui o mais meridional dos vestígios deste género, sublinha o facto de no início do período imperial ainda não estarem completamente esquecidos os falares dessa região. Como este notável monumento epigráfico atesta, persistem ainda, em contextos rituais específicos onde a tradição se mantém por via da regra durante mais tempo, o uso da língua local.

3.

Subsistem, enfim, mas já em número bastante mais reduzido, os apelativos das antigas divindades desta área da Lusitânia, assunto que será objecto de uma análise mais circunstanciada.

Pelo que se conhece, o quadro linguístico do Ocidente hispânico no início do império apresenta, de uma maneira geral, uma considerável coerência, permitindo sustentar a existência de afinidades culturais entre esta parte do

${ }^{4}$ Ver, por exemplo, as inscrições IRCP 416 (Igrejinha, Arraiolos), IRCP 420 (Vidigão, Arraiolos), IRCP 428 (N. . ${ }^{\text {Sr. }}{ }^{\text {a }}$ do Bispo, Montemor-o-Novo), alguns do mais notórios casos desta perduração da antroponímia hispânica no território eborense. 
território a sul do Tejo e o extremo noroeste da Península Ibérica. A distribuição do sufixo -aico, um dos elementos de derivação mais característicos do ocidente hispânico, põe em evidência precisamente essas afinidades que se estendem até à área ásture e galaica, prolongando-se para sul por uma faixa que se projecta para o interior da província, vindo terminar por alturas do vale do Guadiana, abarcando, por isso, uma região que corresponde actualmente a uma boa parte da Beira Baixa, do Alto Alentejo e da Estremadura espanhola.

Não é surpreendente que uma mancha distribucional idêntica se possa encontrar no caso das atestações do teónimo Bandue / Bandi e afins. Embora se lide com um elemento de natureza distinta, faz sentido esta correspondência, que repercute as afinidades culturais de um conjunto amplo de populações do ocidente peninsular. E numa outra formulação, poder-se-ia dizer que a distribuição das peculiaridades enunciadas se situa a norte de uma linha que passa precisamente por Ebora.

Faz sentido, por isso, dizer que o território eborense constitui uma área onde convivem com especial evidência as duas culturas em confronto no processo romanizador: a das populações exógenas, de matriz itálica, e a que marca a tradição local. Trata-se, por isso, também na esfera religiosa, de uma área de transição entre duas realidades muito diferenciadas.

No que concerne a este domínio das divindades e seus cultos, dois casos concretos ilustram exemplarmente esta situação e permitem ao mesmo tempo analisar a complexidade do fenómeno religioso no percurso evolutivo das sociedades hispânicas. De um lado tecer-se-ão algumas considerações a respeito do templo existente na localidade de Santana do Campo e da divindade que aí se cultuaria, Carneus Calanticensis; do outro chamar-se-á mais uma vez à colação o caso bem conhecido, mas nem por isso menos problemático, de Endovélico.

Nos seus traços gerais apresentam um conjunto de características comuns. Une-os desde logo a sua condição de santuários "rurais", termo que aqui pretende exprimir apenas a ideia de corresponderem a divindades cujos espaços sagrados se encontram fora dos centros urbanos. Em ambos os casos o culto anda associado a divindades tópicas, aspecto que se exprime pela sua identificação através de um adjectivo derivado do nome do lugar a que estas se encontram vinculadas. Por fim, cada um dos deuses se liga aparentemente a um único sítio, no qual subsistem vestígios mais ou menos evidentes de estruturas com alguma monumentalidade, a marcar esse espaço sagrado.

\section{1.}

Há de uma forma geral consenso em aceitar que a estrutura identificada em Santana do Campo corresponde a um antigo templo romano, componente fundamental de um santuário de uma divindade conhecida através da epigrafia dessa área. A informação mais consistente a este respeito decorre de duas inscrições que e encontravam em tempos nas paredes da igreja dessa localidade (IRCP 410 e 411), actualmente perdidas, mas cujas transcrições se consideram fiáveis, em que se gravou o seu nome por extenso, sob a invocação 
Carneo Calanticensi. Num outro monumento atribuído a esta mesma entidade ocorre apenas uma abreviatura, pouco explícita, cujo desenvolvimento radica unicamente nos dados desta epígrafe. A proximidade geográfica dos achados e a ausência de alternativas mais credíveis acabaram por dar consistência a esta interpretação tradicional ${ }^{5}$.

Há todavia algumas questões que se colocam a respeito das estruturas identificadas. Como o estudo de Th. Schattner pôs em evidência, o complexo de construções em causa, inequivocamente de período romano imperial, patenteia um conjunto de características pouco comuns no âmbito da arquitectura religiosa romana e hispânica deste período. Constata-se, talvez de uma forma algo surpreendente, que os paralelos para este templo se encontram especialmente no Norte de África ${ }^{6}$.

Estas afinidades estruturais não encontram uma explicação evidente. É claro que todo o espaço sob domínio romano, mesmo algumas regiões periféricas, como poderia ser o caso, partilham elementos culturais. E, nesta circunstância concreta, em que a proximidade geográfica é evidente, mais ainda se poderiam justificar eventuais influências. A circulação de pessoas com as mais diversas profissões e origens num território global pode, por si só, justificar esta ocorrência aparentemente estranha e que se assume, pelo menos de momento, como um caso único.

Mas, paralelamente, suscita-se uma outra possibilidade interpretativa ao sugerir-se que as afinidades com exemplos norte-africanos poderiam remontar a uma fase mais precoce, isto é, a um momento anterior à conquista romana. Entrever-se-ia, assim, a possibilidade de se dever a um influência púnica, explicável pelo domínio que Cartago teria exercido nesta região nos momentos que precederam a romanização.

Os elementos com que contamos para suportar esta conjectura são manifestamente ténues, em particular se nos reportarmos a esta área específica. Possuímos, todavia, informação mais consistente para as zonas litorais mais próximas, muito especialmente para a antiga Salacia, cidade a que, no entanto, tem sido atribuída uma situação geográfica excepcional, que acaba por ser uma justificação para presença de populações exógenas, em especial com origem africana. Não surpreendem, neste caso, as abundantes marcas de cultura semita que se prolongam até a um momento avançado da romanização ${ }^{7}$; nem a ocorrência entre as elites locais de algumas figuras com essa mesma origem, como é patente em alguns casos mais famosos. Alude-se, naturalmente, aos vários elementos da notável família dos Cornelii Bocchi (um dos quais explicitamente identificado como Salaciensis), que se afirmam

${ }^{5}$ Nestes casos o teónimo transcreve-se como C. C. e regista-se numa epígrafe que se atribuiu a S. Justa de Arraiolos (J. d'Encarnação 1984 491) ou, segundo uma recente proposta (V. G. Mantas 2008 4-6), a S. Justa do Couço, Coruche.

${ }^{6}$ Th. Schattner 1995-97 508-512.

${ }^{7}$ C. T. da Silva et alii 1980-81. 
como figuras públicas de grande prestígio, não apenas no âmbito da sua civitas, mas sobretudo na esfera política provincial.

Todavia, torna-se difícil avaliar o impacto regional que a presença de populações forâneas teve nas áreas mais interiores, em ambientes rurais, no período que se segue à conquista romana. Aí os elementos são praticamente inexistentes, carência que infelizmente se apresenta como um lugar comum para esta fase da nossa História.

Não podem, no entanto, esquecer-se alguns factos transmitidos pelas fontes clássicas e correspondentes ao início do período de conquista desta região, em que se reflectem aspectos do domínio púnico. $\mathrm{O}$ primeiro diz respeito à organização militar cartaginesa em determinado momento do seu conflito com Roma, situável no ano 210 a. C., a qual, nas palavras de Políbio (10.7.4), estava divida em três frentes, da seguinte forma: de uma delas " $/ . . . /$ se encarregava Magão, nesta parte das colunas de Hércules, entre os que eram chamados Cónios; a outra, sob o comando de Asdrúbal, filho de Giscão, encontrava-se na Lusitânia e na foz do Tejo; e o segundo Asdrúbal sitiava uma cidade dos Carpetanos /.../".

Esta associação dos interesses púnicos com os lusitanos decorre igualmente das informações relativas aos conflitos que opõem estes últimos aos romanos e transparecem, de forma mais evidente, na identificação do primeiro chefe militar dos Lusitanos, sugestivamente designado como "Púnico", certamente mais em consequência da sua origem que devido ao seu nome pessoal. De resto, é fácil compreender quanto as duas principais forças de resistência à conquista romana no Ocidente teriam interesse em partilhar esforços contra um inimigo comum. Embora tratando-se de referências genéricas que se reportam a um território muito vasto e limitado a norte pelo vale do Tejo, reflectem, pelos menos, os interesses estratégicos de Cartago nesta região.

No que respeita à divindade e ao seu nome, integra-se no que habitualmente designamos por "teonímia lusitano-galaica", que se distribuiu por uma área situada a norte da região de Évora e que se prolonga para o interior da província romana da Lusitânia. Pode dizer-se, genericamente, que este santuário se situa no limite meridional da área de distribuição das divindades assim classificadas.

No teónimo Carneo Calanticensi se identificam dois elementos distintos: o primeiro, que tenderíamos a chamar teónimo, acaba por ser uma atestação segura única, cuja etimologia chegou a ser sugestivamente relacionada com *karno "monte de pedras" o segundo corresponde a um epíteto de evidentes características tópicas, uma vez que a terminação -ensis respeita a uma formação latina de derivados toponímicos. Por esse facto se toma como relativamente seguro que o nome de lugar em que se encontra a actual Santana do Campo seria, na antiguidade, * Calantica. Esta forma, por sua vez, é igualmente um derivado em que se

\footnotetext{
${ }^{8}$ C. Búa 2000 110; B. Prósper 2002174.
} 
usa um dos mais vulgares sufixos, que tanto pode ser de origem latina como pertencer a uma língua local,

$\mathrm{Na}$ sua designação e mesmo na sua estrutura, Carneus Calanticensis remete claramente para a realidade pré-romana, mas desconhecemos as suas características. O processo de transformação cultural desenvolvido após a conquista romana está patente, neste caso, no desenvolvimento de uma estrutura de consideráveis dimensões e de certa monumentalidade. Apesar de o estudo das religiões hispânicas ter uma ampla tradição, raramente se teve a possibilidade de associar uma entidade divina a um conjunto de construções relativas ao seu culto ${ }^{9}$.

Parece evidente o contraste com o que se passa, por exemplo - e para falar de um caso concreto em que se conhecem alguns aspectos da organização do espaço sagrado - , com o monumento a Lari Berobreo (Monte do Facho, Cangas de Morrazo, Pontevedra), recentemente escavado ${ }^{10}$. Aparentemente não há verdadeiras estruturas e muito menos algo que se pareça com um templo, sendo a natureza do lugar, o topo de uma montanha com um extenso domínio visual em boa parte virado para o oceano Atlântico, o que o diferencia. Mas percebe-se igualmente que a sua especificidade se encontra na progressiva acumulação, no sítio, de ex-votos constituídos por aras de granito geralmente alongadas e com uma base muito diferente do habitual. Em vez de uma superfície plana, esta desenvolve uma parte terminal afilada, destinada a facilitar a sua fixação no solo, para o que se deveria abrir um pequena fossa. A configuração da área sacra consistia, deste modo, num espaço aberto no qual se dispunha um conjunto de aras fixadas no solo, por vezes organizadas em pequenos "recintos" "1, algumas de altura considerável - de resto, deveria ser esta dimensão que tornava tais objectos sagrados assinaláveis.

Mesmo que se englobem estas duas entidades distintas sobre o amplo conceito de "divindades indígenas do Ocidente peninsular", há substanciais diferenças entre elas, porque é igualmente muito contrastante o que separa as duas regiões no que respeita à sua assimilação duma cultura de matriz romana ou, mais genericamente, de fácies mediterrâneo. E ainda que o templo revele afinidades estruturais com construções idênticas do Norte de África, toda a concepção do espaço sacro revela marcas culturais exógenas, em resultado da inserção desta área numa esfera cultural globalizada, consequência da sua inserção no domínio romano.

\section{2 .}

Outro caso paradigmático no estudo regional das divindades "lusitanoromanas" (na sua estrutura este termo acaba por exprimir a duplicidade que

\footnotetext{
${ }^{9}$ São raros os templos em contexto rural da Lusitânia. Para além dos que se tratam aqui, merece uma referência o de Orjais, Covilhã, para o qual se sugeriu uma ligação com a divindade tópica invocada sob a forma Bandue Brialeacui (Carvalho 2003 166; 2007 325-332, esp. p. 332 ).

${ }^{10}$ Th. Schattner, J. Suárez Otero, M. Koch 2004 e 2006.

${ }^{11}$ Th. Schattner, J. Suárez Otero, M. Koch 2004 e 2006 183-184.
} 
inevitavelmente marca todo este mundo e por manter uma ambiguidade que pode ser vantajosa) corresponde a Endovélico, a entidade cultuada num santuário situado na colina de S. Miguel da Mota (Terena, Alandroal). Este apresenta-se habitualmente como o mais notável dos cultos pré-romanos e essa notoriedade deriva essencialmente da riqueza e abundâncias dos vestígios materiais que foram identificados nesse lugar e que constituem um importante repertório de dados para o seu estudo ${ }^{12}$. No essencial, esta documentação é constituída por um conjunto notável de escultura e epigrafia, uma vez que os outros elementos relativos à caracterização arqueológica deste espaço sagrado se revelam ainda extremamente limitados na informação que contêm ${ }^{13}$.

Endovélico detém, por esse facto, o estatuto de divindade pré-romana mais bem documentada, o que a converteu numa espécie de paradigma desse âmbito religioso. Não pode esquecer-se, todavia, que este caso é manifestamente excepcional, não apenas no que respeita à dimensão dos vestígios que patenteia, mas acima de tudo no que concerne à própria natureza do culto e ao seu "grau de romanização". Por essa razão, quando se procura a terminologia para definir o deus, apresenta-se com mais evidente a solução que adopta José Cardim Ribeiro, ao colocar o qualificativo "indígena" entre aspas, uma vez que, se procurarmos inventariar os elementos que permitiram atribuir-lhe essa classificação, neste momento nada mais no resta que o próprio nome da divindade ${ }^{14}$.

Como procurei sublinhar recentemente ${ }^{15}$, o único elemento de que dispomos, de momento, para definir a sua especificidade e o caracterizar como divindade hispânica, é essencialmente o lugar do seu santuário com as suas eventuais peculiaridades. Quanto ao resto, como já sublinhou J. Cardim Ribeiro (2002 80), revela-se aqui um deus com "um cunho perfeitamente 'clássico', de feição plenamente romana".

A questão onomástica constitui, de facto, a grande base em que sempre assentou a ideia de uma divindade cuja origem radicava no mundo préromano, continuando naturalmente a ser objecto de culto após a conquista romana. O seu santuário ter-se-ia tornado progressivamente mais famoso e, em consequência, teria ganhado uma dimensão extraordinária, manifestada na riqueza e abundância dos restos materiais. Toda a tradição e mesmo a investigação conduzida no séc. XX sublinham o enraizamento deste culto numa fase anterior ao domínio romano, uma vez que o nome da divindade

${ }^{12}$ Para a escultura, v. V. de Souza 1990 33-38; J. L. R. Gonçalves 2007203 ss; para a epigrafia, v. J. d'Encarnação 1984 561-629; J. M. Garcia 1991 310-329; Guerra et alii 2003 457-461; para o conjunto, constitui um contributo importante a documentação apresentada por J. Cardim Ribeiro no catálogo da exposição Religiões da Lusitânia: Loquuntur saxa, pp. 379400.

${ }^{13}$ A. Guerra et alii $2002470-471$.

${ }^{14}$ J. C. Ribeiro $200279-81$.

15 A. Guerra 2008. 
apresentaria, para uma boa parte dos eruditos, um significado que ajudaria a definir a sua natureza.

A aproximação do teónimo com as línguas célticas revelou-se como uma das opções tradicionalmente mais seguidas, em especial a ideia consagrada com a obra Vasconcelos, de que o o teónimo se poderia traduzir como "muito bom"16, definindo em boa parte as características benfazejas da divindade. No entanto, as últimas considerações etimológicas de Carlos Búa (2000 72-73) Cardim Ribeiro (2002 88) e Blanca Prósper (2002 351-352) recuperaram a mais antiga proposta conhecida e, ao que parece, a mais acertada, sugerida por André de Resende (1593 236), segundo a qual o nome corresponde a um derivado toponímico. Neste caso, o significado do nome seria pouco relevante para a caracterização do deus, uma vez que corresponderia simplesmente a uma designação que apenas o associava a um lugar específico, cujo significado seria independente das qualidades da entidade divina que lhe estava associada.

Nestas circunstâncias, a própria existência de um culto anterior ao período romano é questionável e os dados arqueológicos parecem mais favoráveis a esta possibilidade que à contrária. Considero, naturalmente, que são fundadas as dúvidas expressas a respeito de eventual relação entre do lugar da Rocha da Mina e o culto de Endovélico numa fase anterior ao séc. I d. C. ${ }^{17}$. Ao mesmo tempo, esta última cronologia apresenta-se como a única que até ao momento poderá ser atribuída às primeiras manifestações cultuais no cabeço de $\mathrm{S}$. Miguel da Mota $^{18}$. Por isso mesmo cheguei a sugerir que deveria aceitar-se seriamente a possibilidade de só nesta fase se iniciar a actividade do santuário, gerada em ambiente cultural já tipicamente romano, mas com o cunho peculiar que lhe poderia conferir a própria natureza do sítio e as circunstâncias históricas em que ele nasce e se desenvolve.

Endovélico apresenta, como característica peculiar, uma valência oracular, já referida por Freret, no século XVIII, retomada e desenvolvida por J. Leite de Vasconcelos (1905 142-143). Se tivermos em conta que a região de Mérida se converteu numa das principais áreas de fixação militares no período augustano e a cidade constituiu o maior pólo de atracção de populações exógenas na Lusitânia, facilmente poderemos imaginar que esta zona reúne condições especiais para a implantação e difusão de realidades específicas como os oráculos, tão frequentes na tradição helenística e já com ampla aceitação e longa história no contexto romano. Embora desconheçamos a natureza da religião pré-romana, não é surpreendente que estas singularidades

16 J. L. de Vasconcelos 1905 124-125; Cfr. S. Lambrino 195194.

17 Não nos reportamos aqui apenas aos resultados correspondentes à primeira campanha, que esta publicação sintetiza, mas remetemos igualmente para as conclusões que se têm apresentado nos sucessivos relatórios de escavação respeitantes às campanhas subsequentes. No amplo mobiliário arqueológico já identificado não subsiste nada que possa remeter para uma fase anterior a essa data, a não ser alguns vestígios materiais calcolíticos, evidentemente sem qualquer relação com a natureza do sítio no período romano. Cf. J. C. Ribeiro 2002 79-80, para a controvérsia.

${ }^{18}$ Guerra et alii 2002 430-433. 
do santuário, responsáveis ao fim ao cabo pela sua fama, tenham essa marca de "orientalismo".

Parece igualmente claro que os qualificativos praesentissimus e praestantissimus, que Sexto Coceio Crátero Honorino, identificado como eques romanus (IRCP 492), atribui à divindade, se inserem precisamente num tradição que pouco tem de hispânico. Que eu saiba, em nenhuma outra circunstância se usam estes termos em âmbito peninsular, de resto relativamente raros também no contexto religioso de todo o mundo romano. Para além de um latiníssimo e original jogo de palavras, esta sequência não ocorre em casos idênticos. Registam-se, todavia, utilizações separadas dos dois adjectivos aplicados a teónimos variados, que a meu ver ajudam a compreender a inscrição referida.

Para a análise desta epígrafe e a explicitação do seu significado, deve terse em consideração a onomástica do dedicante, uma personagem da ordem equestre, o que o colocaria numa posição social de destaque. A estrutura da sua onomástica insere-se bem na tradição romana, mas o seu primeiro cognomen, Craterus, versão latina de um antropónimo grego, permite associá-lo ao mundo oriental. E embora esta ilação não seja em muitos casos vinculativa, uma vez que há outras razões pelas quais se pode receber um nome com esta proveniência, em particular nos casos de ligação com o mundo servil, no exemplo em análise essa atribuição de origem parece ser bastante provável.

Pode ser relevante compreender o contexto em que se usa esta terminologia, em boa verdade relativamente rara para designar os deuses. Embora Vasconcelos tenho afirmado que "todos estes epithetos se encontram com frequencia", limita-se a apontar algumas referências literárias latinas similares à expressão praesentissimus usada neste monumento e uma única inscrição, de Roma, em que este qualificativo se aplica ao numen montis Tarpe $i^{19}$. Mas, de facto, a epigrafia não patenteia assim tantos exemplos e, por isso, talvez seja interessante reanalisar paralelos para estas expressões.

Apresentam-se seguidamente dois quadros que sintetizam a informação pertinente à inscrições latinas onde comparece um destes termos:

QUADRO I. praesentissimus

\begin{tabular}{|l|l|l|l|}
\hline Origem & Divindades & Personagens & Observações \\
\hline Floridia (Sicilia) & Aesculapio & $\begin{array}{l}\text { Roscius Aelianus } \\
\text { Salvius }\end{array}$ & \\
\hline $\begin{array}{l}\text { Samisegetuza } \\
\text { (Dacia) }\end{array}$ & Core & $\begin{array}{l}\text { M. Luceius Felix } \\
\text { Hostilia Faustina }\end{array}$ & procurator Aug. \\
\hline $\begin{array}{l}\text { Samisegetuza } \\
\text { (Dacia) }\end{array}$ & Apollini et Bono Puero & M. Aurelius Marcus & procurator Aug. \\
\hline Roma & $?$ & Aemiliana & aedem fecit \\
\hline
\end{tabular}

${ }_{19}$ J. L. de Vasconcelos 1905141. 


\begin{tabular}{|l|l|l|l|}
\hline Roma & $\begin{array}{l}\text { Deae Virgini Caelestis } \\
\text { Numini loci montis } \\
\text { Tarpei }\end{array}$ & $\begin{array}{l}\text { Flaviae Epichar[idi] } \\
\text { Sextia Olympias } \\
\text { Chrestina Dorcadius }\end{array}$ & sacerdotia (!) \\
\hline $\begin{array}{l}\text { S. Miguel da Mota } \\
\text { (Lusitania) }\end{array}$ & Endovellico & $\begin{array}{l}\text { Sex. Cocceius } \\
\text { Craterus Honorinus }\end{array}$ & eques Romanus \\
\hline $\begin{array}{l}\text { Aps (Gall. } \\
\text { Narbon.) }\end{array}$ & Deo Invicto & T. Lurius M[yr]on \\
\hline $\begin{array}{l}\text { Corbridge } \\
\text { (Britan.) }\end{array}$ & numinis dei & $\begin{array}{l}\text { Q. Calpurnius } \\
\text { Concessinius }\end{array}$ & praef. equitum \\
\hline Khaznah (Palaest.) & Mag. Sarapidem & Iulius Isidorianus & primus pilus \\
\hline
\end{tabular}

QUADRO II. praestantissimus

\begin{tabular}{|l|l|l|l|}
\hline Origem & Divindades & Personagens & Observações \\
\hline Roma & I. O. M. D(olicheno) & L. Tettius Hermes & eques Romanus \\
\hline $\begin{array}{l}\text { Aquileia (Ven. } \\
\text { Hist.) }\end{array}$ & (numen) et Diana Aug. & $\begin{array}{l}\text { M. Appius } \\
\text { Helpidianus }\end{array}$ & Cent. Leg. IIII Flav. \\
\hline $\begin{array}{l}\text { Concordia } \\
\text { Sagittaria (Venet. } \\
\text { Hist.) }\end{array}$ & $\begin{array}{l}\text { I. O. P(raestantissimo?) } \\
\text { M(aximo) Dolicheno }\end{array}$ & Val. Maximus & \\
\hline Apulum (Dacia) & Deo Apollini & Aur. Vitalis & L. Vander(ius?) \\
\hline $\begin{array}{l}\text { Ptuj (Pannonia } \\
\text { Sup.) }\end{array}$ & $\begin{array}{l}\text { D(eo) S(oli) Invicto } \\
\text { M(ithrae) numini sancto }\end{array}$ & $\begin{array}{l}\text { Sex. Cocceius } \\
\text { Craterus Honorinus }\end{array}$ & eques Romanus \\
\hline $\begin{array}{l}\text { S. Miguel da Mota } \\
\text { (Lusitania) }\end{array}$ & \begin{tabular}{l} 
Endovellico \\
\hline
\end{tabular} & & \\
\hline
\end{tabular}

Trata-se de uma amostra manifestamente diversificada do ponto de vista geográfico, mas preferencialmente respeitante ao mundo romano ocidental, circunstância que decorre de uma condicionante linguístico-cultural. É que estamos a lidar com termos latinos, necessariamente menos representados numa vasta região em que predominava a língua grega. Mas poderá deduzir-se deste conjunto que o elo de ligação entre a maioria destas dedicatórias divinas se encontra na origem das próprias entidades nelas representadas. Nota-se uma clara presença de teónimos com vínculos culturais ao mundo oriental, de forma mais ou menos evidente, por vezes em contexto de claro sincretismo.

Um dos casos mais sugestivos é o da dedicatória a Core, equivalente de Perséfone / Prosérpina, mas escassamente representada nessa forma, mas atestada, por exemplo, em âmbito hispânico, num interessante e excepcional documento epigráfico originário de Astorga. Aí se associam a divindades mistéricas (Isis, Serapis), mas também Apollo Granus e Mars Sagatus, numa 
manifestação de tendências sincréticas que marcam especialmente o que se designa como "cultos orientais".

Já o antigo estudo de A. D. Nock (1925) sobre fórmulas votivas como iussu, imperio, ex imperio, ex praecepto (e, no caso vertente, a original ex imperato averno), bem como as suas correspondentes gregas, tinha posto em evidência, para além naturalmente da sua relação com oráculos, a frequente ligação com o âmbito a que pertencem as "divindades orientais", na sua qualidade de reguladoras e soberanas em relação às pessoas ${ }^{20}$. Não é sem razão que o superlativo praestantissimus se usa tipicamente em contexto epigráfico para qualificar o patronus. Encontrando-se numa elevada posição social e política que lhe conferem um poder especial, podem manifestar essas suas qualidades na missão de auxiliar os seus dependentes. Trata-se, ao fim ao cabo, de exercer a sua função tutelar ${ }^{21}$, muito própria das entidades superiores, como a que compete também aos deus sanctus Endovellicus.

Enfim, o conjunto sagrado de S. Miguel da Mota e os elementos que caracterizam Endovélico e o seu culto atestam bem uma profunda transformação desta região da Lusitânia. Se os vestígios epigráficos e escultóricos já permitem caracterizar o ambiente social e cultural, ainda nos falta perceber o verdadeiro impacto que o próprio santuário teria na paisagem. A missão da arqueologia parece bem difícil neste caso.

\section{Bibliografia}

C. Búa (2000), Estudio lingüístico de la teonimia lusitano-gallega. Salamanca (dissertação de doutoramento).

A. Carneiro, J. d'Encarnação, J. de Oliveira, C. Teixeira (2008), "Uma inscrição votiva em língua lusitana (Arronches, Portalegre)", Palaeohispanica 7 167-178.

P. C. Carvalho (2003), "O templo romano de Nossa Senhora das Cabeças (Orjais, Covilhã) e a sua integração num território rural", Conimbriga 42 153-182.

P. C. Carvalho (2007), Cova da Beira: Ocupação e exploração do território na época romana. Fundão / Coimbra.

L. A. Curchin (1991), Roman Spain: Conquest and Assimilation. London, Routledge.

M. M. A. Dias, L. Coelho, L. (1995-97), "Endovélico; caracterização social da romanidade dos cultuantese do seu santuário (S. Miguel da Mota, Terena, Alandroal)", O Arqueólogo Português, série IV, 13/15 233-265.

J. d'Encarnação (1984), Inscrições romanas do conventus Pacensis. Coimbra (=IRCP).

J. M. Garcia (1991), Religiões antigas de Portugal. Lisboa.

L. J. R. Gonçalves (2007), Escultura romana em Portugal: uma arte do quotidiano. Mérida.

A. Guerra, Th. Schattner, C. Fabião, R. Almeida (2003), "Novas investigações no

\footnotetext{
${ }^{20}$ A. D. Nock 192597.

${ }^{21}$ J. C. Ribeiro 200285.
} 
santuário de Endovélico (S. Miguel da Mota, Alandroal): a campanha de 2002", Revista Portuguesa de Arqueologia 6.2 415-479.

A. Guerra (2008), "La documentation épigraphique sur Endouellicus et les nouvelles recherches dans son sanctuaire à S. Miguel da Mota", in R. Haeussler, A. C. King, eds., Continuity and Innovation in Religion in the Roman West, vol. 2. Portsmouth, Rhode Island, 159-167.

S. Lambrino (1951), "Le dieu lusitanien Endovellicus", BOPor, nouvelle série, 15 93-147.

V. G. Mantas (2008), Epigrafia romana de Coruche. Coruche.

A. D. Nock (1925), "Studies in the Graeco-Roman beliefs of the empire", JHS 45.1 84-101.

T. Nogales, L. J. Gonçalves (2005), “Imagens e mensagens: as esculturas do Museu de Évora como testemunho da romanização, in J. O. Caetano, T. Nogales, coord., Imagens e mensagens: Escultura romana do Museu de Évora. Évora, 33-40.

B. Prósper (2002), Lenguas y religiones prerromanas del Occidente de la Península Ibérica. Salamanca.

A. de Resende (1593), Libri quatuor de antiquitatibus Lusitaniae. Évora.

J. C. Ribeiro (2002), "Endovellicus", in J. C. Ribeiro, Religiões da Lusitânia: Loquuntur Saxa. Lisboa, 79-90.

Th. G. Schattner (1995-97), “A igreja de Sant'Ana do Campo: observações num templo romano invulgar”, O Arqueólogo Português, 4a Série, 13 485-558.

Th. G. Schattner , J. Suárez Otero, M. Koch (2004), “Monte do Facho, Donón (O Hío / prov. Pontevedra) 2003. Informe sobre las excavaciones en el santuario de Berobreo", AEArq. 77 23-72.

Th. G. Schattner; J. Suárez Otero; M. Koch (2006), "Monte do Facho (O Hío, prov. Pontevedra) 2004. Informe sobre las excavaciones en el santuario de Berobreo", Palaeohispanica 6 183-223.

C. T. da Silva, J. Soares, C. de M. Beirão, L. F. Dias, A. Soares (1980-81), "Escavações arqueológicas no Castelo de Alcácer do Sal (campanha de 1979)”, Setúbal Arqueológica 6-7 149-218.

V. de Souza (1990), Corpus signorum imperii Romani: Portugal. Coimbra.

J. L. de Vasconcelos (1905), Religiões da Lusitânia na parte que principalmente se refere a Portugal, 2. ${ }^{\circ}$ vol. Lisboa. 


\title{
A ROMANIZAÇÃO DA PAISAGEM NA LUSITÂNIA
}

\author{
VASCO GIL MANTAS \\ Universidade de Coimbra
}

\begin{abstract}
The several centuries of Roman domain changed profoundly the Hispanic landscape, physical and human, through a continuum process, we may refer to as Romanization. The establishment of an urban web and a long distance communications network, both well adapted to the local reality and serving a new administrative structure, contributed, as much as the rural settlement patterns then introduced, to the development of the Lusitanian-Roman culture, the way of life mentioned by Aelius Aristides as the greatest benefit offered to the people of the Empire. Many of these fundamental changes endured beyond the time of Rome, marking the land and the people of what was once Lusitania.
\end{abstract}

Keywords: culture, landscape, Lusitania, Romanization.

Palavras-chave: cultura, Lusitânia, paisagem, romanização.

Os vários séculos de domínio romano na Hispânia marcaram profundamente a paisagem peninsular, transformando-a política e fisicamente. Ao contrário dos anteriores contactos mediterrâneos, de alguma forma sempre limitados no tempo e nos objectivos, a integração do território hispânico no mundo romano permitiu o desenvolvimento de uma dinâmica integradora, largamente inspirada pelo poder central, que podemos identificar como romanização ${ }^{1}$. Numa fase inicial da presença romana na Península Ibérica, na verdade praticamente durante todo o período republicano, esta vontade de modificar a realidade local conheceu fraco desenvolvimento, limitando-se a uma imposição da soberania que apenas numa ou noutra situação conduziu à formação de núcleos romanizadores significativos e actuantes ${ }^{2}$.

$\mathrm{O}$ quadro que escolhemos obriga a duas explicações preliminares, considerando as suas características artificiais do ponto de vista administrativo e as diferenças naturais que enriquecem a paisagem física. Com efeito, a província Lusitânia resultou de um processo evolutivo pragmático, através do qual o seu território (Fig. 1), inicialmente uma área de intervenção militar a norte do Tejo, sofreu alterações até se fixar com a última das reorganizações empreendidas por Augusto ${ }^{3}$. No interior destas fronteiras as fontes de época

1 J.C. Barret 1997. Agradecemos cordialmente ao Dr. Luís Madeira a preparação das figuras desta comunicação. Abreviaturas utilizadas no texto: J. d'Encarnação (1984), Inscrições romanas do Conventus Pacensis, Coimbra, Instituto de Arqueologia da Faculdade de Letras (= IRCP); E. Hübner (1869), Corpus Inscriptionum Latinarum, II, Consilio et Auctoritate Academiae Litterarum Regiae Borussicae Editum, Berlim, Reimer (= CIL).

${ }^{2}$ M. A. Marin Diaz 1988 251-256.

${ }^{3}$ Dião Cássio, 54.25; P. Le Roux 1982 69-72. 
imperial situaram quatro populações, difíceis de distinguir em termos de registo arqueológico: Celtas, Túrdulos, Lusitanos e Vetões ${ }^{4}$. Julgamos que esta diversidade resulta, em primeiro lugar, de aspectos relacionados com a base económica de cada um destes grupos à época da conquista romana, em larga medida relacionada com a região que ocupavam.

A variedade da paisagem lusitana é, em parte, explicação suficiente para estilos de vida distintos e para diferentes soluções de enquadramento destas populações por parte da administração romana, conduzindo com frequência os investigadores a resvalarem na velha apreciação dos maiores e menores graus de romanização. Basta comparar a paisagem alentejana com a de algum rincão nortenho para se compreender imediatamente a inexistência de um modelo, ou melhor, de uma prática única de romanização, pois os objectivos da administração romana não deixaram de ter em conta, naturalmente, as realidades sócio-económicas regionais. Esta percepção da diferença, motivadora de respostas adaptadas, é evidente, por exemplo, nos escritos de Estrabão sobre a Hispânia 5 .

Quando falamos de romanização da paisagem referimo-nos à introdução nesta, independentemente das suas características naturais, de elementos característicos da civilização romana. O conceito romano de paisagem implica uma visão agónica, resultante da oposição entre natura e cultura, patente de forma muito clara em autores como Terêncio, Cícero, Tito Lívio ou Higino. Uma paisagem romana só pode ser uma paisagem com forte marca antrópica, ou seja, uma paisagem transformada pelo esforço do homem. As cidades, as vias, os campos trabalhados e os mares navegados fazem parte dessa ideia romana da submissão da natureza para bem da humanidade ${ }^{6}$, organizada em comunidades morais em torno da lei e sancionadas pela divindade. A paisagem romana, tantas vezes estilizada no interior das próprias casas através de jardins e pinturas ${ }^{7}$, é uma paisagem cultivada, oposta aos desertos vazios de que falou Élio Aristides, contrapondo-os ao mundo transformado pela hegemonia romana ${ }^{8}$. É essa ideia de mundo ordenado que o conhecido relevo achado no Lago Fucino (Fig. 2), ilustrando uma cidade de traçado ideal e os campos adjacentes, humanizados pela presença das villae, transmite com a força habitual da arte italiota9.

É evidente que a intervenção na paisagem não se iniciou no território lusitano com a presença romana, mas é com ela que surgem elementos comuns a todo o território e suficientemente fortes para, com frequência, prevalecerem como marcas facilmente identificáveis nas paisagens posteriores, directamente ou através de estudos de geoarqueologia, consoante o tipo de vestígios em causa. Mas, para além dos traços materiais da elaboração de uma paisagem que foi

\footnotetext{
${ }^{4}$ J. Alarcão 1990 352-359.

${ }^{5}$ Estrabão, 3.1.2; 1.6.

${ }^{6}$ Juvenal, Schol., 12.75; F. S. Kleine 1991 182-192.

${ }^{7}$ J.Alarcão, R. Étienne 1981 69-80; S. Settis 2002.

${ }^{8}$ Élio Aristides, Or. Rom., 94-96.

${ }^{9}$ M. Wheeler 1964 186-187, 243.
} 
o cenário da civilização luso-romana, construída durante séculos, outros há, imateriais, talvez por isso mesmo menos sensíveis a uma análise imediata, mas que constituem a essência de uma maneira de estar e de sentir próprias de uma cultura que assenta a sua identidade indeclinável, de uma ou de outra forma, no legado material e espiritual da romanidade e das relações atlânticas.

Uma das primeiras grandes modificações introduzidas pelo domínio romano verificou-se a nível da paisagem política, em primeiro lugar criando as províncias a partir dos dois grandes espaços operacionais em que se dividiu a Península Ibérica durante os dois séculos do período republicano. Foi um processo algo complicado, que conheceu diversos ajustamentos, susceptíveis de interpretações nem sempre coincidentes ${ }^{10}$, processo largamente condicionado pela evolução da política interna romana e das diferentes opções do centro do poder para com as áreas dominadas. Não se trata já de uma amálgama de populi, belicosos ou colaborantes, ocupando espaços sem outro tipo de relações entre si a não ser aquelas ditadas por factores ocasionais, de colaboração ou conflito, mas sim de territórios onde estes povos, sujeitos eventualmente a operações de reordenamento e fixados dentro de fronteiras definidas oficialmente e materializadas através de padrões, quando necessário, se integram num todo submetido a uma autoridade superior e geral, o governador da província, estabelecido numa cidade distinguida com a função, nova, de capital permanente do território.

Neste quadro se insere a criação das civitates, definidas em grande parte a partir de territórios tribais, dotadas de uma capital, estabelecida numa povoação já existente ou, como parece ter acontecido maioritariamente no interior da Lusitânia, construída de raíz. Este processo situa-se, com uma ou outra excepção, no cenário da reforma augustana, ainda que a questão do estatuto jurídico destas comunidades se mostre mais complexa que a cronologia do seu estabelecimento. Seja como fôr, não há argumentos sólidos contrários à criação das civitates, que não seriam sistematicamente confinantes e que poderão ter conhecido alterações nos seus limites, civitates que ficaram a constituir o mosaico político-administrativo fundamental do território lusitano. O que levou a administração imperial a escolher esta povoação indígena e a preterir aquela, quando tratou de definir as diferentes capitais regionais, nem sempre é de fácil entendimento. Razões de ordem política, seguramente, e económicas, facilmente compreensíveis em casos como o de Olisipo (Lisboa) ou de Myrtilis (Mértola), explicarão a continuidade e expansão conhecidas por alguns destes centros na época romana, enquanto que a dinâmica introduzida pelos colonizadores implicou, em determinadas circunstâncias, soluções novas.

Assim, a rede urbana desenvolvida para servir a administração, pois era esta a sua função principal, naturalmente aliada à criação de referências ideológicas fundamentais, contou com uma razoável diversidade, parcialmente relacionada com antecedentes pré-romanos, verificando-se que, mesmo as cidade novas, mostram notáveis diferenças entre si, reflectindo as características específicas

\footnotetext{
${ }^{10}$ F. Martín 2003 593-609; V. Mantas 2004 73-76.
} 
da região onde foram construídas ${ }^{11}$. No Alentejo, a cidade de Ammaia conheceu uma dimensão excepcional, quando comparada com outras situadas na interior da Lusitânia, o que reflecte a sua localização numa zona onde coexistem outros grandes centros urbanos relativamente próximos, caso das colónias de Norba Caesarina (Cáceres) e Emerita Augusta (Mérida), bem como do município de Liberalitas Iulia Ebora (Évora), exemplos prestigiosos de uma bem conseguida romanização das gentes e da paisagem. A maior parte destas cidades incluiram no topónimo romano o seu nome primitivo ou uma referência étnica, existindo em toda a província poucas cidades com denominações exclusivamente latinas, entre as quais se contam quatro das cinco colónias lusitanas.

A maior parte destes centros urbanos surgiram como cidades peregrinas, com uma organização administrativa inspirada na organização típica dos municípios italianos, alcançando posteriormente o direito latino e o título municipal, que podem não coincidir cronologicamente ${ }^{12}$. $\mathrm{O}$ processo evolutivo de promoção jurídica das cidades deixou testemunhos seguros na epigrafia, como demonstra uma inscrição de Capera (Ventas de Cáparra), onde se refere M. Fidius Macer, construtor do conhecido arco monumental, como magistrado (magister) e depois duúnviro ${ }^{13}$. Se algumas destas cidades luso-romanas respeitaram traçados anteriores, como sucedeu em Conimbriga (Condeixa-a-Velha), outras conheceram um traçado urbano regular, ortogonal, inspirado na cidade ideal romana, como aconteceu em Ammaia, por exemplo (Fig. 3), impondo definitivamente a sua memória na estrutura das cidades actuais, como em Mérida, Évora ou Beja. Pelos finais do século I, marcado pelas promoções flavianas, a Lusitânia contava com uma rede urbana razoável, ainda que longe de igualar a de outras regiões peninsulares, mas que ainda assim somava uma meia centena de cidades, parte das quais subsistirão até aos nossos dias, sobretudo no território ocidental da Lusitânia, entre os principais centros urbanos portugueses.

A presença destas cidades teve consequências significativas a nível do reordenamento das áreas suburbanas, ainda que o crescimento em períodos posteriores tenha obliterado, em muito casos, os vestígios de elementos característicos da paisagem periférica ${ }^{14}$, como necrópoles, pequenos santuários, instalações fabris ou habitações, desaparecidos pela acção urbanizadora ou devido à industrialização, sobretudo a partir do século XIX. A periferia urbana, numa área radial de meia dúzia de quilómetros, dependendo das facilidades de comunicação, constituía uma zona de grande importância no tocante à sustentabilidade das cidades, nela se situando grande parte das actividades que garantiam a sua subsistência. É interessante verificar a presença de autênticas constelações de sítios, de categoria diversa, que envolvem as cidades e mesmo algumas aglomerações secundárias (Fig. 4), como acontece, por exemplo, em

11 B. Cunllife 1995 5-28; J. Alarcão 2006 180-182.

12 P. Le Roux 1995 83-85; V. Mantas 2006 49-92.

${ }^{13}$ E. Cerrillo et alii 1995: 206-209; CIL II 834, 836.

14 J. Alarcão 1999 31-37. 
Lacobriga (Lagos) e em Ierabriga (Paredes, Alenquer). Também este aspecto marcou vigorosamente a paisagem luso-romana.

O exercício das funções de ordem administrativa e ideológica conferidas às cidades obrigava a um equipamento operacional e de prestígio que, desde logo, as distinguiu dos povoados indígenas mais ou menos romanizados que, naturalmente, continuaram a existir um pouco por toda a província, atingindo nalguns casos, como Las Merchanas, na região de Salamanca, dimensões que superavam largamente a área construída de numerosas cidades. Como é evidente, a dimensão constituía um aspecto secundário neste contexto. Todavia, se as cidades capitais podiam ser pequenas, e algumas eram realmente muito pequenas, era imprescindível que o equipamento urbano contasse com os monumentos considerados essenciais para o exercício da capitalidade. Um desses monumentos era o forum, conjunto de edifícios ao serviço da vida religiosa, política, judicial e económica, centro moral da cidade, cujos restos impressionam ainda a paisagem rural e urbana do que foi a Lusitânia, como em Caparra ou em Évora. Entre os monumentos relacionados com a utilitas, e esta pode ser compreendida duplamente, como serviço aos cidadãos e elogio da majestade estatal, devemos destacar termas e edifícios de espectáculo, elementos indispensáveis da prática e propagação do estilo de vida romano ${ }^{15}$. Os últimos, pelas dimensões que lhe eram próprias, impuseram a sua imagem, quer na paisagem urbana antiga, quer, sob diversas formas, na actual ${ }^{16}$, independentemente da qualidade arquitectónica, excelente numa cidade como Mérida (Fig. 5), muito modesta noutras, como Bobadela.

A existência de uma rede urbana coerente exigia, fundamentalmente pelas mesmas razões administrativas, uma rede viária funcional. Esta foi construída e modificada ao longo dos vários séculos do domínio romano, ainda que os grandes eixos, largamente estabelecidos sobre troços de caminhos préromanos e sobre corredores de circulação utilizados anteriormente, caso da via pelo litoral lusitano a norte de Lisboa ou pela chamada Via de la Plata, através da Vetónia. As estradas, de vários tipos, com especial destaque para as vias do cursus publicus, por vezes identificadas nos miliários como vias militares e construídas cuidadosamente, representavam uma teia de elementos estruturantes da paisagem, suficientemente fortes para definirem divisões territoriais posteriores e persistirem como base do sistema de comunicações até às grandes alterações da Revolução Industrial, quando os caminhos de ferro reproduzem os princípios das grandes estradas romanas, lançadas para estabelecer comunicações entre pontos importantes do território da forma mais directa possível.

A rede viária romana facilitava as comunicações a longa distância, eliminando ou atenuando significativamente os particularismos locais, ainda que a civitas pareça ter permanecido como referência identitária básica, o que, numa província com as características artificiais que se reconhecem

\footnotetext{
${ }^{15}$ G. Picard 1965 41-49; M. Grant 1995 50-59.

${ }^{16}$ R. Chevallier 1964 164-168, 205.
} 
na Lusitânia, não pode ser considerado anormal ${ }^{17}$. Na verdade, situação semelhante à que as vias do Império facultaram, só a voltará a conhecer a Europa muitos séculos depois, quando o Estado moderno começa a impor-se gradualmente. Para compreendermos o alcance do impacto das estradas na paisagem lusitana bastará considerar, para além dos vestígios arqueológicos sobreviventes, o efeito que teve na imaginação de épocas posteriores, quando cultos e não cultos louvaram e admiraram, cada um à sua maneira, a obra viária romana, garante de uma mobilidade até então desconhecida. As estradas implicavam a existência de uma paisagem peculiar, para além das modificações que imprimiam, por vezes de forma definitiva, nas regiões que atravessavam, paisagem construída pela presença de elementos característicos, tais como pontes, miliários e estações viárias.

As pontes, localizadas nos locais mais convenientes de travessia de rios, ajudaram a fixar os traçados, condicionando assim os padrões de povoamento desta ou daquela região, constituindo mesmo elementos funcionais essenciais de determinadas cidades, como Mérida, Coimbra ou Salamanca (Fig. 6). As pontes urbanas ou construídas em meio rural, como a de Vila Formosa, na estrada Emerita-Olisipo, ou a formidável ponte de Alcântara, sobre o Tejo, eram também monumentos simbólicos da hegemonia romana e do que ela permitia fazer, unindo gentes que só assim conheceram a ordem e a paz. A célebre inscrição da ponte de Alcântara, indicando os povos que contribuiram para a sua edificação (CIL II 760), é exemplar da capacidade política desta grandeza pragmática, naturalmente ignorada pelos cultores da chamada póscolonialidade. Preferimos antes a antítese das realizações romanas e da sua marca na paisagem tal como a encontramos em Herculano, quando opõe a natureza selvagem da torrente do Sália, agora atravessada por uma árvore tombada, às ruínas da ponte romana, sinal de tempos menos bárbaros ${ }^{18}$.

Sobre miliários já se escreveu muito, banalizando, até, o que o não era. Mais raros do que se pensa, pois só as grandes vias os possuiam, a suas funções não se limitavam à indicação de informações estritamente viárias, pois se revestiam de outras potencialidades colaterais. Com efeito, estamos perante um dos mais interessantes exemplos da chamada literatura de rua, colocada ao serviço da propaganda imperial e, simultaneamente, ao serviço da difusão do Latim e daquilo que poderemos designar, simplesmente, como paisagem cultural luso-romana. Mas não fica por aqui a influência da presença dos miliários nos campos. Materializando pontos de referência na paisagem, muitos assim subsistirão, mesmo perdida a função viária, ou a sua memória persistirá ligada a um determinado local, muitas vezes sob a forma de um topónimo, como por exemplo, Quarto, seis quilómetros a norte de Castro Marim, ou Achete (Ad Septimum), a cerca de 11 quilómetros de Santarém. A análise cronológica dos miliários permite ainda detectar alterações na

\footnotetext{
${ }^{17}$ V. Mantas 2004 82-83.

${ }^{18}$ A. Herculano (s/d): 159-161.
} 
paisagem provocadas por modificações nos traçados, por vezes implicando o abandono ou a decadência de troços anteriores.

As estações viárias constituíram também, fossem mutationes ou mansiones, núcleos de povoamento, particularmente importantes nas zonas menos urbanizadas, pois funcionaram como elementos de atracção e de concentração do povoamento, introduzindo elementos de tipo urbano onde eles não existiam. Uma mansio contava com um grupo de edifícios que podia ser importante, destacando-se termas, albergaria, instalações para o pessoal e animais, oficinas e, seguramente, um local de culto. As mansiones, quando situadas no campo, deram origem a pequenas povoações, vici, como pensamos ter acontecido, apesar de propostas divergentes, com a Torre de Centum Celas, perto de Belmonte. Infelizmente, em parte pela razão referida, conhecem-se mal estes importantes elementos da paisagem lusitana, núcleos básicos da urbanização. Os santuários, junto das estradas ou afastados delas, representaram também elementos relevantes da paisagem provincial, mesmo quando apenas renovados na época romana. A multiplicidade de inscrições votivas, sobretudo consagradas a divindades indígenas, achadas em ambiente rural, não permite dúvidas a esse respeito, não sendo difícil imaginar a influência dos grandes santuários, como o de Santana do Campo (Arraiolos) ou de S. Miguel da Mota (Terena), na estruturação regional da paisagem provincial, ainda que os locais fossem já frequentados antes do domínio romano, o que não é absolutamente seguro.

Um dos elementos fundamentais da romanização da paisagem consistiu na introdução de um novo padrão de povoamento rural e litoral assente nas villae. É claro que antes da colonização romana existia um povoamento rural, cujas características variavam de região para região e que continuamos a conhecer mal. As villae, pelo contrário, representam um modelo de exploração e de organização dos campos que já foi considerado como a expressão mais simples do urbanismo romano ${ }^{19}$, estendendo-se a todo o território. As diferenças arquitectónicas que estes estabelecimentos rurais mostram entre si, sobretudo os das regiões setentrionais da Lusitânia enquanto comparados com os das regiões litorais e meridionais, resultam, fundamentalmente de razões de ordem prática, verificando-se a existência de modelos básicos adaptados às diferentes condições do território. Reconhecida a inspiração tipológica comum destas villae, devemos admitir que a presença próxima ou afastada de centros urbanos exerceu inegável influência sobre o seu aspecto, mais do que sobre as suas funções. As villae, independentemente da sua categoria, constituiram elementos característicos da paisagem lusitana (Fig. 7), impondo, pela sua dispersão, uma nova estruturação dos campos. Ao mesmo tempo, se quisermos conservar alguma coisa da tese da atlantização do povoamento, então é a nível das villae que o poderemos fazer. Finalmente, não podemos esquecer a vizinhança quase simbiótica que muitos destes estabelecimentos

\footnotetext{
19 J.-G. Gorges 1990 91-113.
} 
tiveram com vici e castella, onde vivia a maior parte da força de trabalho necessária.

Quanto às centuriações e operações cadastrais, que parecem agora sub judice, por razões nem sempre claras, deixaram marcas na paisagem e, para os que delas duvidarem, restam sempre os escritos dos gromatici que as referem, por exemplo, em relação ao território de Mérida e ao de Salamanca ${ }^{20}$. A este propósito recordamos que a prospecção sistemática efectuada em torno da villa de S. Cucufate, abrangendo uma área de cerca de 2800 hectares situada na zona setentrional da centuriação de Pax Iulia (Beja), comprovou a existência contemporânea de sete villae, o que atribue a cada uma delas uma área de exploração aproximada da que foi concedida aos colonos de Mérida. É provável que nalguns cadastros se tenham apenas marcado o Cardo e o Decumanus, definindo as grandes linhas da organização do território. No caso de Beja, a centuriação augustana corresponde ao tipo de paisagem ideal, aquela em que os eixos orientadores do urbanismo organizam também o ager colonial ${ }^{21}$, posteriormente sujeito, como tantos outros, a uma operação de renormatio, talvez no período tetrárquico, por razões fiscais. No território lusitano sobrevivem outros traços mais ou menos evidentes de centuriações coloniais e de cadastros (Fig. 8), ilustrando a preocupação romana na construção de uma paisagem domesticada ${ }^{22}$, que podemos, em muitos casos, considerar monumental.

A gestão da água, de forma completamente nova e a uma escala só muito recentemente ultrapassada, foi outra das novidades introduzidas na paisagem pelo domínio romano, sem excluirmos a hipótese de, num ou noutro local da Hispânia meridional, ter existido alguma coisa rudimentar, por influência fenício-púnica. Barragens, aquedutos e reservatórios passam a enriquecer a paisagem lusitana ${ }^{23}$, quer se destinem ao abastecimento de cidades, villae ou explorações mineiras ou industriais. A civilização romana foi, entre outras coisas, uma civilização da água, inclusive da água monumentalizada. Os aquedutos de Mérida, as barragens alentejanas e algarvias ou a bacia e castellum elevatório do aqueduto de Conimbriga são excelentes exemplos da capacidade técnica romana e da preocupação com um recurso fundamental para a vida urbana e para a nova agricultura e pecuária (Fig. 9), seguramente enriquecida por espécies exóticas.

Gostaríamos de continuar, pois resta muito para dizer. Lembramos apenas as grandes transformações sofridas pela paisagem devido às explorações mineiras, da maior importância na economia provincial, assim como pelas pedreiras e actividades fabris diversas, caso da produção massiva de preparados piscícolas e de ânforas e materiais de construção cerâmicos ${ }^{24}$. Não

${ }^{20}$ Higino 1996 24-29 (Th.135-136); Frontino 1998 4-7, 32-33 (Th.1-2, 9).

${ }^{21}$ Higino 1996 59-61 (Th.144).

${ }^{22}$ Uma obra recente questiona, de forma polémica e a merecer leitura crítica, princípios sobre os quais se estabeleceram sólidas análises de estruturas cadastrais antigas: G. Chouquer 2007.

${ }^{23}$ A. Quintela et alii 1986.

24 J. Alarcão 1990 409-441. 
esqueçamos também que muitas destas actividades implicavam larguíssimos consumos de madeira, o que, em certas regiões, terá tido influência no coberto vegetal, explicando, talvez, a obrigatoriedade do concessionário das termas de Vipasca (Aljustrel) manter uma reserva de lenha (CIL II 5181=IRCP 142).

É indiscutível que o domínio romano introduziu alterações de vulto na paisagem da Lusitânia, quer do ponto de vista puramente estético, o que apenas aparentemente pode parecer secundário, quer quanto à construção de um ordenamento inspirado por princípios muito diferentes dos antecedentes, mesmo quando se aproveitou alguma coisa pré-existente, tudo partindo de e conduzindo a uma nova interpretação do espaço, dos recursos e do povoamento, traduzida na criação, se assim o podemos dizer, de novas funções para a paisagem. Heidegger defendeu ser a temporalidade indissociável da palavra, ou seja, da acção, se quisermos reinterpretar o seu pensamento. Foi a acção que marcou o tempo romano na Lusitânia e as paisagens de então e de agora proclamam o triunfo dos que não se limitaram a vencer pelas armas, conferindo sentido a mais de meio milénio de história peninsular.

\section{Anexos}

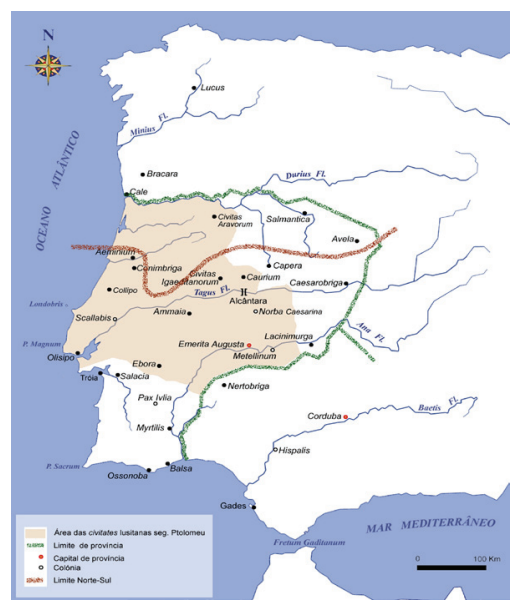

Fig.1. A Lusitânia e os Lusitanos no século II 


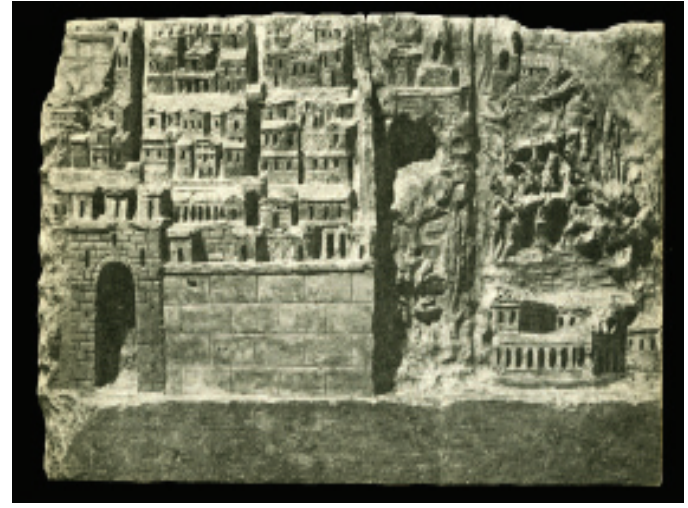

Fig.2. Cidade e campo no relevo de Avezzano (Colecção Torlonia)

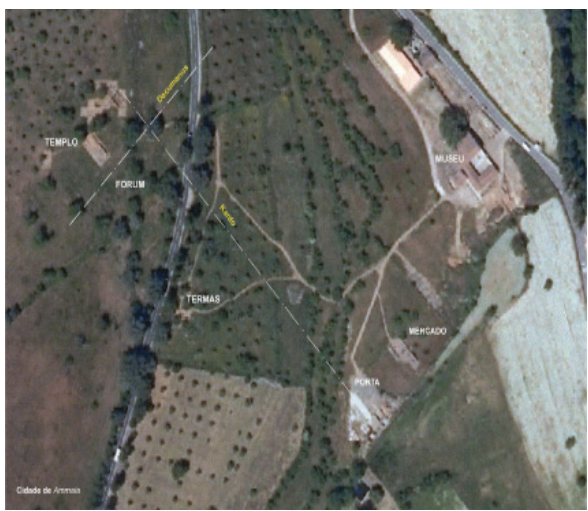

Fig.3. Urbanismo ortogonal na cidade de Ammaia (São Salvador de Aramenha)

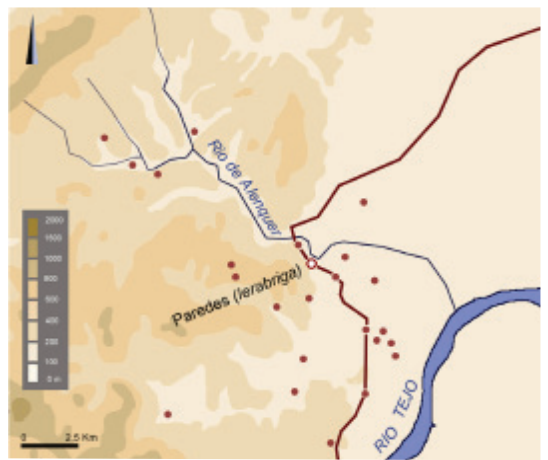

Fig.4. Povoamento romano em torno de Ierabriga (Paredes) 


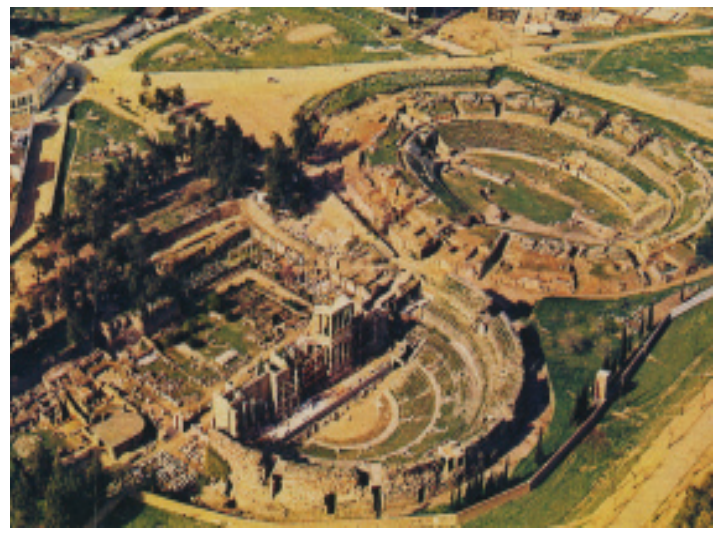

Fig.5. O teatro e o anfiteatro de Mérida em 1968

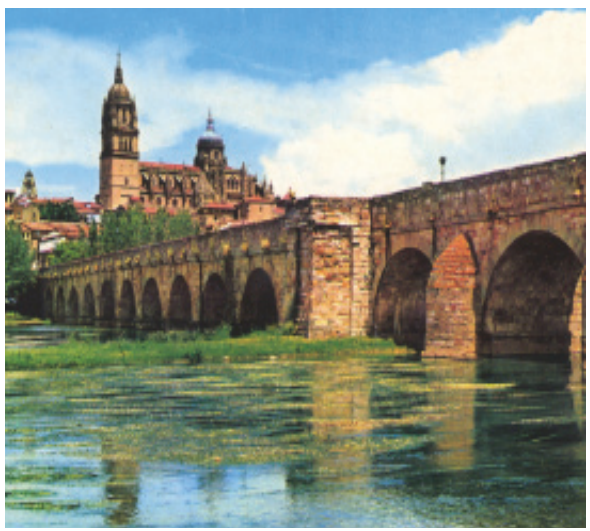

Fig.6. A ponte de Salamanca, parcialmente reconstruída

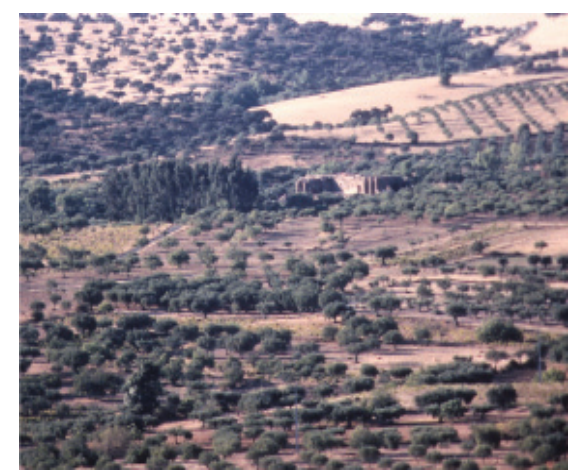

Fig.7. A villa romana de S. Cucufate (Vidigueira) e a paisagem envolvente 


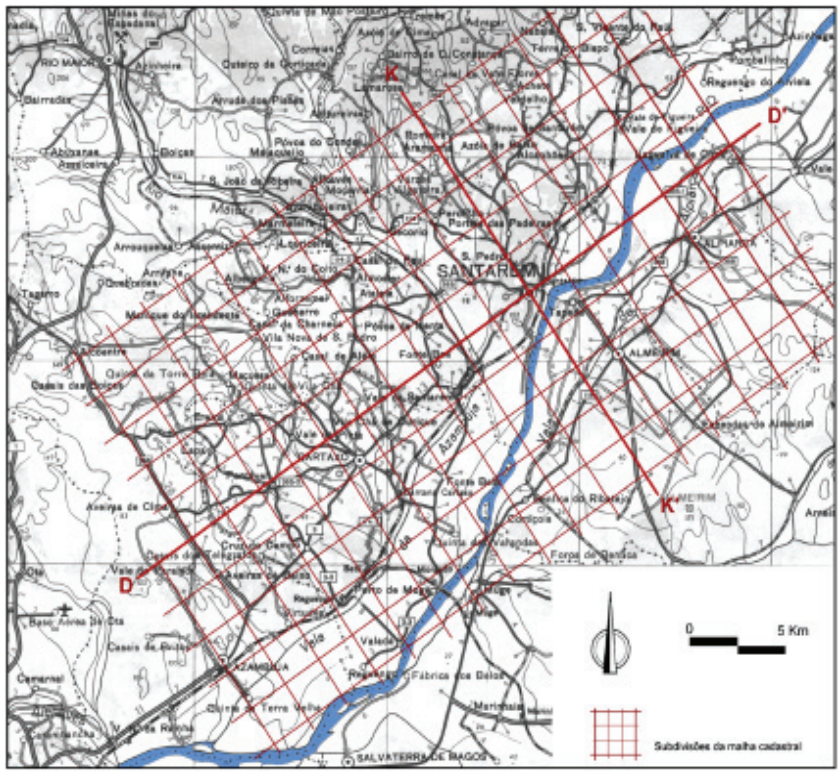

Fig.8. Esboço da centuriação da colónia de Scallabis (Santarém)

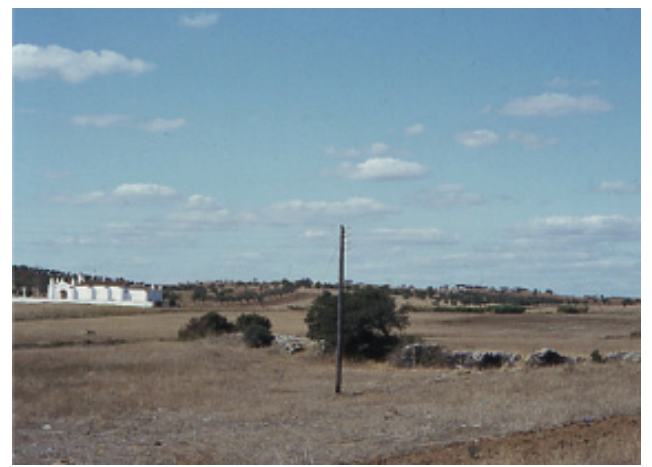

Fig.9. Barragem romana e capela de Nossa Senhora da Represa (Cuba) 


\section{Bibliografia}

\section{Edições e traduções}

Dião Cássio (1969), Dio’s Roman History (trad. E. Cary). Londres, The Loeb Classical Library.

Élio Aristides (2007), A Roma (trad. F. Fontanela). Pisa, Edizioni della Normale.

Estrabão (1960), The Geography of Strabo (trad. H. L. Jones). II. Cambridge (USA), Harvard University Press.

Juvenal (1979), Juvenal and Persius (trad. G. G. Ramsay). Cambridge (USA), Harvard University Press.

Frontino (1998), De Agrorum Qualitate (trad. O. Behrends et al.). Luxemburgo, Comission Européenne.

Higino (1996), Constitutio Limitum (trad. M. Clavel-Lévêque et al.). Nápoles, Editrici Eugenio Jovene.

\section{Estudos}

J. Alarcão (1990), "O domínio romano" in J. Alarcão, coord., Nova História de Portugal. I. Lisboa, Editorial Presença, 344-441.

J. Alarcão (1999), "Os arredores das cidades romanas de Portugal”, Archivo Español de Arqueología 72 31-37.

J. Alarcão (2006), "Os modelos romanos e os traslados provinciais na Lusitânia" in D. V. Gil e J. F. Murillo Redondo, coords., El concepto del provincial en el mundo antiguo. Córdova, Universidad de Córdoba, 175-188.

J. Alarcão, R. Étienne (1981), "Les jardins à Conimbriga (Portugal)" in E. B. MacDougal e W. F. Jashemski, eds., Ancient Roman Gardens, Dumbarton Oaks Library, Washington, Harvard University Press, 69-80.

J. C. Barret (1997), "Romanization: a critical comment", in D. J. Mattingly, ed., Dialogues in Roman Imperialism. Portsmouth (USA), The Society for the Promotion of Roman Studies, 51-64.

E. Cerrillo et al . (1995), "Excavaciones en el forum de Cáparra. La curia”, Extremadura Arqueológica 5 195-209.

R. Chevallier (1964), L'avion à la découverte du passé. Paris, Fayard.

G. Chouquer (2007), Quels scénarios pour l'histoire du paysage? Orientations de recherche pour l'archéogeographie. Coimbra, Centro de Estudos Arqueológicos das Universidades de Coimbra e Porto.

B. Cunliffe (1995), "Diversity in Landscape: the geographical background to urbanism in Iberia" in B. Cunliffe e S. Keay, eds., Social Complexity and the Development of Towns in Iberia. Oxford, Oxford University Press, 5-28.

J.-G. Gorges (1990), "Villes et villas en Lusitanie" in J.-G. Gorges, org., Les Villes de Lusitanie Romaine. Paris, Centre National de la Recherche Scientifique, 91-113.

M. Grant (1995), Art in the Roman Empire. Londres, Routledge.

A. Herculano (s/d), Eurico o presbitero. Lisboa, Europa-América. 
F. S. Kleine (1991), "The trophy on the bridge and the Roman triumph over nature", L'Antiquité Classique 60 182-192.

P. Le Roux (1982), L'armée romaine et l'organisation des provinces ibériques d'Auguste à l'invasion de 409. Paris, De Boccard.

P. Le Roux (1995), Romains d'Espagne. Cités et politique dans les provinces. Paris, Armand Colin.

M. A. Marin Díaz (1988), Emigración, colonización y municipalización en la Hispania republicana. Granada, Universidad de Granada.

F. Martín (2003), "Sobre el significado de Provincia" in C. Alonso del Real et al., eds., Vrbs Aeterna. Roma entre la Literatura y la Historia. Pamplona, Eunsa: 593-609.

V. G. Mantas (2004), "A Lusitânia e o Mediterrâneo: identidade e diversidade numa província romana", Conimbriga 43 63-83.

V. G. Mantas (2006), Cidadania e estatuto urbano na Civitas Igaeditanorum (Idanhaa-Velha)", Biblos, nova série, 4 42-92.

G. Picard (1964), Empire Romain. Friburgo, Office du Livre.

A. Quintela et al. (1986), Aproveitamentos hidráulicos romanos no sul de Portugal. Lisboa, Direcção Geral dos Recursos e Aproveitamentos Hidráulicos.

S. Settis (2002), Le pareti ingannevoli. La villa di Livia e la pittura di giardino. Milão, Electa.

M. Wheeler (1964), Roman Art and Architecture. Londres, Thames and Hudson. 


\title{
O IMPACTO DA CAVALARIA ROMANA NA PAISAGEM
}

\author{
JoÃo Costa FerReIRA \\ Médico Veterinário \\ Ex-director da Coudelaria de Alter
}

\begin{abstract}
This presentation aims to demonstrate how the Romans, seeking to use the potentialities of the horse to the full, caused the first "global" impact on the landscape - the road network.
\end{abstract}

Keywords: highway, Roman cavalary, Space Shuttle

Palavras-chave: cavalaria romana, rede viária, Space Shuttle

O maior, ou menor, impacto de uma rede viária resulta, necessariamente, do bom critério do seu traçado. Os romanos, tanto quanto se sabe, concebiam o traçado das suas estradas não fruto de projectos, vistos e revistos, em face da contestação de comissões de moradores, de proprietários, de ambientalistas, de arqueólogos e outros fundamentalistas, com o patrocínio de Bruxelas, mas do percurso que um burro fazia desde o ponto onde se pretendia chegar, ao ponto de partida onde o referido burro tinha o seu palheiro.

Repare-se que este modo de fazer não é tão tolo como parece, pois o burro, que de burro pouco tem, sendo na escala de inteligência das espécies domésticas o segundo, logo a seguir ao cão, optaria por um traçado que seria o melhor compromisso entre o percurso mais curto entre dois pontos e a maior horizontalidade, por razões de economia de esforço. O burro procuraria o piso de melhor consistência, pois, por força da sua pequena base de sustentação, é de todos os animais o que exerce maior força de pressão sobre o terreno, o que o torna muito vulnerável aos terrenos que mais atolem. $\mathrm{O}$ burro, por ser um animal tímido, que tem na fuga a sua principal defesa dos predadores, escolherá o melhor percurso, de onde os possa avistar a tempo de deles fugir.

Interpretando estas particularidades para a óptica do construtor, haverá que considerar que era do seu interesse óbvio o percurso mais curto e de maior horizontalidade, assim como a qualidade do piso, e também o é pela evidente economia da construção da estrada. O percurso condicionado a "ver antes de ser visto", ou a tempo de fuga, também se coadunava com o interesse dos exércitos romanos em marcha, pois estes, pela supremacia que detinham, o 
que mais lhes interessava não era surpreender as forças inimigas, mas não ser surpreendido por elas.

A relação do romano com o cavalo assumiu formas muito peculiares que importa referir, para que se possa entender o que foi a sua utilização.

A cultura hípica foi coisa importada, com a sua divulgação a fazer-se a partir das classes ricas, que dela se serviu como modo de diferenciação social. Nunca foi de prática popular como o foi noutras zonas - Lusitânia, Numídia, entre os Partos, que tanto tiveram a ver com a história militar de Roma, estando na base de alguns dos desaires mais rotundos das suas legiões.

Outras razões haverá para justificar a maior aptidão dos povos dessas regiões para a equitação, ao invés dos romanos, mas foi, estamos em crer, por aqueles praticarem uma economia pastoril, com maior ou menor transumância e/ou nomadização dos gados, cujo sucesso em muito dependia da utilização do cavalo. Estes factores foram determinantes para a vulgarização da utilização do cavalo nesses povos. É nossa convicção que esta capacidade de uso determinou a domesticação do cavalo. O uso militar do cavalo foi consequência das suas capacidades reveladas na utilização civil e nunca o contrário, como é frequente ser referido.

O cavalo assumiu em Roma particular relevância na tracção, no transporte de pessoas e bens, pela velocidade que permitia, versus alternativa existente, o boi.

Aimportância estratégica da rapidez das comunicações na vida do Império, por imperativos de ordem económica, social ou militar, vá-se lá saber se ditames de ordem política de tipo Keynesiano, também não tiveram a sua influência, ou simples imposição do lobbies dos construtores, que levaram à construção de uma formidável rede viária, de cujo impacto na paisagem não nos chegou notícia de contestação ambientalista.

Muitos desses troços chegaram aos nossos dias, mas de principal relevância são as obras de arte, de uma engenharia prodigiosa, que permite ainda hoje a sua utilização, algumas ainda integradas na actual rede viária, suportando cargas que estariam bem longe das previsões mais acauteladas dos seus engenheiros.

Se a capacidade de carga dessas pontes ultrapassava, em muito, as necessidades da época, por feliz acaso, ou erro de cálculo, tornou-as adequadas às cargas de hoje. Já a dimensão da via (largura) se revelou correcta para os dias de hoje, não sendo necessário soltar a imaginação para justificar tal facto, pois que o foi pela simples razão de a base de cálculo ser a mesma de hoje em dia.

As nossas viaturas automóveis são fruto de uma evolução que teve como base o carro de cavalos, os trens, com quem durante muito tempo partilharam as estradas e pontes.

Até parece redundante afirmar-se que os carros de cavalos estavam dimensionados pelo cavalo no que aqui mais importa - a largura, cuja medida foi ditada pela soma da largura da garupa de dois animais lado a lado, 
a parelha, que constitui a unidade tipo do engate, fazendo-se a sua variação por múltiplos desta unidade em tandem.

A diferença de tamanho do cavalo de então para os dias de hoje é significativa, penso aliás que é no pequeno tamanho do cavalo daqueles tempos que reside a explicação para o não uso de estribos pelos cavaleiros romanos, mas essa diferença não é suficiente para invalidar a base de cálculo da largura das vias, de modo a permitir ainda hoje a sua utilização plena.

A maior propensão do romano pela utilização do cavalo na tracção do que na sela, julgo que fica bem evidenciada pelos espectáculos de base competitiva, também ditos desportivos, pelos quais nutria paixão exaltada. As corridas de cavalos de velocidade pura faziam-se não com o cavalo montado, como hoje, mas com o cavalo tirando um carro, as famosas bigas ou quadrigas.

Os hipódromos, formidáveis construções feitas especificamente para as corridas de carros de cavalos, não são mais que uma pista dividida no seu eixo maior por uma simples separação, a spina, que obrigava nos seus topos a voltas de 180 graus tão apertadas quanto possível, feitas à velocidade que o virtuosismo do auriga permitisse. Esta manobra, que nos merece todo o respeito pela dificuldade que encerra, é imaginável ser feita por uma equipagem, mas já não o é por um cavalo montado e sem estribos lançado a galope, em competição, em grupo e debaixo dos incitamentos da multidão.

Nas pistas dos hipódromos de hoje as curvas não têm um raio inferior a cinquenta metros e as corridas são feitas com os cavalos montados, não há corridas de velocidade pura com cavalos engatados.

Importa referir que o cavalo ibérico (o nosso puro-sangue Lusitano) é tido como o cavalo mais capaz para conseguir efectuar voltas apertadas, fruto da sua anatomia, de que resulta um equilíbrio muito próprio. Talvez esteja aqui a explicação para o sucesso, em Roma, dos cavalos de Torre de Palma, sucesso bem assinalado nos mosaicos multiplamente conhecidos.

Na evolução do transporte, ao surgir a máquina a vapor, como bem refere Richard J. Salomon no livro The Gordian Knot, editado em 1999, a bitola (distância entre carris) esteve condicionada à dimensão da via, que, por sua vez, condicionou todas as obras de arte que a rede de caminhos de ferro obrigou a construir. Daqui resultou nomeadamente pelo gabarito, vão e altura dos túneis, um condicionalismo no dimensionamento dos foguetes externos do Space Shuttle, os SRB, Solid Rocket Booster, que tiveram que ser alterados quando foi tomada a decisão de os fazer deslocar, por via-férrea, do local de fabrico, em Utah, para Cabo Canaveral. Assim sendo, assume-se que a garupa do cavalo romano projectou a sua influência desde a largura das carruagens à largura das vias e pontes romanas, que se mantiveram em uso por toda a Idade Média e Moderna, e que os projectistas dos caminhos-de-ferro, no século XIX, se sujeitaram a essa medida, que condicionou, igualmente, a dimensão dos nossos automóveis; e mesmo a conquista do espaço não se furtou à bitola da garupa do cavalo romano. 
Anexos:

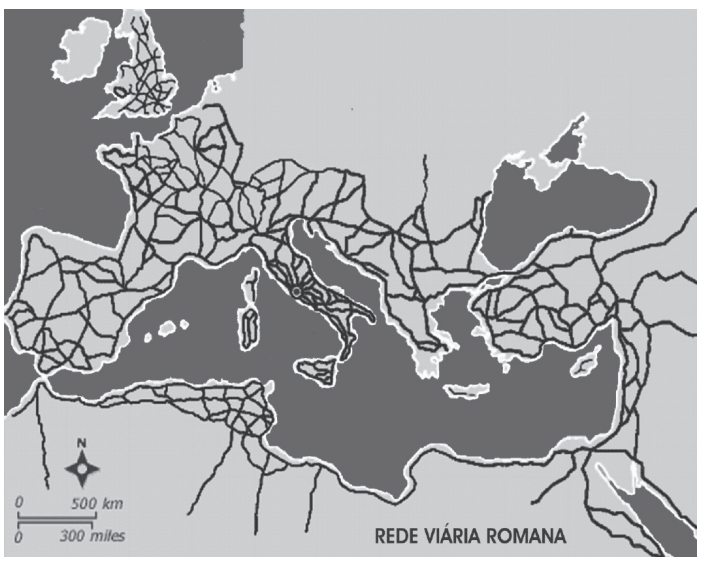

Fig.1. Principal rede viária romana

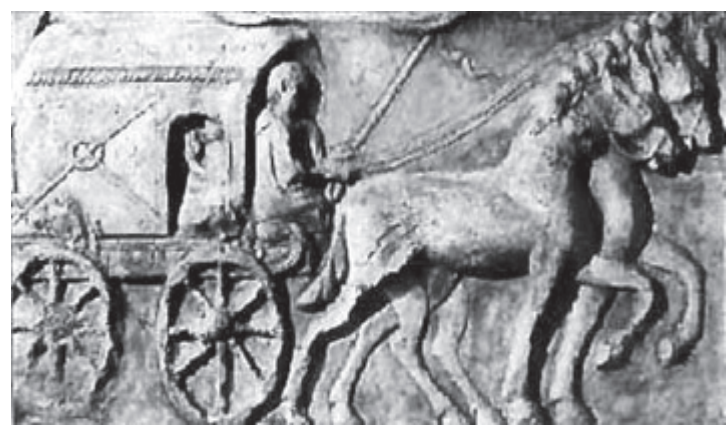

Fig.2. Carro de cavalos romano

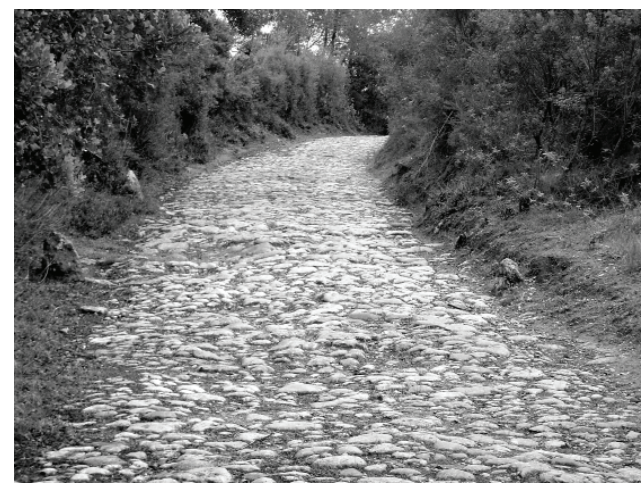

Fig.3. Estrada romana 


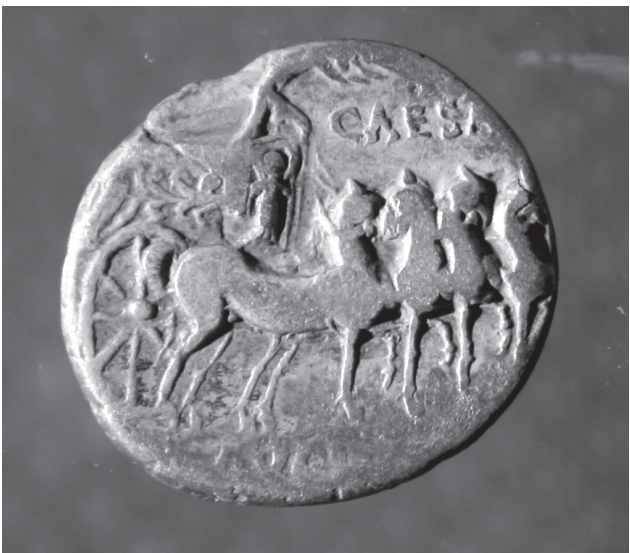

Fig.4. Quadriga em moeda romana (Coudelaria de Alter)

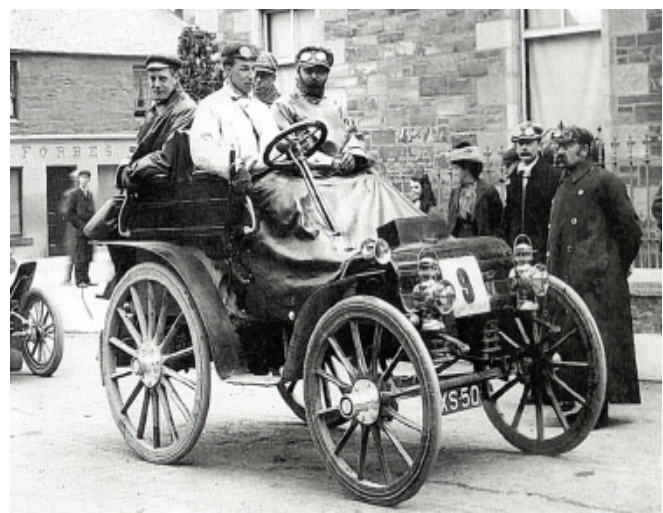

Fig.5. Automóvel de finais do séc. XIX

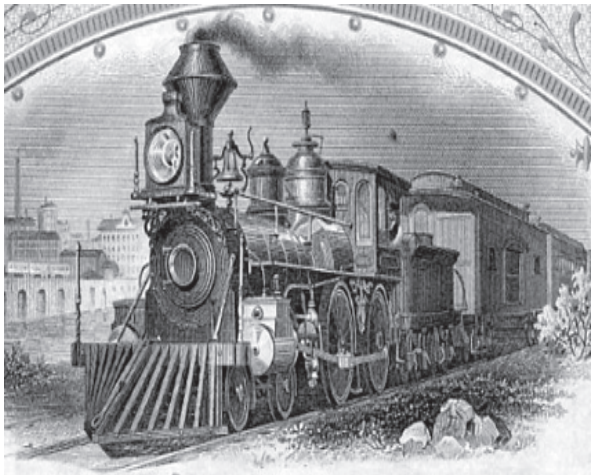

Fig.6. Comboio de finais do séc. XIX 
João Costa Ferreira

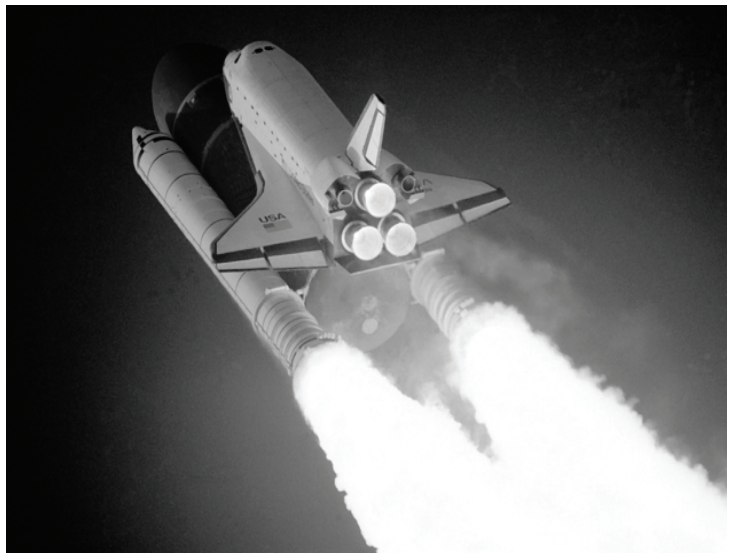

Fig.7. Space Shuttle

(Créditos fotográficos das Fig. ${ }^{\circ} 1$, 2, 5, 6, 7: www.picturehistory.com) 


\title{
A QUE PASSADO REGRESSAR? RECONFIGURAR E RENOMEAR O URBANISMO EM ROMA NA ÉPOCA DE SEVERO ALEXANDRE: O CASO DO PALATINO
}

RODRIGO FURTADO

Universidade de Lisboa

\begin{abstract}
We know that Severus Alexander's reign was certainly the last notable moment for imperial shaping of Roman topography, before Aurelian's and the Tetrarchs' labours at the end of the III rd century. The restoration of the theatrum Marcelli, or the new name given to the stadium Domitiani or to the thermae Neronianae are some relevant examples of Alexander's urban plans. However, in observing the impact of Alexander's labours in Rome, we discern that they often had focused in central areas of major ideological significance. In this paper I try to focus my analysis on Alexander's intervention in the Palatine, essaying to reveal its political and ideological pattern.
\end{abstract}

Keywords: Palatine, Princeps, Severi, Severus Alexander.

Palavras-chave: Palatino, Princeps, Severo Alexandre, Severos.

Roma. 11 de Março de 222 d.C. A cidade vive dias agitados. O imperador Heliogábalo acaba de ser assassinado nos Castra Praetoriana do alto do Viminal. Em seu lugar, os guardas proclamam o seu jovem primo, de treze anos, Severo Alexandre (Herod. 5.8.6-8, Dio 80.20.1-2, SHA Elag. 16.517.1). Desde a morte de Septímio Severo há onze anos, sucederam-se já cinco Augusti. Todos foram assassinados. Comparada com esta, a época dos não muito longínquos Antoninos deve parecer uma espécie de oásis: entre 96 e 192 tinham-se sucedido sete imperadores; destes, apenas Cómodo fora assassinado.

Desejoso de se filiar nestes tempos de prosperidade, depois dos conturbados momentos a seguir ao assassínio de Cómodo, já Septímio Severo havia percebido as potencialidades ideológicas dos Antoninos: declarara-se filho do divino Marco Aurélio e as epígrafes passaram a anunciar que ele seria afinal neto do pius Antonino, bisneto de Adriano e trineto de Trajano ${ }^{1}$. O seu filho, Caracala, virá a assumir o nome do seu «novo» avô, Marco Aurélio Antonino ${ }^{2}$. Mais tarde Heliogábalo fará o mesmo: será o terceiro Marco Aurélio Antonino 3 . Contudo, o contraste entre os graues Antoninos, respeitadores do senado, amigos do Pretório e queridos pela plebe urbana, e

\footnotetext{
${ }^{1}$ Dio 75.7.4, 76.9.4, SHA Seu. 10.6. Cf. BMC 5.91, 140ff., RIC 4.1.99, nº6.

${ }^{2}$ Herod. 3.10.5, SHA Seu. 10.6.

${ }^{3}$ Heliogábalo assume o nome de Caracala, declarando-se a posteriori seu filho. Antes, Heliogábalo chamava-se Vário Avito Bassiano. Cf. Herod. 5.3.10, Dio 79.31.3, SHA Elag. 2.1.
} 
este último príncipe de origem síria deve ter parecido flagrante 4 . Uma política religiosa rápida e inábil, acusada pelos adversários de querer afrontar os mores da cidade, acabou por o perder. Os pretorianos tomarão a iniciativa de se desembaraçar de um príncipe pouco prudente. Ao que parece o seu primo, Severo Alexandre, tinha alguma popularidade: era menos exuberante que o Augusto e parecia menos provocador do que ele. O senado apreciava a sua modéstia e não é improvável que antevisse as possibilidades de maior intervenção no governo do Império. A esta juventude acrescentava-se ainda a franca antipatia que Heliogábalo começara a nutrir por ele (Dio 80.19.23, SHA Elag. 13.6-15.4). Mas Heliogábalo não foi suficientemente rápido. Antes que ele o matasse, lincharam-no os pretorianos, e aclamaram imperador Severo Alexandre (Herod. 5.8.6-8, Dio 80.20.1-2, SHA Elag. 16.5-17.1).

Muito mais hábil que Heliogábalo, pelo menos no contexto do seu assassínio, foi a sua já pequena família (reduzida ao novo príncipe, à mãe deste e à avó, também avó do defunto imperador), com origem na cidade síria de Émesa: é que, surpreendentemente, com o assassínio de Heliogábalo, a família imperial conseguiu não ser arrastada na sua queda; de resto, nem parece ter posto a hipótese de se ver afastada do poder; nem que para isso toda a memória de convivência com Heliogábalo tivesse de ser eliminada; nem que isso significasse em Roma a supressão de todos os sinais de Émesa, para que a dinastia com origem nessa cidade continuasse no poder. Como se Severo Alexandre não fosse primo de Heliogábalo, não tivesse sido César durante o seu principado e não tivesse sido também sacerdote do deus emesiano, Elagábalo ${ }^{5}$ Herod. 5.3.2-5).

Também merece reparo a reacção senatorial: confere rapidamente a Severo Alexandre todos os títulos imperiais e ordena a damnatio memoriae de Heliogábalo com o apagamento de documentos e epígrafes do nomen 'Antonino' que ele havia assumido (SHA Elag. 17.4; Alex. 1.1-2). Ora, ao apagar-se apenas 'Antonino' do nome de Heliogábalo, não se estava a negar que o imperador o tivesse utilizado, mas a condenar publicamente a sua utilização ${ }^{6}$. Não é, certamente, por acaso que a Vita Alexandri apresenta um longo diálogo entre Severo Alexandre e o senado em torno deste nomen (SHA Alex. 7-10). Segundo este texto, o senado quis concedê-lo ao novo príncipe. Contudo, Severo Alexandre, em gesto significativo, recusa-o, por se julgar indigno dele. Mas a oferta, nem que seja meramente retórica, é verosímil. Ela constitui medida simétrica da damnatio de Heliogábalo: o que se retirava ao imperador assassinado, era oferecido ao novo. Na óptica senatorial, que

\footnotetext{
${ }^{4}$ Cf. R. Furtado 2008.
}

5 Elagabalos é o nome da divindade síria de quem o imperador era devoto. Nenhuma das fontes contemporâneas refere o Príncipe com este nome e não há notícia de que ele o tenha realmente assumido. Em latim, a Vita Heliogabali da Historia Augusta refere-o como Heliogabalus, o que é uma óbvia corruptela do nome da divindade. Uma vez que divindade e Imperador têm tradicionalmente o mesmo nome, apenas por uma questão de clareza optei por utilizar em português sempre Elagábalo para referir o deus e Heliogábalo, para o príncipe.

${ }^{6}$ Para uma boa análise sobre a damnatio memoriae em Roma, veja-se C. W. Hedrick Jr. 2000 89-126. 
apaga um nome para o propor a um novo indivíduo, era todo um modelo que se queria projectar sobre o imperador: como um novo Antonino, Severo Alexandre deveria encontrar nos imperadores «seus antepassados» o exemplo a seguir.

Por isso mesmo, enquanto se martelava o nome do ex-imperador, ou até já antes, nos últimos meses do principado deste (Herod. 5.8.2, Dio 80.19.1, SHA Elag. 13.3), começara a construir-se à volta de Severo Alexandre uma outra imagem tópica, que mais do que procurar esquecer a de Heliogábalo, intentava estar nos seus antípodas. A mãe de Severo Alexandre, Júlia Mameia, fora das primeiras a compreender a necessidade de uma «nova imagem» para o próprio filho. As fontes contam-nos que ela confiara a sua educação a homens de 'romanidade' insuspeita (SHA Alex. 3), compreendendo que continuava a marcar pontos o modelo imperial que assumia o imperador como uma espécie de primus inter pares no senado e na Urbe. E as fontes garantemnos topicamente isso mesmo: ao vestuário excêntrico de Heliogábalo oporse-ia agora a sobriedade da veste branca, não dourada, e as togas banais ${ }^{7}$. Socialmente, a philanthropia e a clemência sobrepor-se-iam à etiqueta distanciadora de Heliogábalo ${ }^{8}$. À anterior extravagância dos banquetes diziase ter sucedido a simplicidade ${ }^{9}$. As fontes garantem que ele teria afastado o entourage de Heliogábalo (Herod. 6.1.5, SHA Alex. 15.1-2, 34.2-4) e os eunucos ${ }^{10}$, o que, mesmo não sendo verdade, deve ter representado um motivo ideológico do novo principado. Contudo, vai ser no espaço público da cidade, que, tal como na damnatio memoriae de Heliogábalo, vamos encontrar os sinais mais evidentes desta construção de uma nova imagem.

É sabido que o principado de Severo Alexandre foi o último momento notável de intervenção imperial no espaço da $V r b s$, antes das reformas urbanísticas motivadas pelo levantamento da muralha de Aureliano e, mais tarde, das extensas construções dos tetrarcas, no final do século III. A Historia Augusta mostra interesse pelas construções e intervenções urbanas de Severo Alexandre, mais do que pelas de qualquer outro príncipe. Apenas com base na Vita Alexandri é possível elencar pelo menos dezanove intervenções ${ }^{11}$, às quais

\footnotetext{
${ }^{7}$ SHA Alex. 4.2, 33.3-4; 34.5; 40.1, 3, 5-11.

${ }^{8}$ Herod. 6.1.6, SHA Alex. 4.3. SHA Alex. 18.3 parece supor que etiqueta de corte da época de Heliogábalo seria inspirada pelo costume persa. Sendo possível, é bem mais provável que o autor esteja a projectar para o século III um dado que remetia para o século IV.

9 SHA Alex. 34.1, 6-8.

${ }^{10}$ SHA Alex. 45.4-5.

11 a) SHA Alex. 22.4: construção de opera mechanica;

b) SHA Alex. 24.3: restauro do teatro [de Marcelo];

c) SHA Alex. 24.3: restauro do circo [máximo];

d) SHA Alex. 24.3: restauro do anfiteatro [flávio];

e) SHA Alex. 24.3: restauro do estádio [de Domiciano];

f) SHA Alex. 25.3: remodelação das termas de Nero, chamadas a partir de então alexandrianae;

g) SHA Alex. 25.4: construção de um aqueduto (aqua alexandriana);

h) SHA Alex. 25.4: construção de um pórtico nas termas de Caracala;

i) SHA Alex. 25.7: pavimentação no Palatino com dois tipos de mármore (opus
} 
se podem acrescentar pelo menos mais oito, não atestadas literariamente, mas para as quais a arqueologia nos fornece informação ${ }^{12}$.

Obviamente estará muito além deste texto uma análise actualizada de todas as evidências que possuímos acerca de cada uma destas intervenções. De qualquer modo, mesmo partindo do princípio de que algumas das construções referidas pela tardia Historia Augusta não estão confirmadas pela arqueologia ou de que, para o último grupo, restam dúvidas sobre a época das obras, não deixa de ser impressionante a extensão das intervenções atribuídas a Severo Alexandre apenas na cidade de Roma, sem paralelo de facto entre os seus antecessores e sucessores imediatos ${ }^{13}$.

Há um primeiro aspecto que se evidencia, de resto já anotado por $\mathrm{F}$. Coarelli ${ }^{14}$ : a importância de construções e restauros relacionados com termas, com o abastecimento e armazenamento de bens ou com edifícios para espectáculos, num total de onze estruturas ${ }^{15}$. A principal beneficiária deveria ser a plebe urbana, em época particularmente agitada. É possível que quem rodeava o príncipe percebesse a necessidade de conquistar a população: o restauro de todos os principais locais de espectáculo mostra bem o esforço do príncipe em granjear o apoio dos habitantes de Roma.

Há, no entanto, um conjunto de construções que merece uma análise mais atenta, pelo que mostra acerca da ideologia dominante na corte de Severo
Alexandrinum);
j) SHA Alex. 26.4: colocação de estátuas no foro de Trajano;
k) SHA Alex. 26.7: início da construção da basílica alexandrina;
l) SHA Alex. 26.8: ornamentação de um Iseu e Serápio;
m) SHA Alex. 26.9: construção dos aposentos de Júlia Mameia;
n) SHA Alex. 26.11: restauro e construção de pontes;
o) SHA Alex. 28.6: colocação de estátuas colossais de imperadores no foro de Nerva;
p) SHA Alex. 39.3: construção de armazéns públicos em todas as regiões de Roma;
q) SHA Alex. 39.3-4: construção de termas nas regiões de Roma que ainda não as
tinham;
r) SHA Alex. 39.5: construção de casas (domi) para privados considerados
merecedores;
12 s) construção/dedicação de um templo de Júpiter Resgatador nos Castra Peregrina;
t) construção/dedicação de um templo de Dea Syria na margem direita do Tibre;
u) construção/dedicação de um templo de Júpiter Vingador;
v) restauro do templo de Vesta;
w) reconstrução de altares compitales, dedicados aos Lares;
x) início da construção do Sessório;
y) restauro do Vmbelicus mundi;
z) construções na domus Laterani.

${ }^{13}$ Os melhores estudos de conjunto sobre a actividade urbanística de Severo Alexandre em Roma são os de H. G. Ramsay 1935 e 1936; de H. W. Benario 1956 720-722; e de F. Coarelli 1987.

${ }^{14}$ F. Coarelli 1987 431, 432-433.

${ }^{15}$ As estruturas que assinalei com as letras a; b; c; d; e; f; g; h; n; p; q. 
Alexandre. Refiro-me ao programa de construções levado a cabo nesta época, sobretudo no Palatino.

De facto, o Palatino constituía a colina onde, segundo a tradição, Rómulo teria fundado a Vrbs. Aí se localizava o Lupercal, a Casa de Rómulo e os palácios que os vários imperadores aí foram construindo e reconstruindo, desde Augusto. O último a ter fixado residência na colina tinha sido o antecessor de Severo Alexandre, e é provável que a família imperial com ele. Aí também ${ }^{16}$ teria Heliogábalo dedicado um templo ao deus sírio, Elagábalo, e instalado a pedra que mandara vir directamente do templo da longínqua Émesa, e que representava o próprio deus ${ }^{17}$. Não está isenta de controvérsia a localização exacta deste Elagabalium ${ }^{18}$. De qualquer modo, desde P. Bigot ${ }^{19}$, tem-se situado este templo no terraço da Igreja de $\mathrm{S}$. Sebastiano al Palatino. $\mathrm{O}$ argumento de Bigot baseia-se num medalhão de bronze de Heliogábalo ${ }^{20}$ e num sestércio de Severo Alexandre ${ }^{21}$. Ambos mostram a representação de um templo com características muito próximas. Contudo, há diferenças que já foram notadas por Bigot. É que o templo representado no medalhão de Heliogábalo contém a pedra cónica de Elagábalo. Por isso, Bigot concluiu dever tratar-se de uma representação do Elagabalium. Na moeda de Alexandre, ao invés da pedra, surge uma personagem masculina com a legenda 'Júpiter Vingador'. Podem obviamente ser dois templos distintos, embora com características próximas. Além disso, as moedas não têm de representar necessariamente a realidade de forma «realista». Mas Bigot propõe uma melhor resolução para esta contradição, baseado no provável reenvio da pedra de Elagábalo para a Síria (pelo menos deixamos de ter notícia dela em Roma), na ausência de qualquer notícia da permanência do templo do deus sírio no Palatino e no silêncio de todas as fontes quanto a uma eventual destruição física do templo de Elagábalo nesta colina. Sendo assim, segundo Bigot, em ambas as espécies monetárias estaria de facto representado o mesmo templo, embora rededicado a Júpiter Vingador por Severo Alexandre. Após a morte de Heliogábalo, o seu sucessor teria mantido a estrutura do templo, mas tê-lo-ia dedicado a uma nova divindade. Contudo, é possível ir um pouco mais longe do que Bigot.

Segundo Jerónimo, Heliogábalo tinha instalado o seu deus no Palatino logo em 220, apenas um ano após a sua chegada a Roma. Devo dizer que um ano me parece pouco tempo para a construção de uma estrutura como

${ }^{16}$ SHA Elag. 3.4, Herod. 5.5.8-10, Aur. Vict. 23.1.

17 "Não havia qualquer estátua do deus feita pelos homens, como os Gregos e Romanos costumam fazer, mas havia uma enorme pedra, arredondada na base, a terminar em bico no cimo, de forma cónica, e preta. Esta pedra é cultuada como se tivesse sido enviada do céu" (Herod. 5.3.5). Cf. também Herod. 5.5.3-7

${ }_{18}$ Cf. R. Furtado 2008 193-194.

19 P. Bigot 1911: 80-85. Este autor propôs identificar o templo de Júpiter Victor referido na Notitia Vrbis Romae com o templo de Júpiter Vltor da moeda de Severo Alexandre e com o Elagabalium do medalhão de Heliogábalo. Cf. também G. Lugli 1960 199, nº 440; F. P. Rosati 1955 e E. Nash 1968 537-41.

${ }^{20}$ F. Gnecchi 1912, $3^{\circ}$ vol: 41, no 6, pl. 152, no 11 .

${ }^{21}$ RIC Alex. 146. 
a que se adivinha no terraço de San Sebastiano: um templo períptero com fachada hexastila e uma esplanada porticada, interrompida por uma colunata encimada por estátuas ${ }^{22}$. E naturalmente não sou o primeiro a ter esta dúvida. Desde pelo menos Domaszewski que se duvida que o terraço de $\mathrm{S}$. Sebastiano tivesse estado desocupado até ao século $\mathrm{III}^{23}$. Sendo assim, porque o tempo foi curto e porque o Palatino deveria estar já, no início do século III, sobrelotado em termos urbanísticos, parece-me seguro que Heliogábalo tenha decidido adaptar um outro edifício pré-existente para instalar o seu Elagabalium. Ora, F. Castagnoli defendeu que no espaço de S. Sebastiano teria havido um templo de Júpiter Vencedor. F. Chausson sugere antes um templo de Júpiter Vingador, precisamente a epiclese da divindade que aparece mais tarde nas moedas de Severo Alexandre ${ }^{24}$. Se estes autores tiverem razão, Heliogábalo teria começado por desalojar Júpiter. Se juntarmos esta hipótese à de Bigot, elas fazem sentido: Heliogábalo desaloja Júpiter para instalar o seu deus sírio; mais tarde, Severo Alexandre teria feito o mesmo a este, para reinstalar Júpiter. Não sabemos quando, mas a pedra de Elagábalo deve ter sido reenviada para Émesa e as moedas de Severo Alexandre (depois de Bigot já se encontraram novos exemplos) começam em 224/5 a mostrar um templo de Júpiter Vingador, que não aparecia antes ${ }^{25}$.

Será preciso avançar até ao século IV para poder compreender melhor o que se terá passado. No Cronógrafo de 354, no «Calendário de Filócalo», um extraordinário calendário ilustrado oferecido no século IV a um aristocrata cristão, para o dia 13 de Março encontra-se a referência Ioui Cultori ${ }^{26}$. Esta epiclese de Júpiter é, tanto quanto sei, muito rara, o que, só por si, causa alguma estranheza num calendário da qualidade deste. Mas há um segundo problema: como os dias dedicados a Júpiter eram os idos de cada mês (e os idos de Março calham a 15, como é sobejamente sabido), então esta estranha festa de Júpiter de dia 13 deve estar relacionada com um acontecimento extraordinário e não com uma festividade ordinária. Ora, julgo que uma observação ao fragmentário feriale Duranum ${ }^{27}$, do próprio século III, permite esclarecer estes dois problemas do Cronógrafo: segundo o feriale Duranum, sem referir no entanto a festa em honra de Júpiter, o dia 13 de Março é o dies imperii de Severo Alexandre. Ou seja, duas fontes independentes atribuem ao mesmo dia dois acontecimentos diferentes: o dia em que Severo Alexandre deve ter sido reconhecido como imperador em Roma é também dia de uma festa dedicada a Júpiter Cultor. Já Coarelli concluiu que 'non é possibile pensare a una

${ }^{22}$ Veja-se R. Turcan 1985121 e F. Chausson 1995738.

${ }^{23}$ Platner-Ashby 1929199.

${ }^{24}$ F. Castagnoli 1979 740-743. E. Rodriguez-Almeida 1981 48-53 identifica o espaço onde se instalará o Elagabalium com os Adonaea.

${ }^{25}$ Outras moedas há da época de Severo Alexandre que mostram a mesma legenda, mas desta vez com a representação da divindade, sentada, com uma lança e a vitória (RIC Alex. 142 aureus, 143, 144, 145) ou com um ceptro nas mãos (RIC Alex. 560).

${ }^{26}$ Th. Mommsen 1893. O estudo mais recente deste documento é o de M. R. Salzman 1991.

${ }^{27}$ R. O. Fink, A. S. Hoey, W. F. Snyder 1940, H. W. Benario 1962. 
coincidenza' ${ }^{28}$. Uma observação ao aparato crítico estabelecido por Mommsen para o "Calendário de Filócalo" permite ir ainda mais longe: já há mais de cem anos, este investigador alemão propôs que a epiclese Iuppiter Cultor fosse um mero erro de transmissão manuscrita e que, na realidade, Cultor deveria constituir uma má leitura copista de Vltor! Se assim for, e se Mommsen tiver razão, no dia da subida ao poder de Severo Alexandre festejar-se-ia (sem que saibamos a partir de quando) ou ter-se-ia começado a festejar uma festa em honra de Iuppiter Vltor. Recapitulemos: é provável que o Elagabalium tenha substituído um templo de Júpiter; é praticamente seguro que depois, na época de Severo Alexandre, este templo tenha sido rededicado a Júpiter Vingador; o imperador é aclamado a 13 de Março, no mesmo dia em que temos a notícia de uma festa em honra de Júpiter, que já Mommsen propõe ser honrado com o título Vltor. Seja porque a festa deste Júpiter Vingador já existia em Roma no dia 13 de Março, o próprio dies imperii do imperador, até talvez centrada no templo de S. Sebastiano, seja porque Severo Alexandre institui esta festa para comemorar a sua subida ao poder, parece facto assegurado a relação entre o dies imperii do príncipe e o deus Júpiter.

Vai no mesmo sentido o templo de Iuppiter Redux nos Castra Peregrina com dedicatória ao novo imperador e à mãe ${ }^{29}$. Com um templo dedicado ao pouco habitual Júpiter «Resgatador», é como se os soldados se estivessem a assumir como instrumento da divindade no resgate do império, do novo príncipe e de sua mãe. De facto, a presença destes na epígrafe constitui sinal da relação entre a 'nova' família real e o Júpiter Resgatador, como se, por intermédio da divindade, o príncipe e a mãe tivessem sido resgatados da perfídia do anterior imperador. De resto, o resgate do império e do próprio imperador ter-se-ia feito precisamente nos Castra (embora não nos Peregrina, mas nos Praetoriana), onde Heliogábalo fora assassinado. Prova desta relação especial entre a família resgatada e o mundo militar encontra-se em pelo menos mais uma epígrafe deste castra, com uma dedicatória à mãe do imperador ${ }^{30}$.

Com o assassínio de Heliogábalo Severo Alexandre poderia ter mantido pelo menos um culto mais soft de Elagábalo no Palatino. Mas não. O corte com o principado anterior tinha de parecer radical. Deixamos de ter notícia da pedra de Elagábalo e não consta que Severo Alexandre tenha voltado a prestar culto ao seu deus familiar. Mas não bastava isso. Era necessário mostrar aos habitantes da Vrbs que o novo príncipe iria ser afinal diferente do anterior. Nesse sentido, há que admitir que qualquer deus tradicional poderia ter sido eleito pelo príncipe para afirmar uma «nova imagem». Mas não foi eleita uma divindade qualquer. Foi logo escolhido o deus principal do panteão, aquele que Heliogábalo fora acusado de ter afrontado, até talvez o deus que ele começara

${ }^{28}$ F. Coarelli 1987438.

${ }^{29}$ CIL 6.428. Cf. Platner-Asby 1929, s.u. 'Jupiter Redux': 105-6 e H. G. Ramsay 1936 170171. O dedicante foi um centurio frumentarius.

${ }^{30}$ CIL 14.7. A VII coorte dos uigiles assume o nome do próprio imperador e de sua mãe, como também notou F. Coarelli, numa óbvia declaração de apoio e fidelidade à pequena família imperial: cf. CIL 6.3008 . 
por desalojar no Palatino. Acontece o mesmo no templo dos Castra Peregrina, onde a epiclese de Júpiter preside a esses novos tempos, em associação com o imperador e a mãe. De algum modo, é como se o principado de Severo Alexandre se tivesse colocado sob a protecção de Júpiter, cujas epicleses, Vingador e Resgatador, ditavam agora todo um programa, já vislumbrado na damnatio memoriae de Heliogábalo. Na eleição de Júpiter residia a derrota de Elagábalo, daí o regresso deste a Émesa. Na vitória de Júpiter, estava também simbolizada a derrota da imprudente política religiosa de Heliogábalo, que procurara identificar Elagábalo e Júpiter e, possivelmente, actualizar a Tríade Capitolina, no templo do Palatino ${ }^{31}$. A vitória de Júpiter sobre Elagábalo, mais do que a vitória de uma tradição religiosa, significava metaforicamente a vitória dos mores e do senado, simbolizados no deus tradicional da Urbe.

Ainda no Palatino, a Historiae Augusta assegura que Severo Alexandre terá mandado construir um pavimento com dois tipos de mármore, lacedemónio (hoje chamado serpentino) e porfírio (vermelho; trazido do Egipto). P. Gros, em artigo sobre estas plateae antoninianae, considera que não há razão para duvidar de tais notícias, uma vez que não se vislumbrariam razões para uma invenção deste tipo por parte do autor desta Vita, que escreve já no século $\mathrm{IV}^{32}$. Ele aceita assim a notícia como verdadeira e localiza este pavimento de luxo nas alas que ladeariam o templo do terraço de San Sebastiano. Embora a arqueologia não confirme explicitamente esta hipótese, ela parece pelo menos admitir que este terraço terá sofrido modificações na época dos Severos. De resto, como vimos, este terraço deve de facto ter sido alvo de intervenções na época quer de Heliogábalo quer de Severo Alexandre, o que torna verosímil a interpretação. Há contudo um problema.

A Vita Alexandri afirma que Severo Alexandre teria sido o primeiro a utilizar tal tipo pavimento. Ora, quem conhece a Vita Heliogabali reconhece esta mesma notícia, mas já neste texto, com uma formulação muito próxima da que é possível ler na Vita Alexandri (SHA Heliog. 24.6). Em ambos os casos, as plateae são do mesmo material e situam-se no mesmo local. Com base nisto, F. Chausson discorda de Gros e defende ser esta notícia uma criação do autor das Vitae, para contrastar os seus tempos, que assistiriam à delapidação e decadência de Roma, com os áureos e luxuosos tempos da Urbe paga $\tilde{a}^{33}$.

É óbvio que Severo Alexandre não poderá ter sido o primeiro a utilizar este opus alexandrinum, se o seu antecessor já o tiver feito. Tanto quanto sei, os dados arqueológicos não permitem datar com precisão eventuais intervenções severianas no terraço de San Sebastiano. Embora o cepticismo de F. Chausson seja aceitável e a sua proposta verosímil, não deixa de ser estranho que precisamente a mesma informação seja repetida em duas Vitae seguidas. A ser pura invenção, não vislumbro bem por que razão se criaria a mesmíssima notícia, para dois imperadores sucessivos, para o mesmo local, com os mesmos pormenores. Parece-me mais provável que o autor das Vitae soubesse

\footnotetext{
${ }^{31}$ R. Furtado 2008 200-202.

${ }^{32}$ P. Gros 1986.

${ }^{33}$ F. Chausson 1995 756-62.
} 
da existência de uma pavimentação luxuosa do Palatino no final da época severiana, mas desconhecesse qual dos imperadores teria sido responsável por ela. Julgo possível, e é essa a minha hipótese, que Heliogábalo tenha começado esse processo de pavimentação do terraço do templo de Elagábalo, mas que tenha cabido a Severo Alexandre concluí-lo ${ }^{34}$.

O Palatino é, de facto, espaço de intervenções urbanas nos principados de Heliogábalo e de Severo Alexandre. Para a época de Severo Alexandre há ainda a assinalar a construção das diaetae de Mameia, confirmadas por Aurélio Victor $^{35}$, ou, segundo Coarelli, o restauro do mundus, estrutura subterrânea que assinalaria o centro da cidade de Rómulo ${ }^{36}$. A confirmar-se esta proposta, esta última intervenção mostraria de novo a intervenção no centro ideológico da Urbe, em linha com o restauro das tradições romanas, e em ruptura com a perspectiva orientalizante atribuída a Heliogábalo.

De qualquer modo parece evidente que a recusa explícita do exemplo de Heliogábalo não implicou da parte de Severo Alexandre o abandono do Palatino, onde o antecessor se havia instalado. A colina era demasiado tradicional e prenhe de simbolismo para que fosse descartável. Contudo, a permanência no Palatino obrigou a eliminar os sinais da presença de Heliogábalo e a induzir uma espécie de regresso ao passado na simbologia do poder. De resto, o Palatino é apenas uma das regiões de Roma onde Severo Alexandre interveio. A esta colina, poder-se-iam acrescentar pelo menos o Campo de Marte e a área dos fora imperiais, onde a opção ideológica de Severo Alexandre, sobretudo na eleição de modelos ideológicos a seguir, se torna ainda mais evidente. O Palatino constitui, no entanto, espaço de eleição para avaliar a política ideológica de Severo Alexandre. A (re)eleição de Júpiter no Palatino, numa interpretação que procura dar sentido aos vestígios arqueológicos e às informações que as fontes nos proporcionam, permite confirmar como o principado de Severo Alexandre se constrói sobre o signo da ruptura com o passado.

Não posso deixar de notar que, pela segunda vez na história de Roma (a primeira teria sido com a sucessão Calígula / Cláudio), um imperador é assassinado, sem se verificar uma ruptura dinástica. Mas, desta feita, apesar da ausência desta, verifica-se ainda assim um outro tipo de ruptura. Severo Alexandre encena-a em si mesmo (na imagem que ele procura propagandear) e no espaço. Concretamente em Roma, essa transformação do espaço levou à eliminação explícita da presença de Heliogábalo, através de uma espécie de nova damnatio memoriae, ainda mais visível e significativa: havia que eliminar os edifícios deste imperador na cidade e mostrar, pela substituição e pela garantia da vitória de Júpiter sobre Elagábalo, que novos tempos haviam

${ }^{34}$ M. Royo 2001/4 65, n. 133, considera possível a "anticipation monumentale du palais par ce type d'espaces, qu'ils aient été réalisés ou seulement envisagés”. Cf. também G. Lugli $1960200, n^{\circ} 448,202, n^{\circ} 460$.

${ }^{35}$ Aur. Vict. 24.5. Cf. H. G. Ramsay 1936 163-167, G. Lugli 1960 202, n 461, L Richardson 1992, s.u. 'Dietae Mammeae' 117.

${ }^{36}$ F. Coarelli 1987443. 
chegado. Uma vez mais é o regresso ao passado que se procurava garantir. Ideologicamente.

\section{Bibilografia}

H. W. Benario (1956), "Rome of the Severi”, Latomus 17 712-722.

H. W. Benario (1962), "The Date of the Feriale Duranum", Historia 11 192-196.

P. Bigot (1911), "Le temple de Jupiter Vltor et la Vigna Barberini”, Bullettino della Commissione archeologica comunale di Roma, 80-85.

A. Cassatela, I. Iacopi (1991), "Il balneum presso le scalae Caci sul Palatino", in M. Lenoir, ed., Les thermes romains. Rome, 129-138.

F. Castagnoli (1979), "Su alcuni problemi topografici del Palatino", Rendiconti della Classe di scienze morali, storiche e filologiche dell'Accademia dei Lincei, 331-347.

F. Chausson (1995), "Vel Ioui uel Soli: quatre études autour de la Vigna Barberini (191-354)", Mélanges de l'École Française de Rome 107 661-765.

F. Chausson (1997), "Le site de la Vigna Barberini de 191 à 455", La Vigna Barberini, I, Histoire d'un site, étude des sources et de la topographie. Rome, 31-85.

F. Coarelli (1987), "La situazione edilizia di Roma sotto Severo Alexandro" in L'Vrbs: espace urbain et histoire (Ier siècle av. J.-C.- IIIe siècle ap. J.-C.). Actes du colloque international (Rome, 8-12 mai 1985). Rome, 429-456.

R. O. Fink, A. S. Hoey, W. F. Snyder (1940), "The Feriale Duranum”, YCS 7 1-222.

R. Furtado (2008), “"Vinho novo em velhos odres»? Porque foi assassinado Marco Aurélio Antonino?", Cadmo 17 187-228.

F. Gnecchi (1912), I medaglioni romani. 3 vol. Milano.

P. Gros (1986), 'Une hypothèse sur les plateae Antoninianae du Palatin', MEFRA 98 255-263.

Jr. C. W. Hedrick (2000), History and silence. Purge and rehabilitation of memory in late Antiquity. Austin.

R. Lanciani (1897), Ruins and excavations of Ancient Rome. London.

G. Lugli (1924), Monumenti Antichi di Roma e suburbio. 1. Zona Archeologica. Roma.

G. Lugli (1946), Roma Antica. Roma

G. Lugli (1960), Mons Palatinus. Fontes ad topographiam veteris urbis Romae pertinentes. Regio X. Roma, 199, $\mathrm{n}^{\circ} 440$.

T. Mommsen, ed. (1893), Inscriptiones Latinae Christianae ad C. Caesaris mortem. Pars prior. Berlin, 254-279.

E. Nash (1968), Pictorial Dictionary of Ancient Rome. 2 vol. New York / Washington, 537-541.

S. B. Platner, T. Ashby (1929), A Topographical Dictionary of Ancient Rome. London. H. G. Ramsay (1935; 1936), “A third century a.C. building program”, AC 4 419-447; 5 147-176.

L. Richardson (1992), A New Topographical Dictionary of Ancient Rome. Baltimore, 


\section{London.}

E. Rodriguez-Almeida (1981), Forma Vrbis Marmorea: aggiornamento generale 1980. Roma.

F. P. Rosati (1955), “Osservazioni sui tipi monetali romani raffiguranti monumenti di Roma", Rivista italiana di numismatica e scienze affini 57 70-83.

M. Royo (1999), Domus Imperatoriae. Topographie, formation et imaginaire des palais impériaux au Palatin (IIe s. av. J.-C. - fin Ier s. apr. J.-C.). Rome.

M. Royo (2001/4), "Le Palatin entre le IIe et le VIe siècle apr. J.-C.: évolution topographique", Revue archéologique 31 37-92.

E. de Ruggiero ed. (1895-1985), Dizionario epigrafico di Antichità Romane. 4 vol. Roma.

M. R. Salzman (1991), On Roman Time: The Codex-Calendar of 354 and the Rhythms of Urban Life in Late Antiquity. Berkeley.

R. Turcan (1985), Heliogabale et le sacre du soleil. Paris. 
(Página deixada propositadamente em branco) 


\title{
AMMAIA: TRANSFORMAÇÃO E MUDANÇA \\ NA PAISAGEM URBANA
}

\author{
SÉrgio PEREIRA \\ Arqueólogo / CIDEHUS
}

\section{Résumé}

La ville romaine de Ammaia marquerait de façon définitive le paysage de la région portugaise que nous connaissons aujourd'hui en tant que Alentejo Nord. Les fouilles arquéologiques commencées en 1995 nous ont permis de découvrir quelques morceaux du paysage urbain. Dès sa fondation jusqu'à son abandon, la ville s'est transformée et adaptée aux nouvelles éxigences publiques et privées. Aujourd'hui, nous pouvons contempler un enchevêtrement de structures, certaines presque effacées, d'autres conservées, d'autres encore superposées, nous difficultant la compréhension. L'analyse des structures et des respectifs contextes arquéologiques nous ont permis d'isoler certaines constructions ou édifices, nous faisant mieux comprendre la transformation et le changement du paysage urbain de Ammaia.

Keywords: Ammaia, Marvão, paysage urbain, période romaine, ville romaine.

Palavras-chave: Ammaia, civitas, Marvão, paisagem urbana, período romano, villa romana.

A expansão territorial desenvolvida pelos romanos na Península Ibérica teve na base o poder militar das legiões romanas, a inexistência de uma unidade indígena politicamente organizada e as próprias condições orográficas das regiões meridionais. Os romanos teriam atingido a região, hoje Norte Alentejo, por volta de 178 a. C. sob o comando de L. Postúmio Albino, embora a consolidação desse domínio só se efectivasse com Décimo Júnio Bruto, a partir de 138 a. C.

Após a pacificação da região ter-se-ia verificado uma fase de transição, em que alguns povoados indígenas foram romanizados, mantendo-se ocupados pelo menos até aos finais do século I a. C., como atestam alguns materiais recolhidos no Castelo dos Vidais, Corregedor e Água Formosa. A orografia e as reduzidas dimensões destes povoados ${ }^{1}$ comportavam uma demografia pouco significativa, inviabilizavam a sua transformação segundo os modelos de povoamento romanos, sendo mais viável a criação de um novo aglomerado, $\mathrm{Ammaia}^{2}$. É provável que a sua fundação se relacione com a reforma políticoadministrativa de Augusto, desenvolvida a partir de 13 a. C., desempenhando

\footnotetext{
${ }^{1}$ Apesar das excelentes condições estratégico-defensivas que o sítio de Marvão encerra, segundo informação oral, cedida pela arqueóloga Cláudia Pereira, os trabalhos de acompanhamento arqueológico e as sondagens realizadas no âmbito da implantação de infraestruturas no Castelo de Marvão não revelaram vestígios arqueológicos anteriores ao período romano.

${ }^{2}$ A cidade romana de Ammaia localiza-se no vale da Aramenha, no lugar e freguesia de S. Salvador da Aramenha, concelho de Marvão, distrito de Portalegre.
} 
um papel fundamental no contexto da reorganização administrativa e da urbanização da Lusitania.

O aglomerado urbano tinha um significado de centro espiritual, sagrado e jurídico surgindo materializado no núcleo construído, traduzindo-se numa inovação na paisagem da região. O padrão de povoamento romano assentava numa base política, económica e administrativa, materializada não apenas nos aglomerados urbanos, mas também nos vici, nas villae e nos casais, alterando assim os conceitos de ocupação e exploração da paisagem.

A grande ara dedicada ao Génio do Ópido Constituído (J. Encarnação, IRCP: n. ${ }^{\circ}$ 604) poderia relacionar-se com a fundação do aglomerado amaiense. A expressão "oppidum constituti" tem sido interpretada no sentido de estabelecido e organizado politicamente, subentendendo a existência de um núcleo urbano. A mesma expressão pode também enquadrar-se com a atribuição do ius latii, concedido a diversos oppida ${ }^{3}$.

A escolha do sítio para implantação do aglomerado vai de encontro a uma fundação de raiz, preenchendo alguns requisitos enunciados por Vitrúvio (5.10), como a existência de recursos hídricos (rio Sever, ribeira dos Alvarrões e nascentes superficiais do Olheirão e Olhos de Água), a proximidade de um vale agrícola e o resguardo dos ventos. A proximidade de uma zona rica em minerais, como a Serra de S. Mamede, pode ter sido determinante (foto 1).

Tratando-se de uma fundação de raiz e o facto de o sítio apresentar uma topografia regular leva-nos a admitir a ortogonalidade da malha urbana, traçada a partir do cardo maximus (noroeste-sudeste) e do decumanus maximus (nordeste-sudoeste). Estes teriam sido os eixos estruturantes a partir dos quais se traçaram paralelamente as restantes ruas e respectivos quarteirões. O cardo maximus arrancava da Porta Sul, passava ao lado nordeste do forum e prolongar-se-ia até outra porta, a noroeste. O decumanus maximus passaria ou à frente ou a meio do forum, neste caso através de uma porta lateral. Até ao momento foram identificados dois decumani secundários, o primeiro a sudeste da estrutura E.19 (Estacionamento 2) e o segundo entre as estruturas Q.14 e Q.44 (edifício Quinta do Deão). O alinhamento de quase todas estruturas ${ }^{4}$, segundo os eixos principais ou secundários, vai confirmando o traçado ortogonal (anexo I; foto 1).

A observação da fotografia aérea permite reconhecer o traçado da muralha, ligeiramente rectangular e arredondado nos ângulos, tal como se reconhece no canto este. Encontrando-se os limites da muralha nordeste e sudeste definidos com precisão, a área urbana intramuros parece-nos menor em relação às propostas de alguns investigadores ${ }^{5}$, aproximando-se dos 16 ou 17 hectares. A muralha teria como largura regular $1,20 \mathrm{~m}$ e a sua construção em opus incertum denota bom aparelho, utilizando quase exclusivamente o granito,

\footnotetext{
${ }^{3}$ J. Encarnação (IRCP: n. ${ }^{\circ}$ 604); A. Guerra 1996 22-23; V. Mantas 2000 411-412.

${ }^{4}$ Para já, a única estrutura que apresenta um alinhamento diferente dos cardines, decumani e das próprias construções é P.6 (Porta Sul), que surgiu no período visigótico.

${ }^{5}$ Para Vasco Mantas 2000413 a área da cidade não seria “inferior a 20 hectares", enquanto Joaquim Carvalho, segundo informação oral, considera aproximar-se dos 25 hectares.
} 
com excepção do alicerce onde predomina o calhau rolado. O perímetro da muralha aproximar-se-ia dos $1600 \mathrm{~m}$, podendo a sua edificação prolongar-se por vários imperadores. Na área do edifício do Deão e dos Estacionamentos, a sua construção parece remontar a Cláudio I ou aos primeiros Flávios. O carácter honorífico e simbólico da muralha reúne consenso, até porque a vulnerabilidade do sítio e o momento da edificação não justificariam um investimento defensivo.

Nos Estacionamentos, a presença de uma vala de perfil em $\mathrm{V}$, que acompanha a muralha, parece conter em simultâneo a função de fosso e de cloaca. A cronologia da vala e da muralha parecem contemporâneas, no entanto, podemos considerar que a abertura do fosso, mais simbólico e delimitativo que estratégico, tenha surgido na fase de implantação, sendo posteriormente adaptado a cloaca, ao mesmo tempo que surgia a muralha (foto 4).

As estruturas mais antigas identificadas na área da Porta Sul apontam para a existência de uma entrada original, constituída por duas torres semicirculares e um arco ou porta, tal como propunha Vitrúvio. Talvez os silhares erodidos, que se observam na face externa do alicerce da torre este, pertençam a essa primeira estrutura. Na mesma área, os vestígios das construções ${ }^{6}$ particulares da fase de implantação observam-se a sudoeste do cardo maximus. Os muros apresentam bom aparelho, não ultrapassam os $50 \mathrm{~cm}$ de largura e deveriam pertencer a uma habitação, em que a fachada (P.11) estaria virada para o cardo, ligeiramente mais largo nesse momento. Do outro lado da rua, na área conhecida por peristylum existia também uma construção, de cariz doméstico, à qual associamos as estruturas (Pr.10, Pr.12 e Pr.13) e uma conduta de água, apesar de os limites não estarem definidos (anexo II).

O próprio forum pode ter surgido no final do governo de Augusto, pouco depois da constituição do oppidum. É certo que em 44-45 d. C., governando o imperador Cláudio I, Ammaia já possuía magistrados ou duumviri, o que de certa forma testemunha a necessidade e a existência de um centro da vida política, económica, social e religiosa, o forum. A largura do edifício era de 66 $\mathrm{m}$. Considerando que a sua construção seguiu a regra vitruviana,é aceitável que o comprimento ${ }^{7}$ fosse de $99 \mathrm{~m}$. A ladear o templo e a praça do forum existiria uma colunata, assente na estrutura F.9, e talvez uma linha de tabernae, entre as paredes F.1 e F.2. O templo, provavelmente tetrastilo, apresenta cerca de 17,3 $\mathrm{m}$ de comprimento por 9,50 $\mathrm{m}$ de largura, restando apenas o seu enchimento de opus incertum. O espaço da cella é o que se apresenta mais destruído, detendo cerca de 9,50 m de comprimento ${ }^{8}$. Desconhecendo a arquitectura e as respectivas dimensões da basilica e da curia, a sua localização não andaria

${ }^{6} \mathrm{Na}$ Porta Sul as primeiras estruturas parecem ser P.1b, P.2b, P.11, P.12, P.13, P.14, P.15, P.25 e P.32.

${ }^{7}$ V. Mantas 2000414 propõe que o forum tivesse $99 \mathrm{~m}$ de comprimento. Outra hipótese considera que a fachada do edifício passaria pela estrutura F.11, reduzindo o seu comprimento até aos $88 \mathrm{~m}$, aproximadamente.

${ }^{8}$ J. Oliveira 1996 17-18; J. Oliveira 1999 132; V. Mantas 2000414. 
longe do topo sudeste do forum, junto à entrada. Pela posição que ocupa parece-nos que a estrutura F.10 pertenceria a um desses edifícios (anexo IIIa). A construção da actual Estrada Nacional n. ${ }^{\circ}$ 359, por alturas de 1874, dividiu a cidade em duas partes, sendo a obra responsável pelo maior impacto verificado nas ruínas e que afectou as fachadas do forum e das termas. A escavação de uma área restrita no edifício balnear levou à identificação de um pequeno tanque, que poderia funcionar como frigidarium, e uma natatio, parcialmente escavada. Foi ainda identificado um pequeno compartimento, talvez um vestíbulo, e uma área porticada, possivelmente a palestra. As termas teriam sido edificadas no período dos Júlios-Cláudios, conjuntamente com as primeiras edificações públicas da cidade, dada a sua posição central e a importância que detinham na sociedade e higiene romanas (anexo IIIb).

$\mathrm{Na}$ área do actual edifício da Quinta do Deão surgiram também, em meados do século I d. C., algumas construções domésticas. As estruturas caracterizam-se pela utilização regular do xisto e granito, não ultrapassam os $49 \mathrm{~cm}$ de largura e denotam um bom aparelho. A existência de uma soleira de granito a meio da estrutura Q.14 talvez se relacione com uma taberna ou oficina, voltada para o decumanus secundário, a sudeste. Pouco podemos adiantar em relação a esta construção de forma quadrangular e de pequenas dimensões. $\mathrm{O}$ facto de a habitação surgir adossada à muralha relega-a para uma cronologia ligeiramente posterior, entre o imperado de Cláudio e o início da governação dos Flávios. A sudeste do decumanus poderia existir outra construção de características idênticas, passando a fachada por Q.17 ou por Q.44. Esta construção que se prolonga para sudeste torna-se mais difícil de reconstituir, face às sucessivas sobreposições de estruturas (anexo IV).

Ammaia surgia assim como núcleo urbano, centro político-administrativo, à volta do qual se estendia um vasto território e no qual certamente existiam vici, villae, casais e pequenos sítios. Esta teia de unidades de exploração agro-pecuárias e minerais implicava a existência de uma extensa rede viária, assente em quatro ou cinco vias principais que irradiavam da cidade e que se interligavam por caminhos secundários.

A riqueza mineral da região poderia constituir a base da economia de Ammaia e um dos motores da transformação da paisagem urbana e rural. Lembramos que Plínio9, em duas ocasiões, referiu o aparecimento de cristal de rocha nos "ammaeensibus iugis" e destacou o ouro aluvial do Tejo, conhecendo-se uma exploração no território da cidade. A existência de jazidas de ouro, prata, chumbo ${ }^{10}$, manganês, ferro e hematite, referenciadas na carta

\footnotetext{
${ }^{9}$ Plínio-o-Velho, Naturalis Historia, 37.24 e 37.127: refere em duas ocasiões o aparecimento de cristal de rocha nos Ammaeensibus iugis, que deveriam corresponder às elevações mais próximas da cidade. Plínio 4.115 informa que o rio Tejo era famoso pelas suas areias auríferas: “Tagus auriferis harenis celebrantur". Segundo informação de Joaquim Carvalho, junto ao rio Tejo no sítio do Conhal (Nisa), confirmam-se os vestígios de exploração de ouro aluvial, na época romana.

${ }^{10}$ A propósito da extracção de chumbo, ou da simples utilização, Laranjo Coelho (1924 27) refere que na escavação dos alicerces de uma casa, no lugar do Porto da Espada, se encontraram muitas cantarias e "várias barras de chumbo".
} 
geológica e nos registos mineiros do século XIX (M. Pestana 1992 e 1998), confirmam também a riqueza mineral da região. Também as prospecções recentes, levadas a cabo na área do concelho de Marvão, revelaram algumas áreas de extracção mineral ${ }^{11}$. Não esqueçamos que a cidade se localiza nas proximidades de uma faixa de calcários dolomíticos, constituindo a produção de cal $^{12}$ uma actividade essencial para as principais obras na cidade e na própria região.

As diferentes actividades teriam impulsionado o desenvolvimento e a transformação do núcleo urbano. Dos primeiros edifícios ao abandono da cidade, muitas foram as mudanças ocorridas tanto no domínio público, como privado. A paisagem urbana deve ser entendida como um todo em constante mutação e adaptação e as fases ou momentos de construção que indicamos resultam de uma primeira leitura, que se afigura prematura face à reduzida área escavada. Algumas fases de edificação mais abrangentes poderiam resultar de acontecimentos políticos, militares ou económicos, contrastando com casos isolados ou privados. Convém lembrar que as remodelações domésticas seriam mais frequentes, resultando de factores como o casamento, a herança, a venda, a falência ou mesmo o enriquecimento.

Não se conhecendo com exactidão os motivos que originaram a ascensão do oppidum a civitas, é certo que até 44 ou 45 d. C. Ammaia foi promovida, como demonstra o pequeno cipo dedicado ao imperador Cláudio I (L. Vasconcelos 1935). A cidade continuou o seu percurso ascendente e no mesmo século foi distinguida com o estatuto de municipium. O pedestal dedicado ao imperador Lúcio Vero (E. Hubner, CIL II 158) pelos municip(es) Ammai(enses), data de 166 d. C. e apenas comprova que Ammaia detinha a municipalidade nessa data ${ }^{13}$. É consensual que a atribuição municipal tenha surgido com os Flávios, encerrando um papel mais honorífico e político que administrativo e gerando importantes transformações urbanísticas, à semelhança do que aconteceu noutras cidades peninsulares.

O período dos Flávios pode ter sido uma das fases económicas mais prósperas da cidade, reconhecendo-se um volume significativo de materiais importados. A remodelação da Porta Sul parece ter ocorrido entre o final da governação dos Flávios e Trajano, talvez relacionada com a alteração de

${ }^{11}$ J. Oliveira, S. Pereira, J. Parreira (2007) na Nova Carta Arqueológica do Concelho de Marvão indicam alguns sítios com indícios evidentes de actividades extractivas e de fundição: Serra Fria (n. ${ }^{\circ}$ 97: ferro); Currais de Ferro I (n. ${ }^{\circ} 121$ : ferro); Pitaranha (n. ${ }^{\circ}$ 149: cristal de rocha e granito); Monte Roxo II ou Tapada do Ferro (n. ${ }^{\circ}$ 53: ferro); Ferrarias (topónimo vulgar nas imediações de Marvão); Gavião II (n. ${ }^{\circ}$ 137: escória, fundição); villa da Tapada da Eira (n. ${ }^{\circ} 131$ : escória, fundição); casal das Naves (n. ${ }^{\circ} 130$ : cristal de rocha, escória, fundição); Cova da Moura I (n. ${ }^{\circ}$ 123: calcário, forno de cal romano).

${ }^{12}$ É bem provável que o forno localizado ao lado da Cova da Moura (S. Salvador da Aramenha) remonte ao período romano e que a exploração da gruta se relacione com a cal de melhor qualidade.

${ }^{13} \mathrm{O}$ momento da atribuição municipal reparte-se entre o final do principado de Cláudio I e o período dos Flávios, nomeadamente por acção do édito de Vespasiano, datado de 74 d.C. (A. Guerra 1996 28-29). 
estatuto e a monumentalização de alguns espaços públicos (J. Oliveira 1996 20-21). Surgiram duas torres circulares, apoiadas lateralmente pela muralha, que ao mesmo tempo servia de contraforte. Entre as torres conservaram-se os elementos de granito pertencentes à soleira da porta. $\mathrm{O}$ "arco ou porta da Aramenha" deveria situar-se entre as duas torres, sendo reutilizado na vila de Castelo de Vide em 1710. Das torres arrancavam duas imponentes paredes construídas em opus mixtum (P.3 e P.4), ladeando o cardo maximus. As duas estruturas sustentariam uma abóbada que se prolongaria até um segundo arco, implantado no limite dos lajeados, criando assim uma entrada coberta (foto 2).

Após as torres passou a existir uma praça lajeada, dividida em duas partes simétricas pelo cardo. Cada parte media $21,30 \mathrm{~m}$ de comprimento, por 10,75 $\mathrm{m}$ de largura, sendo constituída por lajes quadrangulares ${ }^{14}$. O lajeado este conservou-se praticamente intacto e a inexistência de seis lajes justificarse-ia pela presença de um pequeno podium. O lajeado oposto foi destruído parcialmente e algumas lajes sofreram um abatimento, devido à cedência do subsolo. O limite de ambos os lajeados seria marcado pela colocação de silhares mais pequenos.

Verificámos que a praça oeste foi edificada sobre estruturas habitacionais datadas da fase de implantação. A monumentalização da entrada da cidade implicou a demolição parcial de um edifício e da fachada, recuando até à estrutura P.21. Ainda não foi possível escavar a área total deste edifício que se prolonga para sul; assim, pouco podemos acrescentar em relação às alterações privadas, levadas a cabo no final do século I d. C. ou inícios do século II. O espaço entre o lajeado oeste, a estrutura P.21 e a torre teria ficado vazio ou eventualmente porticado, se considerarmos que as lajes com molduras quadrangulares, posicionadas no canto sul e na quadrícula 2533 , funcionariam como bases de assentamento de colunas (anexo II).

A nordeste da praça, na área conhecida por peristylum, teriam acontecido mudanças significativas. Segundo a proposta de Vasco Mantas (2000 414), é provável que tenha existido aqui um macellum. A construção de um grande edifício, limitado pelas estruturas Pr.1, Pr.4 (adossada à muralha), P.5 e Pr.5, e ladeado por cellae regulares (C.1, C.2 e C.3) aproxima-se de outros mercados já escavados na Hispania (foto 3), nomeadamente o de Baelo Claudia.

$\mathrm{Na}$ área do edifício da Quinta do Deão, podemos remeter para o período dos Flávios - Trajano a construção das estruturas Q.54 e Q.56, pertencentes a uma domus que se prolonga para sudeste, desconhecendo-se os respectivos contornos. Talvez estejam relacionadas com esta construção as estruturas E.19, E.20 e E.21, adossadas à muralha (M.1b). A pequena conduta de xisto (Q.62) pode também reportar-se ao mesmo período. Ainda nesta fase, mas na área extramuros (Estacionamento 1), teria surgido uma construção de que apenas conhecemos três muros. Não foi possível reconhecer a sua função, porém podemos considerar a presença de uma oficina, face ao elevado de número de escórias recolhidas nas quadrículas contíguas. Um pouco a sudeste

${ }^{14}$ J.Oliveira 1999133 refere que as lajes dos lajeados apresentando uma forma quadrangular não possuem medidas exactas, variando entre os 90 e os $110 \mathrm{~cm}$ de lado. 
teria surgido a estrutura E.13, delimitativa de uma área funerária ou necrópole, que se estenderia até ao rio Sever. As próprias sepulturas 1 e 2 parecem datar do período Flávio a meados do século II. Também a construção do mausoléu, em forma de templo, pode datar do século II. O investimento num edifício fúnebre imponente e de dimensões consideráveis faria sentido se pertencesse a uma família de notáveis, quem sabe se relacionado com a primeira sepultura.

No século II d. C., a cidade mantinha a mesma vitalidade e prosperidade que caracterizou a segunda metade do século anterior. As terrae sigillatae hispânicas secundarizaram as produções itálicas e sudgálicas, destacando-se ainda os vidros importados, abundantes em contextos domésticos.

Confirma-se a existência de um teatro no local conhecido por "Picadeiro", não longe do ângulo oeste da cidade. Observa-se no sopé da encosta um recorte intencional e semicircular, que aproveitou a orografia do terreno para implantação da cavea. Quanto à arquitectura do espaço lúdico pouco podemos adiantar, uma vez que no local só foram efectuadas prospecções geofísicas ${ }^{15}$, indiciando a presença de estruturas na orquestra e scaena. A ausência de vestígios materiais da cavea poderia justificar-se pela existência de uma construção de madeira ou pela reutilização dos silhares. A possibilidade de existirem outros edifícios de espectáculos, anfiteatro e circo, é menos provável, apesar de algumas anomalias observáveis na fotografia aérea levantarem suspeitas.

Em Ammaia, para a primeira metade do século III reconhece-se um vazio de informação, motivado pela dificuldade em reconhecer vestígios materiais exclusivos desse período. Na própria numismática amaiense não se reconhecem muitos espécimes representativos deste período.

No último quartel do século III ou inícios do século IV teriam ocorrido transformações na área envolvente ao lajeado e torre oeste (Porta Sul), verificando-se a demolição de uma construção, à qual pertencia a estrutura P.21. O novo edifício e respectivas estruturas sobrepõem-se e reutilizam o espaço desocupado entre a praça oeste e a torre. Neste local surgiram duas tabernae (C.19 e C.11). As estruturas de aparelho menos cuidado são mais largas, sobressaindo o emprego de silhares nos ângulos e no cruzamento de estruturas. A ocupação ou usurpação de espaços anteriormente públicos tornase evidente.

$\mathrm{Na}$ área do pátio do actual edifício do Deão aconteciam algumas alterações, surgindo a estrutura Q.8, embora interligada às primeiras construções. Este muro seria ainda reutilizado na fase seguinte. No canto este do pátio observase o alicerce de um pequeno anexo (Q.15 e Q.16), que ocupava uma parte do decumanus. Na Sala 5 e 6 emerge uma nova construção limitada por Q.27,

${ }^{15}$ As prospecções geofísicas na área do provável teatro tiveram lugar em 2004 e foram desenvolvidas pela Universidade de Gent (Bélgica). Igualmente realizaram-se prospecções na área onde se prevê a existência de um anfiteatro, um pouco a nordeste do primeiro espaço. 
Q.29 e Q.52, igualmente a usurpar a rua. As construções desta fase denotam um bom aparelho e consistência.

Os resultados das primeiras escavações referem que "a cidade foi obrigada a reforçar a sua fortificação, o que poderá ter ocorrido durante o século IV" (Oliveira 1996 20-22). Não refutando para já este cenário, também não o podemos corroborar, dado que não registámos indícios relacionáveis com um eventual reforço defensivo. A avaliar pelo volume de materiais importados, como terrae sigillatae hispânicas e africanas ${ }^{16}$, vidros e objectos de adorno de pasta vítrea, característicos do século IV - meados do século V, a cidade aparenta manter alguma prosperidade.

Sob o actual edifício do Deão verificaram-se importantes alterações, ditadas pela desmontagem das primeiras estruturas. Estas deram lugar a novas construções mais robustas, melhor alicerçadas e encostadas à muralha, mantendo no entanto a reduzida dimensão. Perante a arquitectura das construções, os elementos materiais e a posição que ocupavam na cidade parecem ser de famílias modestas, com algum poder económico, o que lhes permitia adquirir produtos importados (sigillatae, vidros e objectos de adorno de pasta vítrea). Aliás, a identificação de várias lareiras numa área restrita, leva-nos a considerar a existência de várias culinae e de várias famílias numa área restrita.

A realidade seria bem diferente do outro lado do cardo secundário, na área que designámos por sanitários. Os vestígios de duas passagens de ar quente, sob as estruturas Q.37 e Q.38, indiciam a existência de pavimentos aquecidos e de umas termas privadas. É ainda provável que o compartimento Cq9.2 tivesse funcionado como praefurnium.

Os primeiros contingentes godos (Suevos, Alanos, Vândalos Asdingos e Vândalos Silingos) chegaram à Hispania em 406, gerando alguma instabilidade e transformação nas cidades hispânicas. Desmistificada a ideia de "invasões bárbaras" e de destruição massiva, a vinda de novas populações teria causado maiores danos na esfera político-administrativa, social e económica, do que na estrutura urbana. As elites hispano-romanas viam assim os seus cargos políticos e os próprios bens ameaçados, perante alguma instabilidade militar, pilhagens pontuais e o controlo de algumas cidades estratégicas (H. Catarino 2004).

Não se registando indícios de conflito militar em Ammaia, a presença de populações de origem goda assenta em escassos elementos materiais, destacando-se uma fivela de cinturão, um anel de bronze e com algumas dúvidas, dois colunelos de mármore ${ }^{17}$. As remodelações ocorridas entre o final

\footnotetext{
${ }^{16}$ Ao longo do século IV - inícios do século V a cidade recebe ainda grande quantidade de terra sigillata hispânica e de origem africana.

${ }^{17}$ Os materiais considerados visigóticos foram recolhidos nas escavações de 1995 a 1998 , desconhecendo-se o contexto arqueológico exacto. A fivela de cinturão de bronze apresenta-se decorada com círculos, marcados a punção e pintados a ouro (séc. V). Os colunelos de mármore foram recolhidos à entrada da torre este (Porta Sul). Afonso Paço (1953 111-112) refere também que na cidade foi recolhido um triente, cunhado sob Justino I (518-527).
} 
do século V e os inícios do século VI talvez se possam relacionar com a vinda de famílias bárbaras. Na Porta Sul surgem algumas alterações que evidenciam um cenário de abuso e usurpação dos espaços públicos, localizados junto às torres. A construção de estruturas anexas às torres criou uma espécie de átrio que, ao aproveitar o espaço vazio, poderia favorecer a presença de uma maior guarnição.

Na zona do pátio do edifício do Deão surge uma pequena construção adossada à muralha e relacionada com os edifícios anteriores. A identificação da lareira L.3 não deixa dúvidas quanto à função do compartimento Cq.9b, que passou a funcionar como cozinha. A deposição de um conjunto de cinquenta e um bronzes sob o pavimento desta divisão encerrava uma função apotropaica, numa fase em que o valor real das moedas seria reduzido. Ainda nesta fase e nas traseiras do actual museu, as termas baixo-imperiais e os pavimentos aquecidos teriam sido desmontados e adaptados a simples espaço habitacional.

A presença de algumas lucernas paleocristãs constitui uma prova de que o cristianismo já se encontrava enraizado na cidade no século IV. Apesar da inexistência de vestígios, podemos considerar no espaço urbano ou na área envolvente a presença de uma basílica paleocristã.

A partir do século VI começam a escassear os materiais importados, nomeadamente sigillatae e vidros. Nesta centúria a cidade pode ter mergulhado numa conjuntura desfavorável sem precedentes. A insegurança das rotas comerciais, a inflação e a crise financeira que apenas reconhecia a cunhagem do ouro, foram regionalizando a actividade produtiva e o próprio mercado. As elites hispano-romanas vão abandonando a cidade, fixando-se nos seus domínios rurais, cada vez mais feudais e auto-suficientes.

A segunda metade do século VI ficou marcada por um movimento de centralização do poder na monarquia visigoda, recebendo maior oposição por parte das elites eclesiásticas regionais, cada vez mais agarradas ao poder político, aos privilégios e ao património. As lutas pelo poder geraram algumas rebeliões, culminando numa espécie de guerra civil. Por seu turno, a monarquia visigótica implementou um conjunto de medidas centralizadoras que imitavam o poder político-administrativo romano do Baixo-império.

Entre a segunda metade do século VI e o século VIII a estrutura urbana amaiense registou ligeiras alterações no pátio e nas traseiras do actual museu. No pátio surge uma lareira de grandes dimensões (L.4) e a própria cozinha é alargada, através da desmontagem de Q.11 e da mudança da entrada para o canto oeste. A sudoeste, o compartimento Cq.6 passou a funcionar como alpendre. Ao lado, no compartimento Cq.1 reconhecemos outra lareira (L.5), de menores dimensões. Esta divisão funcionava em simultâneo como cozinha e espaço de armazenamento, perante a identificação de dois dolia ${ }^{18}$, in situ (d.1 e d.2), e o negativo de um terceiro (d.3).

Não dispondo para o forum de informações de âmbito cronológico, as escavações no canto oeste revelaram algumas estruturas tardias. Ali foi

${ }^{18}$ Em 2001, as escavações no pátio do edifício da Quinta do Deão revelaram dois dolia, um intacto e o outro fragmentado. O primeiro serviria para guardar azeite e o segundo fora ali 
construído um muro de pedra solta e duas colunas de tijolos, ligados por terra. Na quadrícula A-704 registou-se também uma estrutura que subdividia a cave da ala nordeste. Estas estruturas poderão reportar-se ao final do período visigótico ou islâmico, transparecendo a perda de funções do edifício e a sua reutilização com outro intuito.

O poder crescente das elites religiosas, ao longo do século VII, consolidouse em parte com a adopção do cristianismo como religião oficial visigótica, em 589. Não existindo documentos que refiram Ammaia como sede de bispado, certamente teria sido uma paróquia detentora de um corpo eclesiástico e de uma basílica cristã, talvez situada na zona limítrofe, onde se viria a implantar a aldeia de S. Salvador da Aramenha.

A extinção da cidade enquanto centro político-administrativo pode ter acontecido no século VII ou VIII, motivada por um conjunto de factores e não apenas por um acontecimento isolado ou cataclismo. Parece-nos que uma conjuntura desfavorável e continuada poderia afundar progressivamente a cidade, gerando difíceis condições de vida à população. Entre o final do século VI e meados do século VIII verifica-se uma proliferação de casais e pequenas aldeias a norte da crista quartzítica de Marvão. É provável que este processo de ruralização e o novo padrão de povoamento Alto Medieval tenha culminado no esvaziamento progressivo da cidade. Estaria em causa a própria sobrevivência dos mais desfavorecidos, ou seja o grosso da população.

As constantes lutas pelo poder entre as elites religiosas e a nobreza visigótica, longe de satisfazerem as necessidades civis, acabariam por beneficiar a implantação do invasor muçulmano a partir de 711. É possível que pela cidade tenha passado uma milícia islâmica no primeiro quartel do século VIII. Estudos recentes ${ }^{19}$ apontam no sentido de a cidade se manter ocupada nos primeiros séculos do período islâmico. Algumas cerâmicas recolhidas na área do Estacionamento 2 e na área da Porta Sul sugerem cronologias dos séculos VIII-IX, reforçando a ideia de continuidade. Algumas construções mais tardias podem ter sido edificadas no período islâmico e neste contexto apontamos estruturas na entrada da cidade (P.7, P.10, P.34, P.26 e P.31), no edifício do Deão (Q.13) e no Estacionamento 2 (E.19).

Na gruta da Cova da Moura, situada nas imediações da cidade, foram recolhidos alguns fragmentos de caçoilas e pequenos potes, datáveis do século $\mathrm{X}-\mathrm{XI}$. Estes vestígios comprovam que ainda se exploravam alguns recursos minerais. Aliás, a alusão de Al-Himyari ao cristal de rocha, quarenta milhas a norte de Badajoz pode relacionar-se com Ammaia e com a extracção daquele mineral semiprecioso (A. Guerra 1996 12). Uma questão ainda em aberto prende-se com a decadência, a queda e a transformação da cidade num campo de ruínas. A perda de estatuto e função teria ocorrido entre o século VII e VIII, acarretando consequências profundas no tecido social e alterações na paisagem urbana e mesmo rural. A memória popular justifica o desaparecimento da

reutilizado, depois de reparado com gatos de chumbo.

${ }^{19}$ J. De Meulemeester, J. Dewwulf, M. Grangé (2003), Rapport de Terrain provisoire conçu à Marvão. Universidade de Gent - Fundação Cidade de Ammaia. Julho-Agosto (não publicado). 
cidade com algumas lendas que referem um terramoto, uma inundação e uma catástrofe que a engoliu de terra (J. Oliveira 1998 e 1999).

As primeiras escavações na Porta Sul revelaram que "entre os séculos VI e IX da nossa era a cidade de Ammaia, já em decadência, sofreu os efeitos de um cataclismo que ao soterrá-la a conservou" (J. Oliveira 1999 130). Parece-nos que uma inundação apenas afectaria a área mais baixa da cidade, topograficamente, não constituindo motivo de abandono da urbe. As escavações que orientámos, nas áreas mais baixas da cidade, não forneceram vestígios de catástrofe. Em nossa opinião o abandono teria sido gradual e não precipitado, concordando com Vasco Mantas (2000 417), que concebe a cidade "como tantas outras, decaindo progressivamente até se transformar num campo de ruínas com uma população residual".

O declínio das principais actividades económicas teria convergido numa conjuntura desfavorável, onde a secundarização, a desagregação do poder municipal e a inércia administrativa foram afluindo num processo irreversível. Outro sinal da perda de influência reconhece-se no facto de a cidade não ter sido sede episcopal, numa época em que o poder religioso emerge como força política e social.

O século IX ficou popular pelas inúmeras revoltas levadas a cabo por alguns rebeldes, como Xurumbaqui e Ibn Maruán. Por volta de 875, depois do saque da região entre Coimbra e Santarém, Ibn Maruán teria seguido para o Alto Alentejo e Beira Baixa, até à cidade de Asitanya (H. Catarino 2004 279-282). Num período de instabilidade político-militar, a cidade tornava-se vulnerável, perigosa e sujeita a pilhagens esporádicas. $\mathrm{O}$ aparecimento do hisn de Marvão e talvez do de Vide ${ }^{20}$ teria implicado a desvitalização e abandono de Ammaia, sendo mais fácil construir uma fortificação de raiz em local estratégico, que recuperar ou fortificar a cidade. Aliás, a edificação de uma fortaleza na crista quartzítica de Marvão ou no cume de Castelo de Vide só se justifica num cenário de instabilidade político-militar. Não esqueçamos que a cidade foi edificada num sítio vulnerável, tornando-se num alvo fácil.

A degradação, a falta de manutenção e o consequente desmoronamento de edifícios públicos e privados conferiam à cidade um cenário de degradação e abandono. A cidade, sem estruturas municipais capazes de recuperar, ia agudizando as já difíceis condições de vida das famílias mais persistentes. A emergência de dois novos centros político-militares islâmicos teria contribuído definitivamente para a morte de Ammaia.

O abandono efectivo da cidade teria ocorrido entre o século IX e os inícios do século XI, transformando irremediavelmente a paisagem urbana num campo de ruínas. A eventual presença de uma basílica paleocristã na zona limítrofe da cidade pode ter fixado alguns habitantes, nascendo ali ao lado uma pequena aldeia, hoje S. Salvador da Aramenha. Ao longo da muralha

${ }^{20}$ J. De Meulemeester, J. Dewwulf, M. Grangé, op.cit., p. 3: "En principe, ce découpage supposé pourrait remonter au X siècle, puisque un texte de Ibn Hawqal, mentionnerait Castelo de Vide comme hisn". 
nordeste surgia uma via externa e entulhava-se a cloaca-fosso, facilitando a circulação ao longo do vale da Aramenha.

A cidade pereceu, mas o sítio nunca deixou de ser ocupado e reutilizado. As ruínas funcionaram por mais de um milénio como pedreira, irradiando dali muitas pedras e elementos arquitectónicos para outros destinos. Em Marvão e nas suas aldeias, na vila de Castelo de Vide e mesmo na cidade de Portalegre foram reutilizadas cantarias romanas que deram vida a novas construções. No interior da cidade foram reutilizadas tardiamente algumas estruturas e construções, observando-se também algumas sobreposições. Recorde-se que o forum serviu de curral de ovicaprinos, a torre oeste foi reconstruída e o macellum modificado.

A reconstrução da torre Oeste teria ocorrido no período Moderno, surgindo talvez como contraforte do arco, ou como construção anexada. O aparelho original era de opus mixtum, mas a sua reconstrução foi efectuada em opus incertum, de má qualidade. A reedificação foi executada a partir da trave da porta, coincidente com o topo da unidade estratigráfica superficial ou nível de circulação agrícola. A reconstrução da torre só se observa na metade interna e o traçado romano não foi respeitado pela nova edificação, verificando-se um desvio para o interior da cidade. Parece-nos que a reconstrução tinha outra função e no momento da reedificação a parte romana estaria parcialmente soterrada, o que justificaria o desvio.

Também na área do provável macellum teria surgido uma construção quadrangular, encimada por colunas, estas construídas à base de materiais romanos reutilizados. Reconhecemos a semelhança entre as estruturas e um peristylum, porém preferimos interpretar esta construção como sendo o suporte de uma latada, cujas semelhanças reconhecemos em estruturas de propriedades agrícolas da região. Convém não esquecer que as próprias estruturas Pr.3, Pr.8 e Pr.21 foram edificadas na actualidade, para apoio da actividade agrícola.

No século XVI, os humanistas Amador Arrais e André de Resende ainda observaram "em todo o valle \& várzea de Aremenha muytas torres \& pontes sobre o Rio Sever, lastros \& solhos de casas nobres bem ladrilhados, \& lageados, \& hum cano de agoa doce, que de hũa fonte corria pela cidade, muros derribados..." (A. Arrais 1589 241-242).

Lentamente, a paisagem urbana foi-se desmontando. As ruínas transformaram-se em pedreira e mais tarde em campo agrícola. As pedras e as cantarias da antiga cidade romana favoreceram a construção de novas casas ou aldeias, contribuindo para a transformação da paisagem, hoje, marcadamente rural. 


\section{Anexos}

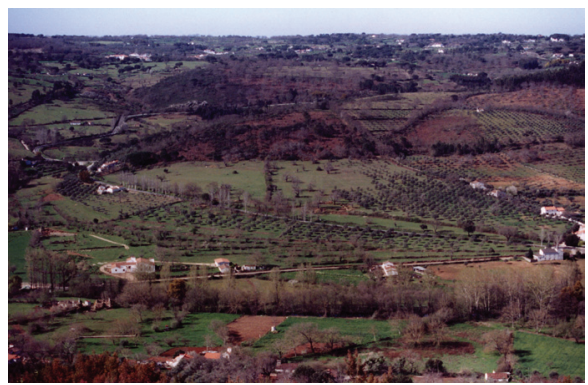

Foto 1: Vista geral de Ammaia, implantada no Vale da Aramenha

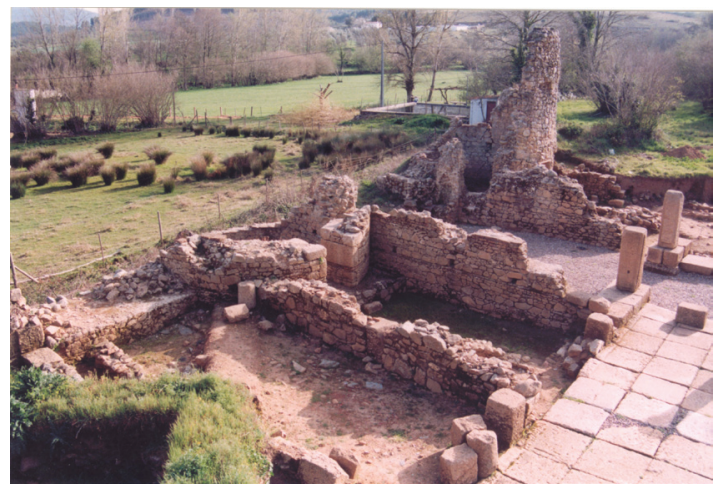

Foto 2: Porta Sul (torre e praça este, cardo maximus e torre oeste)

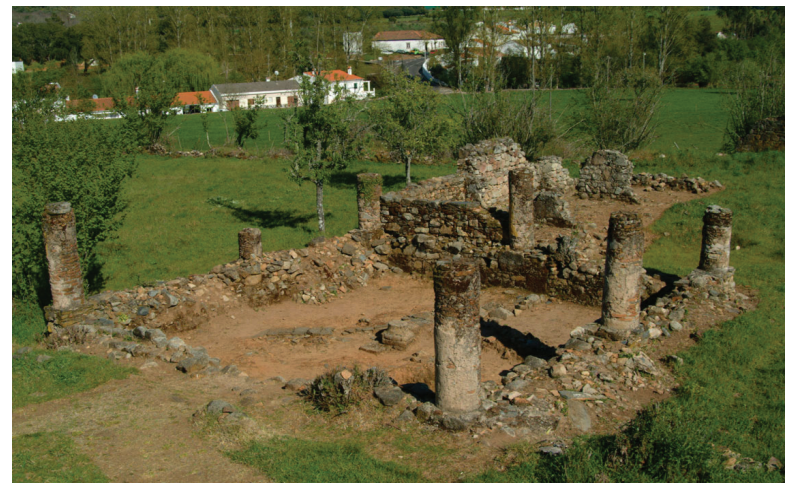

Foto 3: Peristilo ou latada, implantado sobre o provável macellum 


\section{Sérgio Pereira}

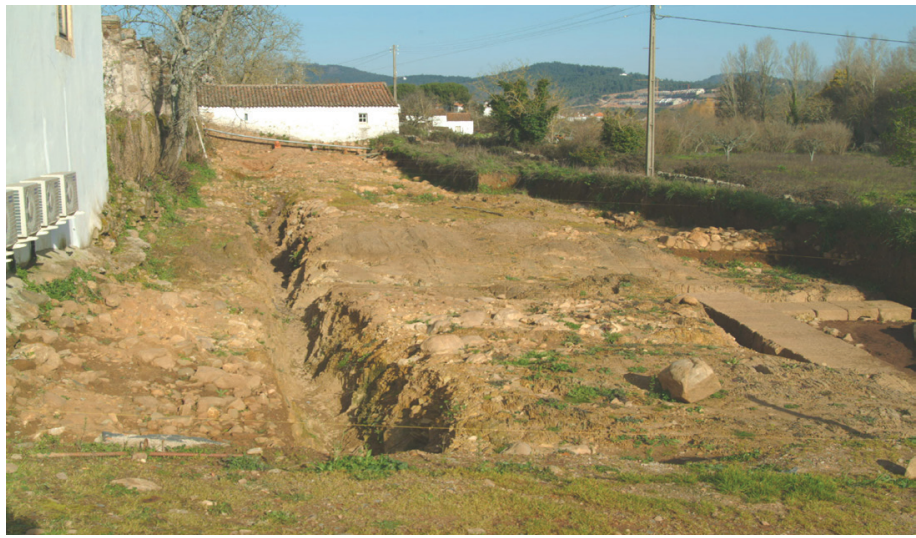

Foto 4: Estacionamento 1 - cloaca-fosso paralela ao museu e à muralha; à direita observa-se parte de um mausoléu

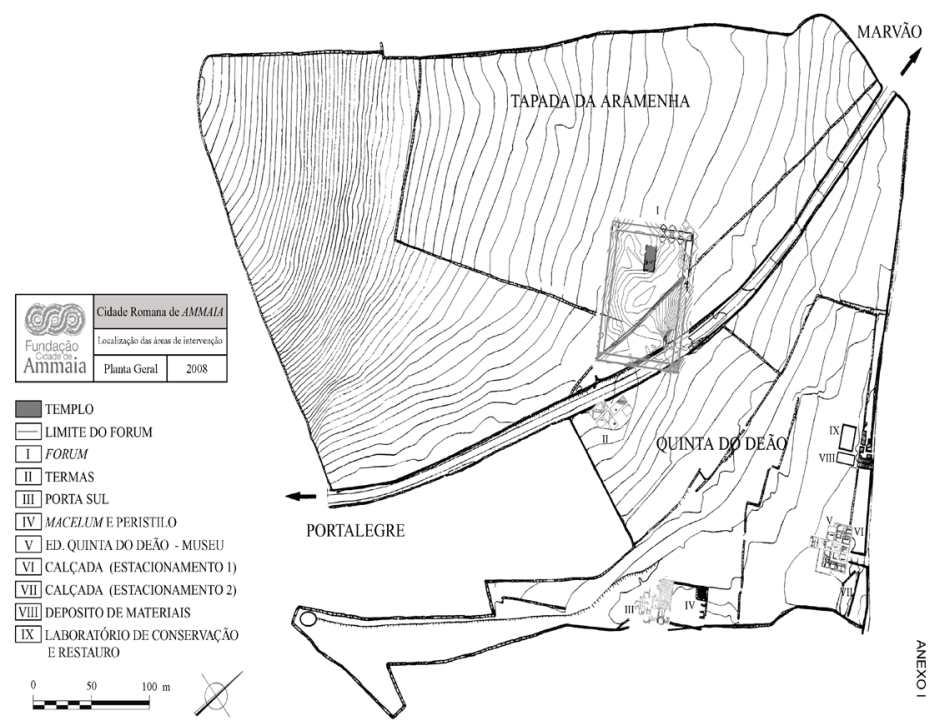

Fig.1. Área da cidade de Ammaia 


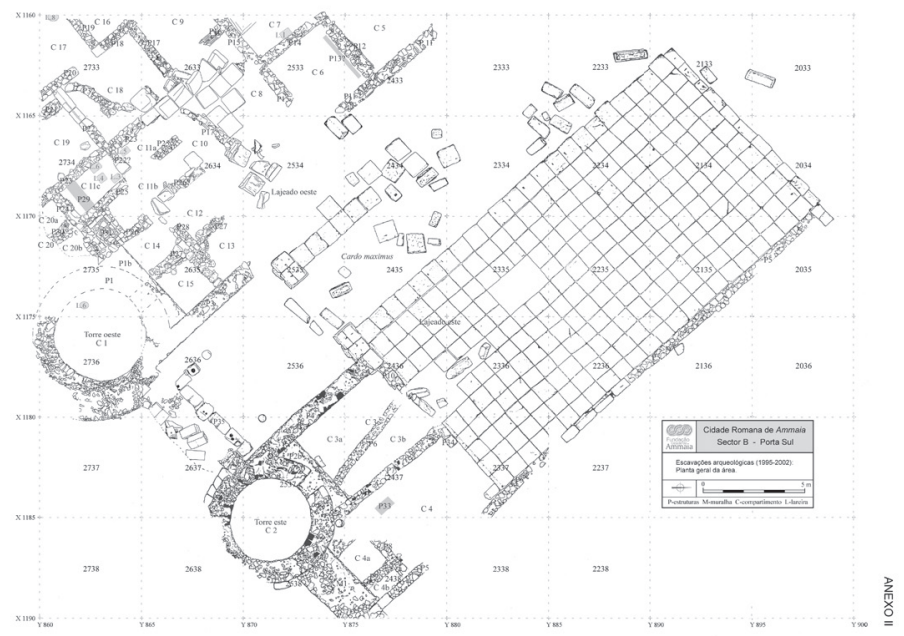

Fig.2. Porta Sul

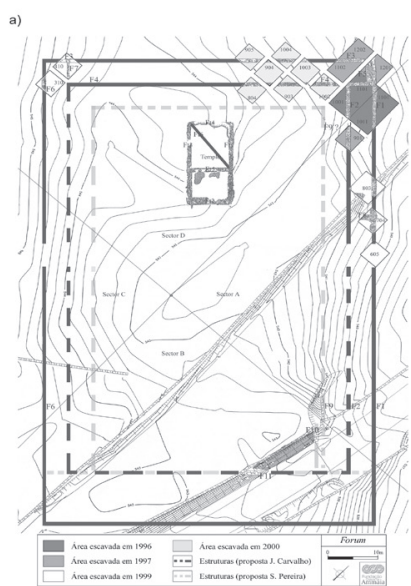

ANEXO III

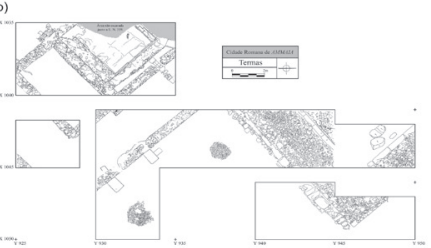

Fig.3. Forum (Mantas 2000) e termas (Relatório de Progresso 2002) 


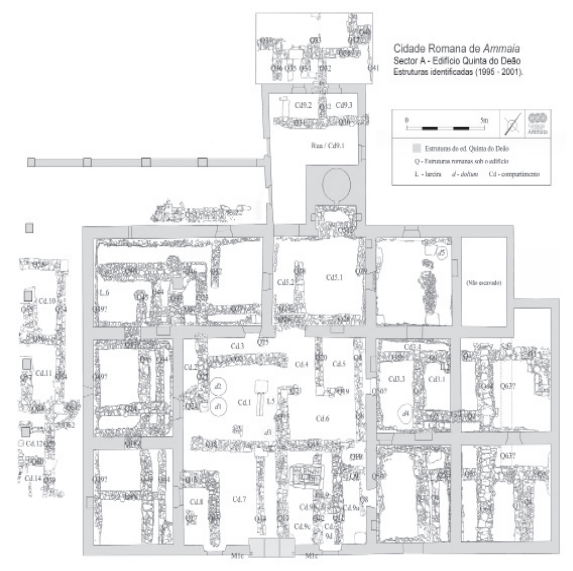

Fig.4. Edifício Quinta do Deão - actual museu

\section{Bibliografia}

Helena Catarino (2004), "A ocupação Islâmica”, in João Medina, dir., História de Portugal. Madrid, Ediclube, $3^{\circ}$ Vol., 279-282.

José d' Encarnação (1987), "A população romana do nordeste alentejano", in Actas das I Jornadas de Arqueologia do Nordeste Alentejano (1985), Castelo de Vide, 167-170.

Amílcar Guerra (1995), Plínio-o-Velho e a Lusitânia. Lisboa, Colibri.

Amílcar Guerra (1996), "Ammaia, Medobriga e as ruínas de S. Salvador de Aramenha: dos antiquários à historiografia actual”, A Cidade, Revista Cultural de Portalegre 11 7-33.

E. Hubner (1869), Corpus Inscriptionum Latinarum (CIL). Berlim. Vol. II.

IRCP: José d' Encarnação (1984), Inscrições Romanas do Conventus Pacensis. Coimbra, Instituto de Arqueologia da Faculdade de Letras.

Vasco Gil Mantas (2000), "A sociedade luso-romana do município de Ammaia", in Sociedade y Cultura en Lusitania Romana. IV Mesa Redonda Internacional, Mérida, Série Estudios Portugueses, 13 391-420.

Jorge de Oliveira, Isabel C. Fernandes, J. Caeiro (1996), "Cidade romana de Ammaia", Ibn Maruan 6. Câmara Municipal de Marvão, Lisboa, Colibri, 15-22.

Jorge de Oliveira, Isabel C. Fernandes, José O. Caeiro (1999), "Cidade romana de Ammaia, S. Salvador de Aramenha, Marvão, Portugal", in Actas do II Congresso de Arqueologia Peninsular. Zamora, Fundação Rey Afonso, Universidade de Alcalá, 129-134.

Jorge de Oliveira, Sérgio Pereira, João Parreira (2007), "Nova Carta Arqueológica do Concelho de Marvão", Ibn Maruán 14. Câmara Municipal de Marvão, 
Lisboa, Colibri.

Afonso do Paço (1953), "Carta arqueológica do concelho de Marvão”, in Actas do XIII Congresso Luso-Espanhol para o Progresso das Ciências (1950), $7^{\text {a }}$ secção, Ciências Históricas e Filológicas. Lisboa, Associação para o Progresso das Ciências, 93-127.

Manuel Inácio Pestana (1992), "Novos registos mineiros na região de Portalegre no período fontista", Ibn Maruán 2. Câmara Municipal de Marvão, Lisboa, Colibri, 207-220.

Manuel Inácio Pestana (1998), "Novos registos mineiros na região de Portalegre”, Ibn Maruán 8. Câmara Municipal de Marvão, Lisboa, Colibri, 297-308. 
(Página deixada propositadamente em branco) 


\title{
A PULVERIZAÇÃO DA AMMAIA NA ALTA IDADE MÉDIA
}

\author{
JoRGE DE OLIVEIRA \\ SÉRgIo PEREIRA \\ CIDEHUS
}

\begin{abstract}
The Spraying of the Ammaia (Marvão) in the High-Middle-Ages
Arising from systematic archaeological surveys on wide area surrounding the Roman city of Ammaia and studies developed here was to understand how the space was anthropized after the end of empire. It is demonstrated in this communication emerged as dozens of small towns, more or less organized in the vicinity of the old city during the called High Middle Ages, while the central urban space was empty. It is evident so the process of spraying Ammaia Roman city, situated near Marvão and the emergence of multiple small towns, some of them developed and survived to the present.
\end{abstract}

Keywords: end of the Empire, High-Middle-Ages, Roman City of Ammaia, spraying.

Palavras-chave: Alta Idade Média, cidade romana de Ammaia, fim do Império, pulverização.

A cidade romana de Ammaia insere-se no contexto da romanização da região que hoje conhecemos como Norte Alentejo. O centro urbano ou oppidum parece ter surgido com a reforma administrativa de Augusto, desenvolvida a partir de 13 a. C., e que desempenhou um papel determinante no contexto da reorganização e urbanização da Hispania (Fig.1).

Surgindo como modelo de fixação, o novo centro urbano pretendia reunir e controlar as comunidades indígenas circundantes. A evolução política do aglomerado afigura-se célere, embora o mesmo processo se tenha verificado noutras cidades provinciais. Comprovada epigraficamente, a elevação do oppidum amaiense a civitas aconteceu antes de 44 ou $45 \mathrm{~d}$. C. e pouco depois, no período Flávio, recebeu nova atribuição, a de municipium. Os testemunhos materiais recolhidos em contexto arqueológico levam-nos a supor que a evolução política se relacione com uma conjuntura económica e administrativa propícia, consolidada no período Flávio, ou com a influência de algumas famílias de notáveis amaienses (figs. 2 e 3 ).

Até finais do século IV, ou inícios do século V, a cidade parece manter uma relativa prosperidade, acedendo a produtos importados e a rotas comerciais de longo curso. A partir da segunda metade do século $\mathrm{V}$ a cidade teria iniciado o seu percurso descendente, que a iria conduzir ao declínio e ao abandono. Os factores que levaram a cidade à decadência parecem dividir opiniões e 
investigadores, sendo certo que o esvaziamento da cidade gerou um novo padrão de povoamento rural e a consequente ruralização da paisagem.

Basta percorrer os campos, sobretudo da encosta norte de Marvão, para se descobrirem abundantes vestígios de habitats atribuíveis à Alta Idade Média. Localmente conhecidos por moreiras, mouratas, ou aldeias dos mouros, estes habitats localizam-se especialmente em vales apertados, por entre grandes afloramentos graníticos e normalmente envoltos por moitas de carvalhos. Constituem-se como testemunhos materiais destes povoados, para além de estruturas habitacionais rectangulares e muito raramente circulares, lagares formados por pias, pesos e apoios de varas, sepulturas escavadas na rocha, antropomórficas ou não, e, mais raramente, ruas calçadas. É nestes contextos que também ocorrem, mas em menor número, os vulgarmente denominados chafurdões. Todos estes testemunhos arqueológicos têm principal incidência na área do actual concelho de Marvão, reconhecendo-se também a sua existência na fachada ocidental do Termo Municipal de Valência de Alcântara, no concelho de Castelo de Vide e na parte norte do concelho de Portalegre, especialmente nas freguesias de Carreiras e Ribeira de Nisa. Estes arqueossítios parecem organizar-se, assim, em torno e na área de influência da cidade romana de Ammaia e terão emergido na sequência do colapso desta cidade. Parece, então, que com o fim da estrutura social e económica do império romano a cidade de Ammaia se pulveriza dando origem a dezenas, se não mesmo centenas de pequenos habitats dispersos pelos vales encaixados e de difícil acesso da Serra de S. Mamede e seus contrafortes (figs. 4 e 5).

Desde os inícios do século XX, com Possidónio Laranjo Coelho e sobretudo em meados do mesmo século, com os trabalhos de Afonso do Paço, que estes vestígios no concelho de Marvão vinham sendo referenciados. A única escavação efectuada e publicada nestes povoados foi promovida por Afonso do Paço no habitat do Monte Velho, situado na freguesia de Beirã.

Em 1948, por convite da Câmara Municipal de Marvão, Afonso do Paço promove escavações em vários locais do Monte Velho, onde identifica um lagar e escava uma habitação rectangular, formada por duas divisões (fig. 6). Numa dessas divisões situar-se-ia uma pequena forja, enquanto na outra, dentro de três grandes potes, guardavam-se sementes de milho painço. Estes testemunhos encontravam-se sob uma camada de fragmentos de imbrices muito irregulares e maioritariamente decorados com serpentiformes digitados ou estrelas pentalfa. Do estado de conservação destes testemunhos deduz Afonso do Paço que o habitat terá sido atacado e incendiado e não abandonado voluntariamente pelos seus habitantes. O seu escavador levanta a hipótese de esta destruição ter sido obra das primeiras vagas de gentes que do norte de África invadiram a Península a partir do século VIII. Tratar-seia, provavelmente, ainda segundo Afonso do Paço, e sobretudo com base na descoberta de uma telha com uma inscrição cristã, (H)IC PAX (H)IC $\mathrm{C}(\mathrm{H}) \mathrm{RIST}(\mathrm{VS})$, de uma comunidade visigótica (fig.7). Este investigador, ao comparar esta inscrição com outras identificadas na Península, posiciona-a entre o século VI e o VIII. Infelizmente, desconhece-se hoje o paradeiro da telha 
que comportava esta inscrição. Durante vários anos expôs-se num pequeno compartimento do Castelo de Marvão onde se guardavam, igualmente, outros materiais arqueológicos. Felizmente que, nos finais da década de cinquenta do século XX, o Sr. Manuel Peixeiro mandou transcrever para um bloco de granito a inscrição que se lia na telha do Monte Velho e aplicou-a na fachada da sua casa na Rua do Castelo, em Marvão, conservando-se como memória do documento original.

Se, na publicação de 1949 - Inscrição Cristã do Monte Velho -, Afonso do Paço não afirma peremptoriamente que estes povoados seriam visigóticos, em momentos posteriores, tanto no texto da comunicação apresentada ao XIII Congresso da Associação Portuguesa para o Progresso das Ciências, intitulado "Carta Arqueológica do Concelho de Marvão" e publicado em 1950, como na conferência que Afonso do Paço profere na Câmara Municipal de Marvão, por altura do lançamento da separata das actas desse congresso e relatada no jornal A Rabeca de 22 de Junho de 1953, o povoado do Monte Velho e todos os outros idênticos, conhecidos na região, pertenceriam a comunidades rurais visigóticas. Ainda segundo o mesmo investigador, a Ammaia teria sobrevivido até à presença visigótica, como já o testemunhavam, em meados do século $\mathrm{XX}$, vários materiais arqueológicos.

A aceitarmos o que o único investigador deste tipo de vestígios nos diz, a cidade não teria sobrevivido para além do século VI, embora à luz dos conhecimentos actuais, decorridos mais de dez anos sobre o início do estudo da Ammaia, reconheçamos indícios de que a cidade possa ter sobrevivido para além daquele século.

Ao analisarmos as causas que motivaram o declínio da cidade e o consequente abandono, é inevitável referir as primeiras escavações na entrada principal da cidade, que relacionaram com um cataclismo o depósito detrítico acumulado nalguns locais com mais de um metro de altura, sobre as praças lajeadas. Observando-se o posicionamento, direcção e desgaste dos elementos líticos do depósito detrítico, poderemos considerar que ele teria resultado de uma avalancha de lamas e água, talvez provocada pela ruptura de uma barragem situada em cota sobrelevada, a montante da Ponte da Madalena. A obtenção de água nesta zona para abastecimento da cidade está confirmada pela presença de uma canalização em granito, cuja trajectória ronda um quilómetro.

Outro cenário possível relaciona o abandono da cidade com um processo gradual iniciado na segunda metade do século $\mathrm{V}$. A instabilidade militar provocada pela vinda de populações bárbaras motivou importantes transformações na esfera política, económica e social. A desagregação do poder municipal foi-se agravando com as constantes lutas pelo poder, onde concorriam as elites hispano-romanas, visigóticas e religiosas. Para além da insegurança crescente nas rotas comerciais e da regionalização dos mercados, há que reconhecer na área de influência da Ammaia uma diferença substancial entre os primeiros séculos de existência e o século VI. A desorganização e a degradação do espaço urbano ter-se-iam agudizado, resultado da própria 
instabilidade político-social. É claro que a população em geral, mais desfavorecida e sem outras bases se sustentação económica, sentia, de forma mais intensa, a crise económica e política que fustigava a cidade e o próprio espaço do antigo império. As próprias elites da Ammaia vão-se refugiando nas villae, contribuindo para a ruralização e a feudalização da economia, onde a agricultura e a ganadaria teriam um papel fundamental. É neste contexto que reconhecemos a continuidade de algumas villae, que ocupavam os solos com melhores aptidões agrícolas. A conjuntura desfavorável verificada a partir do final do século V ter-se-ia arrastado para além do século VII. A vaga muçulmana teria acentuado o cenário de crise, sem sinais de recuperação. A emergência do isn de Marvão como local estratégico-militar e como novo centro de poder político teria efectivado a morte anunciada da cidade (fig. 4).

Em qualquer dos casos, o colapso da cidade provocou a pulverização da população urbana, emergindo diversos habitats na área envolvente da velha Ammaia. A estrutura económica que sustentava a cidade deixou de fazer sentido, denotando-se um regresso a uma economia de subsistência, muito semelhante à que se conhecia na região, antes da chegada das gentes de Roma (fig. 5).

Os povoados já anteriormente assinalados por Afonso do Paço, como o do Monte Velho, por ele parcialmente escavado, terão emergido na sequência da pulverização da Ammaia.

Decorrente dos trabalhos de prospecção efectuados por Afonso do Paço, durante 15 dias, entre 1946 e 1947 no concelho de Marvão, publicou este arqueólogo, em 1950, a Carta Arqueológica do Concelho de Marvão. Neste estudo o autor regista 25 sítios com vestígios atribuíveis ao "período visigótico" e 20 como romanos. Sessenta anos depois das prospecções efectuadas por Afonso do Paço, a Câmara Municipal de Marvão contrata a Área de Arqueologia da Universidade de Évora para realizar prospecções sistemáticas na área daquele concelho conducentes à actualização do levantamento efectuado em meados do século passado. Na sequência deste levantamento foi possível identificar 272 arqueossítios, entre os quais 84 atribuíveis à Alta Idade Média e 47 ao período romano. Assim, 30,8 \% dos sítios arqueológicos do concelho de Marvão são atribuíveis ao período compreendido entre o fim do império romano e a islamização, podendo prolongar-se até à Reconquista Cristã, enquanto que $17,2 \%$ dos testemunhos arqueológicos são romanos. Se somarmos o cômputo destes dois períodos, verificamos que correspondem a $48,16 \%$ do total de sítios arqueológicos na área do concelho, reflectindo a importância que a romanização teve nesta região, especialmente com o assentamento da Ammaia (ver gráficos). Da análise destes dados e sobretudo do seu posicionamento geográfico podemos retirar algumas ilações interessantes. Haverá que reconhecer que o número de sítios com testemunhos da Alta Idade Média quase que duplica em relação aos que considerámos com ocupação romana, evidenciando não um aumento populacional, mas sim a fragmentação da sociedade em pequenos habitats auto-sustentáveis, demonstração clara de 
como uma cidade, em clima de instabilidade política, não consegue sobreviver (figs. 4 e 5).

Se analisarmos a dispersão geográfica dos sítios romanos, verificamos que eles ocupam, preferencialmente, zonas de solos com grande aptidão agrícola, observando-se a sua maior concentração no longo vale fértil que se estende desde o Porto da Espada até ao Prado de Castelo de Vide. Igualmente, as terras com melhor aptidão agrícola na zona norte do concelho, directamente drenadas pelo Sever, como a zona dos Pombais, Vale do Cano, Pereiro, Garreancho ou Azinhal, foram ocupadas por villae.

Quando observamos a localização dos sítios atribuídos à Alta Idade Média, verificamos que eles ocupam solos com menor aptidão agrícola, maioritariamente solos de classe $\mathrm{D}$, enquanto que os testemunhos romanos se posicionam preferencialmente em solos de classe A e B.

Perante esta realidade importa compreender o que terá levado a população que abandona a Ammaia a ocupar os solos com menor aptidão agrícola em detrimento de solos de classe A ou B.

A partir do século VI verificou-se uma intensa ruralização da paisagem, que se iria prolongar até ao século IX. Este processo poderia relacionar-se com um contexto de crise económica, com o declínio da cidade e abandono progressivo, projectando inúmeras famílias para o campo, através da atribuição ou usurpação de terras. As famílias, ora isoladas, ora em aglomerados ou aldeias, iriam ocupar áreas inóspitas, estabelecendo um novo padrão de fixação humana. Os novos sítios, a norte da crista quartzítica de Marvão, localizaram-se no limite dos terrenos agrícolas ou no início das zonas graníticas, reflectindo a preocupação de não ocupar os terrenos potencialmente aráveis. A presença ou a proximidade de recursos hídricos favoreceu a fixação e o desenvolvimento das hortas, essenciais numa economia de subsistência. Pontualmente construíramse canais de irrigação em pedra solta, ou canalizações de granito.

Não sabemos se a intenção destas populações era a procura de locais discretos na paisagem, não longe de caminhos ou calçadas, ou se não lhes restaria outra alternativa, já que os melhores terrenos agrícolas estariam desde a época romana na posse das elites. A presença de enormes moroiços sugere que muitos terrenos tenham sido arroteados e desbravados, o mesmo acontecendo com o controlo da floresta, maioritariamente de carvalhos. É evidente o aproveitando máximo dos pequenos vales e recantos, limitados pelos maciços graníticos. Nestas áreas ter-se-ia verificado uma expansão do olival, confirmada pela proliferação de lagares. A grande quantidade de pesos de lagar e de estruturas ou sítios associados a lagares permitem-nos reconhecer a importância do azeite na economia regional. A presença pontual de lagaretas (Vale do Cano, Lagareta da Anta, Vidais, Ribeiro do Lobo e Ranginha) relacionava-se, provavelmente, com a produção e importância do vinho, embora estas estruturas escavadas na rocha possam ser mais numerosas, dado que a sua detecção nem sempre é fácil. Reconheçamos que algumas 
destas lagaretas poderão remontar à Proto-História, com fins transformadores diversos e continuamente utilizadas.

Seria fastidioso enumerarmos os sítios que surgiram na Alta Idade Média, destacando-se apenas os aglomerados mais relevantes, como o Vale do Cano IV e V, Monte Velho I, Fonte de Souto, Pasmal, Mouta Raza I e II, Maral, Aldeia, Vale do Ródão e Estaca III. Nestes locais, a abundância de imbrices contrasta com a escassez de tegulae. No Vale do Cano IV e V e Monte Velho I, este escavado por Afonso do Paço, os imbrices observados denotam uma intensa decoração penteada e digitada. Nos aglomerados do Ribeiro do Lobo e da Patinha da Burra, não registámos qualquer vestígio de cerâmica de cobertura, sugerindo-se a utilização de giesta, solução que se prolongou até aos nossos dias, nas choças (figs. 9, 10 e 13).

Relativamente ao novo padrão de povoamento, a freguesia de S. Salvador da Aramenha constitui uma excepção, já que em contexto rural não reconhecemos vestígios seguros de ocupação alto medieval. Esta situação poderá justificar-se pelo facto de ser uma área próxima da Ammaia, em que os terrenos mais próximos e com melhor aptidão pertenceriam às elites urbanas. Nessas propriedades trabalhariam servos, sujeitos a fluxos diários entre a cidade e a periferia.

Num período em que o cristianismo se assumia como religião dominante, surgiram novos rituais de inumação, associados às novas formas de povoamento rural. As sepulturas eram escavadas nas formações graníticas, de uma forma isolada (Vale do Cano VI e VII, Pereiro Velho II ou Estaca I, fig.12) ou em necrópoles (Vale do Cano III, Mouta Raza III e IV, Herdade do Pereiro III, Monte Velho I ou Vale do Ródão I, fig. 8 e 14). Este tipo de tumulação pode ter derivado dos sarcófagos romanos, cuja tradição se manteve no período alto medieval (Vale do Cano III, Cancho Ruivo, Herdade dos Pombais II ou Mãe Velha II). A presença de duas sepulturas tipo cista, que ladeiam outras duas escavadas na rocha (Vale do Luso II e Vale do Cano VI), poderia representar a evolução para o novo tipo de sepultura escavada na rocha, que implicava um notável investimento de tempo e de trabalho. Esta inovação difundida pelo mundo cristão poderia justificar-se com inúmeros argumentos, como uma figuração do sepulcro de Jesus, uma melhor sinalização da sepultura, a elevação de uma sepultura em relação aos restantes enterramentos, uma forma de distinção social ou familiar, a imobilidade do sepulcro, que impedia a sua reutilização, ou a simples economia de terreno arável. A violação da maioria das sepulturas impede-nos de conhecer outros pormenores destes rituais funerários. A cobertura da sepultura era feita com terra e pedras, lajes de xisto ou de granito, mais vulgares e ainda observáveis. Em muitos casos foi esculpido um rebordo que facilitava a colocação da tampa, impedindo infiltrações das águas pluviais. $\mathrm{O}$ interior da sepultura pode assumir uma forma simples, ou uma forma antropomórfica, variando os contornos da cabeceira, do corpo e dos pés. É geralmente aceite que as mais antigas seriam as sepulturas mais simples, ovaladas, rectangulares e trapezoidais, balizáveis entre os séculos VII-VIII e os séculos XII-XIII. As formas antropomórficas surgiriam a partir 
de meados do século IX. Por vezes, encontramos os vários tipos, lado a lado, com as mais variadas orientações, no interior dos aglomerados ou na periferia, ora em necrópoles, ora isoladas, contrariando várias teorias ou modelos propostos.

Ainda que não seja claro, face aos conhecimentos actuais, saber a quem se destinavam estes sepulcros, haverá que reconhecer que, pelo investimento que a abertura destas sepulturas implicava, seguramente elas não se destinariam a todos os membros da comunidade. Reforça esta leitura o número reduzido de sepulcros relativamente à extensão de alguns povoados, como seja o do Ribeiro do Lobo (fig. 14). Poderemos, eventualmente, pensar que este tipo de sepultura se destinaria a alguma elite com maior número de excedentes. Haverá que ressaltar que alguns destes sepulcros parecem organizar-se aos pares, podendo deduzir-se estarmos em presença de casais. Ocorrem, ainda que em número reduzido, sepulcros de criança, sendo neste caso os antropomórficos muito raros.

No contexto destes povoados ocorrem, ainda que em número reduzido, as interessantes construções localmente conhecidas por chafurdões. Referimonos, a construções, algumas monumentais, de planta circular e cobertura de falsa cúpula em pedra. Unicamente construídas sobre afloramentos graníticos, inviabilizam qualquer sondagem arqueológica e tornam a sua datação muito insegura. Utilizados até aos nossos dias, ainda que actualmente apenas para guardar animais ou palha, ou eventualmente para abrigo temporário de pastores, os chafurdões, pela sua monumentalidade, implantação, organização no espaço e por vezes proximidade a sepulturas escavadas na rocha, como acontece pelo menos nos concelhos de Castelo de Vide, Nisa e Marvão, poderão estar relacionados com aspectos religiosos, ou mesmo funerários. Contudo, conhecemos alguns, sobretudo na Extremadura espanhola, que apresentam datas dos séculos XVIII e XIX, nos lintéis das portas, originando ainda maiores dúvidas quanto à sua origem e funcionalidade (fig. 15).

Se alguns destes habitats parecem estar na origem de algumas povoações que hoje se mantêm, como Ranginha, Barretos, Asseiceira e eventualmente Santo António das Areias, Escusa e Pitaranha, a maioria terá sucumbido em data bastante recuada. O povoado que melhor se conhece, o do Monte Velho, na freguesia da Beirã, porque foi o único objecto de uma curta escavação, terá sucumbido, segundo o seu investigador, de uma forma abrupta e com sinais evidentes de um violento incêndio que impossibilitou os seus proprietários de recuperarem os bens que aí se encontravam. Segundo Afonso do Paço (Paço, 1949) o fim do povoado do Monte Velho e de todos os outros contemporâneos teria resultado da invasão muçulmana desta região. Haverá que reconhecer que algum tempo antes da chegada das gentes do norte de África outras convulsões se conheceram. A luta pelo poder extrema-se no século VII, opondo o poder central às elites locais, gerando alguma instabilidade políticosocial a que podemos juntar os maus anos agrícolas, que resultaram em fome, epidemias, endividamento e servidão, afectando particularmente o grosso da população rural cada vez menos livre e mais descontente. A fragmentação 
do poder, a crescente supremacia da religião sobre a nobreza visigoda e as constantes disputas entre nobres iriam provocar conflitos internos, alguns dos quais assumiram contornos militares. Os conflitos entre as famílias nobres visigodas acentuaram-se com a morte do rei Égica, em 702, sucedendo-lhe o seu filho Vitiza, cujo reinado durou até 710 .

Embora sem certezas quanto ao fim deste povoado e de outros semelhantes, haverá que reconhecer, que as evidências arqueológicas do Monte Velho indiciam um fim não esperado e uma saída sem regresso dos seus habitantes. Se se tratasse unicamente de um incêndio deste povoado, os bens teriam sido recuperados pelos seus habitantes ou pelos habitantes de outros povoados vizinhos. A abundância de telhas inteiras nas casas ardidas e, sobretudo, o forno ainda cheio delas que posteriormente às escavações de Afonso do Paço se veio a descobrir neste habitat, mostram que os seus habitantes e os dos povoados vizinhos não puderam recuperar os bens. Este abandono sem regresso poderá estar relacionado com uma chacina total ou, mais provavelmente, com a captura e consequente escravização das pessoas destes povoados. Se foram, ou não, os invasores oriundos do norte de África os autores desta destruição, não o podemos afirmar por agora. Para explicar esta e tantas outras dúvidas que se colocam em torno destes povoados, torna-se urgente organizar projectos de investigação que contemplem a escavação de alguns destes sítios, de forma a trazer mais luz sobre um período tão desconhecido como é o que antecede a islamização da Península Ibérica.

Embora muitas incertezas se coloquem em torno destes povoados localizados nos concelhos de Marvão, Castelo de Vide e Valência de Alcântara, temos, pelo menos, a certeza de que eles resultam do fim e consequente pulverização da velha cidade romana de Ammaia, que após o seu esplendor se vê esquecida e substituída por povoados que, se não ocupassem cotas tão baixas, seriam facilmente confundidos com os habitats da Idade do Ferro que os romanos aqui encontraram à sua chegada. Parece, assim, reconhecer-se um profundo retrocesso económico, social e cultural desta região com o colapso e consequente pulverização da Ammaia. 
A pulverização da Ammaia na Alta Idade Média

\section{Anexos}

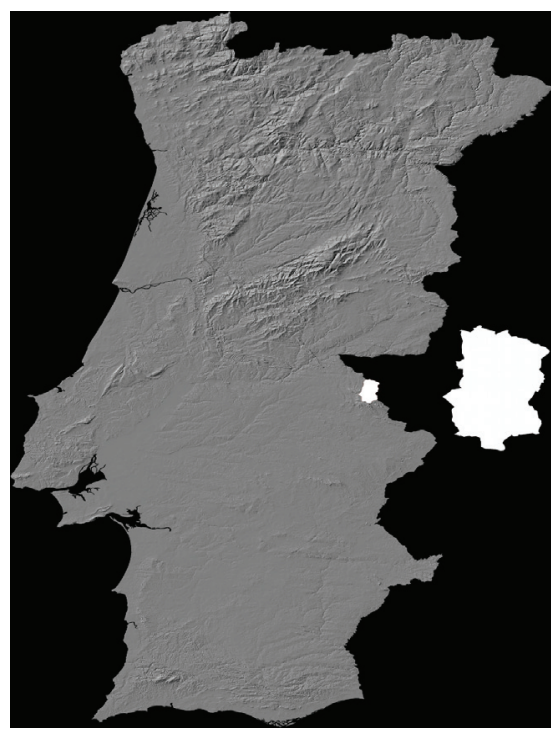

Fig.1. Localização do concelho de Marvão

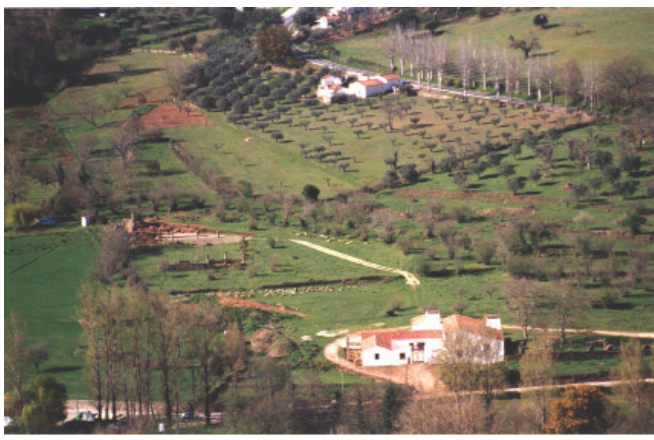

Fig.2. Ammaia vista de nascente 


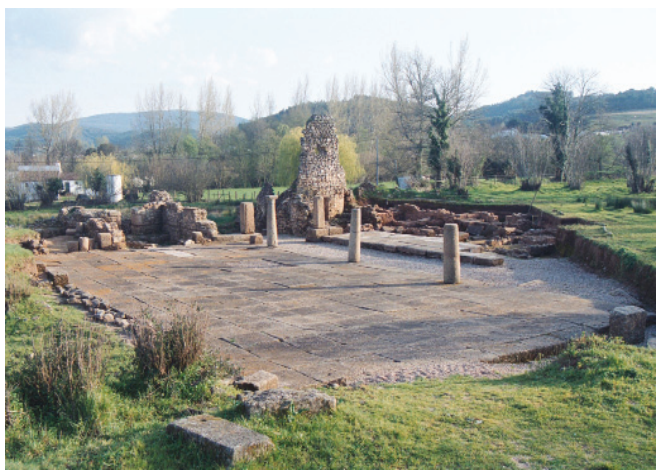

Fig.3. Ammaia - Porta Sul

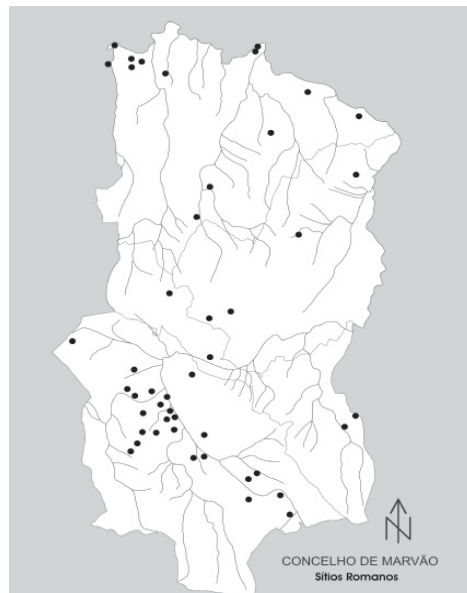

Fig.4. Sítios Romanos do concelho de Marvão

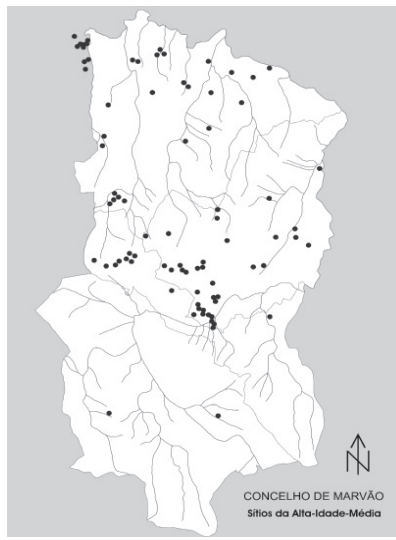

Fig.5. Sítios da Alta-Idade-Média do concelho de Marvão 


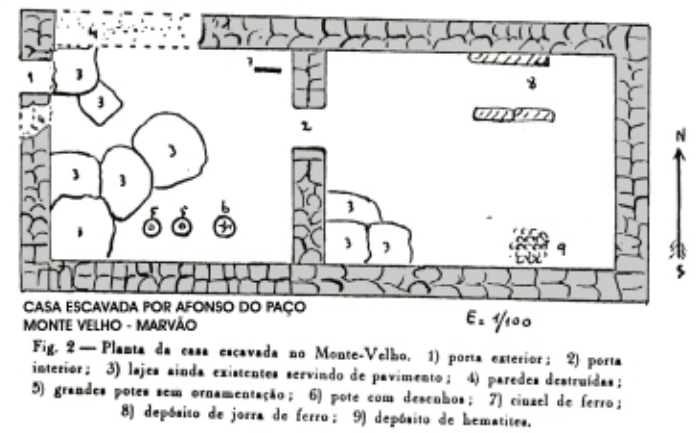

Fig.6. Planta de casa escavada por A. do Paço no Monte Velho - Marvão

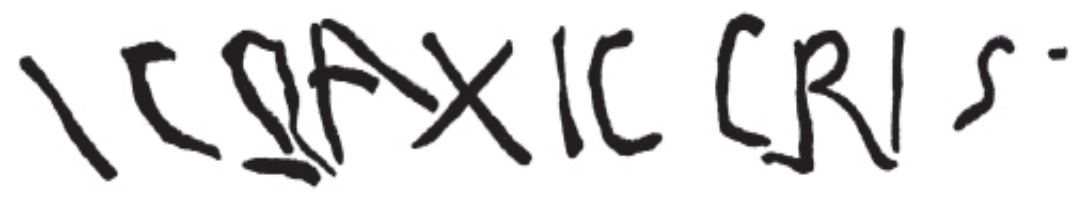

Fig.7. Inscrição cristã do Monte Velho, seg. Afonso do Paço

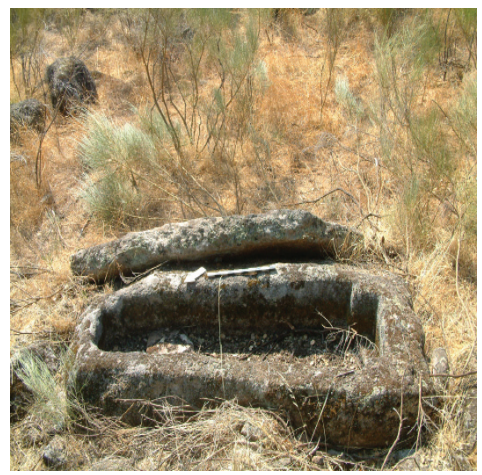

Fig.8. Sepultura com tampa do Monte Velho 
Jorge de Oliveira e Sérgio Pereira

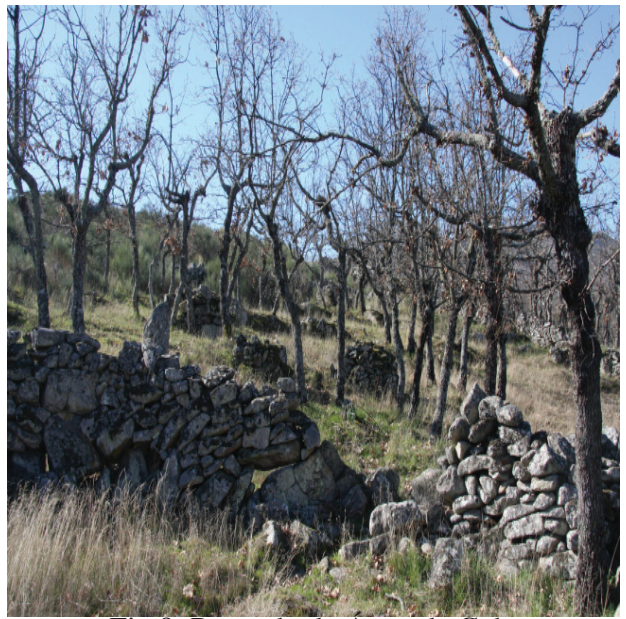

Fig.9. Povoado da Agua da Cuba

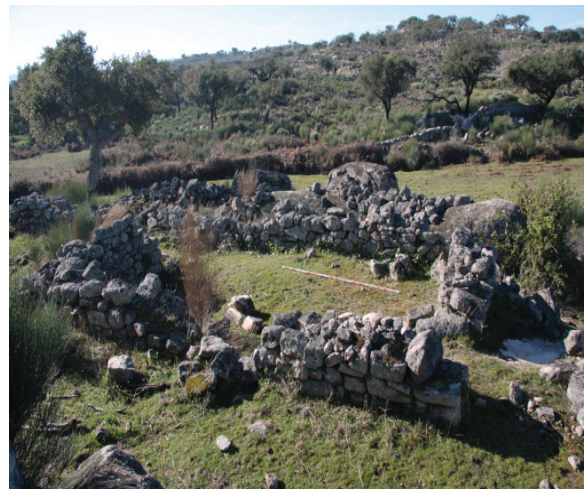

Fig.10. Povoado da Patinha da Burra

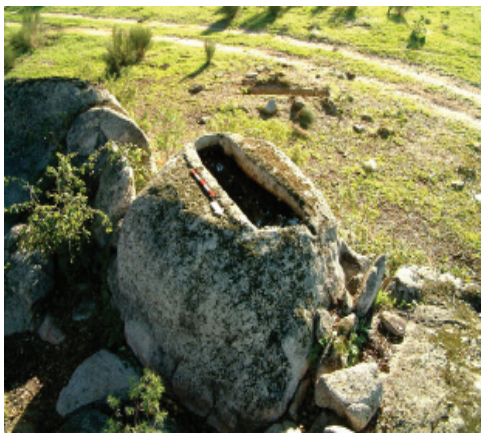

Fig.11. Necrópole do Vale de Luso 


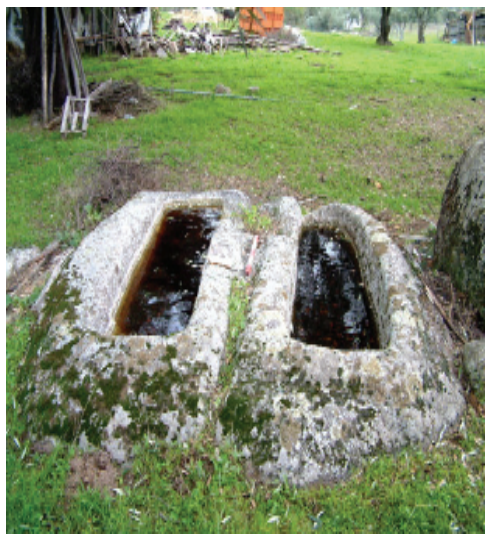

Fig.12. Necrópole da Fonte de Souto

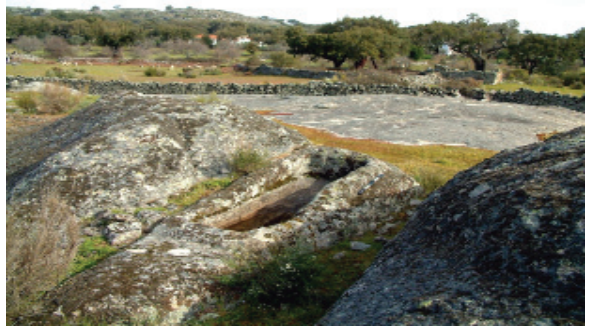

Fig.13. Povoado e necrópole da Relva

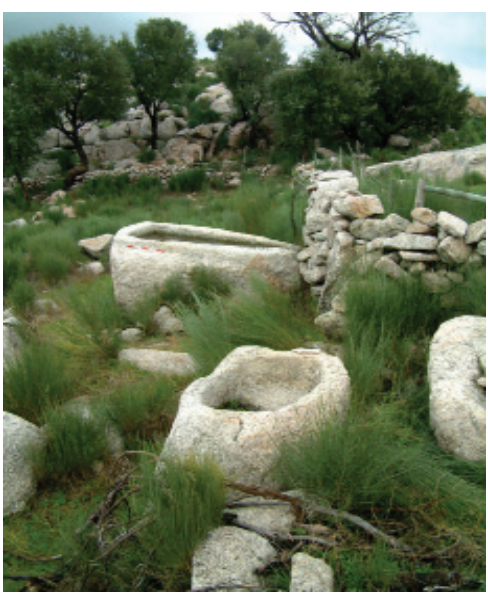

Fig.14. Povoado do Ribeiro do Lobo 


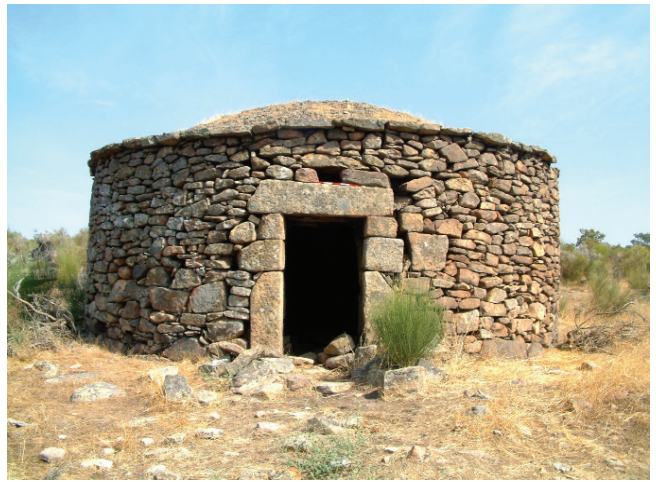

Fig.15. Chafurdão da Mouta Rasa
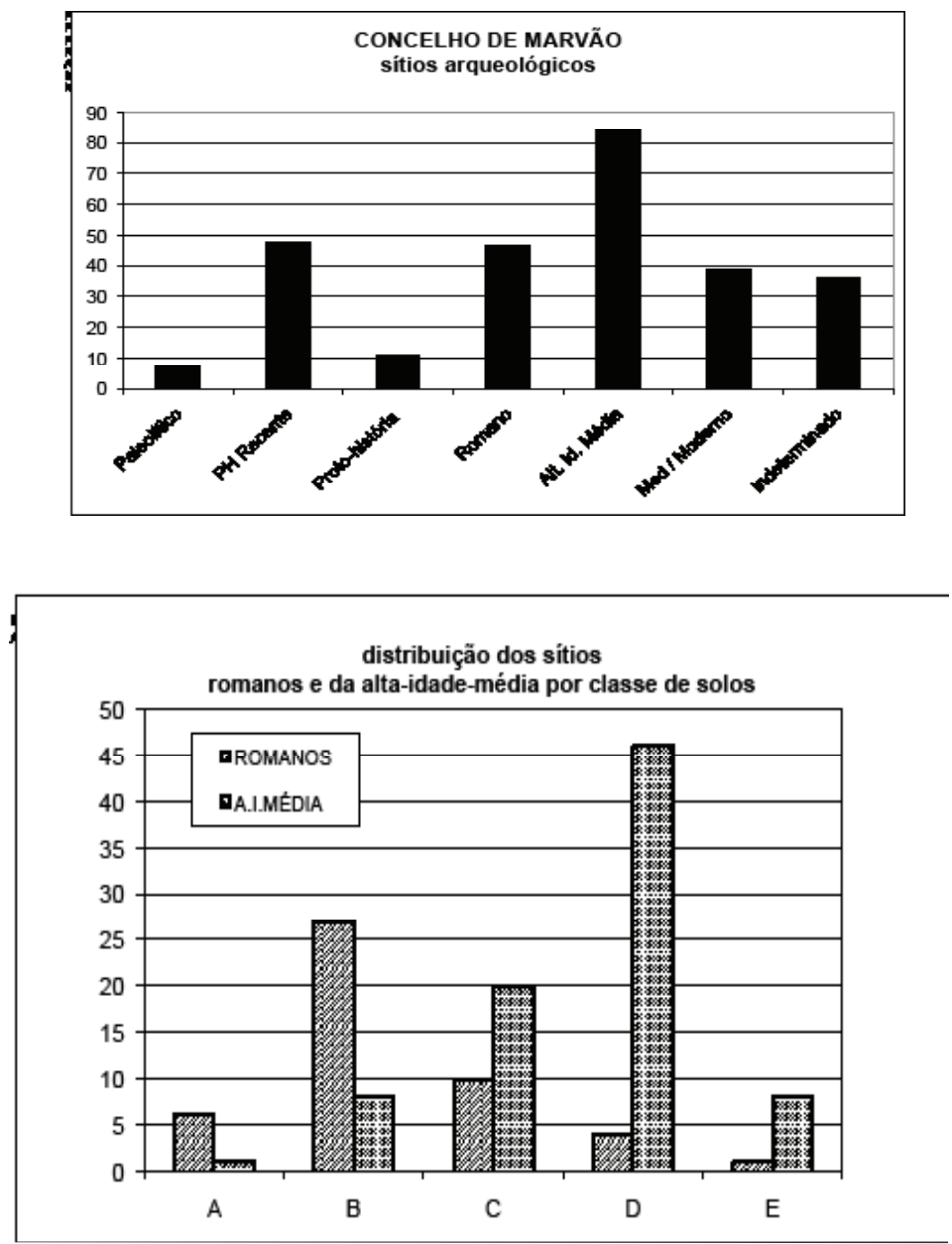


\section{Bibliografia}

Jorge de Alarcão (1985), "Sobre a romanização do Alentejo e Algarve. A propósito de uma obra de José d'Encarnação", Arqueologia 11, G.E.A.P., Porto, 99-123.

Jorge de Alarcão (1988), O Domínio Romano em Portugal. Mem-Martins.

André Carneiro (2002), "O fim do império e a cristianização no território da civitas ammaiensis: mudança e continuidade no concelho de Fronteira", Ibn Maruán 12, Câmara Municipal de Marvão. Lisboa, Colibri, 135-157.

Possidónio M. Laranjo Coelho (1924/2001), Terras de Odiana. Subsidios para a sua História Documentada. Edição fac-simile da edição de 1924. Ibn Maruán 11, Câmara Municipal de Marvão. Lisboa, Colibri.

José d'Encarnação (1984), Inscrições Romanas do Conventus Pacensis. Coimbra.

Robert Étienne (1995), «À propos du territoire d'Emerita Augusta (Mérida) in Monique Clavel-Lévêque», Rosa Plana-Mallart, eds., Cité et Territoire. Colloque Européen (Béziers, 14-16 Octobre 1994). Paris, 27-32.

Isabel Cristina Fernandes, Jorge de Oliveira (1995), "Os mosaicos romanos do Garriancho (Beirã-Marvão)”. Ibn Maruán 5, Câmara Municipal de Marvão, $13-23$.

Amílcar Guerra (1996), “Ammaia, Medobriga e as ruínas de S. Salvador de Aramenha: dos antiquários à historiografia actual", A Cidade - Revista Cultural de Portalegre 11 7-33.

Eugénio Jalhay (1947), "Epigrafia amaiense. Contribuição para o estudo da Aramenha romana (concelho de Marvão)", Brotéria 45.6 5-23.

Vasco Gil Mantas (2000), “A sociedade luso-romana do município de Ammaia”, in Sociedade y Cultura en Lusitania Romana.IV Mesa Redonda Internacional. Mérida, Série Estudios Portugueses, 391-420. (2002), "Libertos e escravos na cidade luso-romana de Ammaia", Ibn Maruán 12, Câmara Municipal de Marvão. Lisboa, Colibri., 49-68

Jorge de Oliveira, Carmen Balesteros (1989), Levantamento Arqueológico da Barragem da Apertadura. Câmara Municipal de Marvão. Portalegre.

Jorge de Oliveira (1991), "A estátua romana da Escusa (Aramenha - Marvão)", Ibn Maruán 1, Câmara Municipal de Marvão, 85-96.

Jorge de Oliveira, Susana S. Cunha (1993-4), "A cidade romana de Ammaia na correspondência entre António Maçãs e Leite de Vasconcelos", O Arqueólogo Português 11-12. Série 4. Lisboa, 103-134.

Jorge de Oliveira et alii (1996), "Cidade da Ammaia (Marvão)", Ibn Maruán 6, Câmara Municipal de Marvão, Colibri, 15-22.

Jorge de Oliveira (1999), "Cidade romana de Ammaia, S. Salvador de Aramenha, Marvão, Portugal", in II Congresso de Arqueologia Peninsular, tomo 4. Zamora, Universidade de Alcalá, 129-134.

Jorge de Oliveira (2002), "A cidade romana de Ammaia, documentos para a sua história recente”, Ibn Maruán 12, Câmara Municipal de Marvão. Lisboa, Colibri, 11-48.

Jorge de Oliveira et alii (2005), São Salvador da Aramenha. História e Memórias da Freguesia, in Jorge de Oliveira, coord., Ibn Maruán 13, Câmara Municipal 
de Marvão. Lisboa, Colibri.

Jorge de Oliveira, Sérgio Pereira, João Parreira (2007), Nova Carta Arqueológica do Concelho de Marvão, Ibn Maruán 14, Câmara Municipal de Marvão. Lisboa, Colibri.

Afonso do Paço (1949), "Inscrição Cristã do Monte-Velho (Beirã-Marvão)", Brotéria 49.1 5-19.

Afonso do Paço (1953), "Carta arqueológica do concelho de Marvão", Actas do XIII Congresso Luso-Espanhol para o Progresso das Ciências, Lisboa (1950). $7^{\mathrm{a}}$ secção. Lisboa, 93-127.

Afonso do Paço, (D.) Fernando de Almeida (1962), "Duas inscrições romanas inéditas do Museu de Marvão", Revista de Guimarães 72 145-151.

Sérgio Pereira et alii (2000), "Numismática ammaiense: notas preliminares", Ibn Maruán 9-10, Câmara Municipal de Marvão. Lisboa, Colibri, 55-70.

Sérgio Pereira (2002), "Dois depósitos monetários encontrados na Porta Sul (Ammaia)", Ibn Maruán 12, Câmara Municipal de Marvão. Lisboa, Colibri, 99-134.

António Rei (1998), “O nordeste alentejano nos geógrafos árabes”, Ibn Maruán 8, Câmara Municipal de Marvão, Lisboa, Colibri, 247-250.

António Rei (2002), "Târiq ibn Ziyâd e o seu exército em Almeida e na Cidade de Ammaia (Marvão) em finais de 711 - inícios 712”, Ibn Maruán 12, Câmara Municipal de Marvão. Lisboa, Colibri, 159-167.

Adel Sidarus (1991), “Amaia de Ibn Maruán: Marvão”, Ibn Maruán 1, Câmara Municipal de Marvão, 13-26. 


\title{
MÉRTOLA - UM ESPAÇO LENDÁRIO E MÍSTICO
}

\author{
Natália Maria Lopes Nunes \\ Universidade Nova de Lisboa \\ Faculdade de Ciências Sociais e Humanas \\ IELT/CEIL
}

\section{Résumé}

La beauté du paysage naturel, près du Guadiana (le fleuve de la déesse), est un espace légendaire et mystique depuis longtemps. Plusieurs découvertes archéologiques (quelques unes exposées au Musée de la Ville et d'autres au Musée National d'Archéologie) sont les témoins d'un passé historique très riche, surtout sous les domaines romain et arabe. De la période romaine, il y a des inscriptions dediées à la déesse Atégina (ou selon quelques auteurs, dediées à la déesse Prosérpine), avec l'épithète Dea Sancta, la sculpture de la tête de la déesse Cybèle et du dieu Dionysos, des amulettes phalliques et quelques monuments funéraires; de la période islamique, il y en a aussi plusieurs vestiges (un quartier, des objets en or, matériel de cuisine, une nécropole, l'église qui a été une mosquée) et c'est la ville du soufi Al-Mîrtulî; de la période chrétienne, il y en a des chapelles et des églises, surtout dediées à la Vierge et aux saints, comme par exemple, S. Barão. Cependant, les légendes de la région, comme l'origine du nom Mértola, «La Ciseaux de la Mauresque» et la légende de S. Barão ont fait de Mértola un espace légendaire e mystique. Mírtilis, Mirtolah, Mértola - région de Romains, d'Arabes et de Chrétiens - a été un espace sacré et partagé par plusieurs cultures, lieu où on a vénéré les déesses Atégina (ou Prosérpine, selon d'autres opinions) et Cybèle, le dieu Dionysos et où a vécu le poète soufi Al-Mîrtulî et le saint chrétien S. Barão, les exemples plus importants de l'espace légendaire et mystique de la ville.

Mots clefs: Al-Mîrtulî, découvertes archéologiques, Grande Déesse, légendes, Mauresque enchantée, Mértola, S. Barão, Serpent, Soufisme.

Palavras-chave: achados arqueológicos, Al-Mîrtulî, Grande Deusa, lendas, Mértola, mouras encantadas, S. Barão, serpente, sufismo.

Mértola, situada no distrito de Beja, foi palco da presença de diversos povos que remontam ao Período Neolítico. No entanto, e de acordo com a temática do presente volume, salientamos as presenças romana, árabe e cristã.

Mértola, com a beleza da paisagem natural, tendo a seus pés o Guadiana (o rio da deusa), tornou-se um espaço lendário e místico ao longo dos séculos. A sua localização, tendo ainda em conta a navegabilidade do rio, exerceu uma forte influência na região. Se a riqueza dos solos era pobre, a do subsolo era muito rica, situação que se revela desde a Antiguidade, integrando a vila na faixa Piritosa Ibérica, destacando-se a exploração de chumbo, cobre, prata 
e ouro. A exploração mineira das Minas de S. Domingos é exemplo dessa ancestralidade já desenvolvida por fenícios e cartagineses.

No período romano julga-se que Mértola fosse um ponto estratégico nas relações com o Mediterrâneo. Segundo o arqueólogo Carlos Fabião, a romanização ter-se-ia iniciado bastante cedo pelo facto de o local ser um porto de entrada dos exércitos romanos.

No que diz respeito à toponímia, segundo alguns autores e geógrafos da Antiguidade, como Estrabão e Plínio, Mértola é a antiga Myrtilis, nome que, segundo Estácio da Veiga, poderia ter origem fenícia, partindo de Myr que significa nova, seguida de Tyri que significa Tiro. Esta relação remete para a conquista de Tiro em 333/332 a.C. por Alexandre Magno, rei da Macedónia; o autor refere ainda a origem grega do nome, partindo do nome Myrtilo, filho de Mercúrio, ou da origem latina, a partir de Myrtus. Contudo, segundo o autor, estas interpretações etimológicas derivariam mais do seu carácter lendário, do que dos aspectos linguísticos, daí as interpretações não serem, por vezes, consideradas fiáveis. A lenda de "Serpínia, a Princesa Feliz" faz alusão à fundação de Mértola, atribuindo o nome ao filho de Mercúrio com a deusa Mirto:

«Cófilas, Rei dos Túrdulos, fez aliança com os chefes Fenícios e, naquele porto, construíram uma cidade a que deram o nome de Mirtilis, em honra da Deusa Mirto, sua mãe que o teve de Mercúrio. [...] Cófilas e Polípio firmaram um tratado de amizade e mútua defesa. Além do casamento com Serpínia estipulou-se que os fenícios estabelecessem uma feitoria comercial em Mirtilis. Nesse porto ficariam sempre equipados com homens e material dois navios fenicios que ao mesmo tempo patrulhariam o litoral da Turdetânia, pelo menos enquanto o perigo não passasse. Em caso de guerra com qualquer adversário cada um dos contratantes prestaria mútuo auxilio.

Com medo de novos ataques a princesa mandou aviso ao pai, que estava em Mirtilis, que hoje se chama Mértola [...]» ${ }^{1}$.

No entanto, como não se comprovou a existência de uma deusa com o nome de Mirto, a mesma foi associada à deusa Afrodite, a deusa da beleza e do amor, através da planta que a simboliza, o mirto.

Ainda do período romano, para além de alguns monumentos funerários dos séculos II-III d.C., de entre eles uma tabela rectangular com um epitáfio a Publicia Lucina e uma ara funerária de Lucius Liburnius Maternus (peças que se encontram expostas no Museu Nacional de Arqueologia), foram encontradas algumas epígrafes que estabelecem uma relação entre o culto da deusa préromana Atégina e da deusa Prosérpina, tal como se verifica na inscrição «Dea

\footnotetext{
${ }^{1}$ Cabral, in http://joraga.net/mertola/pags/20lendas1.htm\#serpinea 165-167.
} 
sancta Ataecina Turibrigensis Proserpina» (em Mérida, Badajoz). No entanto, como afirma Juan Manuel Abascal Palazón:

«A própria evidência epigráfica mostra que não se realizou uma autêntica hypostasis e que ambos os cultos possuem áreas especificas de desenvolvimento. Haveria agora que trazer à colação as epígrafes que mencionam só dea sancta e que afastámos como evidências de Ataecina: cinco procedem de Mérida, Mértola, Beja e Serpa, ou seja, sobre a latitude ou a sul da latitude de Mérida [...] é fácil de deduzir que estas tácitas alusões a uma dea sancta devem pois referir-se a Proserpina e não a Ataecina»².

Em Mértola foi também encontrada uma cabeça da deusa Cíbele e do deus Dioniso ${ }^{3}$. Além disso, e talvez em correlação com o culto dionisíaco, foi encontrado um amuleto fálico na Mina de S. Domingos datado do período pré-romano, um phallus cum scroto pubeque ${ }^{4}$. Desde a Pré-História que o uso de amuletos ou de talismãs era uma prática comum. Estes objectos sagrados reflectiam as crenças, detinham poderes mágicos e tinham como principal função a protecção do ser humano contra os males que o poderiam prejudicar.

O período da ocupação islâmica também legou a Mértola um património muito importante. A Espanha muçulmana tornara-se independente com os Abássidas, tendo Córdova como grande centro da cultura islâmica. No entanto, as influências dessa cultura expandiram-se também à zona correspondente a Portugal, embora se encontrassem nesses territórios outras tradições ancestrais. Como afirma Dominique Sourdel, partindo dos estudos de E. Lévi-Provençal:

«Nos séculos X e XI, a Andaluzia, onde as tradições sírias permaneciam vivas, conheceu uma cultura requintada, a qual não só rivalizou com o sucesso com a sua iniciadora oriental, à qual se mantivera fielmente ligada, mas também «se soube impor fora dos limites muçulmanos e determinou em parte a evolução do pensamento e do saber europeus dos séculos antes do Renascimento» (E. Lévi-Provençal) ».

Certamente, tal como aconteceu em outras regiões, Mértola também presenciou a sobreposição de culturas e de religiões diferentes ao longo das épocas, desde o Período Neolítico. A relação da vila com o Mediterrâneo, estabelecida já no período pré-romano, tornou a região um centro de contacto entre o Ocidente e o Oriente. A nível arqueológico existem diversos elementos: vestígios de um bairro, utensílios de cozinha, objectos em ouro (anéis, brincos,

\footnotetext{
${ }^{2}$ Palazón 200256.

${ }^{3}$ Cf. Souza 2002 247-250.

${ }^{4}$ Ponte 2002 269-272.

${ }^{5}$ Lévi-Provençal, apud Sourdel 199132.
} 
fivelas, etc.), a necrópole e a Igreja Matriz de Mértola, outrora mesquita (como atestam alguns vestígios).

Porém, desta época sobreviveram em Portugal muitas lendas de mouras. "A Tesourinha da Moura" é uma dessas lendas que estabelecem a ponte entre os primitivos cultos de Mértola que sobreviveram na lenda. Segundo a lenda:

«Ali para os lados de Mértola, aconteceu, certa vez, um caso fantástico e temeroso provocado por uma moura encantada.

Vinha um homem do amanho do campo, de enxada ao ombro, quando ao passar pelo sitio da Mortilhera viu uma cobra que da cintura para cima tinha corpo de mulher. A cobra, que era uma moura encantada, meteu-se a conversar com o homem, e o homem cheio de medo, a suar e a limpar o suor com o lenço.

A moura foi perguntando ao homem como lhe corria a vida, que tal as colheitas, se a seara era dele ou se tinha patrão, e muitas outras coisas com as quais talvez viesse a entreter-se nos longos serões que de Inverno era obrigada a passar sozinha debaixo da terra. Quando acabou de saber tudo o que a interessava, a moura estendeu ao homem um capacho com figos secos, que estava a seu lado, dizendo-lhe que tirasse quantos quisesse.

O homem, que durante todo o tempo da conversa suara frio, de medo e nervos, tirou meia dúzia de figos e meteu-os na algibeira do colete. Despediu-se da cobra com alguns salamaleques e partiu aliviado e desejoso de se ver bem longe dali.

Ao chegar a casa contou à mulher o que lhe acontecera e por fim, quando ia a tirar os figos do bolso do colete, encontrou no lugar deles seis moedas de ouro. A mulher desatou logo a ralhar com ele:

—Ó homem, pois então a moura dá-te figos que são ouro e tu só trazes isto?! Valha-te Deus, que estás mas é a ficar taralhouco! Vai mas é buscar o resto, antes que a cobra volte à cova, vai depressa, ouviste?!

O homem, que não sabia bem se havia de temer mais o bicho ou a mulher, lá foi, dizendo mal à sua vida. E quando passou pela cobra, disse-lhe, para que ela não desconfiasse:

- Adeus, senhora moura! Vou outra vez ao campo, que me esqueci de uma coisa!

Mas a moura sabia tudo:

- Não vais, não! Não te esqueceste de nada, o que tu querias era mais figos, mas já não há! Olha, leva daqui qualquer coisa que te sirva. 
E estendeu ao homem o seu açafate da costura, donde ele sacou uma tesourinha com cabos de ouro e pedras preciosas. Partiu e a moura ficou a dizer-lhe adeus com um estranho sorriso.

A caminho de casa, o homem, que ia distraído com os seus pensamentos, escorregou à beira de uma ladeira, caiu, espetou a tesoura no peito e morreu.

Assim acontece quando os encontros com mouras não são mantidos em segredo!» ${ }^{6}$

Desta lenda destacamos a personagem feminina da moura encantada, metade mulher, metade serpente, articulando-a com os vestígios arqueológicos da região, nomeadamente com o culto de Cíbele, Prosérpina e Dioniso. A ancestralidade da serpente como animal sagrado, ctónico e aquático tem raízes indo-europeias. Por outro lado, ela é ainda uma das representações das grandes deusas, das deusas-mães ligadas à fertilidade e à regeneração que, no Cristianismo, sobreviveram nas diversas lendas e na figura da Virgem Maria. Citando Ria Lemaire:

"Associada à fertilidade, a Serpente-Deusa é imaginada quase sempre boa, benéfica, generosa; os ritos que lhe são dedicados celebram a sua soberania sobre a vida, a fertilidade, a felicidade dos seres humanos, apelam para os seus poderes curativos, lenitivos e divinatórios»? ${ }^{7}$.

O imaginário da mulher serpente encontra-se no mito de Melusina, também ela uma mulher serpente, mito ancestral, remetendo para a mulher com um carácter sobrenatural. Assim, a moura da lenda é uma sobrevivência desse imaginário. Saliente-se ainda o facto de a serpente ser uma das representações da deusa Cíbele, a Grande Deusa, mãe dos deuses que, como vimos pelos vestígios arqueológicos, também foi venerada em Mértola, articulando-se ainda com Dioniso, também cultuado nesta região e que tem uma estreita relação com o culto da respectiva deusa, como se pode verificar n'As Bacantes de Eurípides. Por outro lado, e estreitamente ligado aos cultos de fertilidade, existe ainda o amuleto fálico encontrado nas Minas de S. Domingos. Além disso, as epígrafes que ligam as deusas Atégina a Prosérpina (tenha sido um ou outro culto) relacionam-se com a fecundidade e com a regeneração. Assim, e citando Jean Chevalier e Alain Gheerbrant, a serpente será, simbolicamente, «ao mesmo tempo útero e falo». ${ }^{8}$

Esta ancestralidade simbólica ligada à serpente subsistiu durante séculos, encontrando-se, actualmente nas lendas, como é o exemplo d' "A Tesourinha da Moura". A figura feminina desta lenda, a moura, na continuidade do poder sagrado das Grandes Deusas, é doadora da vida e da morte, sendo benéfica

\footnotetext{
${ }^{6}$ Frazão s/d 89-91.

${ }^{7}$ Lemaire 1999-2001 85.

${ }^{8}$ Chevalier e Gheerbrant 1994600.
} 
ou maléfica, tecendo o destino do homem. O poder da mulher serpente sobre o destino está bem explícito na lenda. Neste sentido, e partindo dos vestígios arqueológicos encontrados em Mértola e em todo o seu concelho, as lendas serão uma sobrevivência de um fundo mítico ligado a antigos cultos da região. A moura é, então, uma hierofania, uma manifestação do sagrado e da vida. Como afirmam os autores anteriormente citados:

«Todas as serpentes possiveis formam juntas uma única multiplicidade primordial, una, indivisivel [...] ligado à ideia da vida; em árabe, a serpente é el-hayyah e a vida é el-hayat (GUES, 159) [...]. Num plano mais precisamente cosmogónico - e que, no Sufismo, se torna a base de uma mística -,é a dilaceração da unicidade primeira, dois em um, que se divide nos seus dois componentes para permitir a ordem humana [...]» ${ }^{9}$.

Para além de todo este imaginário lendário ligado às mouras, não poderemos deixar de referir outro aspecto de extrema relevância e que tornou Mértola um espaço místico - o Sufismo. Esta corrente teve um papel importante na Península Ibérica, nomeadamente em Portugal e, para além de influenciar a literatura da época, teve uma função preponderante na espiritualidade. $\mathrm{Na}$ Península Ibérica, desenvolveu-se sobretudo a partir dos séculos IX e X com Ibn Masarra, de Córdova. Um dos grandes poetas sufis foi Ibn Arabi (séculos XII-XIII). O seu Tratado do Amor influenciou a mística medieval, tendo subjacente a concepção platónica do Belo.

Um dos mestres de Ibn Arabi foi o sufi de Mértola, Al-Mîrtulî (século XIII). Este místico de Mértola passou uma vida de ascese baseada na meditação e no recolhimento. Devido à sua relevância, não poderemos deixar de apresentar dois dos seus poemas, publicados em $O$ meu Coração é Árabe de Adalberto Alves:

\author{
«quanto do que intento que não faço \\ e como, sem fio, eu vagueio. \\ falo à minha alma, ela não escuta \\ critico tudo e inda assim não creio. \\ a quanto do que fica sempre por fazer \\ eu direi «mais tarde!» e tudo tarda. \\ me atraso confiado em longa vida: \\ cedo vem a morte que nunca se guarda. \\ todos os dias ela, feita pregoeira, \\ diz «alto!» a muitos dos que vão passando. \\ setenta e nove anos já voaram. \\ que mais estarei eu ainda esperando?» ${ }^{10}$
}

\footnotetext{
${ }^{9}$ Idem 1994596.

${ }^{10}$ Alves 1999234.
} 


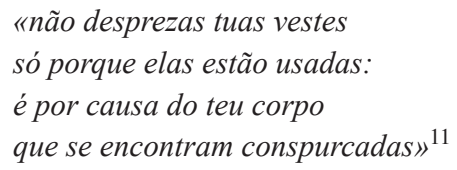

Posteriormente, o Cristianismo, através da devoção da Virgem, continuou o culto das deusas Cíbele e Prosérpina sob os mais diversos nomes, de entre eles: Nossa Senhora da Anunciação, Nossa Senhora das Neves, Nossa Senhora da Conceição, Nossa Senhora do Carmo, Nossa Senhora da Graça, Nossa Senhora da Cabeça, Nossa Senhora dos Remédios, etc. Citando Joaquim Manuel Ferreira Boiça:

«Na religiosidade popular, a Virgem é a «Senhora dos mil nomes», título que expressa bem a multiplicidade das suas invocações e que deixa perceber a dimensão plural do culto que lhe é prestado. São mil os nomes porque são incontáveis as suas associações devotivas: à maternidade divina e aos mistérios da Paixão e Morte de Cristo; sentimentos e estados de alma; a lugares e elementos da natureza; a crenças intemporais do inconsciente colectivo; a necessidades quotidianas dos homens e do seu porvir; a paixões místicas; a festividades da vivência rural e urbana, etc.» ${ }^{12}$.

Quanto ao culto dos santos, eles foram os sucessores dos deuses pagãos, atingindo o seu carácter de santidade um elevado nível místico, aproximandoos da figura de Cristo. Alguns deles foram de culto local ou regional. Como tal, não poderemos deixar de fazer alusão a um santo considerado local e que, pela sua vida ascética, se aproxima do sufi de Mértola Al-Mîrtulî, S. Barão. Este santo, pelas suas características, reflecte a continuidade dos cultos ligados à fertilidade, cura e regeneração, à semelhança das divindades outrora cultuadas em Mértola.

Alguns cronistas, ao narrarem a vida de S. Barão, fazem dele um santo local que, para além de se articular com os cultos ancestrais, também tem semelhanças com a vida do sufi Al-Mîrtulî. Segundo Frei Leão de S. Tomás, é narrado o seguinte:

«Legoa e meya deste sitio do Mosteyro sobredito do Salvador para Mertola esta huma ermida de S. Barão em huma áspera serra, a quem ele dá o nome, e não longe da ermida se vê a cova, a que chamão a Cella, na qual dizem que vivia este santo vida solitária sostendo-se das ervas que cultivava e regava com a agua de huma fonte que no mesmo sitio nasce. A devoção deste santo he muy antiga em Mertola aonde ha muitos homens deste nome, porque os casados o têm por advogado seu, para thes alcançar fruto de bênção». ${ }^{13}$

\footnotetext{
${ }^{11}$ Idem 237.

${ }^{12}$ Boiça 1998141.

${ }^{13} \mathrm{~S}$. Tomás 1644438 .
} 
Os milagres do santo foram diversos. Para além dos milagres climatéricos ligados aos pedidos de chuva para fertilizar os campos, os milagres de "fecundidade" foram os mais afamados. Como afirma Joaquim Manuel Ferreira Boiça:

«Os prodígios reconhecidos a S. Barão eram muitos e variados. À sua imagem dirigiamse padecentes de mil infortúnios, particularmente na sexta-feira de Ramos e no dia nove de Agosto, ocasiões em que se realizavam grandes romarias reunindo gentes oriundas das paróquias de Mértola e de muitas outras dos concelhos vizinhos. Houve quem, presenciando as festividades em sua honra, declarasse não haver «moléstia alguma que este Santo nam cure» embora fosse no «soldar quebrados e fecundar os casados» que os seus poderes mais se solicitavam». ${ }^{14}$

Pelos aspectos referidos, pode verificar-se que Mértola - um espaço lendário e místico - é um dos símbolos da continuidade de diversos cultos, desde a época pré-romana até à época cristã. Mértola, com os seus vestígios arqueológicos, com as suas lendas, com a presença do sufi Al-Mîrtulî e de S. Barão, incluindo o forte enraizamento do culto mariano, é prova do sincretismo religioso operado ao longo dos séculos. Tal como afirmou Teófilo Braga, «o cristianismo foi o resultado de uma transformação metafísica da tradição religiosa, sendo apenas o sincretismo informe de todos os elementos proselíticos que o precederam». ${ }^{15}$

Em conclusão, Mírtilis, Mirtolah, Mértola - terra de Romanos, de Árabes e de Cristãos - foi um espaço sacralizado e partilhado por diversas culturas, onde se cultuaram divindades pagãs (Prosérpina, Cíbele, Dioniso) e cristãs (os santos e a Virgem), onde "nasceram" lendas de mouras encantadas (a mulher serpente) e viveram os místicos Al-Mîrtulî e S. Barão, exemplos máximos do carácter lendário e místico da vila.

\section{Bibliografia}

AL-MÎRTULî (31998), "Quanto do que intento que não faço", in Adalberto Alves (trad.), O теи Coração é Árabe. Lisboa, Assírio \& Alvim.

(31998) "Não desprezas tuas vestes", in Adalberto Alves (trad.), $O$ meu Coração é Árabe. Lisboa, Assírio \& Alvim.

BOIÇA, Joaquim Manuel Ferreira (1998), Imaginária de Mértola - tempos, espaços e representações. s/l, edição co-financiada pela Comunidade Europeia FEDER/ PORA, Comissão de Coordenação da Região Alentejo, Campo Arqueológico de Mértola.

BRAGA, Teófilo (2000), Poesia do Direito - Raizes Poéticas do Cristianismo Lendas Cristãs. Lisboa, Imprensa Nacional - Casa da Moeda, col.«Pensamento

\footnotetext{
${ }^{14}$ Boiça 1998141.

${ }^{15}$ Braga 2000138.
} 
Português».

CABRAL, João, "Serpínia, a Princesa Feliz”, Arquivos de Serpa, 165-167, in http:// joraga.net/mertola/pags/20lendas1.htm\#serpinea

CHEVALIER, Jean; GHEERBRANT, Alain (1994), Dicionário dos Símbolos. Trad. de Cristina Rodrigues e Artur Guerra. Lisboa, Teorema.

FRAZÃO, Fernanda (s/d), Lendas Portuguesas, vol. 5. Lisboa, Amigos do Livro Editores, 89-90.

LEMAIRE, Ria (1999-2001), "Mélusine - Melusina / Mélusines - Melusinas: serpentes, sereias e dragões", Revista Lusitana, Nova Série, 19-21. Centro de Tradições Populares Portuguesas "Professor Manuel Viegas Guerreiro". Universidade de Lisboa, Faculdade de Letras, 81-107.

PALAZÁN, Juan Manuel Abascal (2002), "Ataecina”, in J. C. Ribeiro (coord.), Religiões da Lusitânia - Loquuntur Saxa. Lisboa, Museu Nacional de Arqueologia, 53-60.

PONTE, Maria de la Salete da (2002), "Amuletos na Província da Lusitânia”, in J. C. Ribeiro (coord.), Religiões da Lusitânia - Loquuntur Saxa. Lisboa, Museu Nacional de Arqueologia, 269-272.

SOURDEL, Dominique (21991), O Islão. Trad. de Mariana Quintela. Mem Martins, Publicações Europa-América, col. «Saber».

SOUZA, Vasco de (2002), "Escultura e Religião na Lusitânia" in J. C. Ribeiro (coord.), Religiões da Lusitânia - Loquuntur Saxa. Lisboa, Museu Nacional de Arqueologia, 247-250.

S. TOMÁS, Frei Leão de (1644), Beneditina Lusitana, Tomo I, Cap. VII. Coimbra, Officina de Diogo de Loureiro, 438-439. 
(Página deixada propositadamente em branco) 


\title{
A FADA-MOURA: DO ESPACCO GALO-ROMANO AO ESPAÇO PENINSULAR
}

\author{
Ana Margarida ChORA \\ Universidade Nova de Lisboa
}

\begin{abstract}
Moira-fairy is a legacy from Classical Antiquity in the Middle Ages, the same character in Gallo-Roman, Celtic and Iberian cultures, which appears associated with two types of space: the first one, a generally undefined water space of chthonic connection (lakes, fountains, rivers, wells and hollows), where the fairy changes into a serpent, such as Sybil, prophetess from classical period and fairy in French texts from XIII and XIVth centuries. This changing skill links her to another important fairy in Celtic world: Morgan le Fay.

The second space type is the result of Gallo-Roman (both Celtic and Roman) and Arab mythologies fusion in Iberian territory, which appears in Iberian-Arab imaginary under the spell of charming Moorish maidens (who offer paradise in return of freedom, as the dangerous Gallo-Roman fairies). These fairies don't come directly from Arab culture, but from GalloRoman heritage and Greek Moirae, who, as Celtic fairies, were responsible for life's destiny.

Therefore, Moira-fairy is classical feminine evidence, who rules a space dominated by different cultures.
\end{abstract}

Keywords: Celtic, fairy, Gallo-Roman, Iberian, Sybil, water.

Palavras-chave: água, Celta, fada, Galo-romano, Peninsular, Sibila.

As fadas povoam o imaginário das culturas clássica, celta, galo-romana e ibérica, surgindo, com características subtilmente distintas, quer na época a que se referem, quer no contexto folclórico em que estão inseridas. A fada da cultura clássica está mais próxima das versões míticas, assumindo contornos diferentes na passagem para a Idade Média, em que uma outra variante, a celta, hegemoniza os padrões femininos do encantamento e, em contacto com rituais autóctones do domínio romano, mistura-se com as personagens feéricas galo-romanas.

A fada é, para além do tempo, senhora do espaço. Nisto, a fada celta ultrapassa todas as outras. Numa postura de preponderância espacial, ela oferece protecção, serve de guia nos caminhos misteriosos, e deixa em aberto a possibilidade do regresso e da recompensa à mercê da decisão do herói. Ela é a fada de grande cavalgada que encarna Rhiannon dos Mabinogion (testemunho literário do folclore e mitologia celtas do País de Gales), a donzela encantadora que conduz Blandin de Cornouaille ao Outro Mundo (herói epónimo de um dos dois únicos romances arturianos provençais), e a sedutora dama do conto que Andreas Capellanus, no seu De Amore do séc. XII, apresenta como exemplo 
de amor livre e descomprometido. Nestes textos, os espaços são marcados por um percurso cavalar, herdeiro da Epona galo-romana, que legou a estas fadas a capacidade da concessão da liberdade. São personagens de mediação entre os mundos, que não se fixam em nenhum deles.

À medida que a complexificação das fadas celtas as torna mais humanas, as reminiscências da tradição oral tratam de lhes conferir raízes tanto mitológicas como folclóricas. Para além dos espaços de circulação livre, a fada apresenta características de fixação a um determinado espaço. Nesse caso, a liberdade que oferece é relativa, negociada, trocada por algo ou recusada. É aqui que surge a fada-moura. Presa a um espaço específico (que pode ser aquático, ctónico ou florestal) tem uma movimentação limitada. A fada-moura ("Moira") é uma fada de lugar, cuja designação tem origem nas Moiras da mitologia grega (Cloto, Láquesis e Átropos), divindades que teciam o destino humano, assim como Moros era o deus do destino.

A água torna-se berço e morada das "Fay", as fadas celtas de uma categoria superior.

As fadas aquáticas podem ser itinerantes (como Aglentine das Prophécies de Merlin), Morgain (fada de Montgibel em Floriant et Florete) ou Niniane (que na Suite du Merlin, na Vulgata, no Lancelot en prose, surge como Dama do Lago), ou ligadas a espaços isolados do Outro Mundo, como a Dama de Avalon (como é referido no Didot-Perceval), ou ctónicos, como Gibel de Jaufré (o outro romance provençal arturiano além de Blandin de Cornouaille). Só estas últimas, presas a um espaço, são fadas-mouras. E, embora também surjam na Matéria da Bretanha, há que ter em conta o contexto em que aparecem para as podermos identificar como tal.

Niniane é a "Dama do Lago" (lago de Diana, sua madrinha e protectora). É lá que vive num sumptuoso castelo e cria três dos principais heróis do ciclo arturiano (Lancelot, Boors e Lionel). Morgain, fada simultaneamente temida e poderosa da Matéria da Bretanha, é outra dessas figuras ligadas ao elemento aquático, cujos nomes Morg-wen (espuma do mar), Murigena ("nascida do mar", em gaélico) ou ainda Muirgen (um dos nomes da mulher aquática Liban na mitologia irlandesa) se relacionam com "Merrow", do gaélico "murúch" ou "muir-gheilt", as sereias na mitologia irlandesa e escocesa, ou ainda as "morgans", sereias da Baixa Bretanha, etimologias que parecem remeter para o imaginário não só aquático como semântico das mouras.

A água é local de encontros com fadas. No Lai de Lanval de Marie de France, o herói cavalga junto a um curso de água, onde duas donzelas o conduzem aos aposentos da sua dama, que requer o seu amor. O início do Tristan en prose, do séc. XIII, narra uma peripécia de Sador, um dos doze filhos de Bron, com uma misteriosa dama vinda das águas. Ao cavalgar junto ao mar, Sador encontra uma nave com todos os navegantes mortos, à excepção de uma bela donzela, Chelinde, filha do rei da Babilónia, prometida ao rei da Pérsia, mas que Sador faz baptizar para casar com ela. O episódio encontra alguma semelhança com De Nugis Curialium de Gautier Map (séc. XII). Aqui conta-se a história de Henno "dos dentes grandes": uma dama, noiva 
do rei de França, sobrevive a um naufrágio e conhece Henno, a quem conta a sua história, que é semelhante à de Melusina, que se transforma em dragão e desaparece pelo tecto ao contacto com água benta.

Outras fadas arturianas estão ligadas a outros elementos, como o vergel (em Yvain), as rochas (que encontramos na Suite du Merlin, e a "Roche as Saines" do Lancelot en prose, onde Gamille encanta Artur), a floresta (onde a Demoisele de Pomenglois, nas Prophecies, seduzia cavaleiros), jardins bloqueados por pedras (Madoine em Claris et Laris), e vales (como o "Val sans Retor" onde Morgain actua).

Porém, uma figura galo-romana interpõe-se na Matéria da Bretanha como fada-moura por excelência. Trata-se de Sibila. Nas Prophecies de Merlin, texto arturiano em prosa do séc. XIII, "Sebile" é uma perigosa encantadeira, amiga de Morgain e da Rainha de Norgales. As três conspiram na detenção e posse de belos cavaleiros, armam as mais ardilosas ciladas e prendem-nos no paraíso prisional dos seus domínios. Em Perceforest, longo romance que mistura a Matéria Clássica com a Matéria da Bretanha, Sebile, que detém o cargo de Dama do Lago, prende Alexandre Magno no seu castelo junto a um lago encantado, no meio da bruma, com o intuito de o curar de ferimentos de batalha, mas fá-lo perder a noção do tempo e fica grávida de um filho que será antecessor da linhagem do rei Artur.

Mas é em Le Paradis de la Reine Sibylle, texto do séc. XV, que ela reúne as componentes aquática e ctónica. Antoine de La Sale propõe-se explicar a geografia dos montes da tapeçaria da duquesa de Bourbon e Auvergne, condessa de Clermont, Fourez e Beaujou, a quem dedica a obra, referindo o lago de Sibila, junto ao qual se situava o Monte Sibilino, nos Apeninos Centrais (estando a lenda ligada a Sibila, à gruta e ao lago).

O espaço sibilino é composto de características aquáticas e ctónicas que constituem entradas para o outro mundo, designadamente uma ilha rochosa no meio do lago, lugar de cultos antigos e magia, e a vila Fougia, junto ao monte, que tinha uma fonte cuja água se dizia ser proveniente do lago e da qual nascia uma ribeira, Lasno, com águas de características maravilhosas. O monte, por seu turno, tinha um castelo, Montemoynaco, perto da caverna. A rocha que coroava o monte tinha duas passagens para a entrada da caverna. Aqui ouviase uma voz que as gentes diziam ser a voz de Sibila.

O ádito da gruta sibilina, o ambiente circundante, arredores e meios de lá chegar, bem como a própria gruta, são minuciosamente descritos. A entrada, tenebrosa e obscura, veda a realidade bela e rica do interior da gruta, onde Sibila vivia acompanhada de um séquito de gentes sofisticadas, tendo como outra característica do Outro Mundo o facto de saber falar todas as línguas. Para chegar ao domínio era preciso passar por várias portas, cada uma mais ornada do que a anterior. Ao entrarem numa pequena e rica câmara, os cavaleiros eram acolhidos, despidos das suas vestes e vestidos novamente com sumptuosidade e ostentação. Havia, no entanto, regras para permanecer naquele espaço: podia sair-se ao fim de nove dias. Mas se não o quisesse, o cavaleiro poderia permanecer até ao trigésimo dia. Depois disso, jamais 
poderia sair. O prazer daquele lugar e a companhia faziam querer prolongar a saída. O cavaleiro teria de escolher uma das damas. Ao fim de algum tempo estaria preso pelo amor. Note-se que a ausência de tempo é uma característica do Outro Mundo que se revela na fada intocada pela acção do tempo.

Ligada a um lago e a um espaço rochoso, Sibila une a mitologia ao folclore, transformando-se de noite em serpente (animal simultaneamente ctónico e aquático), juntamente com os que com ela habitavam. Ela e as suas damas separavam-se dos homens e transformavam-se em cobras e serpentes de sextafeira à meia-noite até sábado à mesma hora, voltando ainda mais belas do que antes. Note-se que é o mesmo dia da semana em que Melusina se transforma em criatura aquática.

Esta fada-moura encontra eco na figura da moura peninsular, a qual não provém necessariamente da cultura árabe invasora, mas sim do imaginário feérico espacial herdado da cultura galo-romana e celta. Segundo Consiglieri Pedroso, "as mouras encantadas eram divindades ou génios femininos das águas (...). Eram também os génios que guardavam os tesouros escondidos no centro da Terra" (Pedroso 1988 217). A moura, do latim "maura" (moura) ou do celta "mahr" (espírito), é uma variante peninsular dessa fada, sendo as narrativas sobre ela esquemas simbólicos que se repetem.

A moura-serpente, ligada a espaços aquáticos (fontes, rios e ribeiras) ou transforma-se em serpente de dia, como na lenda do Castelo de Noudar (Alentejo), ou é uma figura híbrida, metade cobra, metade mulher, como na lenda do Monte d'Assaia (Barcelos). Se a primeira encarna a divisão dual do tempo, tendo ficado presa a uma metade que impede a circularidade, a segunda simboliza a mediação com o mundo subterrâneo das riquezas em troca da submissão a provas. Esta serpente liga-se ao conhecimento e remete também para a que aparece em Le Bel Inconnu, tex to francês em verso do séc. XIII, que se transforma numa bela mulher, Blonde Esmerée, depois de revelar a identidade do herói.

Esta variante ctónica encontra paralelo num conto da Baixa Bretanha, "La Groac'h de l'Île du Lok", segundo o qual uma riquíssima e bela fada viúva que habitava uma ilha num lago prendia quem disputasse os seus tesouros. A "Groac'h" (fada) põe à disposição do jovem Houam todas as suas riquezas se este aceitar casar com ela.

As mouras são guardiãs de tesouros, que na cultura peninsular são deixados pelos mouros, mas na cultura celta são tesouros próprios com os quais as fadas seduzem os homens. A moura peninsular vive aprisionada no seu próprio encantamento, por engano ou magia, mas num profundo sofrimento.

No caso do espaço aquático, na Lenda da Moura Cássima de Loulé, de acordo com Ataíde de Oliveira, as filhas do governador maometano (Zara,Lídia e Cássima) encontravam-se encantadas numa fonte e seriam desencantadas na noite de S. João. Cássima fica eternamente presa à fonte, suspirando tristemente o seu encantamento, por ter sofrido um golpe numa perna enquanto ainda encantada sob a forma de um pão. O encantamento espacial tem, na maior parte das vezes, uma conexão ao problema do andar, que reporta ao domínio, 
deslocação, capacidade de entrada, saída e circulação no Outro Mundo. A impossibilidade de se mover pode gerar a petrificação do espaço, como a Pedra-Moura, lugar aprisionador por encantamento, relacionado com grutas, rochas flutuantes ou mouras que vivem dentro das pedras.

$\mathrm{Na}$ lenda da Moura Encantada de Vinhais (Trás-os-Montes), uma princesa moura torna-se invisível para escapar ao cerco de Almutamid, ficando presa à fraga de Pena-Cabreira. Só o seu pai podia salvá-la, mas este havia desaparecido.

As mouras devem, muitas vezes, o seu desencantamento à figura paterna, com a qual têm uma relação de cumplicidade, contrariamente à fada celta, que mantém uma relação maternal com o herói ou com o pai do herói. A fadamoura peninsular é muito mais "frágil" e vitimizada. Na cultura celta, a fada prende sem se deixar prender.

Talvez o caso mais paradigmático de sedução feminina em contexto arturiano, junto a uma rocha , seja o da "Roche aux Pucelles" da Suite du Merlin. Doze donzelas, em cima de uma rocha, indicam o caminho aos cavaleiros, mas não sem antes os fazerem permanecer no seu magnífico domínio dentro da rocha. Gauvain e Morholt aceitam guarida nos aposentos, cada um escolhe a sua donzela, mas ao fim de pouco tempo estão encantados, sem terem a noção do tempo que já passou.

A manipulação feminina é também o que acontece com Merlin, preso por Niniane numa rocha. Aí é o homem que fica preso. Num caso semelhante de sedução da mulher, que resulta no aprisionamento, presente no "Romance de Reginaldo" do Romanceiro Tradicional Português, o pajem deixa-se seduzir pela infanta. Neste romance, a voz que se ouve na Noite de S. João não é de mulher, mas sim do pobre Reginaldo encarcerado ("«Não são os anjos no céu, / Nem as sereias no mar, / (...) Prende-o tu, infanta, agora, / Pois contigo háde casar»"), que ficará preso à infanta, casando com ela (Pinto-Correia 1984 301). Aqui a voz é a dos que ficam presos por causa do desnivelamento dos mundos.

A moura é uma criatura presa na passagem dos mundos. Por que razão, então, se encontram estas figuras presas ao espaço? "Sibylle, déese des lieux", como afirmou Fernand Desonay (1930 36), vive presa à rocha, ao lago e ao encantamento, assim como as demais fadas-mouras.

Em Dona Branca ou a Conquista do Algarve, poema em dez cantos sobre o amor entre uma princesa cristã (Dona Branca, filha de D. Afonso III e freira de Lorvão) e um chefe mouro (Ibn Mahfot, conhecido entre nós por AbenAfan), assunto nacional tirado da Crónica de D. Afonso III de Duarte Nunes de Leão, explorando o folclore nacional, Almeida Garrett refere-se às "mouras encantadas" (que penteiam os cabelos nas noites de São João junto às fontes) equiparando-as aos poderes mágicos celtas, na figura do sábio e travesso Merlin. Numa nota sobre o poema, diz ainda: "É crença popular entre nós que na noute de san' João todos os incantamentos se quebram: as mouras incantadas, que ordinariamente andam em figura de cobras, tomam n'essa noute sua bella e natural presença, e vão pôr-se ao pé das fontes, ou á borda 
dos regatos a pentear os seus cabellos de ouro. Os thesouros sumidos no fundo dos poços véem á tona d'agua, e mil outras maravilhas succedem em tam milagrosa noute" (Garrett 1826239 ).

Na noite de Solstício de Verão, as fadas saem do seu domínio e circulam livremente. É também essa a ideia que transmite Shakespeare em Midsummer Night's Dream, altura do festival celta do fogo que representava o meio do Verão.

Os dias que marcam as festas solares do calendário celta caracterizam-se, devido à equidade do tempo solar com o lunar, por uma aproximação dos mundos. O mundo real e o Outro Mundo ficam ao mesmo nível, podendo circular-se livremente entre eles. É por isso que seres feéricos passam para este mundo e seres do mundo real passam para o Outro Mundo. A questão reside em poder voltar ao mundo de pertença sem se ficar preso noutra lógica temporal. Daí o perigo das mouras presas, que também podem prender...

Na cultura celta, a fada nunca está presa. É ela que prende. A "Fay" era um estatuto e não um destino. É por isso que Sibila, quando referida na Matéria da Bretanha, passa ao "cargo" de fada. A fada arturiana não oferece tesouros (mas sim poder, cavalaria e o senhorio do castelo habitado). Apenas o fazem as fadas galo-romanas e peninsulares.

A fada-moura é um ser preso num dos mundos, não conseguindo transpor a barreira do tempo, como é o caso de Sibila, contrariamente a Niniane, circulando esta livremente entre a sua floresta lacustre e a corte de Artur. E não o consegue porque não tem dupla natureza, própria dos heróis medievais, principalmente celtas. A cultura celta "inventa" a composição das personagens, mas mais a nível do herói, porque é a mulher que o compõe. As "moiras" gregas, por seu turno, estão mais próximas de uma forma mais primitiva do mito, em que ainda não são compósitas.

As mouras não são oriundas do espaço árabe-muçulmano peninsular. Simplesmente, na Península Ibérica tornam-se propriedade do fascinante, maravilhoso e mágico mundo oriental herdado da mitologia árabe. E é essa magnífica síntese que prevalece no nosso imaginário.

\section{Bibliografia}

Renée L. Curtis, ed., (1985), Le Roman de Tristan en Prose. 3 vols. Cambridge, D. S. Brewer.

M. Fernanda Frazão (1982), Lendas Portuguesas, 6 vols. Lisboa, Amigos do Livro. João Baptista da Silva Leitão de Almeida Garrett (1826), Dona Branca ou a Conquista do Algarve. Paris, J. P. Aillaud.

Walter Map, De Nugis Curialium, ed. e tr. M.R. James et al.,(1983). Oxford Clarendon Press.

F. Xavier Ataíde de Oliveira (2002), Contos Tradicionais do Algarve. Lisboa, Vega.

Consiglieri Pedroso (1988), Contribuições para uma Mitologia Popular Portuguesa 
A Fada-Moura: do espaço galo-romano ao Espaço PENinsular

e Outros Escritos Etnográficos. Lisboa, Dom Quixote.

João David Pinto-Correia, org., (1984), Romanceiro Tradicional Português. Lisboa. Editorial Comunicação.

Antoine de la Sale, Le Paradis de la Reine Sibylle, ed. Fernand Desonay (1930). Paris, Droz.

Émile Souvestre et al. (1891), Contes et Légendes de Basse-Bretagne. Nantes, Société des Bibliophiles Bretons et de l'Histoire de Bretagne. 
(Página deixada propositadamente em branco) 


\title{
A MEMÓRIA DO ESPACO NO ESPAÇO DA MEMÓRIA: ENTRE A ANALISSTICA E OS PRIMÓRDIOS DA CRONÍSTICA MEDIEVAL ${ }^{1}$
}

\author{
ORLANDO GAMA \\ Instituto Politécnico de Bragança
}

\begin{abstract}
The Memory of Space in the Space of Memory: notes on Lusitania in Medieval Historiographic Narrative.

The relationship between Past and Memory isn't pacific. Reflection upon these matters requires a special attention with identity forms and narrative speech. There's no identity without memory. How possible is to study the identity in medieval times? how to read medieval iconography and thought in Iberia and Portugal's formation? We have to look forward and perceive the historicity of the identity's idea and the coexistence of different levels of identity. So, it's very important to analyse the data of narrative speech (particularly the Chronicle's) about that subjects, in connection with the evolution of the space representation and the meaning of Lusitania's idea.
\end{abstract}

Keywords: historiography, Lusitania, memory, power, space.

Palavras-chave: espaço, historiografia, Lusitânia, memória, poder.

A relação do passado com a memória não é, de todo, pacífica. Nem sequer existe uma condição de linearidade e de espontaneidade entre o vivido e o registado, na forma como cada comunidade, em qualquer época, se concebe e se identifica. Para o período que se convencionou designar de medieval, a dificuldade de análise é, naturalmente, acrescida pela distância temporal e mental que nos separam e pelas limitações de quantidade e qualidade da sua documentação.

Como se sabe, a Lusitânia começa por se definir, historicamente, como designação regional (determinando a sua futura e primordial forma na memória nacional) com a organização administrativa romana e, posteriormente, numa solução de continuidade, com a ocupação sueva e visigótica. Não cabe aqui a exploração e explicitação da complexa e abundante discussão em torno dos factores que enformam as origens da nacionalidade, nomeadamente o da permanência/alteração de estruturas político-administrativas e da sua evolução, no quadro relacional da geografia física e humana e das características sócioculturais do ocidente peninsular.

Um outro factor, estritamente ligado ao anterior, remete para as condições de manutenção do nome Lusitânia, em íntima relação com a evolução e

\footnotetext{
${ }^{1}$ Algumas notas deste texto foram editadas em Rumos e Escrita da História. Estudos em Homenagem a A. A. Marques de Almeida, ed. M. Fátima Reis. Lisboa, Edições Colibri, 2006, pp.661-679. Por sua vez, o que aqui se apresenta, por imposição das regras de publicação do presente volume, corresponde à totalidade da comunicação apresentada.
} 
limites das posteriores configurações político-administrativas vigentes no território peninsular medievo, em resultado da sua longa e atribulada trama conjuntural. Sabemos que o nome dos lugares não se desliga das condições históricas e populacionais que os caracterizam. A solução de continuidade atrás mencionada é, no entanto, quebrada, a partir do início do século VIII, pela presença árabe, que, numa leitura de época, constitui uma espécie de pausa no "natural" evoluir da história peninsular. Aliás, pura recriação discursiva. Não só porque a influência árabe foi um facto de indiscutível peso (pela duração, expressão territorial e qualidade das influências), mas também porque a Reconquista, baseada na afirmação do conceito de legitimidade jurisdicional (político-religiosa) sobre o espaço era, na verdade, remetido para o direito ao exercício da autoridade sobre a gestão desse mesmo espaço, não implicando, necessariamente, luta e expulsão, havendo muitos exemplos de coabitação ${ }^{2}$. As centúrias seguintes serão, efectivamente, ocupadas entre essa mesma Reconquista e a (re)configuração de um novo mapa político da Península, com o que isso implicou na formação de novos e afirmativos poderes e na introdução de novas visões e concepções do espaço. A Lusitânia sofre o seu primeiro grande embate. Numa realidade em aberto, em longa, disputada e difícil construção, já não havia lugar para a sua manutenção como realidade político-administrativa. Mas não foi completamente esquecida, embora não fosse do interesse, nem constituísse preocupação imediata dos reinos em formação. Renasce, então, com a identidade que lhe ficará até hoje: no seio da estruturação do discurso historiográfico, vindo mesmo a assumir, mais tarde, contornos de figura alegórica. Mas a sua ligação à realidade não foi descomprometida. A sua invocação narrativa, mesmo que residual, ou mesmo a sua ausência, em tessituras discursivas diferenciadas, só pode constituir-se em significativo sinal de valor. Na verdade, tal como adiante demonstraremos, as variantes na invocação de referentes, em contextos diversificados, projectada numa semântica historiográfica plural, são um claro sinal da forma de entender e construir a realidade, enfim, demonstrando-se, em última análise, a importância dos textos na percepção do campo mental e do aparelho ideológico dos seus produtores.

As fontes utilizadas neste breve apontamento são, na essência da sua forma e conteúdo, recorrendo à divisão notada por Pierre David ${ }^{3}$, de dois tipos: as analísticas e as cronísticas. Se bem que privilegiando as segundas. Demarcação que, para o que nos move, não é de secundarizar. Na verdade, ela revela numa primeira abordagem, uma identidade cronológica pois, como salientou o referido autor, os registos historiográficos primordiais da cultura europeia assumiram esta forma, remontando os exemplares iniciais ao século VIII, correspondendo à fixação de notas anuais inscritas nas "tábuas pascais" e transmitindo-se, em forma de estrutura e conteúdos, até às crónicas régias dos séculos XIII a XV. Num segundo patamar saliente-se que existe

${ }^{2}$ Situação semelhante à que se viveu durante a autoridade muçulmana. $C f$. J. Antonio Maravall 1964 268-269.

${ }^{3}$ Pierre David 1947. 
uma conformidade de contexto de produção e de uso eminentemente prático, que remete para o meio monástico, preocupado em compilar dados de cariz político, militar e eclesiástico, fixando a memória do que se considerava digno de registo. Note-se, no entanto, que neste grupo de fontes, a par das analísticas, encontramos já formas mais elaboradas na composição e no conteúdo, embora incipientes, comparando com os registos cronísticos posteriores (século XIII em diante). Conjunto de registos que abrem, de forma sistemática, a historiografia do ocidente peninsular, produzida a partir da reconquista. Trabalho de análise que deverá, como sempre nestes casos, ser tido por provisório, dadas as dificuldades que ainda persistem no quadro de uma necessária e urgente contextualização, delimitação cronológica e estabelecimento da tradição textual de cada um dos registos citados, e entre eles.

Numa leitura das referidas fontes, observamos que a noção de Lusitânia é utilizada com pouca frequência, sendo mencionada em cinco destes textos: na Chronica Gothorum (versão extensa e versão abreviada), na Translatio et Miracula S. Vicentii, na Vita Sancti Theotoni, nos Annales D. Alfonsi e no De Expugnatione Olisiponis A.D. MCXLVII, concretamente na Crucesignati Anglici Epistola de Expugnatione Oilisiponis. Antes de mais, verifica-se, pois, uma subdivisão entre as referências e os silêncios, ou melhor, as ausências. Neste último caso, algumas notas poderão ajudar a entender melhor esta constante. Encontramos aí fontes analísticas e narrativas que se apresentam com várias procedências, cronologia e contextos de produção. No entanto, alguns factores comuns ajudam-nos a agrupá-los e a dar algum sentido ao seu perfil e código discursivos, apesar de conscientes dos perigos que a generalização acarreta ${ }^{4}$. Mas como proceder quando, à referida genética do discurso historiográfico, se junta uma linha condutora que entra na própria estrutura do discurso narrativo posterior e mais elaborado?

Façamos uma breve abordagem no campo das fontes cronísticas. A análise, assumidamente encarada como parcial e não exaustiva, recai sobre o primeiro registo ibérico comummente considerado nesta categoria: a Primera Crónica General de España. Que mandó componer Alfonso el Sabio y se continuaba Bajo Sancho IV en $1289^{5}$. Duas razões sustentam a nossa escolha: por um lado, por ser precursora na afirmação e estruturação de um discurso cronístico régio; por outro, por ter uma identidade espacial e política (castelhana) mais vincada no contexto peninsular. Importa realçar, para o efeito, algumas notas extraídas do estudo que acompanha a publicação desta fonte:

1 - O texto da crónica não possui homogeneidade, nem na forma, nem no conteúdo. $\mathrm{O}$ reinado de Afonso $\mathrm{X}$ é marcado por vários períodos de actividade científico-literária ${ }^{6}$, com intervenção de tradutores, "ayuntadores"

\footnotetext{
${ }^{4}$ Para uma análise do tema veja-se o nosso artigo, op.cit.

${ }^{5}$ Utilizamos a edição da responsabilidade de R. Menéndez Pidal 1955. A menção a esta fonte far-se-á pela sigla $C G E$.

${ }^{6}$ Menéndez Pidal fala-nos de 2 períodos: 1250-1260 e 1269-1284, fim do reinado.
} 
ou compiladores e capituladores. Acresce o trabalho de intervenção directa do próprio Afonso X.

2 - A crónica foi concluída sob os auspícios de Sancho IV, filho de Afonso $\mathrm{X}$, tendo-se iniciado, pelo menos, em 1270 e estando ainda a ser redigida em 1289 .

3 - Constata-se uma bipartição, em dois tomos, que mais do que física, corresponde a algo constitutivo da própria Crónica, sendo cada tomo referente a cada reinado dos monarcas mencionados. Afonso $\mathrm{X}$ revela, nas suas fontes e nos conteúdos perpetuados, um significativo gosto erudito pelo passado legitimador.

4 - A divisão interna da obra é feita por partes de desigual tamanho, cada uma referente a cada senhorio que dominou España, com uma significativa falta de atenção ao domínio árabe e uma identificação, na linha dos anais e fontes anteriores, entre a história peninsular e história dos godos.

5 - Os 108 primeiros capítulos, crê-se de vários autores/compiladores, revelam uma falta de unidade e um estilo arcaizante, provavelmente de geração mais velha e com possível intervenção directa e activa de Afonso $\mathrm{X}$; na mesma linha, Menéndez Pidal aponta uma continuidade até ao final da história gótica (cap. 565), revelando uma certa unidade material com o grupo anterior; ainda de salientar que, até ao capítulo 965 (morte de Afonso VI), o texto apresenta uma característica própria: a forma de redacção aproximada às fontes anteriores - os anais - sendo, enfim, os últimos 170 capítulos significativamente diferentes, num relato mais contemporâneo, em forma e conteúdo da própria redacção.

Neste sentido, façamos uma rápida leitura dos conteúdos e do enquadramento do tema da Lusitânia neste texto. Começaremos por notar que, de acordo com o que atrás afirmámos, verifica-se uma alternância entre modos de fixação do nome ("Lusitania", "Luzenna", "Luzeña", "Lucenna"), não só, certamente, devido às múltiplas fontes e compiladores/tradutores, como também às múltiplas influências linguísticas que produziram o vernáculo, com forte influência da oralidade na grafia, particularmente em termos cujo uso quotidiano era diminuto. Comprova-se esta asserção pelo facto da aplicação do termo de origem latina (Lusitania/Lusitanna) apenas surgir nos capítulos 7 (p.10, a propósito da presença e acção povoadora de Hércules) e 77 (p. 56, sobre Sertório e Pompeu), entre a corrente utilização vernácula.

Mas afinal em que contextos surge o tema? A este propósito poderemos estabelecer algumas categorias de uso, respeitando a referida multiforme 
divisão interna da obra que destacámos nas notas iniciais anteriores. Senão vejamos:

Para os 108 primeiros capítulos,

a) a da origem e identificação do topónimo, marca da tradição clássica que permanecerá em transdiscursividade posterior, nomeadamente em textos historiográficos dos séculos seguintes - ex. cap. 3 (p.6) e 7 (p.10). Através desta referência acentua-se uma clara separação entre Portugal e a Lusitânia, com diversos antecedentes histórico-mitológicos: aquele, curiosamente, radicando a origem na Galiza; esta, demarcando uma região entre o Guadiana e o Tejo, terra dos Lusios, invocando a presença de Hércules.

b) em estreita ligação com o ponto anterior, a da afirmação da matriz espacial de origem étnica, contribuindo para a sua leitura como etnónimo cap.s 3 (p. 6, "Lusios"), 42 (p. 28, "los de Luzenna").

c) a da identidade vincada pela autonomia de "los de tierra de Luzenna" (cap. 39, p. 27), que merece o propósito do relato do episódio de Viriato ("y era natural de tierra de Luzenna", cap. 43, p. 28), aliás,

remetendo para a categoria de localização de acontecimentos históricos relevantes (passim).

Até ao capítulo 565:

procede-se à continuação do relato sobre a presença romana na península, permitindo o uso regular do tema para contextualização de acontecimentos e definição da matriz espacial da identidade peninsular. Não sem hesitações e incongruências, pois,

se mantém firme a divisão entre Galiza e Luzenna (cap. 367, p. 210; 372, p. $212 ; 374$, p. $213 ; 417$, p. 238), tal como surgira inicialmente,

ainda reforçando essa cartografia através da separação com Coimbra (cap. 423 , p. 241), fazendo recuar o limite para sul,

recupera da primeira parte (cap. 41, p. 27) a categoria de circunscrição administrativa, através da noção de "província" e admite a sua coincidência com o Algarve (cap. 366, p. 209), para mais à frente redimensionar o espaço e juntar a referência ao Guadiana e a Mérida (cap. 374, p. 213) e terminar numa significativa "provincia de Luzenna, que es tierra de Badajoz et dell Algarve" (cap. 417, p. 239).

A partir do capítulo 565:

a) o fim da história gótica e o ciclo dos reis asturianos fica, desde logo, marcado por uma significativa menção do reinado de Afonso III, levando-nos a estabelecer uma ponte com as fontes analísticas já analisadas: os $A P V$ e a sua apresentação na $C G$. Fonte de origem regional propusera, como acima vimos, uma menção enquadrada por referências espaciais coerentes com o território que viria a ser português, remetendo para a escala de leitura intermédia assumida pela Lusitânia. Na CGE, cap. 658, pp. 377-378, o mesmo assunto e cronologia, tratados significativamente de modo diferente, abreviado e omisso no que toca à Lusitânia: "[Afonso III] Et poblo en Portogal estas cibdades que 
eran destroydas de moros: Bragana, Viseo, Lamego, Edanna et el Puerto. (...) Et poblo y otrossi toda essa tierra bien fastal rio de Taio";

b) mais do nunca surgem as incongruências com o texto anterior. Atentese no cap. 673, p. 385, em que separa Mérida da "tierra de Luzenna"; no cap. 722 , p. 423, em que separa a Galiza de Luzenna pelo rio Douro (quando atrás dissera ser Luzenna o Algarve...); para, logo a seguir, distinguir a Galiza de Portugal (cap. 744, p. 443); mas, afinal, ainda consegue demarcar Portugal de Luzenna, sendo esta "tierra de Badaioz et de Mérida" (!), (cap. 805, p. 486); para, no fim, coerentemente com as conclusões que acima retirámos das fontes anteriores, aproximar, pela via da presença árabe, Portugal e a Lusitânia (cap. 815 , p. 495). Como vimos, fora esta identidade de destino que legitimara, na leitura das fontes anteriores, o papel e a acção dos monarcas portugueses (particularmente D. Afonso Henriques), bem como a matriz espacial do regnum.

c) por último, importa referir que, no conjunto dos capítulos finais (a partir do cap. 965), apenas surge uma breve menção a "Luzenna", identificada com as ribeiras do Guadiana (cap. 968, p. 649), situação coerente com um discurso de outra natureza, mais próximo cronologicamente e consentâneo com um enquadramento espacial definido pela matriz político-administrativa contemporânea da escrita.

Se bem que provisória, por questões de economia de tempo e de discurso, esta análise permite-nos perceber os efeitos da transdiscursividade e a importância de se equacionar o uso situado da linguagem, bem como a representatividade contextual do tema na evolução do discurso historiográfico. Remete-nos, ainda, para as condições de produção e recepção do textos, invocando estratégias discursivas no seio das várias tessituras de poderes e apela para a necessidade de proceder a estudos mais sistemáticos sobre a linguagem, o espaço e o poder, privilegiando perspectivas comparativas e filiações significativas.

\section{Bibliografia}

Pierre David (1947), Études Historiques sur la Galice et le Portugal du VI au XII siècle. Lisboa.

J. Antonio Maravall (1964), El Concepto de España en la Edad Media. Madrid, Instituto de Estudios Politicos, 268-269.

R. Menéndez Pidal (1955), Primera Crónica General de España. Que mandó componer Alfonso el Sabio y se continuaba Bajo Sancho IV en 1289. Madrid, Ed. Gredos. 


\title{
DA SCALLABIS ROMANA A SANCTAREN MEDIEVAL: ESPAÇO, GENTES E LENDAS
}

\author{
LiNA MARIA SOARES \\ Universidade Nova de Lisboa / CEIL-IELT
}

\begin{abstract}
When the Romans conquered Lusitania they divided it into conventi iuridici, one of them being conventus scallabitanus, where Scallabis was the name given to the territory which today is the municipality of Santarém. Under Visigoth rule, the worship of a martyr - Iria or Irene changed the name of the town to Chantirene, a name which the Moors maintained (Xantarin) and when the Charter was given to the municipality in 1179, King Afonso I had the following written: ego Alfonsus (...) per uigili astucia mei et meorum hominum opidum sanctaren sarracenis abstuli. What reasons would have had these peoples to covet this territory? The place of bloody fights that required so much effort from the first Portuguese king, it was only thanks to his cunningness and that of his men that he was able to permanently reconquer this territory. Could it be because of the fields rich in crops and pastures, fertilized by the floods of the Tejo, like the River Nile or because of the legends and mysteries that have led poets and chroniclers, throughout the centuries, to describe this territory as a place of delights?
\end{abstract}

Keywords: Abidis, cult, Iria, Santarem

Palavras-chave: Ábidis, culto, Iria, Santarém

Seguindo o percurso do herói de Homero que, depois de aportar naquela a que daria o nome de Lisboa, subiu o Tejo, vamos encontrar um outro local que igualmente o encantou, numa das margens verdejantes do rio, que é hoje a cidade de Santarém. Aí encontramos os nomes Ábidis e Iria entre pastelarias ou hotéis, figuras lendárias da fundação da cidade e que se tornaram protagonistas de crónicas, cancioneiros e romances de inúmeros autores ao longo dos séculos. Eis, pois, Santarém, majestosa na sua fértil planície, encimada pela urbe ameiada, onde o olhar se maravilha perante os domínios férteis de vinhas e pastagens deste rio que nos lembra o Nilo, o que contribuiu, sem dúvida, para que esta terra tenha sido tão cobiçada pelos diversos povos que a conheceram.

No século XVII, Manuel de Sousa Coutinho, na sua História de São Domingos, já referia o rio "que fertiliza com suas enchentes, como faz ao Egipto o seu Nilo (...) pelos montes se vêem infinitas quintas (...) cercadas de vinhas, e pomares, e hortas, regadas de fontes e arroios de águas excelentes"1. Almeida Garrett, nas Viagens, classifica esta paisagem como "um dos mais

\footnotetext{
${ }^{1}$ Virgílio Arruda 199916.
} 
belos panoramas do mundo (...) o Tejo, suas ilhotas e areais morenos (...) prados esmeraldinos (...) a planura branca das águas". Talvez tenham sido estas margens do Tejo que, no século XII, inspiraram Ibn Sara, natural de Santarém, no poema:

\section{Leva-nos uma barca,}

Qual jovem grávida,

$A$ vela panda na viração ligeira,

Sobre um rio:

Espelho puro como o paraiso

Onde se reflecte a face imperscrutável do céu².

O geógrafo Estrabão, no século I, já descrevia a lezíria como rica em cereais, vinha e azeite, referindo a existência de ouro nas areias do Tejo ${ }^{3}$.

Avieno, no século IV, na Ora Marítima, refere o ocidente da Ibéria como a região de Ofiusa, habitada pelos Sepes, entre o Douro e o Tejo; os Cempses e os Cinetes, entre o Tejo, o Guadiana e o mar; e os Lígures ou Lucis, ao norte e litoral do Douro. A Ibéria adopta este nome a partir do século III a.c., em que aparecem as primeiras referências aos Lusitanos, povos pré-célticos aparentados com os Iberos ${ }^{4}$.

Quando os romanos conquistaram a Península Ibérica, dividiram-na em três províncias: a Bética, a Citerior ou Tarraconense e a Lusitânia (esta compreendendo a área entre o Douro e o Guadiana $)^{5}$. Por sua vez, esta última dividiram-na em conventus jurídicos, sendo um deles o conventus scallabitanus, região que comportaria a actual Santarém, designada por Scallabis Praesidium Iulium ou Scallabicastrum. Pensa-se que a origem deste topónimo esteja relacionada com a lenda de Ábidis ("Esca Ábidis", que significa o manjar de Ábidis).

A lenda, sobejamente estudada por vários autores, refere-nos a passagem de Ulisses por esta região, onde se apaixona por Calipso, que a versão portuguesa diz ser filha de Gargoris ${ }^{6}$, o rei Melícola, provavelmente ligado à grande produção de mel, que seria fonte de riqueza nas margens do Tejo ${ }^{7}$. Tal como na lenda da fundação de Lisboa, Ulisses permanece alguns anos na região, e do relacionamento amoroso com Calipso, nasce Ábidis. A criança é

${ }^{2}$ Adalberto Alves 1991.

${ }^{3}$ www.ipa.min-cultura.pt/pubs/TA/folder/26/017.pdf.

${ }^{4}$ João de Barros 1952.

${ }^{5}$ C. Guardado da Silva 2004.

${ }^{6}$ descargas .cervantesvirtual.com/servlet/Sirve Obras Biblioteca Real, Libro primero de los Anales de España reducidos a Epítome: Túbal, o primeiro monarca de Espanha; Gargoris II, monarca $24^{\circ}$ de Espanha, avô de Abides (1188 a.c.).

${ }^{7}$ Fernandes Hermenegildo 1986: "Nas zonas de Almada e Palmela abundam o mel e a caça (Idrisi, 1165)". 
rejeitada pelo avô, que ordena que a ponham numa cesta, à deriva, no Tejo, à semelhança do mito bíblico de Moisés. A cesta encalha numa das margens do rio e a criança sobrevive, é alimentada por uma corça, cresce e torna-se num jovem guerreiro, mais tarde rei e fundador da localidade, lembrando-nos o mito de fundação de Roma, em que os gémeos são alimentados igualmente por uma fêmea selvagem, neste caso tratando-se de uma loba.

Decerto que o imaginário dos soldados de Roma não seria muito diferente do dos povos da Península, igualmente recheado de lendas e mitos, deuses e heróis. Se os romanos importaram os seus deuses, não aboliram os cultos já existentes nas terras que iam conquistando, antes adoptavam as divindades, mudavam-lhes os nomes, mas mantendo as características dos cultos ${ }^{8}$. Assim, as deidades cultuadas junto de rios e nascentes, deuses de fertilidade relacionados com as cheias dos rios, com o ciclo da Natureza, ou com os ciclos lunares, não teriam sofrido alterações. Até porque, e citando José d'Encarnação, "os povos do Norte e Centro de Portugal resistiram longamente à influência da religião romana" 9 .

Os Lusitanos, que viviam essencialmente da pastorícia e agricultura e habitavam em castros, prestavam culto ao deus Endovélico, de carácter ctónico e profético, de que ainda restam vestígios no santuário de S. Miguel da Mota, no Alentejo. Mas de cultos de outras deidades indígenas existem igualmente vestígios na Península, como é o caso de Ataegina, deusa ctónica da fertilidade e do renascimento, em santuários no Alentejo e na Estremadura espanhola. O que algumas vezes constatamos é determinada divindade, de que há referências documentais a localizá-la numa dada região, surgir numa outra, por vezes bastante distante.

Blázquez refere o caso de um soldado da legião VII das tropas de Adriano, que traz o culto de Conventina ou Coventene quando regressa à Galiza, tratandose de uma ninfa venerada junto de uma fonte, em terreno que é actualmente a quinta Carragwburgh, na Grã-Bretanha, culto que provavelmente se terá estendido a outras regiões do território ${ }^{10}$. E, como afirma José d'Encarnação, "Admite-se, portanto, que o natural de uma região possa cultuar noutra o deus da sua terra" 11 .

Se a ocupação romana de Santarém se fez sentir entre meados do século II a.c. e o século VI, é natural que o panteão divino se tivesse mesclado de deidades pré-romanas, romanas pagãs e romanas cristãs. Assim se explicaria a semelhança entre cultos pré-cristãos, por exemplo ligados a rios e fontes, e

\footnotetext{
${ }^{8}$ João de Barros 1952 54: "Entram no culto dos naturais as divindades romanas (...) Atégina é a deusa da fertilidade".

9 J. d’Encarnação 1975.

${ }^{10}$ J. M. Blázquez 1983.

${ }^{11}$ J. d'Encarnação 1975301.
} 
cultos cristãos com capelas, igrejas e mosteiros construídos, na maior parte das vezes, sobre antigos templos, anteriores ao cristianismo.

Nabia ou Navia, deusa aquática adorada na Lusitânia, parece ter sido cultuada a 5 de Abril, segundo a inscrição numa ara de Marecos ${ }^{12}$ e surge relacionada com nomes de rios e de localidades próximas de ribeiras e nascentes. São exemplos os rios Nábios, Neiva e mesmo Nabia ${ }^{13}$, ou a vila de Nava, na Galiza; Nabais e Nabainhos, na Serra da Estrela; Naves, povoação próxima de Envendos, região de nascentes e barragens; ou o rio Nabão, que deu origem a Nabância, a 2 km do que é hoje Tomar. Em Braga, a milenar Fonte do Ídolo, que secou há bem pouco tempo, tem uma pedra com a inscrição "Tongoe Nabiago" que algumas versões apontam como um juramento a Nabia.

Entre Tomar e Santarém, vários rios e ribeiras confluem, o Nabão com o Zêzere, e este com o Tejo, além dos pequenos cursos de água que desaguam nestes três rios, revelando-se uma região bastante fértil, propensa à adoração de deuses aquáticos ou de deusas-mães, como Nabicca, outro teónimo que se pensa igualmente relacionado com a fertilidade da Natureza.

Segundo a lenda de Santa Iria, em 653, quando a jovem professa rezava próximo de Tomar, numa capela situada na margem do Nabão, terá sido morta e lançada ao rio, vindo o corpo a navegar até Santarém. Tratar-se-ia de uma freira do convento beneditino fundado em 640 por S. Frutuoso, bispo de Braga, na margem do Nabão? Ou, de facto, nunca passara de uma lenda incomprovada?

A poucos quilómetros de Tomar, e não longe do rio, há uma povoação que tomou o nome de uma santa, igualmente assassinada e atirada ao Nabão. Trata-se de Santa Cita, uma jovem freira, de época muito anterior à da outra mártir.

Poder-se-ia aceitar, inquestionavelmente, a existência destas duas virgens do martirológio cristão, como santas portuguesas, se não fossem as suas homónimas de regiões distantes com semelhante percurso hagiográfico. Pululam as santas Irena ou Irina, bizantina, grega e romana. Se atentarmos na Vitae de Santa Irina de Magedon, nas Balcãs, que a situa no ano de 305 e aponta o seu culto para o dia 5 de Abril (e aqui saliente-se a curiosa coincidência com a data do culto a Nabia, inscrita na ara de Marecos), constatamos que a santa, depois de torturada, é fechada num túmulo, e ao cabo de uns dias, quando o abrem, o corpo terá desaparecido, o que se torna uma situação muito idêntica ao da Iria peninsular!

Se pensarmos que os Godos no século $\mathrm{V}$ dominam todo o território que pertencera ao império romano do Ocidente, não recusamos a hipótese de o culto de uma santa bizantina ter chegado até nós e se ter imiscuído fortemente,

${ }^{12} \mathrm{http}$ //groups.msn.com/HISPANIADEORVM/nabia.msnw.

13 J. M. Blázquez 1983 294: "El rio Nabia gozó de gran culto, a juzgar por el número de dedicatorias. Nabia es palabra que indica corriente de agua y que aparece con diferentes denominaciones". 
sob o comando de Rocesvindo, de tal forma que Scallabis tomou o nome de Chantirene.

Com o avanço dos povos visigóticos, a geografia dos grandes centros urbanos vai-se alterando, florescendo uns, enquanto outros, devido a guerras e saques, tendem a desaparecer. No século IV, Roma deixa de ser a capital do Império para ceder o lugar a Constantinopla, que se torna um grande porto. A partir do século VIII, com as invasões árabes, os grandes portos, como Marselha, ficam desertos. Segundo Pirenne, "No século IX, a Provença, outrora a região mais rica da Gália, tornara-se a mais pobre"14. Nascem então as cidades com função protectora das populações contra possíveis invasores. Na Península Ibérica, palco de lutas constantes entre cristãos e muçulmanos, as cidades são fortificadas - com a designação de oppidum ou castrum guardadas por cavaleiros, uma espécie de guarda permanente, ficando os que trabalham nas terras, no exterior. Em caso de guerra, toda a população se refugia no seu interior.

Os mercadores aumentam o seu poder económico, começam a fixar-se no interior das muralhas, cresce o comércio, incrementam-se as indústrias de olaria, de têxteis, de couros. A Santarém muçulmana (Xantarin) prospera, cobiçada por Afonso Henriques, e que com a "astúcia" dele e dos seus homens a tomará de assalto, como ele próprio afirma na sua carta de foro de $1179^{15}$.

A cidade escalabitana reconquistada pelos cristãos passa a chamar-se Sanctaren, e vê a necessidade, como em outras urbes reconquistadas, de reforçar a organização administrativa, dar autonomia comunal com costumes e privilégios. No mercado semanal, os camponeses dos arredores trazem os seus produtos para vender; há que se criar impostos (a portagem) para os produtos que entram e os que saem. Nobres e burgueses reagem ao poder autoritário dos bispos, tornam-se mais místicos, contribuem para a fundação de mosteiros e hospitais dos Mendicantes e dos Pregadores. Os monjes não são mais os que vivem em locais ermos, constroem mosteiros e igrejas ao longo das ruas, dentro das muralhas, e tornam-se os directores espirituais da população. Há que reforçar os cultos cristãos face aos sarracenos; as relíquias de santos e os milagres proliferam; no scriptorium dos mosteiros copiamse bíblias, hagiografias, exempla e crónicas. Nestas últimas, além das regras e vidas dos fundadores das Ordens, ensinam-se comportamentos morais e espirituais, condenam-se determinadas atitudes e faz-se a apologia de outras. Cite-se como exemplo, uma situação ocorrida em Santarém durante o reinado de D. Dinis, referida na Crónica dos Gerais da Ordem dos Frades Menores ${ }^{16}$ : "era hua molher muy pecador assombrada do diabo (...) espirando-lhe que se matasse 'se te fores ao rio, que chamam Tejo, e te lançares em ele' (...) E ela

${ }^{14}$ Henry Pirenne 197729.

${ }^{15}$ Lina Soares 2005 113: "Eu affonso polo sancto catameto. Rey do portugal per trabalho do corpo e per uulgauil arteirice minha e dos meus homéés O Castello de sanctare aos mouros tolhy e elle entregey ao sacrificio de deus e a uos meus homéés e vassalos e criados pera morar per dereyto d'erdade dey".

${ }^{16}$ Estudo e Edição Crítica, minha dissertação de Doutoramento em preparação. 
confessou-se com contriçom e lagrimas devotamente (...) por vinte anos viveo em santa conversaçom e acabou em paz os seus dias". Parece-nos que o lançarse ao rio Tejo continua, em testemunhos dos finais do século XIII, a ser uma prática sacrificial comum. E é curiosamente no tempo deste mesmo rei que, segundo a lenda, as águas do Tejo se abrem para mostrar o túmulo de mármore de Iria à rainha santa, que lhe rezava na margem, no local onde tinha aparecido outrora o corpo da mártir, e que, de novo, desaparece sob as águas do rio, tal como no culto bizantino de Santa Irena, cujo corpo nunca fora encontrado. Aliás, é provável que a rainha $\mathrm{D}$. Isabel tivesse conhecimento desse culto, dada a sua proximidade com uma das suas aias, a princesa bizantina D. Vataça.

Para que o culto se perpetuasse, mandaria o rei erigir nesse mesmo sítio um padrão com uma imagem da santa nabantina, que viria a ser restaurado no século XVIII, apresentando a forma actual.

\section{Bibliografia}

Adalberto Alves (1991), O meu coração é árabe. Lisboa, Assírio \& Alvim. Virgílio Arruda (1999), Santarém no Tempo. Câmara Municipal de Santarém.

João de Barros (1952), "Portugal na História”, Portugal Maravilhoso 1. Lisboa, Edições Universo.

J. M. Blázquez (1983), Religiones Prerromanas in Primitivas Religiones Ibericas, Tomo II. Madrid, Ediciones Cristiandad.

Maria Helena da Cruz Coelho (1986), "Vataça: uma dona na vida e na morte", separata da Revista da FLHP 3, $3^{\text {a }}$ série.

José d'Encarnação (1975), Divindades Indígenas sob o domínio romano em Portugal. Lisboa, IN-CM.

Fernandes Hermenegildo (1986), "Uma Cidade no Imaginário Medieval. Lisboa muçulmana nas descrições de Idrisi e de Ranulfo de Granville", separata de Estudos Medievais 7. Porto.

Henry Pirenne (1977), As cidades da Idade Média. Mem Martins, Europa-América, Col. Saber.

Carlos Guardado da Silva (2004), Lisboa medieval: a organização e a estruturação do espaço urbano. Lisboa, ULFL.

Lina Soares (2005), Foral Antigo de Santarém, Edição Crítica e Estudo. Lisboa, Colibri.

\section{WEBGRAFIA}

www.descargas.cervantesvirtual.com/servlet/SirveObras.pdf, Biblioteca Real, Libro primero de los Anales de España reducidos a Epitome: Túbal, o primeiro monarca de Espanha; Gargoris II, monarca $24^{\circ}$ de Espanha, avô de Abides (1188 a.c.)

http://groups.msn.com/HISPANIADEORVM/nabia.msnw.

www.ipa.min-cultura.pt/pubs/TA/folder/26/017.pdf. 


\title{
«NÃO TIREM A LUZ NEM A VISTA»: O RESPEITO PELO ESPAÇO DOS OUTROS
}

\author{
Adriana Freire Nogueira \\ Universidade do Algarve
}

\begin{abstract}
This paper will deal with the so-called Zeno's Constitution, De aedificiis privatis, designed to be applied to Constantinople but used by Justinian in all of the Roman Empire at 531. This text explains thoroughly the measures taken at that time to protect the public and private rights concerning private buildings.

Special attention will be given to the modern concerns in this area of urbanism, such as the pleasure that citizens are entitled to derive from their homes, and they will be compared with the kind of concerns that can be found in Zeno's Constitution. In order to do so, the law before his instructions will be referred to and modern laws of urbanism will be studied, notably in the MMP, or Municipal Master Plan.
\end{abstract}

Key-words: Roman law, urbanism, Zeno's Constitution

Palavras-chave: Constituição de Zenão, direito romano, urbanismo

A chamada «constituição de Zenão» ${ }^{1}$ ou De aedificiis privatis é um texto do século V d.C., que se encontra no Corpus Iuris Civilis - Codex Iustinianus. Justiniano fê-la aplicar por todo império romano a partir de 531 e é considerada uma das mais importantes peças de direito romano no que se refere a esta matéria específica do direito urbanístico (Malavé Osuna 2000 17).

De seu nome Tarasicodissa, este imperador bizantino era isauro por naturalidade (a Isáuria é actualmente a região da Antália, na Turquia), mas tomou o nome de Flávio Zenão, agradando, com este nome grego, aos súbditos do Império Romano do Oriente, que governou entre 474 e 491.

A lei que aqui está em causa, Sobre Edifícios Privados, foi escrita especificamente para a cidade de Constantinopla e explicita as medidas tomadas na época para a protecção dos direitos públicos e privados referentes a construções particulares. $\mathrm{O}$ que nos chamou especialmente a atenção foi a modernidade das preocupações, em muito semelhantes às que se sentem hoje na área do urbanismo, tais como as que se relacionam quer com o prazer que os cidadãos tiram dos seus espaços privados quer com a necessidade de preservação de qualidade de vida nos espaços públicos.

O nosso país tem em projecto a actualização do Regimento Geral das Edificações Urbanas (RGEU), mas enquanto a proposta que foi trabalhada pelo

\footnotetext{
${ }^{1}$ A tradução dos passos citados foi retirada do texto completo, vertido por nós a partir do texto grego, a pedido da Associação para o Desenvolvimento do Direito Urbanístico e da Construção - Ad Vrbem, aquando das comemorações dos 250 anos da Legislação Urbanística.
} 
Conselho Superior de Obras Públicas e Transportes (CSOPT) não é aprovada e posta em prática, continua a ser regido pelo Decreto-Lei n. ${ }^{\circ} 38382$ de 07-081951. Aliás, para este nosso trabalho, a proposta feita pela subcomissão para a revisão do RGEU, à qual tivemos acesso, não apresenta alterações nas áreas que nos interessam em concreto.

«Não tirem a luz nem a vista».

Com este título pretendíamos chamar a atenção para uma qualidade bastante valorizada aquando da compra de casas actualmente, que é a vista. Como se pode depreender, este tipo de preocupação acontece mais em zonas em que aquilo que se vê, sobretudo o mar, é um factor de atracção, para quem vem de fora, e de bem-estar, para quem já vive nesses locais.

Ter uma vista desafogada sobre o mar é privilégio de poucos, tendo os hotéis da região de onde vimos (Algarve) conseguido os melhores lugares na fila da frente. E, ou somos donos de todo o terreno que se estende até à faixa costeira (de administração marítima), ou construir uma casa em frente ao mar não garante que se possa manter as vistas.

Constantinopla (antes Bizâncio, hoje Istambul) era (e é) uma cidade marítima, como muitas no litoral algarvio e, apesar de distarem cerca de $1500 \operatorname{anos}^{2}$ as normas apresentadas por Zenão a Adamâncio, o governador da cidade, muitas delas seriam bem-vindas e a sua aplicação resolveria eficazmente muitas querelas provocadas com construções, reconstruções ou aproveitamento de ruínas para novas construções.

Há, neste decreto que analisámos, uma posição clara de esclarecimento de quaisquer ambiguidades que a legislação em vigor pudesse ter. De modo a evitar mal-entendidos verdadeiros ou falsos, fruto da imaginação dos que gostam de contornar a lei, diz Zenão:

sabemos (...) que a divina lei de imortal memória do nosso pai Leão, que foi posta aos que queriam construir aqui nesta gloriosa cidade, parece que é ambígua em algumas partes devido às concepções dos que interpretam mal (8.10.12.1a).

E, mais adiante, dá um exemplo dessa clarificação:

Posto que se diz na minha constituição também que o que está prestes a construir deve deixar doze pés entre a sua própria casa e a do vizinho, e ainda se acrescenta «mais ou menos $»^{3}$, o que provoca justamente uma grande incerteza ${ }^{4}$ (pois o que levanta dúvida não é apropriado para resolver ambiguidades), ordenamos claramente que entre cada casa haja doze pés, começando efectivamente do chão do edifício e continuando até

${ }^{2} \mathrm{O}$ mesmo tipo de semelhança, desta vez entre o aspecto da cidade Roma e as nossas actuais cidades, é referido por Robertson 1943308.

${ }^{3}$ Todas as aspas no texto são nossas.

${ }^{4}$ Seguimos a lição de H. Iordan, pois a sequência do texto mostra que se quer aclarar uma

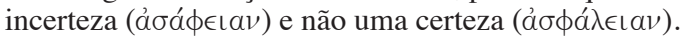

${ }^{5}$ Reforçando a escolha anterior, chamamos a atenção para a uariatio como forma de 
ao limite mais alto. (8.10.12.2).

Contudo, há, paralelamente, uma vontade evidente de não interferir em demasia com as decisões dos particulares (8.10.12.1):

Não vou impor a quem quer que seja o que deveria possuir; se o construtor possuir uma propriedade legal no edificio, para si, proveniente de acordo ou de consulta, autorizo que mude, se quiser, a forma antiga.

Esta política de não ingerência em assuntos particulares está patente neste passo em que, desde que houvesse acordo entre as partes contratantes, se autoriza (4b):

erigir os edificios (...), ainda que prejudicasse a vista para o mar daqueles que concordaram ou daqueles que lhes sucederam nas suas casas, dado que não convém destruir através de leis gerais os direitos resultantes de um acordo que já existem para alguém.

É óbvio que esses acordos só poderiam envolver as casas dos implicados e não de terceiros, a quem não poderiam deixar de respeitar elementos como as vistas, sendo estas algo diferente de entradas de luz, como se verá (8.10.12.1$2 a)$ :

Ordenamos que os que querem renovar as suas próprias casas de modo algum ultrapassem a forma anterior, de modo que os que estão a construir uma casa não tirem a luz nem a vista dos vizinhos, violando o que estava estabelecido há muito tempo (...) Aquele que obedecer a isto, que daqui em diante lhe seja autorizado a erigir a sua casa até ao limite que desejar, e rasgar tanto janelas chamadas próprias para se debruçar, como janelas para dar luz, segundo a legislação sagrada ${ }^{6}$, quer queira construir uma casa nova, quer renovar uma antiga, quer reconstruir uma que tenha sido destruida pelo fogo. [2a] Daí, de modo algum, será permitido que tire do vizinho a vista de mar que este tem, directa e não forçada, de qualquer lado da casa, quer esteja de pé nos seus aposentos, ou sentado, sem que tenha de se virar sobre si ao debruçar-se, torcido e forçado, para ver o mar.

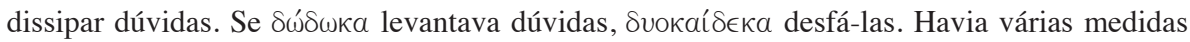
gregas que correspondiam a um pé: o pé eginético, de $0,328 \mathrm{~m}$, o pé olímpico, de 0,320 , etc, sendo mais comum o pé ático soloniano, de $0,296 \mathrm{~m}$, também usado pelos romanos. Malavé Osuna (2000 40) refere que, «a partir de Septimio Severo el pie utilizado en arquitectura seria de 0,2942 metros, por lo cual, los doce pies zenonianos equivaldrían en nuestro sistema métrico a 3,54 metros».

${ }^{6}$ Porque imperial. 
Há, contudo, situações em que a abertura de janelas não é autorizada, como quando se trata de espaços estreitos. Como foi referido atrás, não se podia construir com distâncias inferiores a 12 pés, ou seja 3,54m (8.10.12.3a-3b):

Mas se a antiga edificação e a forma anterior eram assim, com uma distância de menos de doze pés entre cada uma das casas, que não se autorize uma estrutura para além da antiga forma ou altura, nem fazer janelas, se não houver dez pés no meio; pois, nestes casos, o construtor não poderá traçar janelas para se debruçar que já não existissem antes, como foi dito, e fará janelas para dar luz de seis pés de altura a partir do solo, e de modo algum se atrevendo a fazer o chamado chão falso neste prédio ao construir janelas para dar luz, contra a referida altura de seis pés, e enganar a lei. (3b) Pois, pelo contrário, se isto fosse autorizado, as janelas para dar luz, por causa do chão falso, serviam como substituto das janelas próprias para debruçar, e iriam prejudicar o vizinho. É precisamente isso que proibimos que aconteça (...).

Assim, Zenão acautelava os vários tipos de utilização que se podiam fazer das janelas: as que facultavam a entrada de luz e as que facilitavam que uma pessoa se debruçasse, implicando que fossem mais baixas (sendo mais altas necessitariam de um chão falso) e mais largas que as primeiras, precisamente para permitir que se fruíssem confortavelmente das vistas para o mar que as casas proporcionariam.

Quando a divisão da casa de onde se podia ver o mar não era uma zona nobre, estava-se perante uma das situações em que a vista podia ser retirada (4a):

Autoriza-se impedir as vistas para o mar se estas são apenas das cozinhas ou das chamadas "latrinas»" ou "privadas», ou das escadas ou passagens para apenas um corredor de utilidades ou também destes a que a maioria chama galerias (...).

Nesta constituição previne-se ainda o abuso que poderia advir após um incêndio de um prédio, aproveitando uns para impedir a sua reconstrução, argumentando, precisamente, que esta lhes tiraria a vista (vista que não tinham originalmente e só lhes tinha sido proporcionada pelo incêndio), coibindo aqueles que sempre a tiveram de continuar a usufruir desse bem que sempre tinha sido seu. Mas o imperador esclarece que

[4] Para além disso, como a lei precedente ordenava que se autorizasse levantar até cem pés as casas anteriormente destruidas pelo fogo, mesmo que outro fosse prejudicado na vista de mar, removendo a dúvida, decretamos que isto mesmo prevaleça para as casas que foram incendiadas, quando reconstruidas, para as que não existiam antes e se construíram agora, e também para as que não tiveram danos pelo fogo mas por causa da idade ou por algum outro motivo tornaram-se uma ruina, para que todas as

${ }^{7} \mathrm{O}$ grego poderia ser traduzido literalmente por «locais para onde nos retiramos para nos aliviarmos». 
casas construídas tenham cem pés de intervalo entre elas e os lugares circundantes, sem obstáculo a que exista um prédio, mesmo se prejudicar a vista de mar de uma casa que pertença a outro.

A preocupação com a altura das casas é antiga e há registos de outras medidas, em épocas diferentes da legislação romana. Por exemplo, Estrabão refere, em 5.3,7 (final), que "César Augusto (...) reduziu a altura das novas construções e proibiu a construção junto a estradas com altura superior a setenta pés".

Este tipo de construção à beira das estradas, junto à via pública, é prevista por Zenão, especificamente no que respeita a ruas estreitas, indicando um preceito que deveria pertencer ao bom senso, mas, se foi legislado, é porque não deveria ser cumprido:

[3] A ninguém que construa uma casa seja permitido, havendo no meio uma rua estreita ou larga acima dos doze pés, por esta razão, tirar uma parte dessa rua larga ou estreita e transferi-la para o seu próprio edifício(...), para que se preservem os próprios direitos da cidade.

Assim, nem havendo uma rua estreita se podia aproveitar o próprio espaço público para alargar a sua casa, nem havendo uma rua larga se poderia fazer o mesmo, de maneira a tornar a sua casa maior.

Pelo que se pôde verificar, o prazer que se tirava de estar na sua sala a ver o mar era considerado um bem a ser preservado, tal como a privacidade necessária que se devia ter em suas casas Gostávamos de ter podido ilustrar as semelhanças ou diferenças legislativas respeitantes a este assunto que continua actual (veja-se, por exemplo, nos preços dos hotéis, a diferença de preços de quarto com vista e quarto sem vista e, dentro das vistas, a vista para a serra e a vista para o mar, sendo este último o mais caro), mas nem os Planos Directores Municipais (PDM) nem o RGEU são específicos nesta matéria.

Curiosamente, apesar de devidamente explorado e preceituado neste texto jurídico, este é o único elemento relativo ao conforto e bem-estar trabalhado no texto. A preservação de espaços verdes, por exemplo, hoje motivo de grande preocupação, não é contemplada. Aliás, para ser exacta, é, de facto, mencionada, mas expressamente colocada de parte:

[2b] Quanto aos jardins e às árvores, não se abrangeu na legislação anterior nem se vai acrescentar na presente, pois nem convém manter tal servidão.

Este documento legisla ainda sobre outras matérias que, entre nós, são de matéria cível ou criminal, como as sanções a aplicar aos transgressores e inadimplentes, por exemplo, bem como também regula pormenores estéticos.

E é com esses que terminamos, pois foi o único ponto de contacto directo encontrado entre a actual legislação e a de Zenão. O Regulamento do Plano 
Director Municipal (PDM) de Faro, ratificado em 2005, prevê, no seu Artigo $15^{\mathrm{a}}$, a protecção de «Zonas de grande sensibilidade paisagística» e é nessas que, no ponto 3 , especifica que «muros de suporte bem como os muros divisórios de propriedade, que vierem a ser autorizados nos termos da legislação que regula a $\mathrm{REN}^{8}$, deverão ser em alvenaria de pedra à vista ou revestidos com pedra da região».

Afinal, o gosto por fachadas decoradas e revestidas a superfícies laváveis (como acontece com os nossos tão utilizados azulejos) não será invenção recente. Ficamo-nos com as pedras decorativas que nos são impostas por Zenão:

[6b] Que estes edifícios ou lojas sejam embelezados com mármores do lado de fora para dar beleza a cidade e agradar a quem passa.

\section{Bibliografia}

CSOPT - Subcomissão para a revisão do RGEU - Portaria n. ${ }^{\circ}$ 62/2003 de 16 de Janeiro. Despacho n. ${ }^{\circ}$ 5493/2003

B. Malavé Osuna (2000), Legislación Urbanistica en la Roma Imperial. Universidad de Málaga.

PDM - Regulamento do Plano Director Municipal de Faro, de 1995, com as alterações introduzidas em 1998 e em 2005.

RGEU - Regulamento Geral das Edificações Urbanas. Decreto-Lei n. ${ }^{038382 / 51}$ de 7 de Agosto.

D. S. Robertson (21943), Greek and Roman Architecture. Cambridge, University Press.

${ }^{8}$ Rede Ecológica Nacional. 


\title{
André De Resende, um NOvo Alberti? \\ UM IDEÓLOGO ENTRE O PRINCEPS E O ARCHITECTUS, NA RECUPERAÇÃO DA VRBS ROMANA DE ÉVORA (1531-1537)
}

\author{
Susana Matos Abreu \\ Faculdade de Letras da Universidade do Porto / CEPESE
}

\begin{abstract}
André de Resende as a new Alberti?: an ideologist between the Princeps and the Architectus in the requalification of the Roman Vrbs of Évora (Portugal 1531-1537).
\end{abstract}

In 1531-37, when the Portuguese court moved temporary from Lisbon to Évora, this city became a stage of bold urban and architectural renovations. King John III (1521-57) commissioned there a series of improvements to host the court, which reorganized and clarified the Roman urban tissue of the city while restoring some of its ancient monuments. His plan, full of symbolic meaning, used the rhetorical power of the Roman ruins to support the increasing absolutism of his political agenda, accordingly to Alberti's ideas about the power of the ancient remains as instruments to the ruler.

The action of the humanist André the Resende (1500-73) as an expert on antiquities and archaeology is noticeable during this period, as he informs us to have been responsible for the monarch's decision to restore the supposed Roman aqueduct of Água de Prata. Moreover, one can suspect him to have guided the whole royal urbanistic, and architectural program in someway, as he also tells us that the king commissioned him the translation of the De re aedificatoria by Leon Battista Alberti (1404-72), just after having finished two other books on aqueducts at his request.

Our approach goes deeper into this conjecture, analysing a narrative that Resende wrote about the history of the city of Évora, focused on its antiquities - the Historia da Antiguidade da Cidade de Évora (Évora: André de Burgos, 1552). In this text, we can find enough potential inspiration to set the guidelines that transformed the city. The idea gets its strength when noticing some thematic and methodological similarities that exist between the Historia and its literary models found in the writings of Flavio Biondo da Forlì (1392-1463). This author, a humanist and archaeologist, was responsible - together with Alberti and others - for setting up the humanistic program of the instauratio imperii of Rome, and for inciting the subsequent renovatio urbis that took place during the pontificate of Nicholas V (1447-1455). It is possible to find striking parallels, both textual and material, between the royal plan designed for Évora as revealed by Resende's Historia and the former papal plan intended to restore the ancient grandeur of the Roman vrbs as described by Giannozzo Manetti (1396-1459). They set forth the idea that Resende acted in Évora as a counsellor to King John III, advising him about the redesign of the city's public space while taking the modern city of Rome as a model. But could this translator of the De re aedificatoria also have acted in Évora as a new Alberti, i. e., as the mediator between the princeps and the architectus, which had been both a counsellor to pope Nicholas V and a mentor to the papal architect Bernardo Rosselino? If so, Resende would probably be following the example of Alberti in Rome during the Quattrocento, as an expert on antiquities and urbanism/architecture, helping to transform the city of Évora into the new capital of the realm. 
Keywords: heritage and politics, heritage and politics, Renaissance architect, Renaissance urban requalification.

Palavras-chave: memória urbana, urbanismo renascentista, requalificação urbana e modelos literários, vestígios arqueológicos e identidade local.

Entre 1531-37, quando a cidade de Évora acolheu a corte portuguesa, o rei D. João III (1521-57) empreendeu um vasto projecto de requalificação daquela cidade, então convertida em cabeça provisória do reino. A reunião de artistas e intelectuais cedo promoveu ali um clima de euforia em torno do restauro dos valores clássicos acompanhando o florescimento do Humanismo; e o programa político joanino, tendencialmente absolutista, foi então moldado à imagem imperial de Augusto - o que derivou no cariz antiquário de tais melhoramentos (R. Moreira 1991 198-405).

A acção do humanista André de Resende (1500-73) destaca-se em Évora durante este período enquanto arqueólogo e perito em antiguidades, estando há muito associada a tal reforma urbana. É o próprio quem afirma ter convencido o monarca a restaurar um suposto aqueduto romano com o auxílio de "dous livros dos aqueductos" que escrevera a pedido do rei (A. Resende 1783: biij), certamente para dar apoio técnico às obras. A sua acção, que já por aqui se adivinha incisiva como consultor sobre hidráulica romana - tais livros deveriam tratar-se da tradução do De Aquaeductibus de Frontinus, que andava apensa ao "Vitrúvio" de 1511 -, sugere ter chegado à de conselheiro régio acerca dos restantes empreendimentos face à notícia, que igualmente dá, de o rei lhe ter encomendado ainda um "livro de architectura" (A. Resende 1783 a.v. v) - este seguramente a tradução do De re aedificatoria (Florença: Niccolo di Lorenzo Alamani, 1486) de Leon Battista Alberti (1404-72), que aparece listada no seu testamento.

O presente estudo aprofunda esta suspeita por análise da fonte de tais notícias - o texto da Historia da Antiguidade da Cidade de Évora (Évora: André de Burgos, 1552) -, a única também acerca da participação do autor na reforma da cidade. Aqui se detectam paralelismos temáticos e metodológicos com certa literatura de Flavio Biondo da Forlì (1392-1463), homem de letras e arqueólogo que foi um dos arautos do programa da instauratio imperii no pontificado de Nicolau V (1447-55). Sabe-se que as investigações arqueológicas de Biondo, registadas em tal literatura, terão ajudado outros, tais como o mencionado Alberti, a enformar o subsequente programa de renovatio urbis destinado a dar lustro à esmaecida Roma imperial enquanto capital da Cristandade (C. Smith; J. O'Connor 2006). E este, por sua vez, encontraria em tal tarefa a ocasião de reflectir acerca do valor da Arquitectura como instrumento de poder, o que registará do De re aedificatoria oferecido a Nicolau V. O jogo de espelhos - ideológico, literário e arquitectónico - que sugerimos existir na Historia de Resende, reflecte o plano urbanístico papal quatrocentista e o plano régio delineado para Évora, questionando assim que o autor, além de gloriar a cidade pelas suas "antiguidades" enquanto arqueólogo, tenha ainda actuado como mediador entre o princeps e o architectus. Nisto se 
poderia equiparar a Alberti na sua actuação enquanto ideólogo do projecto urbanístico nicolino - o que aqui propomos.

1. De Roma a Évora: modelos literários da Historia

A Historia da Antiguidade da Cidade de Évora trata-se do primeiro texto que André de Resende dedicou às antiguidades nacionais, aí se compilando, naquele que é também o primeiro ensaio peninsular sobre antiguidades e monografia de um município ibérico, o rol dos achados arqueológicos feitos pelo humanista na cidade e no seu aro. Encomendada pelas autoridades locais e redigida entre 1541-47 (já após o regresso da corte a Lisboa), a Historia trata-se ainda de um hábil manifesto político que pretende convencer o monarca a retornar a Évora e a consagrá-la como capital do reino. Para tal, André de Resende apoia a descrição das "antiguidades" na história da cidade, cuja confecção, dourando os seus pergaminhos de antiguidade, procura afagar as expectativas de D. João III de revestir-se de dignidade "à romana" (I. Sousa 1993 18-23, 54-68).

Já foi notado que teria sido concretamente no exemplo de Roma que André de Resende se terá inspirado para compor o texto (S. Abreu 2004 4-6). O autor divide-o em três partes de acordo com a concepção renascentista tripartida da História - Antiga, Medieval e Moderna - explorada por autores como Flavio Biondo da Forlì, que foi dos primeiros a utilizá-la a propósito da renovatio imperii. Como ele, Resende privilegia o esplendor romano da cidade e, após deter-se brevemente sobre o período de decadência gótica e moura, enaltecelhe a glória presente pela instauração da fé cristã. Para isso recorre a exempla: Sertório V, caudilho dos Lusitanos, é o herói do domínio romano; S. Manços, protoapóstolo que foi primeiro bispo de Évora, e Giraldo-Sem-Pavor, bravo que a reconquistou aos mouros, exaltam o passado cristão. Nesta polaridade temática Resende procura, à semelhança do humanista de Nicolau V, usar o prestígio do passado latino da cidade para realçar o presente, sem deixar de afirmar a superioridade deste último tempo por via da fé (S. Abreu 2004 6). Os vestígios arqueológicos, oscilando entre antiguidades pagãs e mirabilia cristãs, são apresentados no texto como provas materiais de veracidade factual (I. Sousa 1993 37-45). A Historia de Resende parece assim alimentar-se directamente da Roma instaurata (1444-46), onde Biondo, autor de pioneiras inventariações e descrições de "antiguidades", recorre à arqueologia para legitimar a Roma papal como continuadora da Civitas Aeterna imperial. E na Roma triumphans (1452-59) Biondo apresenta, poeticamente, uma narrativa histórica da cidade igualmente sustentada por evidências arqueológicas, a que 
a Historia de Resende se aproxima pelos objectivos, o temário e o estratagema ${ }^{1}$ (S. Abreu 2004 6).

2. O paradigma romano de renovação urbana de Évora

$\mathrm{O}$ paralelo que por aqui se estabelece entre os objectivos da Historia e os da renovatio imperii, ambos ligados na sua origem ao ideário imperial, legitimam que, em Roma como em Évora, se tenha adoptado uma estética classicizante nos novos empreendimentos urbanísticos e arquitectónicos. Mas também os modelos textuais da Historia apontam para Roma enquanto paradigma formal dos investimentos feitos em Évora: o texto de Resende parece cifrar a organização simbólico-topológica da cidade joanina na história da urbe, procurando estabelecê-la, em traços muito gerais, sobre a imagem da Roma moderna.

Para se compreender tal aderência ao paradigma não basta relembrar as qualidades do lugar de Évora tal como o autor as descreve - as colinas que rodeiam a cidade, os arredores férteis ou a relativa proximidade ao mar, mas também os malefícios que a escassez de água lhe trazia, como se lê em Vitrúvio, Frontino e Alberti a respeito de Roma. Importa ainda atender ao edificado que, segundo Resende, documenta o passado da cidade. Neste ponto, a acção de Sertório V, descrito como o verdadeiro fundador da urbe, revela-se fundamental. No seu tempo teriam sido construídas três grandes obras, cujos vestígios arqueológicos Resende identifica: 1 . as "casas" (ou palácio) onde o herói assentou a coorte; 2 . as muralhas da cidade; 3 . e o aqueduto (Resende 1783 9-10v); elenco que, pese embora magro, decreta o nascimento de Évora enquanto centro político, militar e cívico. É neste passo da Historia que o moderno arquétipo romano nas obras de Évora mais se evidencia - e, com ele, também a intuição de Resende acerca do altíssimo significado do modelo morfológico da Vrbs romana fixado na Civitas renascentista papal.

Salvaguardando diferenças de escala, verifica-se que o programa eborense se ilumina em concreto pelo vasto plano de "restauros" empreendido por Nicolau V, tal como aparece descrito no Liber Secundus de Vita ac Gestis Nicolai Quinti de Gianozzo Manetti (1396-1459) (S. Abreu 2004 6-9). Aqui, Manetti destaca os cinco grandes vectores que orientaram o plano: 1. a reparação da muralha de Aureliano; 2. a reabilitação do aqueduto de Acqua Vergine; 3 . o restauro dos melhores edifícios da Antiguidade e seu resgate ao culto cristão; 4. a construção do Borgo Vaticano, com o palácio papal; 5. e a edificação de uma nova igreja de S. Pedro (do que ficou apenas a intenção) ${ }^{2}$. Além do registo economicista e utilitário do plano, este pautou-se por rara inteligência

${ }^{1}$ Existem na B.P.E.: F. Biondo (1548), Roma ristaurata, et italia illustrata. Veneza; F. Biondo (1548), Roma trionfante. Veneza; F. Blondus (1503), De Roma Instaurata [...] de Italia Illustrata. Veneza, e ainda um Mirabilia vrbis Romae (1535). Roma.

2 "Cinque grandi emprese erano fitte nella mente del papa: il rassettamento delle mura urbane, degli acquedotti e ponti, il restauro delle 40 chiese cosidette stazionali, la nuova costruzione del Borgo Vaticano, del palazzo papale e della chiesa di S. Pietro" (apud F. Borsi 1973 37). 
do facto urbano enquanto estratificação da memória e repositório de sentidos simbólicos - ainda evidente no melhoramento da rede viária clarificando o antigo traçado romano, ou na limpeza urbana das construções parasitas que desvirtuavam os principais edifícios antigos. Os elementos destacados por Manetti denotam atenção ao valor da obra singular no seio do tecido edificado anónimo, tal como postulado por Alberti no De re aedificatoria (Argan 1998); e ainda atendem ao carácter semiológico das estruturas a que hoje chamaríamos "monumentos históricos" (F. Choay 1997; F. Choay 2000 38) enquanto marcos fundamentais do urbanismo que se pretendia realçar. Assim, não foi somente a morfologia da Vrbs que se reencenou na Roma de Nicolau V, mas também a da Civitas, estrutura material complexa que representa o Estado e o cidadão, bem como a teia de relações entre um e outro.

A hermenêutica do texto resendiano permite fazer uma leitura do espaço joanino de Évora semelhante à desta lição: também aqui os principais investimentos podem ser descritos como uma série de melhoramentos que clarificam o antigo traçado da $V r b s$ de herança romana e valorizam as estruturas singulares desse passado, à boleia de cujos sentidos simbólicos se criam novas polaridades monumentais. É concretamente da Vita de Nicolau $V$ que nos parece decalcar-se a lista dos principais investimentos: o palácio, a muralha e o aqueduto; no plano prático, foram precisamente as antiguidades sertorianas listadas na Historia, saliências simbólicas dos poderes político, militar e cívico, que constituíram os mais importantes pontos de intervenção valorativa e de restauro: 1. o repristinamento das "casas" (ou palácio) de Sertório; 2. a revalorização da muralha romana (que foi limpa de construções espúrias); 3. a reposição do suposto aqueduto romano em funcionamento. Todas estas pontuações monumentais foram articuladas com o centro cívico da época - a Praça do Giraldo -, relacionando-se com ele de modo periférico, isto de feição que se diria acompanhar a narrativa histórica de Resende por acentuar a importância romana da urbe, sem todavia deixar de conceder primazia (simbólico-topológica) ao presente (que era cristão). A obra do palácio - os actuais Paços do Concelho - acompanhou-se da regularização do traçado da praça fronteira, a qual foi então rebaptizada como "Praça de Sertório" ancorando toponimicamente o edifício no passado latino da urbe confeccionado pela Historia. As operações de desimpedimento da cerca romana, ali bem perto, deixaram a nu alguns troços desta estrutura em memória da sua antiga grandeza, concorrendo para o mesmo efeito que terá tido, noutra escala e repercussões na memória colectiva, a restituição do Aqueduto da Água de Prata à sua glória primeva em 1537. Os restantes itens do programa de Manetti não teriam escapado ao plano resendiano no âmbito de uma reconstrução do passado paleocristão da cidade ${ }^{3}$ : ainda em tempo de permanência da corte em Évora, Resende fez campanhas arqueológicas nos

${ }^{3} \mathrm{O}$ restante programa papal teve paralelo em Évora: a Sé - equivalente a S. Pedro enquanto sede do poder religioso - fora beneficiada entre 1522-25 por D. João III, que em 1528 a dotou de ornamentos. A sua contrapartida civil - os paços reais, equivalentes do Vaticano - foram alvo de vastos melhoramentos antes de a corte se instalar na cidade, em 1525. 
arredores do burgo para identificar os vestígios da primitiva basílica de S. Manços construída pelo santo, talvez na mira de que D. João III a beneficiasse. Certo é, a Historia instigará à reedificação da pequena ermida de S. Vicente (mártir documentado na Historia), que o autor supõe ter identificado nas imediações da Sé (P. Gomes 2001 36-39). Esta seria uma medida simbólica equivalente à de restauro dos melhores edifícios romanos e seu resgate para o culto cristão, tal como em Roma se fizera por competentes restauros do arquitecto Bernardo Rosselino aconselhados por Alberti - e, aqui como ali, realizados com avisado conhecimento da arquitectura paleocristã. À acção nestes "monumentos históricos" não faltou sentido de oportunidade tal como avisava Alberti no De re aedificatoria: o palácio, a muralha e o aqueduto estabelecem entre si uma triangulação simbólica justificando o nascimento do facto urbano, em raciocínio certamente estimulado pela actuação deste humanista e arquitecto na Roma nicolina.

3. André de Resende, um ideólogo entre o princeps e o architectus?

Por tudo isto, a compilação das "antiguidades" de Évora e a confecção do seu mítico passado na Historia - tarefas realizadas enquanto decorriam as obras da cidade - constituem um forte elo conceptual que une André de Resende a Alberti. Tal como esta figura explorou e documentou a arquitectura, a topografia e a história de Roma empenhado na renovatio imperii, também Resende terá agido como arqueólogo e escritor para, talvez enquanto ideólogo, enformar o programa régio de renovação da cidade de Évora "à antiga". Não existe, porém, qualquer suspeita de que tenha actuado como verdadeiro architectus tal como teorizara Alberti; mas não será que este tradutor português do De re aedificatoria se possa ter inspirado concretamente naquela figura para moldar a sua própria actuação em Évora? Enquanto tradutor de tratados técnicos e de Arquitectura, Resende assemelha-se a um novo Alberti porquanto tentando adquirir os conhecimentos científicos e a teoria arquitectural dos Antigos que lhe faltavam para assim ajudar a cumprir o programa de reforma urbana.

As considerações aqui tecidas levantam a necessidade de se interpelar as relações entre Resende e os artistas ao serviço do programa edílico joanino all'antica, nomeadamente com o arquitecto régio Miguel de Arruda e o escultor Nicolau Chanterene. Obras como a do palácio "de Sertório" ou a fonte que em tempos rematou o aqueduto em frente do palácio real (ambas de desenho e cinzel de Chanterene), e, sobretudo, a Igreja de N. Sra. da Graça (construída e ornamentada por Arruda e Chanterene), vêm alimentando a suspeita da participação de Resende nos densos programas humanísticos de que são eivadas. A fachada da igreja da Graça, particularmente, porque talvez destinada a panteão real e por exibir um programa iconográfico digno de um temple-of-fortune (R. Moreira 1991 364-405) -, sugere uma colaboração estreita entre Resende e o rei, semelhante à que se estabeleceu em Rimini entre Alberti e o poderoso Frederico Malatesta na sua intenção de representar-se publicamente "à antiga". Neste episódio (melhor conhecido que o antecedente de Roma), Alberti elaborou o desenho arquitectónico de um 
panteão sobre arrojado programa iconográfico, mediando assim as intenções daquele princeps e os executantes da obra: o arquitecto Agostino de Duccio (encarregue dos trabalhos de construção) e o escultor Matteo de'Pasti (autor da delicada escultura monumental). De facto, também tudo permite que, em Évora, Resende se tenha colocado na posição de mediador entre o dono da obra e os seus artistas, tal como Alberti terá mediado o papa Nicolau V e o arquitecto Bernardo Rosselino (o principal braço executor do projecto de Roma) - o que estudos futuros deverão indagar.

\section{Bibliografia}

S. Abreu (2004), "De Roma a Évora, com André de Resende: Cidade e 'Património' na História da Antiguidade da cidade de Évora", in @pha.Boletim 2. http:// www.apha.pt/boletim/boletim2/default.htm.

G. Argan ( $\left.{ }^{4} 1998\right)$, "O tratato De Re Aedificatoria", in História da Arte como História da Cidade. São Paulo.

F. Borsi (1973), Leon Battista Alberti. Milano.

S. Borsi (2009), Nicolò V e Roma. Alberti, Angelico, Manetti e un grande piano urbano. Firenze.

M. Carpo (1998), Architecture in the Age of Printing. Cambridge, Massachusetts; London.

F. Choay, (1997), The Rule and the Model. Cambridge, Massachussetts.

F. Choay (2000), A Alegoria do Património. Lisboa.

R. Moreira (1991), A Arquitectura do Renascimento no Sul de Portugal. Lisboa.

A. Resende (1783), Historia da antiguidade da Cidade de Euora. Lisboa.

I. Sousa (1993), André de Resende e a História da Antiguidade da Cidade de Évora. Estarreja. 
(Página deixada propositadamente em branco) 


\title{
CONTRIBUTOS PARA O ESTUDO DAS FONTES CLÁSSICAS NA PRODUÇÃO DE GÁRGULAS EM CONTEXTO QUINHENTISTA EM PORTUGAL
}

\author{
CATARINA BARREIRA \\ Bolseira da FCT
}

\begin{abstract}
: contributions for the study of classic sources in the production of figurative gargoyles in the Portuguese context of the sixteenth century
\end{abstract}

Our research concerns gargoyles as elements of monumental sculpture, integrated in religious buildings that played an important pedagogical and symbolic role from the 13th century to the 16th century. Characteristic of the Central European Gothic, gargoyles reached their apogee in the national context in the first half of the 16th century, a phenomenon for which two things contributed a great deal: the first is related to the conventual complex of Santa Maria da Vitória, Batalha, where gargoyles can be seen in all the construction, with an iconographic program unknown among us until then. The second is the presence, in Portugal, of a very significant number of artists proceeding from other countries, who were acquainted with its existence in buildings. Therefore, in the first quarter of the 16th century, a significant number of religious buildings have gargoyles, but the phenomenon of their integration and the legitimating of their iconographic programs will have continuity in buildings where classical trends can be detected. Our presentation reflects upon gargoyles sculpted under Renaissance inspiration, upon the classic aesthetic principles, revealing an important process of formal and thematic update, but also revealing some formal and iconographic persistence that will originate very special gargoyles, in particular the sculptured gargoyles made by French sculptor João de Ruão for the Manga's Cloister, in Coimbra.

Keywords: artistic persistence's, artistic news, gargoyles, Gothic, Manuelino, iconographic program, Renaissance

Palavras-chave: formas, gárgulas, Gótico, Manuelino, persistências e novidades, programas iconográficos, Renascimento e Classicismo.

\section{Introdução}

O trabalho que nos encontramos a desenvolver reflecte sobre as gárgulas figurativas enquanto elementos da escultura monumental, integradas em edifícios religiosos, que, do século XIII ao século XVI, desempenharam importantes funções, quer em termos pedagógicos, quer em termos simbólicos. Poucas vezes atraíram a atenção dos nossos historiadores de arte e talvez por isso ainda estejam por fazer os levantamentos históricos e artísticos dos edifícios nacionais onde se articulem os vários programas iconográficos 
presentes na escultura monumental com outras formas artísticas como os vitrais, os retábulos, os cadeirais, etc.

A marginalização das gárgulas face aos programas iconográficos e a produção de um discurso epidérmico que as ligou a aspectos pagãos e populares, frutos do livre arbítrio dos imaginários, retirou-lhes o carácter erudito que caracteriza uma boa percentagem das mesmas e a complexidade de alguns conjuntos. Por outro lado, fomentou-se a ligação das gárgulas a um tipo de marginalia resultante de uma fuga ao controlo iconográfico. A ser verdade, este mito anularia a principal função das gárgulas, que é a função pedagógica. Esta vocação pedagógica estabeleceu uma importante ponte com os sermões edificantes, com a literatura moralizante e com a "devotio moderna".

Em articulação com estes aspectos está o facto de as gárgulas demonstrarem de uma forma evidente a actualização dos seus autores no que concerne ao contexto da época: os melhores exemplos são as gárgulas 'índio' em Sta. $\mathrm{M}^{\mathrm{a}}$ da Vitória, pertencentes à coordenação de Mateus Fernandes e a gárgula 'rinoceronte' do claustro de Sta. $\mathbf{M}^{\mathrm{a}}$ de Alcobaça, fruto das intervenções de João de Castilho.

\section{As fontes}

Convém esclarecer desde já o que entendemos como fonte ou modelo para a realização de gárgulas. É algo bastante complexo, que articula diversos aspectos da produção artística deste tipo de escultura monumental, que vão logo desde o modo como o artista se integrou na sua época e com as mentalidades, ou seja, de que modo e porquê o artista foi influenciado pelo tecido social envolvente (religioso, artístico, cultural, económico, etc.). Não nos devemos esquecer que o processo de produção das gárgulas, para além desta componente que retirou ou não inspiração do contexto, resultou também em grande parte do percurso pessoal do artista, da sua bagagem visual, da sua imaginação e criatividade, em articulação com a aquisição de competências técnicas e tecnológicas. A partir de alguns cadernos de obras (Sta. $\mathbf{M}^{\mathrm{a}}$ de Belém, Sta. Cruz de Coimbra) lavrar gárgulas era um ofício especializado: os lavrantes dedicavam-se, em paralelo, a outras formas de escultura monumental e de vulto, como foi o caso de João de Ruão. Significativo foi também o papel dos mecenas para quem os artistas trabalhavam, que tinham uma palavra a dizer na delineação dos programas e dos temas. Por último, outro aspecto não menos importante foi a articulação dos temas representados com os destinatários, ou seja, o artista produtor de gárgulas soube distinguir os diferentes tipos de públicos - alvo e realizar programas de acordo com essa distinção. Neste âmbito, temos dois exemplos: os programas claustrais de Sta. $\mathrm{M}^{\mathrm{a}}$ de Belém e de Sta. $\mathbf{M}^{\mathrm{a}}$ de Alcobaça são diferentes, em termos temáticos, das gárgulas do exterior.

\section{As gárgulas em contexto quinhentista}

Apesar da colocação de gárgulas figurativas em edifícios religiosos ter tido o seu início entre nós no séc. XIII, as gárgulas tiveram o seu apogeu em 
contexto nacional no primeiro quartel do século XVI, fenómeno para o qual muito contribuíram dois factores. O primeiro diz respeito a Sta. $\mathrm{M}^{\mathrm{a}}$ da Vitória, onde as gárgulas, resultantes de várias campanhas e diferentes coordenações, pontuam toda a edificação, num programa iconográfico até então inédito entre nós e que recorreu a um grande e diversificado conjunto de fontes. O estaleiro batalhino espelha a evolução formal e temática das gárgulas em território nacional.

O segundo factor foi a presença, no nosso país, de um número muito significativo de artistas provenientes de outros países, familiarizados com a sua realização e colocação e, em paralelo, responsáveis pela sua renovação em termos formais e temáticos. Este fenómeno designa-se por "nomadismo artístico" e foi introduzido na historiografia artística em Portugal pela mão do professor João Barreira (1866-1961) ${ }^{1}$ questão à qual demos algum seguimento. ${ }^{2}$ A "bagagem visual" destes artistas trouxe contributos significativos para o nosso panorama artístico, mas constituiu-se como um processo duplo, pois os "nómadas" também se adaptaram à nossa escala, aos materiais e ao gosto dos comitentes. Conjuntamente, a presença de obras de arte e de tratados, oriundos do exterior, enriqueceram e dilataram o panorama artístico e, por isso, foram igualmente uma forma de "nomadismo artístico".

Assim, no primeiro quartel de quinhentos uma percentagem significativa de edificações religiosas exibia gárgulas integradas num fenómeno complexo de saturação ornamental que misturou elementos do gótico (o que constituiu um interessante caso de persistência artística) com a introdução de novidades, os elementos "à romano". Esta mescla, contribuiu para o despoletar do processo da dissolução da decoração gótica e tardo-gótica, em prol de uma crescente familiarização com algum vocabulário clássico, durante o período que, em termos cronológicos corresponde, grosso modo, ao reinado de D. Manuel, ou seja, o fenómeno da decoração "à romano" precedeu, em algumas décadas, a arquitectura renascença e os princípios estruturais clássicos.

A tendência para a mudança no panorama ocorreu a partir da subida ao trono de D. João III, embora mantendo a importância do papel desempenhado pelo "nomadismo artístico", pois tínhamos ainda uma percentagem significativa de artistas estrangeiros a trabalhar entre nós. Podemos dividir em dois os tipos de edificações religiosas com gárgulas figurativas pertencentes a esse período: por um lado, temos edifícios de charneira e proto-renascentistas, que oscilam entre as duas tendências, quer a nível estrutural, quer decorativo, por outro temos edifícios construídos já sob alguns dos princípios clássicos

\footnotetext{
${ }^{1}$ João Barreira instaura o conceito de "nomadismo artístico" em 1928, no catálogo de Portugal dedicado à Escultura, para a Exposição de Sevilha, mas desenvolve-o na "Arte Portuguesa" no volume dedicado à Arquitectura e Escultura, relativamente ao manuelino; cf. C. F. Barreira 2004 104-105.

${ }^{2}$ C. F. Barreira (2006), "João Barreira, o Manuelino e o conceito de "nomadismo artístico" in Actas do III Congresso Internacional da A.P.H.A. - Portugal na Encruzilhada da Cultura, das Artes e das Sensibilidades. Porto (in www.apha.pt/boletim4/defaultt.htm).
} 
que caracterizaram o Renascimento, como o Claustro da Manga, que vamos desenvolver.

Dentro dos edifícios de charneira e dos proto-renascentistas verificamos ainda dois tipos de situação no que concerne às gárgulas: a realização de um programa iconográfico "de raiz", como na Matriz de Torre de Moncorvo,

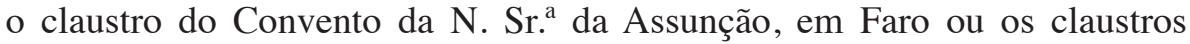
levantados por João de Castilho no Convento de Cristo em Tomar. Dada a extensão do assunto, não podemos aqui desenvolvê-lo, mas ficam as referências, importantes porque as gárgulas mantiveram uma certa valorização.

Por outro lado, temos duas intervenções pontuais, com vista à conclusão de empreitadas antes iniciadas: as gárgulas de João de Castilho em Sta. M ${ }^{\mathrm{a}}$ da Vitória; e a gárgula de Diogo de Torralva, no claustro de Sta. $\mathbf{M}^{\mathrm{a}}$ de Belém (ângulo NO). Estes dois últimos casos são particularmente interessantes porque reflectem uma certa continuidade temática em relação ao programa inicial das gárgulas, embora em ambas as situações se verifique uma actualização formal, mais flagrante em Belém, pois o programa das gárgulas do claustro reporta-se ao universo da Alquimia e da sabedoria hermética (assim como uma boa percentagem da sua decoração, segundo A. Telmo e Paulo Pereira ${ }^{4}$ ). A gárgula com que Torralva finalizou a empreitada, concluindo os dois lanços do piso superior do claustro, passadas mais de duas décadas da realização das outras gárgulas, é uma representação do protagonista da Grande Obra, o Iniciado, que exibe um barrete frígio, atributo do Adepto que identificava o seu portador como conhecedor da filosofia hermética. Esta gárgula atesta em definitivo o conhecimento, por parte de Torralva, da simbólica claustral ligada à linguagem hermética, o que lhe permitiu uma conclusão com continuidade temática.

A continuação da colocação de gárgulas em edifícios de charneira e protorenascentistas está directamente relacionada com a educação dos mestres, quer os nacionais, quer os "nómadas", educados na sua maioria em contexto tardogótico e familiarizados com a sua colocação e com um tipo de gosto que se pode caracterizar como eclético. Mas a resposta também pode ser enriquecida com o estudo das gárgulas do Jardim da Manga, que constitui o núcleo desta nossa comunicação.

\section{As gárgulas do Claustro da Manga}

O Claustro ou Jardim da Manga faz parte do complexo de edifícios do Mosteiro de Sta. Cruz de Coimbra. É constituído por um templete central, que exibe oito gárgulas no entablamento e por quatro capelas-oratórios, de planta cilíndrica, com duas gárgulas cada, a ladear a entrada, num total de dezasseis gárgulas. A partir de uma descrição de D. Francisco de Mendanha, realizada em 1541, às capelas-oratórios (cada uma dedicada a um santo eremita) acediase a partir do edifício central "por pequenas pontes levadiças que uma vez

\footnotetext{
${ }^{3}$ A. Telmo 1997 79-115.

${ }^{4}$ P. Pereira 2004 62-89.
} 
içadas dos eremitérios, permitiam aos religiosos a quebradura de laços com o exterior." 5

A autoria pertence a João de Ruão, como se pode ler no Livro de Receitas e Despesas de Sta. Cruz, de 1534-1535, fl. 18: "Item pagamos a Joham de Ruão e a Jheronymo Afonso cemto e setenta e seis mjll e seiscemtos reais pêra a obra q fizera dos cubelos na crasta terceira da pedraria laurada somente" Esta soma dividiu-se entre 140600 reais para Ruão e 36000 para o português Jerónimo Afonso.

A inovadora planta do claustro revela uma simbólica bastante complexa, constituindo-se como uma metáfora do jardim do paraíso, hortus conclusus, em articulação com noções de Numerologia, e foi fruto da iniciativa de Frei Brás de Barros (1500 - 1559) que, desde a segunda década de quinhentos, mais concretamente a partir de 1527 , foi o grande responsável pela reforma do Mosteiro de Coimbra.

Segundo a historiadora da arte Susana Abreu, "este conjunto é uma metáfora do cerne da doutrina de Henrique Hárfio exposta no "Espelho da Perfeycam", ideia com a qual concordamos. Henricus Herp foi um místico franciscano do séc. XV e a sua obra, significativa para as ordens reformadas, foi traduzida por Frei Brás de Barros em 1533. O livro faz a apologia de uma vida eremítica, ascética e despojada, onde cada um deve procurar o desapego ao mundo material, numa procura da perfeição espiritual e da rejeição do pecado.

Nas oito gárgulas do templete central somente uma representa a figura humana, um putti. Todas as outras são híbridos, pertencendo pois à esfera do bestiário. Em relação aos eremitérios, marca presença a figura humana. Vamos tentar problematizar o programa iconográfico articulando aspectos variados, uns ligados a continuidades ou persistências e outros à introdução de novidades.

No que concerne a aspectos que se ligam a persistências formais, temos as gárgulas figurativas enquanto elementos característicos do gótico e do tardogótico, inseridas numa edificação clássica. Como sabemos, o Renascimento adoptou as gárgulas-canhão, ou tubo, que depois serão substituídas pelos algerozes. Ainda neste campo, também encaramos como uma persistência o hibridismo das gárgulas do templete central. Tal hibridismo resultou do uso da analogia inusual, uma técnica criativa, fruto do pensamento analógicometafórico, que se baseia na junção harmoniosa entre diferentes partes

\footnotetext{
${ }^{5}$ Citado por S. M. Abreu 199965.

${ }^{6}$ Citado por V. Correia 1946241.

7 S. M. Abreu 199965.
} 
de diferente seres, muito comum, por exemplo, nos seres fantásticos das iluminuras e dos capitéis.

Em termos estéticos, no Gótico, este hibridismo foi legitimado e discutido pela escolástica através da categoria estética do Feio, enquanto no Renascimento o hibridismo foi conotado com o Grotesco.

Em relação a persistências temáticas, as gárgulas mantiveram aqui a função pedagógica que as havia caracterizado até então, ou seja, também neste contexto funcionaram como exempla e no templete central constituíram uma metáfora da representação dos pecados, expressa pelo bestiário, em que 0 mesmo recupera o importante papel moralizante que havia tido no seu apogeu, pois no séc. XV e inícios do séc. XVI, nas gárgulas, o pecado foi vulgarmente ilustrado através da representação da figura humana. Ainda neste âmbito, a sua inspiração na literatura de origem religiosa, de carácter moralizante, revela-se igualmente como uma forma de persistência temática, embora neste contexto associada ao humanismo reformista.

Mas nas gárgulas do Jardim da Manga também temos importantes actualizações, quer formais, quer temáticas. No campo das novidades formais, estas gárgulas são caracterizadas por uma grande expressividade, que resulta em parte da experiência do próprio artista, que se reflecte nas proporções dos corpos, mais longos, animados por movimento implícito, e na sua autonomia face à estrutura de suporte, quase uma agitação maneirista dos corpos que se contorcionam em pose serpentinata. Estão a uma grande distância plástica das primeiras gárgulas nacionais, que se projectam tão-só das paredes dos edifícios numa perpendicularidade extática, caracterizadas por uma rigidez hierática. A animosidade destas gárgulas torna-as únicas entre nós.

Em relação às novidades temáticas, a mais evidente é a representação do putti, pois é a única gárgula putti que conhecemos. A sua integração com as representações dos pecados devia ser lida na época como indiciadora da sua associação aos mesmos, em particular ao amor carnal e à condenação da sensualidade, da deleitação, do gosto e do tacto que no "Espelho da Perfeycam" Henricus condena veementemente, pois choca com a procura da perfeição espiritual.

Nos eremitérios a protagonista é a figura humana, representada como o homem do quotidiano quinhentista, mas que exibe uma expressão de horror, num rosto deformado: parece-nos que Ruão insistiu na possibilidade que cada homem tem de fuga aos pecados (a convivência do homem com o pecado deformou-lhe a expressão), na sua vocação para ser religioso e por último, na fuga do mundo através do eremitismo e do isolamento espiritual necessários à elevação religiosa.

\section{Notas finais}

Perante este cenário, onde contrapusemos as persistências e as novidades que caracterizam as gárgulas do Claustro da Manga, pretendíamos compreender e justificar a sua presença numa estrutura clássica, edificada sob princípios do Renascimento, mas onde ainda se verificam alguns aspectos medievais. As 
gárgulas evidenciam uma falha na compreensão dos princípios clássicos ou confirmam a importância pedagógica que a sua presença ainda tem perante um público-alvo específico, neste caso a comunidade religiosa masculina dos cónegos regrantes de Sto. Agostinho?

A resposta reside justamente nessa duplicidade, por princípio antagónica, em conjugar aspectos que ainda são herdeiros do universo medieval e tardomedieval, como os aspectos simbólicos da planta e as gárgulas, com a arquitectura clássica.

A fonte da Manga não constitui verdadeiramente um corte face à tradição, mas uma harmoniosa síntese entre continuidades e rupturas. A linguagem usada nesta fons vitae é a da tratadística clássica, modelo de identidade face à reforma que Frei Brás de Barros quer imprimir em Coimbra, ou seja, existe uma clara intenção de associar os valores clássicos aos valores reformistas, através de uma planta que valoriza e articula aspectos como a contemplação, a oração e o eremitismo monástico. Ora estes princípios, derivados de um desejo de renovação espiritual, saem reforçados pela presença das gárgulas cujo programa, de grande pertinência pedagógica, reflecte uma profunda articulação com o seu público-alvo.

\section{Anexos}

Gárgulas do Claustro da Manga. A primeira imagem representa uma gárgula de um eremitério. Todas as outras pertencem ao templete central.

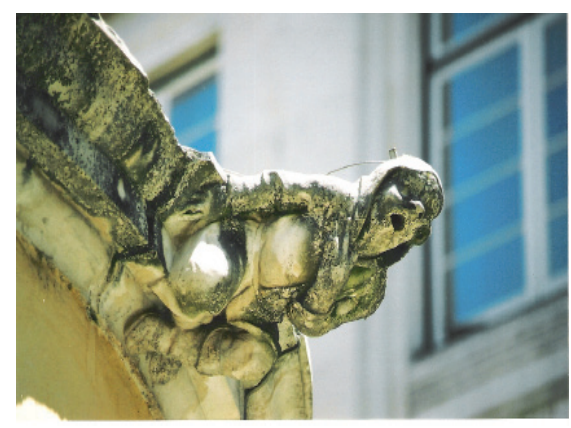

Fig.1 


\section{Catarina Barreira}

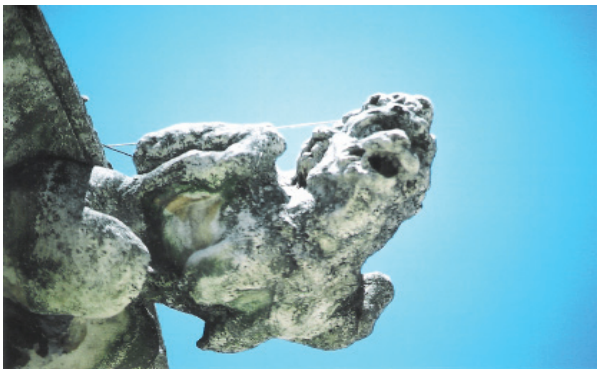

Fig.2

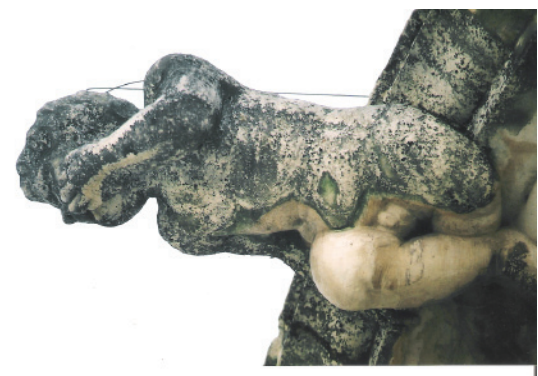

Fig.3

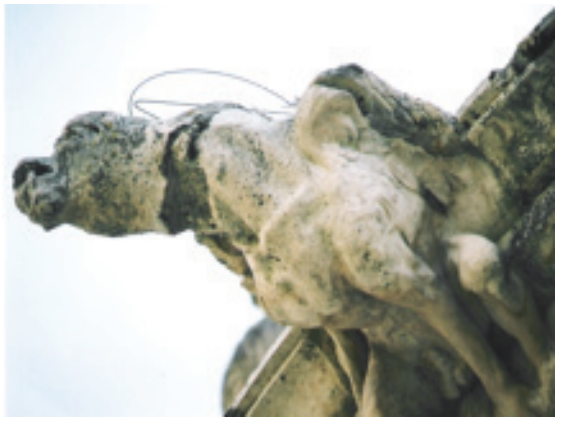

Fig. 4 


\section{Bibliografia}

S. M. Abreu (1999), A Docta Pietas ou a Arquitectura do Mosteiro de S. Salvador também chamado Santo Agostinho da Serra (1537 - 1692). Porto (dissertação de Mestrado em História da Arte em Portugal, Fac. de Letras da Universidade do Porto)

C. F. Barreira (2004), João Barreira e a Historiografia da Arte Portuguesa. Lisboa (dissertação de Mestrado, Faculdade Belas Artes, Universidade de Lisboa).

V. Correia (1946), Obras. 1. Coimbra, Imprensa da Universidade,

H. Hierp (1533), Espelho da perfeyçam: em lingoa portugues. Tradução por Frei Brás de Barros. Coimbra, Moesteyro de Sancta Cruz (Microfilme)

P. Pereira (2004), Enigmas - Lugares mágicos de Portugal. Idades do Ouro. 3. Lisboa, Círculo de Leitores.

A. Telmo (1997), Horóscopo de Portugal. Lisboa, Guimarães Editores. 
(Página deixada propositadamente em branco) 


\title{
SINAIS DE UMA CULTURA DA MONUMENTALIDADE: AS FORMAS CLÁSSICAS NA ARQUITECTURA PROGRAMÁTICA ALENTEJANA DOS SÉCS. XVI-XVII
}

\author{
Manuel F. S. Do Patrocínio \\ Universidade de Évora \\ Departamento de História
}

Centro de História da Arte e Investigação Artística

\begin{abstract}
All over the major constructive cycles that took place in Portuguese late $16^{\text {th }}$. and late $17^{\text {th }}$. Centuries, architectural treatises were the main obvious influence, giving origin both to the Mannerism and the so-called «Plain Style» local programmes and, later, at the birth of the $1^{\text {st }}$ Baroque in Portuguese arts. Vitruvian inspiration and, mostly, the lesson of Sebastiano Serlio brought to Portuguese creators the means to a new visual understatement which, nonetheless, conveyed the conceptual language of Classicism. The sense of order, ratio and reasoning was well suited to the constructive spirit of such times, having resulted in most distinctive works even in contexts of smaller scale, as in the case of accomplishments currently under survey as significant Heritage examples in the Évora territory, where they remain as signs of a longstanding tradition based on Classical formulae and aesthetics.
\end{abstract}

Keywords: Alentejo, architectural forms, architecture treatises, modern Classicism, Portuguese 'Plain-Style'.

Palavras-chave: Alentejo, Classicismo moderno, «Estilo-Chão», formas arquitectónicas, tratadística de arquitectura.

"Um edificio clássico é aquele cujos elementos decorativos derivam directa ou indirectamente do vocabulário arquitectónico do mundo antigo» ${ }^{I}$

O Classicismo formal e estético emerge da composição cultural e civilizacional que traz consigo a dignificação do indivíduo e da cidade, e que, sendo distintiva para o mundo grego, se reconhece no propósito de regra e harmonia essencial à convivência colectiva. A regra e a harmonia vieram também promulgar-se como essenciais à intenção construtiva. Neste âmbito, o classicismo arquitectónico tanto é pensamento, como linguagem que exprime esse pensamento através de elementos que são as formas construtivas ou decorativas. O modo prático como a arquitectura materializou tais pressupostos, tomou, entre os Romanos, a designação de ordem, aplicada

\footnotetext{
${ }^{1}$ J. Summerson 19943.
} 
à organização exterior com que se rematava a construção dos edifícios, na articulação proporcional do elemento coluna com o que lhe era superior: epistílio, arquitrave e friso, a cornija. Sendo a parte em que a edificação se oferecia à observação, o sistema de estrutura e super-estrutura identificará a ordem, no elemento formal que completa a obra ${ }^{2}$.

A lógica das formas e os sentidos subjacentes ao edificado constituem-se, como cerne da ideia construtiva, no âmbito do que se possa entender como uma apologia da monumentalidade, numa cultura em que a arquitectura é o objecto concreto de uma actividade, de reflexão e juízo. Nos sécs. XV-XVI, essa cultura toma uma forma escrita, ganhando estatuto de literatura. O precedente, ainda na Antiguidade, esteve na enumeração e descrição dos princípios a aplicar à arte da edificação (ou aedificatio) que coube ao protagonismo do Tratado de Vitrúvio, De architectura (séc. I), o primeiro texto a teorizar assumidamente a intervenção técnica e a propor um discurso conducente à monumentalidade, com os seus temas, num desígnio de perpetuar sentidos de memória. O discurso vitruviano comportava, de resto, uma notória marca historicista, à qual, conforme considerou Françoise Choay, se veio contrapor a concepção organicista que coube, a seguir, a Leon Battista Alberti (séc. XV), o primeiro tratadista moderno ${ }^{3}$.

Mas, ainda que com base numa justificação histórica em que se apela ao passado e à atenção ao exemplo, há um cunho de cientificidade e matematicidade em Vitrúvio, que, nomeadamente, recuperou a questão da teoria das proporções contida no anterior Cânone de Policleto (séc. V a.C.), e dirigida à arte da escultura, ou seja como técnica de aperfeiçoar a representação . Vitrúvio aplicará a proporcionalidade às relações das partes constitutivas dos edifícios, como instrumento de criação, enquanto individualiza, no âmbito das reflexões técnicas e teóricas, a objectividade da metodologia dos raciocínios de escala 4 .

O Tratado de Vitrúvio, consagrando a normatização técnica que era a súmula do Classicismo antigo e subordinando a intenção edificatória à apologia do Belo, concebe também o edifício como uma obra visual. Não havia estrutura que se pudesse desenhar que não fosse para suporte de determinados efeitos de imagem, nem imagem que se executasse, que pudesse subsistir sem tal suporte. Deste modo, as formas clássicas, resultado de ponderação, cálculo e técnica, adequavam-se não menos a sentidos estéticos, sendo um referente da interpretação da Natureza, como de significado histórico,

${ }^{2}$ Se «o património grego (...), foi o primeiro a superar uma posição étnica,», no seu «carácter de um modelo universal» (L. Benévolo e B. Albrecht 2003 200), a arquitectura clássica emerge, então, da síntese de soluções fixadas para «a arquitectura dos templos gregos e na arquitectura religiosa, militar e civil dos Romanos» (J. Summerson 1994 3).

${ }^{3}$ F. Choay 2007 133-143.

${ }^{4}$ Porque «a finalidade da proporção é estabelecer a harmonia de uma estrutura»(J. Summerson 1994 4), também as formas são elementos de valência aritmética. Portanto, «não é somente na forma das ordens em si que reside o carácter da arquitectura clássica. Na verdade, o seu carácter reside muito mais no modo como as ordens são desenvolvidas» (J. Summerson 1994 8-9). 
porque se assinalava, ao cabo das épocas, um auge no progresso humano, quanto à habilidade e domínio material. Também a emblemática dos motivos decorativos se reportaria a uma convergência com a memória, dadas as origens dos ornamentos, que teriam surgido em períodos arcaicos, persistindo nos costumes ${ }^{5}$.

No séc. XVI, Sebastiano Serlio (1475-1554) reactualiza a tratadística, oferecendo, na sua obra Regole generali d'architettura, formas e modelos visuais, que seriam, então, seguidos com o mesmo labor de ponderação que, na Antiguidade, se havia usado na programática edificada romana. A questão da concepção dos interiores é não menos importante, mas os edifícios que se fazem no séc. XVI são os que trazem já consigo a tradição europeia, formada na arquitectura cristã. As soluções de Serlio serão, sobretudo, de carácter formal. Cabe-lhe a canonização final do conjunto das ordens, que, em Vitrúvio, se consignavam ao dórico, jónico e coríntio, embora alargando-se também ao toscano, porém remetido a uma condição de uso arcaico e inscrito no cálculo do estabelecimento formal do dórico. Na obra de Serlio, o toscano, bem como o compósito, porque o primado é, agora, o do resultado da intenção de distinção das fachadas, são elevados à categoria de ordem, porque o objectivo torna-se, assim, o realce formal, conforme patente, de resto, noutro tratadista: Andrea Palladio (1508-1580), autor de I Quattri Libri dell'Architettura, de 1570 , de notável posteridade.

Mais que cópia ou retorno, ou mais do que mera ruptura com a «velha» edilícia, haverá antes uma síntese quanto à procura construtiva, que, em ciclos sucessivos, se liberta de uma antiga engenharia e acompanha o progresso do conhecimento científico, oferecendo um novo compêndio. O resumo serliano teve especial influência nos programas portugueses, sobretudo com o fomento subsequente ao reinado de D. João III (1527-1557) e, a partir de 1562, à regência de D. Henrique (futuro Cardeal-Rei), reflectindo-se em dois factos arquitectónicos como o novo Claustro do Convento de Cristo (Tomar) ou S. Vicente de Fora (Lisboa) ${ }^{6}$.

É pelo modo de aplicação das formas e no inequívoco propósito de monumentalidade que tais programas se assumem, em definição, como clássicos. A identificação das formas e elementos de ordem torna-se numa metodologia da observação da qualidade arquitectónica, fruto de recepção e

\footnotetext{
${ }^{5}$ «Ficarão surpresos com a quantidade de elementos curiosos que compõem o entablamento, todos com nomes próprios (...). Porquê mútulos, porquê tríglifos e métopas? Porquê gotas» (J. Summerson 1994 10). Seria a sobrevivência de ornamentos, ainda elaborados em madeira, que, em períodos primitivos, ornamentavam os templos, em funcionalidade ritual.

${ }_{6}$ Dada a influência de Serlio, «será pelo estabelecimento de séries morfológicas de capitéis, primeiro, e pelo reconhecimento dos sistemas de proporções utilizados (ou não) em função das ordens arquitectónicas, depois, que poderemos estabelecer com rigor científico estes importantes aspectos formais do nosso Renascimento» (J. E. Horta Correia 1991 34). Cf., também: J. E. Horta Correia 2002.
} 
transmissão de uma cultura erudita, ajudando a explicar o cerne estético de novos ciclos?

Na segunda metade do séc. XVI, também a cidade de Évora teve um surto arquitectónico importante de renovação construtiva, subdividida em dois momentos principais. No primeiro, entre 1540-1550, de fomento joanino, surgem realizações como a Igreja de $\mathrm{N}^{\mathrm{a}} \mathrm{Sr}^{\mathrm{a}}$ da Graça e a Capela do Bom Jesus de Valverde. No segundo momento, entre 1550-1570, edificou-se o Colégio do Espírito Santo, e seu complexo, e a Igreja de Santo Antão, evidenciando uma programática já tardo-quinhentista, que se acompanha em mais encomendas, com circunstância nas fundações monásticas e conventuais. Sente-se o papel pioneiro, tipológico e criativo de tais obras, de que derivam soluções técnicas e estéticas com caracterização duradoura da paisagem urbana eborense, como da paisagem monumental do território centro-alentejano. Denota-se, então, o início de clara diferenciação estilística, no meio-termo entre o Maneirismo e o vindouro «Estilo Chão», que prenuncia uma austeridade baseada no formalismo clássico.

A actual edificação da Igreja de Santo Antão comporta duas fases, subsequentes à demolição, circa 1550 , da primitiva capela medieval de Santo Agostinho e da Albergaria do Corpo de Deus (Ordem dos Templários). Na I fase (1557-1563), intervém o arquitecto Manuel Pires, que concebe o interior segundo o esquema de igreja-salão, de áreas intercomunicantes somente divididas com altas colunas. Um sismo de 1568 derruba a abóbada e, iniciandose a II fase (1570-1577), por falecimento do anterior mestre, intervêm Afonso Álvares e Brás Godinho, trazendo o aparato definitivo do templo ${ }^{8}$.

Destacam-se, a unir os três alçados da fachada, os pilares-contraforte de escala gigante e de ordem dórica, evidenciando uma concepção geométrica, em esquadria, formando módulos em que se inscreverão aberturas. Horizontalmente, definem-se igualmente três tramos, que projectam a divisão interior das naves e que estão, precisamente, divididos pelos pilares da fachada, a que se adiciona o reforço das esquinas em cunhal, nas quais, por sua vez, termina a própria Praça do Giraldo, área central do espaço urbano eborense. Em distinção, além do despojamento ornamental, a fachada não comporta, por exemplo, nichos, mas, ao invés, proporciona o rasgar de janelas em disposição

\footnotetext{
${ }^{7}$ O novo Claustro de Tomar será «o exemplo máximo da assimilação profunda dessa nova cultura reveladora das possibilidades da arquitectura portuguesa renascentista (...)», também «coeva de obras de idêntico sentido de pesquisa inovadora por parte de Andrea Palladio em Veneza», em «utilização exaustiva de uma aprofundada noção de espaço conjugada com um jogo hábil em que são utilizadas as ordens canonizadas, em composição de grande riqueza rítimica» (J. E. Horta Correia 1991 34).

${ }^{8}$ Brás Godinho era «oficial de pedraria muito competente (...), [que] levantou das ruínas todo o edifício (...), [e] teve de consolidar as colunas (...), rebocou internamente toda a obra, incluindo os fustes e fechou-se a nova cobertura» (T. Espanca 1966 247).
} 
equilibrada, repetindo a projecção vertical dos pilares, que, sendo estas janelas rectangulares, é salientada pelo respectivo recorte de moldura (fig. 1).

Ao nível da entrada, aparecendo o triplo portal, a monumentalidade adquire mais erudição, a partir da concepção com frontão triangular superior envolto num arco de volta perfeita, de simbólica triunfal, inserido no paramento e apoiando-se em pilastras que se desdobram junto aos elementos contrafortados. As portas laterais caracterizam-se pelo seu remate em duplo lintel, mais rebaixados, mas cumprindo papel essencial no equilíbrio visual, cuja dinâmica se encontra, não na projecção decorativa, mas na articulação acometida entre formas curvas, triangulares e rectas, acrescentando-se o efeito de desdobramento de forma, que surge como o duplo adintelado. Esta composição adquire, assim, o significado erudito que advém da aplicação das formas de acordo com a tratadística, sendo que em Serlio (Regoli, 1,1, 13) que encontraremos o esquema recuperado para o desenho de fachada de Santo Antão (fig. 2) ${ }^{9}$.

Salientando-se a iniciativa de uso destas formas, essenciais à identificação de um ciclo clássico eborense, Afonso Álvares teve igualmente responsabilidade na edificação da Igreja do Colégio do Espírito Santo, terminada em 1567, cabendo-lhe uma outra reconstrução significativa, também coeva: o Convento de Santa Helena do Monte Calvário. O Calvário, fundado em 1565, por instâncias da Infanta D. Maria de Portugal, seguia a regra monástica de $\mathrm{St}^{\mathrm{a}}$ Clara e S. Francisco, vindo o respectivo edifício ocupar o lugar de outra ermida medieval consagrada a Vera Cruz, cujo simbolismo se ligava à exaltação da figura de Santa Helena. Em 1569, os terrenos, sitos às Portas da Lagoa, que, a norte, se abriam na cerca amuralhada, começam a ser levantados, e, entre 1570-1578, Afonso Álvares encarregou-se do desenho. Sendo um convento feminino, não há entrada principal axial, e a respectiva monumentalização deste espaço revelou-se, então, na parede norte da igreja, que veio deter assim o papel de fachada, onde se repetiu a aplicação de pilares-contrafortados dóricos, na projecção dos tramos transversais do corpo da igreja, que se destacam com a sua base desenvolvida sobre plinto quadrangular (fig. 3).

Ao meio desta longa parede está a porta, pela qual se acedia para a igreja, também de emolduramento com lintel desdobrado. Tal emolduramento insere-se na estética formal toscana, que se fazia combinar com o dórico dos pilares, exprimindo-se assim o recurso às ordens arquitectónicas recuperadas da monumentalidade antiga, que sugeriam maior robustez e sobriedade, adequando-se à intenção austera de programas de função religiosa. A distinção

${ }^{9}$ «If a workman will make a Gate or a Door in a Temple or a Church, which is to be proportionated according to the place, then he must take the wideness within the Church, or else the breadth of the wall without. If the Church bee small, and have pilasters or pillars within it, then he may take the wideness between them, and let the same width in a four square, that is, as high as broad, in which four Square, the diagonal lines, and the other two cross cutting lines will not only thew you the wideness of the Dome, but also the places and points of the ornaments of the same Dome, as you see in this Figure» (Serlio, Regoli..., 1,1, 13; transcrição de Robert Peake, in Sebastiano Serlio 1982). 
entre toscano e dórico é sobretudo formal. Os pilares identificar-se-ão como dóricos devido à sua função estrutural, de suporte e apoio. Os emolduramentos identificam-se como toscanos, por aspectos que tanto se referem a efeitos de simplificação, como de desvio quanto às descrições vitruvianas que expunham a organização dos entablamentos, no que é, enfim, uma interpolação moderna. De facto, a origem para esta forma está no epistílio nos templos antigos, nas colunatas que suportavam uma dupla trave. A superior correspondia ao friso decorado com vários ornamentos (as placas de métopa, às vezes esculpidas, alternando com placas de tríglifo; gotas e mútulos, colocados na divisão entre trave e friso).

Em diferenciação, o toscano, mantendo a dupla trave, caracterizava-se pela ausência dos indicados ornamentos. Mas, emoldurando portais e janelas, transpõe, em imitação de forma, o efeito visual de réplica da super-estrutura dos antigos templos. Ou seja, não se tornava «útil» mas contribuía para o arranjo combinado de formas visuais, denotando o uso do decorativo do próprio elemento arquitectónico, sem que fosse necessária mais ornamentação que contrariasse o uso austero destas obras. O uso do duplo lintel, apoiado no modelo serliano, surge nas realizações de Afonso Álvares, mas prolonga-se, como forma essencial da própria arquitectura que se desenvolve a seguir (fig. 4 e 5).

O recurso manteve-se, exemplo da Igreja do Convento do Senhor Salvador do Mundo (Praça do Sertório), com tipologia de fachada que se sucede já em período filipino, composta de parede unificada, própria de espaço com nave única, em que se distinguem os cunhais reforçados de pilar, a porta monumentalizada com duplo lintel e frontão de empena, a definir um eixo vertical onde se inscreve um largo óculo redondo. O modelo repete-se no portal lateral (poente), de idênticas dimensões ao axial (fig. 6).

Reporta-se este Convento, e sua igreja, a outra comunidade instituída ainda em 1550, entretanto desalojada pela obra do Colégio do Espírito Santo, pois esse primeiro edifício ocupava os terrenos da Companhia de Jesus que foram aproveitados para o estabelecimento da Universidade. A Abadessa Catarina de Aguiar diligenciou, então, a aquisição do velho Palácio dos Condes de Sortelha, que viria a ser derrubado sobre inícios de séc. XVII. A clausura mudou-se em 1604, ano que marca o início da construção da citada Igreja e Convento, e cuja primeira missa se realizou em 1610. Conforme Túlio Espanca, esboçouse então a «alta empena de cunhais de granito emparelhado, ornamentados nos vértices por guarnição de tríglifos» e «discreto portal assente sobre três degraus, da mesma pedra, terminado por frontão triangular onde subsistem vestígios de composição pintada a fresco» ${ }^{10}$.

Os pilares exteriores da Igreja do Salvador mantêm, pois, em combinação com portais toscanos, os elementos de decoração dórica, tríglifos e gotas, na zona de remate do pilar, que, desprovido de capitel, conserva no entanto, sobre a sua gola e a saliência de equino, uma zona apta à função de friso; na

10 T. Espanca 1966231. 
verdade, a cornija da parede prolonga-se pelo pilar, em continuidade. Surge, neste desenho, o que se designa precisamente como ordem abreviada, método não menos decisivo para a caracterização arquitectónica deste período, pois corresponderá ao cerne técnico que, apoiado na tratadística, origina o «EstiloChão» português, e que surgia também aplicado na fachada da Igreja de Santo Antão ${ }^{11}$ (fig. 7).

Ciclos posteriores prolongarão tais soluções de depuramento formal, mantendo-se no próprio arranque do Barroco português, em realizações já da época de D. Pedro II e persistindo o uso de formas clássicas na tradição portuguesa. Um caso de interesse está na Vila de Mourão, que, embora sendo de fundação leonesa, parece ter sido reconstruída nos finais do séc. XVII, talvez indicando a importância que grupos sociais locais adquiriram na sequência da Restauração.

Com efeito, o Castelo foi o único vestígio construtivo medieval que se manteve na Vila, correspondendo os restantes exemplos a obras subsequentes a 1681, em que se confere, por Decreto régio, instrução para a reconstrução da Igreja Matriz, consagrada a $\mathrm{N}^{\mathrm{a}} \mathrm{Sr}^{\mathrm{a}}$ das Candeias, de que existira um anterior templo manuelino. Reedificada entre o alinhamento das muralhas, onde está em proeminência visual, destaca-se, na fachada, a respectiva esquadria, demarcada por pilares, gigantes, em xisto, cruzados com molduras horizontais que definem as linhas de alçado. Mas o Barroco anunciava-se no nártex reentrante, que, pela primeira vez, corta o sentido rígido das linhas de frontaria vigentes (fig. 8).

Foi engenheiro responsável D. Diogo Pardo Osório, arquitecto militar, que, no séc. XVII, esteve também envolvido nos projectos de arranjo dos sistemas defensivos alentejanos, de que resultou não só a edificação dos revelins e baluartes em torno da Muralha de Évora, como a própria cerca seiscentista de Mourão, sobranceira ao Castelo e que obrigara à demolição do núcleo adjacente, onde estava, de resto, a velha igreja. As ruas da Vila terão mantido um sentido linear, semi-radial quanto ao ponto de partida de que o Castelo é o centro, mas que, de qualquer forma, seria já o anterior. Porém, outras marcas subsistiram, nomeadamente, os nichos de altar dispostos por várias ruas, que servem o propósito das celebrações da Paixão. Certo é, tais altares, inicialmente sete, indicando as Estações dos Passos do Senhor, seguem ainda o modelo erudito serliano, clássico, com abertura encimada de frontão triangular $^{12}$ (fig. 9 e fig. 10).

Indissociáveis, pois, de uma paisagem cultural única, todos estes exemplos de uma arquitectura programática são, por definição, clássicos, e não apenas

\footnotetext{
${ }^{11}$ Ordem abreviada é aquela onde os elementos formais da arquitectura se compõem a partir da «economia de alguns dos seus elementos constituintes» (P. Varela Gomes 2002 187). Com efeito, «a cornija servirá de capitel, diz Serlio»; assim temos «uma ordem apilastrada dórica na qual parte do capitel aparece em ressalto sobre o entablamento. A cimalha e o ábaco do capitel desaparecem sob a cornija e o friso do entablamento» (P. Varela Gomes 2002 188).

${ }^{12}$ Dos cinco Passos subsistentes, o que está na Rua Machado Santos comporta o cronograma de 1698. Na Praça da República conserva-se igualmente, num friso de janela de duplo lintel
} 
porque decorrem de uma linguagem e um pensamento construtivo, com sintaxe formal de origem antiga. São clássicos pelo pensamento que lhes está subjacente quanto a valores de equilíbrio, proporcionalidade, harmonia e imponência monumental, ainda que adequando-se ao propósito austero, mas reatando o sinal visível de uso e organização das formas arquitectónicas que exprimiam uma cultura erudita, a qual era, assim, apanágio de encomendas promovidas pela iniciativa régia ou eclesiástica que se alargavam a uma geografia definida. 


\section{Anexos}

Fotografias de Manuel F. S. Patrocínio (Évora e Mourão) e Clara Duarte Oliveira (Évora)

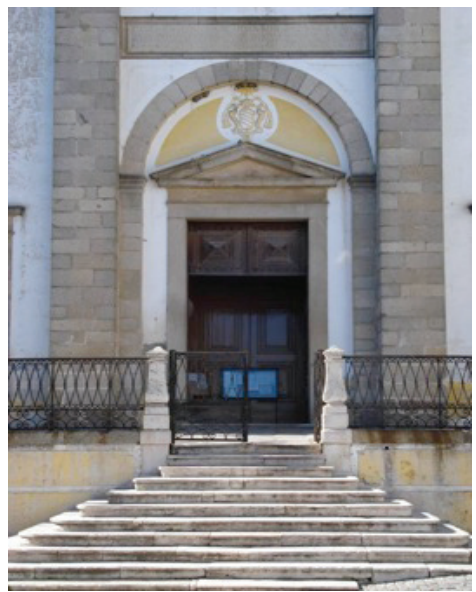

Fig.1 . Manuel Pires, Afonso Álvares e Brás Godinho. Igreja de Santo Antão. Évora (1577). Fachada axial. Acesso e portal central emoldurado entre arco redondo e pilares-contraforte centrais

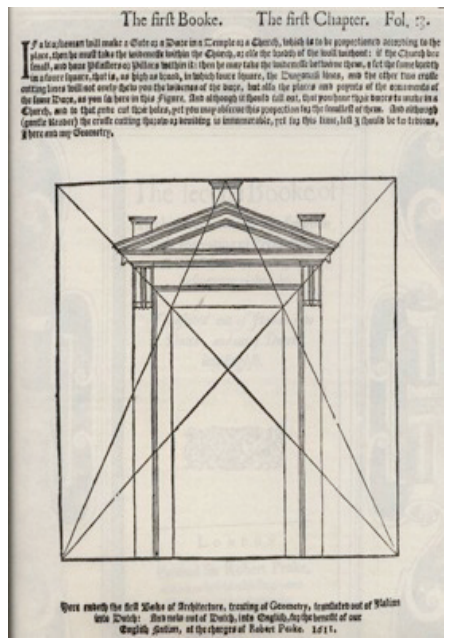

Fig.2. Sebastiano Serlio (1537). Modelo de portal dórico, in The Five Books of Architecture. Nova Iorque,

Ed. Robert Peake [1611] (1982, edição facsimile), 1,1, fl. 13 


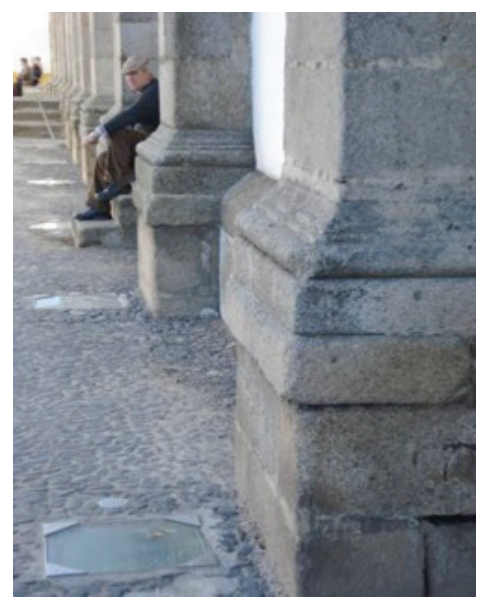

Fig.3. Afonso Álvares. Igreja do Convento de Santa Helena do Monte Calvário. Évora (1578). Fachada lateral. Detalhe dos embasamentos dos pilares-contraforte

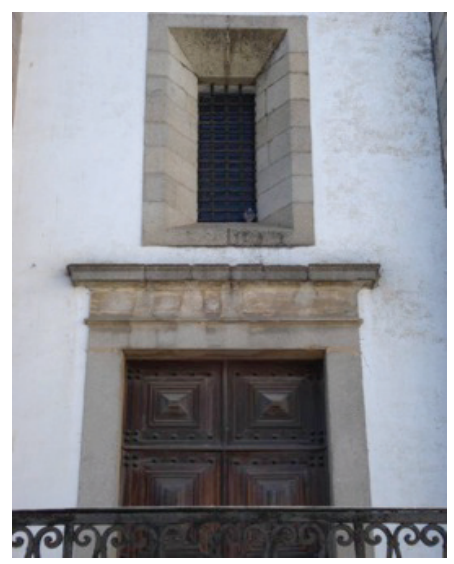

Fig.4. Igreja de Santo Antão. Évora (1577). Fachada. Detalhe do portal lateral nascente, com duplo adintelado, e abertura superior 


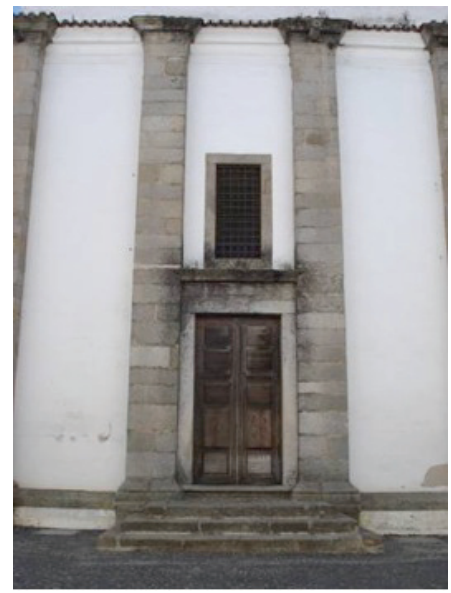

Fig.5. Igreja do Convento de Santa Helena do Monte Calvário. Évora (1578). Fachada lateral. Detalhe do portal central, com duplo adintelado, e articulação com abertura superior entre pilares-contraforte

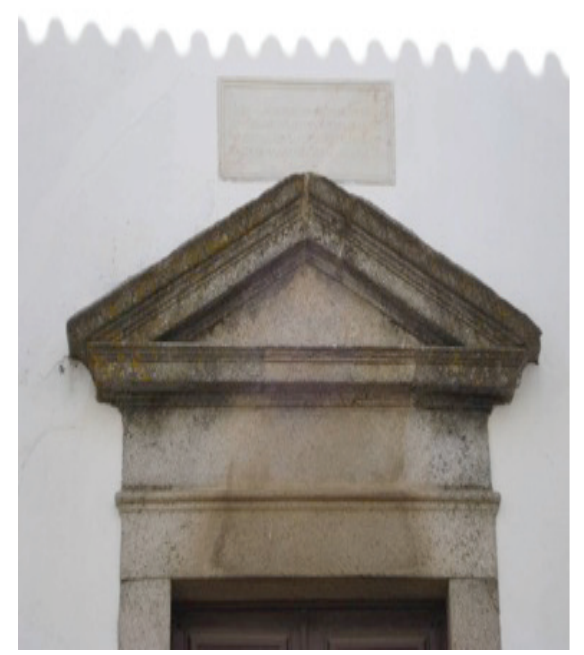

Fig.6. Igreja do Convento do Senhor Salvador do Mundo. Évora (1610). Fachada lateral poente. Detalhe do portal central, com duplo adintelado e frontão triangular com cornija e múltiplo ressalto 


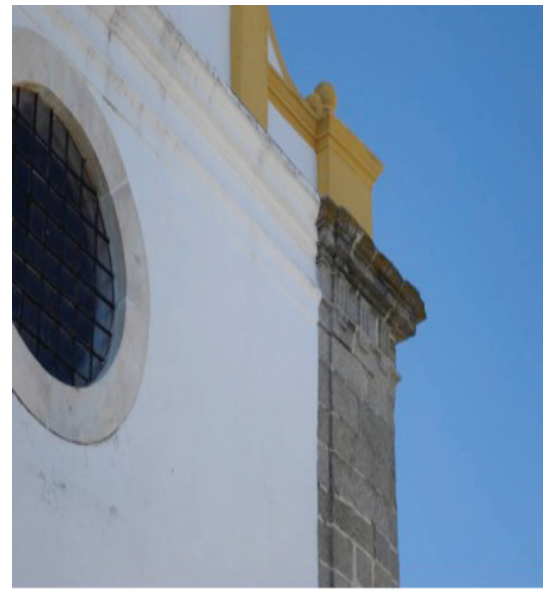

Fig.7. Igreja do Convento do Senhor Salvador do Mundo. Évora (1610). Fachada axial. Detalhe de óculo, friso contínuo liso e cornija de múltiplo ressalto e cunhal com elementos decorativos de tipologia dórica

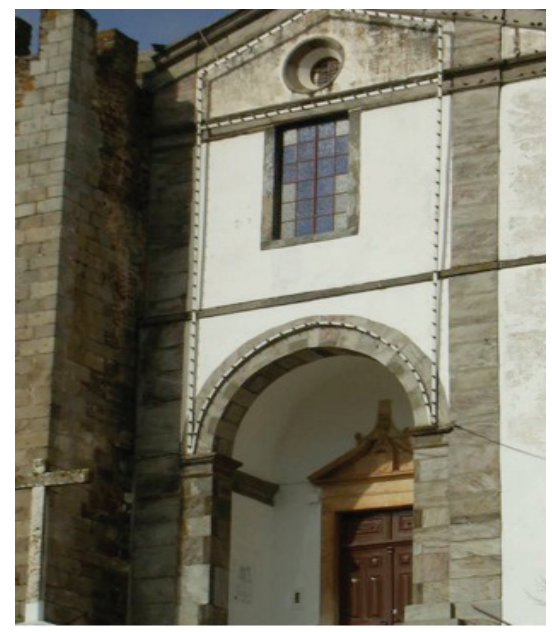

Fig.8. Diogo Pardo Osório. Igreja-Matriz de Nossa Senhora das Candeias. Mourão (ca. 1690). Fachada axial. Detalhe do portal central, entre pilares-contraforte inscritos e torreão da muralha medieval, com nártex reentrante sob arco redondo e em articulação com abertura superior e óculo no tímpano de frontão 


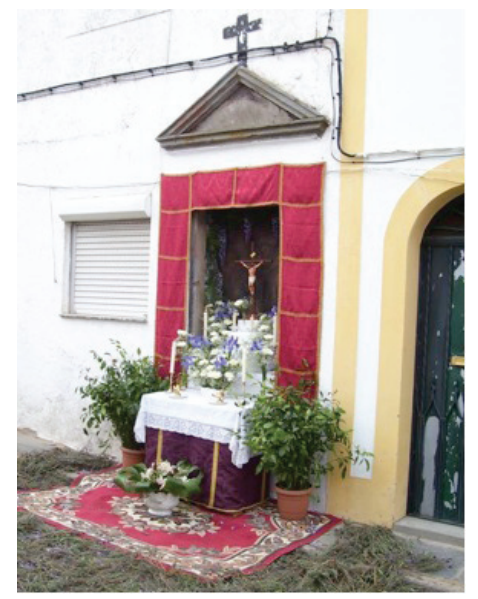

Fig.9. Estação dos Passos da Paixão do Senhor. Rua Joaquim José Vasconcelos Gusmão, Mourão (ca. 1690-1700). Aspecto geral, com arranjo para as festividades da Páscoa

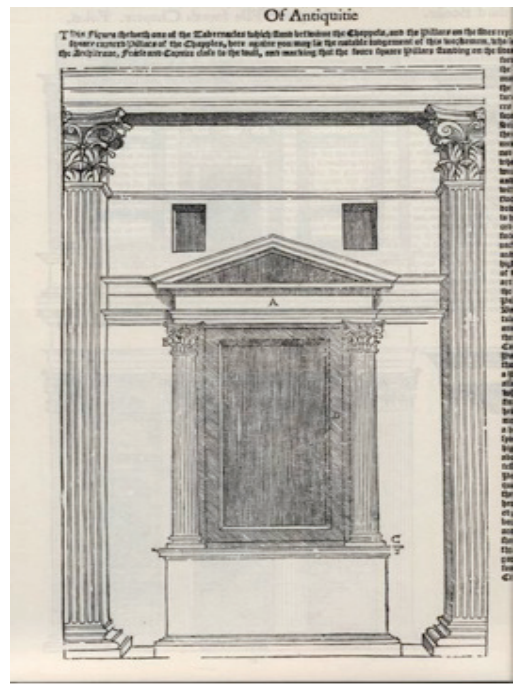

Fig.10. Sebastiano Serlio (1537). Modelo de altar coríntio, in The Five Books of Architecture. Nova Iorque, Ed. Robert Peake [1611] (1982, edição facsimile), 3, 4, fl. 16 


\section{Bibliografia}

1. Fontes tratadísticas

Sebastiano Serlio (1982) The Five Books of Architecture. Nova Iorque Ed. Robert Peake [1611] (edição facsimile).

Vitrúvio (2006), Tratado de Arquitectura. Ed e trad. M. Justino Maciel. Lisboa

2. Referências teórico-críticas

Leonardo Benevolo e Brenno Albrecht (2003), As Origens da Arquitectura. Lisboa. Françoise Choay (2007), A Regra e o Modelo. Casal de Cambra.

John Summerson (1994), A Linguagem Clássica da Arquitectura. S. Paulo.

3. Referências monográficas

J. E. Horta Correia (1991), Arquitectura Portuguesa. Lisboa.

J. E. Horta Correia (2002), “A importância da arquitectura de programa na História do Urbanismo português", in Actas do V Congresso Luso-Brasileiro de História da Arte. Faro 161-170.

Túlio Espanca (1966), Inventário Artístico de Portugal. Concelho de Évora. Lisboa.

Paulo Varela Gomes (2002), "Ordem abreviada e moldura de faixas, Contribuição para a discussão do conceito de 'Estilo Chão"', in Actas do V Congresso LusoBrasileiro de História da Arte. Faro. 


\title{
A MURALHA, O TEMPLO E O AQUEDUTO NA TRADIČ̃̃O DE SERTÓRIO CONSTRUTOR DA ÉVORA ROMANA (SÉCS. XVI-XIX).
}

\author{
PaUlo Simões Rodrigues \\ Universidade de Évora \\ Departamento de História e Centro de História da Arte \\ e Investigação Artística
}

\begin{abstract}
By writing the History of Antiquity of the City of Évora (1553), André de Resende gave rise to a historiographic tradition that considered the presence of Sertório in Évora, city where he supposedly lived, a certainty, as well as his responsibility in the edification of the first belt of walls of the city, and in the edification of the temple and supposed aqueduct. Although it is based on fragile and very empirical associations of Roman architectonic traces present in the city with the archeology and readings of Plutarch, who mentions the presence of the Roman general in Hispania, such a tradition was cyclically revisited and revitalized until the nineteenth century, by authors like Diogo Mendes de Vasconcelos, Manuel Fialho, António Franco, Francisco da Fonseca, and Augusto Filipes Simões. The longevity of the tradition is explained by the manner in which the material evidence that supposedly confirm it was used to ascertain the antiquity of Évora and the relevance of its past, which was more ancient than the Kingdom itself and whose relevance was confused with that of the Roman Empire. We propose to address such a tradition because it demonstrates the perennial nature of history and classical culture as a paradigm of civilization, and also demonstrates how this paradigm was able to shape the way in which all the successive ages interpreted Roman architecture.
\end{abstract}

Keywords: architecture, Évora, historiography, monuments, Sertorius

Palavras-chave: arquitectura, Évora, historiografia, monumentos, Sertório

No ano de 1864, o número 6 do jornal Archivo Pittoresco abria com uma gravura do aqueduto de Évora, designadamente do troço que entra na área intramuros, sobre o pano da muralha, entre a Porta da Lagoa e a Porta de Avis, no flanco nordeste da cidade. Destaca-se a imagem pela representação, no limite do eixo que o aqueduto traça, acima da cota do muro da cerca, da torre circular de uma Mãe de Água, decorada com elementos clássicos, em tudo igual a outra que existia frente à fachada da Igreja de S. Francisco, desmantelada em 1872. Segundo o texto que acompanhava a gravura, da autoria do escritor Inácio Vilhena Barbosa (1811-1890), um dos fundadores e principais redactores do Archivo Pittoresco, a Mãe de Água que aparecia na ilustração, juntamente com a do largo de S. Francisco, eram estruturas remanescentes do primitivo aqueduto romano, mandado construir pelo general Quinto Sertório no século I a.C. e reconstruído por D. João III no século XVI. O desenho clássico das duas torres - com as suas colunas dóricas, os nichos, a abóbada e a lanterna - e o 
uso de tijolo para as edificar corroboravam essa asserção e fundamentavam a denominação que o artigo lhe atribuía: "Aqueducto de Sertorio"1.

Nem a imagem, nem a teoria que a imagem ilustrava constituíam novidade em 1864. A imagem repetia uma já publicada no L'Univers Pittoresque, cuja primeira versão portuguesa saiu impressa no Archivo Popular. O seu provável modelo terá sido uma gravura editada pelo Magasin Pittoresque (tome III, $\mathrm{n}^{\circ}$. 49, Décembre, p. 385) em 1835, em que o ângulo da visão do espectador está mais aproximado da figuração da Mãe de Água. Quanto à teoria da fundação romana do aqueduto, comprovada pela sobrevivência das duas torres, havia sido já veiculada por Vilhena Barbosa no mesmo periódico, no ano anterior ${ }^{2}$.

Embora a imagem e o artigo que o Archivo Pittoresco havia dedicado ao aqueduto de Évora tivessem, efectivamente, a finalidade da divulgação de um conhecimento estabelecido e não de uma descoberta arqueológica ou de uma conclusão historiográfica recentes, padeciam de uma incongruência que o historiador Augusto Filipe Simões (1835-1884), então a dirigir a Biblioteca Pública de Évora, se apressou a denunciar nas páginas do jornal eborense Folha do Sul. Num artigo que intitulou sintomaticamente de "O aqueducto de Evora e o Archivo Pittoresco", declarava aquilo que todos os eborenses sabiam: a Mãe de Água representada na ilustração do Archivo Pittoresco e um dos sustentáculos da tese da origem romana do aqueduto, partilhada por Vilhena Barbosa, não existia ${ }^{3}$. Apenas a torre sita no largo de S. Francisco era real.

Vilhena Barbosa reage ao artigo de Augusto Filipe Simões dirigindo-lhe uma carta justificativa, na qual explica que a intenção da gravura do Archivo Pittoresco era reconstituir graficamente uma estrutura que não existia de facto, mas que, segundo o humanista e arqueólogo eborense André de Resende (c. 1500-1573), teria existido igual "na fórma e na architectura" ao de S. Francisco ${ }^{4}$. André de Resende referir-se-ia aos dois pavilhões como romanos numa sua Apologia pelo aqueducto de Sertorio contra D. Miguel da Silva, bispo de Vizeu, texto desaparecido, mas que Vilhena Barbosa afirmava ter consultado através de uma cópia do século XVII ou XVIII ${ }^{5}$.

Percebe-se por que razão Vilhena Barbosa recorreu a André de Resende como argumento de autoridade para defesa do seu artigo. Enquanto autor de História da Antiguidade da Cidade de Évora, obra de cariz historiográfico publicada em 1553, ele fora o primeiro a associar aquela urbe alentejana a Quinto Sertório, o general romano que, em conformidade com as fontes

${ }^{1}$ I. V. Barbosa 1864.

${ }^{2}$ I. V. Barbosa 1863.

${ }^{3}$ I. V. Barbosa 1867a.

${ }^{4}$ A missiva de I. V. Barbosa foi posteriormente publicada pelo próprio no jornal Archivo Pittoresco, no n. ${ }^{\circ} 5$ de 1867 , p.34-35.

5 Juntamente com a Apologia, Vilhena Barbosa também terá consultado cópias da correspondência trocada entre o humanista eborense e o Bispo de Viseu. Todos estes documentos, Apologia e correspondência, seriam duplicados, redigidos com letra de finais do século XVII ou dos inícios do século XVIII, de outras cópias guardadas na livraria do Conde do Vimieiro. I. V. Barbosa 1867b. 
literárias latinas ${ }^{6}$, teria vivido na Hispânia durante as guerras civis do século I a.C. No texto de Resende, Évora era apresentada como a principal residência na Península Ibérica do general romano, a quem atribuía a responsabilidade pela construção da sua primeira cintura de muralhas e do primitivo aqueduto da Água da Prata: "Item mandou Sertório cercar a cidade de cantaria lavrada, como se inda em muitas partes mostra por onde é a cerca velha, e assi fez trazer a água da Prata ao pórtico [muito provavelmente o templo] em o mais alto da cidade"

$\mathrm{Na}$ sequência imediata da afirmação citada, André de Resende alude efectivamente a uma "apologia ou resposta que contra o bispo de Viseu" escrevera, por motivo de este prelado, escrivão da puridade de D. João III, ter declarado ao rei que os romanos nunca haviam edificado um aqueduto em Évora, nem sequer Sertório tinha alguma vez morado na cidade transtagana ${ }^{8}$. Diogo Mendes de Vasconcelos (1523-1599), amigo e biógrafo de André de Resende, no seu Libro V do Municipio Eborense, publicado em latim no ano de $1593^{9}$, corrobora a redacção da dita Apologia ... ao mencionar a sua intenção de a mandar imprimir, juntamente com outras pequenas obras do mesmo autor, para que não se perdessem ${ }^{10}$. À Apologia ... ter-se-iam seguido dois opúsculos mais desenvolvidos sobre aquedutos, redigidos por Resende a mando do rei, a quem os entregou no início de 1543 e dos quais também se perdeu o rasto ${ }^{11}$.

Apesar de hoje não podermos conhecer os conteúdos quer da Apologia, quer dos dois opúsculos dedicados aos aquedutos, as circunstâncias da sua produção, a edificação do Aqueduto da Água da Prata em Évora e a controvérsia gerada com D. Miguel da Silva, permitem-nos compreender melhor o esforço investido por André de Resende na demonstração cabal da presença de Sertório em Évora, alicerçando-a num testemunho empírico muito concreto, uma inscrição epigráfica que transcreve no capítulo III da História

${ }^{6}$ Plutarco (Sertório), Apiano (História Romana), Lúcio Floro (Epitome da História de Tito Livio), Paulo Orósio (História Contra os Pagãos), Valério Máximo (Factos e Ditos Memoráveis), Frontino (Strategemata), etc. A. Resende 1996 159-160.

${ }^{7}$ A. Resende 1963 17-18.

${ }^{8}$ A. Resende 196318.

${ }^{9}$ Publicado por necessidade de completar De Antiquitatibus Lusitaniae (As Antiguidades da Lusitânia) de Resende, cujo Livro Quatro, o último, que trata das cidades, não inclui Évora.

10 “Ao qual [D. Miguel da Silva, bispo de Viseu] tam compridamente respondeo Rezende com h ua muy fermoza Apologia, que nella paresse emborcou e esgotou em favor da Patria os escondidos thezouros, e arrecadados cabedais de suas antiguidades e sabedoria. [...] Esta Apologia temos nõs tençam de mandar imprimir juntamente com outras obrinhas delle, que separadamente foram impressas, e ja estam esquecidas e quazi consumidas e acabadas". D. M. Vasconcelos, "Libro V do Municipio Eborense", in B. J. S. Farinha 178545.

11 "Também falei disso em dous livros dos aquedutos que a El-Rei, Nosso Senhor, per seu mandado escrevi e, portanto, agora nom é necessário torná-lo repetir. Antes me parecia que os mesmos livros, porquanto tratam como se devem fazer os aquedutos e como conservar, se deviam ajuntar a este tratado e às vezes se lerem para que deles se tomasse algua utilidade, se a neles há". A. Resende 1963 18. "Há alguns anos, tendo-me eu dirigido a Almeirim, para ver o rei e lhe oferecer dois opúsculos que a seu pedido eu compusera sobre aquedutos". A. C. Ramalho 1982 48-352. Ver ainda S. Deswarte 1992b 171. 
da Antiguidade da Cidade de Évora ${ }^{12}$, provavelmente descoberta durante os seus périplos arqueológicos pela cidade e seus arredores.

O registo epigráfico vinha não só comprovar, em termos materiais, as fontes literárias da Antiguidade como também, associado ao monumento edificado (a muralha e o aqueduto), atribuir, inovadoramente, um relevante valor heurístico à arquitectura. Esta, por outro lado, serviu a André de Resende de reforço ao testemunho prestado pelas inscrições, cuja idoneidade havia sido posta em causa pelo Bispo de Viseu, não sem razão, como ficou demonstrado por um estudo de José de Encarnação ${ }^{13}$.

D. Miguel da Silva havia acusado André de Resende de forjar um "letreiro" que comemorava o empreendedorismo de Sertório na construção da muralha e de um aqueduto de Évora: "Quinto Sertorio em louvor do seu nom e da campanha dos muy esforçados Eborenses, per seu ardimento na guerra Celtiberia, cercou e afortalezou a Cidade Municipíio de soldados velhos, e aposentados, e fez trazer por níveis muita agoa colhida de varias fontes para proveito publico do dito Municipio"14. Sustentava-se a acusação no facto do general aparecer com o nome da mãe e não com o do pai, como era costume entre os romanos. Segundo o bispo de Viseu, de acordo com o veiculado por Diogo Mendes de Vasconcelos, André de Resende fora impelido a falsificar a inscrição pelo seu desejo de persuadir D. João III a construir um aqueduto em Évora, convencendo-o que, na prática, estava a reconstruir uma preexistência ${ }^{15}$. Ora, tendo em conta que a contenda com D. Miguel da Silva terá decorrido nos anos de 1530, em virtude da inauguração do Aqueduto da Água da Prata ter acontecido em 1537 e do bispo ter fugido de Portugal em 1540, deduzimos que o "letreiro" em causa foi intencionalmente não incluindo entre os documentos epigráficos transcritos por André de Resende na História da Antiguidade da Cidade de Évora, impresso em 1553. A sua não inclusão poderá significar que, apesar da ausência de D. Miguel da Silva do país, este permanecia um assunto sensível para Resende. De resto, devemos a Diogo Mendes de Vasconcelos o conhecimento desta placa comemorativa, integrada por ele no Livro V do Municipio Eborense, quando historia, em defesa do seu amigo Resende, a controvérsia despoletada pelo bispo de Viseu ${ }^{16}$.

A importância concedida a Sertório por André de Resende na História da Antiguidade da Cidade de Évora ultrapassava, no entanto, o circunstancialismo da construção do aqueduto de Évora. Visava sobretudo mostrar a ancestralidade da cidade alentejana e a antiguidade do seu prestígio, que remontavam à romanização e que estavam expressas, acreditava Resende, na elevação de Évora ao estatuto de município, concedido por Júlio César, de que decorreu o cognome então recebido de Liberalitas Iulia, a autorização para cunhar

\footnotetext{
12 A. Resende 196317.

13 J. Encarnação 1991 193-221.

14 Transcrição publicada em S. Deswarte 1989 86, 87, 210.

${ }^{15}$ S. Deswarte 198987.

16 Idem, 86.
} 
moeda e a capacidade para ter clero próprio ${ }^{17}$. André de Resende parece querer aplicar o louvor do rei arquitecto da felicidade e do bem comum - patente nas crónicas, nas entradas reais, nos panegíricos, nas orações universitárias, nos tratados de educação de príncipes - a Sertório ${ }^{18}$. Ao considerar que D. João III tinha reconstruído o aqueduto romano, estava a fazer reflectir o louvor do seu primeiro construtor, Sertório, no rei de que era súbdito. Parece que D. Miguel da Silva não estava enganado quanto às verdadeiras motivações de André de Resende.

A suposta preexistência de um aqueduto romano também se inscrevia no contexto mais amplo da condição histórica da cidade, factor que foi fundamental para o sucesso da tese "sertoriana" de Resende nos anos sequentes, triunfante sobre a suspeição que lhe fora levantada - assim é atestado pela ordem dada por D. Filipe II em 1602, aquando da promulgação do novo regimento do Aqueduto da Água da Prata, de expor publicamente, na Praça Maior (actual Praça do Geraldo), todas as inscrições antigas alusivas à presença de Sertório em Évora ${ }^{19}$. Esta consagração da tese "sertoriana" ficou a dever-se tanto à natureza conjuntural do discurso de André de Resende, que se enquadrava nas descrições panegíricas das cidades tão caras à cultura moderna ${ }^{20}$, como à sua actualização pelos autores que se seguiram na narrativa da história de Évora.

O primeiro a enriquecer a tese "sertoriana" é Frei Bernardo de Brito (15691617), na sua Monarchia Lusitana, publicada em duas partes nos anos de 1597 e 1609. Nesta história do reino, que recua aos seus antecedentes, Frei Bernardo de Brito faz alusão ao achado acidental de uma inscrição antiga aquando da construção da Igreja de S. Luís, a qual continha o presumível epitáfio de Quinto Sertório, em que este era intitulado de "Capitão dos Lusytanos" e se rogava à deusa Diana que encaminhasse o seu corpo até aos Campos Elísios ${ }^{21}$. A discutível romanidade do registo epigráfico torna-se logo evidente na relação estabelecida entre a Lusitânia, Sertório e a divindade Diana, que está em harmonia com a biografia que Plutarco faz do "Capitão dos Lusytanos" nas Vidas Paralelas.

Plutarco conta como Sertório montou um ardil para elevar a moral dos seus soldados na Hispânia, utilizando uma corça que lhe havia sido oferecida por um camponês local para fingir que fora uma dádiva da deusa Diana, com a missão de avisá-lo, durante o sono, dos perigos que o ameaçavam e das medidas que devia tomar para se defender ${ }^{22}$. O episódio é invocado por

${ }^{17}$ A. Resende 1963 23, 27-31.

18 N. N. C. Soares 2003601.

${ }_{19}$ T. Espanca 1944 33-35.

${ }^{20}$ N. N. C. Soares 2003598 e 599. De salvaguardar, contudo, que o discurso de André de Resende sobre Évora não obedece exactamente ao modelo do elogio da urbe quinhentista, que, por sua vez, seguia as coordenadas da cidade ideal do Renascimento. Resende não faz quaisquer referências à organização sócio-económica ou à estética arquitectónica de Évora, é o passado da cidade que idealiza ao pô-la a protagonizar factos importantes das histórias de Roma, da cristianização e do reino.

${ }^{21}$ B. Brito $2004303 v^{\circ}-304$.

${ }^{22}$ Plut. Sert. 10-11. 
Camões em Os Lusíadas (1572): "Vês, connosco também vence as bandeiras / Dessas aves de Júpiter validas; / Que já naquele tempo as mais guerreiras / Gentes de nós souberam ser vencidas. / Olha tão sotis artes e maneiras / Pera adquerir os povos, tão fingidas: / A fatídica cerva que o avisa. / Ele é Sertório, e ela a sua divisa"23. Retoma-o Manuel Fialho (1646-1718) no manuscrito Évora Ilustrada (c. 1718), ao declarar que o templo romano da cidade fora dedicado à deusa da caça, cabendo-lhe a paternidade da tradicional e popular designação de "Templo de Diana"24. A intenção foi, mais uma vez, estabelecer um vínculo directo entre um vestígio material / arquitectónico do passado e a figura histórica de Quinto Sertório, a fim de o monumento poder testemunhar a ligação do general romano à cidade.

Na Monarchia Lusitana, Frei Bernardo de Brito também menciona duas sumptuosas casas que Sertório teria na cidade para sua residência, sem especificar onde. Frei António Brandão (1584-1637), na terceira parte da Monarchia Lusitana (1630), localiza-as nas casas que os Sortelha cederam para a instalação do Convento do Salvador e que estavam coladas ao seu palácio, edifício onde a Câmara Municipal está actualmente sedeada ${ }^{25}$. Gaspar Estaço (1560-1626), em 1625, indica, com precisão, o Convento do Salvador como tendo sido levantado sobre os vestígios arquitectónicos do Palácio de Sertório ${ }^{26}$.

No século XVIII, a presença de Sertório em Évora e a sua responsabilidade na edificação da primeira cintura amuralhada da cidade, do aqueduto e do templo era um dado adquirido. Confirmamo-lo nos viajantes estrangeiros que escreveram sobre Évora. É o presumível carácter clássico do aqueduto que atrai a atenção do arquitecto inglês James Murphy (1760-1814), que o desenha com acentuado pormenor, em particular a cobertura da Mãe de Água de S. Francisco, mais o templo, com os vãos intercolunares entaipados para que servisse de açougue, função que mantinha desde a Idade Média ${ }^{27}$. Na centúria seguinte, houve quem chegasse a considerar que o aqueduto era um dos mais belos exemplares da arquitectura clássica que ainda se conservavam em Portugal $^{28}$. Mas foi também no século XIX que se manifestaram as primeiras dissidências da tese "sertoriana" anteriores a Augusto Filipe Simões. Em 1844, o bispo de Beja, Manuel Pires de Azevedo Loureiro, numa carta enviada à Revista Universal Lisbonense e divulgada naquele periódico a 25 de Abril desse ano, opinava contra o "erro popular" que dedicava o templo de Évora à deusa Diana, com o argumento que os romanos antigos destinavam a ordem coríntia aos deuses e a jónica às deusas. Sendo o templo de Évora da ordem

${ }^{23}$ L. V. Camões, Os Lusiadas, 8, 8.

${ }^{24}$ M. Fialho 194525.

${ }^{25}$ A. Brandão 1973285.

${ }^{26}$ G. Estaço, "Várias Antiguidades de Portugal” in B. J. S. Farinha 1785 123-125.

${ }^{27}$ A primeira visita de James Murphy a Évora decorreu entre 1789 e 1790 . A narrativa e os desenhos da sua viagem foram publicados em 1795, no volume Travels in Portugal. J. Murphy $1998255,257,259-264$.

${ }^{28}$ Ver A. Balbi 2004 196; e J. Urcullu 1837 85-86. 
coríntia, fora necessariamente consagrado a um deus ${ }^{29}$. Dois anos depois, o Conde Athanasius Rackzynski, ministro do rei da Prússia em Portugal de Maio de 1842 a 1845, declarou com ironia que do antigo aqueduto romano só restavam vestígios e, mesmo assim, havia que descobri-los ${ }^{30}$.

O desenvolvimento dos estudos arqueológicos no século XIX e a aplicação dos princípios do pensamento positivista às diferentes áreas do saber a partir dos anos de 1860, que na História e na Arqueologia conduziu à regulação da dedução especulativa pelos limites impostos pelos conteúdos e pela natureza dos documentos, veio fomentar a reavaliação crítica da contribuição de Sertório para a Évora romana. Porém, é precisamente esse espírito positivista que obriga Augusto Filipe Simões a recuar e a aceitar a convicção dominante de que o aqueduto de Évora não era uma construção quinhentista de raiz, mas um restauro, entendido no seu significado mais extremo de reconstrução, da preexistência romana ${ }^{31}$. Ou seja, o bibliotecário eborense vê-se obrigado a render-se à evidência da cópia da Apologia... descoberta por Vilhena Barbosa, conforme foi atrás enunciado, cuja superior relevância é sublinhada por ele, pois, até àquele momento, era conhecida somente por citação.

Augusto Filipe Simões faz publicar a missiva de Vilhena Barbosa no jornal eborense Folha do Sul, acrescentando-lhe uma série de observações relativas à sua inflexão que provocam alguma controvérsia local, o que denota não ser este tema pacífico em Évora, tal como no século $\mathrm{XVI}^{32}$. Também não o era ainda para Augusto Filipe Simões, que retoma a questão após cerca de dois anos de observação, estudo e reflexão. Em nova missiva dirigida a Vilhena Barbosa, datada de 12 de Julho de 1866, ele reconsidera a sua posição anterior, concluindo que a torrinha de S. Francisco não era romana e que a da entrada da cidade não tinha sequer existido. Sobre esta última, não havia qualquer registo ou memória na literatura, nem restavam vestígios materiais, incluindo dos arcos que deveriam suportar uma construção com as suas supostas dimensões, para além da área disponível ser insuficiente para a base circular de uma Mãe de Água igual à do largo de S. Francisco. Relativamente a esta, a análise comparativa com o que restava da galeria principal do paço de D. Manuel, a chamada Galeria das Damas ou Trem, permitiu-lhe verificar que tinham sido construídas com tijolos e pedras iguais, devendo ser, por isso, coetâneas ${ }^{33}$.

A prova material impôs-se ao documento escrito, cuja credibilidade era fragilizada por não ser um original, e Vilhena Barbosa reconsidera a sua posição, aceitando a conclusão de Augusto Filipe Simões. Vilhena Barbosa admite que as cópias da Apologia ... e da correspondência que consultou podiam ser apócrifos ${ }^{34}$. Também a imagem do Univers Pittoresque, que servira

${ }^{29}$ M. P. A. Loureiro 1844430.

${ }^{30}$ A. Raczynski 1846359.

${ }^{31}$ I. V. Barbosa 1867 34-35.

${ }^{32}$ A. F. Simões 186464 1-2.

${ }^{33}$ I. V. Barbosa 186747.

${ }^{34} \mathrm{Em}$ virtude de terem pertencido à livraria do Conde do Vimeiro, conhecido por pagar generosamente pela aquisição tanto de manuscritos raros como, na falta dos originais, de 
de modelo às do Archivo Popular e ao Archivo Pittoresco, devem ter resultado da má interpretação que Adrien Balbi, a sua fonte, fez de James Murphy, que descreve a Mãe de Água do largo de S. Francisco na entrada da cidade, provavelmente por estar localizada no limite da muralha, nas proximidades da Porta do Rossio.

Não se pense, contudo, que se encerrou aqui a tradição erudita de Sertório construtor da Évora romana. Ainda é convocada no dicionário corográfico Portugal Antigo e Moderno, no contributo "Évora", de Pinho Leal ${ }^{35}$, e Gabriel Pereira é obrigado a criticar os seus fundamentos históricos e arqueológicos com veemência entre 1879 e 1884, garantindo que mesmo sem Sertório, o passado de Évora permanecia na esfera do paradigma de civilização que era o Império Romano ${ }^{36}$, que se mantinha garante da antiguidade e do valor histórico da cidade alentejana.

\section{Bibliografia}

Archivo Pittoresco, Lisboa, 1863 (n. $\left.{ }^{\circ} 36\right), 1864 *\left(\mathrm{n} .{ }^{\circ} 6\right), 1867$ (n. ${ }^{\circ} 5$ e n. $\left.{ }^{\circ} 6\right)$.

A. Balbi (2004), Essai statistique sur le royaume de Portugal et d'Algarve. Tome Second. Lisboa, IN - CM, 2 vols.

I. V. Barbosa (1863), "O Arco Triumphal Romano da Praça de Evora", Archivo Pittoresco 36286.

I. V. Barbosa (1864), s/título, Archivo Pittoresco 6 41-42.

I. V. Barbosa (1867a) "Aqueducto de Evora I", Archivo Pittoresco 5 34-35.

I. V. Barbosa (1867b) "Aqueducto de Evora", Archivo Pittoresco 648.

Frei António Brandão (1973), Monarquia Lusitana II. Lisboa, IN - CM.

Frei Bernardo de Brito (2004), Monarquia Lusitana I. Introd. de A. da Silva Rego. 15 , s.l., IN - CM.

Luís Vaz de Camões (s.d.), Os Lusíadas. Porto, Porto Editora.

Sylvie Deswarte (1989), Il "Perfeito Cortegiano". D. Miguel da Silva. Roma, Bulzoni Editore.

Sylvie Deswarte (1992a), Ideias e Imagens em Portugal na Época dos Descobrimentos. Francisco de Holanda e a Teoria da Arte. Lisboa, Difel.

Sylvie Deswarte (1992b), "Aqueducto de Évora I", Archivo Pittoresco, 534.

José Encarnação (1991), "Da Invenção de Inscrições Romanas pelo Humanista André de Resende", Biblos 67 193-221.

Túlio Espanca (1944), "O Aqueduto da Água da Prata", Cadernos de Estudo e Arte Eborense. Évora, Nazareth \& Filho, Lda.

Bento José de Sousa Farinha (1785), Colleçam das Antiguidades de Évora Escriptas por Andre de Resende, Diogo Mendes de Vasconcellos, Gaspar Estaco, Fr. Bernardo de Brito e Manoel Severim de Faria. Lisboa, Officina de Filipe da

falsificações. I. V. Barbosa 186748.

${ }^{35}$ A. S. A. B. P. Leal 1874 89-91.

${ }^{36}$ G. Pereira 194739. 
Silva e Azevedo.

Manuel Fialho, António Franco (1945), Évora Ilustrada. Introd. Armando de Gusmão. Évora, Edições Nazareth,

Augusto Soares d'Azevedo Barbosa de Pinho Leal (1874), Portugal Antigo e Moderno. 3. Lisboa, Livraria Editora de Mattos Moreira \& Cia.

M. A. Azevedo Loureiro (1844), "Sobre o Templo Romano de Évora”, Revista Universal Lisbonence 36.

James Murphy (1998), Viagens em Portugal. Lisboa, Livros Horizonte.

Gabriel Pereira (1947), "Évora Romana. 1ª Parte. O Templo Romano. As inscrições Lapidares". in Estudos Eborenses. vol. 1. Évora, Edições Nazareth, 33-55.

Conte Athanasius Raczynski (1846), Les Arts en Portugal. Léttres adrésses a la Societé Artistique et Scientifique de Berlin et accompagnés de documents. Paris.

Américo da Costa Ramalho (1983), “A Conversão Maravilhosa do Português D. Gil um diálogo latino quase ignorado - da autoria de André de Resende”, Estudos sobre o século XVI. Lisboa, IN-CM, 348-352.

André Resende (1996), As Antiguidades da Lusitânia. Lisboa, Fundação Calouste Gulbenkian.

André Resende (1963), "História da Antiguidade da Cidade de Évora", Obras Portuguesas. Lisboa, Livraria Sá da Costa, 3-69.

A. F. Simões (1864), "Descobrimento Archeologico", Folha do Sul 62.

Nair de Nazaré Castro Soares (2003), Cidades ideais e elogio de cidades no Renascimento e em Damião de Góis. In Congresso Internacional Damião de Góis na Europa do Renascimento. Braga, Universidade Católica Portuguesa, 583-608.

J. Urcullu (1837), Tratado elementar de Geografia, Astronomia, Fizica, Historica ou Politica Antiga e Moderna. 2. Porto, Tipografia Comercial Eborense. 
(Página deixada propositadamente em branco) 


\title{
A PRÉ-EXISTÊNCIA DO CARDO / DECUMANUS NO PLANO POMBALINO E A SUA HERANÇA NA LISBOA CONTEMPORÂNEA
}

\author{
PAUla ANDRÉ \\ Departamento de Arquitectura e Urbanismo
}

ISCTE

\begin{abstract}
Cardo / Decumanus in the $18^{\text {th }}$ century Pombaline Plan for Lisbon and their inheritance in contemporary Lisbon.

The logic of Pombal's Plan for the reconstruction of Lisbon after the earthquake of 1755 , is set in the enlightened and hygienist thought of Ribeiro Sanches and his work Tratado de conservaçam da saude dos povos (1756). According to this work, based on the classic thought of Vitruvius, "the Romans built the (main) streets with the same width of military lanes, or royal roads; they led to city gates or the squares: the second type of streets was narrower and corresponded to the width of the paths that came from the military lanes". This hierarchy is present in Pombal's Plan, carried out by the engineers/urbanists, composed of main streets and secondary streets, and shows that city planning never forgot the two pre-existing structural axis, the Rua Nova d'El Rei - Cardo - and the Rua Nova dos Mercadores - Decumanus denouncing its classical references. The regularity of this plan, and its imbued classical tradition, is a landmark of Lisbon, which we see today elevated to the category of monument.
\end{abstract}

Keywords: Cardo-Decumanus, Lisbon, Pombal's Plan.

Palavras-chave: Cardo-Decumanus, Lisboa, Plano Pombalino.

A Lisboa conquistada por D. Afonso Henriques era já constituída pelo conjunto amuralhado (Cerca Moura) e pelos bairros extramuros. No reinado de D. Dinis, executam-se os primeiros aterros na zona do esteiro, de modo a permitir a construção das Tercenas Reais e Estaleiros, junto à escarpa de S. Francisco, o que denota já uma descida e um avanço da cidade em relação ao rio. D. Dinis constrói ainda a segunda muralha da cidade, a primeira da ribeira, com o intuito de proteger os novos núcleos que entretanto se expandiram, como o da Baixa (a ocidente) e o de Alfama (a oriente). Contudo, essa muralha não chegou a ser concluída e efectivamente só no reinado de D. Fernando, em 1373 , com a construção de uma nova muralha, mais próxima do rio ${ }^{1}$, essas novas áreas urbanas passaram a ficar englobadas no seu interior.

No século $\mathrm{XV}$, será nesta nova ribeira que se irá desenvolver todo um conjunto de equipamentos relacionados com expansão ultramarina: a Casa de

1 “Quando D. Diniz construiu a sua muralha na Ribeira, era a rua Nova uma praia ou um 
Ceuta, a partir de 1434, e a Casa dos Escravos, em 1486. D. Manuel I decidiu descer da Alcáçova ${ }^{2}$, iniciar novos aterros na ribeira e construir o Paço sobre a casa da Índia, Mina e Guiné. O terreiro, antes esteiro, praia e ribeira, tomou então a designação de Terreiro do Paço, gerando-se ali um palco privilegiado da cidade e da sua imagem.

A Norte da cidade existia um outro grande vazio, o Rossio de Lisboa Rossio ou Ressio que, segundo Luis de Vasconcelos, na sua obra Etnografia Portuguesa, tem origem no adjectivo latino residuus, que significa «remanescente» - onde se realizavam feiras ${ }^{3}$. Este espaço seria marcado, a Norte, pelo paço dos Estaus, mandado construir por D. Pedro, e, a Nascente, pelo conjunto do Hospital de Todos os Santos, obra encomendada por D. João II. Esses dois grandes vazios da cidade de Lisboa, a ribeira tornada Terreiro do Paço e o Rossio, exibidos na gravura de Lisboa Olissipo quae nunc..., que G. Braunio publicou no Vrbium Praeciparum Mundi Theatrum Quintum em 1598 , foram sempre polos estruturadores do desenvolvimento urbano, palcos preferenciais dos diferentes tempos, mantendo essa identidade mesmo depois do terramoto no plano pombalino. Para além destes dois grandes vazios, a cidade de Lisboa foi estruturada por outros dois eixos de desenvolvimento, duas ruas que também se mantiveram estruturantes no plano pombalino: a Rua Nova, eixo paralelo ao rio, e a Rua Nova d'El Rei, eixo perpendicular ao rio.

A Rua Nova, eixo paralelo e aberto ao rio, provavelmente já existiria no reinado de D. Dinis. Encontramo-la na regularização e ampliação da mesma Rua Nova em 1294, empreitada que obrigou ao derrube das casas "para que a rua fique de 8 braças, como chamou a atenção Helder Carita na sua obra Lisboa manuelina e formação de modelos urbanísticos da época moderna (1495-1521). No séc. XV, a Rua Nova passa a ter a designação de Rua Nova dos Mercadores, sendo também referida ainda nesse século como Praça dos Homens de Negócios. As primeiras notícias do projecto de calcetamento da Rua Nova de Lisboa "constam de uma carta de D. João II, datada de Novembro de 1482, onde o rei (...) determinou, como trabalho prévio, a execução de uma planta «pyntada em papell», para melhor poder estudá-la e emitir o seu parecer"4. Após a viagem ao Porto em 1483, D. João II, tendo apreciado na

aterro de formação recente, que tiveram de alargar contra o rio para a fundação do muro. Mais tarde, já no aterro que pouco a pouco se havia conquistado ao Tejo, poude D. Fernando fundar a sua muralha, à frente da de D. Diniz, contra o mar", A. Silva 1987129.

${ }^{2}$ Esta descida da cidade em relação ao rio traduz-se também na deslocação de alguns centros sociais, nomeadamente a substituição do Largo da Sé e da Madalena pela Praça do Pelourinho Velho, na extremidade Oriental da Rua Nova dos Mercadores, que adquire uma nova centralidade.

3“A Feira da Ladra trocara, no decurso de quatrocentos, o Largo da Feira, que dela tomou nome, junto da entrada do Castelejo, pelo Rossio de Santa Justa, onde permanecerá até ao Terramoto de 1755"; desde finais do séc. XV, esta feira realizava-se todas as $3^{\text {as }}$ feiras defronte do Hospital Real de Todos os Santos, "na qual, de mistura com as manufacturas da terra, começavam a aparecer produtos vindos do Norte de África e do Oriente, em primeira ou segunda mão", I. Moita 1983 9, 14.

${ }^{4}$ I. Gonçalves 1995105. 
Rua Nova a qualidade do trabalho e da pedra utilizada, ordenou que em Lisboa fosse utilizado igual processo e a pedra dali trazida ${ }^{5}$. Seria assim aprovada "a despeza orçada para o calcetamento da Rua Nova Grande dos Mercadores, devendo empregar-se n'essa obra pedra do Porto [granito], «por que a outra dapnase na maneira que vêdes ${ }^{6}$. Para além destes melhoramentos, há uma preocupação com o reordenamento alinhado do centro da cidade, com a regularização, o alinhamento das ruas, denotando uma estética da linha recta, presente em várias cartas para o Senado de Lisboa, como podemos verificar na referência do secretário António Carneiro: «...como os (esteios) da rua nova dereitos e muy bem obrados e ainda nalguns lugares em que convem the seja dado tanto chão como convinha para todas as casas ficarem yguais e por cordel e que hua não saya mais que outra...»" o facto de na Rua Nova dos Mercadores ainda existirem "casas construídas com materiais menos nobres, como a madeira, (...) deu um prazo de um ano

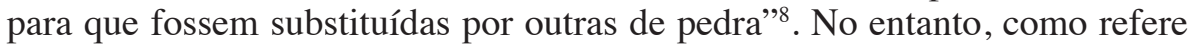
Walter Rossa, "já em 1462 D. Afonso V tentou impor que as casas da Rua Nova de Lisboa fossem feitas sobre arcos de cantaria e daí até ao telhado em alvenaria de pedra e cal, sem tabuados" ". Seria através da acção de D. Manuel que a referida rua passaria a ter "um notável perfil urbano com edifícios de habitação de cinco andares, onde o piso térreo era ocupado pelas mais bem fornecidas lojas de toda a Europa em matérias-primas e objectos provenientes do Oriente e de África, autênticos «gabinetes de curiosidades»" 10 . Em meados do séc. XVI, a Rua Nova divide-se em duas partes: a ocidente passa a ter o nome de Rua Nova dos Mercadores e a oriente de Rua Nova dos Ferros, com grades de ferro dispostas longitudinalmente. Mais tarde, a denominação de Rua dos Ferros estende-se a toda a rua, sendo esta a sua designação em 1755. Esta rua, porém, era conhecida simplesmente como Rua Nova.

A Rua Nova d'El-Rei, eixo perpendicular ao rio, mandada abrir por D. João I, é referida no século XIV como o rego, passando depois a ser mencionada como Rua do Cano Nova. Quando D. Manuel I prolonga a Rua Nova d'El Rei, o Rossio passou a ficar ligado à zona da Ribeira, tendo sido necessário demolir construções para que ficasse alinhada. A partir de meados do séc. XVI, esta rua passa a ser mencionada de Rua da Ourivesaria do Ouro ou dos Ourives do Ouro, sendo essa a sua designação em 1755. À semelhança do que tinha sido feito com a Rua dos Ourives da Prata ${ }^{11}$, as obras de alargamento da Rua

${ }^{5}$ W. Rossa 1999261.

${ }^{6}$ E. Oliveira 1885 384. "Quando D. João II morreu, em finais de Outubro de 1495, treze anos volvidos após o seu início, ignoramos o adiantamento dos trabalhos, mas sabemos que estavam ainda longe do fim. D. Manuel retomou o empenhamento do seu antecessor", I. Gonçalves 1995107.

${ }^{7}$ H. Carita 200041.

${ }^{8}$ I. Gonçalves 1986170.

${ }^{9}$ W. Rossa 1999261.

10 P. Pereira 200643.

11 «esta obra tem consequencias mui uteis, porque cresce a cidade em formosura, e para a nobreza fica facil a serventia que pela Padaria é tão dificultosa (...)», in Consulta da Câmara 
dos Ourives do Ouro, que ficaria com quarenta palmos de largura, de modo a ser "a mais pública e principal"12, prosseguem com D. Pedro II. Esta obra é mencionada em carta do Secretário de Estado, Pedro Sanches de Farinha, de 13 de Setembro de 1686: “(...) e também ordena que V. S ${ }^{a}$, vendo, com os ministros do senado, o quanto se necessita de que a Rua dos Ourives do Ouro se largue, por ser o concurso de toda a cidade, e por esta causa haver sempre n'ella contendas nas passagens por não caberem dois coches por ella, se trate dos effeitos que pode haver para esta obra que é tanto em utilidade do commum"13.

Aimportância da Rua Nova d'El Rei (cardo) e da Rua Nova dos Mercadores (decumanus), eixos e pólos estruturadores do fazer e do traçado urbano, fica também patente nas referências feitas nas mais diversas fontes.

Cristovão Rodrigues de Oliveira, em inícios do século XVI, refere que do "Rossio, querendo ir para o mar, entram na rua Nova d'El-Rei, comprida e direita rua, que vai dar na grande rua Nova dos Mercadores, que por ser na principal parte da cidade e junto do mar ao longo dele, é lugar onde concorrem todos os mercadores e toda a mais gente de trato, que tem de comprido duzentos passos e de largo vinte; e sabe-se que rende em alugueres de casas oitenta mil cruzados"14. Também o Padre Sande referiu, em 1584, que "há nesta rua, além d'outras coisas, edifícios admiráveis, de tantos pavimentos e com tantos inquilinos, que não se conhecem uns aos outros nem de cara nem de nome"15. Damião de Góis menciona que do Rossio, "passando a Praça Nova do Rei, que transborda de entalhadores, joalheiros, ourives, cinzeladores, fabricantes de vasos, artistas da prata, de bronze e de ouro, bem como de banqueiros, cortando á esquerda, chegaremos a uma outra artéria que tem o nome de Rua Nova dos Mercadores, muito mais vasta que todas as outras ruas da cidade, ornada, de um lado e de outro, com belíssimos edifícios" "16. E Francisco Javier Pizarro Gómez refere também que "Filipe II assistiu a várias representações teatrais alegóricas do dia da entrada oficial do monarca, realizadas na Rua Nova"17, ganhando a rua a dimensão de palco por excelência da cidade.

Concordamos com José Custódio Vieira da Silva quando refere, por um lado, que as "cidades da Idade Média (...) se constituem como continuum em relação aos modelos da arquitectura e urbanismo da Antiguidade grega e romana", e, por outro, que na "Lisboa medieval houve três momentos decisivos de alargamento estruturado: o primeiro, em tempos do rei D. Dinis e

ao Rei de 23 de Novembro de 1676, Liv IV de Cons. e Decr. Do Principe D. Pedro, fl. 386 (AHCML), citado por E. Oliveira 1885 173: “em que se tornou necessário derrubar vinte e seis «moradas de casas»". H. Murteira 199988.

${ }^{12}$ H. Murteira 199992 e 85, respectivamente.

${ }^{13}$ H. Murteira 199985.

${ }^{14}$ C. Oliveira 198719.

${ }^{15}$ C. Oliveira 1987103.

${ }^{16}$ D. Góis 200216.

${ }^{17}$ F. Pizarro Gómez 1987127. 
D. Fernando; o segundo com D. João I até à regência de D. Pedro; o terceiro, sob D. João II e D. Manuel"18.

Há uma preocupação pré-pombalina com a regularidade e a simetria, presente em todas as determinações. Tal como refere Helena Murteira, a propósito de um pedido de construção de um palheiro na Praça da Ribeira, a 6 de Março de 1704, uma Consulta da Câmara ao Rei, menciona que “(...) o Senado, por decretos e resoluções de V. Majestade está dispendendo e dispendeu considerável fazenda em alargar as ruas, (...) cordeamentos regulares que devem ter as ruas para formosura da cidade" 19 . E denotando exactamente o mesmo tipo de preocupação em 1751, a Coroa decide que o arquitecto camarário, Eugénio dos Santos, deveria estar presente em todas as vistorias das obras da cidade e o Presidente do Senado defende: "não pode haver vistoria alguma que não respeite ao ornato e symetria da cidade"20.

Com o terramoto, maremoto e incêndio de 1755 , as construções desta zona da cidade ficaram destruídas e Sebastião José de Carvalho e Melo, Secretário de Estado dos Negócios Estrangeiros e da Guerra, encarrega Manuel da Maia, o mestre de campo-general e engenheiro-mor do Reino, de estudar propostas para a reconstrução da cidade de Lisboa. Entre 4 de Dezembro de 1755 e 19 de Abril de 1756, este engenheiro redige a sua Dissertação sobre a renovação da Cidade de Lisboa, na qual apresenta cinco modos alternativos, devidamente justificados, para a reconstrução. O futuro Marquês de Pombal opta pelo quarto modo, ou seja, a reconstrução in loco com um novo plano. São então propostos seis novos planos, dos quais é eleito o do capitão Eugénio dos Santos, arquitecto do Senado. Este era o mais "abstracto e geométrico", em que as praças do Rossio e do Terreiro do Paço eram "regularizadas e redefinidas na sua forma e orientação" "21. Na proposta de Eugénio dos Santos, os dois grandes vazios pré-existentes parecem adquirir a dimensão sagrada atribuída normalmente aos espaços das igrejas que, por sua vez, não são repostas nos locais préexistentes $^{22}$, mas são assimiladas na ordem imposta pela malha urbana. É por esta quase sacralização do secular que a lógica iluminista começa por estar presente no projecto pombalino da Baixa de Lisboa, na qual se enquadra também o pensamento esclarecido e higienista de Ribeiro Sanches, presente na sua obra Tratado de conservaçam da saude dos povos (1756). Ribeiro Sanches, chamando a atenção para a conveniência em consultar os médicos para a fundação de qualquer povoação, refere que se deve ordenar e "fabricar ruas largas e diretas que se terminem nas grandes praças" 23 . Tendo por base

18 J. Silva 200636.

${ }^{19}$ Consulta da Câmara ao Rei de 6 de Março de 1704, Liv ${ }^{\circ}$ XIX de Cons. e Decr. de D. Pedro II, fl. 84 (AHCML), citado por E. Oliveira 1885 232-233. M. Murteira 1999 69-79.

${ }^{20}$ Consulta da Câmara ao Rei de 17 de Janeiro de 1754, Liv $^{\circ}$ V de Cons. e Decr. de D. José I, fl. 25 (AHCML), citado por E. Oliveira 1885 232,233. M. Murteira 1999 69-79.

${ }^{21}$ M. Teixeira, M. Valla 1999 290-291.

${ }^{22}$ Embora José Augusto França refira que Eugénio dos Santos tenha tido remorsos “de ter lesado as igrejas da Baixa com os seus planos, mais atentos aos interesses novos do urbanismo que a outros, tradicionais da religião". J. França 1987107.

${ }^{23}$ A. Sanches 175648. 
uma raiz clássica fundamentada em Vitrúvio e Alberti, Sanches relembra que "os Romanos fazião as ruas das cidades da mesma largura, que tinhão as vias militares, ou estradas reaes; terminavão-se nas portas dellas, ou nas praças: a segunda sorte de ruas era mais estreita, e conrespondia a sua largura à dos caminhos de travessa, que sahião das vias militares" ${ }^{24}$, hierarquia viária que se aproxima claramente da lógica que encontramos no plano da Baixa de Eugénio dos Santos. É já sob a direcção de Eugénio dos Santos que, a 12 de Junho, em substituição da Aula do Paço da Ribeira, se constitui a Casa do Risco das Obras Públicas. É na Casa do Risco que Eugénio dos Santos ${ }^{25}$ elabora o projecto da futura Praça do Comércio, redesenhando o espaço pré-existente com a construção de aterros, mantendo a abertura a Sul, para o rio Tejo, e pontuando-a com a estátua equestre de D. José I. A Praça do Comércio tem uma espacialidade permanente que promove a descodificação da representação perspéctica, procurando entender a maneira de representar, de expressar e de apresentar o espaço. Os arquitectos/engenheiros militares do Reino desenharam-na aplicando a matriz da linha recta, absorvendo a lição da composição urbana das missões jesuíticas e à maneira dos arquitectos cenógrafos, podendo ser olhada como um desenho arquitectónico para uma perspectiva de cena. Quando percorremos a praça, vemos esse espaço como a scaenae frons dos teatros romanos e quando estamos no seu centro, lugar da skene e da orchestra, somos simultaneamente actores e espectadores. O modo particular de articular espaço fechado e espaço aberto, abrindo um dos lados da praça ao rio, sugere, simultaneamente, que se olhe a praça como espectador e que se use a praça como actor.

Pedro Vieira de Almeida refere que o "Pombalino surge como uma estrutura imagética articulada não em edifícios ou objectos urbanos particularmente significativos, nem em frentes-fachada particularmente ricas, mas em espaços urbanos, espaços-rua e espaços-praça" ${ }^{26}$. Os arquitectos/engenheiros de Pombal, contudo, também não terão certamente esquecido "as plantas de tudo o que ha celebre no Mundo, e modellos de todas as Igrejas, e mais famosos Palacios de Roma"27, que D. João V mandava vir da cidade pontificia e reunia no salões do Paço da Ribeira. Se no Plano Regulador para Roma de Sixto V, elaborado por Domenico Fontana, as vias traçadas unem edifícios notáveis, no Plano de Pombal, elaborado pelos engenheiros/urbanistas, onde contracenam ruas principais e ruas secundárias, as vias unem os dois grandes vazios notáveis: Rossio e Terreiro do Paço.

O plano pombalino é também caracterizado pelos espaços intermédios, pelas conexões e pelo modo como se justapõem os seus elementos, ou seja, o modo como a moderna plataforma se liga com a antiga malha urbana da

${ }^{24}$ A. Sanches 175648.

${ }^{25}$ Coadjuvado pelo tenente-coronel húngaro Carlos Mardel, arquitecto dos Paços Reais e das Ordens Militares.

${ }^{26} \mathrm{P}$. Almeida 1973457.

${ }^{27}$ F. Silva 1750267. 
cidade $^{28}$. É a regularidade de todo o plano da Baixa de Lisboa que se torna num excelente meio de comunicação da imagem da cidade. É a matriz da linha recta como fundamento e espírito de regularidade e uniformidade que serve de base tanto à arquitectura como ao desenho da cidade. O que mostra que o fazer da cidade passou pelo fazer/desenhar os vazios, não esquecendo nunca os dois eixos estruturantes, a Rua Nova d'El Rei - cardo - e a Rua Nova dos Mercadores $^{29}$ - decumanus - , denunciando uma ancestralidade clássica.

A estética da linha recta revela-se uma matriz fruto não só do desejo, mas também da regra e, mais interessante, da prática. A atenção ao lugar, ao sítio, característica da arquitectura e do desenho urbano português, advém precisamente não de um modelo, mas sim da pré-existência de um modo de fazer. E é exactamente porque existe essa matriz fundamentada numa prática que o fazer urbano é competência dos engenheiros militares, uma competência erudita e pragmática e que se revelaria programática. É a tradição da estética da linha recta no projecto arquitectónico e no projecto urbano que vemos elevada à categoria de monumento.

\section{Anexos}

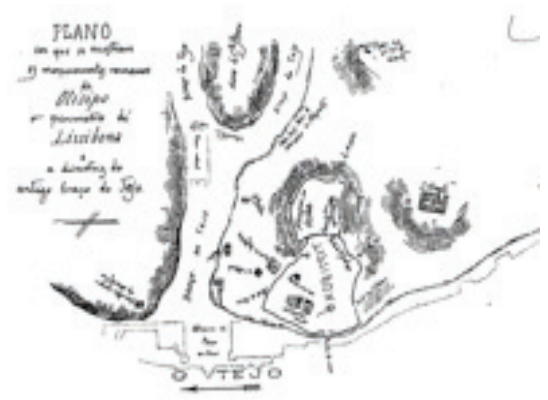

Fig.1. Planta de Lisboa anterior ao séc. XII segundo Júlio de Castilho (1893)

28 “Não posso deixar de acrescentar aqui ser muito preciza huma especial attenção na elleição das pessoas que hajão de ter por sua conta a execução desta difficultosa obra da renovação de Lisboa baixa, para a guiarem livre dos embaraços que se poderão encontrar, ou incluir entre a correspondencia do antigo com o moderno, no cazo de haver alguma commutação do velho, como o novo que he aonde consiste a mayor difficuldade" (Dissertação de Manuel da Maia, III parte). J. França 1987323.

29 "Plano de 12 de Junho de 1758; 42 - Em primeiro lugar: devendo a antiga Rua Nova dos Ferros, e antiga Rua da Confeitaria ser reduzidas a huma só, e unica Rua, com a denominação de Rua Nova de ElRey: nos terrenos, que antes ocupavão as referidas duas Ruas; pareceu, que ou haverá o espaço, que baste, ou não faltará muito para se alinhar a nova Rua, que deve cortarse com a largura de sessenta palmos por fora dos edificios, que formarem o lado Septentrional do Terreiro do Paço, na forma acima declarada. (Belém, 12 de Junho de 1758, Sebastião José de Carvalho e Melo)". J. França 1987337. 


\section{PAUla André}

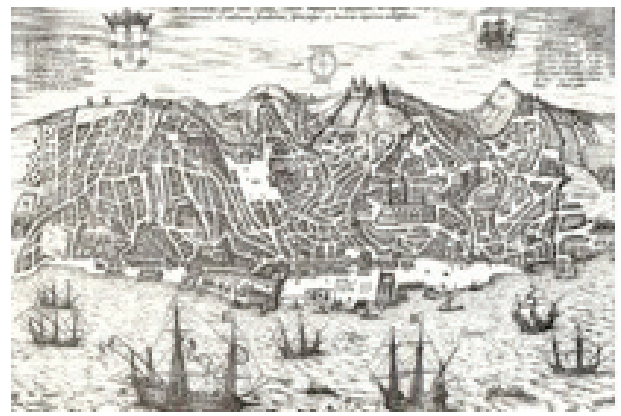

Fig.2. Olissipo quae nunc..., gravura em cobre, Georgius Braunius,

Vrbium Proecipuarum Mundi Theatrum Quintum, 1598

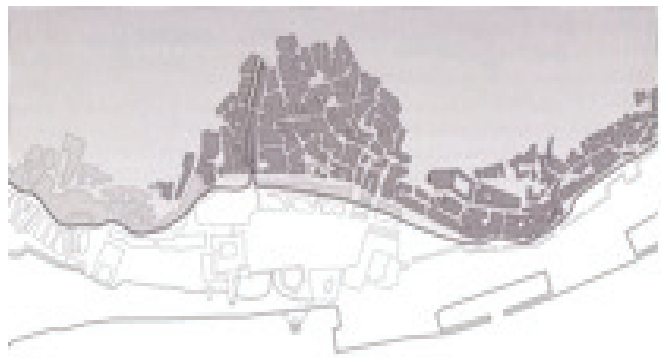

Fig.3. Traçado conjectural da praia medieval na segunda metade do séc. XIII; desenho de José António; C. Caetano 200434

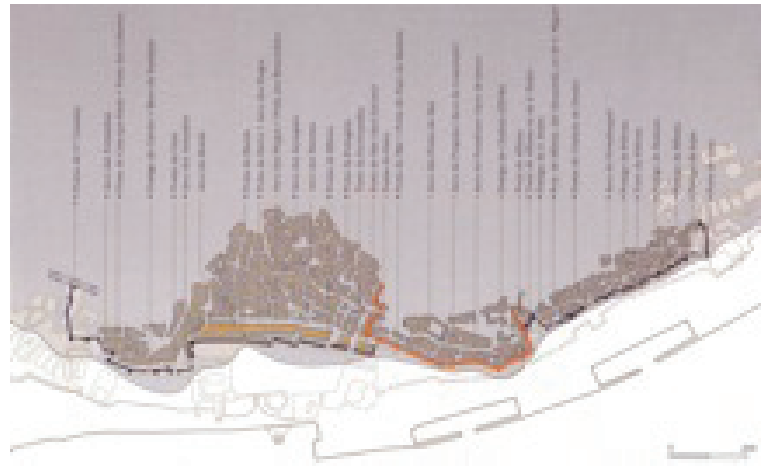

Fig.4. Portas e postigos das Cerca Moura e Fernandina; desenho de José António; vermelho - Cerca Moura; amarelo - Muralha de D. Diniz; azul - Muralha de D. Fernando; Linha cinza - traçado conjectural da linha de praia do fim do séc. XIV; C. Caetano 200437 


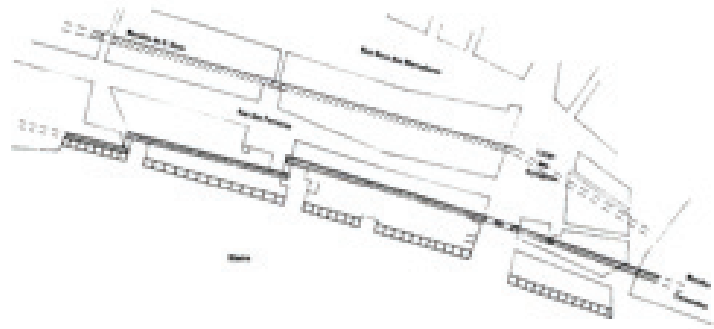

Fig.5. Planta de localização do conjunto da Ribeira no Terreiro do Paço, com base na planta de João Nunes Tinoco de 1650. H. Carita 199965

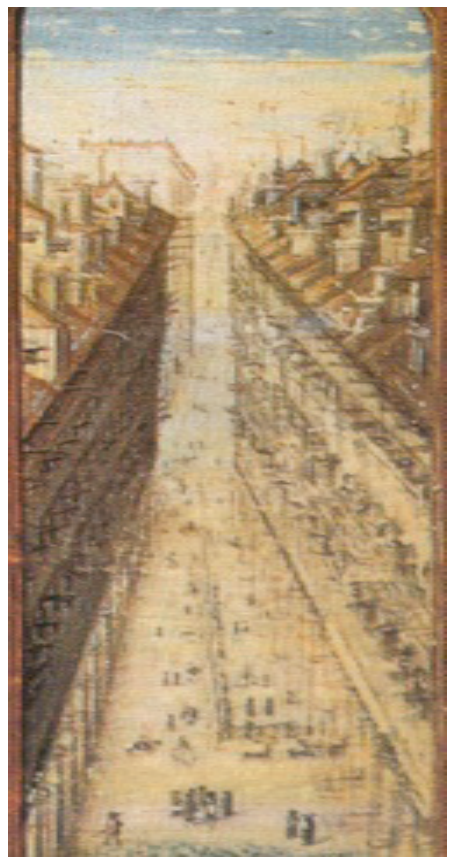

Fig.6. Iluminura em pergaminho, Livro de Horas [dito] de D. Manuel, Séc. XVI, fl. 130, MNAA. 


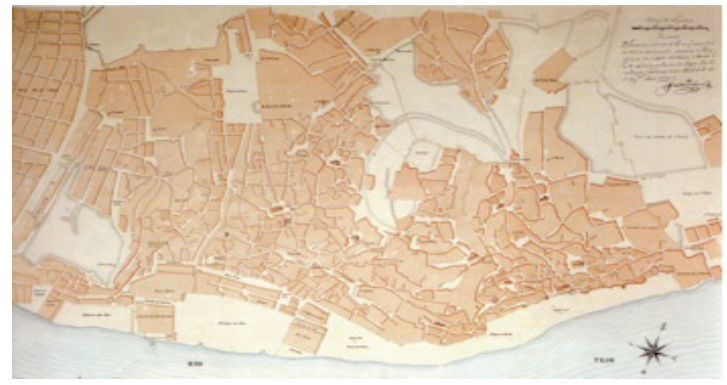

Fig.7. Planta da Cidade de Lisboa, gravura, João Nunes Tinoco, 1650, Museu da Cidade, Lisboa

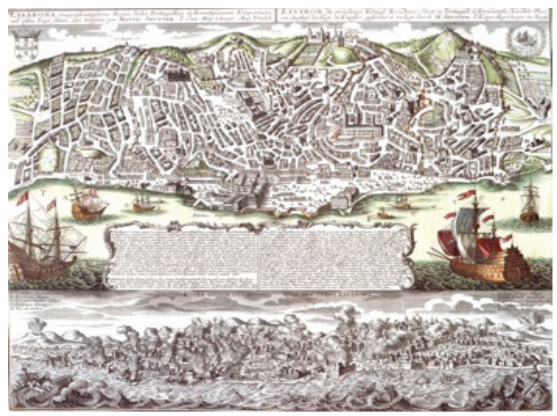

Fig.8. Lisboa, antes e depois do terramoto de 1755, representação bipartida inspirada pela perspectiva quinhentista de Braunio Matthaus Seuter

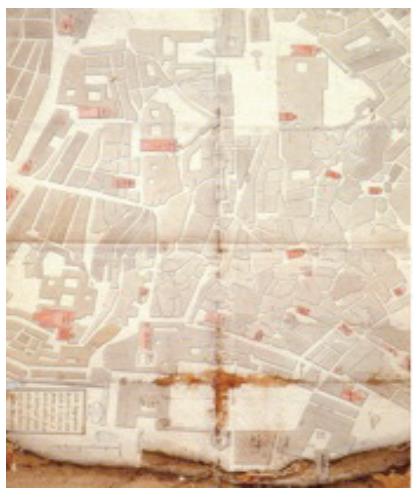

Fig.9. Carta topográfica da parte mais arruinada de Lisboa na forma, em que se achava antes da sua destruição para sobre ela se observarem os melhoramentos necessários, Manuel da Maia; Gabinete de Estudos de Arqueologia e Engenharia Militar. W. Rossa 200425 


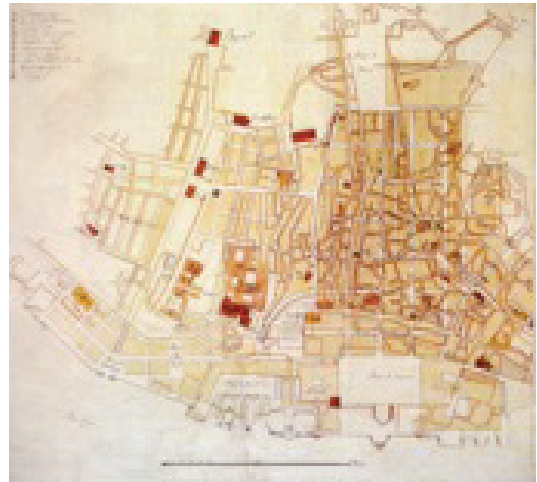

Fig.10. Carlos Mardel e Eugénio dos Santos, um dos dois estudos, para o plano-piloto da Baixa-Chiado, 1758; Instituto Geográfico Português www.igeo.pt. W. Rossa 200429

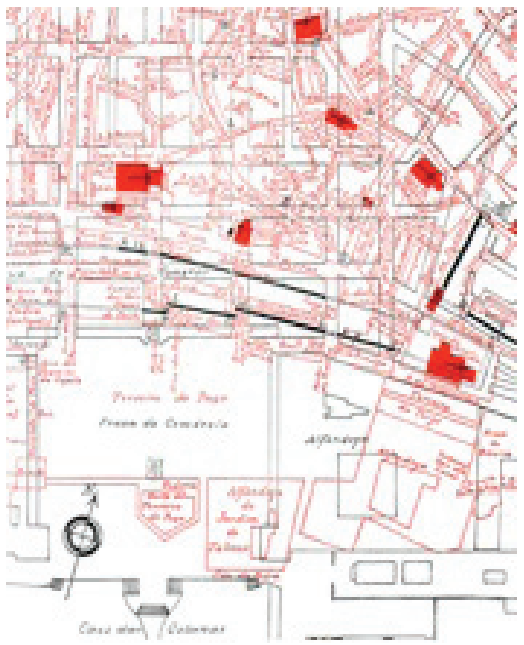

Fig.11. Fragmento da Planta de Lisboa; O traçado e dizeres a preto correspondem à actualidade; o traçado e dizeres a vermelho correspondem à Lisboa anterior ao terramoto de 1755 . A. Silva 1987 vol. 1 


\section{PAUla André}

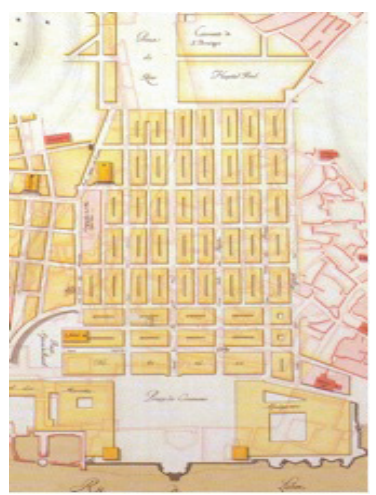

Fig.12. Nova Lisboa, cópia da denominada planta número 5(?). Desenho a tinta-da-china, aguarelado a carmim e a amarelo in Monumentos. Lisboa, $\mathrm{n}^{\circ}$ 21, Setembro, 200468

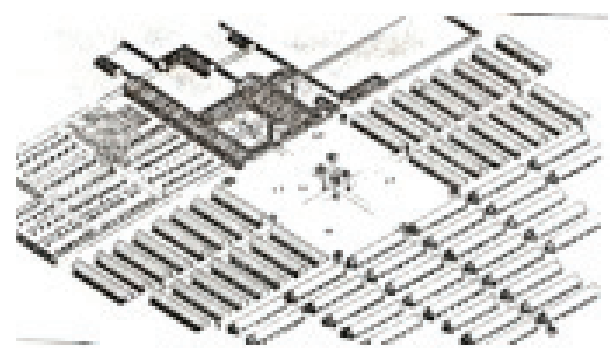

Fig.13. Missão Jesuítica San José de Chiquitos, Fr. Felipe Suarez; Fr. Dionisio Ávila, 1698, Bolívia. G. Rocha Filho 1995

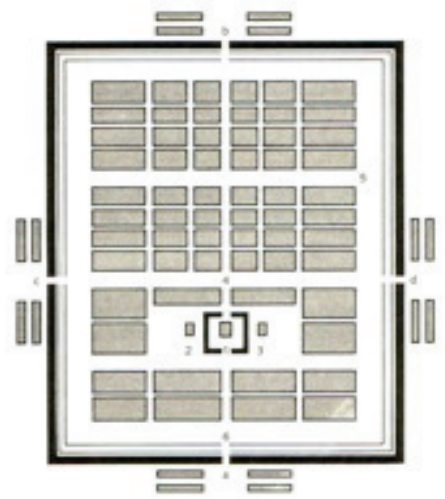

Fig.14. Esquema do castrum romano: a-b. Decumano; c-d. Cardo; 1. Praetorium; 2 e 3. Tribunal, questores; 4. Tribunos; 5. Cavalaria; 6. Tropas auxiliares. G. Argan 200396 


\section{Bibliografia}

P. Almeida (1973), “A Arquitectura do século XVIII em Portugal. Pretexto e argumento para uma aproximação semiológica", Bracara Augusta. Revista Cultural de Regionalismo e História da Câmara Municipal de Braga. Braga, nº 27.

G. Argan (2003), Historia da Arte Italiana. Da Antiguidade a Duccio. São Paulo. vol. 1.

C. Caetano (2004), A Ribeira de Lisboa. Lisboa.

H. Carita (1999), Lisboa manuelina e a formação de modelos urbanisticos da época moderna (1495-1521). Lisboa.

H. Carita (2000), "Reforma Urbanística da Lisboa Manuelina. Início da escola moderna de arquitectura", História 40 36-45.

J. A. França (1987), Lisboa Pombalina e o Iluminismo. Lisboa.

D. Góis (2002), Elogio da Cidade de Lisboa. Lisboa.

I. Gonçalves (1986), "Posturas Municipais e Vida Urbana na Baixa Idade Média. O Exemplo de Lisboa", Estudos Medievais 7 155-172.

I. Gonçalves (1995), "Uma Realização Urbanística Medieval: o Calcetamento da Rua Nova de Lisboa", in Estudos de Arte e História - Homenagem a Artur Nobre de Gusmão. Lisboa.

M. da Maia (1987), Dissertação, I-III parte), in J. França, Lisboa Pombalina e o Iluminismo. Lisboa, 311-326.

I. Moita, ed. (1983), Lisboa Quinhentista: a imagem e a vida da cidade. Lisboa.

H. Murteira (1999), Lisboa da Restauração às Luzes. Lisboa.

M. Murteira (1999), "Lisboa - O Iluminismo e a Cidade", in Lisboa - Utopias na Viragem do Milénio. Lisboa, 69-79.

C. Oliveira (1987), Lisboa em 1511. Sumário em que brevemente se contêm algumas coisas assim eclesiásticas como seculares que há na cidade de Lisboa (1551). Lisboa.

E. Oliveira (1885), Elementos para a História do Município de Lisboa. Lisboa.

P. Pereira (2006), "Lisboa Manuelina. Problemas de Conceito", Revista de História da Arte 4 43-55.

F. Pizarro Gómez (1987), "La jornada de Felipe III a Portugal en 1619 y la arquitectura efímera", in II Simpósio Luso-Espanhol de História da Arte. As Relações Artísticas entre Portugal e Espanha na Época dos Descobrimentos. Coimbra, 123-146.

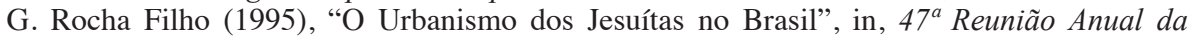
Sociedade Brasileira para o Progresso da Ciência. Universidade Federal do Maranhão, 1995.

W. Rossa (1999), “A cidade portuguesa”, in P. Pereira, coord., História da Arte Portuguesa. Lisboa. vol.3 232-323.

W. Rossa (2004), "Do plano de 1755-1758 para a Baixa-Chiado", in Monumentos. Lisboa.

A. Sanches (1756), Tratado de conservaçam da saude dos povos: obra util, e igualmente neseffaria aos Magiftrados, Capitaens Generaes, Capitaes de Mar, e Guerra, Prelados, Abbadeffas, Medicos, e Pays de familias. Paris.

A. Silva (1987), As Muralhas da Ribeira de Lisboa. Lisboa.

F. Silva (1750), Elogio funebre e historico do muito alto, poderoso, augusto, pio e fidelissimo Rey de Portugal, e Senhor D. João V. Lisboa.

J. Silva (2006), "Lisboa Medieval. Breves reflexões“, Revista de História da Arte 36.

M. Teixeira, M. Valla (1999), O Urbanismo Português, séculos XIII-XVIII. Portugal-Brasil. Lisboa. 
(Página deixada propositadamente em branco) 


\title{
TRAÇADOS URBANOS PORTUGUESES, SIMBIOSE DE CULTURAS
}

\author{
MANuel TEIXEIRA \\ Departamento de Arquitectura e Urbanismo do ISCTE \\ CEURBAN - Centro de Estudos Urbanos
}

\begin{abstract}
Portuguese urban layouts, symbiosis of cultures
Portuguese urban layouts express the symbiosis of two main cultural references: the geometry and the regularity, which is a heritage of the Roman culture; and a careful adaptation to the physical characteristics of the site, which is a heritage of the pre-Roman Mediterranean culture, later reinforced by the Muslim presence.

This means that, on the one hand, on Portuguese urban layouts there is always a plan, or an idea of plan, based on a regular geometry. That is the regularity that characterizes Roman colonial cities, and which became a fundamental component of our urban culture. On the other hand, in the actual act of construction, this plan is confronted with the site, and adapted to the site's physical characteristics. That corresponds to our Mediterranean culture of the territory, which later on the Muslims came to adopt as part of its own urban strategies, and which is also an important component of our urban culture.

This symbiosis of principles, apparently contradictory, became one of the main characteristics of Portuguese urban layouts, and is translated into urban morphologies that, although when observed in plan do not present an absolute geometrical regularity, when experienced on the site, they do present a remarkable sense of order and regularity, and at the same time an intelligent adaptation to the topography, taking advantage of its characteristics.
\end{abstract}

Keywords: geometry, Mediterranean culture, Portuguese urban layouts.

Palavras-chave: cultura mediterrânica, geometria, traçados urbanos portugueses.

\section{Introdução}

A cidade portuguesa evidencia uma variedade de influências de diferentes períodos históricos, expressando a simbiose de duas referências culturais fundamentais: a articulação com o território, herança da cultura mediterrânica, reforçada mais tarde pela presença muçulmana, e a geometria e a regularidade, herança da cultura romana.

A cidade portuguesa tem sempre em consideração as particularidades do sítio em que se implanta, localizando os principais edifícios em situações topograficamente dominantes. Neste caso, são estes edifícios que vão estruturar os espaços urbanos envolventes. Por outro lado, a construção da cidade portuguesa parte sempre de um plano geometrizado que a estrutura. 
Neste caso, o principal elemento de ordenamento urbano é o próprio traçado regulador.

Correspondendo as estas duas diferentes concepções de espaço, em todas as cidades portuguesas encontramos uma componente vernácula e uma componente erudita. A componente vernácula corresponde à cidade que é construída sem o recurso a técnicos especializados e em que existe uma estreita relação do traçado urbano com a topografia. Este modelo de cidade tende a ser menos regular e a cidade é muitas vezes designada como não planeada, ou orgânica, porque é o resultado acumulado das acções de muitos indivíduos, ao longo de gerações.

A componente erudita corresponde à participação de técnicos especializados, detentores de um saber intelectual, no desenho da cidade. Este modelo de cidade tende a ser mais regular e construído de acordo com um esquema racional. Esta é a cidade habitualmente designada por planeada, porque resultou de um plano pré-concebido, da autoria de um indivíduo ou de um número reduzido de indivíduos.

O resultado desta simbiose de princípios, aparentemente contraditórios, traduz-se em traçados urbanos que embora em planta não apresentem uma absoluta regularidade geométrica, nos transmitem no local um grande sentido de ordem e uma cómoda adaptação ao sítio, sabendo tirar partido das suas particularidades físicas. A cidade portuguesa harmoniza num todo coerente estas duas formas de fazer cidade, aí residindo, em grande parte, a sua especificidade.

A componente erudita da cidade portuguesa insere-se plenamente na cultura urbana ocidental. Existe uma herança cultural comum a toda a Europa, cuja matriz se encontra na cultura da antiguidade clássica, reformulada no Renascimento, e que se traduz em formas urbanas partilhando idênticas características morfológicas de rigor, de regularidade e de geometria. $\mathrm{O}$ urbanismo português participa inteiramente desta evolução, tornando-se cada vez mais racional e regular, identificado com uma cultura urbana europeia de raíz erudita.

\section{A cultura mediterrânica, Roma e o Islão}

São diversas as características mediterrânicas que subsistem na tradição urbana portuguesa: a localização privilegiada na costa marítima, a escolha de sítios elevados para a implantação do núcleo defensivo, a estruturação das cidades em cidade alta, institucional e política, e cidade baixa, portuária e comerciante, a cuidadosa adaptação do traçado das ruas às características topográficas locais e o papel dos edifícios singulares na estruturação dos espaços urbanos.

As características topográficas eram determinantes para a localização do núcleo urbano inicial, frequentemente num planalto ou no topo de uma colina, para a definição do perímetro das fortificações, que acompanhava a estrutura do terreno, para a implantação dos principais edifícios institucionais 
em locais dominantes do território, e para a definição das principais direcções do crescimento urbano, sobre as linha naturais do terreno. Os edifícios singulares, de natureza institucional, assumiam uma importância primordial na organização da cidade. Localizados em posições dominantes, davam sentido e organizavam os espaços envolventes, tornando-se os elementos estruturantes fundamentais da malha urbana.

A partir do século II a.C. os princípios urbanísticos da cidade romana de colonização, baseados na regularidade, na racionalidade e na ordem foram impostos a várias cidades portuguesas, quer através da fundação de cidades, quer através da ocupação e da reestruturação de cidades já existentes. Duas ruas perpendiculares entre si - o cardus e o decumanus - constituíam os dois eixos viários principais e as directrizes fundamentais da cidade, a partir das quais se definia uma estrutura ortogonal de ruas e de quarteirões. Adjacente à intersecção destes dois eixos, no centro da cidade, localizava-se o fórum, que era ao mesmo tempo centro da vida pública e religiosa, local de reunião e mercado, concentrando-se nele os principais edifícios dedicados às funções político-administrativas, judiciais, religiosas e comerciais da cidade. Outros equipamentos localizavam-se em diversos pontos da cidade, sujeitando-se a sua implantação à lógica geométrica pré-estabelecida pela malha urbana.

Embora em muitas cidades de fundação romana em Portugal não se expressem tão plenamente os princípios de rigor e de geometria presentes noutras situações, os ideais de regularidade e de ortogonalidade, e a concepção de espaço subjacente à cidade romana de colonização radicaram-se suficientemente para passar a ser uma componente importante do pensamento urbanístico português. Nesta concepção de cidade, é o espaço urbano racionalmente organizado e definido por um traçado regular que constitui o elemento primordial.

As cidades de origem romana, e a tradição dos traçados ortogonais vai permear a cultura urbanística europeia ao longo de séculos, mantendo-se viva ao longo da Idade Média, ainda pontuavam o território europeu e as mais importantes continuavam a ser habitadas e a manter o seu papel de principais centros administrativos; os acampamentos militares continuaram a ser organizados de acordo com padrões regulares de origem romana, e mesmo em programas não militares a tradição de regularidade era mantida.

O urbanismo português, a par de outras culturas do sul da Europa, teve também a influência muçulmana, que terá contribuído para um reforço da cultura territorial mediterrânica já presente nas nossas cidades. Na sua permanência em Portugal até ao século XIII os muçulmanos deixaram inscritas em muitas cidades a sua cultura urbana, constituindo estes traçados, com os princípios que lhes deram forma, uma importante componente da tradição urbana portuguesa.

Nas cidades muçulmanas confluem três tipos de factores determinantes da sua forma: aqueles que derivam das características morfológicas dos espaços urbanos já existentes e que ocuparam, nomeadamente as cidades de fundação 
romana; aqueles que derivam das características ambientais do espaço em que se implantam; e aqueles que derivam da sua religião e cultura específicas.

A estrutura formal da cidade caracterizava-se por uma clara hierarquia de vias. Duas vias principais atravessavam habitualmente a cidade, ligando portas localizadas em lados opostos da muralha e cruzando-se no centro. A partir destas vias principais saíam ruas secundárias que progressivamente se iam ramificando, com um carácter cada vez mais privado. As necessidades de defesa, as características ecológicas do espaço geográfico em que estas cidades se construíam, e o estilo de vida prescrito pelo Corão contribuíam para o carácter íntimo destas vias secundárias, tortuosas, com diferentes perfis ao longo do seu percurso, das quais saíam travessas em cotovelo ou becos que davam acesso a pequenos conjuntos de casas construídas em torno de impasses. As casas eram viradas para pátios interiores, e as poucas aberturas para a rua eram protegidas por janelas, rótulas e muxarabis. Muitas destas características da cidade islâmica vão permanecer na cidade medieval cristã portuguesa, passando a fazer parte das suas características e tornando-a específica no contexto europeu.

\section{A crescente afirmação da regularidade}

A tradição dos traçados regulares da antiguidade manteve-se viva ao longo da idade média. As cidades medievais construídas do século XII ao século XIV de acordo com planos regulares, geralmente ortogonais, são a expressão mais visível desta continuidade. Em Portugal, a construção a partir do século XIII de cidades com traçados urbanos regulares estava relacionada com o processo da Reconquista e a necessidade de colonizar e de reorganizar economicamente o território. Muitas cidades foram fundadas em zonas de fronteira ou em áreas que necessitavam de ser colonizadas ou desenvolvidas economicamente.

Os traçados destas cidades portuguesas não evidenciam tão explicitamente como outras cidades europeias suas contemporâneas as suas referências aos cânones da antiguidade. Não existem traçados em quadrícula e a praça ou não se localizava no centro ou não existia, só se vindo a estruturar gradualmente ao longo dos tempos. Apesar disso, os traçados destas cidades medievais tinham uma base regular, concebidos de acordo com um padrão geométrico e tendendo para uma organização ortogonal de ruas e quarteirões.

A partir de finais do século XV observa-se um movimento de renovação urbanística em Portugal consistindo na reforma, alteração ou expansão de cidades existentes. Nalguns casos, estas intervenções incidiam na estruturação de praças urbanas, associadas à construção de novos edifícios institucionais, na maior parte dos casos Casas de Câmara, Misericórdias e Igrejas Matrizes. Noutros casos, tratava-se da construção de novas expansões urbanas planeadas, em que eram adoptados novos princípios urbanísticos de regularidade e de 
ordenamento, e onde se expressava uma concepção moderna de espaços públicos.

No início de quinhentos, a cidade de Angra apresentava já um traçado ortogonal, com uma praça rectangular que correspondia, nas suas dimensões e na sua relação com a restante malha urbana, a um quarteirão não construído e onde se situava a Sé. As ruas principais estavam orientadas perpendicularmente ao mar e as secundárias cruzavam-nas em ângulo recto, definindo um conjunto de quarteirões rectangulares orientados na direcção do mar. O traçado de Angra representa claramente uma ruptura com modelos medievais, explorando concepções modernas de estrutura urbana e de estrutura de quarteirões. Outras intervenções quinhentistas que se baseiam nos mesmos princípios de regularidade incluem o Bairro Alto de Lisboa e Salvador da Bahia, no Brasil.

A cada vez maior regularidade dos traçados urbanos portugueses é expressão da crescente racionalização da cultura urbana europeia. A escolha de sítios planos, que para as novas fundações quer para a construção de novas expansões, em vez dos sítios acidentados preferidos anteriormente, foi um factor importante para a adopção de padrões regulares. Por outro lado, o planeamento das cidades passou a ser, cada vez mais, função dos engenheiros militares, com uma sólida formação teórica, cuja acção se traduzia na adopção da geometria como base para o planeamento de traçados urbanos regulares. São Luis de Maranhão, de 1615, de Francisco Frias de Mesquita, é um exemplo de cidade seiscentista que adoptou um plano regular, ortogonal, com uma praça central de forma rectangular inserida na quadrícula, onde se localiza a igreja de Nossa Senhora do Carmo. Esta é uma praça moderna, de inspiração renascentista, concebida de raíz com uma forma regular, e que desde o início se assume como centro formal e funcional da cidade.

No século XVIII são construídas cidades, quer em Portugal quer no Brasil, com planos absolutamente regulares, concebidos segundo traçados geométricos ortogonais, onde se expressam os grandes temas do urbanismo clássico: a cidade planeada racionalmente de forma global, a praça como elemento central da malha urbana, a beleza da cidade associada à regularidade do traçado e à adopção de modelos arquitectónicos uniformes. Nestas fundações urbanas existia uma preocupação com a regularidade do plano e o alinhamento de ruas e de fachadas. $\mathrm{O}$ rigoroso ordenamento urbano subjacente a estas novas fundações era ao mesmo tempo expressão da cultura racional europeia que se pretendia implantar e uma marca do bom governo. A formosura e o ordenamento destes núcleos urbanos passavam também pela normalização da arquitectura, em que todos os edifícios de habitação tinham fachadas construídas de acordo com o mesmo projecto.

Uma praça, geralmente de forma quadrada e localizada no centro da povoação, constituía o elemento gerador da malha urbana, sendo a partir dela que se definia o traçado das ruas. Nesta praça, eram edificadas a Igreja, a Casa da Câmara e a Cadeia. Quando existia mais de uma praça, cada uma era 
destinada a uma função distinta: numa delas estava localizada a igreja, com o cruzeiro, enquanto na outra se localizava a casa da câmara e o pelourinho.

É em Setecentos que a racionalidade do urbanismo português vai ter a sua expressão mais estruturada. Os planos para a reconstrução da Baixa de Lisboa após o terramoto de 1755, as reformas urbanas do Porto na segunda metade do século XVIII, e o plano para Vila Real de Santo António, de 1775, constituem o resultado da longa experiência de urbanização e da cada vez maior racionalização dos traçados urbanos portugueses que se observa ao longo dos séculos XVII e XVIII. Eles constituem, de diferentes formas, a síntese da experiência urbanística portuguesa de séculos anteriores e a expressão de uma teoria urbanística portuguesa.

\section{As Sínteses. Salvador da Bahia e a Baixa de Lisboa}

A cidade de Salvador da Bahia, construída a partir de 1549, é um dos melhores exemplos da síntese de um plano racionalmente estruturado com uma cuidadosa adaptação ao sítio. A cidade alta de Salvador da Bahia, construída sobre um planalto sobranceiro ao mar, apresenta uma estrutura urbana constituída por quarteirões rectangulares que foi adaptada às características topográficas do sítio, daí resultando uma malha urbana regular, mas não perfeitamente ortogonal.

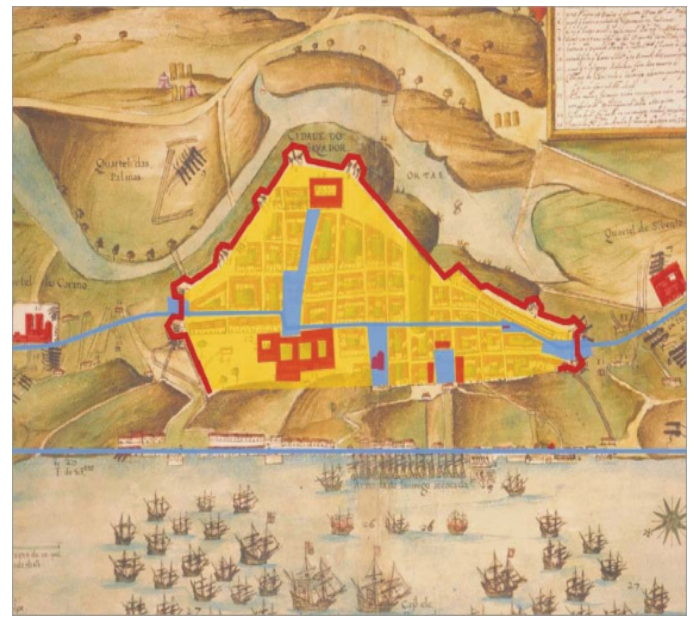

Fig.1. A relação do traçado urbano com a estrutura física do território.

Salvador da Bahia. Desenho do autor sobre: Planta da restituição da Bahia, João Teixeira Albernaz, 1631, B.N.R.J.

O modo como a cidade de Salvador se relacionou com o sítio e se adaptou às suas características, construindo-se com ele, observa-se no traçado da muralha, que se ajustou à topografia do terreno, situando-se sempre à mesma cota, daí resultando um perímetro urbano de forma trapezoidal irregular; no traçado da cidade, que conciliava o rigor do plano com a realidade da 
topografia, construindo a sua principal via estruturante ao longo de um caminho de cumeada; e no modo como as praças se desenvolveram nos nós de articulação das malhas urbanas e nos pontos de inflexão desta via estruturante.

Salvador da Bahia obedece a um desenho global, planeado, que lhe dá unidade e regularidade, ao mesmo tempo que tira partido dos acidentes do sítio, explorando as particularidades locais, estruturando os percursos fundamentais da cidade sobre as linhas naturais do território, aproveitando os desníveis para valorizar edifícios e monumentos, pontuando as colinas por igrejas e conventos, perspectivando as ruas em direcção a edifícios singulares, resolvendo as inflexões da linha de cumeada através da localização de praças. Ao tirar partido das particularidades do sítio, enfatizando-as, ao mesmo tempo que as integra num plano ordenador, Salvador da Baía pode ser vista como uma síntese dos diferentes modelos e concepções de cidade que estão presentes no urbanismo português.

Em todos os momentos de construção da cidade Portuguesa a racionalidade e a ordem geométrica era caldeada por uma atenção particular ao território e a princípios de estruturação urbana que não tinham uma base geométrica. Os seis planos elaborados para a reconstrução da Baixa de Lisboa após o terramoto de 1755 ilustram, no seu conjunto, diferentes sínteses das vertentes vernácula e erudita que, em todas as épocas, foram componentes fundamentais do urbanismo português. Em cada um destes planos encontramos uma atitude diferente para com o sítio, as pré-existências construídas e o antigo traçado da cidade, e uma diferente relação entre as duas componentes do urbanismo português, construindo uma síntese diferente das culturas urbanísticas em confronto.

Nas suas várias formulações, estes planos vão de uma total aceitação das pré-existências e das particularidades locais, como era o plano de Gualter da Fonseca e de Francisco Pinheiro da Cunha, que respeitava o traçado anterior e a localização das igrejas e capelas, até uma aparente abstracção do seu traçado geométrico, como era o projecto de Eugénio dos Santos que viria a ser seleccionado, que se estruturava através de uma lógica racional, aparentemente liberto de todos os condicionantes, com excepção das praças do Rossio e do Terreiro do Paço. É no entanto o plano, não seleccionado, de Eugénio dos Santos Carvalho e de António Carlos Andreas aquele que conseguia conciliar de uma forma mais equilibrada o respeito por linhas estruturantes fundamentais da cidade, por percursos e pela localização das igrejas antes do 
terramoto, com um traçado inovador e racional, onde é patente o ordenamento e a regularidade que se pretendia impôr ao plano.

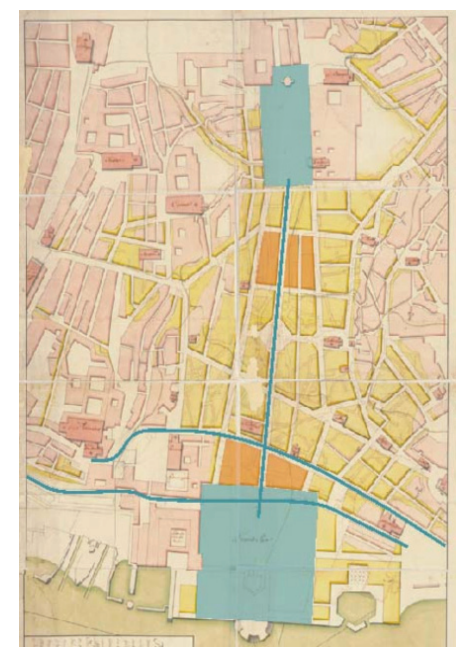

Fig.2. As linhas estruturantes do plano de Eugénio dos Santos e Carvalho e António Carlos Andreas: praças, vias principais, orientação dos lotes. Desenho do autor sobre: Planta $n^{\circ} 3$. $^{\circ}$, Plano da Cidade de Lisboa baixa destruída, em que vaõ signaladas com punctuaçã̃ preta todas as ruas, travessas e becos antigos, e as ruas escolhidas de novo com toda a liberdade se mostraõ em branco, e os sítios dos edificios novos de amarello, e as Igrejas e lugares se conservaõ sem mudança de carmim forte, a alfandega do tabaco, Baluarte do terreyro do Paço e sua cortina, que se devem derribar para restar formado o grande terreyro do Paço vaõ lavados de huma agoada de carmim, como também algumas porções de edifícios do arco do açougue té á entrada do Pelourinho, que taõ bem se haõ de derribar para complemento do mesmo terreyro do Paço com semelhante agoada e a divizaõ das fregas com a cor azul, Eugénio dos Santos e Carvalho, António Carlos Andreas, [Séc. XVIII], M.C.L.

O plano para a Baixa de Lisboa é herdeiro da cultura urbanística erudita europeia, caldeada com a experiência prática do urbanismo português acumulada ao longo dos séculos, em grande parte nos territórios ultramarinos. Este era o património de saber de que os engenheiros militares setecentistas eram herdeiros. Não obstante o conhecimento teórico dos engenheiros portugueses, ou precisamente pelo seu domínio desse saber teórico, a componente vernácula do urbanismo português, que se baseava num entendimento íntimo do território sobre o qual se construía, nunca foi rejeitada, mas antes assimilada pelos profissionais.

O plano de Eugénio dos Santos faz deliberadamente uma revisitação dos principais temas do urbanismo tradicional português. Partindo de formas urbanas tradicionais da cidade portuguesa de diferentes períodos históricos, 
Eugénio dos Santos elaborou, a partir delas, um plano racional e erudito. As habituais dualidades que se estabelecem entre traçados vernaculares e eruditos, planeados e não planeados, esbatem-se. O plano da Baixa dilui estas fronteiras e mostra que não há incompatibilidade entre uma e outra destas formas de fazer cidade. O plano de Eugénio dos Santos tem a capacidade de simultaneamente se enquadrar na cultura arquitectónica e urbanística do momento em que foi concebido, responder adequadamente ao programa estabelecido, articular-se de perto com as características físicas do sítio em que se constrói e basear-se em princípios fundamentais de estruturação da cidade tradicional portuguesa. Desta forma, Eugénio dos Santos faz uma síntese perfeita dos vários componentes que caracterizam os traçados urbanos portugueses.

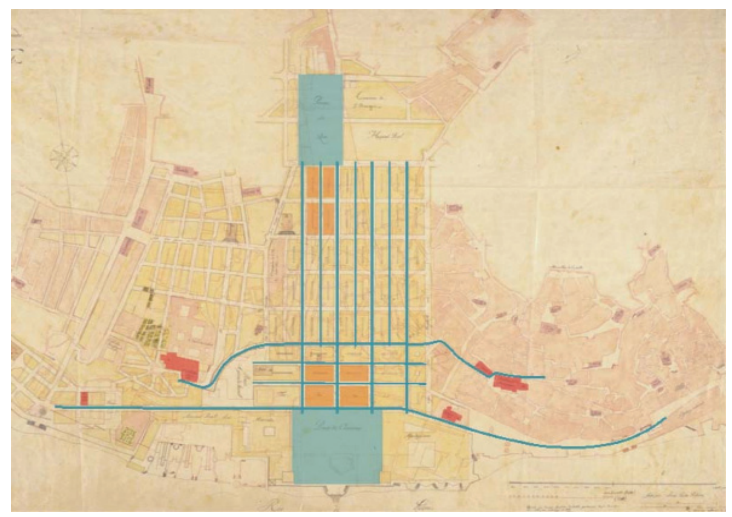

Fig.3. As linhas estruturantes do plano de Eugénio dos Santos e Carlos Mardel: praças, vias principais, orientação dos lotes. A hierarquia das ruas. Desenho do autor sobre: Planta Thopografhica da Cidade de Lisboa arruinada, tambem Segundo o novo Alinhamento dos Architétos. Eugénio dos Santos e Carvalho, e Carlos Mardel, [Séc.XVIII], M.C.L.

Em todas as épocas, a cidade portuguesa procurava responder à realidade material de cada situação, não se limitando a reproduzir modelos abstractos. Mesmo quando se estruturava segundo modelos planeados, eruditos, racionais e geométricos, procurava sempre adaptar-se à realidade física em que se situava. A prática urbanística portuguesa constituiu sempre a síntese de dois modos de conceber e construir o espaço, fruto da sua dupla herança cultural e civilizacional: de um lado o plano idealizado, o desenho e o rigor da 
geometria, do outro, a experiência prática, o confronto com a realidade física, a demarcação no terreno.

\section{Bibliografia}

José-Augusto França (1987), Lisboa Pombalina e o Iluminismo. Lisboa, Bertrand Editora.

Américo Simas Filho, coord. (1979), Evolução Física de Salvador. 2 vols. Salvador da Bahia Universidade Federal da Bahia, Faculdade de Arquitectura.

Manoel da Maya (1910), "1 . Dissertação sobre a renovação da cidade de Lisboa por Manoel da Maya, Engenhr. ${ }^{\circ}$ mor do R.no", in Christovam Ayres, Manuel da Maya e os Engenheiros Militares Portugueses no Terremoto de 1755. Lisboa.

Manuel C. Teixeira, Margarida Valla (1999), O Urbanismo Português, Séculos XIIIXVIII. Portugal-Brasil. Lisboa, Livros Horizonte.

Manuel C. Teixeira (2008), A Forma da Cidade de Origem Portuguesa, in http:// cartografiaurbana.ceurban.com/publicacoes.php. 


\title{
O CONTRIBUTO DOS RELATOS E GUIAS DE VIAGENS PARA O ESTUDO DA ANTIGUIDADE CLÁSSICA NO SUL DE PORTUGAL
}

\author{
Ana Cardoso de Matos \\ ANTÓNIA FialHo CONDE \\ Maria Ana Bernardo \\ Universidade de Évora \\ CIDEHUS
}

\begin{abstract}
The aim of this communication is to stress the potential of reports, travel accounts and guidebooks as sources for the study of classical Antiquity. The area of analysis is Alentejo, from the seventeenth to the twentieth century.

The description of landscape elements, forms of territorial occupation and settlements, the action of men on the landscape, as well as assessments of evaluative and aesthetics parameters are an integral part of guidebooks and travel accounts. But they also have potential as repositories of information that could be used by anyone who is interested in the study of classical Antiquity. The successive images and perceptions about the classical legacy, the importance given to them in terms of speech, the reference to material and privileged vestiges and even the omissions reflect, among others, the various perspectives that authors and editors transmitted at different times and at distinct historical contexts.
\end{abstract} Keywords: heritage, memory, Reports and Guidebooks, South, travel Accounts.

Palavras-chave: memória, património, Relatos e Guias de Viagem, Sul.

\section{Introdução}

Nos últimos anos os relatos e guias de viagem têm assumido uma importância crescente como fontes históricas ${ }^{1}$. Este facto prende-se com as próprias características destas obras, nas quais se associa à descrição de determinados lugares a sua representação gráfica. Primeiro sob a forma de gravuras e mapas, depois, com a invenção e divulgação da fotografia, cada vez mais sob esta forma de fixação de imagens.

A despeito de outras eventuais funcionalidades, estes materiais pretendiam ser um "auxiliar" dos viajantes coevos. E, sendo assim, eles compreendem pelo menos dois níveis de leitura sobre o período clássico. Por um lado, num sentido mais denotativo, disponibilizam informações mais ou menos detalhadas

${ }^{1}$ F. Carmona Fernandéz; J.M. Garcia Cano 2005; J. Garcia Mercadal 1999; C. G. Romeral Pérez 2001; G. Chabaud et alii 2000. 
e rigorosas sobre sítios e vestígios arqueológicos dessa época. Podem, assim, constituir-se num pertinente meio de monitorização da evolução da produção de conhecimentos históricos e arqueológicos do período clássico. Por outro lado, os discursos veiculados em tais documentos traduzem os olhares que os respectivos autores tinham sobre as diferentes épocas e os contextos históricos a que se referiam. Os discursos veiculados permitem, também, acompanhar a produção, reprodução e apropriação de imagens sobre a importância do legado clássico num determinado país, região ou localidade.

O presente texto não é uma abordagem sistemática do tema enunciado, destinando-se tão somente a ilustrar a vantagem da inclusão dos relatos, mapas e guias de viagem para a diversificação e enriquecimento das perspectivas de estudo sobre a época clássica. Os exemplos, se bem que algo casuísticos, incidem fundamentalmente sobre o Sul de Portugal e em particular sobre Évora, região e cidade que têm sido o nosso espaço de análise preferencial quando, em função de outras problemáticas, inquirimos os relatos, a cartografia e os guias de viagens ${ }^{2}$.

\section{Mapas, itinerários e relatos de viagem no período moderno}

$\mathrm{O}$ interesse que se verificou no período moderno em relação ao mundo clássico e aos vestígios que os romanos tinham deixado na Península Ibérica foi contemporâneo de um racionalismo que se manifestou na elaboração de uma cartografia cada vez mais exacta e fiel ${ }^{3}$.

Desta forma, são diversos os mapas sobre a presença dos romanos na Ibéria e eles fornecem, nas suas legendas, para além de uma riqueza iconográfica invejável, vasta informação, de que destacamos a revelação dos Autores e documentos considerados de referência, a alusão/comparação entre os sistemas métricos coevos e os usados pelos romanos, o estatuto dos núcleos urbanos em tempos romanos, as designações latinas dos sítios, os itinerários imperiais ou a até localização de templos.

A feitura destes mapas tinha presente não apenas a literatura e a produção científica coevas como também obras que a história imortalizaria. Entre estas, eram normalmente tidas em conta as abordagens geográficas da Península por Estrabão, Pompónio Mela, Plínio e Ptolomeu, ao lado de Mapas Gerais da Espanha Antiga, impressos no século XVI, como os de Abraão Ortelio, Cristóvão Celário, Mr. D’Anville, Nicolau Sanson e Roberto Vaugondi. Em Seiscentos, os geógrafos tinham em atenção, para a feitura dos mapas, algumas obras como a Espanha Ilustrada, impressa em Frankfurt em 1603, e que, por sua vez, se inspirara em Autores portugueses: André de Resende, nas Antiguidades da Lusitânia, e Diogo Mendes de Vasconcelos, num livro

\footnotetext{
${ }^{2}$ Este texto decorre dos trabalhos que temos desenvolvido no âmbito do projecto Viagens, Turismo e Património no Sul em perspectiva histórica (séc. XVII-XX), que se encontra sedeado no CIDEHUS -UE.

3 Não esqueçamos que um dos primeiros interesses por Portugal (e das primeiras manifestações de turismo) foi o termalismo, desde o tempo dos romanos, mantendo-se ainda nos séculos XVII e XVIII. Cf. A. F. Conde 2007.
} 
sobre o município de Évora. Vemos, pois, como o mundo clássico, de forma directa ou por abordagens a esse mesmo mundo ocorridas no Renascimento, acaba por chegar aos mapas do período moderno. Temos ainda que, se em Setecentos as abordagens sobre a Lusitânia romana, em matéria cartográfica, passaram também a considerar algumas indicações da Monarquia Lusitana, de Bernardo de Brito e Frei António Brandão, e alguns tomos da Espanha Sagrada, de Fr. Henrique Florez (1756-58), esse exercício era feito depurando o discurso: sublinham-se temas como a Lusitânia e a sua metrópole (Mérida), e as áreas diocesanas (Évora, Lamego, Egitânia, Faro, por exemplo) são confrontadas com as tábuas de Ptolomeu. Também eram consultadas a obra do Padre João Baptista de Castro e a sua proposta para as vias militares romanas e para os itinerários de Antonino Pio.

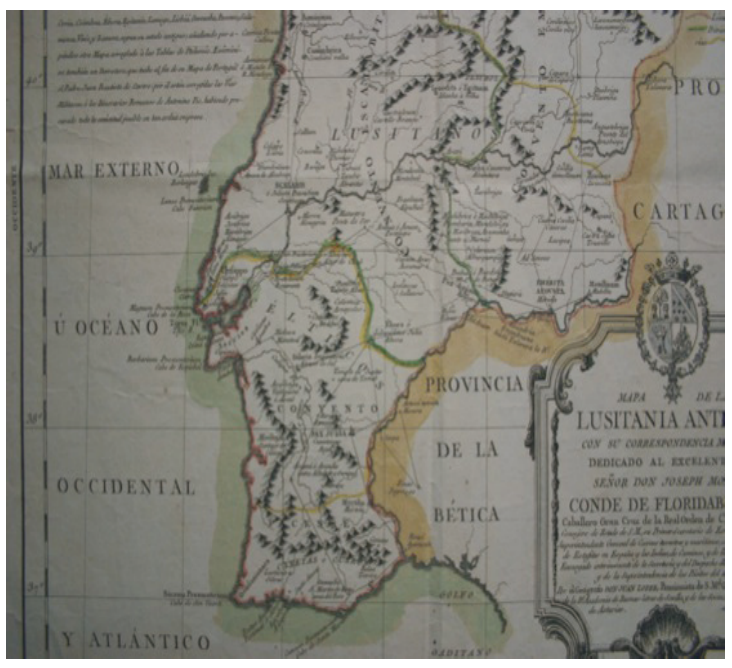

Fig.1. Mapa de la Lusitania Antigua com su correspondencia moderna, do geógrafo D. Juan Lopez, de 1789. B.P.E., Gaveta 1, Pasta A, n. ${ }^{\circ} 29$

O exemplo que escolhemos, neste contexto, é o Mapa de la Lusitania Antigua com su correspondencia moderna, do geógrafo D. Juan Lopez, de $1789^{4}$, que consideramos ser interessante para as abordagens ao tema da dominação romana na Península. Estas informações eram, à altura, bastante inovadoras, numa época em que a construção do vocabulário científico se tornava pertinente ${ }^{5}$. Este geógrafo, pensionista do rei espanhol em Paris, pertencia à Academia de Belas Artes de Sevilha e às Sociedades de Geografia da Biscaia e Astúrias. Este Mapa, que tem a preocupação de fazer corresponder os lugares da Lusitânia antiga com os topónimos coevos, foi dedicado a D. José Moñino, conde de Floridablanca. Explicita os limites das Províncias, a divisão

${ }^{4}$ B.P.E., Gaveta 1, Pasta A, n. ${ }^{\circ}$ 29. Existe exemplar semelhante na Biblioteca Nacional de Madrid (Sala Goya: Mr/2 Portugal). Cf. Figs 1 a 3.

${ }^{5}$ H. Capel 1985. 
dos conventus (para a Lusitânia, o pacense e o escalabitano) aludindo ainda aos diversos povos que aí habitaram. Na legenda, temos estatuto dos locais a que se refere: a cidade capital e convento jurídico; a colónia, o município e a cidade; a cidade mais pequena ou vila, que gozava de direito latino; os povos confederados e os estipendiários, e ainda os lugares ou aldeias. No que respeita à Lusitânia, se Beja é sinalizada como cidade capital e sede de convento jurídico, Évora, Mértola e Alcácer do Sal são indicadas como cidades menores que gozavam do direito latino, sendo Portalegre anotada como povo estipendiário e Elvas como lugar ou aldeia, ao lado de Arraiolos, Serpa, Moura.

Como acima sublinhámos, são relevadas as designações romanas das localidades, por vezes mais do que uma, bem como a sua correspondência, à altura ${ }^{6}$.

Além da precisão das coordenadas, temos também informações acerca das escalas usadas, fazendo as suas correspondências com os registos romanos e com os caminhos percorridos, em termos de tempo (um grau, em termos de longitude, correspondia a 75 milhas romanas, e cada uma correspondia, por sua vez, a 1755 varas castelhanas, por exemplo).

Este mapa permite ainda reconstituir os cinco itinerários de Antonino Augusto a partir da capital de província, Emerita Augusta; para o território português são referenciados dois itinerários, um seguindo mais pelo Norte alentejano e o curso do rio Tejo. Saía de Emerita Augusta, passava por Plagiaria, Pax Augusta e ia até Septem Aras, onde bifurcava; uma das vias seguia por Malusaro, Alberteri, Bretolacum e chegava a Ollisypo. A outra seguia no sentido da Aramenha, povo estipendiário, Fraavium, Tucubis, Scalabis, Arabriga, outro povo estipendiário, chegando a Olissipo.

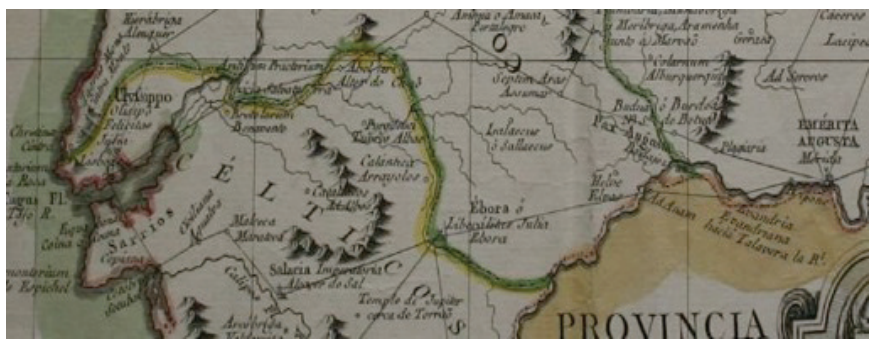

Fig.2. Itinerários a partir de Emerita Augusta. B.P.E., Gaveta 1, Pasta A, n. ${ }^{\circ} 29$

O outro itinerário vinha mais para o sul, dividindo-se, em Liberalitas Julia em duas vias, uma mais longa, que percorria o interior, e outra que seguia no sentido do litoral. Assim, de Emerita Augusta este itinerário seguia por Evandria até Liberalitas Julia, onde se dividia: uma das vias seguia para Salacia Imperatoria, Malceca, Ciciliana, Cetobriga, Equabona e atingia Olissypo. A outra seguia no sentido de Rarapia, Aranni (entre Alvalade e Ourique, povo

\footnotetext{
${ }^{6}$ Casos de Balsa, Tavira; Myrtilis, Mértola; Pax Augusta, Badajoz; Malusaro, Ponte de Sôr; Fraavium, Alpalhão; Mendicular, Montalvão; Moren, Almeirim.
} 
estipendiário), Ossonoba/Estoi, Balsa, Esuri (Ayamonte), Myrtillis, Pax Julia, Arucci Novum, Fines (povo estipendiário), Serpa, e chegava de novo a Liberalitas Julia. O testemunho do mapa pode ser confrontado com fontes documentais existentes em Évora? ${ }^{7}$.

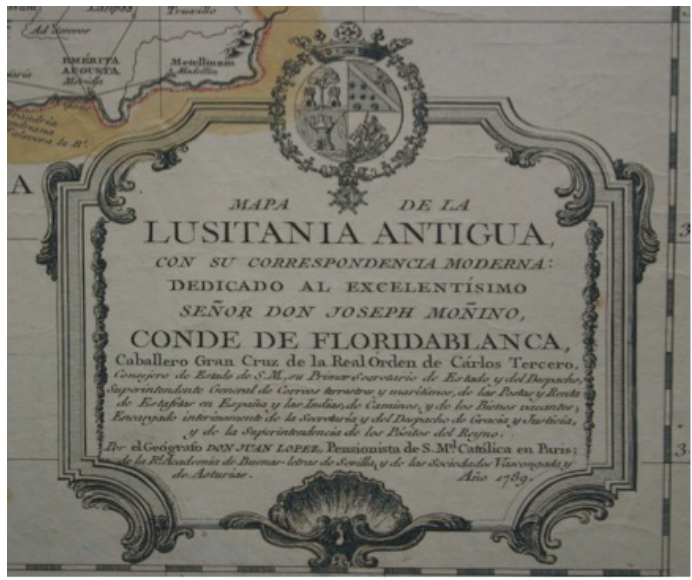

Fig.3. Mapa da Lusitânia Antiga: autoria, dedicatória e data. B.P.E. Gaveta 1, Pasta A, nº29

Nos Relatos de Viagens, para este período e dentro desta temática, salientamos o discurso de D. Juan Alvarez de Colmenar, no terceiro tomo da obra Annales d'Espagne et de Portugal, da década de 40 do século XVIII. Na obra é feita uma descrição geral do reino e das cidades a partir das províncias onde se localizavam. Embora os aspectos bélicos estejam muito presentes, o autor preocupa-se com a descrição latina dos sítios, descrevendo ainda vestígios antigos, como o templo de Prosérpina, em Vila Viçosa, ou fazendo a transcrição lapidar do que encontrou no convento dos Agostinhos da mesma vila. Em relação a Évora, elogia a sua ancestralidade, em particular a sua romanidade: Júlio César dera-lhe o direito de cidade latina, com o nome de Liberalitas Julia, designação que, segundo o viajante, terá encontrado numa inscrição aquando da sua visita à cidade; Sertório guarnecera-a de boa cintura de muralhas, bem como de um magnífico aqueduto, mais tarde elogiado também por James Murphy.

Murphy foi outro viajante que, no século XVIII, visitou o Sul de Portugal, tendo como objectivo primordial estudar e desenhar os monumentos portugueses e as preciosidades arqueológicas a pedido de William Burton Conyngham, seu protector, e que antes visitara o país. Mercê da sua formação em arquitectura e arqueologia, o seu relato revela um grande interesse pelos vestígios antigos, particularmente os romanos. Deste modo, sublinha as

${ }^{7}$ B.P.E., Cód. 76 da Manizola, Peça 33. Neste códice são transcritas diversas inscrições encontradas ao longo do Itinerário, muitas vezes socorrendo-se do trabalho já efectuado por André de Resende. 
qualidades de Salacia Imperatoria (Alcácer do Sal) como estância balnear desde a época romana e os vestígios romanos próximos, como os de um templo dedicado à deusa Salacia. Já em Beja, além dos elogios às recentes escavações, o Autor admira a colecção de objectos recolhidos por Frei Manuel do Cenáculo. Desenha-os, deixando-nos na sua obra, também enquanto artista, um importante testemunho para o estudo da época. Teve comportamento similar em Évora, onde se detém nos seus símbolos maiores de ligação à presença romana: o templo e o aqueduto, que desenha, descreve e elogia. Descreve também em pormenor a torre/reservatório existente na extremidade do aqueduto, com a designação de $\mathrm{S}$. Francisco, elogiando os materiais e a sua harmonia, lembrando-lhe as obras gregas. Refere-se a essa torre como o mais bem conservado e mais belo monumento da Antiguidade de Évora.

\section{Os guias de viagens nos períodos moderno e contemporâneo}

Os guias de viagem têm uma tradição que remonta a períodos recuados e os primeiros que se conhecem eram destinados aos peregrinos que se dirigiam Roma, S. Tiago de Compostela ou Jerusalém e estavam escritos em latim. Nestes guias eram dadas indicações como as etapas da viagem, as grandes hospedarias, as cidades e vilas por onde se devia passar. No período moderno foram impressos vários guias, como foi o caso do Guide de chemins de France da autoria de Charles Estienne, datado de 1552, ou do guia Le Guide des chemins d'Angleterre, da autoria de Jean Bernard, que foi publicado em $1579^{8}$. Contudo foi a partir do século XVIII que se desenvolveu a publicação de guias de viagens em que se davam indicações concretas e úteis sobre os espaços a visitar, como é o caso do Guide du Voyageur par Angleterre et Hollande (Paris, 1786). Surgiram mesmo colecções de bolso em que se indicavam os monumentos mais representativos ou pitorescos de cada localidade, como foi o caso da colecção francesa Delices de..., na qual em 1707 se publicou a obra Delices de l'Espagne et du Portugal ${ }^{9}$.

Os guias de viagens do período contemporâneo inserem-se numa literatura utilitária e pedagógica que visa dar àqueles a quem se dirigem uma série de indicações práticas sobre as viagens a empreender e sobre os espaços a $\operatorname{visitar}^{10}$. Disponibilizavam igualmente informações de carácter histórico, mais ou menos pormenorizadas e rigorosas, sobre os vários lugares ou monumentos referidos nos itinerários que eram propostos ${ }^{11}$.

Entre as estratégias concebidas para incentivar a visita a determinados espaços e locais, contam-se as referências à sua antiguidade, fazendo-a remontar, em alguns casos, ao período clássico. Nos guias de viagem, a antiguidade clássica está presente através de aspectos como: referências e descrição de determinados espaços, tais como os museus de arqueologia;

${ }^{8}$ G. Guilcher 200082.

${ }^{9}$ P. van der Aa 1707. Nas versões francesas surge como autor Juan Álvarez de Colmenar, talvez um pseudónimo do verdadeiro autor.

${ }^{10}$ Sobre os Guias de Turismo veja-se A. C. de Matos e M. L. Santos 2004.

${ }^{11}$ M. L. Santos, A. C. de Matos, M. A. Bernardo 2008. 
chamadas de atenção para a relevância que determinadas povoações ou lugares tinham no período clássico; localização e descrição mais ou menos detalhada de sítios com vestígios daquele período; reconstituições de viagens e da rede viária; imagens da cidade, etc.

Por efeito de um processo de especialização temática em função dos públicos a que se dirigiam, já no século XX, no final dos anos 1970 início de 1980, os arqueólogos e historiadores Filippo Coarelli e Mario Torelli criaram a colecção Guide Archaelogiche Laterza, que era composta por 14 volumes e abrangia a Itália, a Sicília e a Sardenha. Esta colecção tinha por objectivo dar a conhecer as descobertas arqueológicas e as campanhas arqueológicas recentes ${ }^{12}$.

O interesse que durante o século XIX se verifica em Portugal relativamente à antiguidade clássica enquadra-se no facto de se iniciarem "neste século, campanhas de pesquisas, sobretudo nos locais arqueológicos há muito conhecidos: Tróia, Lisboa, Conímbriga e Évora, sítios onde as investigações se assumem já com um carácter tendencialmente institucionalizado"13. Campanhas que eram largamente divulgadas não só em publicações especializadas que se destinavam aos arqueólogos, mas também noutras que eram dedicadas a um público mais heterogéneo, como no caso de $O$ Archivo Popular, que em 1838 noticia o aparecimento de uma inscrição numa parede de uma casa, na Travessa do Almada em Lisboa, ou do Archivo Pittoresco, que em 1863 refere o achado de uma urna de vidro, presumivelmente romana, com inscrição funerária, numa escavação em Setúbal ${ }^{14}$.

Os exemplos que se seguem, relativos ao Sul do país, e em especial a Évora, ilustram o testemunho da presença da antiguidade clássica nos guias de viagem dos séculos XIX e XX editados em português.

Comecemos pelo Novo Guia Luso-Brasileiro do viajante na Europa ${ }^{15}$, datado de 1876 e da autoria de Guilherme João Carlos Henriques, que se destinava aos viajantes portugueses e brasileiros que pretendiam conhecer a Europa. Nesta obra são várias as referências aos monumentos da antiguidade que o autor aconselha o viajante/turista a visitar, como é o caso do "Templo de Diana, uma antigualha romana muito visitada pelos archeologos estranjeiros; o aqueducto do Sertorio, que data da mesma era; a Torre da extremidade do aqueducto, um primor de architectura romana" ${ }^{16}$, ou o caso de "S. Thiago de Cacem. Cabeça de Comarca e aceiada povoação. É muito frequentada pelos

${ }^{12}$ G. Guilcher 2000181 e 184 . Todos os autores dos guias eram arqueólogos.

${ }^{13}$ O. Matos 2007 75-96.

${ }^{14}$ Idem.

15 Tratava-se de um livro de pequenas dimensões, com 541 páginas, o qual, após uma introdução, se dividida em capítulos que correspondiam aos diferentes países, terminando com um índice geral alfabético. A principal razão que levou o autor a escrever foi o facto de "Por muitos annos houve falta d'um livro em portuguez que indicasse aos viajantes portuguezes e brazileiros os itenerarios mais seguidos e os meios de communicação mais asselerados entre as diversas capitaes da Europa".

${ }^{16}$ G. J. C. Henriques 1876 38-39. 
estrangeiros que vão ver as ruinas da antiga Merobriga, cidade romana, que fica a 1 kilometro de S. Thiago"17.

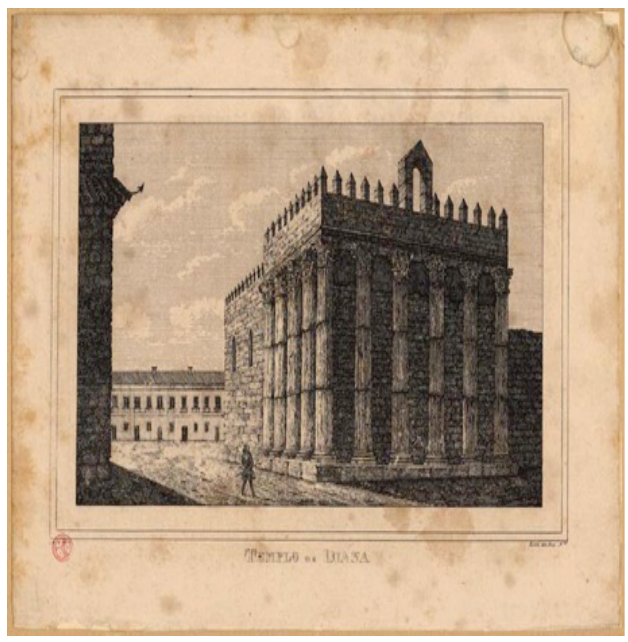

Fig.4. Templo de Diana em Évora, in James Murphy, Voyage en Portugal a Travers les

Provinces D'Entre Douro et Minho, de Beira, D'Estremadure et D'Alenteju dans les Annés 1789 et 1790. Paris, Chez Denné Jeune, 1797.

O interesse de Guilherme João Carlos Henriques ${ }^{18}$ pela antiguidade clássica estava também seguramente ligado ao facto de ele ser um erudito que pertenceu à Real Associação dos Arquitectos e Arqueólogos Portugueses, onde naturalmente existia um grande interesse pelas referências à antiguidade clássica.

No início do século XX o engenheiro Caetano da Câmara Manuel, que durante largos anos dirigiu as obras públicas na cidade de Évora, tendo-se mesmo tornado um eborense de adopção ${ }^{19}$, escreveu a obra Atravez da Cidade de Évora. Apontamentos sobre a cidade de Évora e os seus arredores ${ }^{20}$, na qual pretendia "Dar uma sumária notícia de Évora monumental, não deixando, contudo, de acompanha-la de alguns apontamentos que possam interessar ao forasteiro", que se destinava aos "interessados da história de Évora" e aos visitantes desta cidade. Não sendo um historiador, baseava-se na Historia de exercito portuguez por Christovão Ayres, para referir que "A cidade romana era cercada de uma muralha que teria $1080 \mathrm{~m}$ de extensão e seguia pela Alcarcova de baixo e de cima, Igreja do Salvador, arco de D. Izabel, muralha

${ }^{17}$ Idem, 39-40.

18 Terá nascido em Londres em 27 de Março de 1846 com o nome de William John Charles Henry, que depois alterou. Era afilhado do Conde de Carnota e foi proprietário rural e autor de obras como Alenquer e o seu concelho. Lisboa, Typographia Universal, 1873.

${ }^{19}$ J. Pereira 2007.

${ }^{20}$ C. C. Manoel 1900. Trata-se de um livro de pequenas dimensões, com 104 páginas e algumas fotografias. 
norte do passeio de Diana, palacio dos Condes de Basto (hoje do conde da Serra da Tourega), onde existiu uma mouchinha, Freiria de baixo ao largo da Misericórdia, e Igreja de S. Vicente"21.

As referências ao período clássico surgiram também num guia editado pela primeira vez em 1907 pela revista Gazeta dos Caminhos de Ferro e coordenado por L. de Mendonça e $\operatorname{Costa}^{22}$, um dos portugueses que no início do século XX mais viajou e mais promoveu o turismo em Portugal. Tal guia tinha por título $\mathrm{O}$ Manual do Viajante em Portugal: com itinerários da viagem em todo o paiz e para Madrid, Paris, Vigo, Sant'Iago, Salamanca, Badajoz e Sevilha ${ }^{23}$.

Sobre a questão da atribuição aos romanos de algum património edificado existente na cidade de Évora pode ler-se, no referido guia: a «Torre do Sertório, que muitos supõem romana. É de construção medieval [...]» ${ }^{24}$.

As referências à antiguidade das várias cidades e vilas do país surgem também no Guia de Portugal de Raul Proença. Aí se refere que "O Templo romano (mon. Nac. Pl. C6 n ${ }^{\circ}$ ), vulgarmente denominado templo de Diana (embora ainda hoje se desconheça a que divindade era dedicado) é único no seu género e uma das mais bem conservadas ruínas romanas de toda a Península. É uma combinação de robustez e graça [...] (Para mais pormenorizada descrição cf. G. Pereira, Estudos Eborenses - Évora romana, $1^{\mathrm{a}}$ parte [...])”.

\section{Considerações finais}

Os exemplos que acima enunciámos permitiram demonstrar o contributo que os mapas, os relatos e os guias de viagem podem fornecer para o estudo da Antiguidade Clássica. Em especial os estudos que têm como objectivo conferir o que em cada momento histórico se sabia sobre os vestígios que os povos antigos deixaram no nosso território e a forma como esse legado foi sendo percepcionado e valorizado ao longo dos tempos.

\section{Bibliografia}

P. van der Aa, ed. (1707), Les delices de l'Espagne et du Portugal. Leide, 3 vols. Biblioteca Nacional de Madrid, (B.N.M.), Sala Goya, Mr/2 Portugal.

Biblioteca Pública de Évora (B.P.E.), Gaveta 1, Pasta A, nº 29 (Cartas Geográficas).

${ }^{21}$ Idem, p.21.

22 Sobre Mendonça e Costa, promotor da referida Gazeta dos Caminhos de Ferro de Portugal e Hespanha, veja-se E. Ribeiro 2006.

${ }^{23}$ Este livro com formato "de bolso" e capa de cor azul imperial e letras brancas (cores da bandeira nacional), possuía 252 páginas de leitura. Mendonça e Costa utilizou como modelo, segundo as próprias palavras, os guias de Baedeker; era seu objectivo proporcionar, em língua portuguesa, um guia de viagem em Portugal, já que os guias existentes eram escritos noutras línguas.

${ }^{24}$ R. Proença 1924-27: Vol. II, p. 62. 
Biblioteca Pública de Évora (B.P.E.), Cód. 76 da Manizola, Peça 33: Itinerário de Antonino pello Reyno de Portugal, e Província de Estremadura, com alguas illustracões. Caminho de Lisboa a Merida, M.P.CXLI.

D. Juan Alvarez de Colmenar (1741), Annales d'Espagne et de Portugal avec la description de ces deux royaumes. Amsterdam, François L'Honoré \& Fils, Vol. III.

L. de Mendonça Costa e Carlos d'Ornells (1940), O Manual do Viajante em Portugal: com itinerários da viagem em todo o paiz e para Madrid, Paris, Vigo, Sant'Iago, Salamanca, Badajoz e Sevilha. Lisboa, Gazeta dos Caminhos de Ferro.

Guilherme João Carlos Henriques (1876), Novo Guia Luso-Brasileiro do viajante na Europa. Lisboa, Editores Ferreira-Lisboa \& $\mathrm{C}^{\mathrm{a}}$.

Caetano da Câmara Manoel (1900), Atravez da Cidade de Évora ou apontamentos sobre a cidade e os seus monumentos. Évora, Minerva Comercial.

James Murphy (1797), Voyage en Portugal a Travers les Provinces d'Entre Douro et Minho, de Beira, d'Estremadure et d'Alenteju dans les annés 1789 et 1790. Paris, Chez Denné Jeune.

Raul Proença (1924-1927), Guia de Portugal. Lisboa, Oficinas Gráficas da Biblioteca Nacional.

Estudos

Horácio Capel (1985), "Geografia y Arte Apodémica en el siglo de los viajes", Geocritica. Cadernos Críticos de Geografia Humana. Universidad de Barcelona, Año 9, $\mathrm{N}^{\circ}$ 56. (disponível em http://www.ub.es/geocrit/geo56 htm). Antónia Fialho Conde (2007), "On Continuity of Choice: the Places and Spaces Visited by Tourists and Travellers in Portugal in the 18th and 19th centuries", Things that move: The material world of tourism and travel. Leeds, Centre for Tourism \& Cultural Change.

Fernando Carmona Fernandéz, José Miguel Garcia Cano, eds., (2005), Libros de viaje y viajeros en la literatura y en la historia. Universidad de Murcia.

Goulven Guilcher (2000), «Naissance et développement du guide de voyage imprimé: du guide unique à la série, une stratégie de conquête des lecteurs ?», in Gilles Chabaud et alii, Les Guides Imprimés du XVIe au XXe Siècle : villes, paysages, voyages. Paris, Belin, 81-93.

Ana Cardoso de Matos, Maria Luísa F. N. dos Santos (2004), "Os guias de Turismo e a emergência do Turismo Contemporâneo em Portugal (dos finais do século XIX às primeiras décadas do século XX)", Scripta Nova. Revista electrónica de Geografía y Ciencias Sociales. Universidad de Barcelona, Vol. VIII, núm. 167. (disponível em http://www.ub.es/geocrit/sn/sn-167.htm).

Olga Matos (2007), "Notas soltas sobre a 'descoberta' da Arqueologia no século XIX" Praxis Archaeologica. Revista Electronica de Teoria, Metodologia e Política da Arqueologia 2 75-96.

José Garcia Mercadal (1999), Viajes de extranjeros por España y Portugal: desde los tiempos remotos hasta comienzos del siglo XX. Salamanca, Junta de Castilla y León, 6 vols. 
João Pereira (2006), A intervenção dos Engenheiros e Condutores na modernização da cidade de Évora (1880-1920). Évora (dissertação de mestrado).

Carlos Garcia Romeral Pérez, (2001), Bio-bibliografía de viajeros por España y Portugal. Madrid, ed. Ollero e Rams, 3 vols.

Elói Ribeiro (2006), A Gazeta dos Caminhos de Ferro e a Promoção do Turismo em Portugal (1888-1940). Évora (dissertação de mestrado).

Maria Luísa Santos, Ana Cardoso de Matos, Maria Ana Bernardo (2008), "Tourism, Guidebooks and the Emergence of Contemporary Tourism in Portugal", Touring the Past. Finnish University Network for Tourism Studies (forthcoming). 
(Página deixada propositadamente em branco) 


\title{
AMEDEO MODIGLIANI (1884-1920) E O TEMPLO DA BELEZA: UMA UTOPIA FIGURATIVA NA ARTE MODERNA
}

\author{
Susana M. Loureiro Restier Grijó PoçAS \\ Licenciada em Filosofia \\ Mestre em História de Arte \\ Universidade do Porto
}

\section{Abstract: Amedeo Modigliani (1884-1920) and the temple of beauty: a figurative utopia in modern art.}

The Italian artist Amedeo Modigliani (1884-1920), whose greatest desire in life was to become a sculptor, idealized a temple of beauty, inspired by the classic heritage, composed of countless heads and caryatids, which he named "columns of tenderness". From this ambitious dream that lasted until 1914, reached us drawings and some sculptures, in which we can see a part of what this monument would be and that, due to the artist's poor health, and also to its utopian dimension, never became totally materialised. However, the originality of this project, as well as the prodigious effort it contained, since the sculptures were made in direct carving, are worthy of a meditation about the blending between tradition and innovation. Modigliani combined the metaphor of plastic language to the transfiguration of an ancient image that he wisely adapted to a modern ideal, thus creating a project that, being part of his artistic tribute to mankind, even today presents itself as holder of an extraordinary uniqueness.

Keywords: Modern Art, Modigliani, utopy.

Palavras-chave: arte moderna, Modigliani, utopia.

"A plenitude aproxima-se."

"Farei tudo em mármore."

Foi desta forma, eloquente e emocionada, que o artista italiano Amedeo Modigliani (1884-1920), descreveu, no Verão de 1913, o seu trabalho de escultor que então realizava em Carrara.

Nascido na pequena cidade portuária de Livorno, em Julho de 1884, no seio de uma família de ascendências judaico-sefarditas, e marcado por uma

1 "Letter despatched from Livorno on 23 April 1913 (Modigliani to Paul).

"My dear Paul a favour - go to the Serbo-Croat's, fetch the head and take it to av. Malakoff and look after it for me. Drop me a line when this is done. Fulfilment is on its way. The keystone won't have been placed in the arch until I have done another fortnight's work... I will do everything in marble. The village near where I shall quite literally pitch my tent - a tent for shelter - has dazzling light and air of the most luminous clarity imaginable. Very best regards to you while waiting to hear from you and to write again to you.

Modigliani. Received Maldoror with thanks. I shall send you photos" (Noël Alexandre 1994 104). 
educação predominantemente literária e filosófica, Modigliani cedo acusou sinais de uma saúde débil, que o levaria a uma morte precoce, assim como de um forte talento artístico, impulsionado pela sua mãe.

Em 1902, durante uma longa viagem de convalescença, Amedeo descobre a obra do escultor Tino da Camaino e o regresso à cidade de origem revelase fugaz, pois Modigliani, de saúde restabelecida, depressa se muda para Pietrasanta, onde experimenta as primeiras incursões na escultura.

Através de um pequeno bilhete dirigido ao amigo Gino Romiti, verificámos que Amedeo esculpia cabeças ao mesmo tempo que trabalhava com algum entusiasmo ${ }^{2}$.

Após a frequência nas Academias de Florença e Veneza, o italiano decide partir rumo a Paris, terra das vanguardas artísticas, onde chega no Inverno de 1906, apresentando-se como escultor, desejando ardentemente cinzelar "não bustos, mas monumentos colossais" 3 .

Evidenciando um estilo de formas exclusivamente humanas e possuidor de particularidades invulgares, o livornês adquire um evolutivo manejar da técnica, enquanto acentuava uma fixação temática específica nestes primeiros anos de trabalho na capital francesa.

Em 1909, após ter conhecido o seu homónimo Amadeu de Sousa Cardoso (1887-1918), que seria o seu grande amigo e único companheiro de trabalho, Modigliani muda-se para o $\mathrm{n}^{\circ} 14$ da Cité Falguière.

Dedicando-se, quase por completo, à sua declarada vocação de artífice do cinzel (Figs. 1 e 2), o italiano perpetua a metodológica romagem aos museus, defrontando-se com a arte primitiva no Museu Etnográfico do Trocadéro e o legado clássico do Museu do Louvre.

A transição de 1910 para os meses inaugurais de 1911 traz consigo um voluntário acréscimo de trabalho, pois Modigliani e Sousa Cardoso escrupulosamente preparavam uma investida artística em parceria.

Os dois Amadeus, imbuídos de uma mútua admiração alicerçada numa forte amizade, esmeravam-se na organização da mostra conjunta que inauguraram

2 "Cher Romiti,

Les agrandissements pourraient être de $18 \times 24$, la tête seulement, bien entendu.

Fais les chics. J'aimerais les avoir vite, trois ou quatre copies chaque (pour toi, en plus, tant que tu veux).

Adresse-les mois ici à Pietrasanta, rue Victor Emmanuel, chez Puliti Emile. J'espère travailler, c'est-à-dire achever et te revoir bientôt.

\section{Salutations}

Modigliani.,"

(Bilhete de Amedeo Modigliani a Gino Romiti, Pietrasanta, 1902?, in Jeanne Modigliani 1961 113).

3 “A son arrivée à Paris au début de 1906, Modigliani descend pour quelques semaines dans un hôtel situé près de l'élégant quartier de la Madeleine. Ortis de Zarate lui avait donné une lettre d'introduction pour le peintre et sculpteur Granowski.

Ce dernier parlait mal le français et le dialogue entre eux fut difficile. Modigliani parvint quand même à faire comprendre à son interlocuteur qu'il volait faire de la sculpture, non des bustes, mais des monuments colossaux”, Jeanne Modigliani 199059. 
no domingo de 5 de Março de 1911, no faustoso atelier do português situado no $\mathrm{n}^{\circ} 3$ da rue $d u$ Colonel Combes.

Antes da abertura ao público, os obstinados artistas tiveram ainda tempo para que Sousa Cardoso fotografasse as esculturas do italiano no decadente estúdio da Cité Falguière, precedendo a passagem das mesmas para a rue du Colonel Combes (Figs. 3, 4, 5 e 6).

As preciosas imagens permitem admirar a figuração que Modigliani arrojadamente realizava em talha directa, técnica introduzida em Paris por dois pintores - Gauguin e Derain - e que não era ensinada nas academias.

Da mostra não foram ainda localizadas fotografias, convites ou o catálogo que certamente a completou, contudo é sabido que Modigliani arriscou uma pré-apresentação de um original ensemble de sete esculturas (cinco das quais o amarantino tinha registado na Cité), a par de guaches representando graciosas cariátides, enquanto Sousa Cardoso expôs inventivos desenhos e coloridas aguarelas.

No sequente ano, entre 1 de Outubro e 8 de Novembro de 1912, tem lugar no magnificente Grand Palais, o X Salon d'Automne que incluía a insólita Sala XI, imortalizada como a Sala dos Cubistas e na qual estavam integradas quatro esculturas de Modigliani.

O livornês remetera ao júri do Salon (que tinha como vice-presidente da Secção de Escultura o carismático Duchamp-Villon) um conjunto de sete cabeças esculpidas que intitulara de Têtes - Ensemble décoratif e cuja disposição, segundo Lipchitz, fazia sugerir os "tubos de um órgão". ${ }^{4}$

A única imagem da disputada sala permite-nos um vislumbre de uma parte integrante do que seria a edificação templária que o toscano vagarosamente tentava erigir, tendo sido o ensaio público mais próximo do utópico sonho, após a mostra com Sousa Cardoso (Fig. 7).

A recepção à peculiar proposta, invulgar no contexto dos burgueses e desejadamente convencionais Salons parisienses, parece ter sido favorável, a acreditar nas palavras do próprio Amedeo em carta ao seu irmão Umberto, na qual partilhava o contentamento em face da excepcional "aceitação em bloco". 5

Pouco depois, no final do ano e vivendo com alegria o sucesso do Salon, o toscano muda-se para o n⿳39 da Passage de l'Elysée des Beaux-Arts em

4 "Lipchitz connut Modigliani par l'intermédiaire de Max Jacob: Modigliani m'invita à aller le voir dans son atelier de la Cité Falguière, écrit il, il faisait de la sculpture à cette époque et, naturellement, j'étais très curieux de voir ses oeuvres. Quand j'arrivai chez lui, il était en train de travailler dehors. Des têtes en pierre, cinq peut-être, étaient alignées sur le sol cimenté de la cour devant l'atelier. Il était en train de les rassembler. Il me semble encore le voir: penché sur ces têtes il m'expliquait que, dans son intention, elles devaient former un tout." Et il poursuit: "Il me semble qu'elles furent exposées quelques mois après, au Salon d'Automne, l'une à côté de l'autre comme des tuyaux d'orgue..." in Jeanne Modigliani 199080.

5 "Mais, dans une lettre non datée, envoyée, avec un dessin - de type idole égyptienne - à son frère Umberto, Modigliani affirme:

"Très cher Umberto, merci, avant tout, du secours inespéré. Avec le temps j'espère arriver à me débrouiller: le tout est de ne pas perdre la tête. In pectore je sens que je finirai ainsi un 
Montmartre, local para onde a sua mãe Eugenia envia uma carta dirigida a "Modigliani Escultor", aparecendo na Cité Falguière estritamente para trabalhar.

Durante os meses preambulares de 1913, Modigliani perpetua a partilha de experiências com Sousa Cardoso, Brancusi, Max Jacob, Ortiz de Zárate e Lipchitz.

São alguns dos artistas que então privavam com o toscano que assistem ao acelerado esgotamento físico do amigo, que alcança proporções alarmantes quando este é encontrado desvanecido no atelier.

Com a ajuda deles, através de uma pequena colecta organizada por Ortiz de Zárate, Modigliani consegue juntar a quantia suficiente para viajar até Livorno, com o intuito de restaurar a sua enfraquecida saúde.

Contando sempre com o apoio familiar, ao qual fora acrescido o humanitário contributo dos amigos, e levando consigo algumas das fotografias que Sousa Cardoso havia tirado às suas esculturas dois anos antes, Modigliani principia em Abril o ambicionado repouso em solo italiano.

Sem conseguir alhear-se da prática da escultura, o livornês prontamente desloca-se a Carrara, onde não hesita em trocar a pedra calcária pelo sublime mármore, material que acolhe a sua produção desta altura e da qual não sobreviveram exemplares.

Maravilhado, Amedeo escreve a Paul Alexandre, reconhecendo com gratidão o envio do seu livro predilecto (os Cantos de Maldoror do misterioso Lautréamont), que a "a plenitude aproxima-se", "farei tudo em mármore"...

Precisamente na altura em que se lançava ao árduo trabalho com um admirável ímpeto, revê os antigos parceiros no lendário Café Bardi e confrontase com uma inesperada e negativa recepção às suas figurações de pedra.

Mostrando orgulhoso as fotografias das esculturas, Amedeo ignorava que os amigos não poderiam compreender os bustos alongados, de esfingéticas e

jour ou l'autre par me frayer la voie.

Le Salon d'Automne a été relativement un succès et l'acceptation en bloc est un cas assez rare de la part de les gens qui passent pour former une coterie fermée. Si je renforce l'effet aux Indépendants, $j$ 'aurais sans doute fait un premier pas. Et toi que deviens-tu?

Salue de ma part tante Lo. Ecris-moi si tu peux. Je t'embrasse, ton Dedo."

Cette lettre, inédite jusqu'à présent, confirme les liens affectueux de Dedo avec sa famille qui, dans les limites de ses possibilités, l'a toujours aidé; elle témoigne du sérieux avec lequel il affrontait son travail; elle confirme enfin les souvenirs incertains de Lipchitz sur la présence de sculptures de Modigliani au Salon d'Automne. Ces oeuvres "acceptées en bloc" pouraient bien être les fameux termes alignés les uns à côté des autres dans la cour de la Cité Falguière. Dans les Archives du Salon d'Automne, le catalogue du Xe Salon, 1912, indique:

"Modigliani, $n^{\circ}$ S 1211-1217 - Têtes, ensemble décoratif." in J. Modigliani 1990 80-81. 
absortas expressões, destinados a um extemporâneo templo enaltecedor de uma beleza para eles perdida.

Incrédulo com o desinteresse, mas nunca consentindo que este se apoderasse dos seus objectivos, Modigliani prossegue com o seu trabalho de escultor.

A 6 de Maio, num dos postais dirigidos ao médico Paul Alexandre, Amedeo, assinando "o ressuscitado", escreve que "a felicidade é um anjo de grave semblante", da qual tentava acercar-se seguindo o curso do seu genuíno chamamento: a escultura.

Em 1914, voltando de forma progressiva à primazia do óleo, o livornês vê-se forçado a renunciar a um sonho que uma saúde precária não conseguira salvar.

O funesto pó liberto ao laborar a pedra (que agravou a sua tuberculose), a falta de forças para uma temerária procura figurativa e a crescente falta de material, provocam uma inevitável concentração na pintura e no contínuo desenho.

Assistindo, com 30 anos, ao rebentar da Primeira Guerra Mundial, Modigliani presencia a mobilização dos seus parceiros e a suspensão das inúmeras edificações parisienses, por esse motivo escasseando a pedra com que planeara formar o seu templo de soberanos "pilares de ternura", tal como denominava as suas cariátides.

Em 1915, Modigliani abandona definitivamente a escultura, transpondo os princípios da anterior actividade para a tela que via, através da predominante técnica do óleo, nascer uma figuração insólita, mas profundamente alicerçada no passado artístico que precedia o livornês e que manterá até à sua morte, aos 35 anos, em Janeiro de 1920.

\section{Cariátides e atlantes: alguns exemplos}

Do seu trabalho de escultor chegaram até nós 26 obras, sendo todas, à excepção de uma realizada em mármore, efectuadas em pedra calcária, e inúmeros desenhos.

Durante o período temporal quase exclusivamente dedicado à escultura e ao desenho, Modigliani empreendeu um assombroso esforço de concretização material de um sonho que, desde o Verão de 1909 passado em Livorno, o 
perseguia: a construção de um templo da beleza, rematado por centenas de hieráticas figuras.

O testemunho dessa incessante e verdadeira luta de realização interior pode ser admirado na mais insólita e invulgar faceta da sua obra: a célebre "galeria" das cariátides.

Aliando o fascínio que sentia pela herança clássica da estátua-coluna à recém-descoberta figuração, o toscano transforma ainda a basilar imagem num receptáculo de fusão de diversas influências que então o cativavam.

Fiel ao conceito (ou opção) estético de beleza que idealizara, Modigliani desenha a um impetuoso ritmo, ao mesmo tempo que revela uma atitude excessivamente prudente na concretização escultórica das figuras delineadas.

Concentrando-se na exploração anímica do corpo humano e através de uma marcante disciplina mental, o livornês demonstra que não só conhecia profundamente os diversos legados que o precediam, como entendia o desenho sob a égide de uma nova percepção, aliada a uma prática constante, distante do mero esboço ou apontamento.

Entre 1910 e 1914, o lápis de Modigliani faz anacronicamente renascer a cariátide (cujo nome, segundo Vitrúvio, derivava das mulheres da pequena cidade grega de Karyai ${ }^{6}$ ) que, numa primeira abordagem, surge marcada por uma imobilidade estruturante de relevante elaboração facial.

Conciliando o modelo caracterizador com uma notória libertação da rigidez formativa antecedente, através de uma subtil torção corpórea, o italiano igualmente elimina a desoladora ausência de elementos secundários ao introduzir não só o apoiante sombreado, como o enquadramento cénico acessório à sugestão do entablamento, tal como a Cariátide, vista de frente, mãos por trás da cabeça confirma (Fig. 8).

Intercalando a ausência cromática e decorativa do plano secundário com a hábil sugestão do interior do templo que a cuidada sombra insinua, Modigliani cria um dos melhores exemplares da série das cariátides - Cariátide, vista de frente; colar e cinto de pérolas (Fig. 9).

Ainda do completo desenho, destacam-se os pormenores ornamentais do colar e cinto de pérolas, a par da peculiar alusão anatómica a tracejado do ângulo central, certamente inspirada numa escultura pré-helénica que o italiano admirara nas suas frequentes visitas ao Louvre, evidenciando que

6 Still, "caryatid" is what Vitruvius called the female equivalent of telamon, and the parallel between them seemed so close that he wanted to establish an analogous etiology of male and female column-statues. He makes no mention of the Doric alternation of column and telamon (as at Agrigento), even though there are parallels to it in a funerary, chthonic context for the Ionic order: in the Nereid monument from Xanthos and in the "mourners"' columnar sarcophagus in the Istambul Museum.Caryatids, Vitruvius explained,were named after the women of the small town of Carya in the Peloponnese. The town had sided with the Persians in the wars ,or at least had remained neutral. After the Persian defeat their enslaved women were shown carrying the heavy weight (of the cornice) to give the same warning the Persian telamones conveyed in Sparta” in Joseph Rykwert 1996133. 
fizera dos museus uma verdadeira escola e não apenas um local de passagem e fruição estética (Fig.10).

Acentuando a marca de devoção associada ao edifício a que as cariátides estavam tradicionalmente unidas, Modigliani coloca-as num plinto que relembra um altar, enquanto vinca o escorado posicionamento, quase alongado, dos braços.

$\mathrm{Na}$ Cariátide sentada de pernas cruzadas sobre uma base de coluna, velas acesas distingue-se a dimensão sensivelmente religiosa que rodeia a passiva imagem, a par da atingida fusão dos membros inferiores (Fig. 11).

Lançando as bases de um cânone humano que não tinha precedentes directos e não deixou sucessores, Amedeo altera a denominação habitual, e nos chamados nus femininos, cariátides de origem, mas por sentimentos e elegância libertos da rigidez primeira, torna-se evidente a marca de uma das grandes influências italianas: a circularidade da cabeça que, ao inclinarse ligeiramente, provoca um discreto alongamento do pescoço e revisita as longínquas obras de Tino da Camaino.

Singular vestígio da colossal dimensão concreta do templo que Amedeo ambicionava erigir, o magnífico Nu feminino sentado sobre a perna esquerda, joelho direito levantado (Fig. 12), embora sendo um sinal de uma variante orientadora de um novo conceito de cariátide, assegura a continuidade de um individualismo que a elaboração "seriada" do motivo poderia aparentemente ofuscar.

A dimensão quase afectiva da releitura do passado faz regressar as obras do artista a uma escultura idolátrica, numa referência mítico-poética de certo modo desadequada ao século em que se manifestava, concedendo assim uma ambiguidade vivencial.

Acusando a matriz referencial, vivificada num contexto de modernidade particular e sem um público direccionado ou conivente, a invulgar cariátide de disposição curvilínea - Cariátide vista da esquerda, ajoelhada no joelho direito sobre uma base de coluna (Fig. 13) - resolve plenamente a ambicionada interacção entre o apoio do edifício e a dependente figura, reforçado pelo negro sombreado envolvente, sendo uma das obras mais aproximadas ao modelo real e concreto da estátua-coluna.

O fortemente traçado Nu feminino de perfil, braços dobrados; colar (Fig. 14), apesar da desajustada estrutura física, que não afecta a sublime feição, é talvez o desenho superiormente comparável à cariátide que o livornês esculpiu no coincidente espaço temporal de 1912-13 (Fig. 15).

A solidez estrutural, de tendências geométricas que o contorno afirma, prefigura o humanizado bloco de pedra, cuja pormenorização não atinge os conflituosos membros inferiores, similarmente disformes, e mostra-se prova 
matérica não só de um árduo esforço, como também da gritante dificuldade em corporalizar os idealizados pilares.

Sem alcançar a diversidade qualitativa (e quantitativa) das cariátides, a sua versão masculina perpetuou-se em parcos, mas curiosos exemplares.

Os atlantes, esses seres que segundo Homero tinham sido condenados por Zeus a suportar as colunas do céu por toda a eternidade, primeiramente recorrem à fixada pose e tutelar suporte superior - Cariátide masculino, mãos por trás da cabeça; capitel (Fig. 16) -, ou à imponência física de formas robustas e precisas que caracterizam o Cariátide masculino, mãos atrás da cabeça (Fig. 17).

Libertando-se do apoio arquitectónico, Modigliani finalmente desenha um $\mathrm{Nu}$ masculino de perfil (Fig. 18) através do qual toca as lembranças dos Kuroi gregos, identicamente simplistas na elaboração e espaçada aceitação dos membros inferiores, mas de notável rigidez estruturante, configurando uma isolada imagem de vocabulário plástico marcante.

O que à partida pode parecer uma mera transposição de formas artísticas de outrora para um início de século em turbilhão, levando a um aparente e enganador entendimento de falta de originalidade por parte do artista, é no fundo um "rebuscar" no passado de forma a poder encontrar a sua personalidade contemporânea.

É através dessa indagação, da qual as cariátides são a sua face mais reveladora, que Amedeo atinge o elevado mérito deste conjunto de figuras que desenha: a humanização das cariátides.

O toscano liberta-as, de forma gradual, da mera função de suportes arquitectónicos e torna-as seres autónomos, plenos de movimentos e expressões emotivas.

Só pela conciliação da beleza, da harmonia e da humanização, Modigliani conseguiria transformá-las em verdadeiros "pilares de ternura".

Ao olharmos a pequena galeria analisada, as cariátides que homenageiam a beleza feminina sobre os auspícios de um novo cânone, não podemos deixar de pensar que a alma que as eleva é a sombra de um sonho.

A sombra de um templo que ficou para sempre inacabado...

\section{Cabeças esculturais: alguns exemplos}

Contemporâneo à série de desenhos dedicados às cariátides e atlantes, o conjunto das cabeças esculturais permite uma evidente percepção do significado que a insistência no exercício de esboços preliminares alcançou na obra de Modigliani.

Na criação de um novo imaginário de legibilidade figurativa singular, o toscano elabora ainda uma poderosa simbologia facial, de densa metáfora significante e intensidade espiritualista.

Reveladoras de uma profunda consciencialização da matéria, os desenhos das cabeças mostram-nos figurações reduzidas a uma essencialidade subjacente 
plena de originalidade, como podemos constatar na magnífica Cabeça, de frente, coroada com capitel (Fig. 19).

Detentora de uma exímia linearidade construtiva, a marcante face revela não só um domínio perfeito da técnica escolhida, como uma intelectualizada certeza do motivo a explorar.

Vincando a consistência escultórica dos seus desenhos, Modigliani pontualmente abandona o habitual lápis para o perfil da estilizada Cabeça vista da esquerda (Fig. 20), cujo relevo é sugerido pela linha circundante ao rosto que, alternada com a precisão do traço caracterizador, confere não só o contrapeso desejado à subjacente regularização, como a proximidade à caracterização de um retrato, por si um esforço notável, considerando a componente repetitiva desta particular abordagem do tema da cabeça direccionada à materialização em pedra.

Conciliando a dominante cabeça com a leve sugestão de torso, o livornês acerca a marcante face à estrutura corporal das cariátides, ou mesmo dos atlantes, evidenciando a dualidade intrínseca à criação das emblemáticas imagens que, se orientadas a uma concreta transposição, continham a utópica dimensão de componentes edificantes de um templo.

Enquanto exercita a contemporânea temática na dicotomia cariátide-cabeça escultural, o toscano analogamente traça a proeminente individualidade dos atlantes que, na transição de 1912-13, atingem uma densidade formativa de equilíbrio marcante, quer na sua perspectiva frontal e corporalmente sectária Cabeça masculina e busto, de frente (Fig. 21)-, quer na sumária e concentrada variante lateral, claramente prenunciando os vindouros nus masculinos Cabeça masculina vista de perfil (Fig. 22).

Alcançando uma notável aproximação à tridimensionalidade da escultura, como podemos constatar na sagaz estrutura facial, a impressionante Cabeça, de frente, como suporte arquitectónico (Fig. 23) permite-nos verificar a importância que o esboço preparatório adquiriu na obra do livornês, nomeadamente no peculiar e cadenciado tracejado dos ângulos laterais do rosto, paralelos ao nariz, e similar aos espaços deixados inacabados (e por isso, reveladores da superfície original da pedra) em algumas das figuras que foram esculpidas.

Terminada a muito breve passagem por alguns dos inúmeros fragmentos do templo sonhado por Modigliani, podemos concluir que esta encerra contudo dois aspectos fundamentais: não só estamos perante a mais aproximada visão da edificação que o artista planeava erguer, juntamente com as esculturas que criou; como temos a rara oportunidade de confirmar a capacidade que o livornês tinha de, por entre a insistência na imagem idealizada, conceder a 
cada desenho pequenos detalhes ou características que o tornam único e por isso diferente de todos os outros.

Este templo da beleza, mesmo fragmentado, permite constatar um percurso fulcral de um artista que foi, através de uma "teleologia do ser vivo", um memorialista e um dos maiores humanistas do século XX. ${ }^{8}$

\section{Anexos}

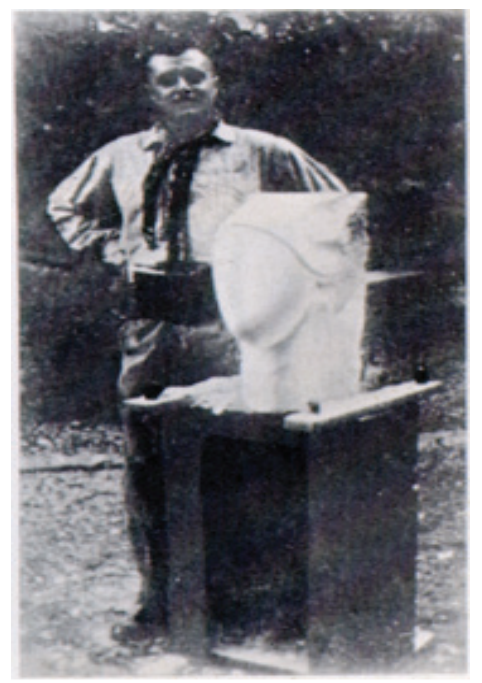

Fig.1. Amedeo Modigliani na Cité Falguière, 1911-12. Paris, in Françoise Cachin e Ambrogio Ceroni 1972106

\footnotetext{
${ }^{7}$ In Alexandre Fradique Morujão 19839.

${ }^{8}$ Este tema, que continuamos a investigar, encontra-se amplamente desenvolvido na nossa dissertação de Mestrado em História da Arte, a publicar pela Universidade do Porto: Susana Maria Loureiro Restier Grijó Poças 1998, Amedeo Modigliani - O preciosismo do desenho e as cumplicidades lusas. 1884-1920. Porto. - Portugal: Dissertação de Mestrado em História da Arte, Faculdade de Letras, Universidade do Porto, 4 Volumes, 1000 pp. (todos os direitos reservados).
} 
Amedeo Modigliani (i 884 -I 920 ) e o templo da beleza. Uma utopia FIGURATIVA NA ARTE MODERNA

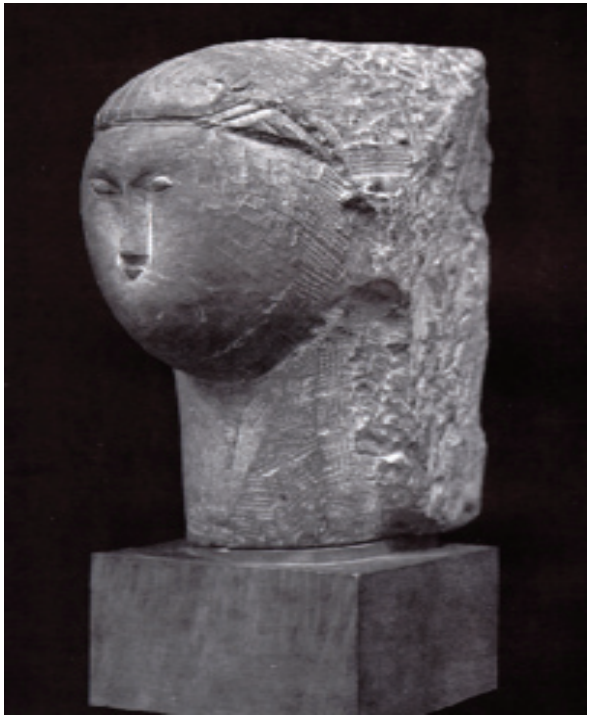

Fig.2. Amedeo Modigliani, Cabeça, 1911-12, Pedra calcária, $51 \mathrm{~cm}$, Colecção Gwendolyn Weiner, Forth Worth- Texas, in Osvaldo Patani 199239

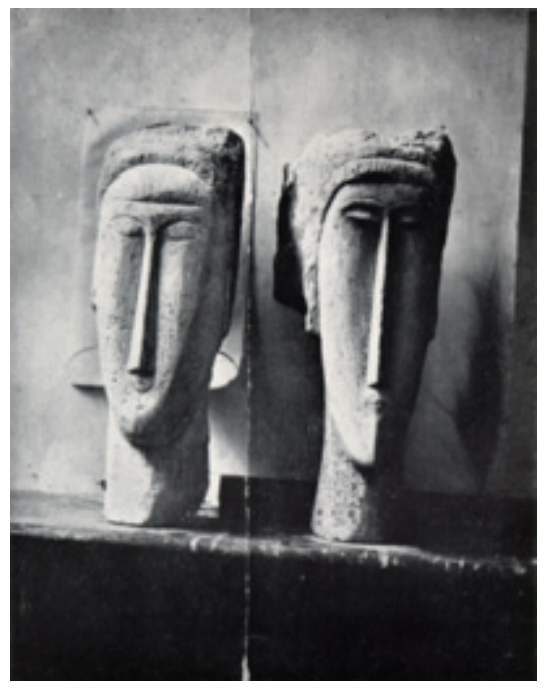

Fig.3. Esculturas de A. Modigliani, fotografadas por Amadeu de Sousa Cardoso no atelier da Cité Falguière, 1911. Paris, in Jeanne Modigliani 196168 


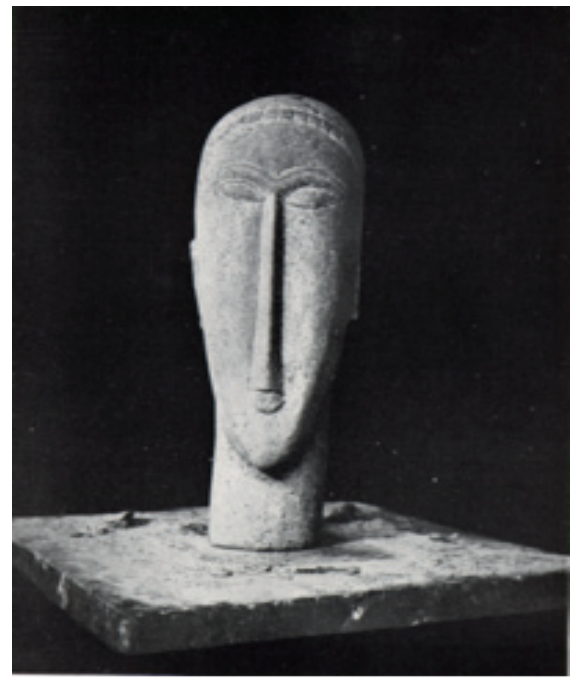

Fig.4. Escultura de A. Modigliani fotografada por Amadeu de S. Cardoso no atelier da Cité Falguière, 1911. Paris, in Jeanne Modigliani 1961, Ilustração 69

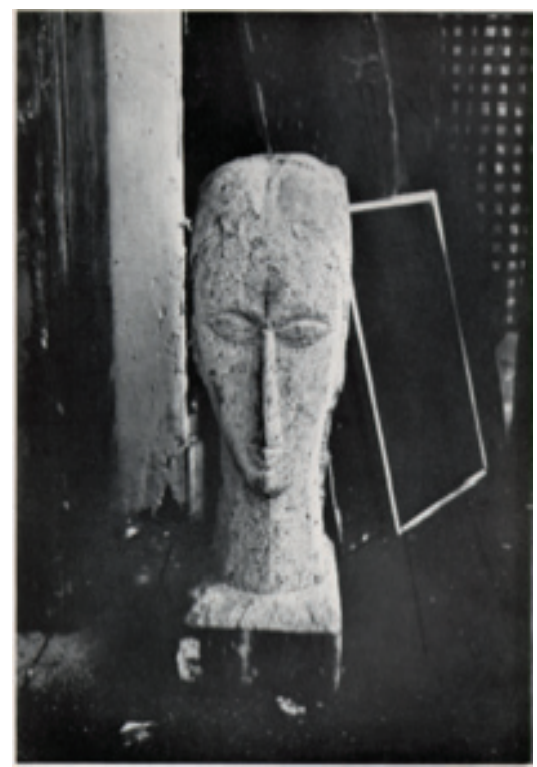

Fig.5. Escultura de A. Modigliani fotografada por Amadeu de S. Cardoso no atelier da Cité Falguière, 1911. Paris, in Jeanne Modigliani 1961, Ilustração 70 
Amedeo Modigliani (i $884^{-1}$ - 920 ) E o templo da Beleza. UMA Utopia FIGURATIVA NA ARTE MODERNA

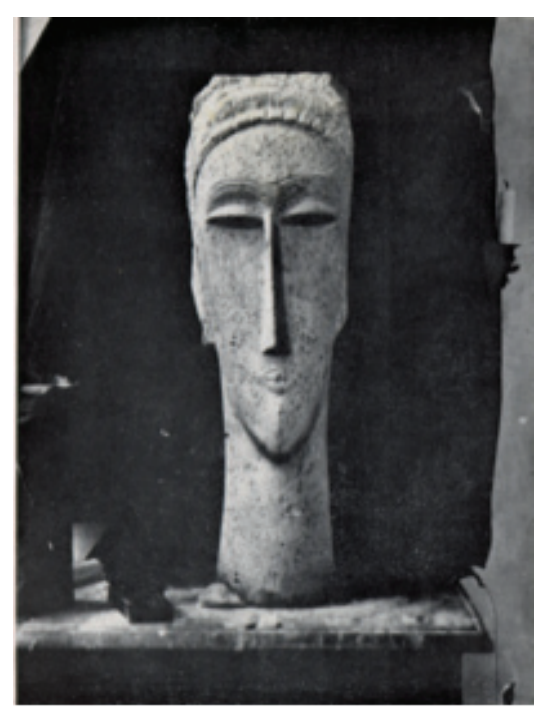

Fig.6. Escultura de A. Modigliani fotografada por Amadeu de S. Cardoso no atelier da Cité Falguière, 1911.Paris, in Jeanne Modigliani 1961, Ilustração 71

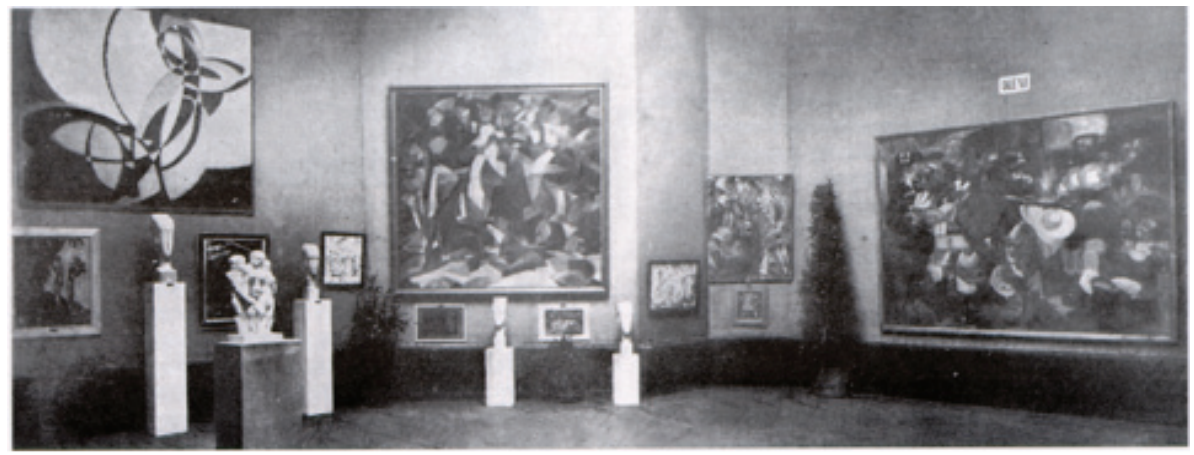

Fig.7. Sala dos Cubistas no X Salon d'Automne. Paris / 1912, in Pierre Durieu 199525 


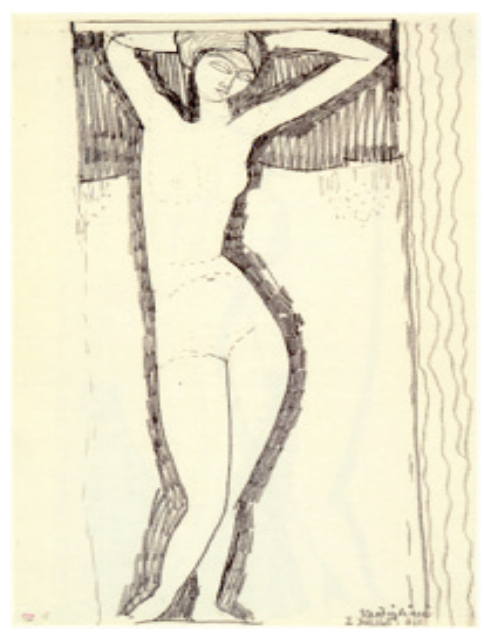

Fig.8. Amedeo Modigliani, Cariátide, vista de frente, mãos por trás da cabeça, 1911, Lápis preto s/papel, 42,8 x 26,4 cm, Antiga Colecção Paul Alexandre, in Noël Alexandre 1994194

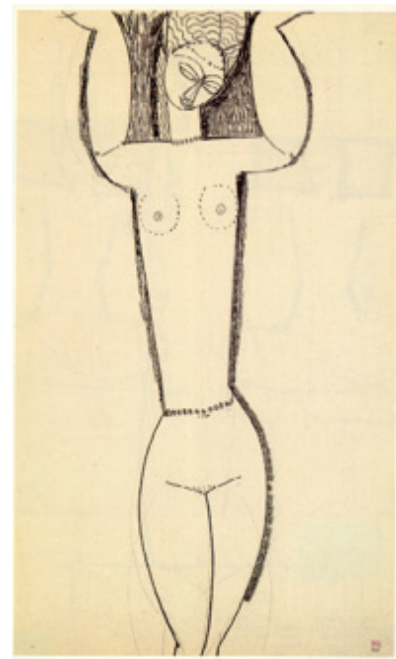

Fig.9. Cariátide, vista de frente; colar e cinto de pérolas, 1911, Lápis preto s/papel, 42,9 x 26,5 cm, Antiga Colecção Paul Alexandre, in Noël Alexandre 1994201 
Amedeo Modigliani (i 884-i 920) e o templo da Beleza. Uma utopia FIGURATIVA NA ARTE MODERNA

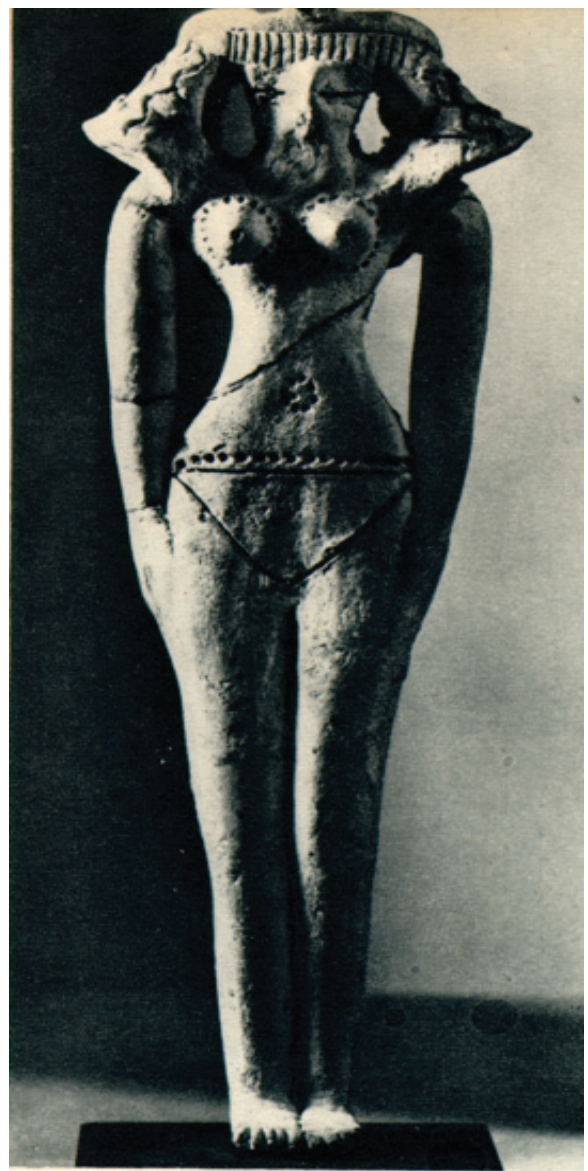

Fig.10. Mulher nua, Época pré-helénica, Museu do Louvre, Paris, in Mya Cinotti 19519 


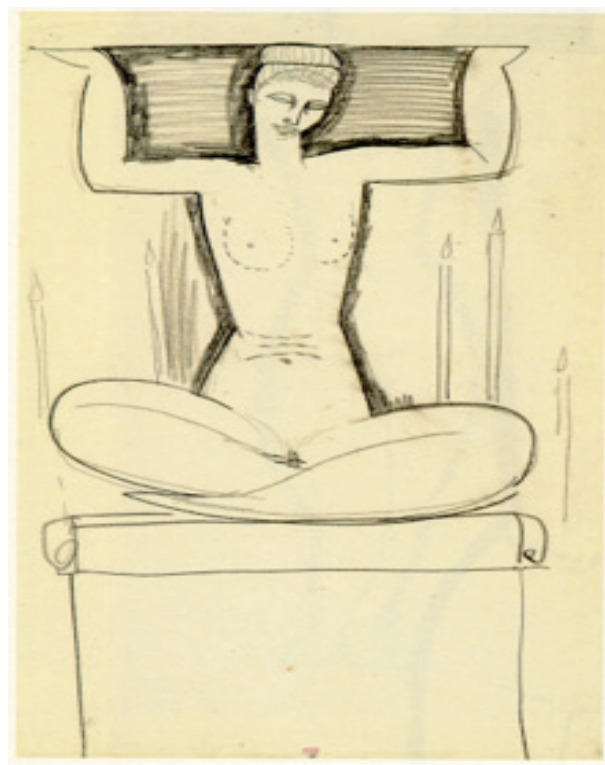

Fig.11. Amedeo Modigliani, Cariátide sentada de pernas cruzadas sobre uma base de coluna, velas acesas, 1911-12, Lápis s/papel, 42,8 x 26,5 cm, Antiga Colecção Paul Alexandre, in Noël Alexandre 1994202

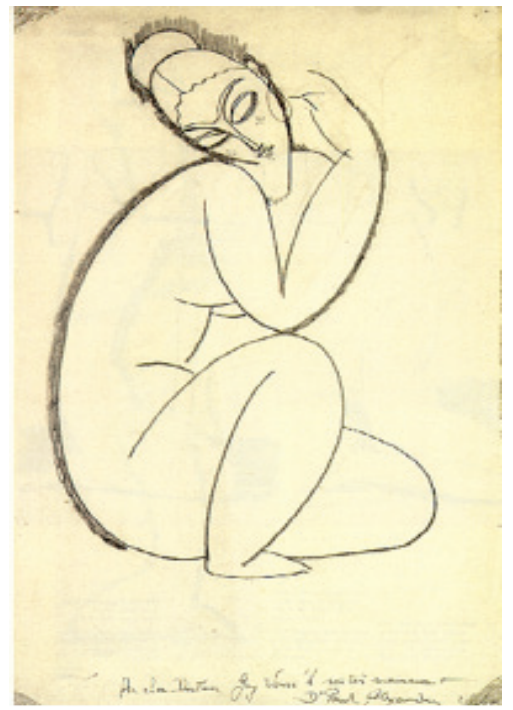

Fig.12. Amedeo Modigliani, Nu feminino sentado sobre a perna esquerda, joelho direito levantado, 1911-12, Lápis preto s/papel, 43 x 26,5, Antiga Colecção Paul Alexandre, in Noël Alexandre 1994206 


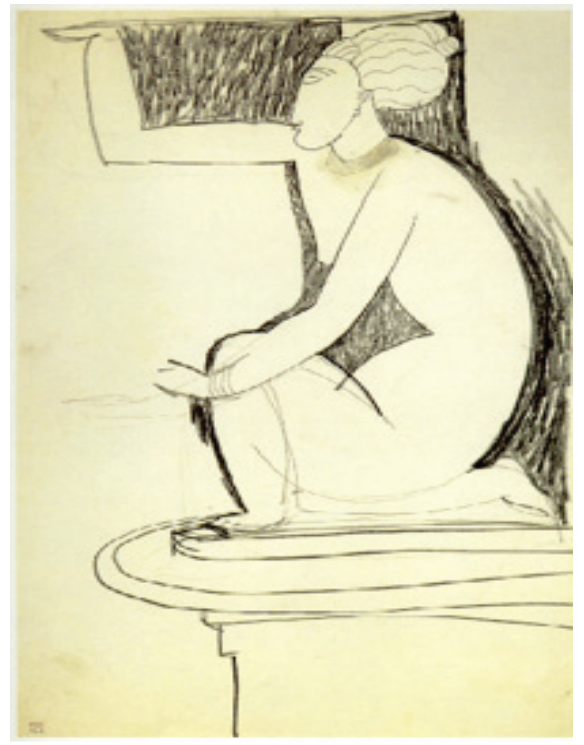

Fig.13. Amedeo Modigliani, Cariátide vista da esquerda, ajoelhada no joelho direito sobre uma base de coluna, 1912, Lápis preto s/papel, 42,7 x 26,5 cm, Antiga Colecção Paul Alexandre, in Noël Alexandre 1994213

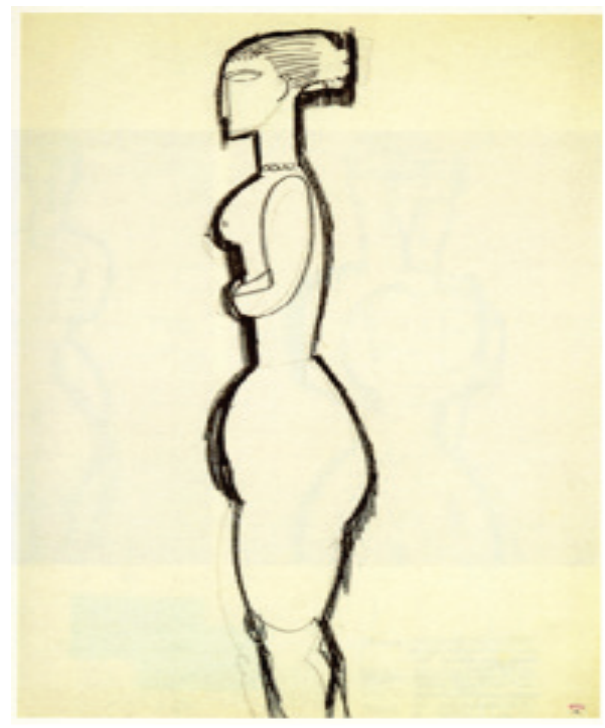

Fig.14. Amedeo Modigliani, Nu feminino de perfil, braços dobrados; colar, 1912-13, Lápis preto s/papel, 42,8 x 26,3 cm, Antiga Colecção Paul Alexandre, in Noël Alexandre 1994221 


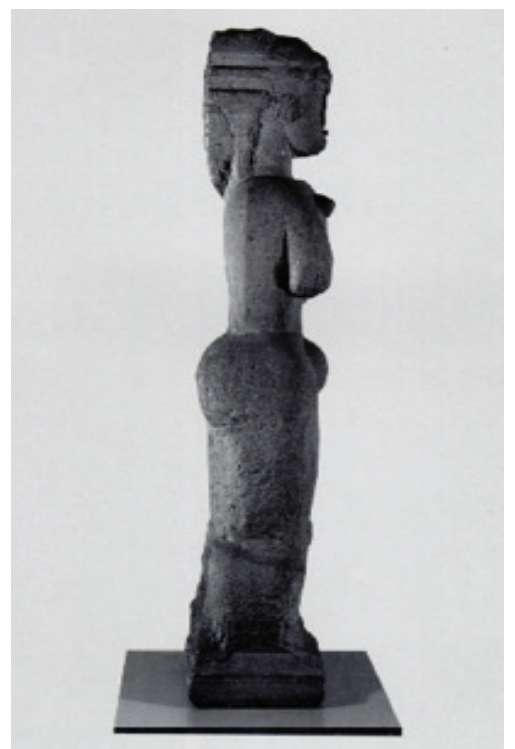

Fig.15. Amedeo Modigliani, Nu feminino em pé (perfil) 1912-13, Pedra calcária, 162,8 x 33,2 x 29,6 cm, Australian National Gallery, Canberra, in Osvaldo Patani 199265

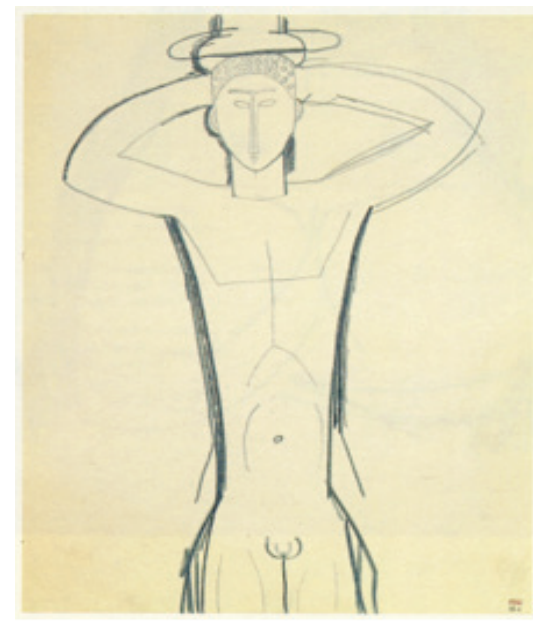

Fig.16. Amedeo Modigliani, Cariátide masculino, mãos por trás da cabeça; capitel, 1913-14, Lápis azul s/papel, 33,8 x 26,5 cm, Antiga Colecção Paul Alexandre, in Noël Alexandre 1994216 
Amedeo Modigliani (i884-i 920) e o templo da Beleza. Uma utopia FIGURATIVA NA ARTE MODERNA

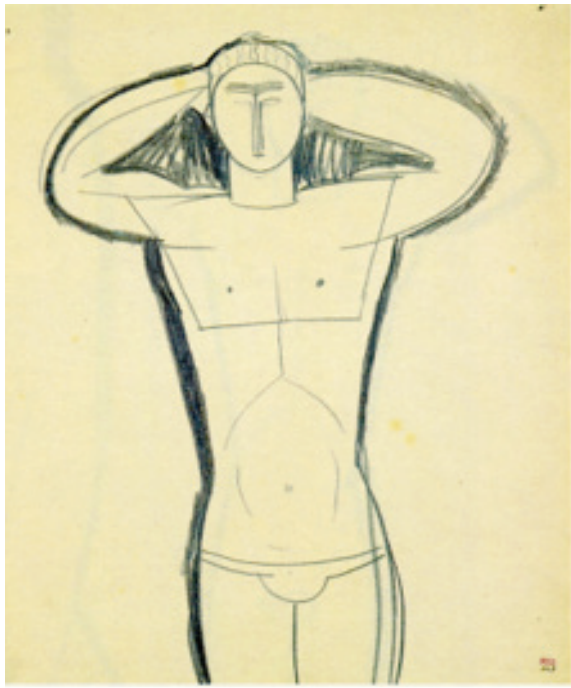

Fig.17. Amedeo Modigliani, Cariátide masculino, mãos atrás da cabeça, 1913-14, Lápis azul s/papel, 33,8 x 26,5 cm, Antiga Colecção Paul Alexandre, in Noël Alexandre 1994217

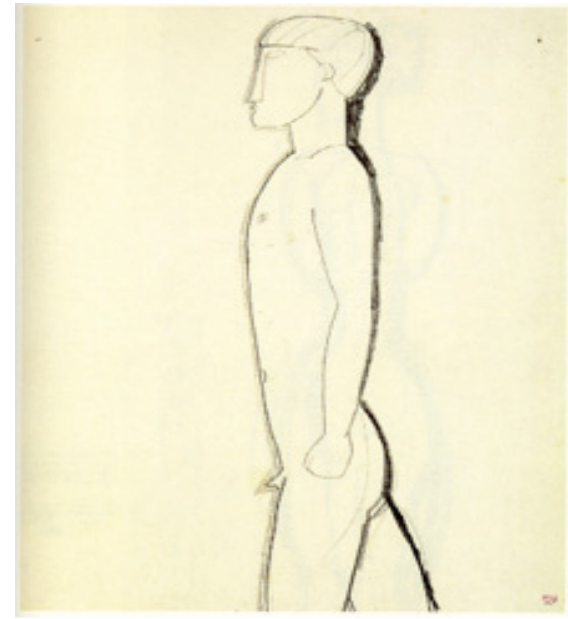

Fig.18. Amedeo Modigliani, Nu masculino de perfil, 1913-14, Lápis preto s/papel, 33,8 x 26,5 cm, Antiga Colecção Paul Alexandre, in Noël Alexandre 1994219 


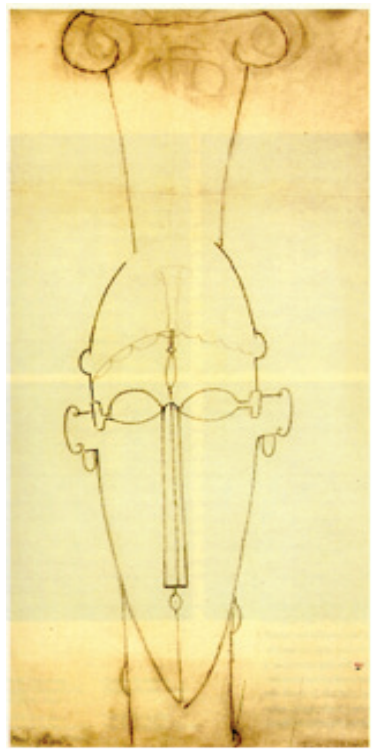

Fig.19. Amedeo Modigliani, Cabeça,de frente, coroada, com capitel, 1910-11, Lápis preto s/papel, 65 x $29 \mathrm{~cm}$,

Antiga Colecção Paul Alexandre, in Noël Alexandre 1994242

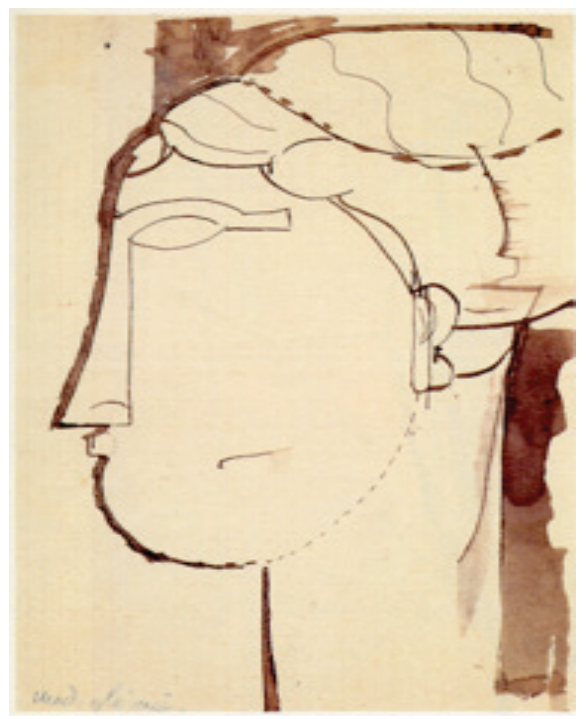

Fig.20. Amedeo Modigliani, Cabeça vista da esquerda, 1912, Tinta misturada com pigmento branco s/papel quadriculado, 26,2 x 20,9 cm, Antiga Colecção Paul Alexandre, in Noël Alexandre 1994256 
Amedeo Modigliani (i 884-i 920) e o templo da Beleza. Uma utopia FIGURATIVA NA ARTE MODERNA

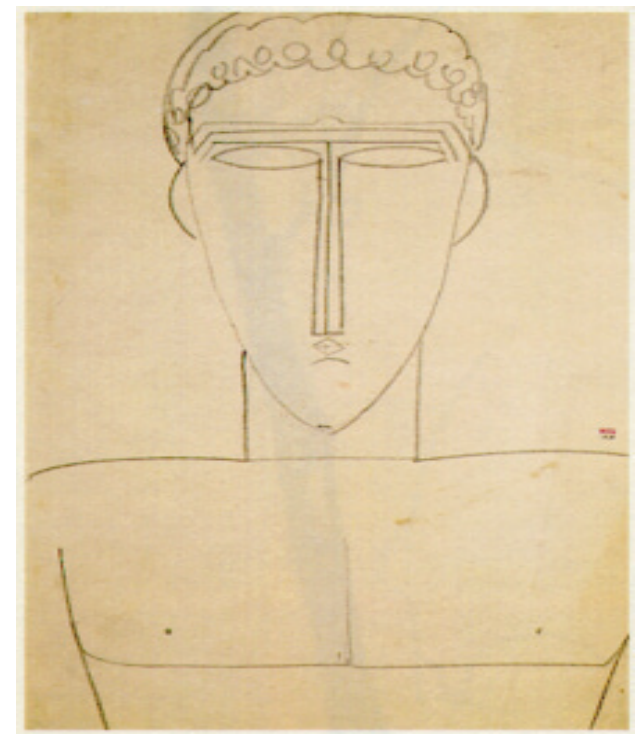

Fig.21. Amedeo Modigliani, Cabeça masculina e busto, de frente, 1912-13, Lápis preto s/ papel, 42,7 x 26,5 cm, Antiga Colecção Paul Alexandre, in Noël Alexandre 1994244

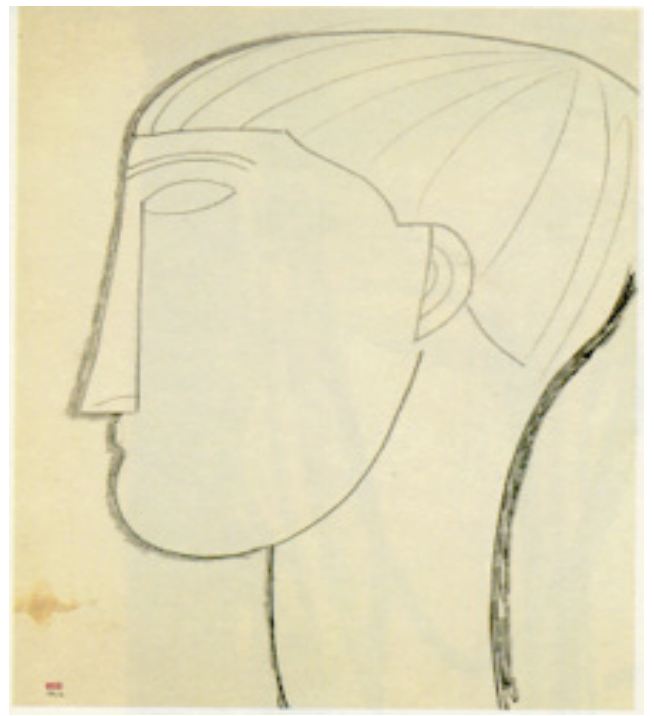

Fig.22. Amedeo Modigliani, Cabeça masculina vista de perfil, 1912-13, Lápis preto s/papel, 33,8 x 26,5 cm, Antiga Colecção Paul Alexandre, in Noël Alexandre 1994245 


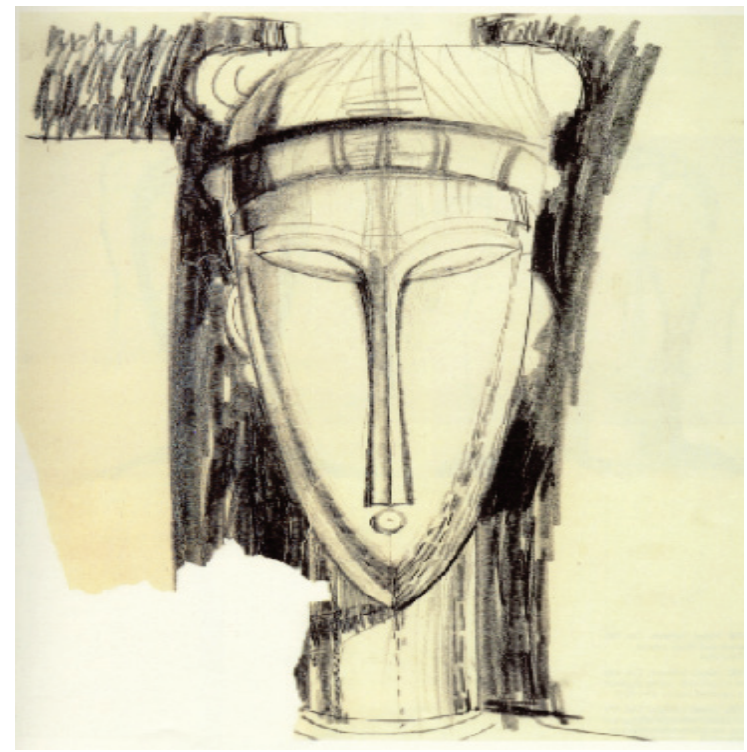

Fig.23. Amedeo Modigliani, Cabeça, de frente, como suporte arquitectónico, 1912-13, Lápis preto s/papel, 33,8 x 26,5 cm, Antiga Colecção Paul Alexandre, in Noël Alexandre 1994247

\section{Bibliografia}

Noël Alexandre (1994), The Unknown Modigliani. Drawings from the Collection of Paul Alexandre. Londres, Royal Academy of Arts / Fonds Mercator (Cat.).

Françoise Cachin e Ambrogio Ceroni (1972), Tout l'oeuvre peint de Modigliani. Paris, Flammarion.

Mya Cinotti (1951), La femme nue dans la sculpture. Paris, Éditions de Varenne.

Pierre Durieu (1995), Modigliani. Paris, Éditions Hazan.

Jeanne Modigliani (1961), Modigliani sans légende. Paris, Librairie Gründ.

Jeanne Modigliani (1990), Modigliani, une biographie. Paris, Éditions Adam Biro.

A. Fradique Morujão (1983), Pintura e filosofia. Coimbra.

Osvaldo Patani (1992), Amedeo Modigliani - Catalogo Generale. Sculture e disegni (19091914). Milão, Leonardo Editore.

S. Grijó Poças (1998), Amedeo Modigliani - O preciosismo do desenho e as cumplicidades lusas. 1884-1920. Porto. - Portugal: Dissertação de Mestrado em História da Arte, Faculdade de Letras, Universidade do Porto, 4 Volumes, 1000 p.

J. Rykwert (1996), The dancing column. On order in architecture. Cambridge, Massachusetts e Londres, Inglaterra, The MIT Press. 
(Página deixada propositadamente em branco) 
(Página deixada propositadamente em branco) 
Índice de palavras-chave

(vol. 3) 
(Página deixada propositadamente em branco) 


\section{A}

Ábidis 211

achados arqueológicos 187

água 197

Alentejo 241

Alentejo Central 69

Al-Mîrtulî 187

Ammaia 153, 171

arquitectura 231,255

arte cicládica 21

arte grega 13

arte moderna 301

arte minóica 21

arte rupestre 53

C

Cardo-Decumanus 265

Carneus Calanticensis 107

cavalaria romana 135

Celtas 197

cérebro grego 13

civitas 153

Classicismo 231

Classicismo moderno 241

culto 211

cultura 121

cultura grega 13

cultura mediterrânica 279

D

Decumanus ver Cardo

direito romano 217

divindades 81

divindades indígenas 99 
$\mathbf{E}$

Ebora 107

Endovelicus 107

epigrafia votiva 81

espaço 205

Estilo-Chão 241

ethnos 33

Évora 255

F

fada 197

formas 231

formas arquitectónicas 241

frescos 21

G

Galo-Romano 197

gárgulas 231

geometria 279

Gótico 231

Grande Deusa 187

H

Hispânia 33

historiografia 205, 255

I

iconografia 53, 231

iconologia 53

Idade do Ferro 53

Idade Média (Alta) 171

identidade local 224

identidades antigas 33

328 
Império Romano (fim do) 171

Iria 211

L

lendas 187

língua lusitana 99

Lisboa 265

Lusitânia 33, 107, 121, 205

M

Manuelino 231

Marvão 153

memória 205, 289

memória urbana 224

Mértola 187

modelos literários 224

Modigliani 301

monumentos 255

mouras encantadas 187

$\mathbf{P}$

paisagem 53, 121

paisagem 13

paisagem urbana 153

Palatino 141

património 289

Peninsular (Ibéria) 197

período romano 153

persistências e novidades 231

poder 205

Pombalino (Plano) 265

povoamento romano 69,81

Princeps 141

programas iconográficos 231

província 33

pulverização 171 
$\mathbf{R}$

rede viária 135

Renascimento 231

requalificação urbana 224

romanização 121

$\mathbf{S}$

S. Barão 187

Santarém 211

santuários romanos 107

Scallabis ver Santarém

serpente 187

Sertório 255

Severo Alexandre 141

Severos 141

Sibila 197

Space Shuttle 135

sufismo 187

Sul 289

$\mathbf{T}$

Tera 21

traçados urbanos portugueses 279

transumância na época romana 99

tratadística de arquitectura 241

$\mathbf{U}$

urbanismo 217

urbanismo português 279

urbanismo renascentista 224

utopia 309 
V

vestígios arqueológicos 224

Viagens, Guias de 289

Viagens, relatos de 289

villa romana 153

$\mathbf{Z}$

Zenão (constituição de) 217 
(Página deixada propositadamente em branco) 

OBRA PUBLICADA

COM A COORDENAÇÃO

CIENTÍFICA

Centro de Estudos

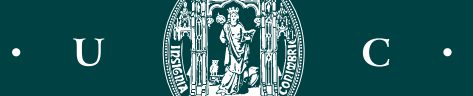

1

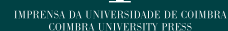

U 